ISSN (Print) 2640-8708

ISSN (Online) 2640-8740

\title{
Geophysical Survey and Test Excavation During 2006 at Larson Village, Burleigh County, North Dakota
}

\author{
Edited by \\ Mark D. Mitchell \\ ORCiD ID: https://orcid.org/0000-0003-4494-8840 \\ With contributions by \\ Stanley A. Ahler \\ George T. Crawford \\ Carl R. Falk \\ Kenneth L. Kvamme \\ Stacey Madden \\ Mark. D. Mitchell \\ Robert K. Nickel \\ Paul R. Picha \\ Fern E. Swenson \\ Prepared by \\ PaleoCultural Research Group \\ P. O. Box EE, Flagstaff, Arizona, 86002 \\ Submitted to the \\ State Historical Society of North Dakota \\ 612 E. Boulevard Avenue \\ Bismarck, North Dakota 58505
}

September 2007

This report is Research Contribution No. 80 of PaleoCultural Research Group.

DOI: https://doi.org/10.32946/PCRG.080 
The survey and testing project at Larson Village that is the subject of this report has been financed in part with Federal funds from the National Park Service, United States Department of Interior, and administered by the State Historical Society of North Dakota. However, the contents and opinions do not necessarily reflect the views or policies of the Department of Interior or the State Historical Society of North Dakota, nor does the mention of trade names or commercial products constitute endorsement or recommendation by the Department of Interior or the State Historical Society of North Dakota.

This program receives Federal financial assistance for identification and protection of historic properties. Under Title VI of the Civil Rights Act of 1964, Section 504 of the Rehabilitation Act of 1973, and the Age Discrimination Act of 1975, as amended, the U. S. Department of the Interior prohibits discrimination on the basis of race, color, national origin, disability or age in its federally assisted programs. If you believe you have been discriminated against in any program, activity, or facility as described above, or if you desire further information, please write to:

\author{
Office of Equal Opportunity \\ National Park Service \\ 1849 C Street, N.W. \\ Washington, D. C. \\ 20240
}




\begin{abstract}
Larson Village (32BL9) is a large, fortified earthlodge settlement located on the east bank of the Missouri River about 20 km north of Bismarck, North Dakota. Geophysical surveys and limited test excavations were carried out during a 13-day period from June 6 to June 18, 2006 by personnel from the PaleoCultural Research Group (PCRG), the Center for Advanced Spatial Technologies at the University of Arkansas (CAST), and the State Historical Society of North Dakota (SHSND). The primary objectives of the project are to determine when the village was founded, to delineate its maximum spatial extent, and to obtain a sample of artifacts that can be compared with similar samples from contemporaneous villages in the Heart region.
\end{abstract}

Previous work at Larson Village documented a deep fortification ditch surrounding the central core of the village, a large basin or plaza located just outside the central core, numerous lodge depressions, and a surrounding ring of large midden mounds. A second fortification ditch was noted by one early observer, but its path through or around the village was not mapped. More recent work at several nearby villages has demonstrated that fortification systems and other features often extend well beyond the visible mounds and lodge depressions. Based on these data, and in keeping with the Larson project's principle goals, the 2006 field effort focused on the comparatively flat and featureless area north of the northernmost perimeter mounds.

Geophysical survey revealed the presence of two previously unrecorded fortification systems arcing around the village, just beyond and beneath the outermost midden mounds, along with numerous discrete anomalies representing hearths, cache pits, and other features. Geophysical surveys also confirmed the presence of a third fortification system winding through the middle of the site. Geophysical survey and hand coring demonstrated that the large basin or plaza adjacent to the central core of the village is nearly devoid of subsurface features or cultural deposits, indicating that this area was maintained as an open plaza throughout the village's history. Guided by geophysical data, test excavations placed on the northern edge of the village documented the presence of a variety of features, including postholes, cache pits, and small basins. The presence of intact postholes and other small features may indicate that substantial portions of earthlodge floors are preserved in this part of the site.

Radiocarbon and other data suggest, but do not conclusively demonstrate, that the village was founded about 1500 . Additional data will be needed to more precisely define its age. The material content of the settlement's earliest occupation bears important similarities with that of nearby Double Ditch Village. The residents of both villages made extensive use of smooth gray Tongue River silicified sediment for stone tools and produced similar types of pottery. In addition to the dominant tropical cultigens, both communities raised sunflowers and marshelder. For both, fishing appears to have been a comparatively minor activity.

The occupational histories of Larson and Double Ditch also are similar. Both villages were founded at about the same time and both contracted progressively over a 
period of about three centuries. Both are ringed by a series of high midden mounds that at one time may have been incorporated in their defenses. Both contain open plazas that were maintained until they were abandoned. However, in other respects Larson and Double Ditch are rather different. Large-scale sediment transport appears to have been less common at Larson. The intact condition of many features on the perimeter of Larson, compared to those on the perimeter of Double Ditch, indicates that the outskirts of the two villages were used in rather different ways. 


\section{TABLE OF CONTENTS}

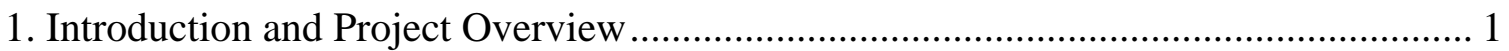
Mark D. Mitchell

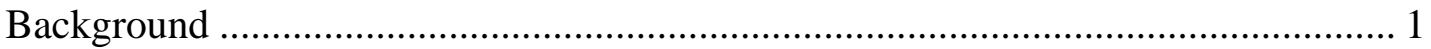

Research Goals ............................................................................................... 4

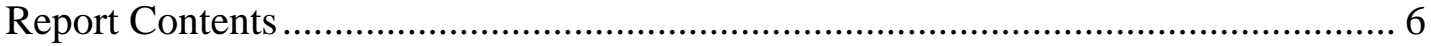

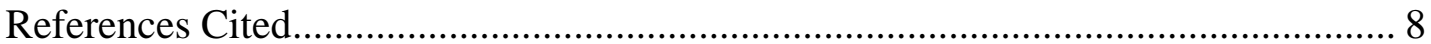

2. Previous Investigations at Larson Village .................................................................. 11

Fern E. Swenson

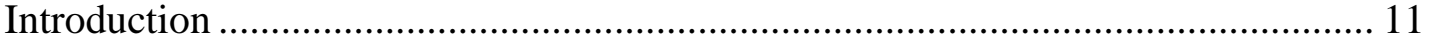

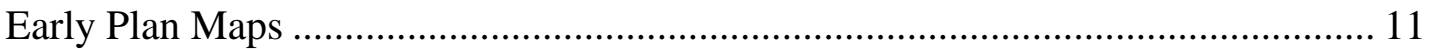

History of Destruction and Archaeological Excavations .......................................... 14

Erosion, Cultivation, Farmstead, and Road Construction $\left(149^{\text {th }}\right.$ Street $)$................ 14

Bowers' (Logan Museum) 1929 Excavation ......................................................... 18

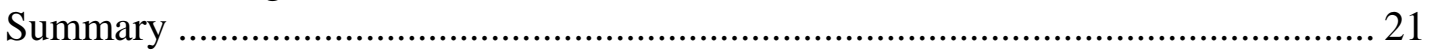

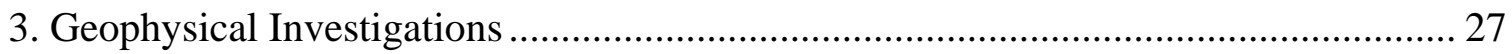

Kenneth L. Kvamme

Introduction ................................................................................................... 27

Study area and Field Methods ......................................................................... 30

Theory and Instrumentation ............................................................................... 31

Magnetic Gradiometry .................................................................................. 32

Electrical Resistance …………………............................................................... 33

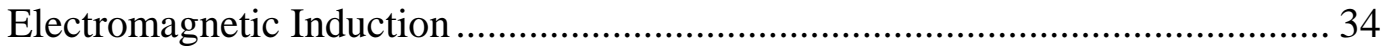

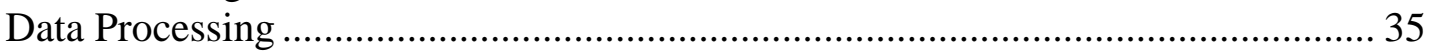

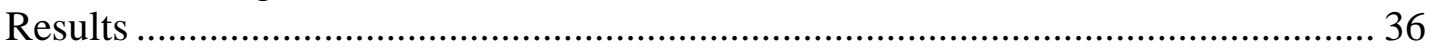

Magnetic Gradiometry Survey.......................................................................... 36

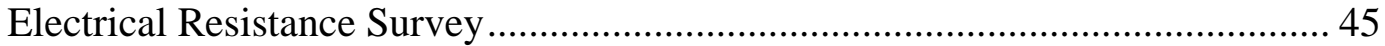

Electromagnetic Induction (EM) Survey ........................................................ 50

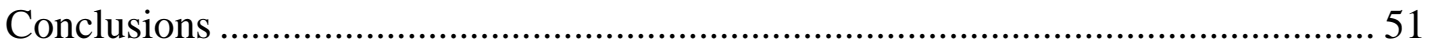

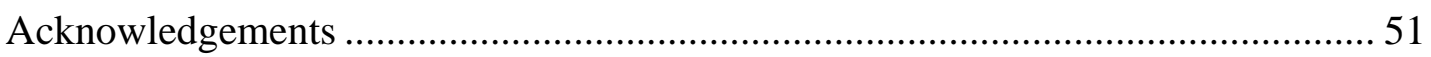

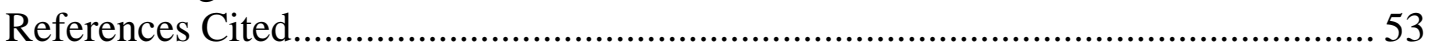

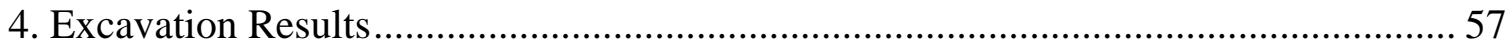

Mark D. Mitchell

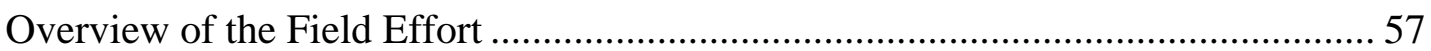

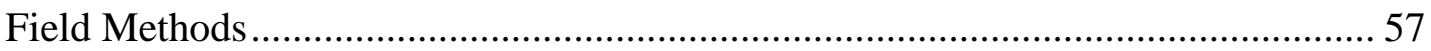

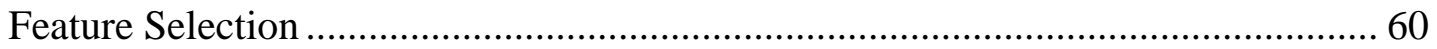

Excavation Unit Summaries and Feature Descriptions ................................................ 63

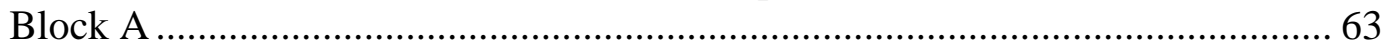

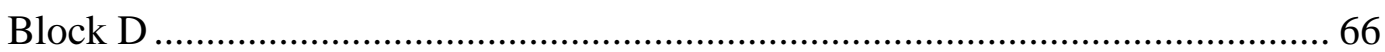

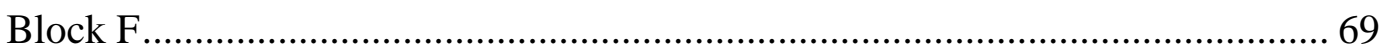

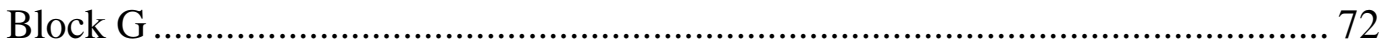

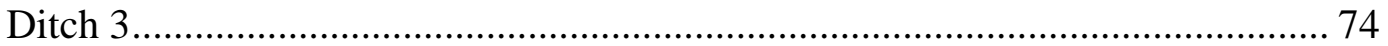




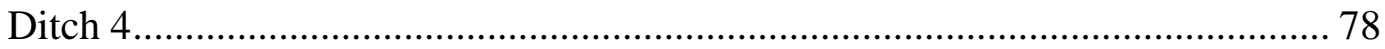

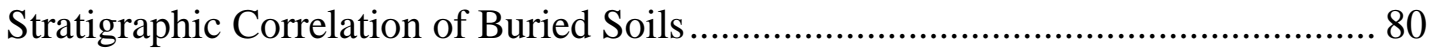

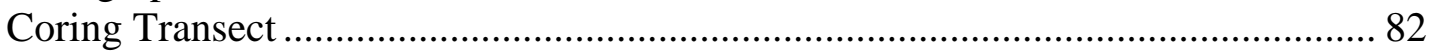

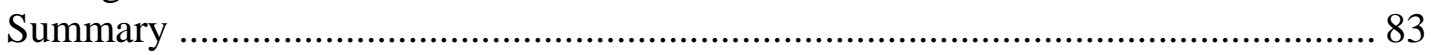

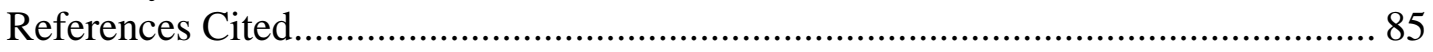

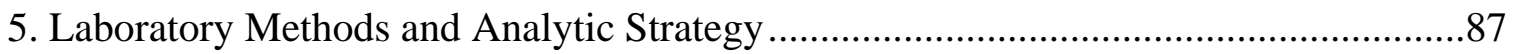

Stanley A. Ahler and Mark D. Mitchell

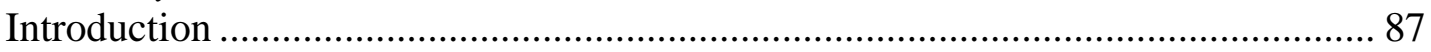

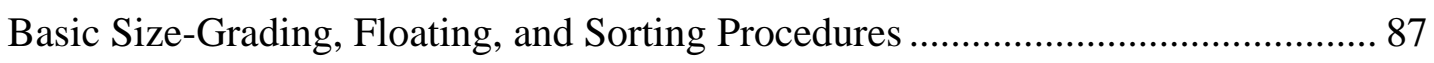

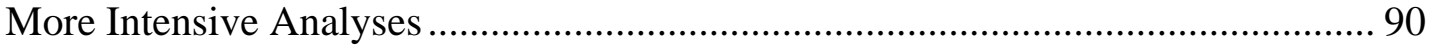

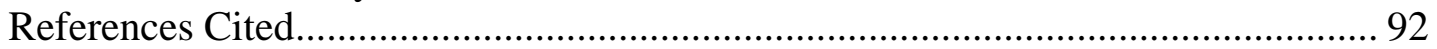

6. Analytic Units and Collection Chronology......................................................... 93

Mark D. Mitchell

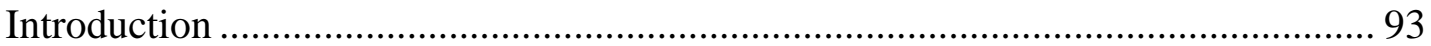

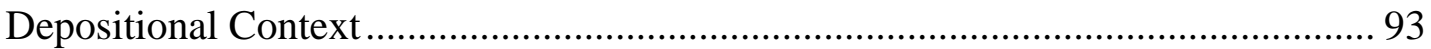

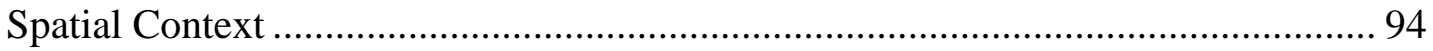

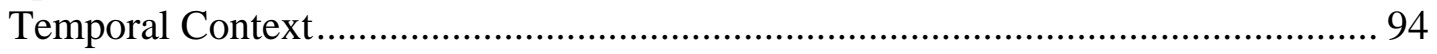

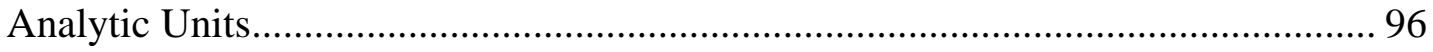

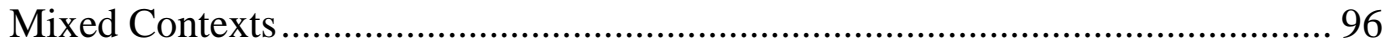

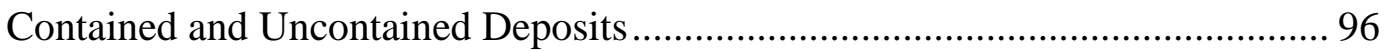

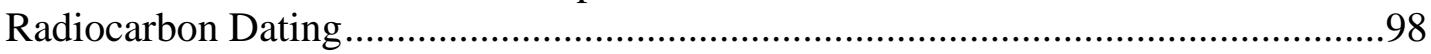

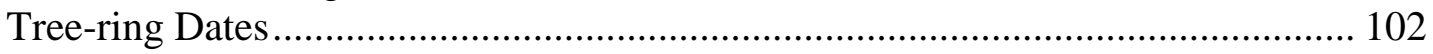

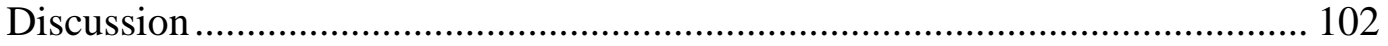

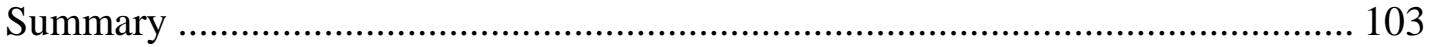

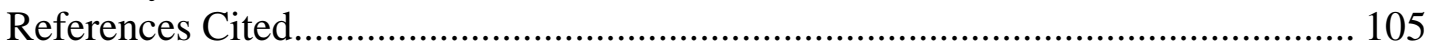

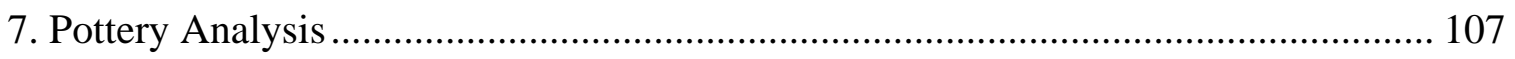

Mark D. Mitchell

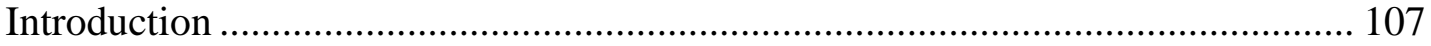

Analytic Methods ...................................................................................... 107

Rim and Body Sherd Separation and Quantification and Body Sherd Analysis 108

Rim Sherd Ware and Variety Analysis and Attribute Coding .......................... 110

S-rim Wares and Varieties........................................................................... 110

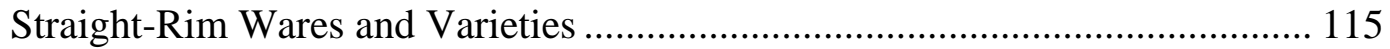

Pottery Distribution and Body Sherd Analysis ................................................ 117

Ware and Variety Quick-code Analysis .......................................................... 121

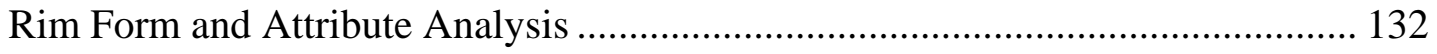

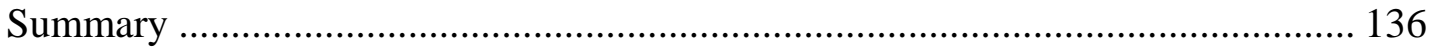

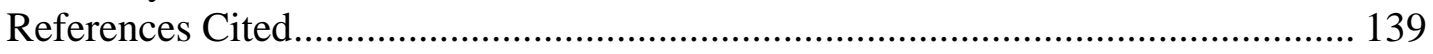

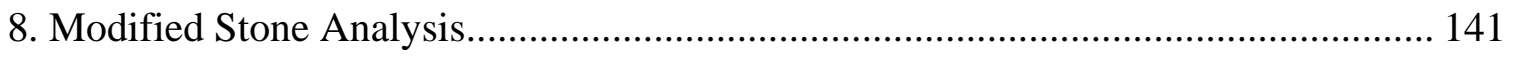

George T. Crawford and Mark D. Mitchell

Stone Tool and Flaking Debris Analysis Methods.............................................. 141 


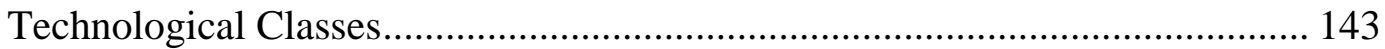

Flaking Debris Analysis .................................................................................... 146

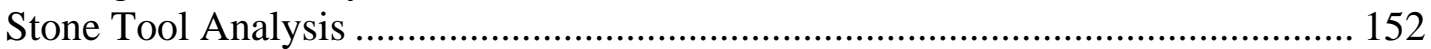

Technological Composition of the Stone Tool Sample ....................................... 152

Regional Comparison of Stone Tool Technological Classes .................................... 157

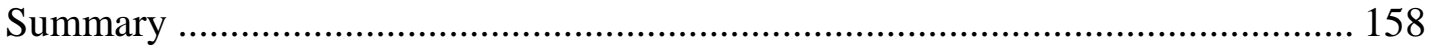

References Cited............................................................................................... 160

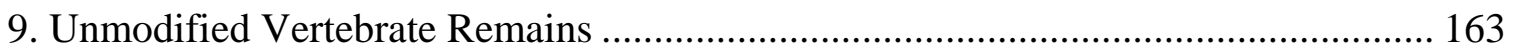

Carl R. Falk

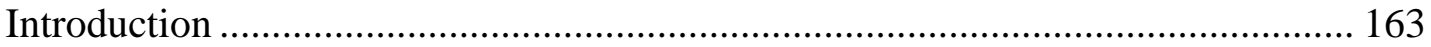

Size Grade and Bone Weight Distributions .......................................................... 163

Identified Vertebrate Specimens ........................................................................ 165

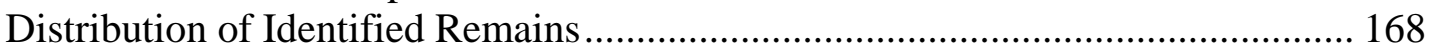

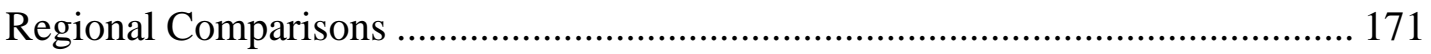

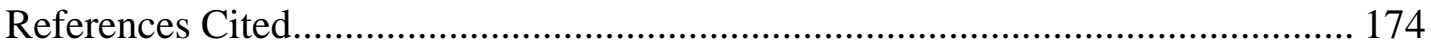

10. Modified Bone and Antler Artifacts ..................................................................... 177

Carl R. Falk

Introduction and Methods ................................................................................... 177

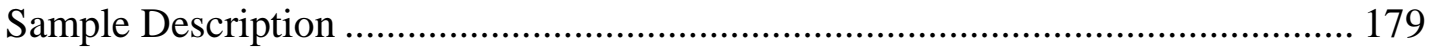

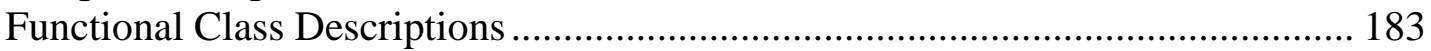

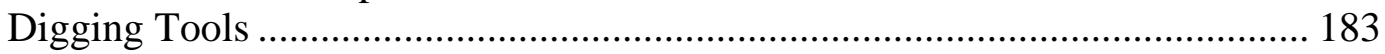

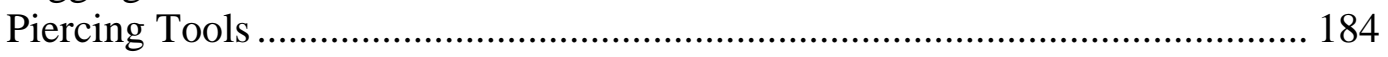

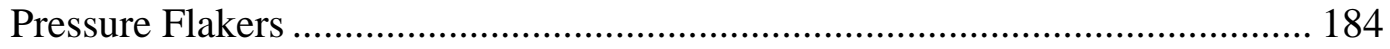

Fishhooks ..................................................................................................... 185

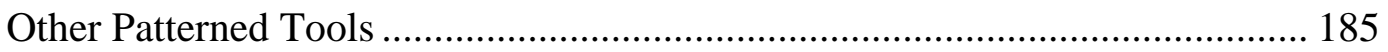

Other Expedient Tools ........................................................................................ 185

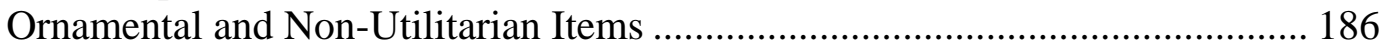

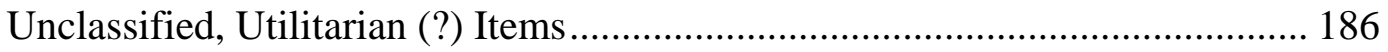

Distribution of Modified Bone and Antler ............................................................ 187

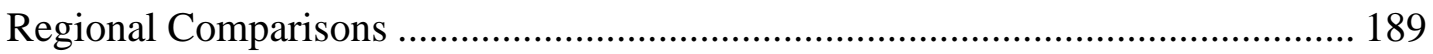

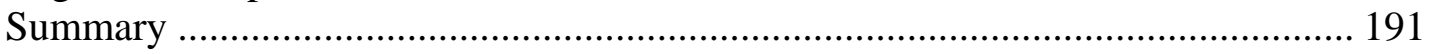

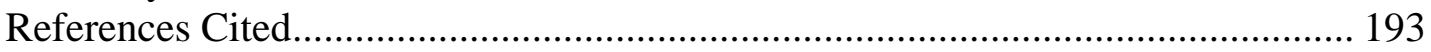

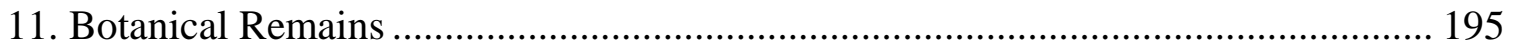

Robert K. Nickel

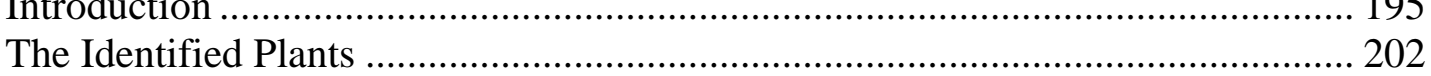

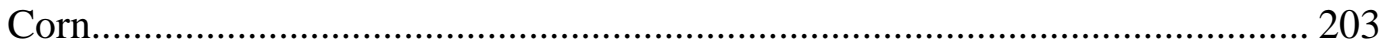

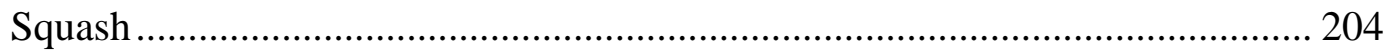

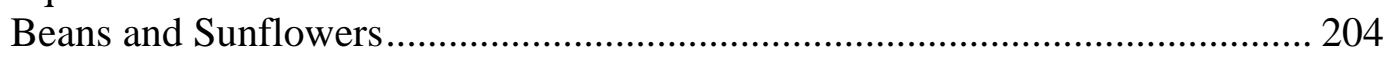

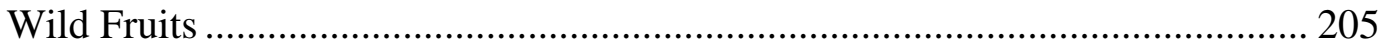

Local Grasses and Weedy Plants .................................................................... 205

Discussion and Conclusions ................................................................................ 207

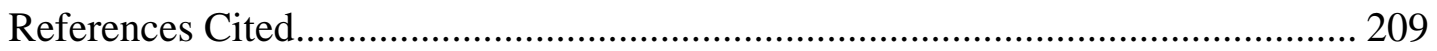


12. Other Artifact and Material Classes............................................................................... 213

Mark D. Mitchell, Paul R. Picha, and Stacey Madden

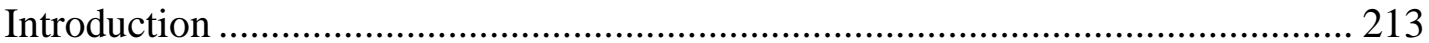

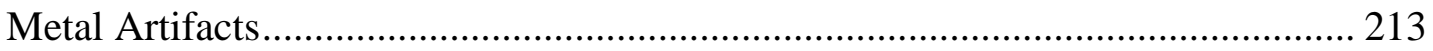

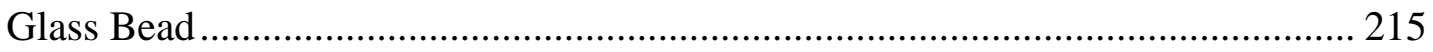

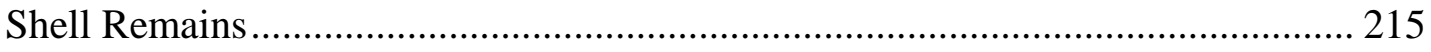

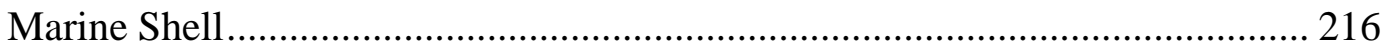

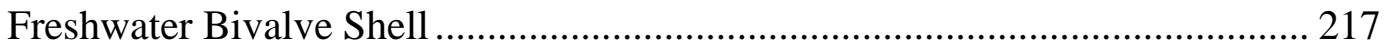

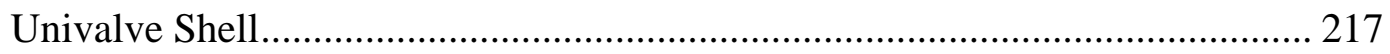

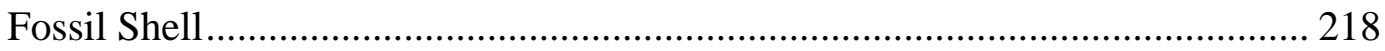

Miscellaneous Plains Village Artifacts .......................................................... 218

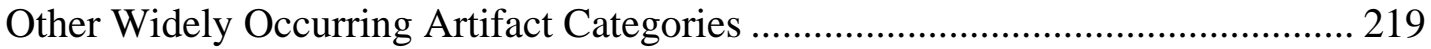

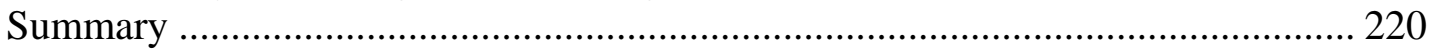

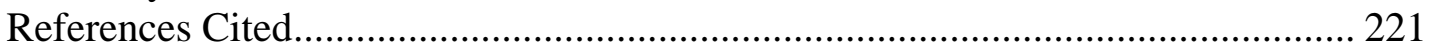

13. Summary and Recommendations ........................................................................... 223

Mark D. Mitchell, Kenneth L. Kvamme, Fern E. Swenson, Carl R. Falk, Robert K. Nickel, and George T. Crawford

Summary ...................................................................................................... 223

Recommendations for Future Research ............................................................ 228

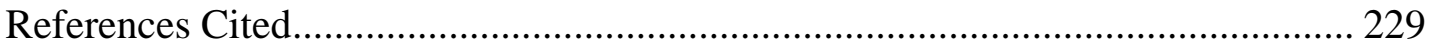




\section{LIST OF TABLES}

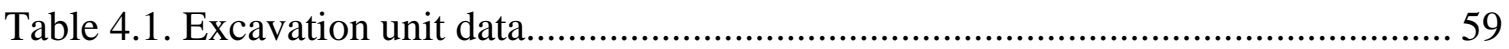

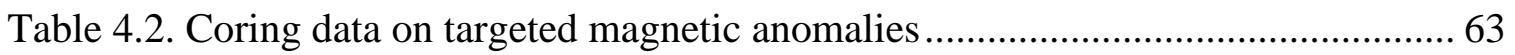

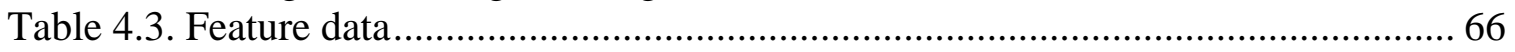

Table 5.1. Sorting guide for heavy fraction remains from waterscreened samples .......... 89

Table 5.2. Summary of analysis and data tables for artifact categories........................... 90

Table 6.1. Trade artifact composition and density data........................................... 95

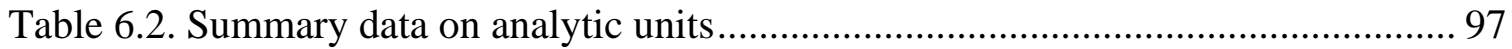

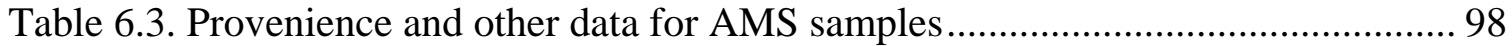

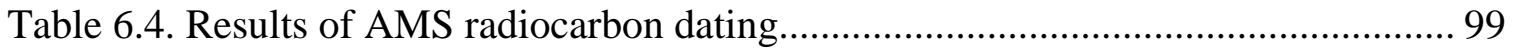

Table 6.5. Calibration data for radiocarbon samples ................................................. 99

Table 6.6. Ages and calibrated date ranges for simulated radiocarbon ages .................. 100

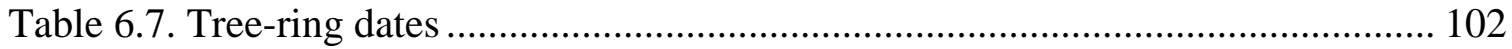

Table 7.1. Sources of comparative data used in the Larson Village pottery study......... 107

Table 7.2. Summary of pottery variables and attribute codes for body sherd study....... 108

Table 7.3. Summary of pottery variables and attribute codes for rim sherd study ......... 111

Table 7.4. Pottery count and weight data by size grade and excavation context............ 117

Table 7.5. Ceramic category and vessel part data by size grade.................................. 118

Table 7.6. Body sherd surface treatment data......................................................... 119

Table 7.7. Body and rim sherd counts and percentages............................................ 120

Table 7.8. Body and rim sherd weights and percentages........................................... 120

Table 7.9. Sherd percentage by weight from three Heart region villages...................... 121

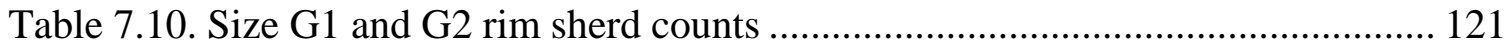

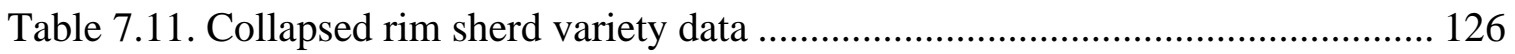

Table 7.12. Collapsed rim sherd variety data ......................................................... 127

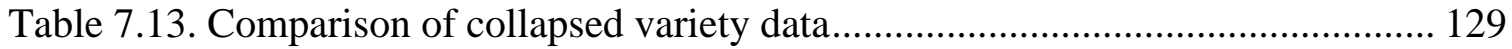

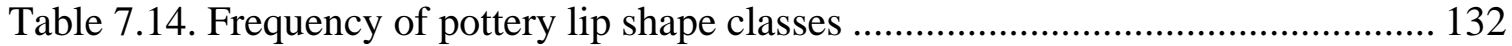

Table 7.15. Frequency of various decorative techniques........................................... 133

Table 7.16. Number of parallel horizontal cord impressions....................................... 134

Table 7.17. Comparison of cord diameter and cord spacing measurements .................. 135

Table 8.1. Summary of variables and attribute codes used in flaking debris study....... 143

Table 8.2. Summary of variables and attributes used in stone tool study...................... 145

Table 8.3. Counts and weights of chipped stone flaking debris .................................. 146

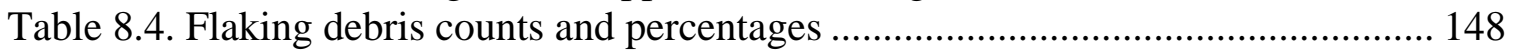

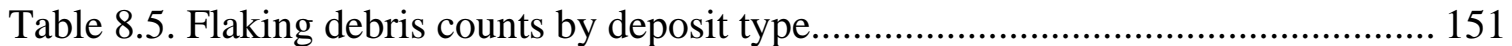

Table 8.6. A comparison of flaking debris provenance ............................................. 152

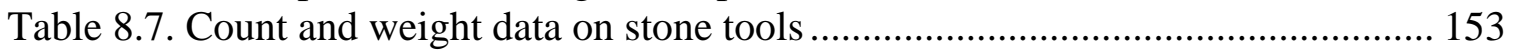

Table 8.8. Stone tool counts and percentages ........................................................... 155

Table 8.9. Heat treatment data on KRF stone tools from the 2006 Larson excavations 156

Table 8.10. Comparison of technological class of chipped stone tools ........................ 157

Table 8.11. Comparison of stone tool technological classes ....................................... 158 
Table 9.1. Count and weight distributions for unmodified vertebrate remains 164

Table 9.2. Bone weight, excavated volume and bone density ..................................... 165

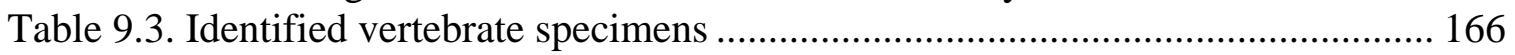

Table 9.4. Presence-absence distributions for identified remains ................................ 168

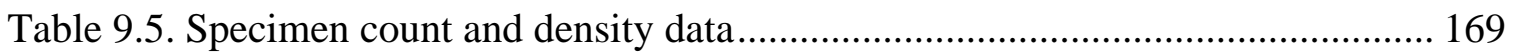

Table 9.6. Specimen counts for major mammals, birds and fish .................................. 169

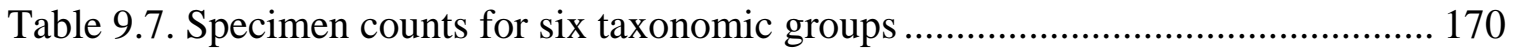

Table 9.8. Specimen counts for six taxonomic groups ............................................. 170

Table 9.9. Specimen counts for six taxonomic groups organized by village. ................ 171

Table 9.10. Specimen counts for major mammals organized by village ....................... 172

Table 10.1. Variables and attribute codes for modified bone and antler artifacts .......... 178

Table 10.2. Distribution of modified bone and antler specimens ................................ 179

Table 10.3. Distribution of modified bone and antler specimens ................................. 180

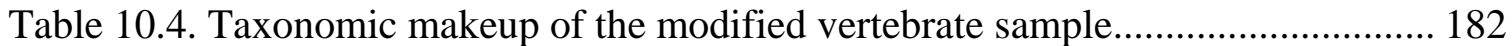

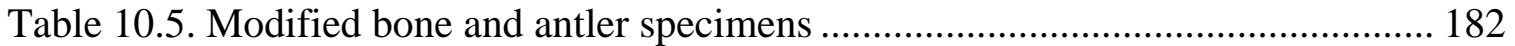

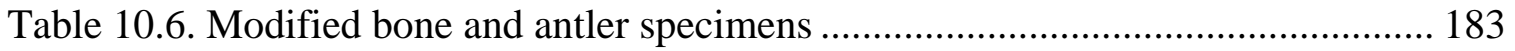

Table 10.7. Distribution of generalized functional classes ........................................ 187

Table 10.8. Distribution of generalized functional classes ........................................ 188

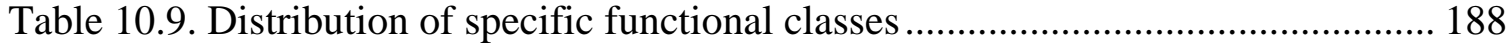

Table 10.10. Distribution of generalized functional classes ....................................... 190

Table 10.11. Comparison of generalized functional class occurrences ......................... 191

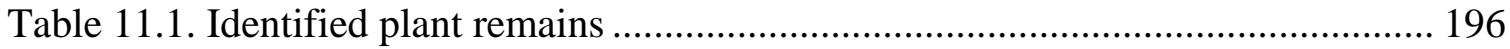

Table 11.2. Counts and densities of maize cob and kernel fragments .......................... 208

Table 12.1. Variables recorded in the analysis of trade metal artifacts ........................ 214

Table 12.2. Summary distribution of trade metal artifacts ........................................ 214

Table 12.3. Summary of modification and classification data on shell remains ............ 216

Table 12.4. Distribution of modified and unmodified shell remains ............................ 216

Table 12.5. Classification of miscellaneous Plains Village artifacts ........................... 219

Table 12.6. Distribution by count and weight of various sort classes .......................... 219 


\section{LIST OF FIGURES}

Figure 1.1. Location map of Larson Village and other sites in the Heart region................ 2 Figure 1.2. Map showing the main channel of the Missouri River in 1804 and 1970........ 3

Figure 1.3. Overview of the northern perimeter of Larson Village ................................. 6

Figure 2.1. Site boundary illustrated on a 2004 aerial photograph................................ 12

Figure 2.2. Historic plan maps of Larson Village.......................................................... 13

Figure 2.3. Plan map of Larson Village showing disturbances ...................................... 15

Figure 2.4. Stripping of Larson Village related to the 1975 road construction ................ 17

Figure 2.5. Vertical aerial photographs of Larson Village taken in 1938 and $1950 \ldots . . . . .18$

Figure 2.6. Aerial photographs of Larson Village taken in 1966 and in 2004 ................ 19

Figure 2.7. Photograph of the excavation at a midden mound (Work D)........................ 20

Figure 2.8. Redrafted plan map of Bowers’ Work H.................................................. 22

Figure 3.1. Aerial photographs of the Larson site ...................................................... 28

Figure 3.2. Panoramic wide-angle view of Larson ................................................... 29

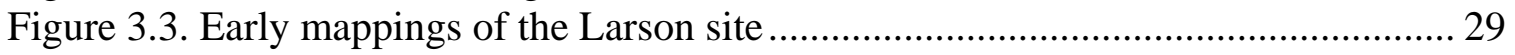

Figure 3.4. Instrumentation utilized in the Larson project............................................ 30

Figure 3.5. Mapping of surface-visible elements in the geophysical study blocks .......... 31

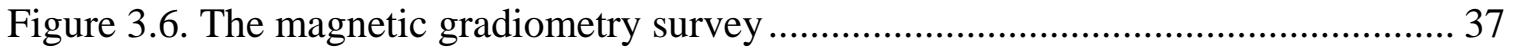

Figure 3.7. Magnetic evidence and interpretations of bastions .................................... 39

Figure 3.8. A series of discontinuous magnetic anomalies......................................... 39

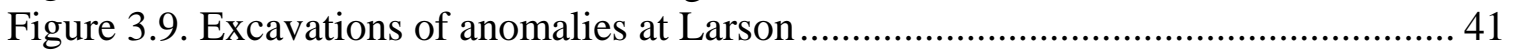

Figure 3.10. Magnetic profiles across Fortification Ditches 1-4 ................................. 42

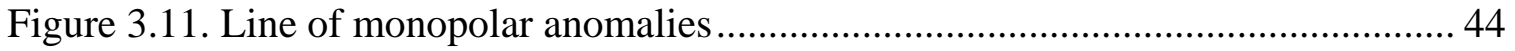

Figure 3.12. Magnetic signature of a vehicle two-track ........................................... 44

Figure 3.13. Magnetic effects of mechanized farming .............................................. 45

Figure 3.14. Initial exploratory electrical resistance results ...................................... 46

Figure 3.15. Site-wide electrical resistance survey results ...................................... 47

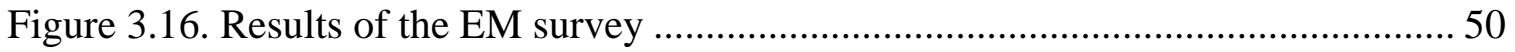

Figure 3.17. Larson Village magnetic gradiometry survey. ........................................ 54

Figure 3.18. Larson Village electrical resistance survey. ........................................... 55

Figure 4.1. Map of Larson Village, showing the site grid and survey area ..................... 58

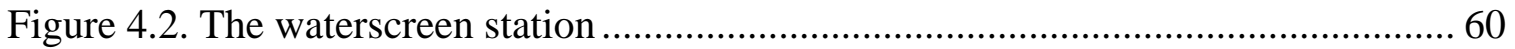

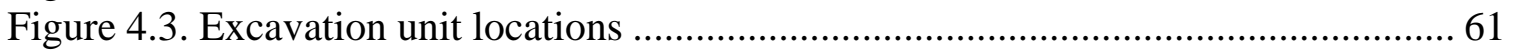

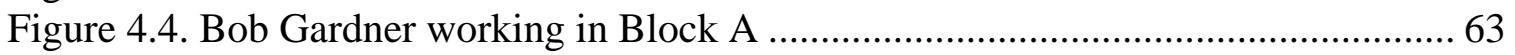

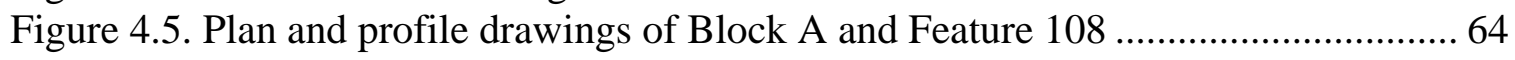

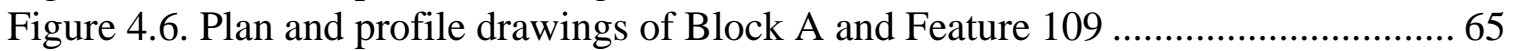

Figure 4.7. Carl Falk and Ed Maixner excavating Block D........................................ 67

Figure 4.8. Plan and profile drawings of Block D and features 101, 102, and 103......... 68

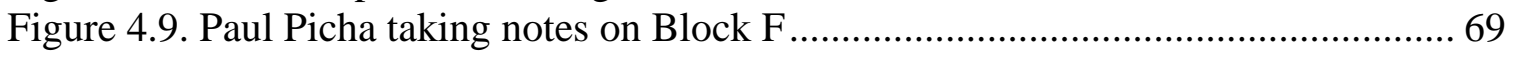

Figure 4.10. Plan and profile drawings of Block F and Feature 104 ............................ 70

Figure 4.11. Plan and profile drawings of Block $F$ and Feature 107 ............................ 71

Figure 4.12. Tim Reed working in Block G ........................................................ 72 
Figure 4.13. Plan and profile drawings of Block G .................................................. 73

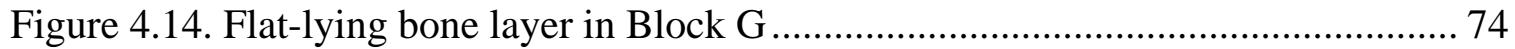

Figure 4.15. Richard Krause, Craig Johnson, and Janet Griffitts working in Ditch 3..... 75

Figure 4.16. Plan and profile drawings of Ditch 3.................................................... 76

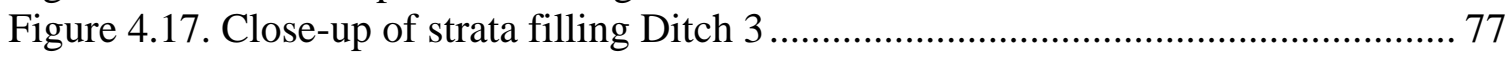

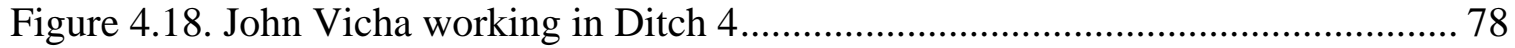

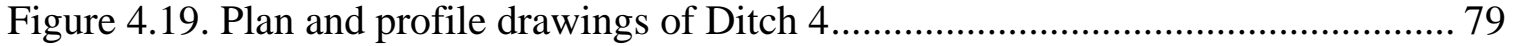

Figure 4.20. Correlation of buried soils across six excavation units .............................. 81

Figure 4.21. Depth of cultural deposits in the Larson Village plaza .............................. 83

Figure 6.1. Calibrated radiocarbon date distributions............................................... 101

Figure 7.1. Pottery from the 2006 Larson collection ................................................. 123

Figure 7.2. Pottery from the 2006 Larson collection ................................................. 124

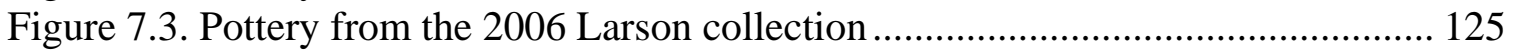

Figure 7.4. Pottery from the 2006 Larson collection .................................................. 128

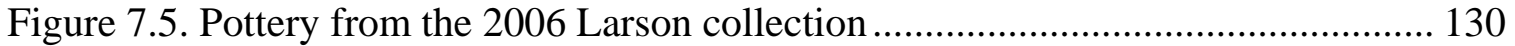

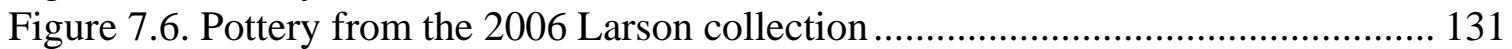

Figure 7.7. Scatterplot showing the relationship between cord spacing and diameter ... 135

Figure 7.8. Distribution of brace heights on Knife River ware rims ............................ 136

Figure 8.1. A comparison of KRF and TRSS flaking debris by count and weight ........ 150

Figure 8.2. Stone tools from Larson Village............................................................ 154

Figure 13.1. Map of Larson Village, showing the site's major features ........................ 225 


\section{ACKNOWLEDGEMENTS}

We dedicate our work at Larson Village to our friend, collaborator, and mentor, Stanley A. Ahler, who passed away February 3, 2007. This project would not have been possible without Stan's vision, leadership, and dedication. We will miss him, but are gratified to be able to contribute to the work that he began nearly four decades ago.

The Larson project relied on the generous contributions of many PCRG members, whose work is gratefully acknowledged in Chapters 3 and 4 . We also are grateful to the site's private landowner and lessee for granting us permission to conduct this work and to Paul Andahl for hosting the field crew and for allowing us to set up a waterscreen station on his property. The artifact sorting and quantification work carried out in PCRG's Flagstaff lab would not have been possible without the considerable talent and dedication of Stacey Madden. She supervised a crew of six lab assistants, including Matthew Curry, Tracy Ellefson, Michael Goldman, Mike Petriello, Michelle Qualls, and Andre Rosenzweig. Austin Candella and George Crawford also volunteered their time to the lab effort. Michael Ratcliffe drafted the excavation plan and profile drawings and photographed the pottery and stone tools. Delia Moder and Kim Spurr kept the organization running smoothly throughout the project.

Over the past decade, PCRG has been privileged to work with the State Historical Society of North Dakota toward common goals. Merl Paaverud, Director of the Society, has for many years strongly supported PCRG's planning, research, and education programs. Fern Swenson, the Director of the Historic Preservation Division, has worked tenaciously to build a comprehensive understanding of culture change in the Heart River region. Amy Munson, Grants Administrator for the Society, has capably administered the grant agreement for this and other recent projects. To each of them we extend our appreciation. 
xiv 


\title{
1. INTRODUCTION AND ProjeCt OVERVIEW
}

\author{
Mark D. Mitchell
}

During June 2006, PaleoCultural Research Group (PCRG), the State Historical Society of North Dakota (SHSND), and the Center for Advanced Spatial Technologies at the University of Arkansas (CAST) carried out collaborative field investigations at Larson Village (32BL9), a large, fortified earthlodge settlement on the east bank of the Missouri River about $20 \mathrm{~km}$ north of Bismarck, North Dakota. This work combined geophysical surveys with targeted test excavations designed to obtain a sample of artifacts and other materials for chronological and comparative purposes. Subsequent analyses of the recovered remains were carried out by a team of PCRG staff, members, and consultants working in Flagstaff (AZ), Boulder (CO), Fayetteville (AR), Cape May (NJ), Lincoln (NE), Bismarck (ND), Columbia (MO), and Las Vegas (NV). The project was supported by the SHSND (Project No. 38-06-21538-26), using Historic Preservation Grant Funds provided by the National Park Service.

\section{Background}

During the eighteenth century, the Mandans occupied at least six and perhaps as many as thirteen or more villages on both sides of the Missouri River in central North Dakota, from Eagle Nose Butte in the south to the Painted Woods district in the north (Figure 1.1). Prior to the devastating smallpox epidemic of 1781, they were divided into four bands or divisions, each of which occupied one or more villages (Bowers 1948, 1950; Wood and Irwin 2001). The Istopa, also known as "Those Who Tattoo Themselves," traditionally occupied the west bank of the Missouri, north of the Heart River in the Painted Woods district (Bowers 1950:25). By the eighteenth century, the Istopa had been joined by a second division, the Awigaxa, who earlier had been living near the mouth of the Grand River in what is now South Dakota. To the south, near the mouth of the Heart River, the Nuitadi or Nuweta occupied a series of large west-bank settlements, including On-A-Slant, Motsiff and Scattered villages. The Nuptadi, or Ruptare (Wood and Irwin 2001), occupied settlements on the east bank of the Missouri. When smallpox struck the Heart region in 1781 the Nuptadi were living in two communities, known as Yellow Bank Village and Round Lodge Village. Several sources identify Double Ditch State Historic Site, located about 5 km south of Larson, as Yellow Bank Village (Bowers 1940, 1950; Thiessen et al. 1979). Crows Heart, one of Alfred Bowers' Mandan informants, identified the Larson site as the location of Round Lodge Village (Bowers 1940).

Unlike many of the other late eighteenth century Heart region villages, Larson does not appear on a native map commissioned in 1906 and 1907 by Orin G. Libby, the Secretary of the SHSND. The map, drawn by a Mandan named Sitting Rabbit, shows the locations of earthlodge villages as well as culturally-significant natural features located along the Missouri River from the South Dakota border to the mouth of the Yellowstone (Thiessen et al. 1979). Neither is Larson on another native map, drawn by the Mandan Wounded Face for Gilbert Wilson (Gilbert Wilson Collection, American Museum of Natural History). Similarly, Lewis's and Clark's detailed maps do 


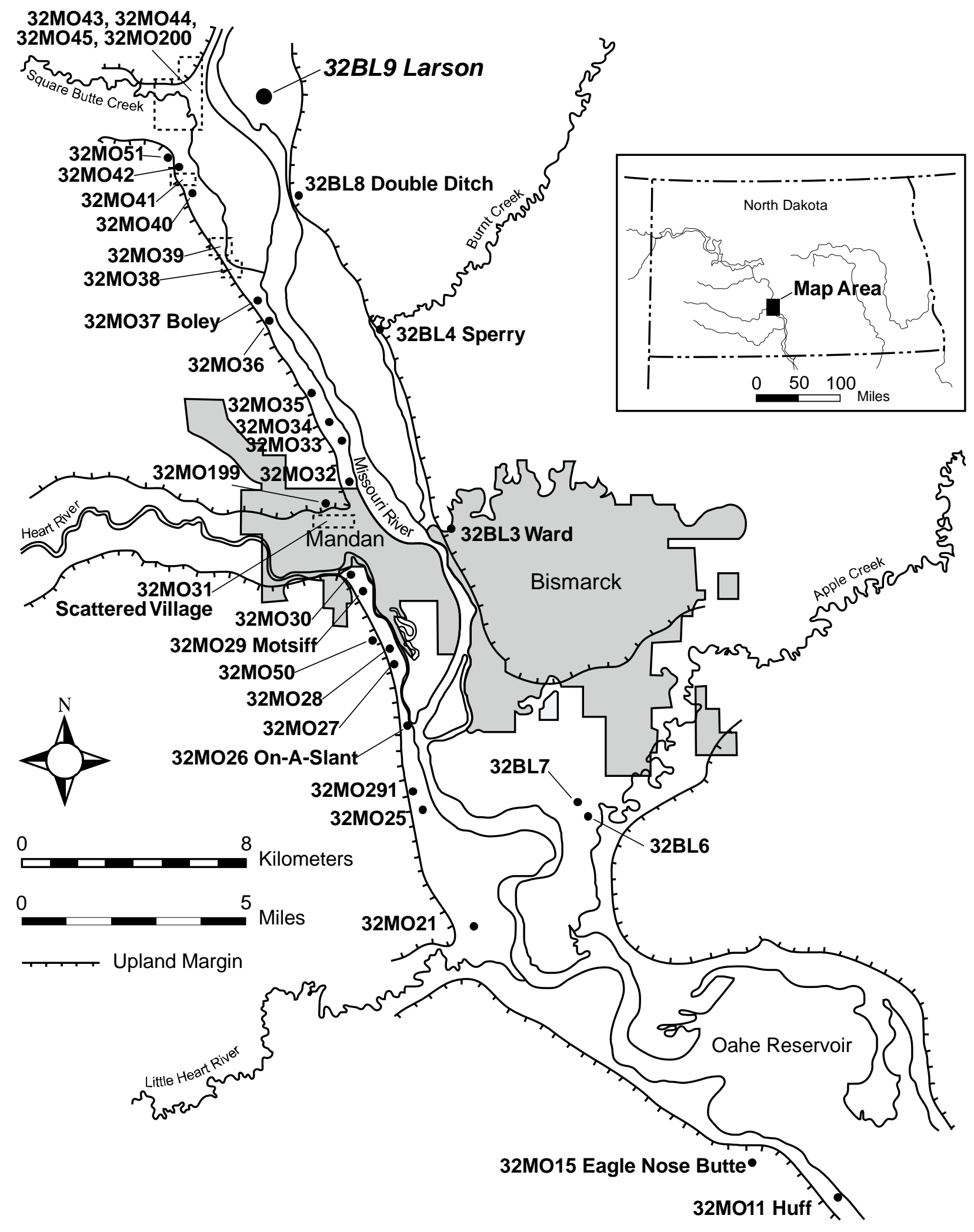

Figure 1.1. Location map of Larson Village and other sites in the Heart region.

not show Larson, even though the Corps of Discovery camped nearby on the night of October 22, 1804. Currently, the Missouri is located more than $1.5 \mathrm{~km}$ from the site, on the western edge of the 
floodplain. It is tempting to think that Larson was omitted from these maps because its distance from the river made it difficult to see. However, in 1804 the river was much closer to the village than it is today (Figure 1.2). In fact, Will and Hecker (1944:50) report that Larson was abandoned

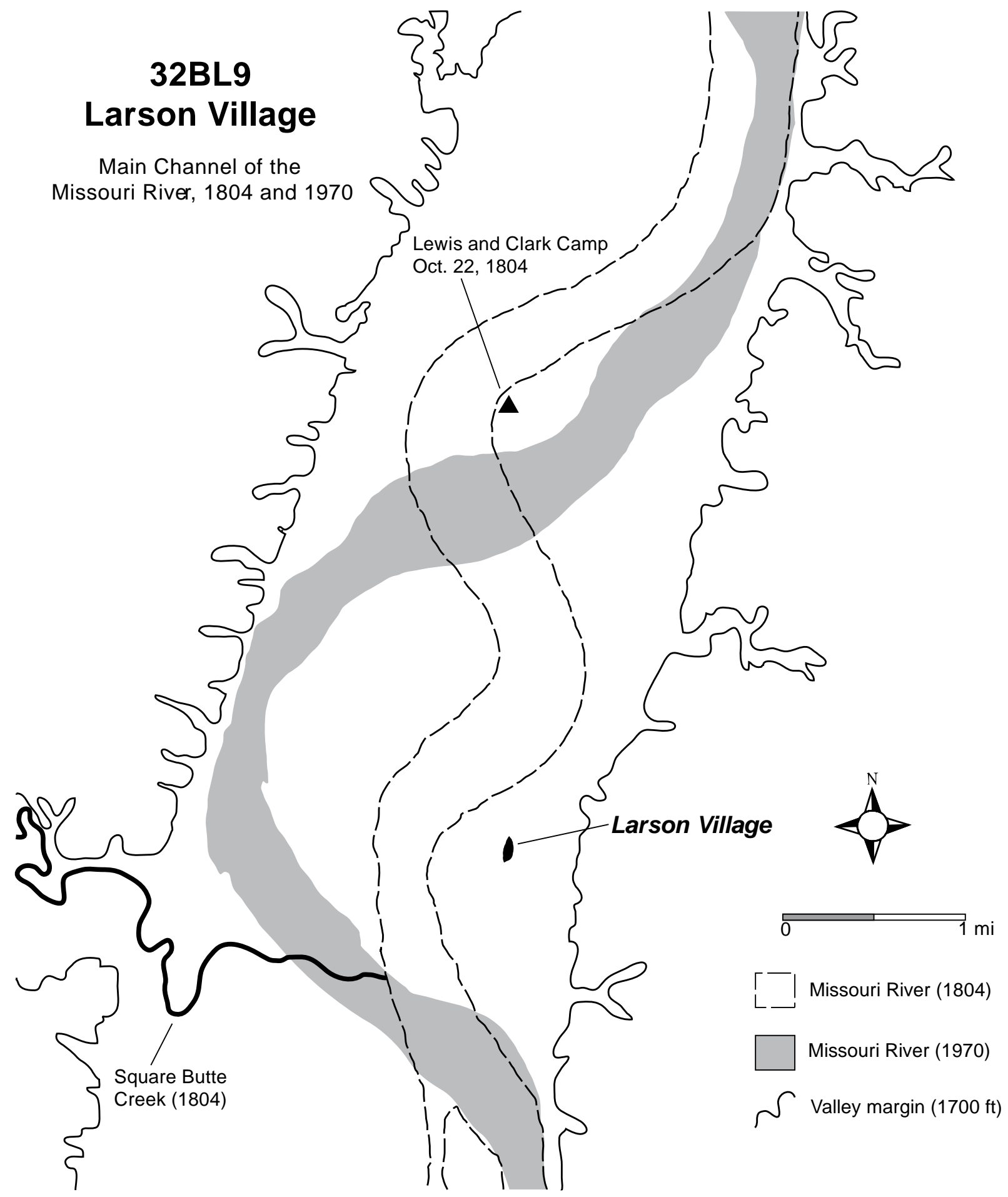

Figure 1.2. Map showing the main channel of the Missouri River adjacent to Larson Village in 1804 and 1970 (after Plamondon 2000). 
because the river was cutting into the terrace on which it is located; however, the source of their information is not known. In any case, these cartographic data may signal that Larson was abandoned earlier in the eighteenth century, long before Lewis and Clark visited the region and therefore was less well known to nineteenth and twentieth century Mandans (see also Bowers 1948:Footnote 141).

The site first received archaeological attention more than a century ago. E. R. Steinbrueck visited the village in 1904 and noted the presence of two fortification ditches. Both features were observed in the cutbank marking the western edge of the site, with the outer ditch approximately 510 feet north of the inner ditch, just beyond the northernmost midden mounds. He also noted that the ditches were only about 100 feet apart on the south side of the village (Steinbrueck 1904:150151; Swenson 2007). However, this outer ditch is not shown on any of the early maps of the site, so its track through or around the site was not known. The village was first mapped the following year by George F. Will and Herbert J. Spinden, two Harvard undergraduates who were working at Double Ditch Village. They describe a "well-marked ditch," an open plaza, and a series of large mounds ringing the settlement. They remark on the seemingly unusual position of the fortification (Steinbrueck's inner ditch), which they believed bisected rather than surrounded the site (Will and Spinden 1906: 149, Map III).

In 1929, Alfred W. Bowers again mapped the village and conducted rather extensive excavations. Like Will and Spinden, Bowers describes a single ditch, an open plaza, and a "virtual wall” of encircling midden mounds (Bowers 1940:36, 48). Bowers counted 76 earthlodge depressions, including six on the east side of the site that had been nearly obliterated by plowing. Twenty-four of these were located within the fortification ditch. Bowers excavated two lodges and three middens, locating numerous features and documenting thick trash deposits between and beneath the lodges. Bowers also demonstrated that the visible fortification system was built after the village had been occupied for some time.

The site presently covers about 12.7 acres, but undoubtedly was larger at one time. When it was first mapped in 1905, bank erosion already had destroyed at least some lodges and the original contours of the site's mounds and ditches had been modified by plowing. By the late 1920s, a garden had been established on the southern part of the site, partially obliterating surface features there. Later, a house and other buildings were constructed on this part of the site. In 1975, a county road was constructed across the southern edge of the village. Extensive unprofessional digging has taken place at various times in the past, but apparently not recently. However, despite these impacts, Larson Village remains one of the best preserved earthlodge settlements in the Heart River region today (Metcalf 2001).

\section{Research Goals}

The research design for the 2006 investigations at Larson Village was framed in relation to discoveries made during recent work at Double Ditch Village (32BL8, 2001-2004), the best preserved of the eighteenth-century Mandan settlements near the Heart River (Ahler, ed. 2003, 2004, 2005; Ahler and Kvamme 2007), and at Boley Village (32MO37), a west-bank village located about four miles north of Mandan (Ahler, ed. 2006). The occupational histories of these two contemporaneous villages contrast rather sharply. At Double Ditch, geophysical and other data 
show that four concentric fortification systems were built around the community. Dates for these features, established by a combination of radiocarbon dating, trade artifact density analysis, and stratigraphic correlation, indicate that the outermost is likely the oldest and that the innermost is the youngest. Thus, the village contracted progressively over time, with a peak population at the time the village was founded in the late 1400s and with a minimal population and size right before abandonment in the AD 1780s. Earthen mounds are prominent at Double Ditch, and testing indicates that some mounds were built rapidly and purposefully and that most of them were likely integral parts of the village defensive system. Extensive earth borrowing - for mound construction, earthlodge covering, and possibly for ceremonial village cleansing — was a frequent and prominent activity at Double Ditch. Material remains at Double Ditch, particularly pottery, changed markedly during the roughly three centuries it was occupied.

At Boley Village, geophysical and topographic data reveal that the village is surrounded by at least three fortification ditches. However, unlike those at Double Ditch, the two outermost Boley fortifications are not concentric, but rather cross one another. Along with ceramic evidence, these data indicate that the village was substantially rebuilt and reoriented, probably in the late 1600s or early 1700s. The magnitude of the shift further suggests that the two occupations of the village may have been interrupted by a hiatus of unknown duration. Radiocarbon dates and ceramic analysis indicate that the oldest sampled features, including one of the fortification ditches, may not be quite as old as the oldest features at Double Ditch, possibly indicating that the village was founded in the late 1500 s or early 1600s. While the artifact assemblage recovered from Boley is broadly similar to that from Double Ditch, the high frequency of exotic lithic raw materials found in some features at Boley indicates that the village's occupants maintained important connections to the south, southwest, and west. Midden mounds are present at Boley, but they are far less prominent than those at Double Ditch; however, a variety of post-occupation processes, most notably unprofessional digging and plowing, may largely be responsible for the current surface appearance of the site. The relationships among Boley's mounds and fortification features are not known.

Data obtained by early twentieth century investigators indicate that Larson Village shares a number of important features with Double Ditch Village. Like Double Ditch, Larson is surrounded by multiple, concentric fortification systems, the innermost of which is the most recent. Both sites exhibit large perimeter mounds that at one time may have been part of the village defenses. Both contain open areas that may have served as public plazas. However, there may also be significant differences between them. Bowers (1940) reported substantial midden accumulations between the lodges at Larson, something not seen during recent excavations at Double Ditch. This may indicate that the extensive sediment borrowing and periodic village renewal that took place at Double Ditch did not occur at Larson. It also is not known when Larson was founded, or whether the occupation was continuous.

Accordingly, the two primary research objectives pursued during the 2006 investigations have been, first, to determine whether the settlement history of Larson was characterized by progressive contraction like that of Double Ditch or by reoccupation and reorientation like that of Boley and, second, to obtain a well-controlled sample of artifacts that will enable finer-grained material comparisons between Larson and other contemporaneous villages. To accomplish these overall goals work focused on determining the age of the village, on locating and documenting its major features, and on conducting basic analyses of the excavated collection. Attention focused mainly on the northern periphery of the village because work at Boley and Double Ditch has shown that a village's outermost features can be among the oldest and because the inner core of a village 
typically contains a confusing morass of overlapping features and midden deposits of different ages (Figure 1.3).

As lab work progressed it became clear that the Larson collection differed in several important ways from other Heart region collections. Specifically, the pottery assemblage appeared to be more fragmented and the diversity and richness of the bone and stone tool assemblages appeared to be comparatively low. To investigate the nature and possible causes of these differences analysis focused in part on characterizing site formation processes. Comparisons of the material content of various deposit types were used to accomplish this task.

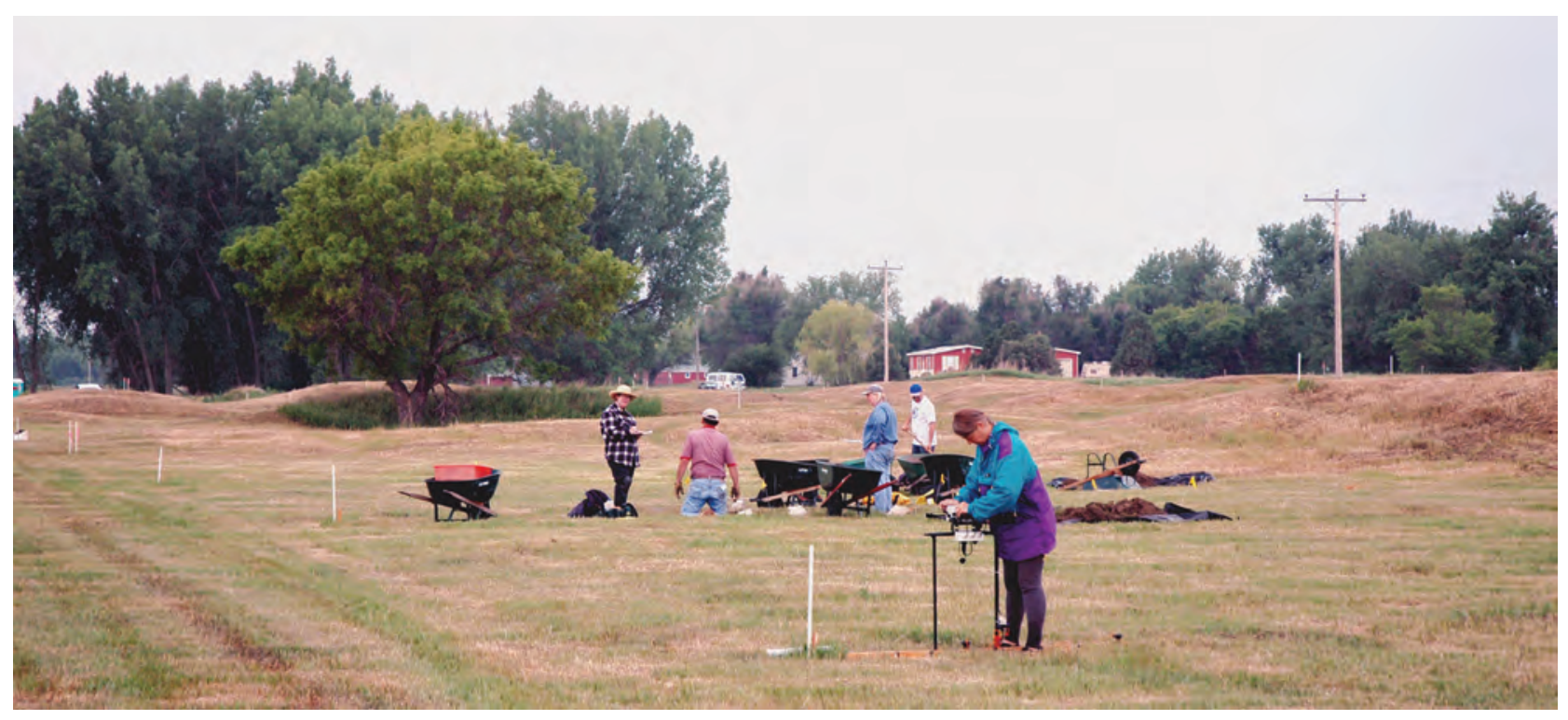

Figure 1.3. Overview of the northern perimeter of Larson Village. In the foreground, Jo Ann Kvamme collects resistivity data. In the background, Laurinda Porter (l), John Vicha, and Fern Swenson work in Ditch 4 and Tim Reed (r) works in Block G.

\section{Report Contents}

In Chapter 2 of this report, Fern Swenson discusses the history of research at Larson Village and documents the type and scope of disturbances to which it has been subjected. Historic photographs and maps are presented, documenting the changing surface condition of the site. Chapter 3 describes in detail the geophysical surveys and their results. This work was carried out by Ken and Jo Ann Kvamme of the Center for Advanced Spatial Technologies at the University of Arkansas. Through magnetic gradiometry and electrical resistance they explored the northern and eastern peripheries of the site. The geophysical surveys document and provide an archival record of the general subsurface condition and layout of this part of the site.

The results of the excavation program, along with the field methods used, are described in Chapter 4. Presentation of the excavation data emphasizes stratigraphic relationships among documented features and strata and provides details about the course of excavation of each unit. The excavation strategies were guided in part by the geophysical results. Specifically, the high precision of the magnetic data made it possible to pinpoint the locations of test units over significant cultural features and thus maximize the limited time available for testing. Criteria for feature 
selection included size, definition, and relationship to the settlement's fortification systems. After potential features were identified in the magnetic gradiometry data hand coring was used to estimate their relative richness and to refine the placement of test units.

The excavated materials were processed in PCRG's Flagstaff lab between September 2006 and March 2007. The basic lab methods used are described in Chapter 5. Chapter 6 discusses the results of the AMS radiocarbon dating program and provides details about the analytic structure used to organize the presentation of data on artifacts and other remains in chapters 7 through 12 .

Pottery data are presented in Chapter 7. Body sherd data were systematically collected and rim sherds were analyzed by variety. These analyses were carried out by Stacey Madden and Mark Mitchell. Analyses of the modified stone assemblage were carried out by George Crawford, Tracy Ellefson, Stacey Madden, and Mark Mitchell and are discussed in Chapter 8. Stone tools were analyzed by technology and raw material composition, and flaking debris was analyzed primarily by raw material classification. Faunal remains have been analyzed at the level of class and size group for mammals, and these data are discussed in Chapter 9 by Carl Falk. Modified bone and antler remains also were analyzed by Falk and are discussed in Chapter 10. A sample of botanical remains was analyzed in detail by Robert Nickel, with the results presented in Chapter 11. Shell, trade artifacts, and other artifact categories were examined by Stacey Madden, Mark Mitchell, and Paul Picha. Data on these classes of artifacts are discussed in Chapter 12. The final chapter summarizes what has been learned from the project, including comparisons with other recently investigated sites near Heart River. 


\section{References Cited}

Ahler, Stanley A. (Editor)

2003a Archaeology at Menoken Village, A Fortified Late Plains Woodland Community in North Central North Dakota.

2003b Archaeological Investigations During 2001 and 2002 at Double Ditch State Historic Site, North Dakota. Research Contribution No. 56. Prepared by PaleoCultural Research Group, Flagstaff, Arizona. Submitted to the State Historical Society of North Dakota, Bismarck.

2004 Archaeological Investigations During 2003 at Double Ditch State Historic Site, North Dakota. Research Contribution No. 60. Prepared by PaleoCultural Research Group, Flagstaff, Arizona. Submitted to the State Historical Society of North Dakota, Bismarck.

2006 Geophysical Survey and Test Excavation During 2006 at Boley Village (32MO37), North Dakota. Research Contribution No. 74. PaleoCultural Research Group, Flagstaff, Arizona. Submitted to the State Historical Society of North Dakota, Bismarck.

Bowers, Alfred W.

1940 Missouri River Earthlodge Archaeology of North Dakota and South Dakota. Manuscript on file at Logan Museum, Beloit College, Beloit, Wisconsin.

1948 A History of the Mandan and Hidatsa. Unpublished Ph.D. dissertation, Department of Anthropology, University of Chicago.

1950 Mandan Social and Ceremonial Organization. University of Chicago Press, Chicago.

Kvamme, Kenneth L., and Stanley A. Ahler

2007 Integrated Remote Sensing and Excavation at Double Ditch State Historic Site, North Dakota. American Antiquity 72(3):539-561.

Metcalf, Michael D.

2001 Plains Village Site Evaluations Near Bismarck, North Dakota, and Inventory of Selected Missouri River Terraces, Burleigh, Morton, and Oliver Counties. Metcalf Archaeological Consultants, Eagle, Colorado. Submitted to the State Historical Society of North Dakota, Bismarck.

Plamondon, III, Martin

2000 Lewis and Clark Trail Maps: A Cartographic Reconstruction. Washington State University Press, Pullman.

Steinbrueck, E. R.

1904 Mandan Village Sites. In Mandan Memoirs of Explorations in the Basin of Mississippi. J.F. Bower Press of McGill-Warner Co., St. Paul, Minnesota.

Swenson, Fern E.

2007 Settlement Plans for Traditional Mandan Villages at Heart River. In Plains Village Archaeology, edited by Marvin Kay and Stanley A. Ahler. University of Utah Press, Salt Lake City.

Thiessen, Thomas D., W. Raymond Wood, and A. Wesley Jones

1979 The Sitting Rabbit 1907 Map of the Missouri River in North Dakota. Plains Anthropologist 24(84, Part 1):145-167.

Will, George F., and Thad. C. Hecker

1944 The Upper Missouri River Valley Aboriginal Culture in North Dakota. North Dakota Historical Quarterly 11(1 and 2):5-126. 
Will, George F., and Herbert J. Spinden

1906 The Mandans: A Study of their Culture, Archaeology and Language. Papers of the Peabody Museum of American Archaeology and Ethnology, Vol. III, No. 4. Harvard University, Cambridge, Massachusetts.

Wood, W. Raymond, and Lee Irwin

2001 Mandan. In Handbook of North American Indians: Plains, Volume 13, Part 1, edited by Raymond J. DeMallie, pp. 349-364. Smithsonian Institution, Washington, D. C. 


\title{
2. Previous InVestigations at Larson Village
}

\author{
Fern E. Swenson
}

\section{Introduction}

The spectacular nature of earthlodge village sites, with fortification systems and large earthen mounds surrounding numerous house remains, undoubtedly contributed to early investigators mapping and excavating at numerous Mandan settlements at the Heart River (Swenson 2004, 2007). Fortunately, Larson Village was one of the sites that were mapped in the early 1900s (Will and Spinden 1906). Although 60 percent of the site is in an excellent state of preservation to date, the remainder of the site has been severely impacted by road construction, a farmstead, and a century of cultivation that have obscured any evidence of features on the ground surface.

Utilizing early maps, notes from various early excavations, and examining a series of aerial photographs a glimpse into the site boundaries is gained. However, it is only with the aid of stateof-the-art geophysical surveys followed by archaeological test excavations that we are able to more fully understand settlement dynamics and chronology of occupation at these complex nucleated settlements at the Heart River as has been demonstrated at Double Ditch Village (Kvamme 2006a; Ahler, ed. 2003, 2004, 2005) and Boley Village (Ahler, ed. 2006). This chapter provides background information regarding the early investigations at the Larson site. Figure 2.1 depicts the site boundary on a 2004 aerial photograph illustrating the current site condition. The site once covered at least 12.7 acres (5.1 ha.). Prior to the current investigations the site was thought to encompass 7.5 acres (3 ha) (Swenson 2004, 2007) to 8 acres (3.2 ha) (Will and Hecker 1944:82-83).

\section{Early Plan Maps}

The location of the Larson site was first recorded on the 1894 Missouri River Commission map (Sheet \#20) along with Double Ditch and Sperry villages. However, the earliest known map of Larson specifically is a contour map produced by Herbert Spinden in 1905 (Will and Spinden 1906). The Larson site was later mapped by Alfred Bowers in 1929 in conjunction with archaeological excavations. These maps have been redrafted and are illustrated in Figure 2.

The Larson site is located on a low terrace on the east side of the Missouri River encompassing 12.7 acres (5.1 ha) at present. Lodge depressions were evident along the cutbank when the site was first mapped indicating it originally was larger. The village was surrounded by midden mounds on three sides and the riverbank on the west side. A gently sloping open plain extends east beyond the midden mounds. The inner fortification ditch bisects a midden mound on the southern part of the site indicating the midden mound existed prior to construction of the inner ditch. The inner ditch has a berm to the inside of the ditch. Based on evidence from the 1950 aerial photograph of the site, the inner ditch surrounds 2.3 acres (0.92 ha) which is approximately 18 percent of the founding village. Similarly, at Double Ditch the final occupation was only about one-fifth the size of the original founding community. 
Will and Spinden (1906:149) specifically discuss a single inner ditch. By this time the site had been cultivated, including the midden mounds (Will and Spinden 1906:149; Will and Hecker 1944:82; Steinbrueck 1904:151). The 60 percent of the site that is currently in relatively pristine condition is unlikely to have been cultivated for very long given the very distinct surface features (ditch, house depressions, plaza, and midden mounds). Ditch 2 is visible on the ground surface today but would be difficult to see with overgrown grass. Bowers likewise only discusses and mapped the inner ditch.

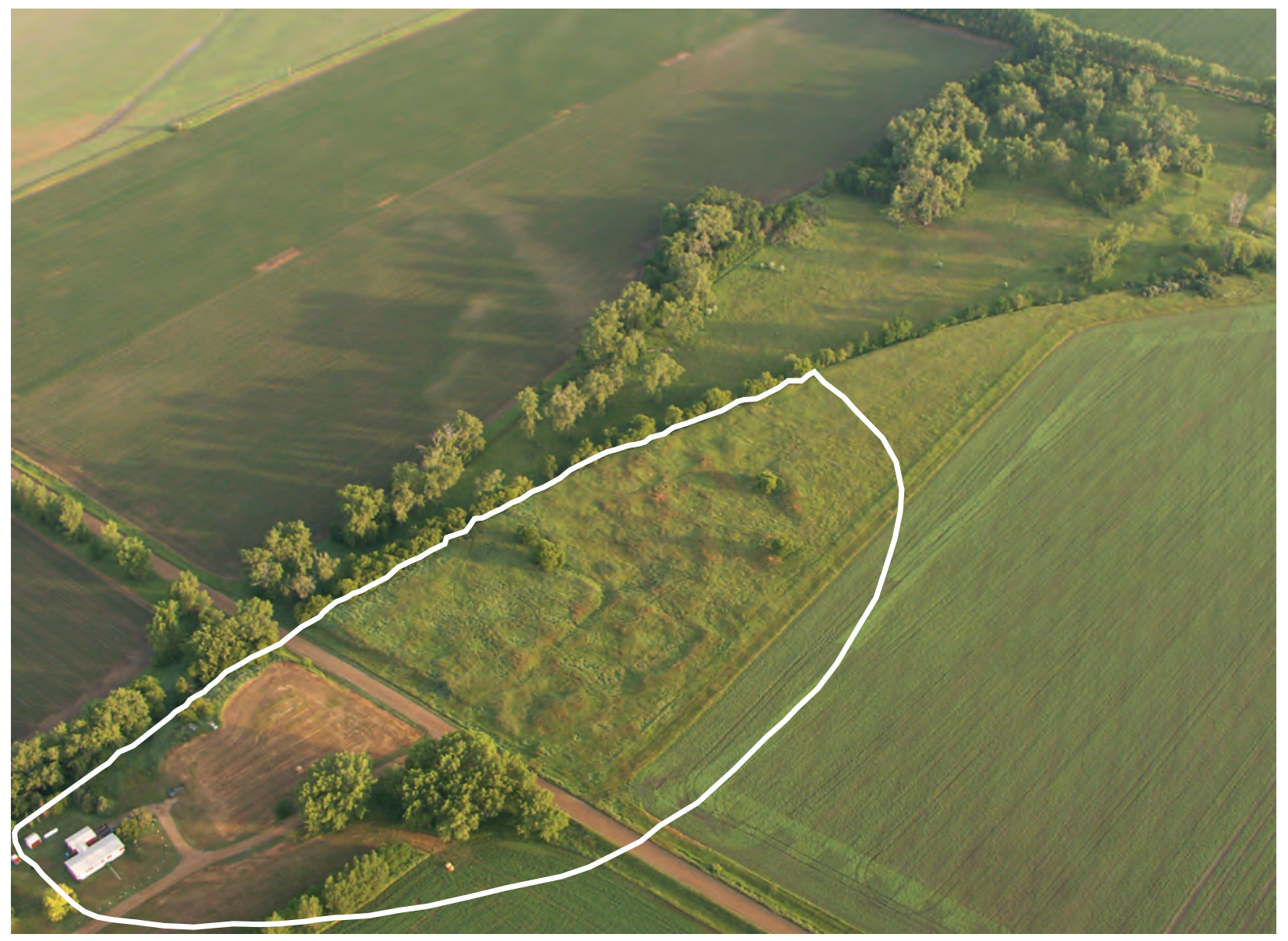

Figure 2.1. Site boundary of Larson Village illustrated on a 2004 aerial photograph.

An outer ditch is explicitly noted by Steinbrueck (1904:150-151), although not illustrated on either the 1905 Spinden or 1929 Bowers maps. The outer ditch is described as being situated just outside the earthworks surrounding the village. At the bank, the outer ditch is described as being $510 \mathrm{ft}(155.4 \mathrm{~m})$ north of the inner ditch but at the southern end of the village the ditches are reported as being only $100 \mathrm{ft}$ (30.5 m) apart (Steinbrueck 1904:150-151). Both ditches are described as beginning and ending at the bank. Based on the geophysical survey (Kvamme 2006a) and archaeological investigations (this volume) it is now known that four ditches are present at Larson. Thus, the ditch $510 \mathrm{ft}(155.4 \mathrm{~m})$ north of the inner ditch observed by Steinbrueck is likely Ditch 4. The southern ditch observed by Steinbrueck is likely Ditch 2 given that $195 \mathrm{ft}$ (59.4 m) south of the inner ditch a farm road was cut down the terrace and lodge floors and several cache pits were uncovered. 


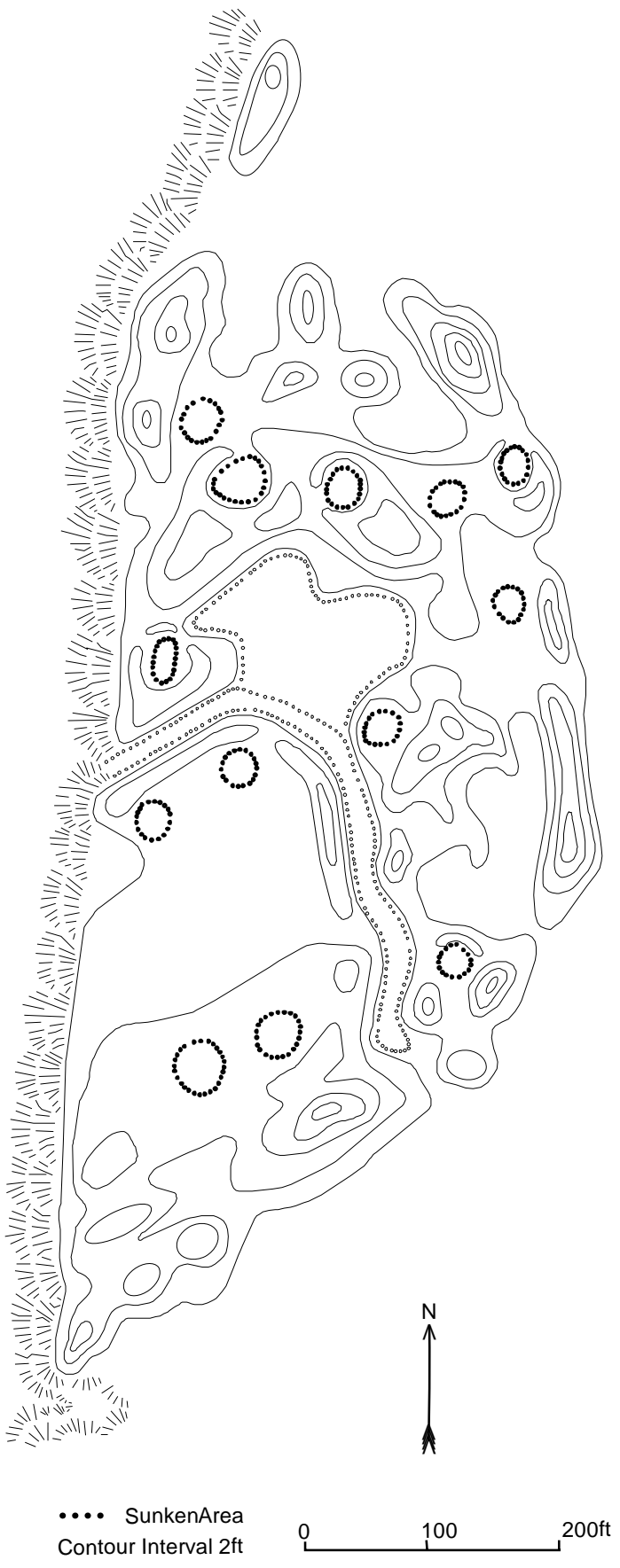

Spinden and Will 1905

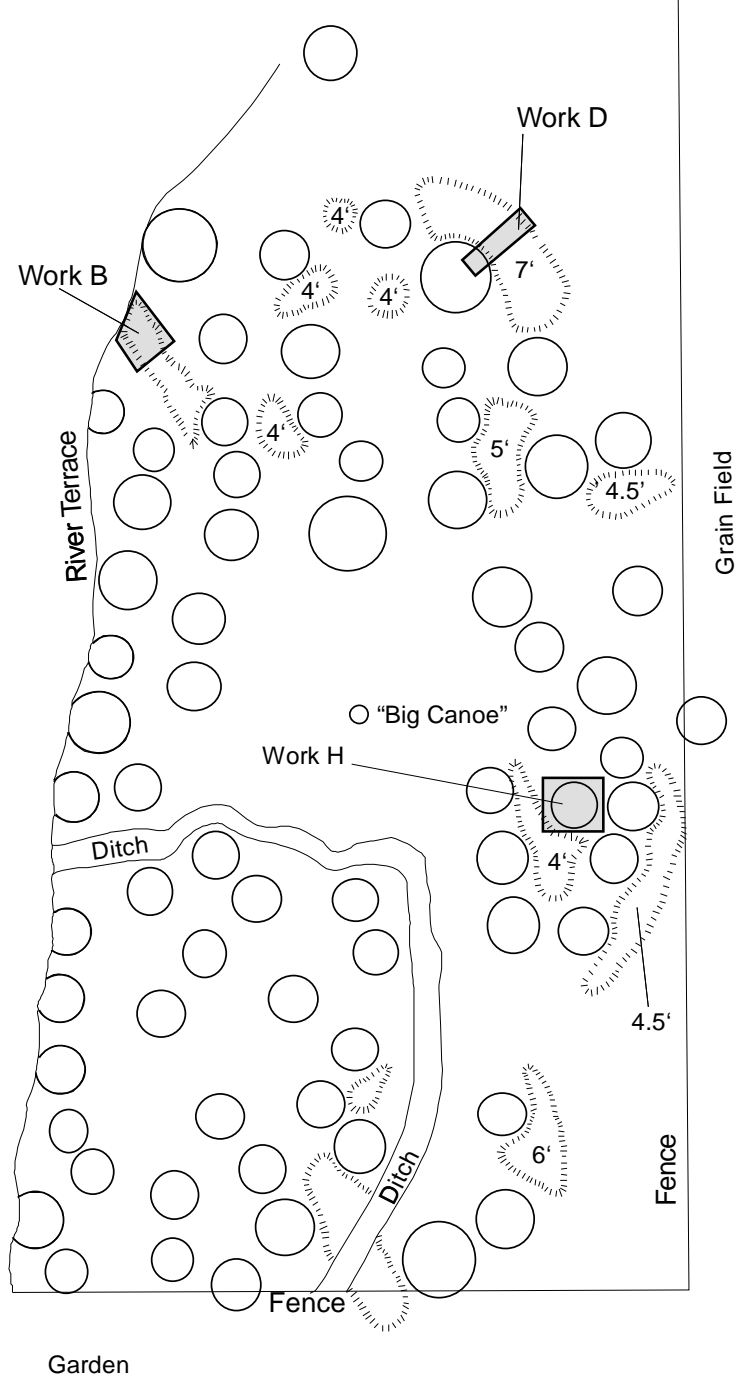

$\stackrel{N}{\Lambda}$

$\wedge$

Excavation

II!) Earthen Mound $\quad$ 100 $10 \mathrm{ft}$

Alfred W. Bowers 1929

Figure 2.2. Plan maps of Larson Village (32BL9). The Spinden and Will map is after the map originally published in Will and Spinden 1906: Map III. The Bowers map is redrafted after the 1929 map by Alfred Bowers during the Logan Museum investigations.

Bowers (1940:56) reported 76 earthlodges at the site with 24 of these within the inner fortification ditch. The number of earthlodge depressions depicted on these early maps tends to be inflated. As was determined at Double Ditch the inner ditch encompassed 32 or 33 clear house 
depressions within an area of 4 acres (1.6 ha) (Ahler et al. 2005:330). If we utilize this as a guide in determining earthlodge density at Larson within the inner ditch approximately 19 houses may have been in the 2.3 acre $(0.92 \mathrm{ha})$ core residential area during the last occupation.

A plaza area is identified by Bowers at the Larson site and is also evident on the Spinden and Will map. An open area (100 x 150 to $175 \mathrm{ft}$ or $30.5 \mathrm{~m} \mathrm{x} 45.7$ to $53.3 \mathrm{~m}$ ) just outside and north of the inner fortification ditch has an elevated point near the center of the circle that is $8 \mathrm{ft}(2.4 \mathrm{~m})$ in diameter and 15 inches $(38.1 \mathrm{~cm})$ higher than the surrounding ground which apparently marks the Mandan sacred cedar. Bowers (1940:58-59) also noted a larger lodge with an indistinct south wall, possibly representing a ceremonial lodge, just north of the plaza.

According to Mandan tradition, there were two important villages on the east side of the Missouri River just prior to the smallpox epidemic of the late eighteenth century. Crows Heart identified these as Round Lodge Village (Larson) and Yellow Earth Village (Double Ditch) (Bowers 1940:59-60). Steinbrueck (1904:149-150) refers to the Larson site as Half Moon Village.

\section{History of Destruction and Archaeological Excavations}

\section{Erosion, Cultivation, Farmstead, and Road Construction $\left(149^{\text {th }}\right.$ Street $)$}

Bank erosion has taken its toll on the site. The site is on a low terrace, $20 \mathrm{ft}(6 \mathrm{~m})$ high. Truncated lodge depressions were evident along the cutbank when the site was originally mapped, indicating that it may have once been a much larger site now reduced by river erosion. The arc of the inner ditch supports the proposition that considerable area has been lost.

The Larson site has undergone a long period of disturbance. A substantial percentage of the site has been destroyed with little solid information about its actual archaeological content being recorded. Figure 3 illustrates the location of various disturbances. Approximately 6.9 percent of the site has been mostly destroyed (except for truncated features) by road construction, 13.7 percent by a farmstead, and approximately 19.1 percent has been greatly altered by cultivation. Although parts of the site have been cultivated for over a hundred years, it is likely that truncated features remain in those areas, as has been demonstrated at the Boley site which had been cultivated for over a hundred years (Ahler, ed. 2006). Just over 60 percent of the Larson site remains in relatively pristine condition.

A farmstead has been located on the southern part of the Larson site at least since the early twentieth century. Construction of farm buildings and farm roads has disturbed a significant portion of the site. The southern boundary of the site as illustrated in Figure 1 is based on what can be gleaned from scant information in the State Historical Society accession records and other information about these disturbances. The accession records indicate that Thad Hecker excavated at the Larson site in 1938 and 1940. Excavations during one of those years (probably 1940) produced the collections relating to a farm road cut down the terrace to the floodplain. At that time, the cut uncovered a lodge floor and several cache pit features both within and outside the lodge (Will and Hecker 1944:23-24). Nine large cache pits were under the lodge floor and five large cache pits 


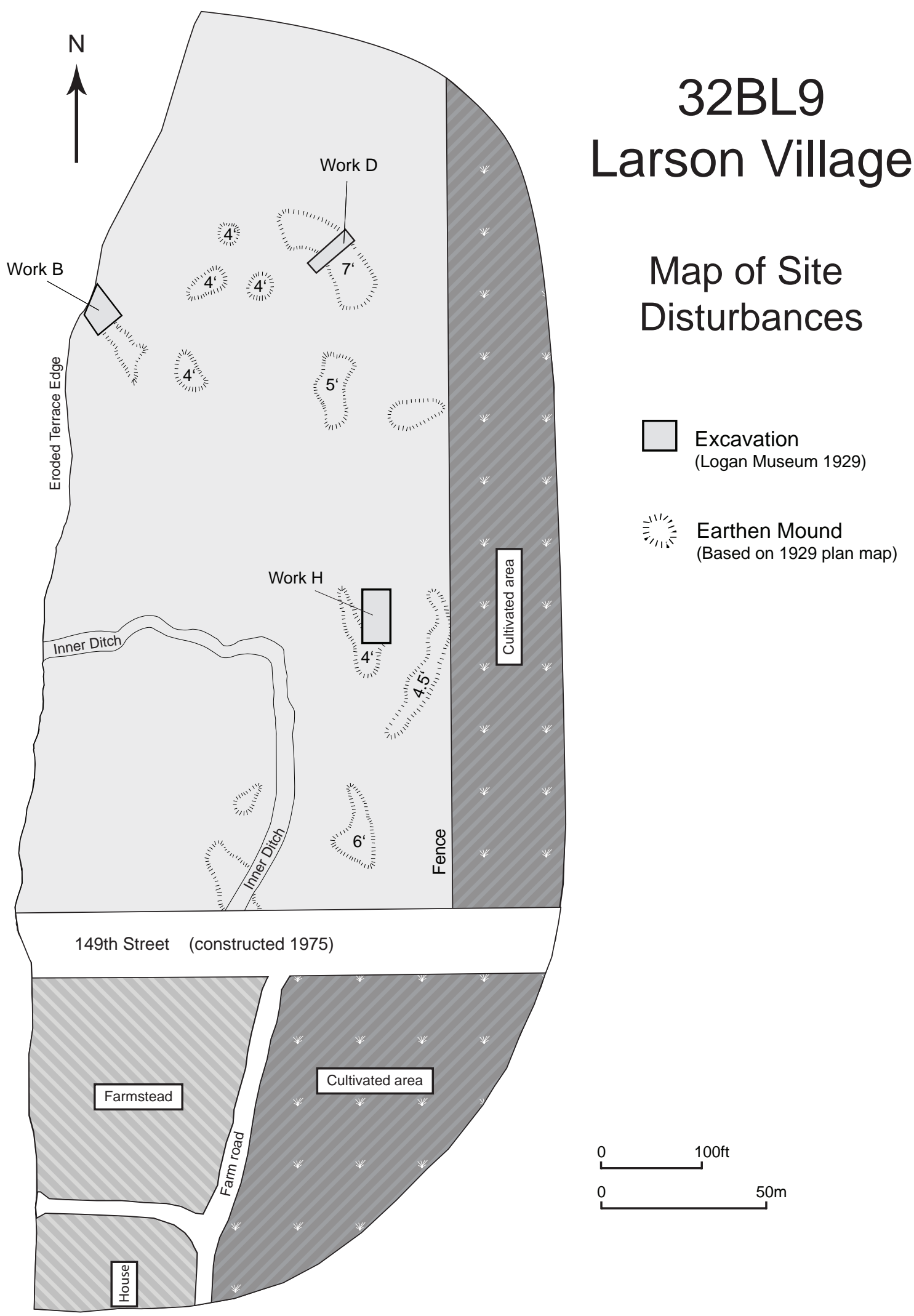

Figure 2.3. Plan map of Larson Village showing approximate locations of various historic disturbances to the site based on data from multiple sources. 
were outside but close to the lodge wall. Post sections were recovered during those excavations. Artifact collections relating to this disturbance have not been analyzed. Other collections have been made south of this location along the bank. Metcalf (2001:20) recently produced a GPS sketch map that illustrates the location of the cut made in 1940 down the terrace, as well as many other features evident today at the site.

Road construction ( $149^{\text {th }}$ Street) in 1975 destroyed a substantial portion (0.87 acres or 6.9 percent) of the site (Figure 4). Prior to 1975 there was a dirt road (with gravel top) located on the southern edge of the village leading to a farm house that can be seen on the 1938, 1950, and 1966 aerials (Figures 5 and 6). The landowner at that time (Mr. Bud Perkins) reported that, during construction of his house (in the early 1970s) and excavation of a road into his field, six burials were uncovered (personal communication to Nick G. Franke, May 19, 1975). Mr. Perkins was opposed to construction of a new road that a developer (Mr. William Clairmont) was proposing go through the site along the section line. In May of 1975, the road was constructed by the developer and it disturbed an area $66 \mathrm{ft}(20 \mathrm{~m})$ wide through the site (Figure 4). According to the engineer, up to $5.4 \mathrm{ft}(1.6 \mathrm{~m})$ of cultural material was removed to sterile soil. By overlaying the right-of-way on Bowers’ 1929 map, it is evident that the road minimally disturbed four houses, the inner fortification ditch and a midden mound. Undoubtedly, this construction also crossed the outer three fortification ditches encircling the village but these were not identified at that time.

Limited salvage of remains was conducted by SHSND archaeologists during the road construction project. However, the road grading occurred rapidly and little information was collected. Field notes indicate that cache pits were hastily excavated. Surface artifacts were collected as the site was extensively disturbed. Six units were excavated, including four in house depressions (XUs 1, 4, 5, and 6), one in a midden mound (XU2), and one in the inner ditch (XU3). A site datum was not established at the time, but the excavation units were plotted on Bowers' 1929 map. Artifacts collected during this work have been catalogued under Accession Numbers 75.36 and 78.138.

A few years later a report was prepared by Taylor (1979) on the salvage from the road construction. One pit feature contained an articulated flexed burial and a bundle burial of a postinfant child. Two other individuals were also represented by the recovered remains. In addition, there were minimally four other individuals represented in the material recovered during road construction. Four crania were recovered and all were damaged by heavy equipment. All human remains were turned over to the North Dakota Intertribal Reinterment Committee in the 1980s.

Taylor's report describes other recovered material including bone tools, fire-cracked rock, chipped stone tools, chipped stone flaking debris, and ground stone. One gun flint and a bone knife handle designed for a metal blade were the only evidence of Euroamerican contact from this sample (Taylor 1979). The pottery assemblage was not described in the Taylor report but a sample of rims from the collection has been studied by Ahler (2001:18).

At the time of the road construction, amateur archaeologist Ralph Thompson made a sizable collection of artifacts from the Larson site that is now housed at the State Historical Society of North Dakota. Thompson collected a number of trade artifacts from the site and later proposed that 

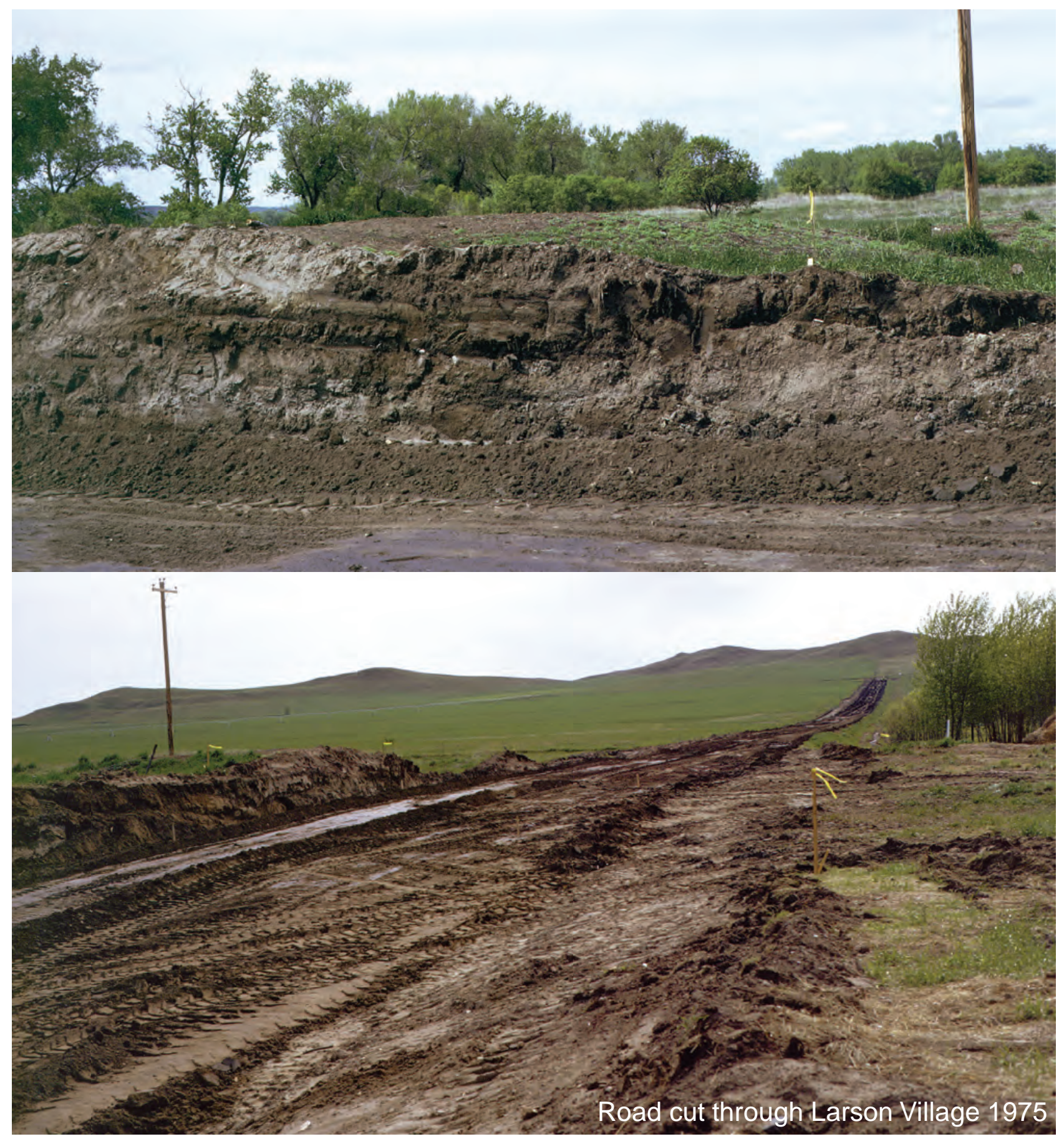

Figure 2.4. Stripping of Larson Village related to the 1975 road construction. Photographs in the collection of the Historic Preservation Division, State Historical Society of North Dakota.

the Larson site may be the Mandan Indian Village visited by Sieur de la Verendrye, a French fur trader and explorer, in 1738 (Thompson 1984). Thompson's collections have not yet been accessioned. 


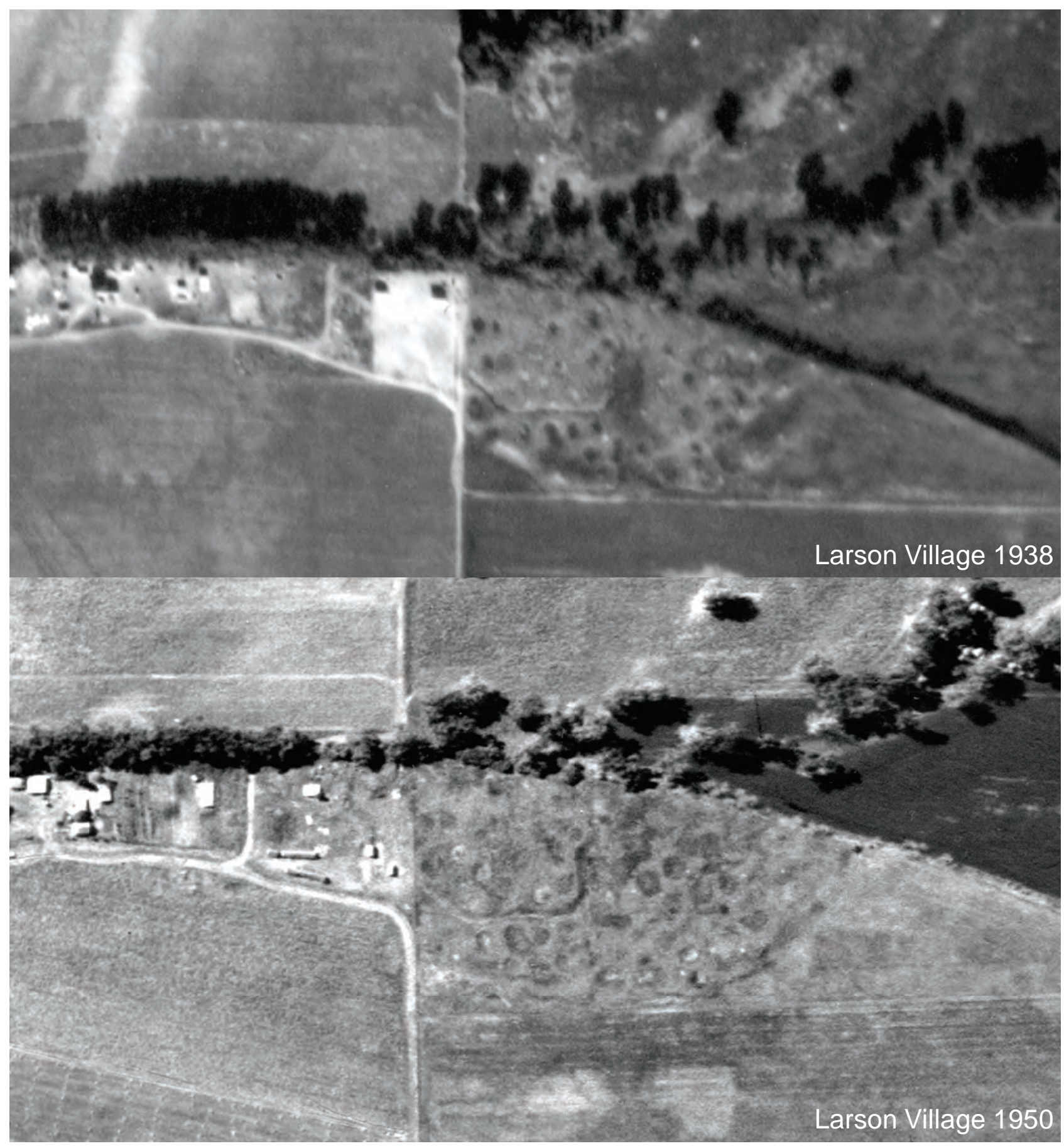

Figure 2.5. Vertical aerial photographs of Larson Village taken in 1938 (top) and 1950 (bottom).

\section{Bowers’ (Logan Museum) 1929 Excavation}

Bowers excavated one midden mound on the northwest edge of the village, one trench through the highest mound on the northeast edge of the village, part of a mound along the east central section of the site, one lodge depression immediately southeast of the open circle, a rectangular area between lodges on the southwest edge of the site, and one L-shaped block between 


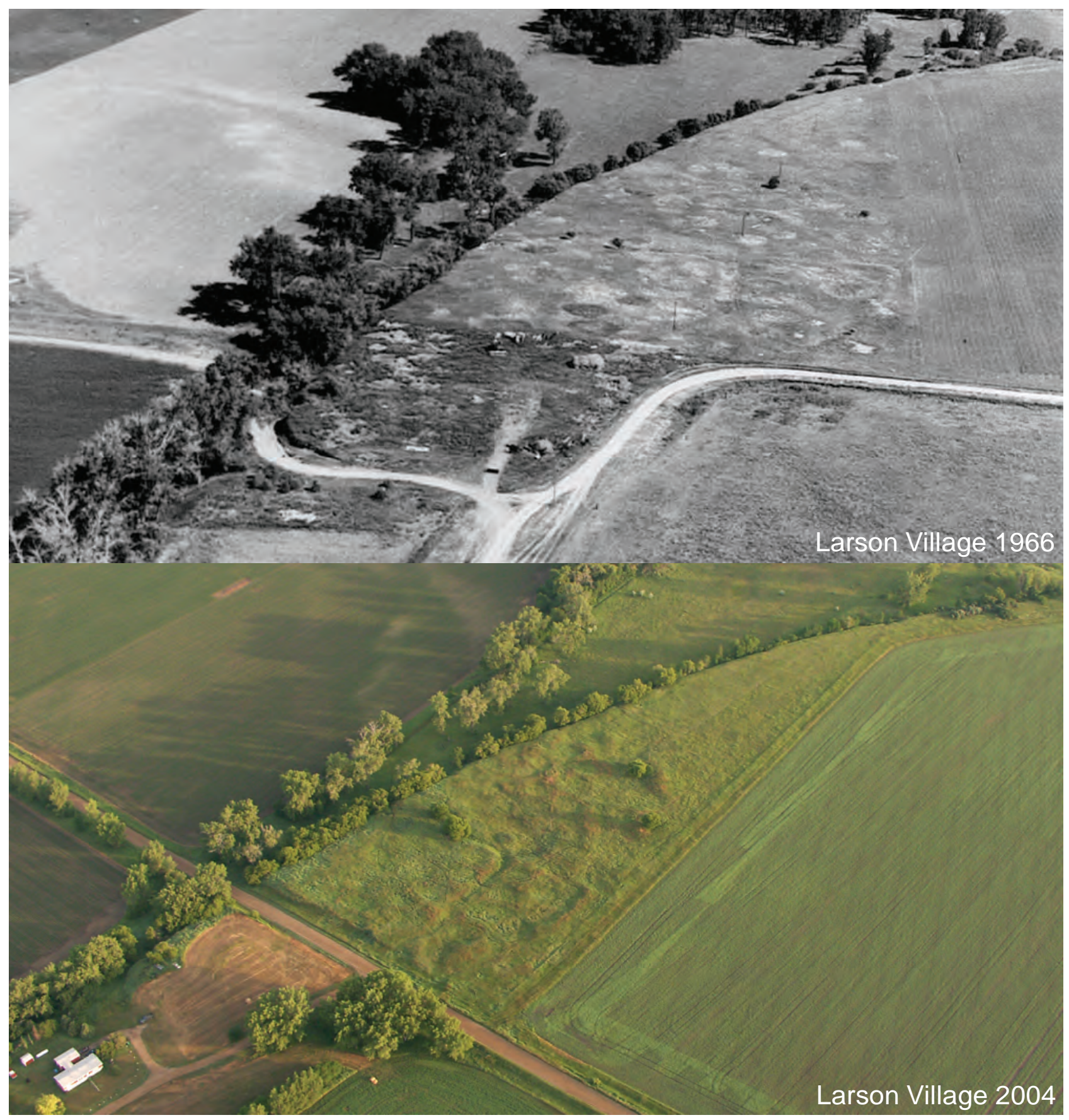

Figure 2.6. Aerial photographs of Larson Village taken in 1966 (top) and in 2004 (bottom). Photographs are in the collection of the Historic Preservation Division, State Historical Society of North Dakota.

lodges within the fortification (Figure 2). A prominent inner ditch encompasses nearly 18 percent of the existing site area. The bank cross-section revealed that this ditch was originally $8 \mathrm{ft}(2.4 \mathrm{~m})$ deep (Bowers 1940:59) and had a berm to the inside as well as small, poorly defined bastions. The surface outline of the ditch averages $22 \mathrm{ft}(6.7 \mathrm{~m})$ across. The inner ditch bisects a mound indicating the mound existed prior to ditch construction. 


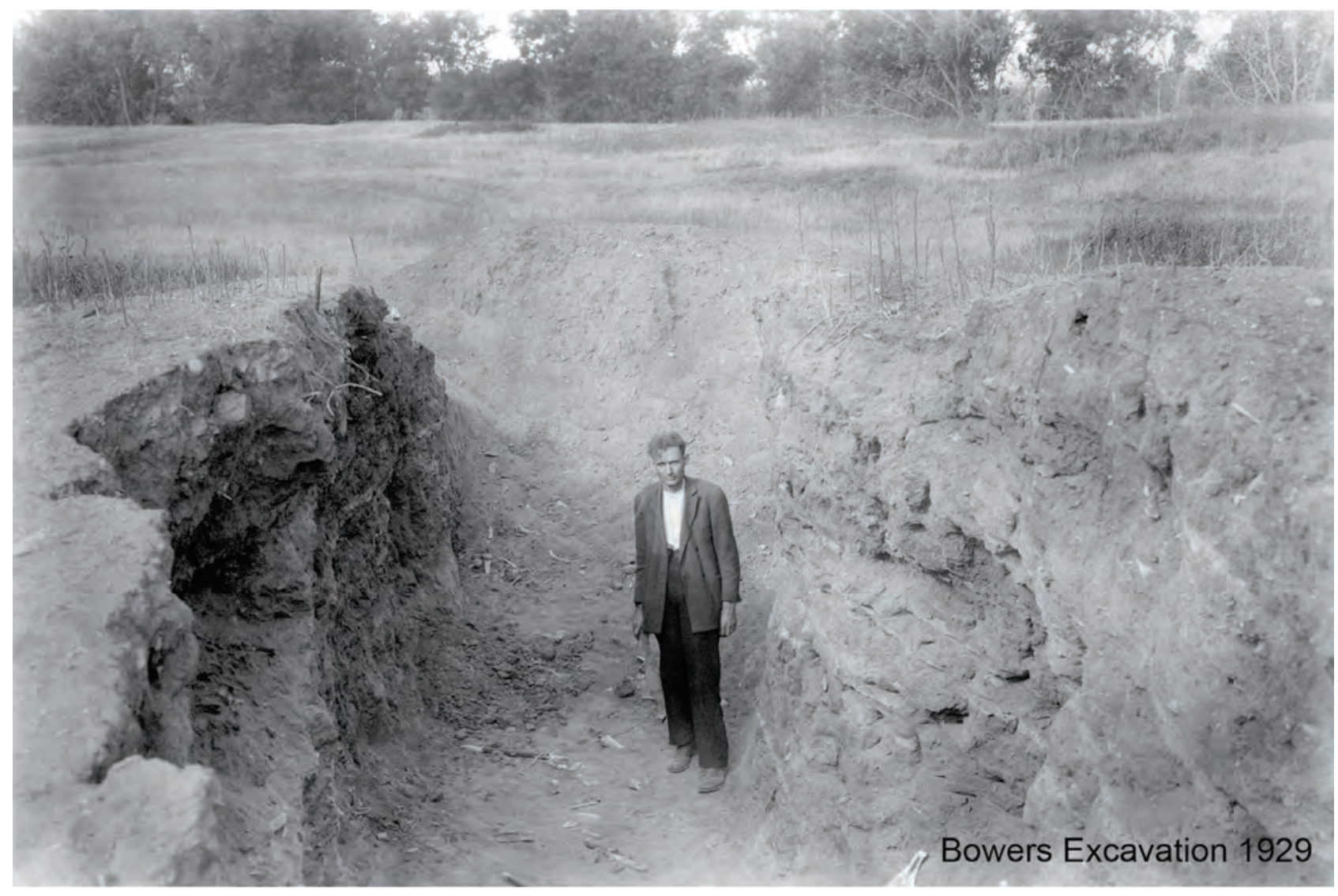

Figure 2.7. Photograph of the excavation at a midden mound (Work D) in the northeast edge of the Larson site in 1929. Photograph in the collections of the State Historical Society of North Dakota.

Little is known about the field methodology utilized during the 1929 excavations. However, notes and maps indicate excavations were conducted in five-foot squares and in some cases fourfoot squares. Maps of the excavation were generated and the State Historical Society does have a copy of the plan map for Work H. The maps for the other work areas have not been located to date. Excavations apparently were done by shovel and no screening of sediment was undertaken.

Bowers excavated one midden mound (designated Work B [30 x $45 \mathrm{ft}$, or 545 x 5-ft squares]) on the northwest edge of the site, the fill of which consisted of lodge refuse. The mound is described as having an average height of $5 \mathrm{ft} 3$ inches $(1.6 \mathrm{~m})$ at the highest point. Below the mound, in surrounding undisturbed beds, were three circular fire pits. The village apparently had been occupied for some time prior to the accumulation of debris comprising this midden mound (Bowers 1940:60-61). No European trade objects were noted.

The second midden mound (designated Work D [10 x $45 \mathrm{ft}$, or 185 x 5-ft squares]) excavated likewise had numerous lens-shaped beds of pure ash and artifacts (Bowers 1940:62). This is described as the highest mound ( $9 \mathrm{ft}$ or $2.7 \mathrm{~m}$ ) at the site and is situated on the northeast edge of the village (Figures 2 and 7). The excavation apparently also included part of lodge adjacent to the midden mound. The lodge was encountered $37 \mathrm{ft}(11.3 \mathrm{~m})$ from the edge of the cut. A cache of stone tools and flintknapping tools was encountered (11 complete points, 34 scrapers, 16 knives, 1 drill, and 5 bone flaking tools). 
Work H consists of a rectangular area 28 x $52 \mathrm{ft}$, staked off in 4 x 4-ft squares, along the east central section of the site. The excavation included a midden mound and part of a lodge. Several cache pits were encountered, both inside the lodge and under or intruding into the midden mound (Figure 8). Pits in squares 56, 61, 66, and 80 were below the midden mound. The pit in square 64 was intrusive to the mound, as was the burial pit in squares $83,84,90$, and 81 . There was also a cache pit that was intrusive in the mound and a burial chamber that penetrated the mound (Bowers 1940:63). Little is revealed in the notes about the house excavations, although an oak post $9 \mathrm{ft}$ $(12.7 \mathrm{~m})$ long, 7 inches $(18 \mathrm{~cm})$ in diameter at the base, and 5 inches $(12.7 \mathrm{~cm})$ in diameter near the top was recovered. A block ( $20 \mathrm{x} 25 \mathrm{ft}$ ) also was excavated along the bank within the inner fortification ditch. Several cache pits were encountered in this area.

Work A consists of an area $20 \mathrm{ft}$ by $25 \mathrm{ft}$, staked off in 5 x 5-ft squares, within the inner fortification ditch and adjacent to the river bank. Midden deposits averaged 11 inches $(27.9 \mathrm{~cm})$ thick. Six cache pits were found in the excavated area (Bowers 1940).

Primary and secondary burials as well as isolated human bones have been reported within the village (Bowers 1940:63-64, 140; Taylor 1979; Will and Hecker 1944). A defined cemetery area is not apparent. To date, perimeter burials have not been identified to date at the Larson site.

\section{Summary}

Approximately 60 percent of the Larson site is in an excellent state of preservation. However, the remaining site area has been severely impacted by road construction, a farmstead, and cultivation. Although artifact collections from the Larson site exist, those collections are clearly limited in their information potential relative to contemporary archaeological problems. The previous archaeological excavations are basically unreported and the collection strategies did not involve systematic artifact recovery.

In early years, uncontrolled collections were made at numerous locations to secure for posterity large artifact samples from Mandan and Hidatsa sites. This practice soon evolved into excavation with the goal of understanding the cultural chronology and history of the village cultures. Recent investigations at Menoken (Ahler, ed. 2003a), Huff (Ahler and Kvamme 2000), On-A-Slant (Ahler, ed. 1997), Scattered (Ahler, ed. 2002), Double Ditch (Ahler, ed. 2003b, 2004, 2005), and Boley (Ahler, ed. 2006) villages have added the impetus for further refining our understanding of the origin and development of the Plains Village lifeway. Field and archival research have begun to untangle the complex archaeological record associated with the Mandans in the Missouri Valley (Ahler 2001:1).

Early maps (1905 and 1929) and aerial photographs provide important information regarding the layout of Larson Village prior to extensive disturbance. Those maps, in addition to the recent work at Double Ditch State Historic Site (Ahler, ed. 2003b, 2004, 2005; Kvamme 2004), greatly aided in identifying target areas for the geophysical survey and related excavations across ditches and pit features. The recent work at Double Ditch and Boley also revealed the previously unrecognized complex nature of these Mandan villages. It is clear that geophysical surveys and acquisition of new collections from extant sites is necessary to begin the serious study of research topics that cannot be addressed with existing collections and information. Then, the integrated 


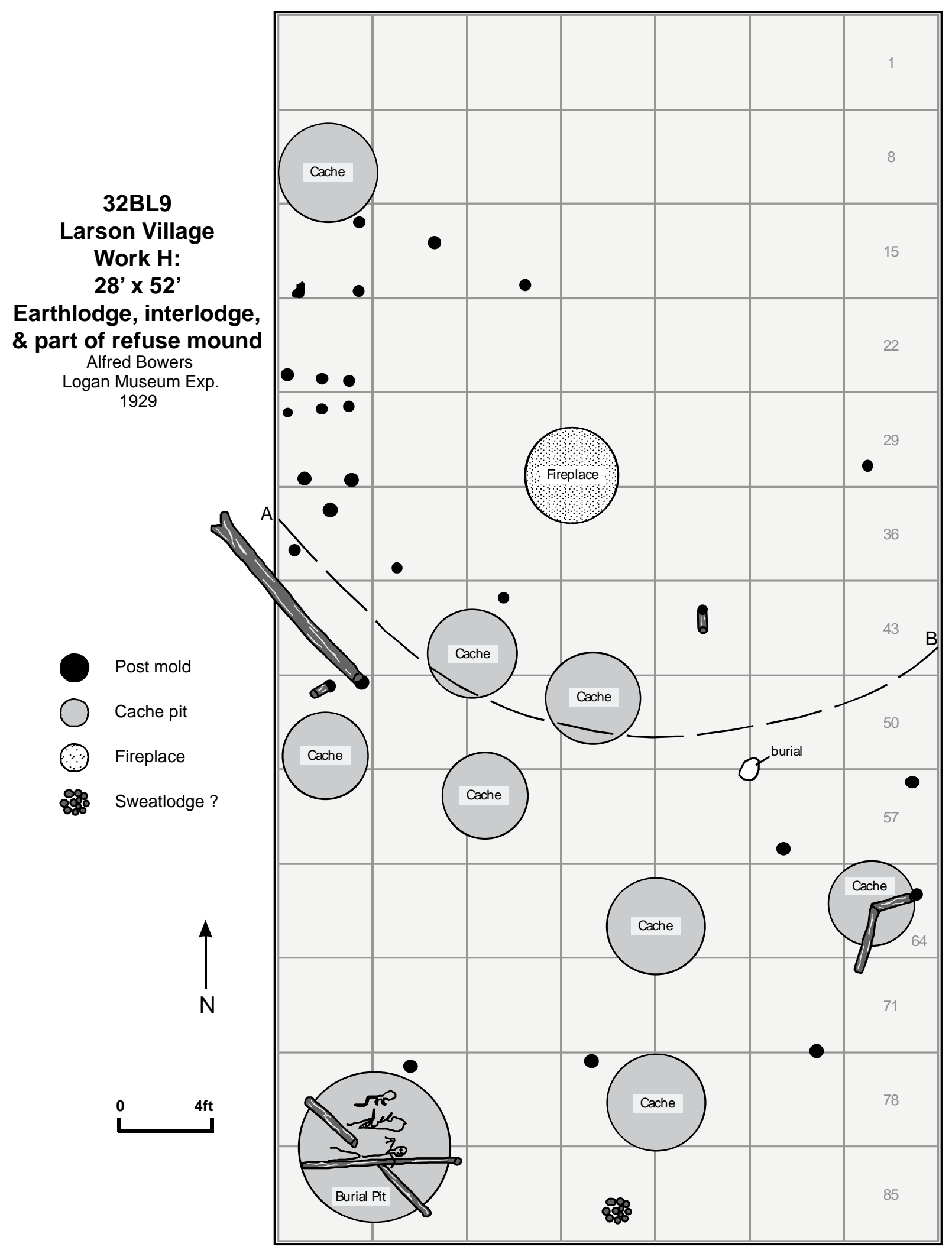

Figure 2.8. Redrafted plan map of Work H. Map was originally produced by Alfred Bowers in 1929. 
study of existing collections along with new ones will likely provide refined understanding of traditional Mandan sites at the Heart region. 


\section{References Cited}

Ahler, Stanley A. (Editor)

1997 Archaeology of the Mandan Indians at On-A-Slant Village (32MO26), Fort Abraham Lincoln State Park, Morton County, North Dakota. Office of Research and Graduate Studies, Northern Arizona University, Flagstaff, Arizona. Submitted to North Dakota Parks and Recreation Department, Bismarck.

2002 Prehistory of First Street NE: The Archaeology of Scattered Village in Mandan, North Dakota. Submitted to the North Dakota Department of Transportation and the City of Mandan, North Dakota.

2003a Archaeology at Menoken Village, A Fortified Late Plains Woodland Community in Central North Dakota. PaleoCultural Research Group, Flagstaff, Arizona. Submitted to the State Historical Society of North Dakota, Bismarck.

2003b Archaeological Investigations During 2001 and 2002 at Double Ditch State Historic Site, North Dakota. PaleoCultural Research Group, Flagstaff, Arizona. Submitted to the State Historical Society of North Dakota, Bismarck.

2004 Archaeological Investigations During 2003 at Double Ditch State Historic Site, North Dakota. PaleoCultural Research Group, Flagstaff, Arizona. Submitted to the State Historical Society of North Dakota, Bismarck.

2005 Archaeological Investigations During 2004 at Double Ditch State Historic Site, North Dakota. PaleoCultural Research Group, Flagstaff, Arizona. Submitted to the State Historical Society of North Dakota, Bismarck.

2006 Geophysical Survey and Test Excavation During 2005 at Boley Village (32MO37), North Dakota. PaleoCultural Research Group, Flagstaff, Arizona. Submitted to the State Historical Society of North Dakota, Bismarck.

Ahler, Stanley A.

2001 Analysis of Curated Plains Village Artifact Collections from the Heart, Knife, and Cannonball Regions, North Dakota. PaleoCultural Research Group, Flagstaff, Arizona. Submitted to the State Historical Society of North Dakota, Bismarck.

Ahler, Stanley A., and Kenneth L. Kvamme

2000 New Geophysical and Archaeological Investigations at Huff Village State Historic Site (32MO11), Morton County, North Dakota. PaleoCultural Research Group, Flagstaff, Arizona. Submitted to the State Historical Society of North Dakota, Bismarck.

Ahler, Stanley A., Fern E. Swenson, Eileen Ernenwein, and Christine Markussen

2005 Interpreted Mapping. In Archaeological Investigations During 2004 at Double Ditch State Historic Site, North Dakota, edited by Stanley A. Ahler, pp. 33-61. PaleoCultural Research Group, Flagstaff, Arizona. Submitted to the State Historical Society of North Dakota, Bismarck.

Bowers, Alfred W.

1940 Missouri River Earthlodge Archaeology of North Dakota and South Dakota. Ms. on file at Logan Museum, Beloit College, Beloit, Wisconsin.

Brower, J.F.

1904 Mandan Memoirs of Explorations in the Basin of Mississippi. Press of McGill-Warner Co., St. Paul, Minnesota.

Kvamme, Kenneth L. 
2006a Four Years of Geophysics and Remote Sensing at the Double Ditch State Historic Site (32BL8) North Dakota, 2001-2004. Archeo-Imaging Lab, University of North Dakota. Submitted to PaleoCultural Research Group, Flagstaff, Arizona and State Historical Society of North Dakota, Bismarck.

2006b Report of Geophysical Investigations at the Larson Site (32BL9), North Dakota. ArcheoImaging Lab, University of North Dakota. Submitted to PaleoCultural Research Group, Flagstaff, Arizona and State Historical Society of North Dakota, Bismarck.

Metcalf, Michael D.

2001 Plains Village Site Evaluations Near Bismarck, North Dakota, and Inventory of Selected Missouri River Terraces, Burleigh, Morton, and Oliver Couinties. Metcalf Archaeological Consultants, Eagle, Colorado. Submitted to the State Historical Society of North Dakota, Bismarck.

Steinbrueck, E. R.

1904 Mandan Village Sites. In Mandan Memoirs of Explorations in the Basin of Mississippi, by J.F. Bower. Press of McGill-Warner Co., St. Paul, Minnesota.

Swenson, Fern E.

2004 Settlement Plans for Traditional Mandan Villages at Heart River. Paper presented at the $62^{\text {nd }}$ Plains Anthropological Conference, October 13-16, Billings, Montana.

2007 Settlement Plans for Traditional Mandan Villages at Heart River. In Plains Village Archaeology: Bison-Hunting Farmers on the Central and Northern Plains, edited by Stanley A. Ahler and Marvin Kay. University of Utah Press, Salt Lake City, in press.

Taylor, John

1979 Human Skeletal Material from the Larson Salvage Project, Burleigh Co., North Dakota. Ms. on file at the State Historical Society of North Dakota, Bismarck.

Thompson, Ralph S.

1984 The Site of the Mandan Indian Village Visited by Verendrye in 1738: A New Look. North Dakota History: Journal of the Northern Plains 51(4):22-28.

Will, George F., and Thad C. Hecker

1944 The Upper Missouri River Valley Aboriginal Culture in North Dakota. North Dakota Historical Quarterly, XI (1-2).

Will, George F., and Herbert J. Spinden

1906 The Mandans: A Study of Their Culture, Archaeology, and Language. Papers of the Peabody Museum of American Archaeology and Ethnology, 3(4):81-219. Harvard University, Cambridge, Massachusetts. 


\title{
3. GEOPHYSICAL INVESTIGATIONS
}

\author{
Kenneth L. Kvamme
}

\section{Introduction}

This chapter describes the results of geophysical surveys carried out from June 6 to 14, 2006. These investigations were performed by the Archeo-Imaging Lab, Department of Anthropology, University of Arkansas, by Kenneth L. Kvamme and Jo Ann Christein Kvamme, under contract agreement with the PaleoCultural Research Group (PCRG) of Flagstaff, Arizona. The purpose of this project was to yield further insights into the structure of this important site and to locate features of archaeological interest for subsequent testing by excavation. The latter entailed locating and mapping elements of the village's outer fortification system(s), which are invisible on the surface, subterranean storage pits, and other features. These elements could then be targeted for precision archaeological excavation and recovery of artifacts, chronometric, and other data necessary for understanding this site in time and place. Excavations were conducted by personnel of PCRG, Mark Mitchell Principal Investigator, and the State Historical Society of North Dakota (SHSND) under the leadership of Fern E. Swenson, Director of the Historic Preservation Division. These excavations partially overlapped the geophysical project and continued for several days afterward.

The Larson site is a large, fortified, earthlodge settlement located on the east bank of the Missouri River several miles north of present-day Bismarck and about two miles north of the Double Ditch State Historic site, which is thought to be roughly contemporaneous. Natural processes and recent development has obliterated much of Larson (see Chapter 2). The site is located on the edge of a terrace that probably was situated close to the Missouri River during its occupation. The River now lies nearly a mile to the west. Prior to its westward migration, a significant western portion of the site was apparently eroded and may have been a cause of the site's abandonment. A county road cuts through the village somewhat south of its center, a late nineteenth century homestead occupies its southern half, and an agricultural field has obliterated its eastern edge through intensive plowing for more than a century. These elements are visible in aerial photographs of the site obtained from the U.S. Geological Survey showing a 1997 view (Figure 3.1a) and by Dr. Tommy Ike Hailey during the Double Ditch Project in 2004 (Figure 3.1b) (see Kvamme 2006a for a summary of this work). The coordinate grid and extent of the magnetic survey is illustrated in these figures, with the loci of the electrical resistance and electromagnetic induction (EM) surveys shown in Figure 3.1c.

Most of Larson's northeastern quarter is relatively undisturbed. Anthropogenic variations in topography that are readily visible on the surface of Larson are better understood from the air (owing largely to vegetation differences), giving an improved sense of the site's structure. Mounds, surface depressions representing former earthlodges or borrow pits, evidence of two fortification ditches, and the likely locus of the village plaza are easily recognized (Figure 3.1d). The inner fortification (Ditch 1) appears to define a rectangular space that abuts the terrace edge to the west. Clear earthlodge depressions, generally circular, are distributed within and outside of Ditch 1 . If 
Larson is similar to nearby Double Ditch, some of these depressions may represent earth borrowing pits, or the loci of former lodges that were later subjected to earth borrowing, especially those of irregular shape (Kvamme 2006a). Several isolated mounds may also be seen as well as the course of Ditch 2 (Figure 3.1). Ditch 2 is also visible on the ground surface with careful inspection. That much of the village area-mounds and depressions-appears to exist exterior to Ditch 2 suggests the likelihood of additional outer fortification systems, a supposition relevant to the geophysical study reported below. The flat area to the north may once have been plowed, but now serves as a pasture for horses (Figure 3.2).
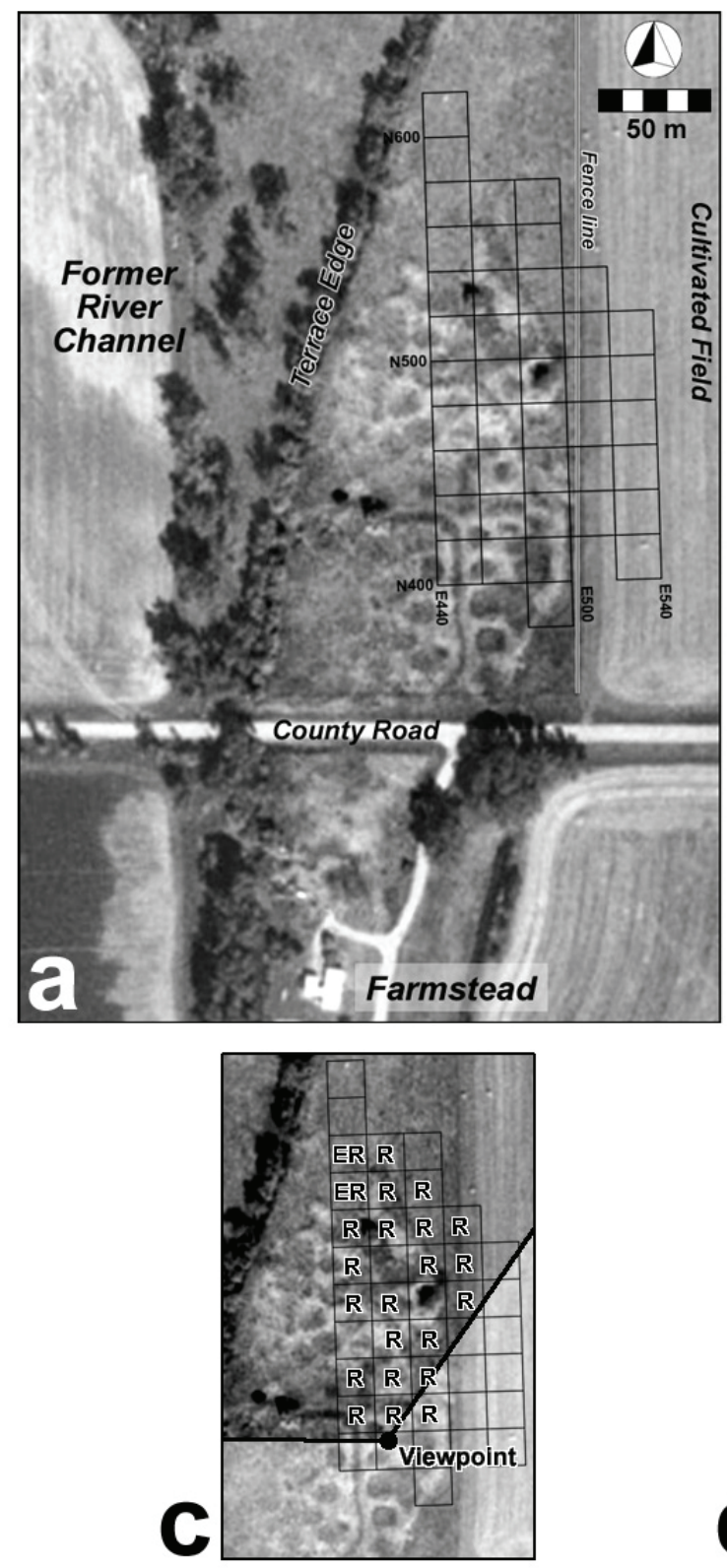
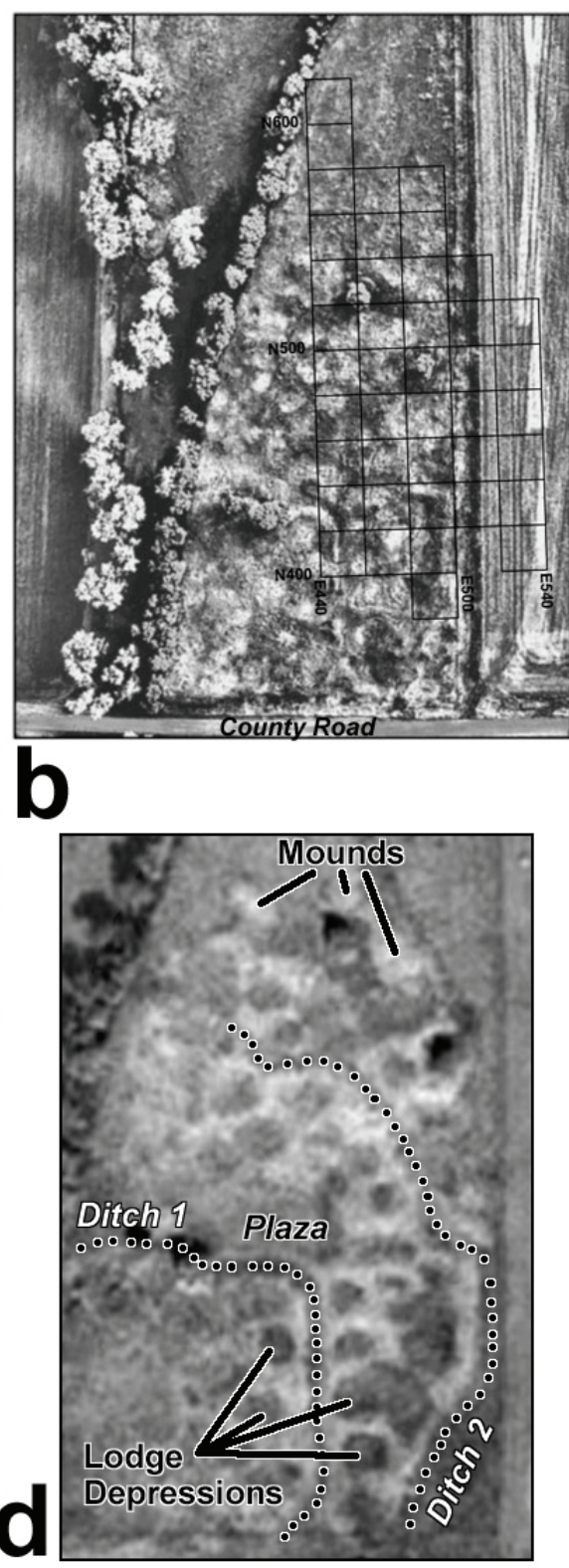

Figure 3.1. Aerial photographs of the Larson site.

a) USGS aerial photo dated September 17, 1997 showing magnetic gradiometry survey grid of $20 \mathrm{~m}$ units and local features. b) Enhanced aerial photo by Hailey dated July 6, 2004. c) Viewpoint and field of view of ground image illustrated in Figure 2 with blocks labeled "R" and "E" denoting units surveyed by electrical resistance and EM methods, respectively. d) Loci of Ditches 1 and 2, also visible on ground, and characteristic site features.

Early twentieth century maps of Larson show numerous mounds, earthlodge depressions, and Ditch 1. These maps by Will and Spinden in 1905 (Will and Spinden 1906:149) and Bowers in 1929 (Bowers 1940) were stretched and scaled to the aerial photograph of Figure 3.1a to achieve approximate "best fits" (Figure 3.3). The results demonstrate the historic maps to be generally 
accurate with many mounds, surface depressions, and segments of Ditch 1 approximately coincident with the photo, testifying to the quality of this early work, although Bowers has a tendency to over-identify earthlodge circles (Figure 3.3b). Bowers identifies the locus of the "Big Canoe," a reference to the locus of the Mandan "Ark of the Lone Man," typically placed within the central plaza. Will and Spinden's map appears to indicate a level space at the same locus (Figure 3.3a). It is interesting that neither map indicates the presence of a second Ditch 2, although Steinbrueck (1904; cited by Swenson 2007) describes two ditches. Bowers' map illustrates the loci of three excavations, Works $\mathrm{B}, \mathrm{D}$, and $\mathrm{H}$, some of which have a bearing on geophysical findings (Figure 3.3b).

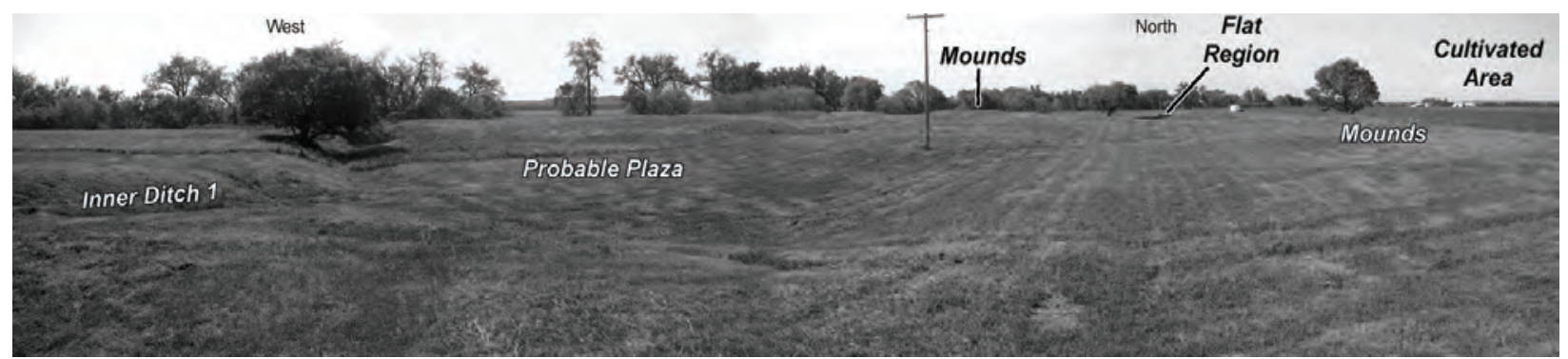

Figure 3.2. Panoramic wide-angle view of Larson to the west and north showing Ditch 1, the likely plaza, mounds, various surface depressions, the flat space to the north, and the cultivated field to the east. This field of view is mapped in Figure 1c.
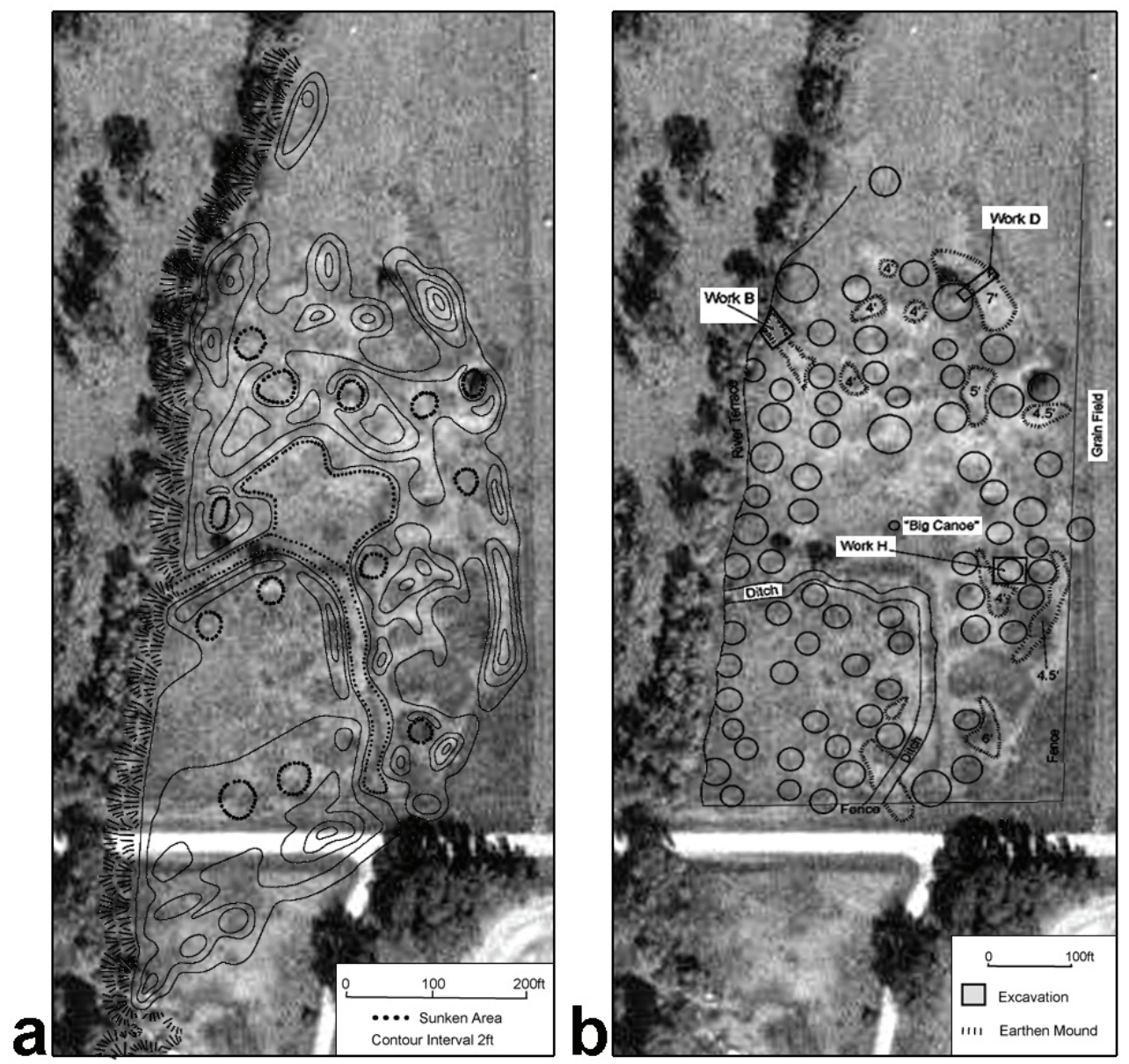

Figure 3.3.Early mappings of the Larson site by a) Will and Spinden (1906) and b) Bowers (1940), "best fit" and superimposed on USGS aerial photo dated September 17, 1997. 


\section{Study area and Field Methods}

The geophysical surveys at Larson were conducted within a single contiguous area, although a significant portion was located in a cultivated agricultural field separated from the main portion of the site by a steel post and barbed wire fence (Figures 3.1-3.3). A focus of the survey was on the outer margins of the site-designed to have the best chance of locating and defining additional village fortifications and associated features hidden beneath the surface. These elements would likely be among the earliest in the site. This focus required much of the survey to be conducted in the flat space north of the area of mounds and surface depressions and east of the fence line in the cultivated field. Once this area was surveyed, work centered on covering as much of the village core area as possible in the allotted remaining time. Weather was favorable and generally cool. Drought conditions over several years made the ground exceedingly dry and the surface was densely compacted, possible from the effects of horse hoofs in this pasture. These conditions posed difficulties to the electrical resistance survey (see below).

The geophysical surveys were uniformly conducted within 20 x 20 m survey blocks that allowed the work to be conducted piecemeal, with several units investigated each day. Personnel of the SHSND accurately located the corners of these $20 \mathrm{~m}$ units within the site's coordinate base using a total station. Each corner of a $20 \mathrm{~m}$ block was marked with a meter-long length of one-inch PVC pipe. Geophysical surveys conducted within each block utilized fiberglass surveyor's tapes staked parallel to each other on the ground, typically two meters apart, to guide spatial location of the instruments during the surveys (some of which are visible in Figure 3.4). A single line or transect of geophysical survey is commonly referred to as a "traverse." Half- or one-meter traverse spacing was uniformly employed for all geophysical surveys to yield high spatial resolution and the possibility of detecting archaeological features of small size. In all surveys, data were sampled at equal intervals along each traverse. This sample spacing varied with each instrument according to its data acquisition speed, described below.

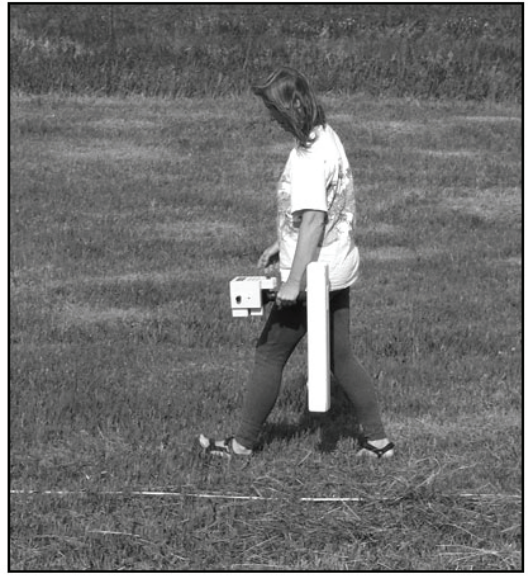

a

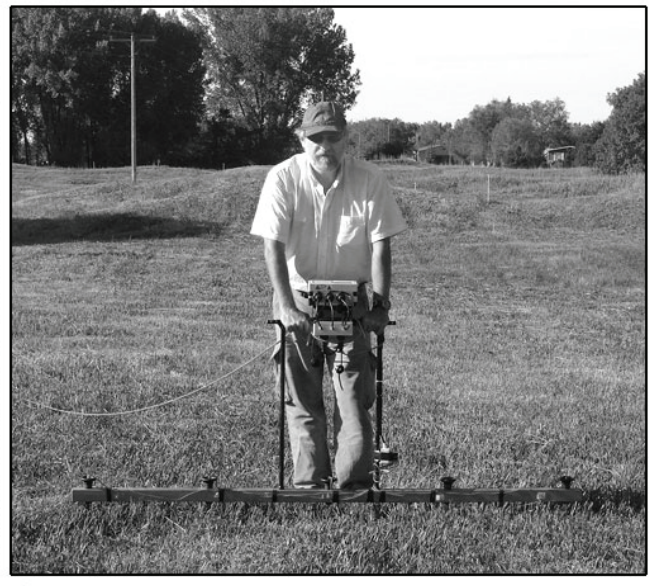

b

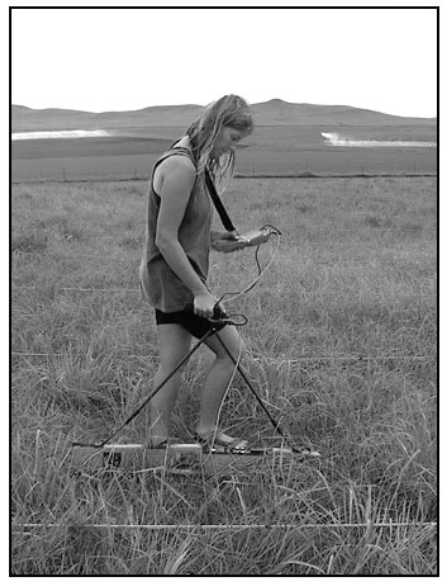

C

Figure 3.4. Instrumentation utilized in the Larson project: a) Geoscan Research FM-256 magnetic gradiometer, b) Geoscan Research RM-15/MXP15 electrical resistance meter, and c) Geonics Ltd. EM-38B electromagnetic induction meter. 
With survey tapes established every two meters within each survey block it is convenient to use them to quickly and approximately map surface-visible features, such as prominences and depressions, rocks, trees, shrubs, rodent work, modern constructions, and other elements that might generate geophysical anomalies. Maps of these features may then be compared against geophysical results and used to explain anomalies that may derive from them, facilitating the task of anomaly interpretation. One or more instruments surveyed a total of 41 whole or partial units during the course of the project (see below for specific details). The surface of most of the 41 study blocks of $20 \mathrm{~m}$ was mapped as the survey progressed, except for a number of units surveyed near the end of the project when time was short or in several units lacking any kind of surface manifestation (e.g., in the cultivated field or northern pasture).

Results of this mapping project are very insightful (Figure 3.5). The mapping clearly illustrates the courses of Ditches 1-2, several large mounds and surface depressions, the plaza area, rodent activity, and what are classed as "small depressions." The last includes several horse trails, truck tracks, looters' holes, and a plethora of small holes that probably derive from the activities of rodents and other animals. Features in this mapping correspond closely with those visible in a corresponding aerial photograph (Figure 3.5, inset) and are employed below to aid geophysical interpretations.

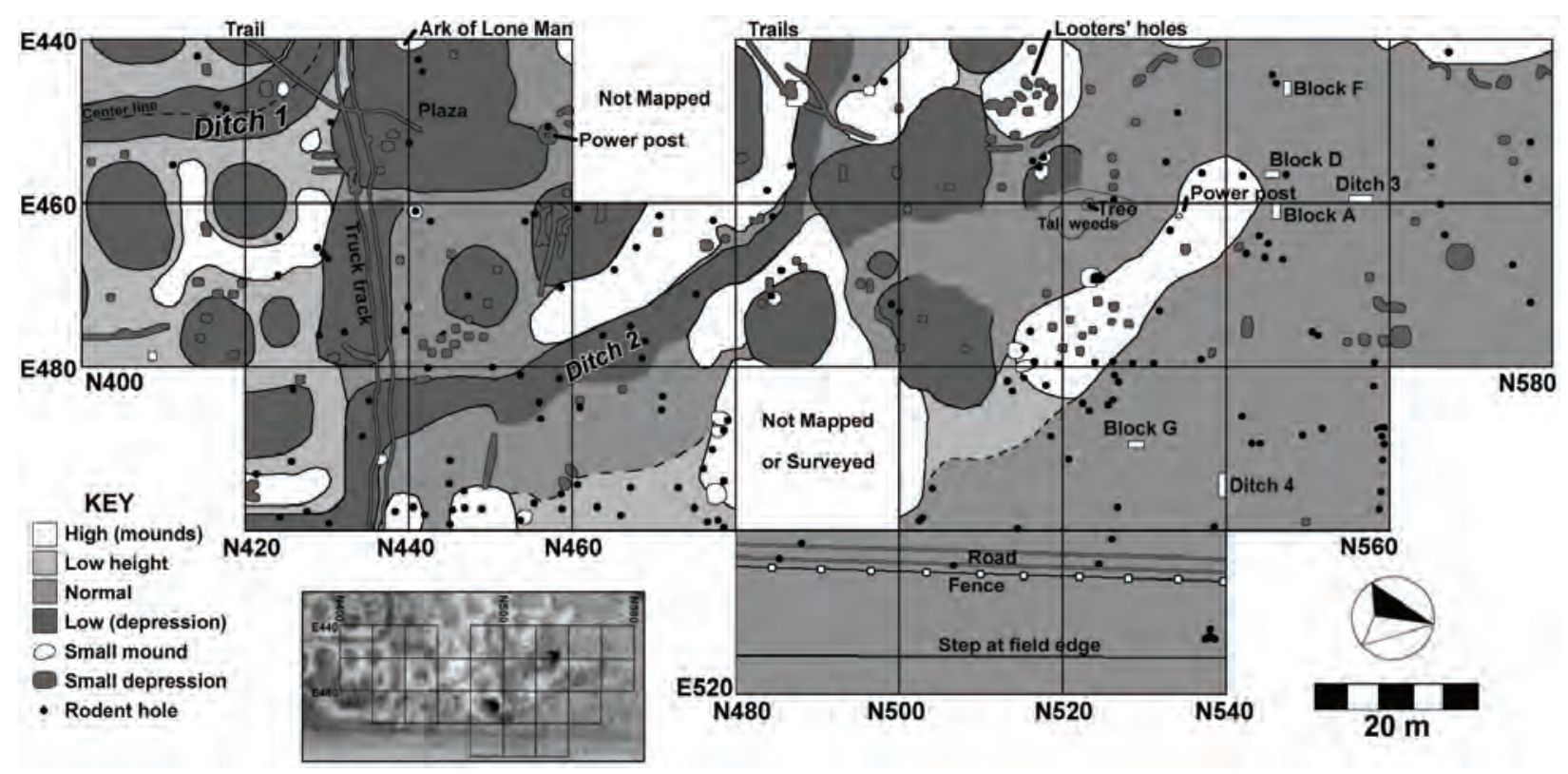

Figure 3.5. Mapping of surface-visible elements in the geophysical study blocks. The inset (lower left) displays a corresponding aerial photograph. The small white rectangles to the north represent the loci of archaeological excavations.

\section{Theory and Instrumentation}

The geophysical survey at Larson utilized two principal geophysical methods, with a third employed in a small region. 


\section{Magnetic Gradiometry}

Magnetometry is a passive detection method that measures the sum of remanent and all forms of induced magnetism below the instrument (whether natural or anthropogenic). Magnetic gradiometry is a form of magnetometry that records differences between two sensors, usually separated vertically (the differencing removes constant temporal changes in the Earth's primary magnetic field). It has proven to be one of the most productive prospecting methods in the northern Great Plains for several reasons. Intense heating of the soil generates pronounced thermoremanent anomalies that represent hearths or the occasional burned house. Magnetometry also responds to accumulations of high magnetic susceptibility - the ability of a substance to become magnetized by an inducing field, such as the Earth's. Topsoil tends to be more susceptible than subsoil due to several processes that include physical and chemical weathering that concentrates magnetic compounds, a fermentation process that changes them to more magnetic forms, and bacteria that accumulate magnetic minerals (Kvamme 2006b). Although topsoil in the northern Plains tends to be only mildly susceptible compared to other regions with older soils, detectable anomalies are nevertheless formed through a number of cultural processes. Abandoned subterranean storage pits (1.5-2 m deep, bell-shaped in cross-section, with a meter-wide orifice at the top and two-meter breadth at the bottom) and fortification ditches ( $\mathrm{U}$ - to V-shaped and 1-2 m deep) eventually become filled with nearby topsoil by erosion, or were purposefully sealed by the occupants, forming large magnetic contrasts owing to the relatively greater volume of magnetically susceptible material they hold. Mounds built from topsoil likewise produce magnetic anomalies and this is especially true of mounded middens that are composed of more magnetically susceptible materials, such as broken ceramics, fire cracked rock, soil from hearth cleanings, and organic matter that promotes growth of bacterial forms that concentrate magnetite. Moreover, natural erosion of soil covering earthlodges, by wind, rain, or foot traffic (lodge roofs were often places of activity), often created small berms around their perimeters that represent a larger volume of magnetically enriched topsoil. All of these processes are further exacerbated in extended occupations because (1) fired clays, fire-cracked rock, and broken ceramics of high susceptibility are constantly introduced to settlement soils through hearth cleanings, reworking of burned deposits, pot breakage, and the like, and (2) the introduction of organic matter can promote growth of magnetite-concentrating bacteria. More details about anthropogenic contributions to soil magnetism are described in Kvamme (2006b).

The primary survey at Larson was by magnetic gradiometry using a Geoscan Research fluxgate magnetic gradiometer (Figure 4a). The FM-256 is designed for the rapid measurement of archaeological magnetic information over broad areas. As a gradiometer it records differences between measurements made by top and bottom sensors vertically separated by $0.5 \mathrm{~m}$. The bottom sensor is more sensitive to magnetic changes in near-surface soils than the top sensor (because magnetic field strength falls of with the cube of distance), which records constant changes in the Earth's field. Differencing the two measurements removes these background changes. In magnetic surveys the great majority of the response is from the uppermost meter; more deeply buried targets must be highly magnetic to be detected. Fluxgate technology is capable of about $0.1 \mathrm{nT}$ resolution, although accuracy is on the order of $\pm 0.4 \mathrm{nT}$ (the nanotesla, $\mathrm{nT}=10^{-9}$ Tesla, is the standard unit if magnetic measurement). The FM-256 is fully computerized and capable of storing 250,000 measurements for later downloading and processing. 


\section{Electrical Resistance}

Resistance of the soil to an electrical current depends on a number of factors including moisture, dissolved ion content, and the structure of soil particles and its components. A resistance survey is an active prospecting method that utilizes two probes to establish a current through conductive earth, which is measured. Two other probes measure voltage, and the ratio of voltage to current yields resistance, according to Ohm's Law (Clark 2000). In the traditional Wenner configuration the four probes are each separated along a line by an equal distance, with current probes on either end. In a uniform deposit (e.g., an alluvial fan) voltage varies with distance from the current probes in regular hemispheres. If voltage is measured on the surface one meter from a current probe, the value recorded is equivalent to the voltage a meter below the surface, allowing a means to control prospecting depth. In practice, the subsurface does not usually present a uniform matrix. Moist or conductive deposits (e.g., clays) provide an easy pathway for the current, but it must flow around more resistant deposits and objects like rock, which alter the voltage and therefore resistance, creating anomalies. The probe separation or depth criterion therefore becomes only an approximation in complex deposits. A further complication is that recorded resistance in ohms is dependent on inter-probe distances and configurations. Consequently, measurements are normally converted to apparent resistivity, a measure reflecting a bulk property of the ground, independent of probe arrangements. For the Wenner array, resistivity in ohms per meter is given by: ohm-m $=2 \pi R d$, where $R$ is resistance in ohms and $d$ is the inter-probe distance in meters (Clark 2000). It should be obvious that "resistance" and "resistivity" differ by only a constant. Although field instruments acquire electrical resistance data, they may easily be converted to measures of resistivity.

Many other probe configurations exist. At Larson a twin-probe array was uniformly employed. This probe configuration is essentially a Wenner array split in half, with one current and one voltage probe held in a rigid frame at a fixed distance, $d$, apart. The remaining current and voltage probes are removed to a remote locus and connected by a cable (a minimum of $30 d$ away from the survey to eliminate a proximity effect at closer distances). Apparent resistivity can be estimated through the following equation (Geoscan Research 1996): $\rho=2 \pi R /\left(1 / d_{1}+1 / d_{2}\right)$, where $R$ is resistance in ohms, $d_{1}$ is the inter-probe distance in the mobile frame, and $d_{2}$ is the inter-probe distance between the remote probes (it is assumed that the remote probes are removed from the mobile probes by at least $30 d_{1}$ ). This configuration offers improved and easier to interpret feature definition and greatly increases survey speed because only the two probes held in the frame, rather than four, are moved per measurement station.

Survey by electrical resistance meter at Larson generally paralleled the magnetic gradiometry survey, but in a somewhat reduced area due to its slowness and environmental circumstances. As noted previously, several years of drought conditions have made the soils of the region very dry and significant rainfall had not occurred in the region for several weeks. This may have contributed to the extreme compactness of the site's surface, possibly made worse by hoof action of horses in this pasture. These conditions combined to make acquisition of resistance data extremely slow because it was difficult to insert probes into the hard ground and the lack of moisture inhibited current flow. Moreover, the data were extremely noisy because numerous data spikes (measurement errors of extreme value) were introduced. Data were obtained for a day and a half under these frustrating conditions when it was ultimately decided to cease further efforts until rainfall might increase ground moisture. Efforts then turned to an EM conductivity survey that, 
theoretically, captures similar data (conductivity is the inverse of resistivity, see below), but which does not use probes and is less sensitive to the moisture of surface soils. The results of this survey were marginally informative (see below). Fortunately, during the night of June 8 major storms passed through the area dumping much needed rain. This sufficiently moistened the ground permitting the acquisition of resistance data for the remainder of the project.

A Geoscan Research RM-15 was employed for the electrical resistance survey, which is specifically designed for rapid data capture. It is fully computerized and capable of storing 30,000 measurements for later downloading and processing (Figure 4b). Resistance measurements are automatically sensed and logged by the RM-15 as fast as the twin-probe array can be lifted and inserted in the ground at the next recording station. The focal prospecting depth is controlled by the separation between the electrodes, which was initially set to $50 \mathrm{~cm}$, a depth that has proved productive in other sites in the region (e.g., at Double Ditch; Kvamme 2006a). After survey and inspection of the data from a number of $20 \mathrm{~m}$ blocks that poorly indicated anomalies (probably due to soil dryness), it was decided to prospect with a one-meter probe separation distance, which ultimately allowed better imaging of the subsurface (see below). The MPX-15 multiplexer is an attachment to the RM-15 that was also employed. It allows near-simultaneous resistance measurements to be acquired from multiple pairs of probes at a single station. In other words, in a two-meter beam four twin-probe arrays separated by a half-meter or two twin-probe arrays separated by a meter can be configured, allowing multiple data points to be acquired with each insertion of the instrument. This allows more rapid survey coverage because only 10 traverses and 400 insertions must be made to completely survey a 20 x 20 m block, compared with up 40 traverses and 1600 insertions without the MPX-15 for half-by-half meter sampling (20 traverses and 800 insertions for one-by-half-meter sampling). Because the RM-15 returns measurements in ohms, it is necessary to multiply them by a constant derived from the above equation to convert to an estimate of apparent resistivity. For the majority of the survey at Larson, with mobile probes separated by $1 \mathrm{~m}$ and the remote probes separated by the same distance, $\rho=2 \pi R /\left(1 / d_{1}+1 / d_{2}\right)$ reduces to $\rho=\pi R$.

\section{Electromagnetic Induction}

An electromagnetic (EM) induction survey was undertaken when the electrical resistance survey failed from a lack of moisture and high probe contact resistance in surface soils. EM instruments utilize low-frequency radio waves (less than $15 \mathrm{kHz}$ ) to actively transmit electromagnetic energy into the ground. The energy causes eddy currents to be generated in subsurface conductors, which in turn transmit a weak secondary electromagnetic field recorded by a receiver within the instrument. These signals contain three important components. The first is the primary signal sent directly to the receiver by the transmitter, which is made null during instrument setup. The second component is made up of electromagnetic energy $90^{\circ}$ out of phase with the transmitted signal, known as the quadrature phase. It is related to the electrical conductivity of the soil, the theoretical inverse of resistivity. Conductivity is measured in millisiemens per meter (mS$\mathrm{m})$, and the theoretical relationship with resistivity is given by: $\mathrm{mS}-\mathrm{m}=1,000 /(\mathrm{ohm}-\mathrm{m})$. The instrument is normally used with coils oriented in a vertical dipole mode (VDM), which allows prospecting to a depth of about $1.5 \mathrm{~m}$, but peak sensitivity is only $40 \mathrm{~cm}$ below the instrument and the bulk of the signal represents conductivity at relatively shallow depths (Clark 2000). The final component is in-phase with the primary signal and is related to the magnetic susceptibility of the 
soil. It represents the ratio in strength of the induced to transmitted signals, generally quantified in "parts per thousand" (ppt). The in-phase or magnetic susceptibility component has a much more limited prospecting depth, because the active signal is attenuated going into the ground and on its return to the receiver, causing sensitivity to fall off at a rate of $1 / d^{6}$ (where $d$ is distance to target), in contrast to a magnetometer's $1 / d^{3}$ (Dalan 2006). Thus, EM instruments are capable of generating two modes of data reflecting resistivity-conductivity and magnetic susceptibility. Although results theoretically parallel electrical resistivity and magnetic gradiometry surveys, in practice different outcomes typically result. The quadrature phase evaluates a different volume of earth than a probecontact resistance survey and is sensitive to conductive metals, unlike a resistance meter. Moreover, the in-phase component only records the induced component of magnetism in the extreme near surface, yielding a result different from magnetometry that records the sum of all types of magnetism to a typical depth of about $1.5 \mathrm{~m}$. Without the need for probes, EM instruments acquire data very rapidly compared to the typical electrical resistance survey.

\section{Data Processing}

The processing of geophysical data sets is a complex topic. Because the data matrices can be treated as imagery standard image processing algorithms apply, but more specialized procedures are also required that are unique to each geophysical data type. Kvamme (2006b) overviews fundamental issues and operations relevant to geophysical data processing in archaeology. This processing typically requires a series of ordered steps.

1. Concatenation. The data from individual 20 m survey units are joined into a single composite in correct spatial arrangement.

2. Despiking. Unusually high or low readings (outliers) that may result from the presence of rodent holes, small rocks, or dense vegetation in resistance surveys or instrument height variations (owing to vegetation) in EM surveys, are removed. This algorithm was applied to all data sets except magnetic gradiometry in order that the loci of ferrous metal artifacts are preserved in the data.

3. Edge matching. Data values are matched between each $20 \mathrm{~m}$ survey unit through the balancing of mean values, necessary in resistance and EM surveys, because the former fluctuates from day-to-day with ground moisture changes and the latter with temperature variations.

4. Data normalization. Fluxgate magnetic gradiometers tend to drift with temperature, meaning that the average of the data moves away from an expected value of zero. Forcing the mean of each transect to equal zero normalizes these data, removing the effects of drift.

5. Filtering. The application of several filters is commonly undertaken. A mild, Gaussianweighted low-pass filter is used to reduce statistical noise in the data and produce a "smooth" looking result.

6. Contrast enhancement. Image quality is improved by "clipping” of high and low values in the data in order to achieve a better distribution of gray levels in an image for visualization 
of subtle features. In general, all presented imagery in this report is clipped within plus or minus two standard deviations of the data mean.

7. Interpolation. Estimates of additional measurements may be made for improved image continuity and interpretation, and to balance unequal sampling densities resulting from field collection methods (see above). Interpolation is not generally used in this report.

\section{Results}

Results of the geophysical surveys at Larson are presented by method. In each case principal anomalies or anomaly types are discussed and interpretive maps are offered.

\section{Magnetic Gradiometry Survey}

At Larson, the magnetic gradiometry survey covered 32 complete and 9 partial blocks of 20 $\mathrm{m}$, for a total of 15,400 $\mathrm{m}^{2}$ (1.54 ha) (the full grid shown in Figures 3.1a-c). Sampling density was eight per linear meter with a half-meter traverse separation for 16 measurements $/ \mathrm{m}^{2}(246,400$ total measurements). Like other sites in the region, Larson is relatively quite magnetically with most anomalies ranging only between about 1-3 nT, with largest non-ferrous metal anomalies approaching $10 \mathrm{nT}$.

The magnetic gradiometry survey was highly successful at Larson, a circumstance consistently demonstrated at village sites of the northern Great Plains (e.g., Ahler and Kvamme 2000; Kvamme 2006a). Numerous anomalies are clearly revealed, many unquestionably of cultural origin (Figure 3.6a). These anomalies may be classified into several groups representing those generated by likely prehistoric features (numbered in Figure 3.6b) and those originating from recent or modern sources (lettered in Figure 3.6b). (A clear, unlabeled, page-size graphic of the magnetic gradiometry results is presented in Figure 3.17).

\section{Pre- and Protohistoric Features}

The magnetic gradiometry data reveal many anomalies that may clearly be assigned to specific classes of archaeological features as well as those that may be classed with a little deductive effort. Thirteen groups of anomalies representing likely prehistoric/protohistoric features of Larson are discussed, corresponding to the numbered labels in Figure 3.6

1. Ditch 1 . Ditch 1 is unambiguously revealed in the landscape, presently more than a meter deep (Figures 3.1, 3.2, and 3.5). Magnetically, it is indicated by a region of negative magnetism down its bottom portion (from -.5 to -6 nT) sandwiched between adjacent areas of high positive magnetism (from 2 to $6 \mathrm{nT}$ ) (Figure 3.6). This is a pattern that has been witnessed at several other sites with open, topographically expressed ditches, such as nearby Double Ditch (Kvamme 2006a). It represents a lack of magnetically enriched topsoil along the ditch bottompresumably removed by its excavation — with mounding of the spoil adjacent to the ditch (and 
thus elevated magnetism). Most of this mounding occurs on the inside edge of the ditch, and the magnetic data testify to this berm with massive and larger-magnitude anomalies.
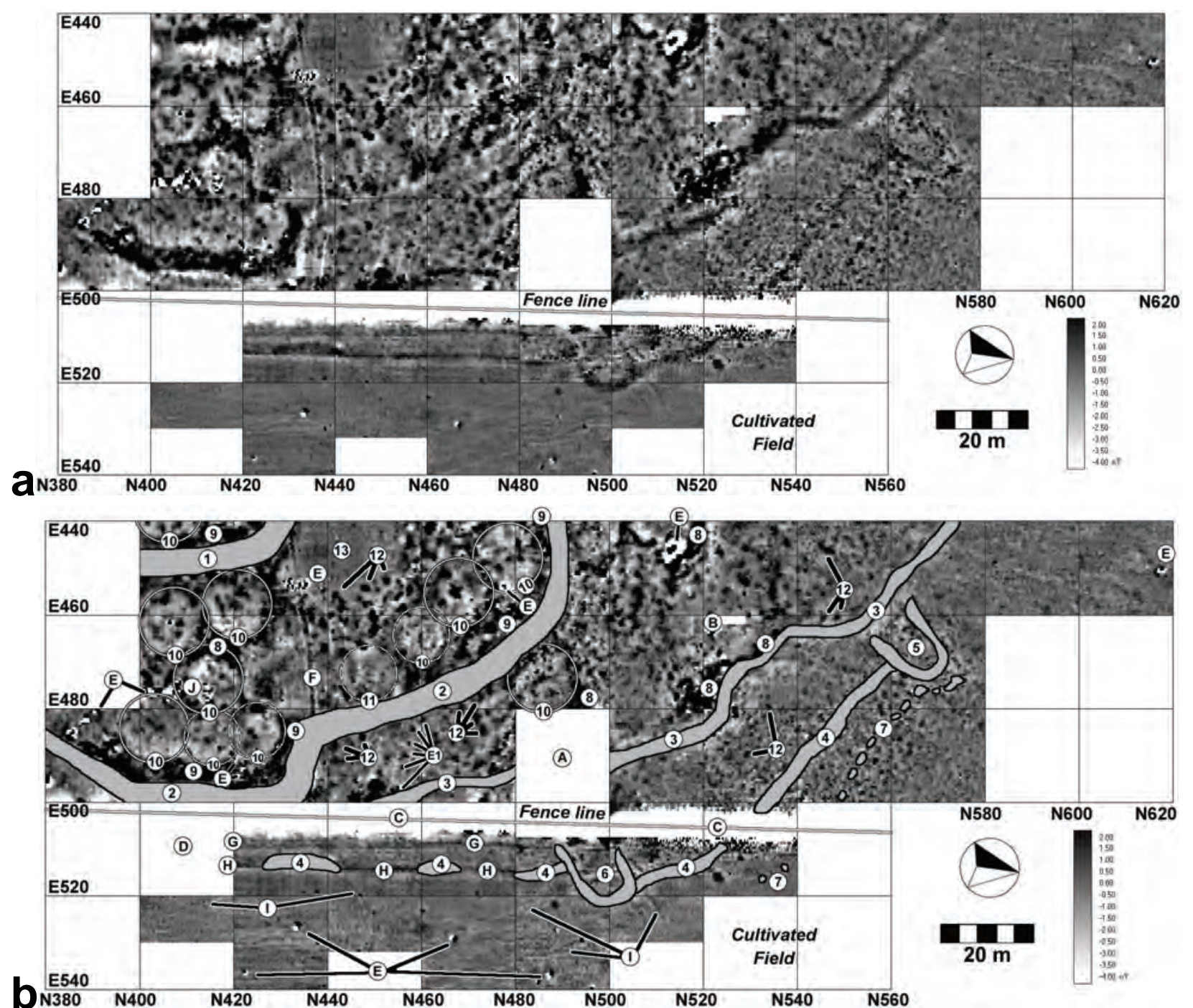

Figure 3.6. The magnetic gradiometry survey at Larson showing a) basic data and b) interpretations. Numbers and letters refer to specific anomalies or classes of anomalies discussed in text. Contrast has been enhanced to better define anomalies labeled 4-7.

2. Ditch 2. This ditch is more subtly visible in the surface topography, but is traceable as low depressions with diligence and experience in the region. It is interesting that neither Will and Spinden (1906) or Bowers (1940) include this ditch in their maps of Larson (Figure 3.3). Yet, it clearly appears in the aerial photograph of Figure 3.1a and 3.1d. Magnetically, its form is identical to Ditch 1, with low or negative magnetism (from .5 to $-4 \mathrm{nT}$ ) along its course with adjacent magnetic berms that are more robust on the interior village edge (ranging as high as 9 nT) (Figure 3.6). This soil mounding is contiguous in the southern portion of the study area, and appears spottier elsewhere, with evidence of highly discontinuous and small mounding along its outside edge. 
3. Ditch 3. The course of this ditch is revealed by magnetometry, but no surface evidence of it is visible in the landscape (Figure 3.6). It therefore represents a completely filled and buried ditch, visible owing to a composition of higher magnetic susceptibility (e.g., magnetically enriched topsoil or settlement soil likely comprises much of the fill). As with Ditch 3 at nearby Double Ditch (Kvamme 2006a), several low mounds or mounded middens that exhibit large magnetic anomalies overly the course of portions of this ditch (labeled "8" in Figure 3.6b), obfuscating its course. Away from these areas Ditch 3 is weakly magnetic in the north (about 1 to 2 nT north of N540), mildly magnetic along its central course (about 1 to 3 nT from N500-520), and more highly magnetic near the southern limits of its detection along the eastern edge of the site (about 2 to $5.5 \mathrm{nT}$ from N460-480). Owing to the interference from the fence line it is unclear whether Ditch 3 connects with the line of Ditch 2 or Ditch 4 (Figure 3.6). This ditch is probably associated with two U-shaped bastions, labeled 5-6 in Figure 3.6b (see below for discussion of these features). Ditch 3 was tested by archaeological excavation, discussed below.

4. Ditch 4. This ditch exhibits extremely weak magnetism, with most measurements at the subnanotesla level and few exceeding $1 \mathrm{nT}$, nearly at the limits of the FM-256 magnetic gradiometer. Its form is similar to Ditch 3 and it is likely composed of midden materials and topsoil fill. This ditch is associated with Bastion 5, connecting at its eastern side, but that bastion appears to terminate the course of the ditch because no magnetic evidence of it can be discerned further west (Figure 3.6). It also apparently connects with Bastion 6 but, because it does so near the outer tip of the bastion (defeating its defensive purpose), it is quite possible that the body of Bastion 6 is intrusive, post-dating the construction and use of Ditch 4 as the village contracted. Several discontiguous but robust indications of a ditch — probably Ditch 4-may be seen to the south of Bastion 6, but their visibility is partially obscured by anomalies generated by the edge of the contemporary cultivated field (labeled " $\mathrm{H}$ ” in Figure 3.6b). Ditch 4 was tested by archaeological excavation, discussed below.

5. Bastion 5. Located at the north end of the village, this bastion is associated with Ditch 4 and apparently Ditch 3, presumed to date later (Figure 3.6). It is U-shaped and measures about $25 \mathrm{~m}$ long by $10 \mathrm{~m}$ wide. The data suggest that both "ends" connect with Ditch 3, but it is clear that Ditch 3 is continuous behind the bastion (Figure 3.7a). Perhaps the bastion was abandoned at some point and Ditch 3 was “closed up" behind it for a linear defense. Only a single side of the bastion, the eastern, connects with Ditch 4, with no evidence of this ditch to the west (Figure 3.7a). This anomaly is extremely subtle and "spotty" (almost all is less than $1.5 \mathrm{nT}$ ) with magnetic characteristics similar to Ditch 4, suggesting construction and fill components more similar to that ditch.

6. Bastion 6. Although the magnetic magnitude of this anomaly is identical to Bastion 5 (measurements from about .5 to $1.3 \mathrm{nT}$ ), this bastion is more robustly indicated because measurements are more consistent and the surrounding background is more uniform in value (about $0 \mathrm{nT}$ ). Unfortunately, the fence line crosses nearby introducing obfuscating noise (Figure 3.6). This bastion is at least $15 \mathrm{~m}$ long and about $11 \mathrm{~m}$ wide. It definitely connects with Ditch 4, but atypically in that Ditch 4 abuts it at its outer tip, defeating its defensive purpose on that side (Figure 3.7b). This circumstance suggests that Bastion 6 could be a construction associated with Ditch 3 that is superimposed over the (presumed) earlier Ditch 4, yet the magnetic evidence shows little discontinuity between it and Ditch 4 . The placement of the fence (which generates considerable magnetic noise owing to its magnetic character) and lack of survey in the $20 \mathrm{~m}$ 
block labeled “A” in Figure 3.6b are inconvenient because they detract from a fuller understanding of this feature.

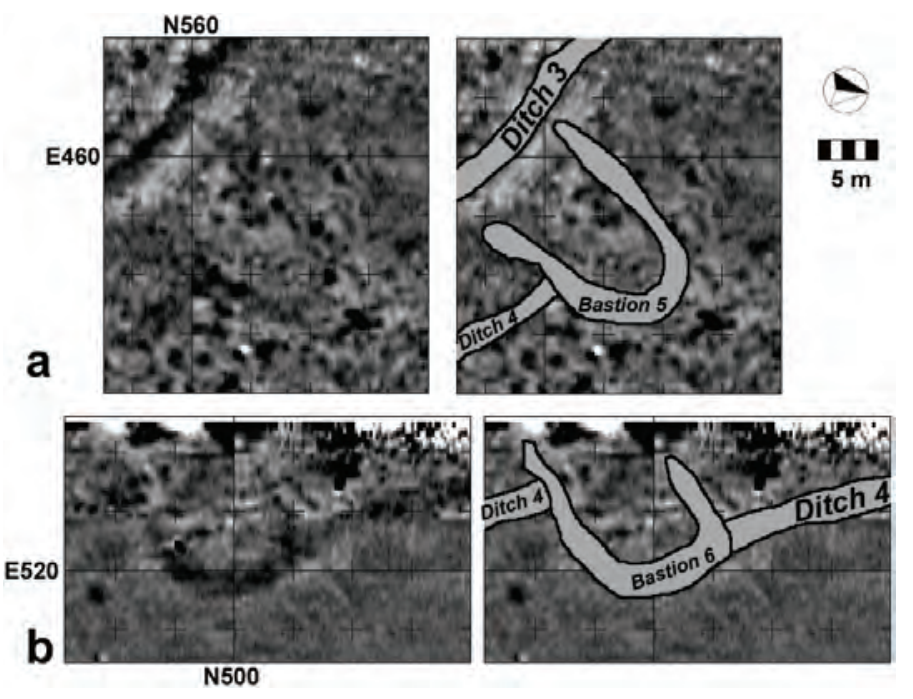

Figure 3.7. Magnetic evidence and interpretations of bastions associated with Ditches 3-4: a) Bastion 5, b) Bastion 6.

7. Discontinuous Lineation - Ditch 5? This highly ephemeral series of anomalies appear to represent a lineation that parallels the course of Ditch 4 (Figure 3.6a,b). They could, collectively, represent the course of yet another outer ditch, but at present the evidence appears too slim to advocate that case (Figure 3.8). Some of these anomalies are robust—up to $2.5 \mathrm{nT}$. They could represent deeper pockets of a continuous ditch, deeper remnants of a ditch that was later truncated (a common occurrence at Double Ditch [Kvamme 2006a]), or pockets of more magnetic fill in a continuous ditch. If they do point to another ditch Larson would represent a unique site in the northern Plains with five ditches, but firm evidence through other geophysical data (e.g., GPR) or excavation will be necessary.

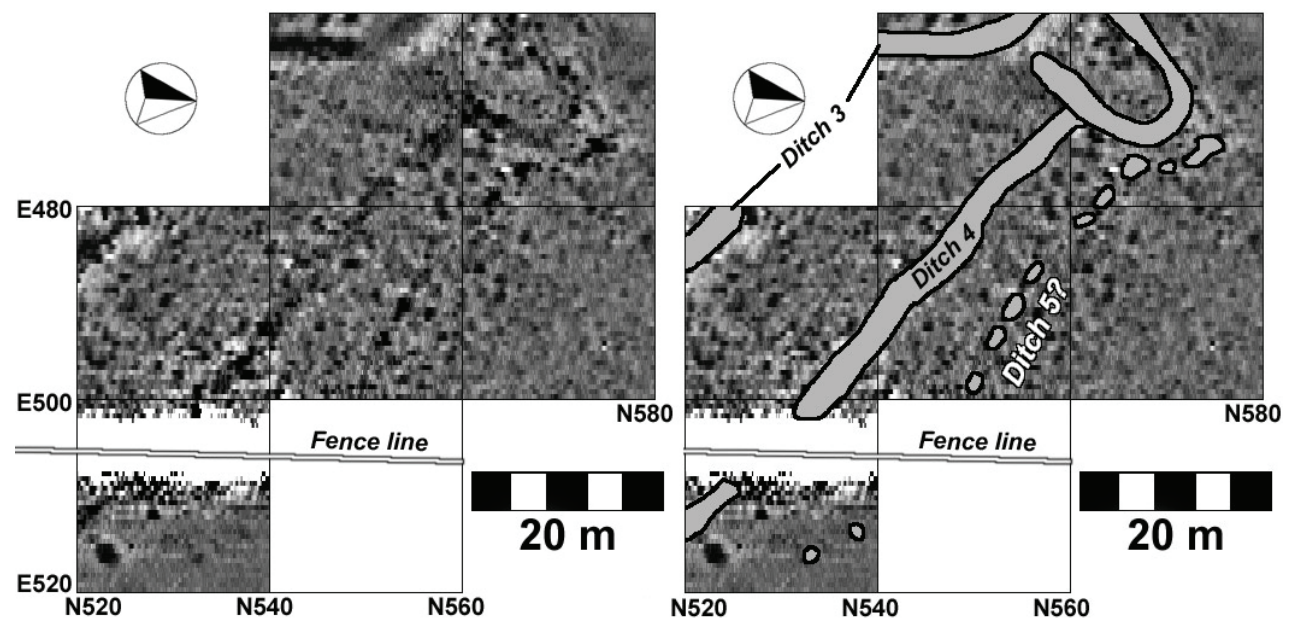

Figure 3.8. A series of discontinuous magnetic anomalies in linear association may represent the course of yet another defensive Ditch 5.

8. Mounds and Mounded Middens. Several prominent mounds are visible throughout Larson, which are thought to represent mounded midden deposits. Several are labeled in Figure 3.6b. Middens tend to express anomalies through mounding of magnetically enriched topsoil, even more magnetic settlement soils, and burned materials such as sediments from hearth cleanings, fire cracked rock, and ceramics. Measurements from 8-10 nT are common. At Double Ditch 
mounds appear to be sited in concert with fortification ditches, as components of defense, or on top of abandoned fortification ditches (Kvamme 2006a). One or both circumstances occur at Larson where portions of a large and elongated mound appear to overly Ditch 3 (from about N525-N540, Figure 3.6a,b), although the bulk of it may be located behind it (from N510-N525), suggesting its use as a possible rampart, bastion, or observation point.

9. Mounded Berms. Soil mounding adjacent to defensive Ditches 1-2 create impressive topographic prominences and robust magnetic anomalies owing to topsoil compositions (Figure 3.6a,b). These anomalies are probably related to mounding elsewhere on the site (label " 8 " in Figure 3.6b), and may have contributed to the village's defenses as ramparts or observation platforms. The mottled nature of these anomalies may point to individual basket dumping episodes of magnetically enriched materials as these berms were created. Midden materials may also occur. They tend to be moderately magnetic with measurements typically in the range of 25 nT. Palisades were probably associated with these ditches.

10. Houses. Many of these circular anomalous areas, 12-17 $\mathrm{m}$ in diameter, likely represent the loci of former earthlodges (Figure 3.6a,b). Some may also represent earth-borrowing pits, as occurred extensively at Double Ditch (Kvamme 2006a). They are characterized by a surrounding perimeter of positive magnetic anomalies (about 1-2 nT), hypothesized to derive from eroded lodge roof sediments. Surrounding anomalies of high magnitude (about 2-5 nT), 1$2 \mathrm{~m}$ diameter, probably represent exterior subterranean storage pits, a circumstance observed at other sites in the region (e.g., at Huff [Ahler and Kvamme 2000] and Double Ditch [Kvamme 2006a]). Centrally located anomalies 1-2 $\mathrm{m}$ in diameter point to likely hearths (2-9 nT) while surrounding interior anomalies of the same size represent a combination of interior storage pits and auxiliary hearths.

11. Earth Borrowing Pit. This broad area, about $15 \mathrm{~m}$ in diameter (Figure 3.6a,b), corresponds with a distinct circular depression visible in the surface (Figure 3.5). Because it lacks interior anomalies, particularly one that might denote a central hearth, it is inferred to represent a borrow pit rather than a house. As was argued at nearby Double Ditch (Kvamme 2006a), it could be the case that the loci of abandoned houses were employed for later borrowing activities, so this perfectly circular depression may represent a former house where interior anomalies, floor, and sub-floor deposits were subsequently removed.

12. Subterranean Storage Pits. Several anomalies thought to represent storage pits are identified in Figure 3.6b. They are typically circular to oval in shape, 1-2 $\mathrm{m}$ in diameter, and measure from 25 nT. Excavations in 2006 verified the identity of several (see below).

13. Plaza. A broad, level, and somewhat sunken region immediately outside and adjacent to Ditch 1 is generally regarded as the Mandan plaza (Figure 3.1b). Both historic maps of the early 20th century appear to identify this region (Figure 3.3). The magnetic gradiometry evidence (Figure 3.6) supports this classification because it shows this area to be almost devoid of anomalies, a circumstance demonstrated at other Mandan sites such as Huff village (32MO11) (Ahler and Kvamme 2000). This lack of anomalies indicates that no constructions or modifications to the surface or subsurface were permitted, suggesting some sort of ritualized authority. The exception was the "Ark of the Lone Man,” a small-diameter wooden post construction that may be visible as a low mound on the surface immediately west of the survey area (its edge is mapped in Figure 5; it is labeled “Big Canoe” in Bowers” map of Figure 3b). 


\section{Excavation Evidence of Indicated Anomalies}

During the tail end of the geophysical surveys, and for several days afterward, excavations were performed at the locations of several anomalies. Specifically, the aim was to obtain material culture samples and dates for the early occupation of Larson, so focus was placed on the outer village margins guided principally by the magnetic gradiometry evidence. Mark Mitchell of PCRG and Fern Swensen of the SHSND directed the excavations. Data from three pit excavations, Blocks A, D, and F, and excavations of Ditches 3 and 4 were provided subsequent to that work, with locations shown in Figure 3.9a and illustrative photos in Figures 3.9b-f. (Editor's Note: Data on a sixth excavation unit, Block $\mathrm{G}$, were inadvertently omitted from a fieldwork summary provided to the author).

- Block $A$, measuring 1 × 2 m, was placed over the north half of an apparent storage pit anomaly with a moderately high maximum of $3.2 \mathrm{nT}$ (Figure 3.9a, inset). Excavations revealed a large undercut pit feature with lenses of magnetic fill adjacent to a large post pit (Figure 3.9b).
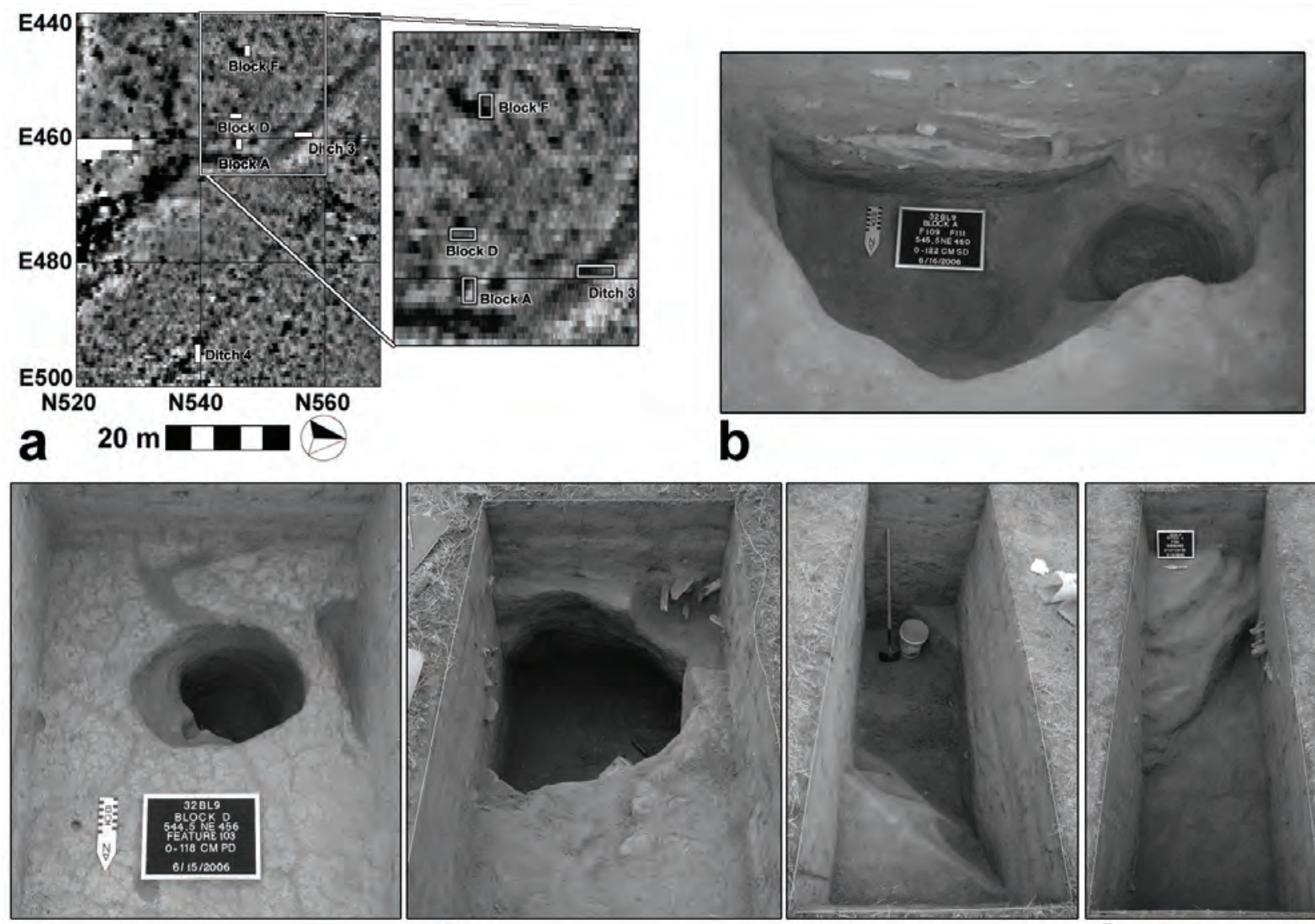

C

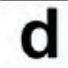

e

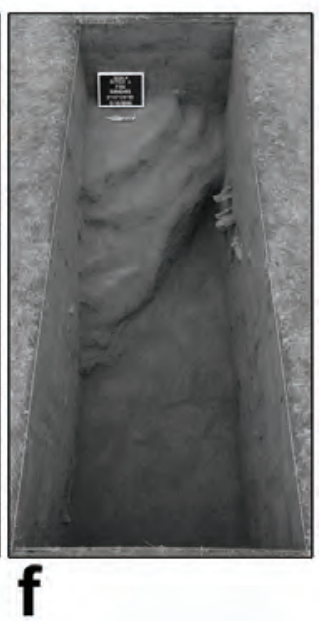

Figure 3.9. Excavations of anomalies at Larson, 2006: a) location map, b) post hole (right) and undercut pit (left) in Block A, c) post hole in Block D, d) undercut storage pit in Block F, e) Ditch 3, f) Ditch 4. 
- Block $D$, measuring 1 x 2 m was, unfortunately, incorrectly located a meter too far to the east (Figure 3.9a, inset), resulting in the targeted storage pit (with a maximum of $3.0 \mathrm{nT}$ ) being missed by the excavation (the edge of it may be visible in the right wall in Figure 3.9c). Revealed, however, was a large post pit not associated with an anomaly. Although pits filled with settlement soils tend to be moderately magnetic, it is hypothesized that post pits may not exhibit magnetic anomalies because they were originally filled with wood (a nonmagnetic material) that later decomposed into soil.

- Block F, measuring 1 x 2 m, was excavated over the eastern of a series of closely spaced anomalies representing three adjacent storage pits (Figure 3.9a, inset). The maximum of this anomaly measures $3.84 \mathrm{nT}$. A very large undercut storage pit was revealed adjacent to a smaller pit containing a collection of bison bone (Figure 3.9d).

- Ditch 3, measuring 1 x 3 m, excavations revealed a deep fortification ditch (Figure 3.9e).

- Ditch 4, measuring 1 × 3 m, excavation revealed a deep fortification ditch (Figure 3.9f).

\section{Fortification Ditch Magnetism}

Ditches 1-2, both discernable as depressions in the surface (the former highly so), were not filled in or sealed by the inhabitants as the village contracted or was abandoned. With the magnetically enriched A-horizon removed by excavation, negative magnetic measurements are
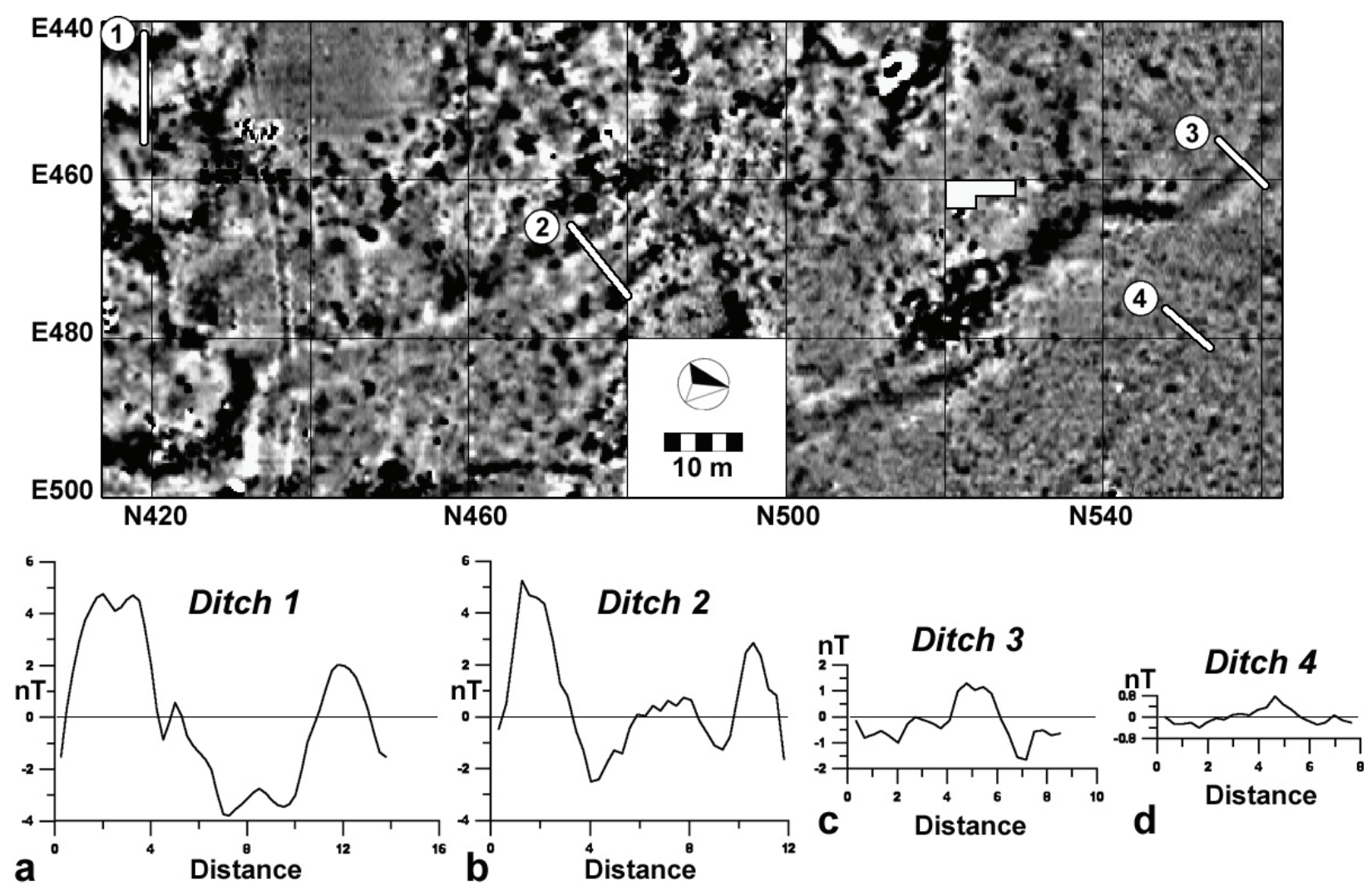

Figure 3.10. Magnetic profiles across Fortification Ditches 1-4 showing loci of profiles (top) and graphs of magnetic variation for a) Ditch 1, b) Ditch 2, c) Ditch 3, d) Ditch 4. All graphs are profiled at the same scale from top-tobottom (west-to-east). 
characteristic, particularly in Ditch 1 (Figure 3.10a). This ditch exhibits much greater negative magnetism than Ditch 2 because the latter is probably older and has partially filled through natural erosion of nearby (magnetic) sediments. Pedogenesis may also contribute to its magnetism, which is somewhat elevated along its central course (Figure 3.10b).

Surface evidence of Ditches 3-4, on the other hand, is absent. These ditches were probably purposely sealed by the occupants as the village contracted. Midden deposits, waste materials, and surface soils were undoubtedly employed, all of which possess elevated magnetic susceptibilities, contributing to positive anomaly creation (Figure 3.10c,d). That Ditch 3 is much more magnetic than Ditch 4 likely occurs because, closer to the village core, the settlement soils at the surface are likely to be more magnetic through anthropogenic enrichment (Kvamme 2006b), although variations in depth and volume of fill may also contribute to magnetic differences.

\section{Magnetic Anomalies from Modern Sources}

Nine regions or classes of anomalies in the area surveyed are likely derived from modern circumstance, recent land modifications, or through the introduction of ferrous metal artifacts. They are summarized below are identified on Figure 3.6 with corresponding alphabetical labels.

A. Unsurveyed $20 \mathrm{~m}$ Block. This block was not surveyed because it contained a large tree within a sizeable surface depression that would make survey extremely difficult (Figure 3.6b). It was also thought at the time to be the locus of one of Bowers' (1940) excavations and was therefore deemed of low priority for survey because of the assumed disturbance to the ground. The georegistration of Bowers' map to the modern landscape (Figure 3.3b) shows this not to be the case.

B. Unsurveyed $3 \times 10 \mathrm{~m}$ Block. This region could not be surveyed owing to the presence of dense foliage and a large tree (Figure 3.6b; see also Figure 3.5).

C. Fence Line. A steel post and barbed wire fence crosses the site, separating pasture from cultivated lands. Massive dipolar anomalies (exceeding $200 \mathrm{nT}$, the instrument's limit) are associated with each fence post and prohibited survey close to the fence (Figure 3.6b).

D. Unsurveyed $20 \mathrm{~m}$ Block. This block could not be surveyed because it was used as a tractor park, which would generate massive dipolar anomalies and preclude meaningful results (Figure 3.6b).

E. Dipolar and Monopolar Anomalies Associated with Ferrous Metals. Numerous anomalies occur throughout the study area that are unequivocally generated by iron or steel artifacts. Many are labeled in Figure 3.6b. They are instantly recognized by a combination of clear dipolar form (seen as adjacent black-white pairs) and compactness (.5-2 $\mathrm{m}$ in diameter). Most probably represent modern or recent artifacts such as tractor parts, nails, fence staples, barbs, and the like. A number may represent iron trade artifacts from protohistoric periods of the site's occupation, but it is impossible to predict which. Most of these anomalies vary between -8 to $+15 \mathrm{nT}$, but several exceed $200 \mathrm{nT}$ pointing to massive or long linear iron or steel artifacts. 
Several compact monopolar anomalies may also represent ferrous metal where sources are smaller or deeper (in these cases the weaker negative poles [white] are less visible). They commonly express magnitudes of 3-8 nT. A line of such anomalies is labeled "E1" in Figure 3.6b that probably represents a string of metal artifacts dropped along a former path or perhaps debris (e.g., barbs, nails) from a former fence line (Figure 3.11). Other anomalies associated with E1 can be traced west of Ditch 2.

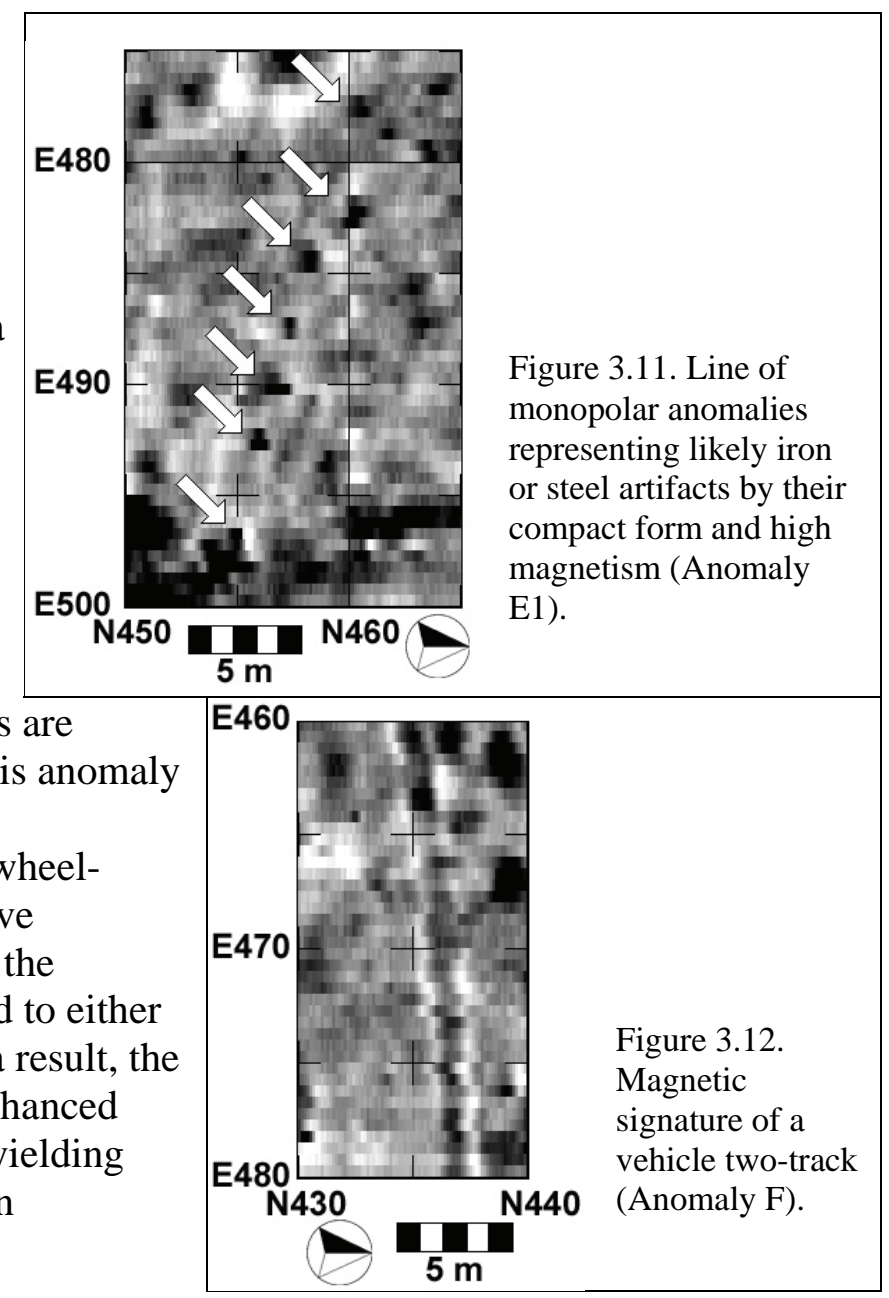

F. Vehicle Track. Two parallel linear depressions are visible in the ground surface at the locus of this anomaly (Figure 6b; see also Figure 3.5), undoubtedly representing a recent vehicle track-way. The wheelcaused depressions are associated with negative magnetism ( -1 to $-3 \mathrm{nT})$, most likely because the magnetically enriched topsoil has been pushed to either side, depleting magnetic source material. As a result, the centerline of this two-track is magnetically enhanced owing to the slight mounding of this topsoil, yielding values between .5 to about $3 \mathrm{nT}$, depending on neighboring parent material (Figure 3.12).

Figure 3.12 Magnetic ignature of a vehicle two-track (Anomaly F).

G. Vehicle Track. This linear anomaly is associated with the locus of a generalized track-way for farm vehicles, adjacent to the cultivated field (Figure 3.6b). It leaves a somewhat indistinct linear anomaly 1-2 m wide that represents areas of variable soil mounding and grooving from vehicle movements and slightly elevated magnetism (about .5-1.5 nT).

H. Step to Cultivated Area. This anomaly corresponds with a 20-30 cm step from the higher tall grass region adjacent to the lower plowed and cultivated field. The lower elevation of the cultivated area is caused by settling of sediments through a century of plowing and compression from regular tractor movements, strikingly indicated by the high density of the soil. The step and associated berm to the more intact topsoil produces a narrow linear anomaly about $.5 \mathrm{~m}$ wide (Figure 3.6b). Unfortunately, the locus of this anomaly overlies the course of portions of what is likely Ditch 4 (Anomaly 4), adding confusion to the latter’s interpretation.

I. Cultivation marks. Clear in the data are two very weak $(<.5 \mathrm{nT})$ arcing anomalies connected with linear components that represent the outer perimeter edges of the effects of large farm equipment, such as plow, disk, or chisel arrays (Figure 3.6b). They are caused by slight soil density or mounding variations. Equipment turn-around arcs appear to be indicated from recent field preparation or maintenance (Figure 3.13). 


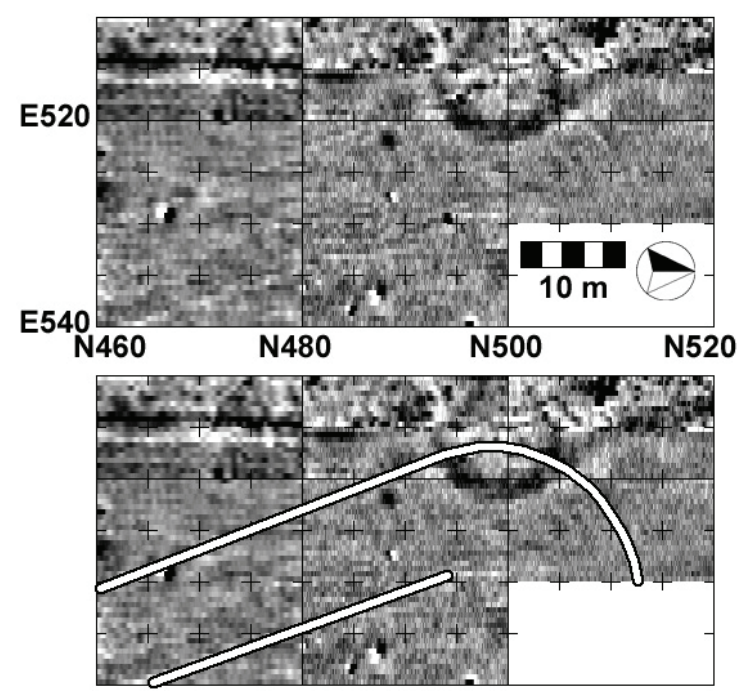

Figure 3.13. Magnetic effects of mechanized farming: turn-around arc of plow, chisel, or disk array.

J. Bowers' Excavation, Work “ $H$ ”. These dipolar, ferrous metal anomalies (Figure 3.6), may coincide with the mapped locus of a major house excavation conducted by Bowers in 1929 (Bowers 1940), labeled "Work H" and illustrated in Figure 3.3b. Many large archaeological excavations leave steel debris behind—nails or rebar for datums, or broken picks, shovels, and wheelbarrows as part of the fill. These anomalies probably point to the fill and activity zone associated with Bowers' excavations. No ready evidence is seen in the data for Bowers' Works B and D, however. It is likely that Work B, on the terrace edge (Figure 3.3b), may be lost in heavy vegetation or altogether removed by erosion. Geophysical evidence of Work $\mathrm{D}$, on the other hand, may simply be obfuscated by high magnitude anomalies common to large mounds, such as the one where this excavation was evidently placed (Figure 3.3b).

\section{Electrical Resistance Survey}

\section{Half-meter Prospecting Depth}

The electrical resistance survey at Larson was initially undertaken on June 6 with a $50 \mathrm{~cm}$ probe separation in the RM-15's twin-probe array, for prospecting at that approximate depth-a depth that has been highly successful at other nearby sites such as Double Ditch (Kvamme 2006a). This survey covered 5 blocks of $20 \mathrm{~m}$ with half-meter probe separation and half-by-half-meter sampling $\left(2,000 \mathrm{~m}^{2} ; .2\right.$ ha; 8,000 measurements). Unfortunately, general drought conditions over the past few years plus a lack of rain in the previous week made the soil extremely dry, causing difficult survey conditions and initially poor results. Probe contact resistance was generally high making it difficult to acquire measurements. Survey of a single $20 \mathrm{~m}$ block required two hours, double the normal amount of time, because each insertion of the probes proved to be a fight to gain electrical contact with moist subsoil. Moreover, the data were of poor quality, containing numerous “data spikes" (erroneous measurements of extreme value derived largely from dry pockets), and only poorly revealing anomalies of potential interest (Figure 3.14a). Geophysical data processing tools-de-spiking algorithms and low-pass filters-were able to improve the quality of these data and demonstrate the usefulness of these data: a segment of Ditch 3 is clearly revealed as well as 
mounded midden deposits (Figure 3.14b). After a day and a half of difficulty and poor results it was decided to temporarily abandon resistance survey until rain might moisten the soil. An EM conductivity survey was investigated in its place as a possible mechanism to gain useful results and increase survey speed. While it proved faster without the need to insert probes and make electrical contact, its results also were poor, unsurprising in that conductivity is the theoretical inverse of resistivity (see section below).

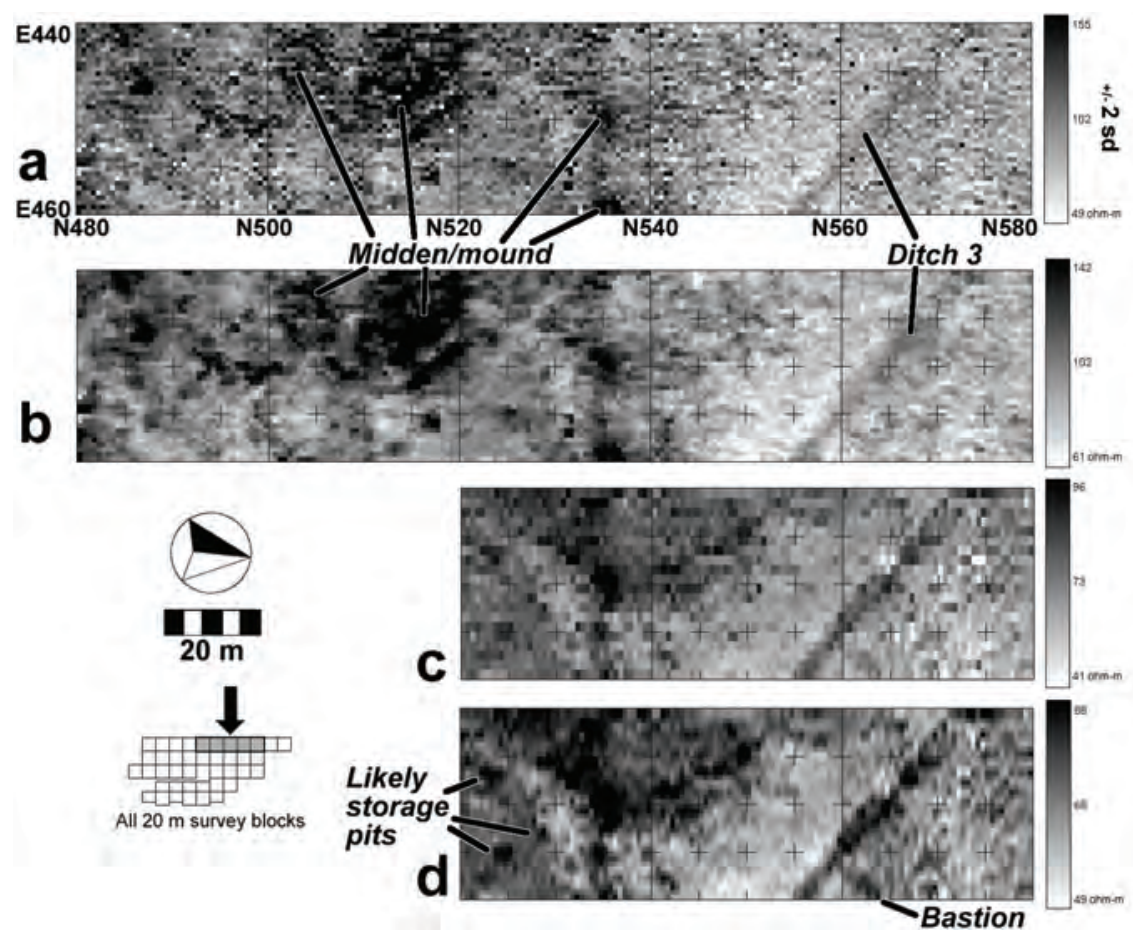

Figure 3.14. Initial exploratory electrical resistance results. a) Raw data at $50 \mathrm{~cm}$, b) $50 \mathrm{~cm}$ data after processing, c) Raw $1 \mathrm{~m}$ data, d) $1 \mathrm{~m}$ data after processing.

One-meter Prospecting Depth

Fortunately, a heavy rain shower crossed the region the night of July 8, allowing resistance survey to recommence the next day with good electrical contact with the soil because the near surface was saturated with moisture. It was decided at this time to increase probe separation and prospecting depth to $1 \mathrm{~m}$ to enhance visibility of large and deep sub-surface constructions, and this tactic proved fruitful. Midden mounds and Ditch 3 all expressed much more robust anomalies than the previous survey (Figure 3.14c,d). Moreover, other anomalies not previously seen, such as likely storage pits (paralleling those suggested by the magnetic gradiometry survey, see above and below) and a bastion associated with Ditch 3, were defined (Figure 3.14d). This prospecting depth was therefore maintained for the remainder of the survey.

A one-meter probe separation and one-by-half-meter sampling was employed in 22 blocks for the electrical resistance survey at Larson (8,800 $\mathrm{m}^{2}$; .88 ha; 17,600 measurements). Adding to this total two $20 \mathrm{~m}$ blocks surveyed at a half-meter depth, but not at a one-meter depth, the maximum area mapped by resistance survey is $9,600 \mathrm{~m}^{2}$ (.96 ha). The $1 \mathrm{~m}$ electrical resistance data (after processing for minor edge-matching) ranged from approximately 12-31 ohms, which translates to about 38-97 ohm-m, showing high resistivity in this pasture setting with a lack of ground moisture. 
The electrical resistance survey at Larson turned out to successfully indicate numerous anomalies of potential cultural significance. In general, resistance data lack some of the detail typical of magnetic gradiometry in northern Plains villages, but they complement those surveys by

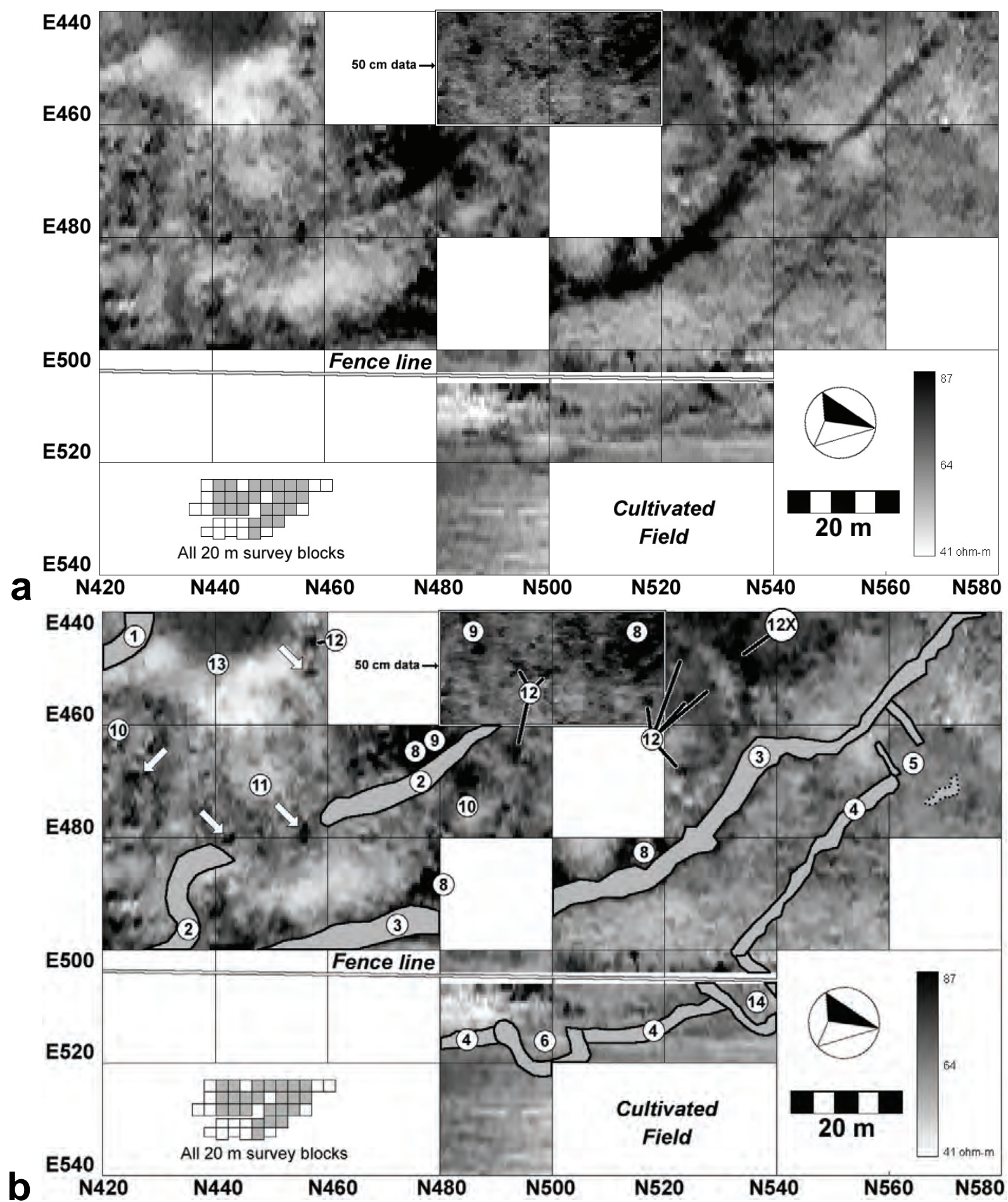

Figure 3.15. Site-wide electrical resistance survey results at Larson village. a) Processed data, b) interpretations. All but two of these $20 \mathrm{~m}$ blocks were acquired with a $1 \mathrm{~m}$ probe separation distance. Numbers refer to specific anomalies or classes of anomalies discussed in text. 
illustrating new anomalies and validating the presence of others. The lesser detail is due, in part, to a lower sampling density ( 2 measurements $/ \mathrm{m}^{2}$ for the $1 \mathrm{~m}$ resistance survey compared to $16 / \mathrm{m}^{2}$ for magnetic gradiometry). Moreover, many archaeological features in northern Plains sites exhibit far stronger magnetic contrasts than occurs in resistivity. Overall, the resistance survey at Larson illustrates many anomalies that parallel those seen magnetically, and important new ones also appear (Figure 3.15a). These anomalies are classified and labeled in several types in Figure 3.15b, paralleling the numbering system used for magnetic gradiometry in Figure 3.6b. A clear, unlabeled, page-size graphic of the electrical resistance results is presented in Figure 3.18.

1. Ditch 1. This fortification ditch, open, unfilled, and more than a meter deep in the surface, leaves only a subtle negative anomaly defining its course (Figure 3.15a,b). This response is characteristic of surface depressions of any kind, because they tend to collect and retain greater moisture, lowering resistivity.

2. Ditch 2. Segments of this ditch are visible as a subtle negative anomaly to the south (around N400), where the surface is somewhat depressed, and as a positive anomaly to the north (around N470-490) (Figure 3.15a,b). A positive anomaly arises most likely because of a looser and drier fill.

3. Ditch 3. This entire ditch is well defined as a positive anomaly (Figure 3.15a,b). Importantly, it makes clear two important characteristics: 1) Bastion 5 is definitely connected with this ditch as is suggested by magnetic gradiometry (Figure 3.6), although most of it is poorly defined, and 2) the course of Ditch 3's middle segment (from N500-540) is made clear. The later was ambiguous in the magnetic data owing to the presence of an overlying mound (Figure 3.6). The resistance data indicate a course that lies well in front of an adjacent linear mound (see Figure 3.5), suggesting that the mound may have served some sort of defensive function behind the ditch.

4. Ditch 4. The presence and location of Ditch 4, somewhat ambiguous in the magnetic data because of its weak magnetic contrast, is made clear by the resistance survey (Figure 3.15a,b). As with the magnetic data, no compelling evidence of Ditch 4 to the west of Bastion 5 can be seen. Importantly, because the resistance survey is immune to the effects of proximate ferrous metals, survey adjacent to the fence line reveals a third U-shaped bastion (labeled “14”) associated with this ditch (see below).

5. Bastion 5. Only the arms of this bastion are strongly expressed in the resistance data (Figure 3.15a,b). With the magnetic contrast also weak (Figure 3.6) it may be that this bastion lacks depth of fill making weak resistance and magnetic anomalies.

6. Bastion 6. The mapping of this bastion by electrical resistance (Figure 3.15a,b) parallels that of the magnetic gradiometry survey (Figure 3.6), with generally weak contrast. This may be due, in part, to its location within the cultivated field. A century of plowing may have removed or homogenized some of its upper portion.

7. No Anomaly Indicated Corresponding with Magnetic Anomaly 7 ( possible Ditch 5)

8. Mounds and Mounded Middens. Several large mounds within the survey area were shown to express positive magnetic anomalies with fills composed of midden materials (Figure 3.6). 
These mounds also illustrate high resistance caused by probable loose fills, and compositions of bone, ceramic, and fire-cracked rock (Figure 3.15a,b).

9. Mounded Berms. Although several areas of soil berms are visible (Figure 3.15a,b) — linear mounded zones adjacent to fortification ditches_-many seen magnetically (Figure 6) are not defined in the resistance data. This may point to composition differences; for example, resistant middens adjacent to ditches versus purposely constructed mounds.

10. Houses. Evidence of houses is weak in the resistance data. Using the surface depression map (Figure 3.5) and the magnetic findings (Figure 3.6) as guides, it is possible to discern subtle circular anomalies that may correspond with earthlodge perimeters (Figure 3.15a,b). This may be due to slight building of roof sediments around lodge perimeters that cause mildly elevated resistance.

11. Earth Borrowing Pit. This circular region lacking anomalies (Figure 3.15a,b) corresponds with a circular surface depression (Figure 3.5) that has been interpreted as a borrow pit (see magnetic discussion, above).

12. Storage Pits. Several likely storage pits, revealed magnetically (Figure 3.6) or shown by excavation to actually represent storage pits (Figure 3.9), are also seen in the resistance data (Figure 3.15a,b). This is likely due to looser fills of unconsolidated materials and compositions of waste materials (e.g., bone, ceramics, and fire-cracked rock). The large resistance anomaly labeled " $12 X$ " probably represents multiple closely spaced storage pits, as suggested by the magnetic data (Figure 3.6) and analogous to pits associated with excavation Block F (Figure 3.9).

13. Plaza. Although exhibiting a resistivity gradient, this region appears nearly devoid of specific anomalies suggesting a lack of constructions and subsurface features, much like the magnetic evidence (Figure 3.15a,b).

14. Bastion 14. This bastion, impossible to locate by magnetic gradiometry due to the overlying ferrous metal fence, represents one of the most important discoveries of the resistance survey, which is unaffected by the fence's metals (Figure 3.15a,b). It helps to define and fill out the nature of Larson's original outlying defenses, and adds to insights concerning bastion form and spacing.

\section{Other Resistance Anomalies}

In addition to the foregoing, the resistance data also point to numerous "point” anomalies of small diameter (1-2 m). Although some may represent subterranean storage pits not revealed by magnetic gradiometry (generally unlikely), most probably result from loose, mounded topsoil or voids produced by rodent activity. Some may also represent small mounded middens, a circumstance that occurred at Double Ditch (Kvamme 2006a). This appears to be true for several such anomalies indicated by arrows in (Figure 3.15b). Striping in cultivated fields is a common artifact of linear plow marks that cause resistivity variations between ridges and furrows. Anomalies 
associated with the fence line generally arise from denser vegetation that commonly grows along fences (large plants can reduce ground moisture, raising resistivity).

\section{Electromagnetic Induction (EM) Survey}

As discussed earlier, an electromagnetic induction survey by the EM-38B was undertaken in two $20 \mathrm{~m}$ blocks as an alternative to the resistance survey when those data were difficult to acquire prior to rainfall on July 8. Four samples per meter were acquired in each phase, with a traverse separation of a half-meter. Consequently, 8 samples $/ \mathrm{m}^{2}$ were obtained within the two study blocks of $20 \mathrm{~m}$, for $800 \mathrm{~m}^{2}$ (.08 ha) of survey and a total of 3,200 conductivity and 3,200 magnetic susceptibility measurements. The quadrature phase responds to soil conductivity through a depth of about $1.5 \mathrm{~m}$ and it was hoped it would penetrate to moist subsurface sediments. The results in Figure 3.16a are disappointing in their lack of detail, but nevertheless successfully point to a curving anomaly that may be associated with hidden Fortification Ditch 3 (dotted line). The data indicate a high conductivity zone that conceivably may point to moist sediments associated with this ditch, but in view of the findings of the resistance survey (Figure 3.16b) this result is puzzling. With conductivity the theoretical inverse of resistivity, the latter should indicate low resistivity, but the results indicate the reverse. This discrepancy may be explained by an apparent offset between conductivity and resistivity anomalies. The conductivity data apparently reveal the more conductive (less resistant) earth inside the ditch while the actual locus of Ditch 3 itself remains undetected by that method, although it is clear in the resistivity findings.

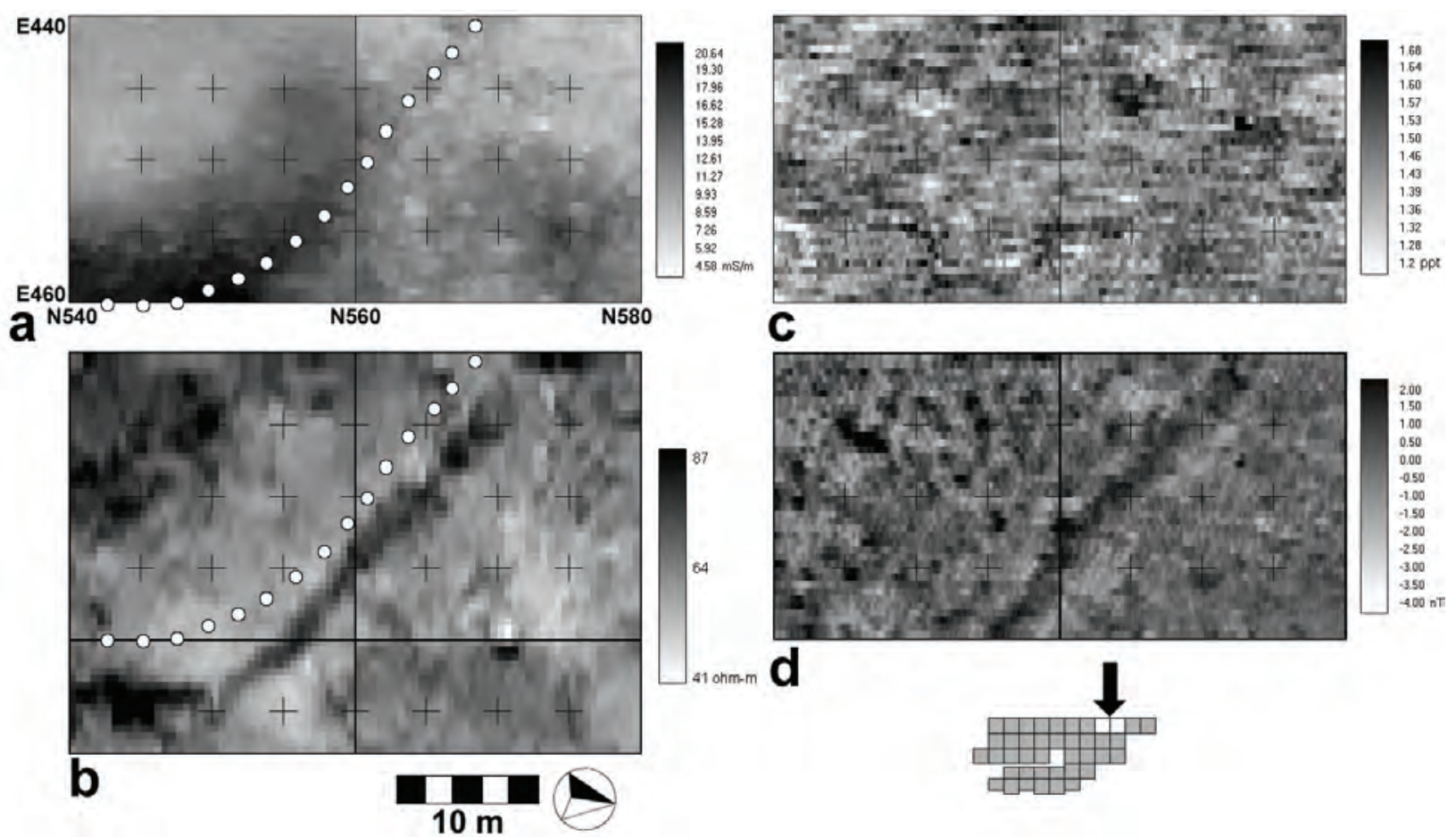

Figure 3.16. Results of the EM survey at Larson compared against electrical resistance and magnetic gradiometry data. a) Quadrature (conductivity) phase with dotted line showing high conductivity anomaly, b) Electrical resistivity data showing locus of linear Ditch 3 alongside dotted line of conductivity anomaly, c) In-phase (magnetic susceptibility) data from EM survey, d) Magnetic gradiometry results. 
The in-phase or magnetic susceptibility (MS) component of the EM survey is disappointing (Figure 3.16c) in that few magnetic anomalies known to exist by the magnetic gradiometry results are indicated (Figure 3.16d). The MS data give only the subtlest hints of several of the most robust of the gradiometry anomalies (compare Figures 3.16c,d). The well-known depth limitation of less than $50 \mathrm{~cm}$ for the EM-38 is likely responsible (Dalan 2006). The high speed of data collection with the EM-38B and its ability to simultaneously collect conductivity and MS data in a single pass makes it a tempting option for applied geophysics in archaeology. Although an in-phase EM survey was informative at Double Ditch (Kvamme 2006a), these results together with a similar lack of findings at nearby Boley Village (32MO37; Kvamme 2006c) support a growing body of evidence that suggests caution and an inability to detect features of cultural significance in some contexts in northern Plains Village archaeological sites.

\section{Conclusions}

Geophysical surveys at Larson Village successfully defined multiple classes of anomalies of archaeological interest. Significant parts of this village were surveyed by magnetic gradiometry and electrical resistance methods. Specifically, in addition to two inner fortification ditches visible on the surface, two buried outer ditches are defined. Three U-shaped bastions are also revealed, associated with Ditches 3 or 4. Massive mounding appears to occur over or adjacent to Ditch 3, a circumstance seen at nearby Double Ditch and interpreted as a defensive measure (Kvamme 2006a). Numerous subterranean storage pits are also located. In combination with the evidence of surface depressions, perhaps as many as 10 houses are defined with anomalies that indicate centrally placed hearths, surrounding storage pits, and auxiliary hearths. One of Bowers' (1940) excavations appears to be indicated by a plethora of ferrous metal debris that agrees with the locus he indicates in a map. A level space commonly viewed as the village plaza gains supporting evidence from the geophysical surveys because no anomalies are indicated, agreeing with the situation learned in the plaza at Huff Village (32MO11) (Ahler and Kvamme 2000).

Although magnetic gradiometry provides greater detail and clarity, many anomalies are also revealed by resistivity, including ditches, bastions, and storage pits. Importantly, the resistance survey reveals the true course of Ditch 3 where it is obscured to gradiometry by overlying mound materials. Moreover, the resistance survey defined a third bastion invisible to gradiometry owing to its locus under a steel barbed-wire fence. The accuracy of the geophysical surveys was such that archaeological excavations, which took place during the closing stages and immediately after the survey, could be accurately targeted over features of interest. These excavations and limited coring confirmed the accuracy of the geophysical surveys. A limited investigation by EM methods gave few insights and demonstrated the limitations of this technology in yet another context.

\section{Acknowledgements}

This research was conducted under a grant from the PaleoCultural Research Group (PCRG) of Flagstaff, Arizona, Stanley A. Ahler, Director, made possible by the funding provided by the State Historical Society of North Dakota (SHSND). Fern E. Swenson, Director of the Historic Preservation Division of the SHSND and Stan Ahler were incredibly supportive of this work, as was Mark Mitchell, project Principal Investigator. SHSND archaeologist Tim Reed provided 
logistical support including site gridding by total station. Instrumentation was provided by the Archeo-Imaging Lab of the University of Arkansas. Much of the fieldwork was conducted by Jo Ann Christein Kvamme, Archeo-Imaging Lab field assistant. 


\section{References Cited}

Ahler, Stanley A., and Kenneth L. Kvamme

2000 New Geophysical and Archaeological Investigations at Huff Village State Historic Site (32MO11), Morton County, North Dakota. PaleoCultural Research Group, Flagstaff, Arizona. Submitted to the State Historical Society of North Dakota, Bismarck.

Bowers, Alfred W.

1940 Missouri River Earthlodge Archaeology of North Dakota and South Dakota. Ms. on file at Logan Museum, Beloit College, Wisconsin.

Clark, Anthony

2000 Seeing Beneath The Soil: Prospection Methods In Archaeology. Reprinted. Routledge, London. Originally Published 1990, B.T. Batsford Ltd., London.

Dalan, Rinita A.

2006 Magnetic Susceptibility. In Remote Sensing in Archaeology: An Explicitly North American Perspective, edited by Jay K. Johnson, pp. 161-203. University of Alabama Press, Tuscaloosa.

Geoscan Research

1996 Instructional Manual: Resistance Meter RM-15. Geoscan Research, Bradford, United Kingdom.

Kvamme, Kenneth L.

2006a Four Years of Geophysics and Remote Sensing at the Double Ditch State Historic Site (32BL8), North Dakota, 2001-2004. Unpublished report on file at the State Historical Society of North Dakota, Bismarck.

2006b Magnetometry: Nature's Gift to Archaeology. In Remote Sensing in Archaeology: An Explicitly North American Perspective, edited by Jay K. Johnson, pp. 205-233. University of Alabama Press, Tuscaloosa.

2006c Report of Geophysical Investigations at Boley Village (32MO37), North Dakota. Unpublished report submitted to PaleoCultural Research Group, Flagstaff, Arizona.

Steinbrueck, E.R.

1904 Mandan Village Sites. In Mandan Memoirs of Explorations in the Basin of Mississippi. J.F. Bower Press of McGill-Warner Co., St. Paul, Minnesota.

Swenson, Fern E.

2007 Settlement Plans for Traditional Mandan Villages at Heart River. In Plains Village Archaeology: Bison-Hunting Farmers on the Central and Northern Plains, edited by Stanley A. Ahler and Marvin Kay. University of Utah Press, in press.

Will, George F., and Herbert J. Spinden

1906 The Mandans: A Study of their Culture, Archaeology and Language. Papers of the Peabody Museum of American Archaeology and Ethnology, Harvard University, Cambridge, Massachusetts. 


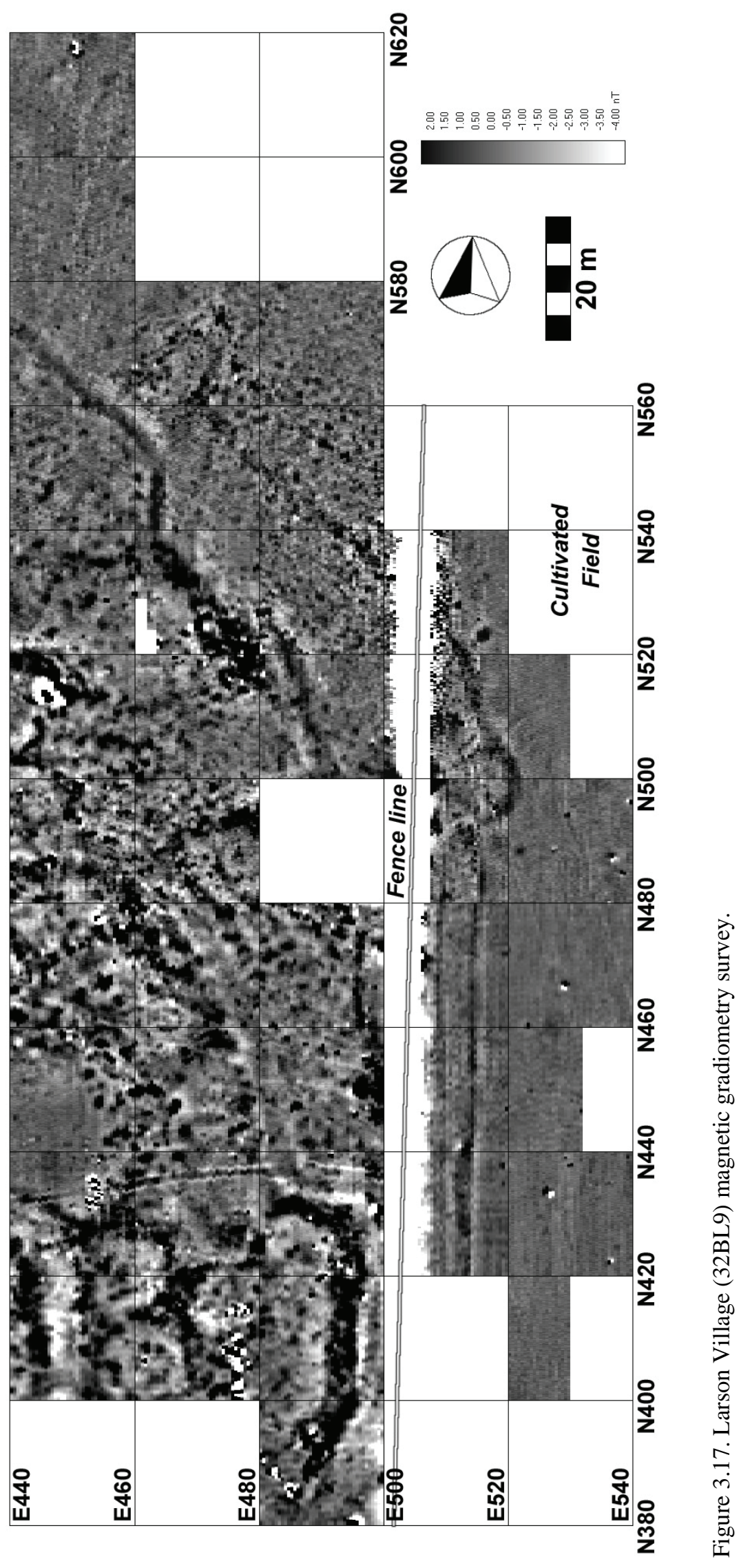




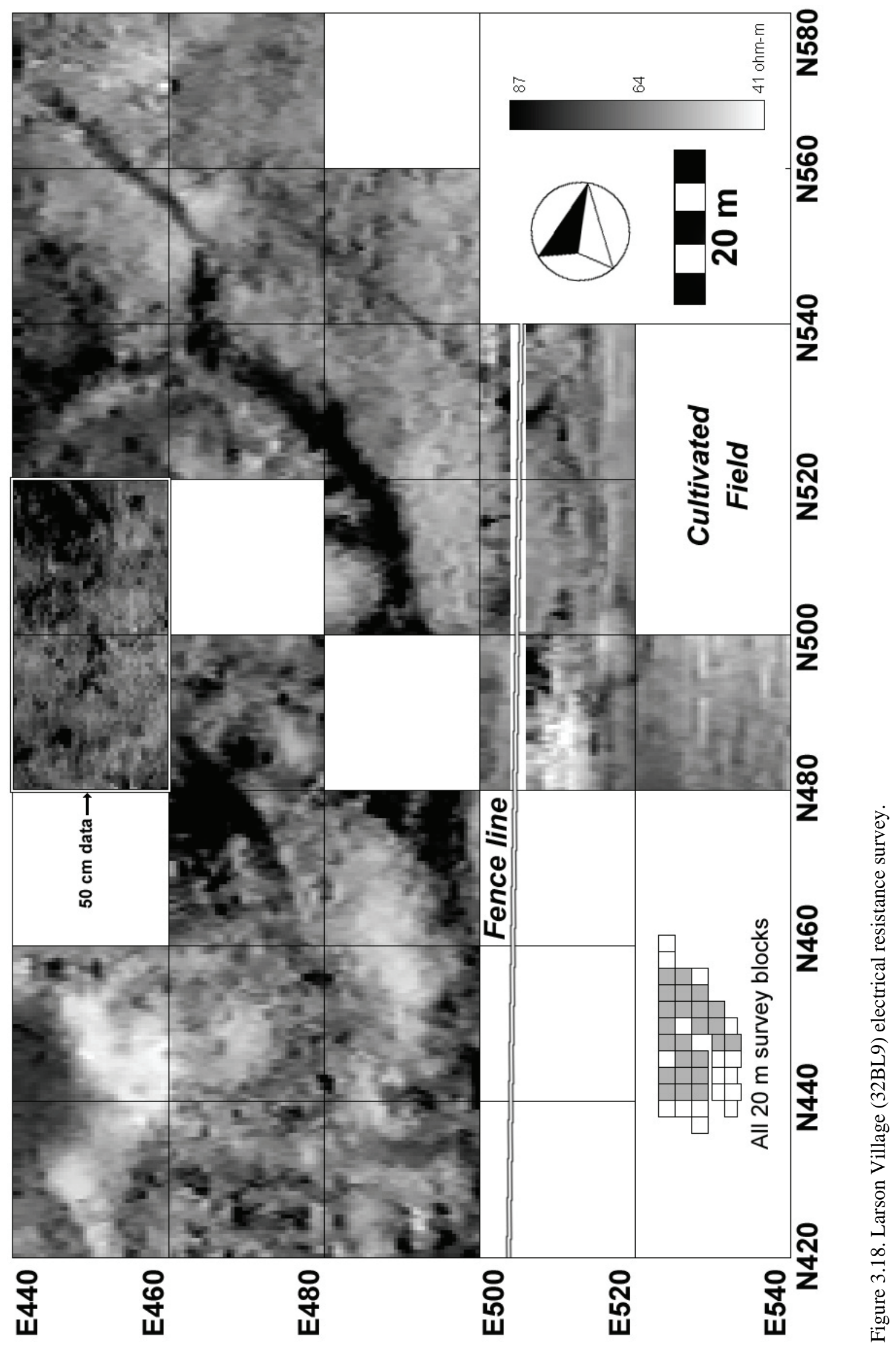




\title{
4. EXCAVATION RESULTS
}

\author{
Mark D. Mitchell
}

\section{Overview of the Field Effort}

PaleoCultural Research Group and the State Historical Society of North Dakota carried out a program of limited test excavation and systematic hand coring at Larson Village from June 9 through June 18, 2006. A total of 17 people participated in the fieldwork, including 12 PCRG volunteers (John Moret, John Vicha, Ed Maixner, Betsy Maixner, Richard Krause, Michael Krause, Janet Griffitts, Bob Gardner, Carl Falk, Laurinda Porter, Craig Johnson and Alicia Johnson), two PCRG staff (Mark Mitchell and Stacey Madden), and four SHSND staff (Fern Swenson, Paul Picha, Tim Reed, and Kelly Heilman). The fieldwork was directed by Mark Mitchell. The first several days of the project were devoted to constructing the waterscreen station (which was located adjacent to a large stock pond on the east side of Highway 1804 about $0.8 \mathrm{~km}$ from the site), to establishing the site grid system, and to coring along a north-south transect running across the large basin near the center of the site. Hand coring also was used to investigate magnetic anomalies identified as potential candidates for excavation by the geophysical survey. Test excavation began on June 12 and continued through the morning of June 17. On each of these days three or four people transported sediment to the waterscreen station and processed it. The remaining members of the crew worked in teams of two or three people in six separate excavation blocks on the northern edge of the site. On June 17, the final day of the project, photographs were taken of each excavation unit and profile drawings were prepared. Permanent datum placement, EDM mapping, breakdown of the waterscreen station, and initial backfilling also took place on June 17. Backfilling with imported sand and gravel was completed on June 19.

\section{Field Methods}

Horizontal control for the coring and excavation program was provided by a metric grid system. Figure 4.1 illustrates the major features of the portion of the site north of $149^{\text {th }}$ Street, along with the site grid and the location of the magnetic survey block. Three permanent datums, each consisting of a steel reinforcing bar set flush with the ground surface, were established on the site. One of the three is located in the village core, approximately $1.3 \mathrm{~m}$ north of the east-west right-ofway fence (351.82NE431.32, $508.73 \mathrm{~m}$ ). Two others are located on the eastern edge of the village, approximately $1.3 \mathrm{~m}$ west of the north-south pasture fence (606.37NE506.04, $507.04 \mathrm{~m}$ and 380.83NE501.39, $507.06 \mathrm{~m}$ ). A portion of the site was staked on a $20 \times 20 \mathrm{~m}$ grid to guide the geophysical survey (see Chapter 3). Once features had been selected for excavation, the corners of the excavation blocks were set with an EDM. Vertical control for each excavation unit was provided by a local datum, which consisted of a large nail driven flush with the ground surface at the southwest corner of the excavation block. In all cases, excavation depths were measured from that point, and designated as "surface depth" (SD). Table 4.1 lists the grid coordinates and elevations of these local datums, along with other information on each of the excavation blocks. The datum elevations given represent the means of two or three EDM measurements. 

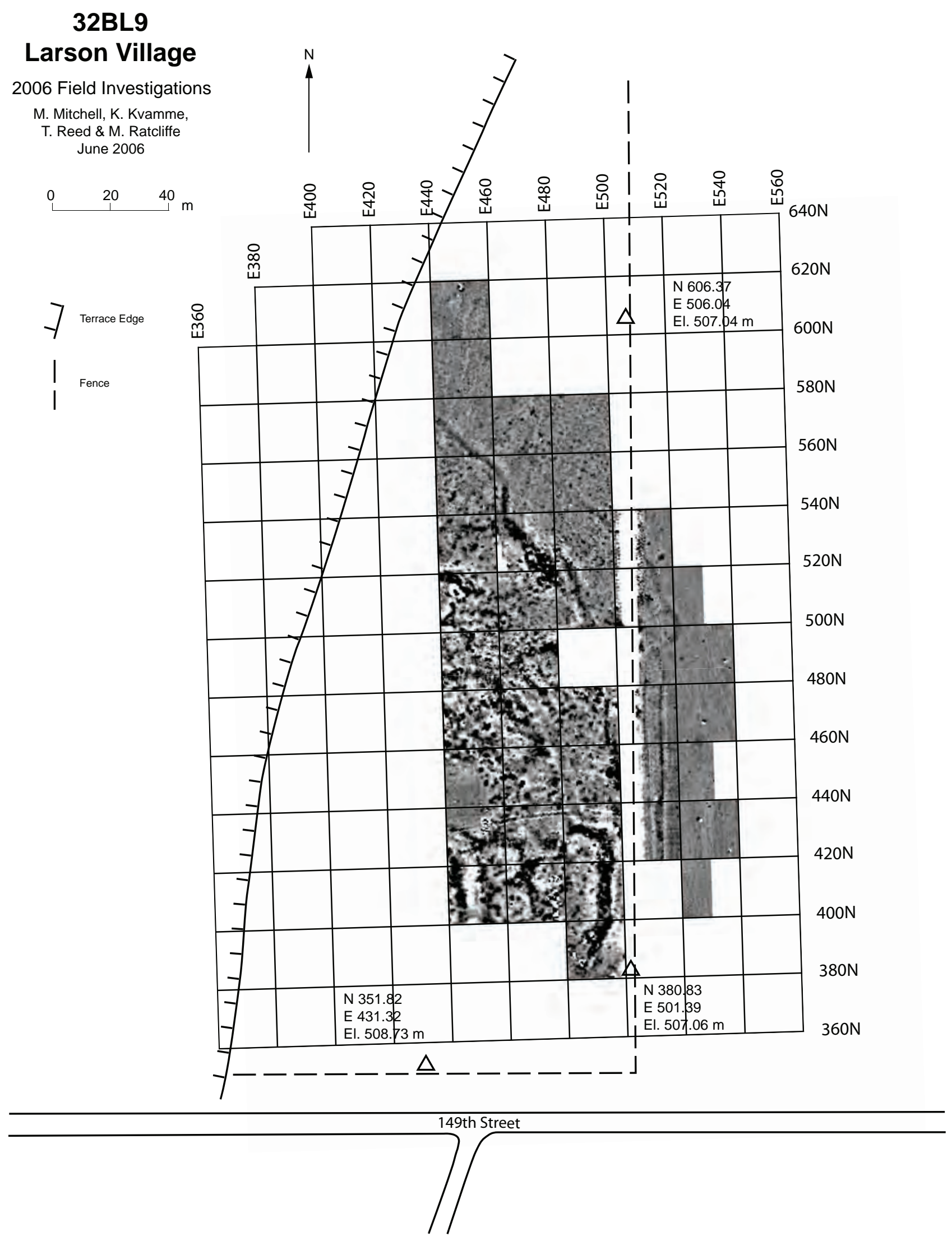

Figure 4.1. Map of Larson Village, showing the site grid and the geophysical survey area. 
After the pit features targeted for excavation were defined through coring (see below), a $1 \mathrm{x}$ 2 m unit or "block" was laid out over the pit such that part of the pit would be excavated within that unit and part of the pit would be preserved outside that unit, creating a profile through the feature along the long wall of the $1 \times 2 \mathrm{~m}$ block. After the excavation blocks were selected and laid out, the sod layer, which varied from 5 to $13 \mathrm{~cm}$ in thickness, was removed without screening. This material was stockpiled adjacent to each unit for later backfilling. Each of the targeted features was then excavated in arbitrary 10-cm thick levels with complete waterscreen recovery. Excavation levels were classified either as "general" levels (GL) if they included material from the entire excavation unit or as "feature" levels (FL) if they only included material from a defined and numbered cultural feature. For exposure and sampling of the ditch features, longer blocks or trenches measuring $1 \times 3 \mathrm{~m}$ were laid out across the trend of each ditch and in alignment with the grid. These trenches were positioned so that one wall of the ditch would be exposed and its form and location could be accurately determined. As a result, only the minimum width of each ditch, measured perpendicular to the walls at the floor level, could be determined. The goal of this procedure was to remove a relatively large volume of sediment from each ditch, sampling its contents, and defining its stratigraphy and depth.

Table 4.1. Excavation unit data, 2006 PCRG excavations at Larson Village.

\begin{tabular}{cccccc}
\hline Area & $\begin{array}{c}\text { SW Corner } \\
\text { Coordinate }\end{array}$ & $\begin{array}{c}\text { Mean Datum } \\
\text { Elevation }(\mathrm{m})\end{array}$ & $\begin{array}{c}\text { General } \\
\text { Levels }\end{array}$ & $\begin{array}{c}\text { General Level } \\
\text { Volume (cu. m.) }\end{array}$ & $\begin{array}{c}\text { Identified } \\
\text { Features }\end{array}$ \\
\hline Block A (1x2 m) & 545.5NE460 & 507.540 & 5 & $0.900^{*}$ & $108,109,111$ \\
Block D (1x2 m) & $544.5 N E 456$ & 507.408 & 6 & 1.200 & $101,102,103$ \\
Block F (1x2 m) & 547NE445 & 507.206 & 4 & 0.780 & $104,107,110$ \\
Block G (1x2 m) & 528NE489 & 506.950 & 11 & 1.925 & 112 \\
Ditch 3 (1x3 m) & 555NE459 & 507.316 & 4 & $1.260^{*}$ & 105 \\
Ditch 4 (1x3 m) & 539NE493 & 507.134 & 5 & 1.455 & 106 \\
\hline
\end{tabular}

* 0.100 cu. $\mathrm{m}$ of sediment from Block A was inadvertently mixed with $0.240 \mathrm{cu}$. $\mathrm{m}$ from Ditch 3 during waterscreen processing.

Skim shovels and trowels were used for the ditch excavations, while the pit excavations were primarily carried out with trowels, brushes, and other small hand tools. Excavated sediment from each unit was transferred to wheelbarrows, which in turn were transported by truck to the waterscreen station (Figure 4.2). Waterscreening procedures were similar to those used for other recent projects in the Heart region. Water was pumped from a local pond and drying of washed residue was conducted on canvas cots near the screen station. All recovered materials were dried, bagged by catalog number, and packed for shipment to PCRG's lab for further processing. No artifact sorting was undertaken in the field.

Data about each excavated level was recorded on PCRG level forms modified for the project. The basic data on these forms include each unit's coordinates, excavation depths, and associated catalog numbers. The forms include space for the excavators to write short narratives describing the sediment and artifacts observed and problems encountered during the course of excavation. A plan map was drawn at the end of each level. Catalog numbers were assigned to each arbitrary level, and all of the objects recovered during waterscreening were grouped under that catalog number. A very small number of artifacts were plotted and assigned individual catalog numbers. A few bulk sediment samples also were taken for subsequent flotation in the lab. With a single exception (see Block G discussion), no human remains were observed in situ during the field investigations. However, several human teeth, phalanges, and other small bones were recognized 


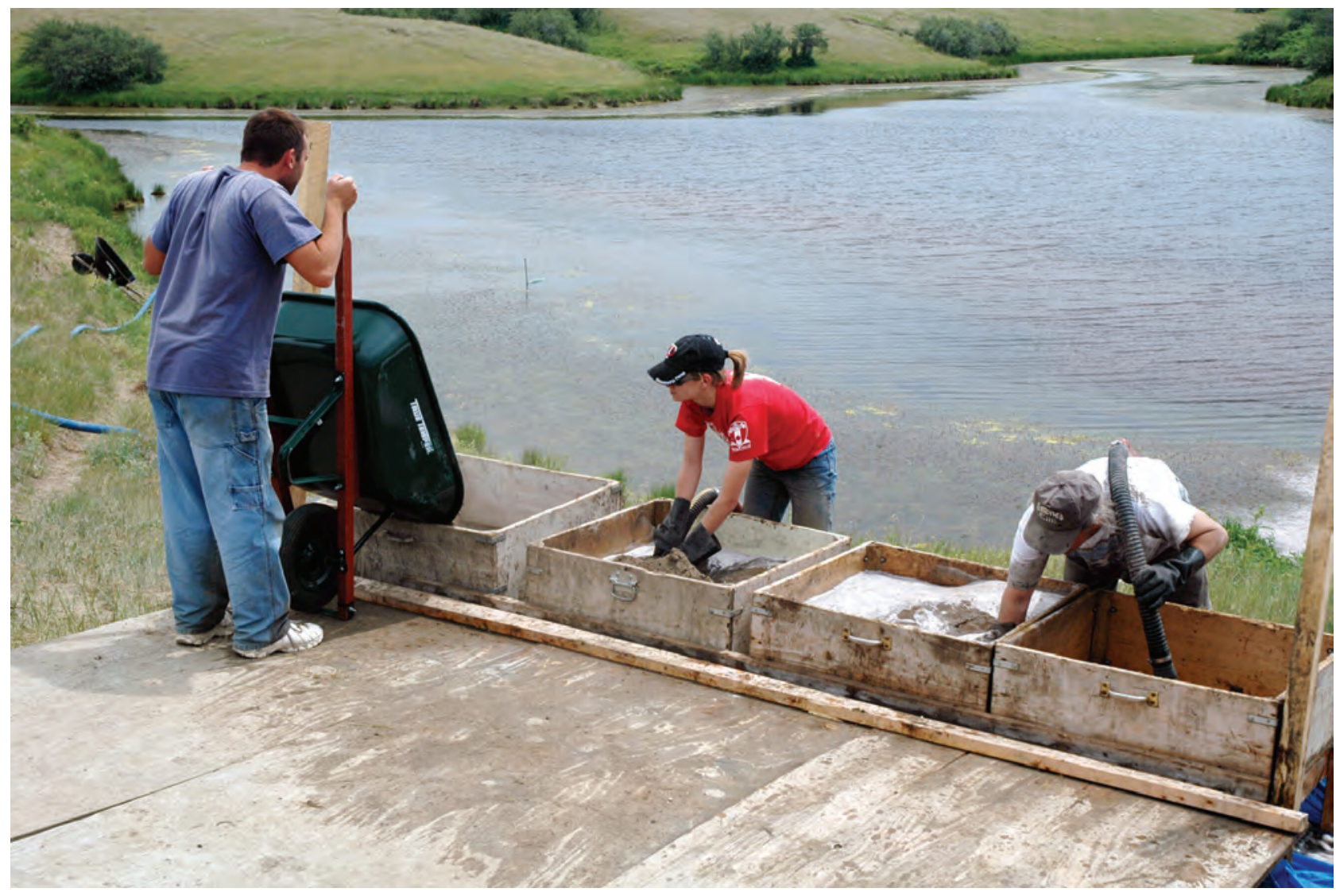

Figure 4.2. The waterscreen station for the project, with Alicia Johnson and Paul Picha screening and Kelly Heilman delivering sediment.

during the lab work phase of the project. These remains were returned to the SHSND for repatriation.

At least two profiles were drawn for each of the six excavated test units. Each profile was drafted by a team of two or three excavators and was checked by the field director. Slide film and digital photographs were taken of each drawn profile. Digital photographs also were taken of the work in progress. A log was maintained of all photographs that included the roll and frame number and the subject of the image. After excavation, each unit was lined with plastic and backfilled first with the stockpiled sod and then with imported sand and gravel.

\section{Feature Selection}

The locations of the six 2006 excavation units are shown in Figure 4.3. The nine geophysical survey grids depicted cover the northeastern rim of the site, from the northernmost midden mounds northward onto the nearly-level terrace beyond. Based on the settlement model developed for nearby Double Ditch Village (discussed in Chapter 1), it was hypothesized that substantial, previously-unrecognized features would be encountered in this part of the site and moreover that such features were abandoned and filled early in the occupation of the settlement. It was further anticipated that features on the margins of the village would be better preserved than 


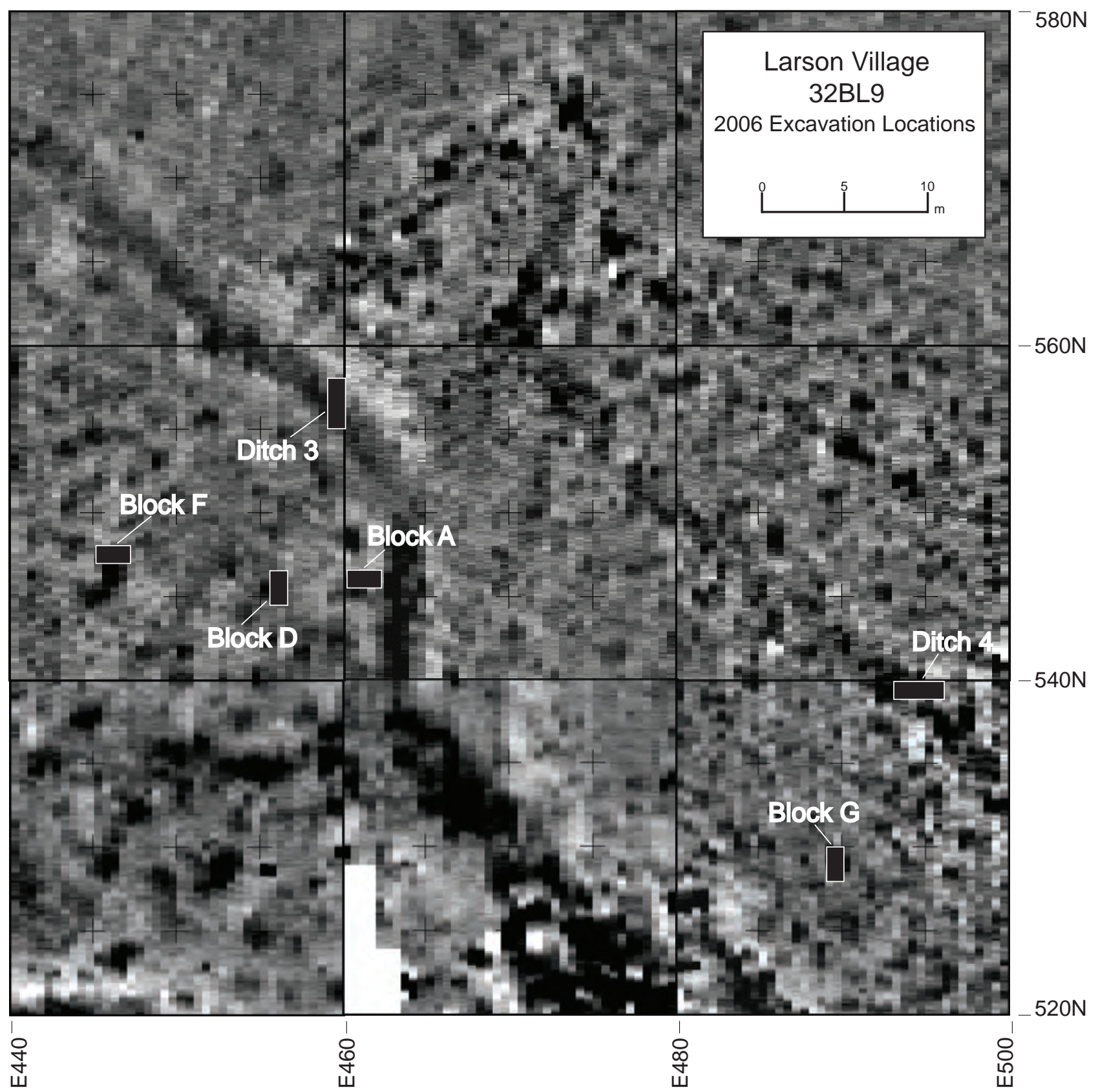

Figure 4.3. Magnetic survey map of the northern periphery of Larson Village showing the locations of excavation units.

those located near the center where periodic construction and remodeling activities had taken place for a longer period of time.

Several aspects of this model were immediately confirmed by the geophysical survey (see Chapter 3). Faint but unmistakable traces of a linear magnetic anomaly interpreted as a fortification ditch containing at least one bastion can be seen in both the magnetic and the resistance data. This feature was designated Ditch 4. A second, somewhat better expressed linear anomaly also thought to represent a fortification ditch was designated Ditch 3. Surrounding both of these features are large numbers of discrete magnetic anomalies 1 to 2 meters in diameter, many of which represent individual cache pits or hearths. 
A one-inch Oakfield soil probe was used to collect data on the fill and depth of each of the targeted anomalies. The depths of stratigraphic boundaries observed in the sediment cores were recorded on standardized data sheets and notes were made about the numbers and kinds of artifacts encountered. Table 4.2 presents data on the anomalies investigated. Short probe transects were placed across each of the linear anomalies. Ditch 3 was investigated where it crosses the E460 grid line, between 553N and 558N. Ditch 4 was investigated where is crosses the $540 \mathrm{~N}$ grid line, between E490 and E496. Probe holes were spaced one meter apart. In each case, the depth of cultural deposits reached a maximum near the middle of the transect, indicating that the anomalies were in fact deep, linear depressions. The observed maximum depth of Ditch 3 was $210 \mathrm{~cm}$, while the maximum depth of Ditch 4 was $143 \mathrm{~cm}$. Thirteen point anomalies also were investigated. Six of these (A through F) are located immediately inside Ditch 3 and were thought most likely to be associated with the construction and use of that feature. Four ( $G$ though J) are located outside Ditch 3, but inside Ditch 4. It was assumed that features located between the two fortification ditches would most likely be associated with the outer, earlier ditch. Coring data also were obtained on three other anomalies ( $\mathrm{K}$ through $\mathrm{M}$ ) located just outside Ditch 2, closer to the center of the village.

Not all of the targeted point anomalies turned out to be identifiable features. Some may represent areas of sheet midden containing highly magnetic refuse, such as burned earth. Others may represent clusters of smaller features, such as postholes or small basins. Several rather weak anomalies located between Ditch 3 and Ditch 4 turned out to be thick accumulations of badger spoil dirt. However, eight anomalies were interpreted as trash-filled storage pits, ranging in apparent

Table 4.2. Coring data on targeted magnetic anomalies, 2006 PCRG field investigations at Larson Village. Anomalies selected for excavation are listed in bold.

\begin{tabular}{|c|c|c|c|c|}
\hline $\begin{array}{l}\text { Geophysical } \\
\text { Block }\end{array}$ & Anomaly & $\begin{array}{c}\text { Center } \\
\text { Coordinate }\end{array}$ & $\begin{array}{c}\text { Maximum Depth } \\
\text { of Cultural } \\
\text { Materials }(\mathrm{cm})\end{array}$ & Interpretation/Comment \\
\hline 7 & $\mathbf{A}$ & 545.5NE461 & 129 & Large pit \\
\hline 7 & B & 548.5NE461 & 65 & No feature identified \\
\hline 9 & $\mathrm{C}$ & 538NE458 & 96 & No feature identified; near midden \\
\hline 6 & D & 545.5NE456 & 132 & Large pit \\
\hline 9 & E & 538NE445 & 120 & Large pit \\
\hline 6 & $\mathbf{F}$ & 547NE446 & 122 & Large pit \\
\hline 11 & G & 529NE490 & 99 & Pit \\
\hline 11 & $\mathrm{H}$ & 522.5NE496.5 & 71 & No feature identified \\
\hline 11 & $\mathrm{I}$ & 538NE498 & 95 & Pit \\
\hline 11 & $\mathrm{~J}$ & 534.5NE479.5 & 62 & No feature identified \\
\hline 24 & K & 473NE485 & 132 & Pit? \\
\hline 24 & $\mathrm{~L}$ & 467NE491 & 119 & Pit \\
\hline 29 & M & 458NE484.5 & 59 & No feature identified \\
\hline 6 & Ditch 3 & 555NE460 & 210 & Ditch with steeply sloping sides \\
\hline 11 & Ditch 4 & 540NE493 & 143 & Ditch with sloping sides \\
\hline
\end{tabular}

depth from 99 to $132 \mathrm{~cm}$. Three of these (A, D, and F) exhibited particularly dense concentrations of bone, charcoal, ash, and other artifacts and were selected for investigation. A fourth magnetic anomaly, designated G, exhibited markedly lower amounts of cultural material, but was chosen for excavation because it appeared to be the most promising feature located between Ditch 3 and Ditch 
4. Once these four features were selected for excavation, additional coring was conducted adjacent to their center points to better define their boundaries and to refine the placement of the excavation blocks that would expose the feature. A 1x2 m block was laid out over each of the selected features, with the blocks labeled according to the original anomaly designations. A 1x3 m block was laid out over each of the fortification ditches, positioned to expose the north or east wall.

\section{Excavation Unit Summaries and Feature Descriptions}

A total of 11 features were fully or partially excavated during the 2006 field effort. These include two large pits, four small pits or basins, two postholes, two fortification ditches, and a single small hearth. A twelfth feature was substantially exposed but not excavated. In the following paragraphs, organized by excavation unit, each of these features and their fill strata are described. Details on the course of excavation also are provided. Table 4.3 summarizes excavation data on each feature. Plan views and profiles of excavation units and features also are provided.

\section{Block A}

Block A is an east-west oriented 1x2 m test unit located immediately inside the village perimeter defined by Ditch 3. Coring demonstrated that cultural deposits at the center of Block A extend to an estimated depth of $129 \mathrm{~cm}$, but that shallower deposits are present to the east, west, and north. Excavation of Block A was carried out by Bob Gardner, with the assistance of Betsy Maixner and Carl Falk (Figure 4.4). The uppermost stratigraphic unit consists of homogenous brown silt 12 to $20 \mathrm{~cm}$ thick with a wavy lower boundary (Figure 4.5 and 4.6). The unit contains comparatively few artifacts. Clear evidence from Blocks D, F, and G (see below) indicates that this unit represents a plowzone. Beneath the plowzone, a complex sequence of relatively thin, intact stratigraphic units is present. Boundaries between the units are abrupt and smooth to slightly wavy, and can be distinguished by color, compaction, and content. Many units dip slightly to the west and north, corresponding to the surface topography around the block and indicating that they were deposited during the accretion of the large mound located south and east of Block A. The limited spatial extent of several of these units complicated the task of feature identification. Rodent disturbance of these upper strata is moderate. Two weakly-developed paleosols were observed in Block A. The organic horizon of the upper soil appeared at a depth of about $65 \mathrm{~cm} \mathrm{SD}$ and is about 5 $\mathrm{cm}$ thick. The organic horizon of the lower soil also is about $5 \mathrm{~cm}$ thick and is located at a depth of $83 \mathrm{~cm} \mathrm{SD.} \mathrm{Both}$ formed in olive brown loess.

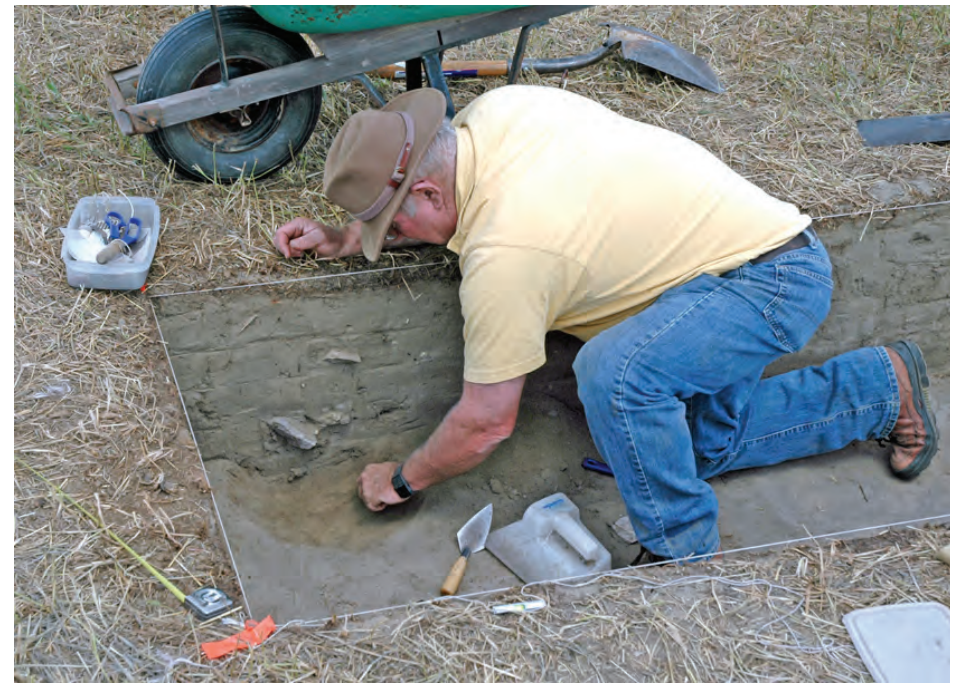

Figure 4.4. Bob Gardner working in Block A. 

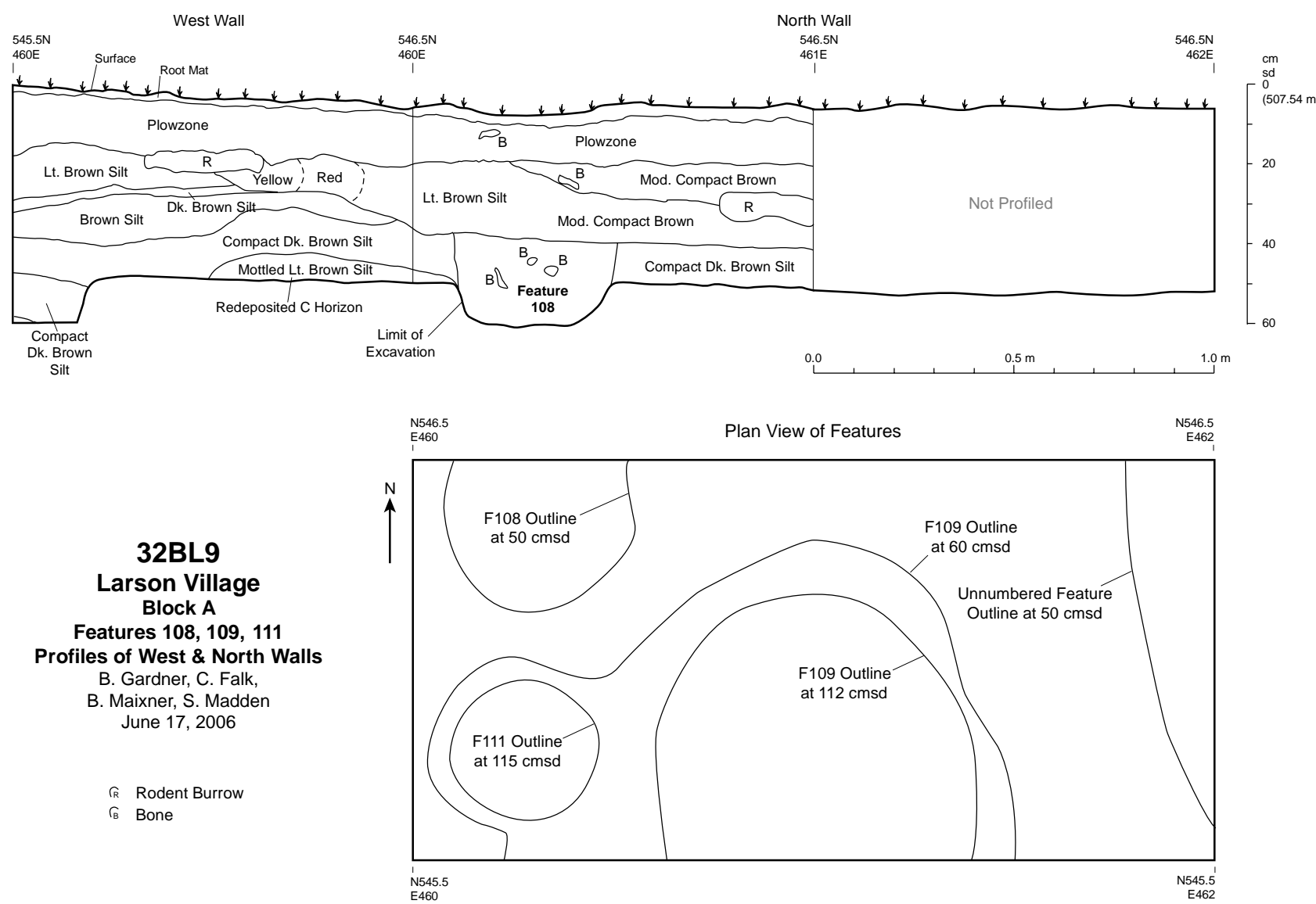

Figure 4.5. Plan and profile drawings of Block A and Feature 108.

Three features were defined in Block A. (A fourth feature was identified on the eastern edge of the block but was not numbered or excavated.) Feature 108, is a small, oblong, nearly straightsided basin 38 to $44 \mathrm{~cm}$ across and about $22 \mathrm{~cm}$ deep (Figure 4.5). Due to the complexity of the overlying midden deposits, the feature was not identified until the excavation had reached $50 \mathrm{~cm}$ $\mathrm{SD}$ (the bottom of GL5) and only the lowest $8 \mathrm{~cm}$ were excavated separately. However, the profile indicates that the pit originates at 37 to $39 \mathrm{~cm}$ SD. The basin was dug into preexisting stratified midden deposits and subsoil displaced during the excavation of earlier pits. The fill of Feature 108 consists of loose brown silt containing domestic debris, along with abundant animal bones and firecracked rock.

Feature 109 is a large, irregular, slightly undercut pit $72 \mathrm{~cm}$ deep (Figure 4.6). The pit originates at 40 to $50 \mathrm{~cm} \mathrm{SD}$, cutting through at least $20 \mathrm{~cm}$ of preexisting midden. Initially, it appeared that two adjacent or slightly overlapping pits might be present. However, both the smaller western lobe of the feature and the larger eastern lobe contained the same fill units and several large animal bones spanned the hypothetical boundary between the lobes. The reason for the unusual shape of Feature 109 became apparent when the remnants of a large posthole (Feature 111, described below) were observed on the western side of the pit at a depth of $110 \mathrm{~cm}$ SD (Figure 4.6). The floor of Feature 109 is slightly concave, with a low ridge or hump of sterile sediment separating the main part of the pit from the remnant of Feature 111. A small circular basin in the floor of the larger, eastern lobe of Feature 109 may represent the former location of a second posthole. 


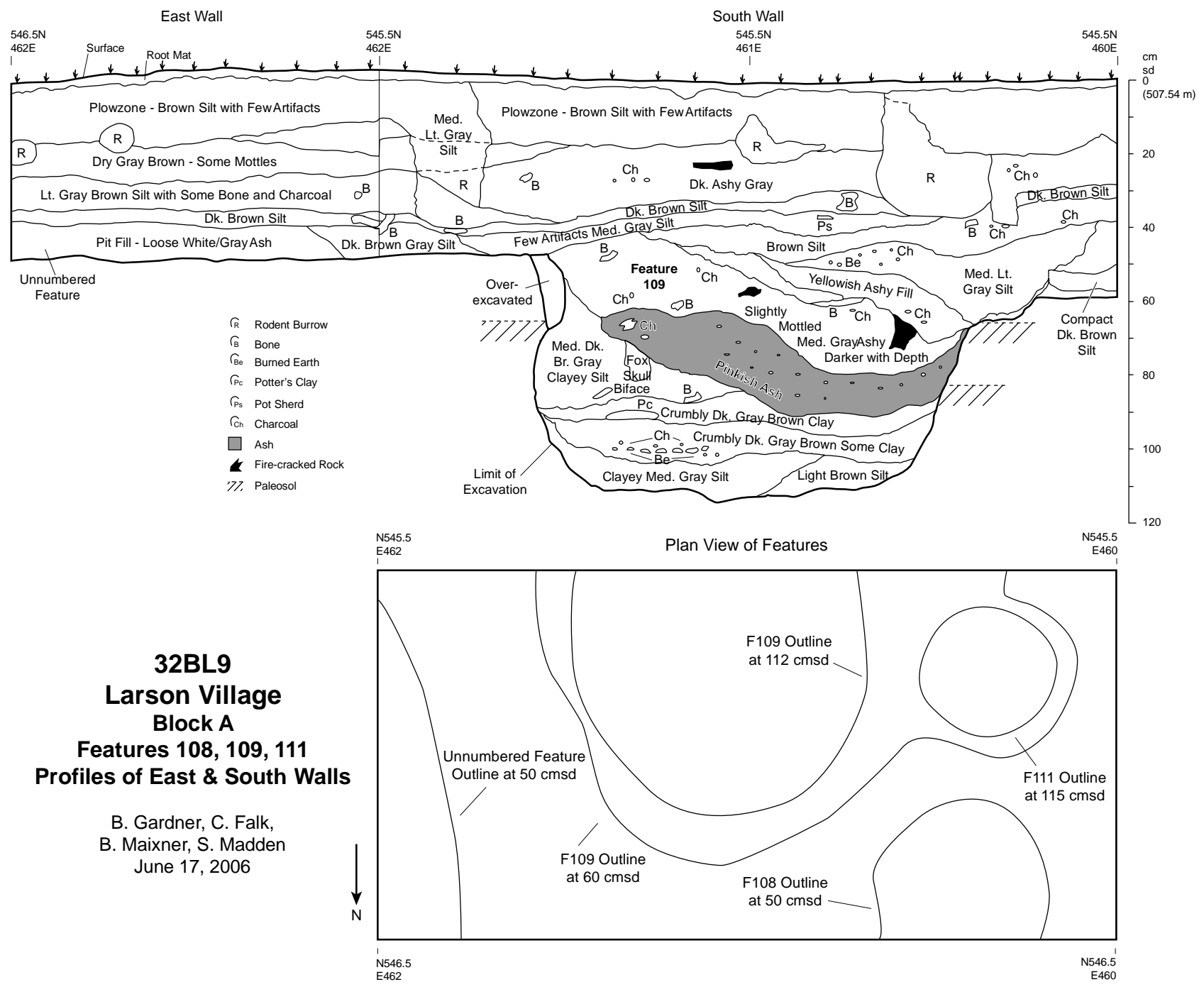

Figure 4.6. Plan and profile drawings of Block A and Feature 109.

The fill of Feature 109 consists of stratified layers of brown to dark brown silt containing abundant artifacts and animal bones. A thick ash layer also is present, from which a large sample was obtained for flotation. Chunks of unfired tempered potter's clay were collected from strata beneath the ash lens. One unusual ceramic vessel with an angular S-rim form was recovered from the pit, as was a large, asymmetrical hafted biface.

Feature 111, the oldest of the three features excavated in Block A, is the remnant of a large posthole. When Feature 109 was dug, it cut into and destroyed most of Feature 111. At most, $5 \mathrm{~cm}$ (from 110 to $115 \mathrm{~cm} \mathrm{SD}$ ) of the original fill of the posthole remained when Feature 109 was abandoned and filled. As previously mentioned, the base of Feature 111 was isolated from the main part of Feature 109 by a low, rounded ridge or hump. Assuming that its size and form were not dramatically altered by the construction of Feature 109 it seems likely that Feature 111 was designed to accommodate a post roughly $30 \mathrm{~cm}$ in diameter. The origin of the feature could not be determined; however, if it was associated with the post identified in Block D (see below), then it probably originated on the upper paleosol in Block A, at a depth of about $65 \mathrm{~cm} \mathrm{SD}$. The fill of Feature 111 contained very few artifacts other than a single Le Beau ware rim sherd. 
Excavation in Block A revealed an unexpectedly complex sequence of superimposed features. Features 108 and 109 were excavated through about $20 \mathrm{~cm}$ of pre-existing midden deposits and therefore must post-date the earliest features at the site. However, it is unclear if they were in use at the same time. Both may have originated from the same surface, but it is also possible that Feature 109 was filled and subsequently disturbed before Feature 108 was dug. In any case, both post-date Feature 111. Judging by its size, depth, and position it seems likely that Feature 111 and Feature 103 in Block D (described below) were once part of the same structure.

Table 4.3. Feature data, 2006 PCRG excavations at Larson Village.

\begin{tabular}{ccccc}
\hline Feature Number & Area & Feature Type & Feature Levels & Excavated Volume \\
\hline 101 & Block D & Basin & 1 & 0.003 \\
102 & Block D & Basin & 1 & 0.001 \\
103 & Block D & Posthole & 4 & 0.064 \\
104 & Block F & Small Pit & 1 & 0.044 \\
105 & Ditch 3 & Ditch & 15 & 3.508 \\
106 & Ditch 4 & Ditch & 9 & 1.743 \\
107 & Block F & Pit & 10 & 0.901 \\
108 & Block A & Small Pit & 1 & 0.011 \\
109 & Block A & Pit & 7 & 0.505 \\
110 & Block F & Pit & Not excavated & n/a \\
111 & Block A & Posthole & 1 & 0.006 \\
112 & Block G & Hearth & 0 & Included in Block G vol. \\
\hline
\end{tabular}

\section{Block D}

The center point of the large magnetic anomaly targeted for excavation in Block D is located at approximately 545.5NE455.5. Unfortunately, the excavation unit was inadvertently laid out (by the project director) on the east side of the E456 grid line, rather than on the west, and as a result the targeted anomaly was not exposed. Instead, excavation revealed three smaller features and a surface that may represent an intact lodge floor.

Excavation of Block D was carried out by Carl Falk, with the assistance of Ed Maixner (Figure 4.7). As in Block A, the uppermost stratigraphic unit in Block D is a plowzone up to $20 \mathrm{~cm}$ thick (Figure 4.8). The base of the plowzone is marked by a discontinuous band of charcoal and organic debris. In the east wall profile, the lower boundary of the plowzone is clear and smooth, but in the north wall profile is wavy to irregular, indicating that the furrows originally were oriented north-south. In contrast with Block A, the strata immediately underlying the plowzone in Block D are massive and comparatively thick with gradual, wavy boundaries. Each consists of light gray brown to brown compact silt containing a moderate number of artifacts and animal bones. Rodent disturbance is quite extensive. Beneath these units is a discontinuous layer of compact olive brown silt roughly $3 \mathrm{~cm}$ thick, which likely represents subsoil derived from the excavation of nearby features. This unit rests directly on an intact, weakly developed soil. The A horizon of the soil is 4 to $5 \mathrm{~cm}$ thick, grading gradually into homogeneous olive brown loess. A second paleosol was observed in the wall of Feature 103 (see below) at a depth of $68 \mathrm{~cm} \mathrm{SD.} \mathrm{Coring} \mathrm{beneath} \mathrm{the} \mathrm{bottom}$ of Feature 103 revealed the presence of two more buried soils, at about $120 \mathrm{~cm}$ SD and $165 \mathrm{~cm}$ SD. 
Two small, shallow basins and one large posthole were identified in Block D. All three were first identified at the base of GL6 (60 $\mathrm{cm} \mathrm{SD),} \mathrm{but}$ may have originated 8 to $10 \mathrm{~cm}$ higher, at the top of the intact soil or possibly at the top of the displaced subsoil. It is likely that all three were in use at the same time. Only a small portion of Feature 101 was exposed in the southwest corner of Block D, but it appears to be a shallow, oblong basin (Figure 4.8). The maximum depth of the excavated part of the feature is 12 $\mathrm{cm}$, although originally it may have

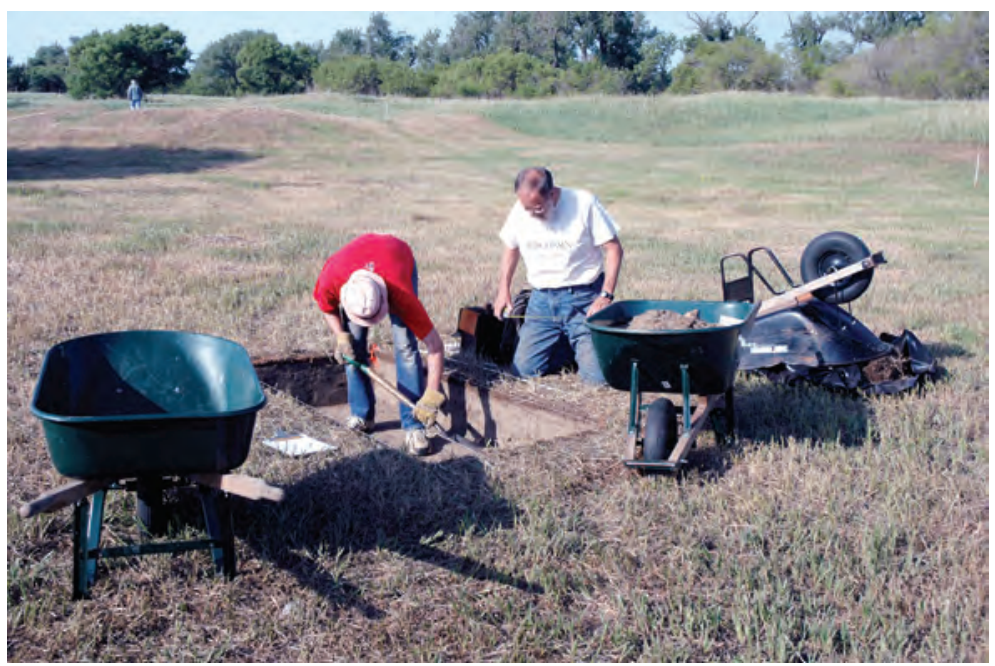

Figure 4.7. Carl Falk (r) and Ed Maixner excavating Block D. been as much as $22 \mathrm{~cm}$ deep. The fill contains charcoal, fire-cracked rock, and a small number of animal bones.

Feature 102 also is a shallow, flat-bottomed basin partially exposed on the west side of Block D (Figure 4.8). The feature is circular in plan, with an excavated depth of $2 \mathrm{~cm}$ and an estimated maximum depth of $12 \mathrm{~cm}$. Charcoal and a few small animal bone fragments are present in the fill.

Feature 103 is a large posthole measuring $53 \mathrm{~cm}$ in maximum diameter and at least $58 \mathrm{~cm}$ deep (Figure 4.8). The posthole likely was constructed to accommodate a timber approximately 32 $\mathrm{cm}$ in diameter. Around the perimeter of the feature the fill consists of moderately compact silt containing animal bone fragments, charcoal, flakes, and sherds. In the center, the fill is looser, and contains decomposed wood along with charcoal and bone fragments.

Interestingly, coring below the limit of excavation (60 cm SD) on the east side of Block D revealed the presence of a large undercut pit just outside the block to the east. The extent to which the undercut portion of the pit intrudes into Block D is unknown; however, the center of the pit likely is located at approximately 545.5NE457.5. The pit is at least $140 \mathrm{~cm}$ deep. The relationship between this pit and the pit represented by the strong magnetic anomaly on the west side of Block D is not known.

The serendipitous discovery of small features in Block D suggests that at least portions of earthlodges may be preserved inside Ditch 3. The presence of a thin, discontinuous layer of displaced subsoil on top of the uppermost buried soil indicates that this soil was forming at the time structures were built on this part of the site. As pits were excavated into this soil the spoil dirt was spread on the adjacent surface, within or between lodges; neither borrowing nor deposition had taken place before features were constructed. Thus, it seems likely that Features 101, 102, and 103 are among the earliest features at the site. This contrasts rather sharply with the situation at Double Ditch Village. There, an extensive “zone of obliteration” extends outward from Ditch 2 to the edge of the village. Within this zone cultural features and soil horizons have been churned to a depth of about 70 or $80 \mathrm{~cm}$, obliterating any trace of lodge floors, leaving intact only the lower portions of deep trash-filled pits. The process or processes responsible for this are not known, but likely include the construction of gardens on the village periphery. The lack of an extensive zone of 

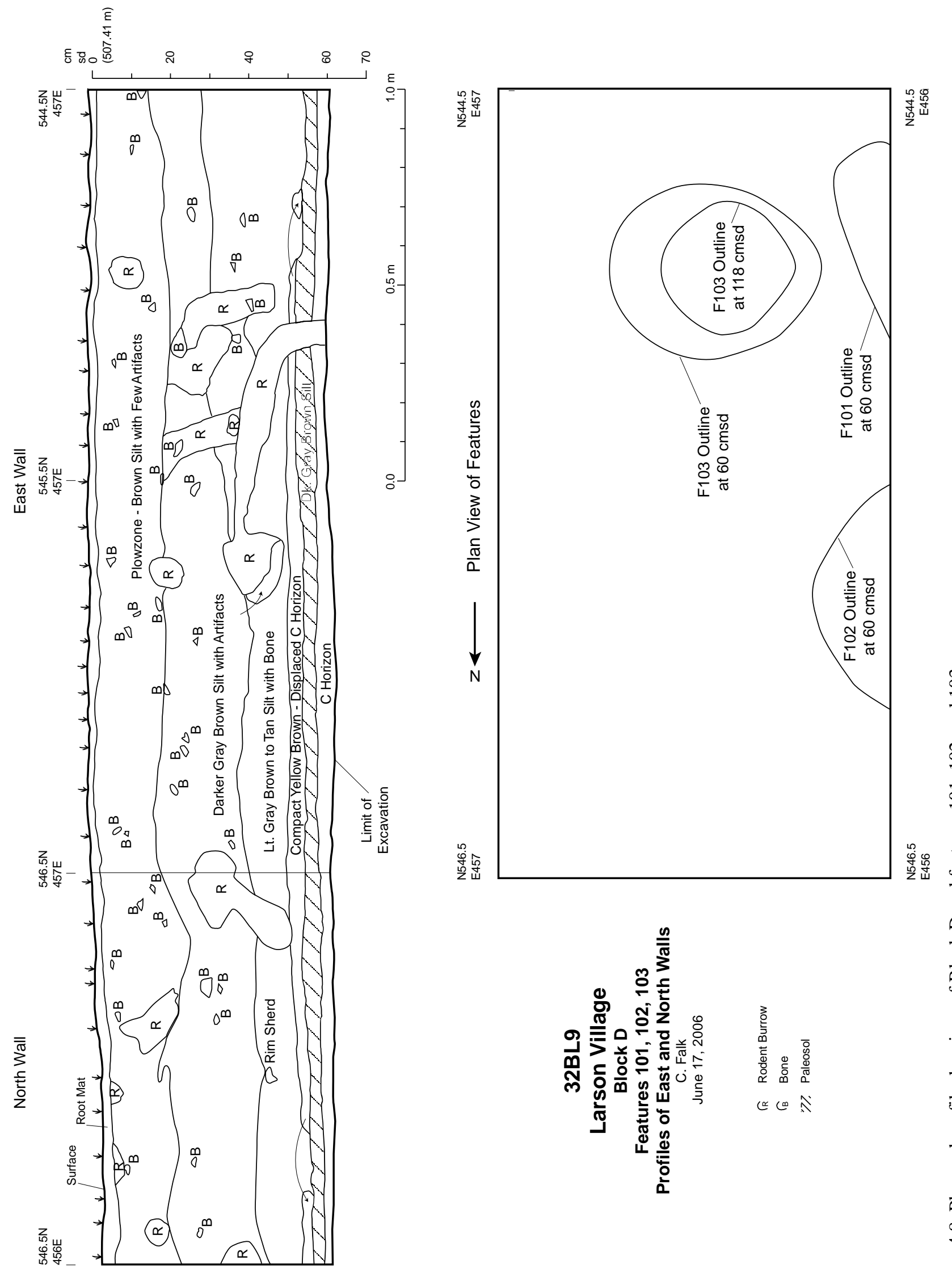

要

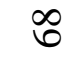

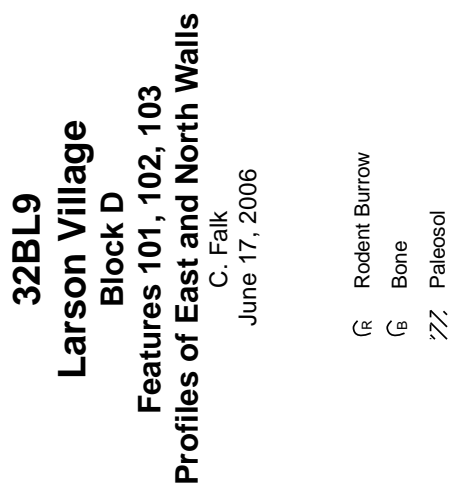


obliteration at Larson Village suggests that the outer rim of the village was used for rather different purposes.

\section{Block F}

Block F was placed over the northern end of a large magnetic anomaly about $10 \mathrm{~m}$ west of Block D. The southern end of the anomaly has been heavily disturbed by badgers. The excavation was carried out by Paul Picha and Stacey Madden, with the assistance of John Moret (Figure 4.9). In Block F, the plowzone varies from 10 to $20 \mathrm{~cm}$ thick (Figures 4.10). Beneath the plowzone is a

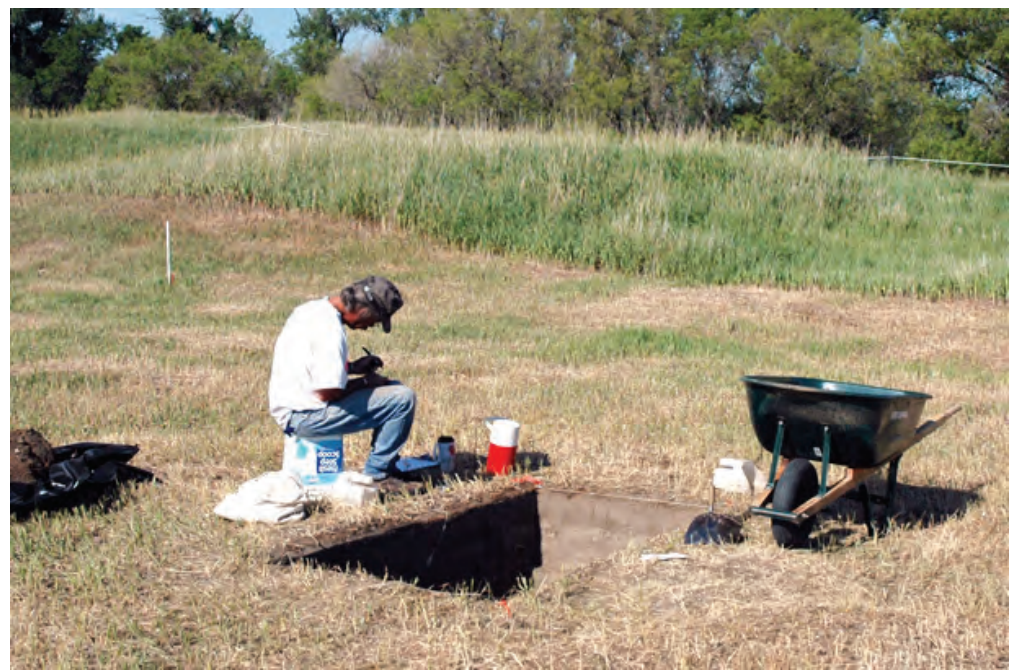

Figure 4.9. Paul Picha taking notes on Block F. comparatively thick, massive stratum composed of compact gray brown silt containing a moderate number of artifacts. This unit is somewhat rodent disturbed. On the eastern end of the block, this compact silt stratum rests directly on a weakly-developed soil. On the western end, a layer of brown silt and a thin layer of olive brown silt (representing displaced subsoil) occur between the base of the compact silt and the paleosol. The A horizon of the paleosol is approximately $15 \mathrm{~cm}$ thick. A second paleosol, approximately 10

cm thick, was observed in the wall of Feature 107, at about $60 \mathrm{~cm}$ SD.

Three sequentially constructed pits were identified in Block $\mathrm{F}$ and the most recent two were excavated. Feature 104 is a shallow, straight-sided pit about $37 \mathrm{~cm}$ deep (Figure 4.10). Its estimated maximum diameter is about 1 meter. The pit originates at about $25 \mathrm{~cm} \mathrm{SD}$, although it was not recognized until the base of GL4 (40 cm SD) and only the lowest $22 \mathrm{~cm}$ was excavated and cataloged separately. Animal burrowing had slightly blurred the boundary between Feature 104 and Feature 107 (described below). However, little difficulty was encountered in distinguishing them because the fill of Feature 104, which includes a dense tangle of bone, including portions of a bison cranium, and large sections of three ceramic vessels, is quite distinctive. A sample of potter's clay also was recovered.

Feature 104 cut into Feature 107, a large undercut pit (Figure 4.11). The orifice of Feature 107, which originates at about $28 \mathrm{~cm} \mathrm{SD}$ and was defined initially at $40 \mathrm{~cm} \mathrm{SD}$, is approximately 50 $\mathrm{cm}$ in diameter. The maximum diameter of the pit is $125 \mathrm{~cm}$. Time did not permit complete excavation of the pit, but its depth based on coring is estimated to be about $178 \mathrm{~cm}(218 \mathrm{~cm} \mathrm{SD})$, perhaps signaling the presence of a second pit dug into the floor of Feature 107. Because Feature 107 is superimposed on an earlier pit (Feature 110, discussed below), its eastern side was somewhat difficult to define. Near the end of the excavation, a "wall cleaning” level (designated FL11), extending from 87 to $130 \mathrm{~cm} \mathrm{SD}$, was excavated on the northern and eastern side of the pit to better define its walls. 


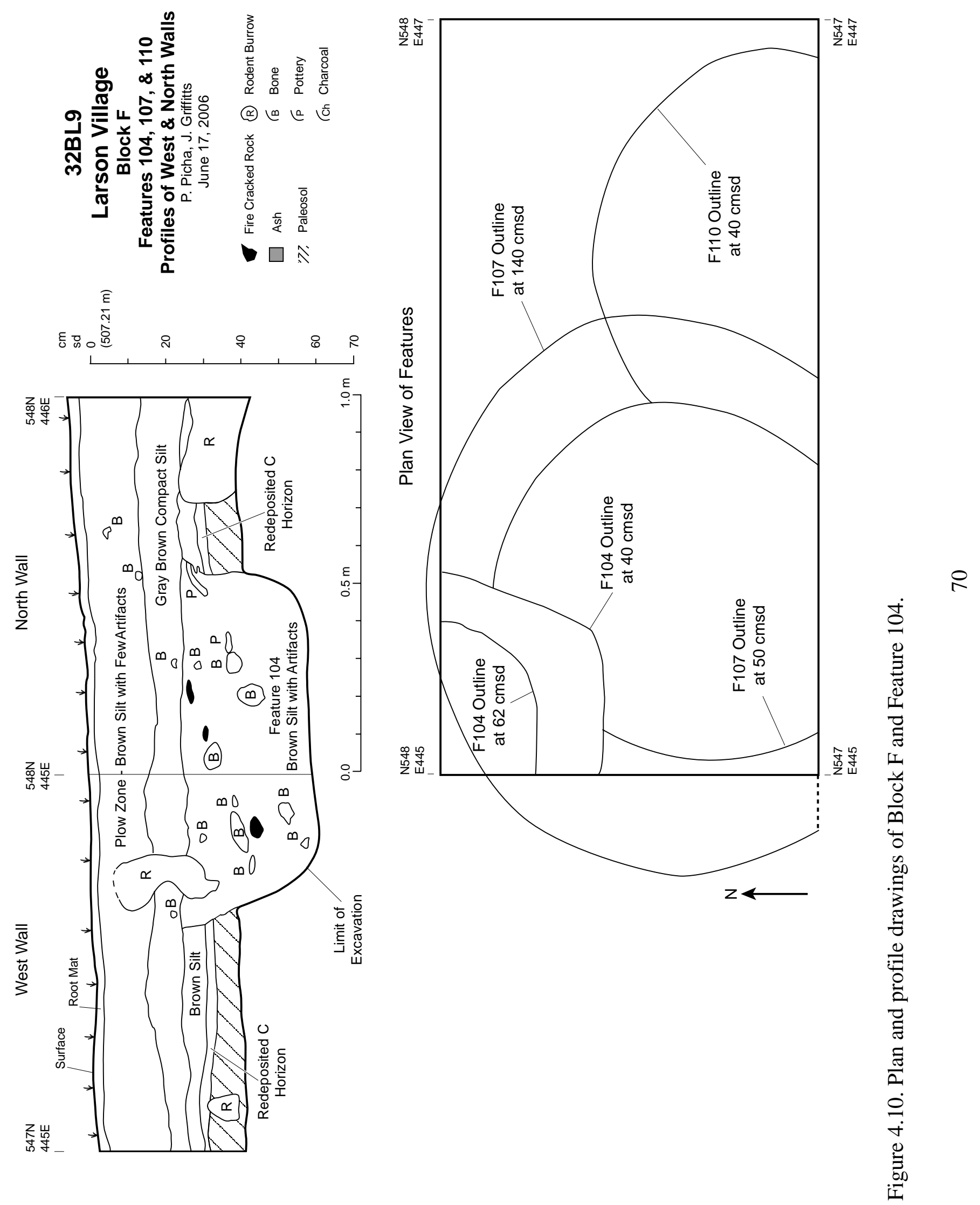




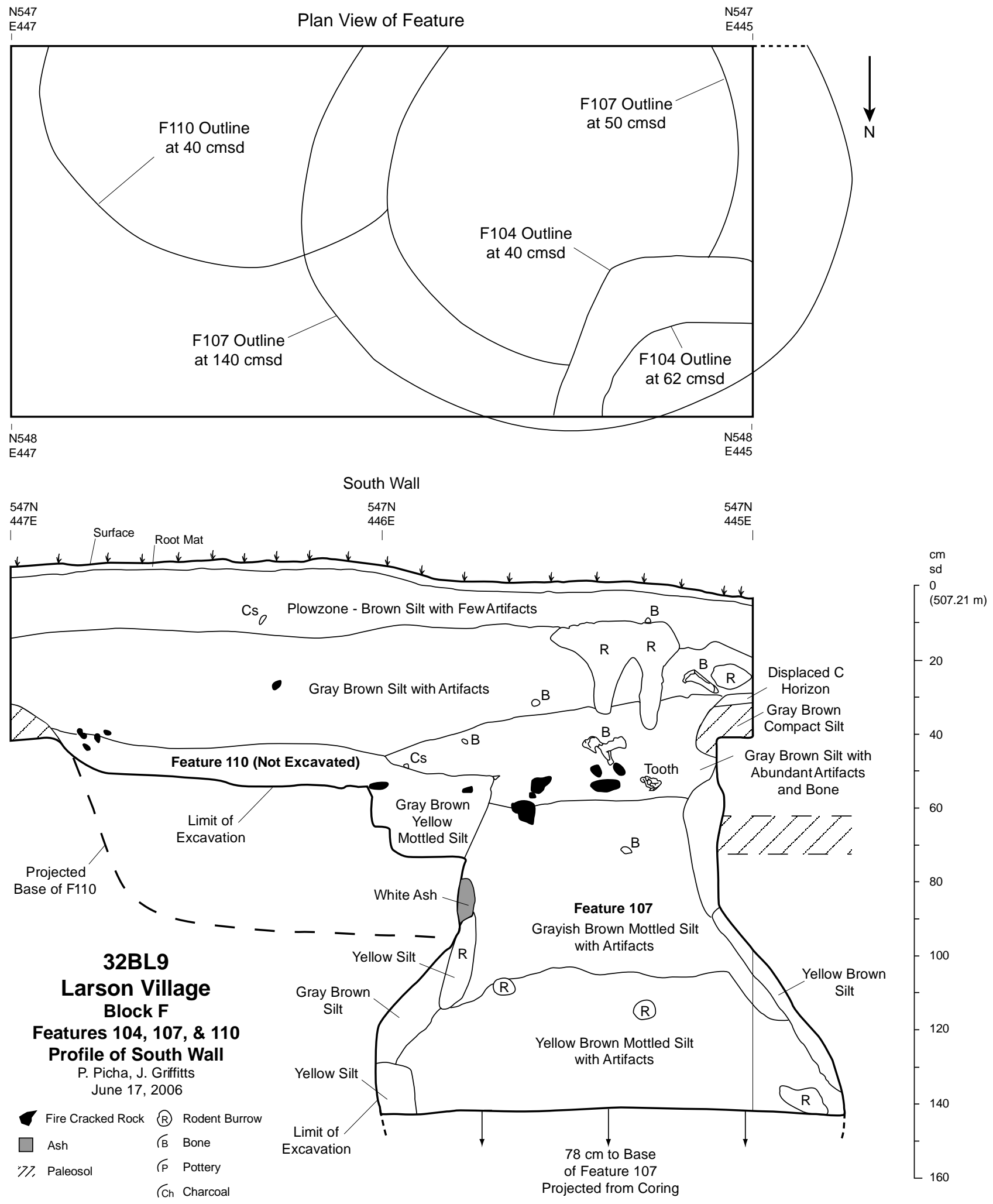

Figure 4.11. Plan and profile drawings of Block F and Feature 107.

Three thick strata were defined in the fill of Feature 107. The uppermost consists of loose gray brown silt containing very abundant animal bones, fire-cracked rock, and other artifacts. 
Beneath that cap is a mottled unit containing fewer bones and artifacts. The lowest unit observed consists of olive brown mottled silt containing even fewer artifacts. Ash deposits and sections of slumped pit wall also were observed. A bulk ash sample was obtained from FL10 $(130-140 \mathrm{~cm}$ $\mathrm{SD})$.

Feature 110 is a circular basin roughly $60 \mathrm{~cm}$ deep (where it intersects with the wall of Feature 107) and $1.1 \mathrm{~m}$ in diameter. Its fill consists of loose, gray brown mottled silt containing few artifacts. It is the oldest of the three features identified in Block F, although it originated at the same surface as Feature 107. Time did not permit its excavation.

Given the large size and irregular shape of the magnetic anomaly targeted for excavation in Block F it is not surprising that work here revealed a sequence of superimposed features. However, it does not seem likely that the features vary greatly in age. Feature 107 and Feature 110 originate from a common surface and Feature 104 likely was constructed not long after Feature 107 was filled. A comparison of the absolute elevations of the paleosols observed across the site (discussed below) indicates that Features 107 and 110 may be contemporaneous with Features 101, 102, 103 in Block D and perhaps Feature 111 in Block A.

\section{Block $G$}

Block $\mathrm{G}$ is the only excavation unit opened in 2006 that is located outside Ditch 3, but inside Ditch 4. Coring data indicated that the cultural deposits in Block $\mathrm{G}$ are only about $1 \mathrm{~m}$ deep and that artifact density is comparatively low. However, it was selected for excavation on the assumption that features located between the two outer ditches likely would date close to the period when the village was founded.

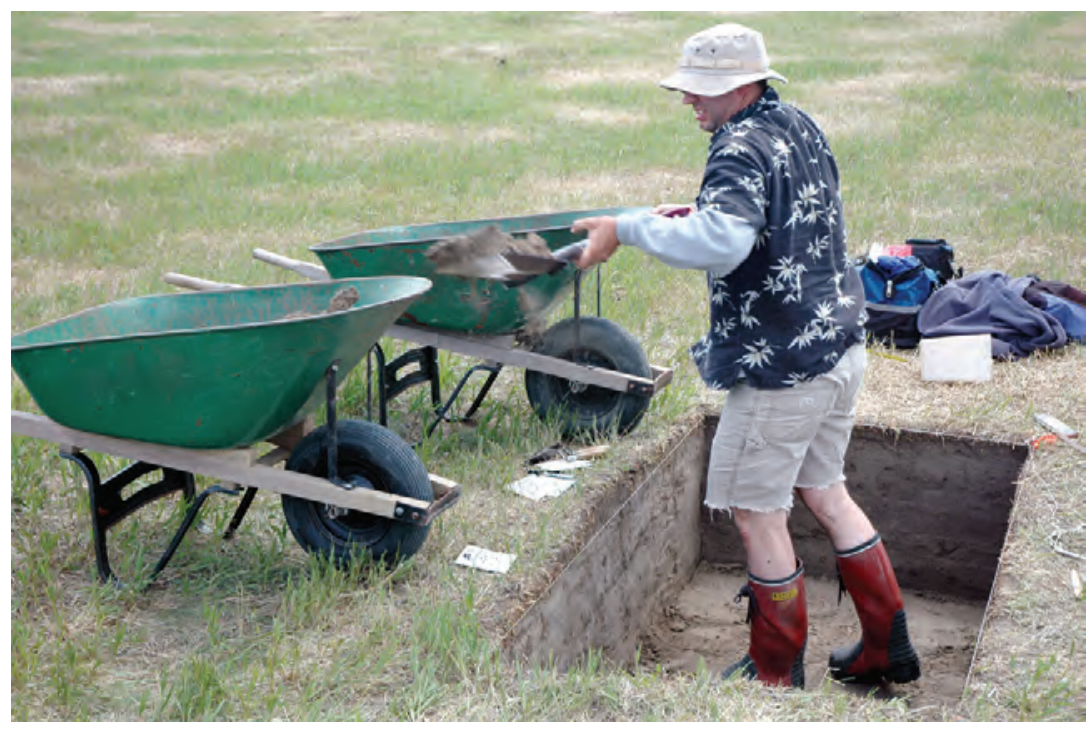

Figure 4.12. Tim Reed working in Block G.
Tim Reed carried out the excavation in Block $\mathrm{G}$ (Figure 4.12). With the exception of the plowzone, the stratigraphy of Block $G$ is rather different than that observed in Blocks A, D, and F (Figure 4.13). Beneath the plowzone is a layer of massive, compact brown silt, 34 to $38 \mathrm{~cm}$ thick, with a clear lower boundary. Numerous krotovina are present. Artifact density is lower than in the excavation blocks located inside Ditch 3. This stratum is underlain by several series of alternating light and dark silt bands of varying thickness. Individual lamina range from $1 \mathrm{~mm}$ to $3 \mathrm{~cm}$ in thickness, with very abrupt boundaries between them. When exposed in plan, these strata revealed evidence of extensive insect burrowing. The uppermost series is discontinuous, suggesting that the base of the overlying silt layer represent 


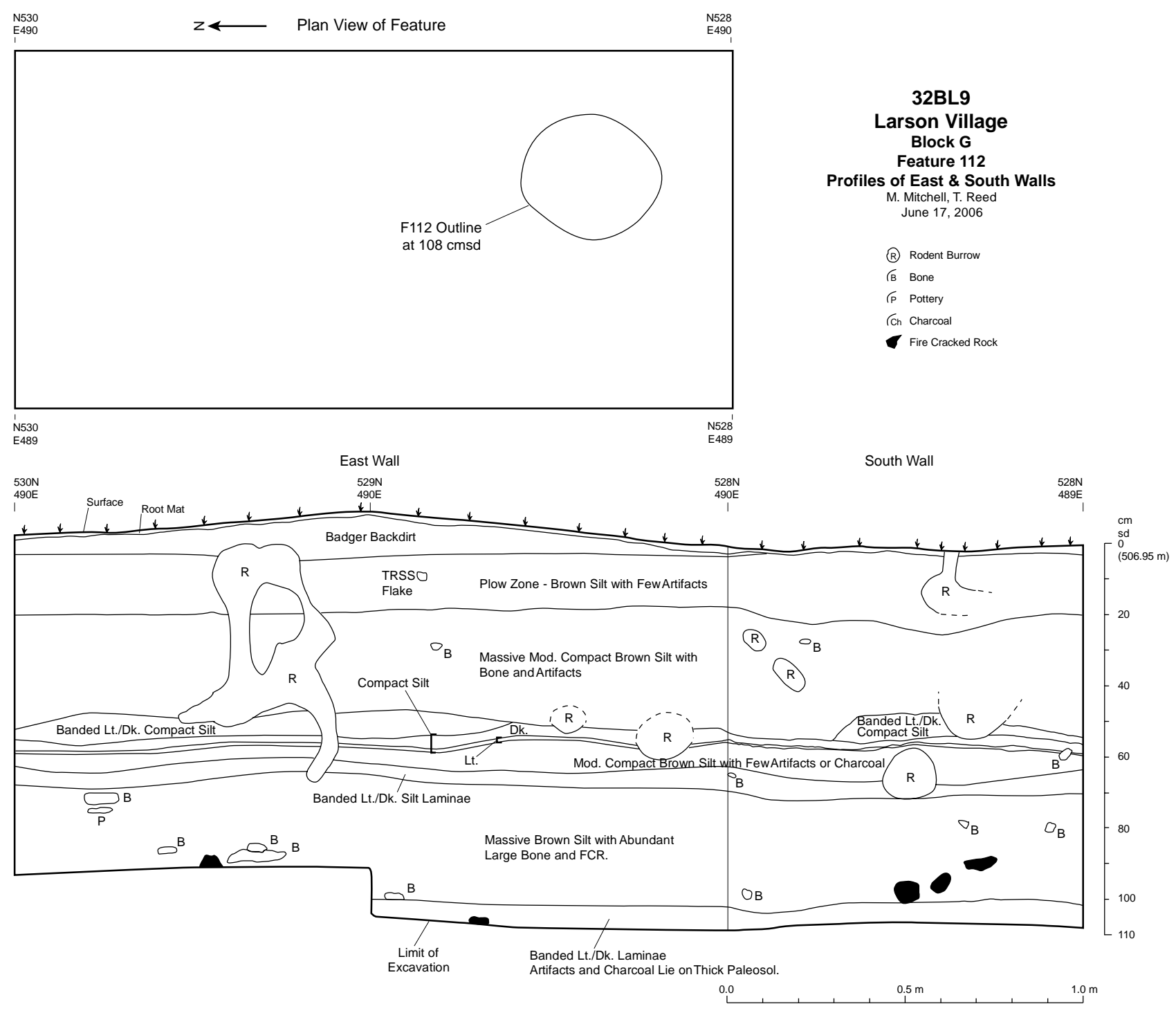

Figure 4.13. Plan and profile drawings of Block G.

an unconformity of some type. A layer of homogenous, moderately compact brown silt 5 to $10 \mathrm{~cm}$ thick is present in the middle banded strata. All of these units dip slightly to the south and east.

Beneath the silt laminae is a massive brown silt about $34 \mathrm{~cm}$ thick containing abundant animal bones and fire-cracked rock. All of the bone elements, which occur primarily between 70 and $90 \mathrm{~cm} \mathrm{SD}$, are flat-lying and distributed uniformly (Figure 4.14). The lowest cultural stratum again consists of alternating bands of light and dark compact silt 5 to $6 \mathrm{~cm}$ thick. However, the density of animal bones, pottery, and fire-cracked rock is higher in this set of laminae than it is in the overlying sets. This stratum rests directly on a well-developed paleosol formed in clay alluvium and containing abundant carbonate stringers and blebs. The upper surface of the paleosol is located at $105 \mathrm{~cm} \mathrm{SD}$; it is unclear whether is was partially truncated.

A single feature was identified in Block G. Feature 112 is a small basin hearth $30 \mathrm{~cm}$ in diameter and at least $3 \mathrm{~cm}$ deep. The feature likely originated near the base of GL11 at $108 \mathrm{~cm} \mathrm{SD,}$ but it also is possible that it may have been somewhat higher, in the stratum overlying the paleosol 
into which the feature was dug. The feature was not excavated separately; however, the fill consists of ash, charcoal, and fire-cracked rock, along with several simple-stamped pottery body sherds. A thin but distinct oxidation rind was observed at the base of the feature. An isolated human astragalus also was observed in GL11. This bone was re-interred in the excavation unit before it was backfilled.

Although the magnetic data, supplemented by hand coring, seemed to indicate the presence of a moderately large storage pit or basin in Block $G$, no features were identified in the excavation. Instead, spatially extensive cultural deposits just over one meter deep were observed. It is possible that the targeted magnetic anomaly was produced by the heavy concentration of fire-cracked rock in the block, or perhaps by the presence of one or more small hearths similar to Feature 112.

In any case, the presence of such thick cultural deposits near the edge of the village indicates that rather extensive sediment borrowing took place on the outer perimeter of the village at about the time it was founded. Available stratigraphic data on pre-village soils (discussed below) indicates that at least $60 \mathrm{~cm}$, and perhaps as much as 1 meter, of sediment was removed from Block $G$ and subsequently replaced with culturally-modified fill derived from several sources. Moreover, the truncation of the uppermost

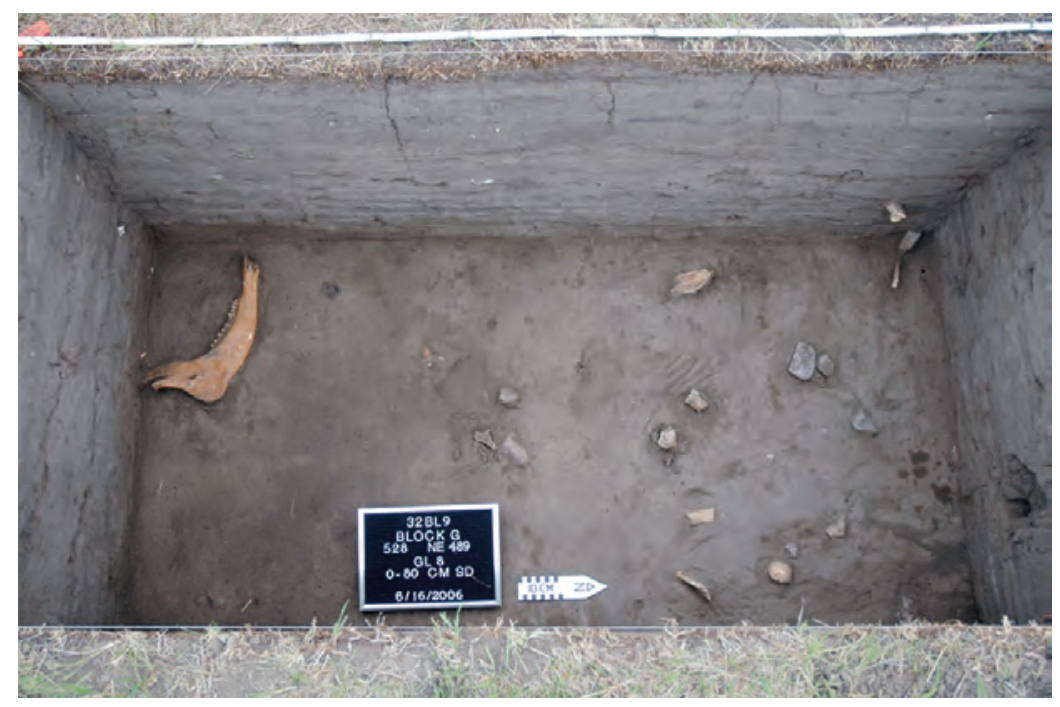

Figure 4.14. Flat-lying bone layer in Block G. banded silt deposits suggests that a second episode of borrowing and refilling took place later. The presence of Feature 112, along with the fact that the exposed fill units are nearly flat-lying, suggests that the borrow basin is likely to have been fairly large. Interestingly, the floor of the basin is at least $67 \mathrm{~cm}$ below the edge of Ditch 4. With the exception of the thin wind- or water-laid silt deposits, the fill of Block $G$ is remarkably similar to that of Ditch 4. Particularly prominent is a thick layer of large, flat-lying animal bones and fire-cracked rock at nearly the same depth in both units. These similarities suggest that the ditch and the basin were filled at the same time, perhaps concurrent with the construction of Ditch 3.

\section{Ditch 3}

Excavations in the 1x3 m block placed over Ditch 3 (Feature 105) were carried out by Craig Johnson, Janet Griffitts, Richard Krause, and John Moret (Figure 4.15). The magnetic expression of Ditch 3 is rather variable. It can be seen most clearly on the northern edge of the site. There, a 30-meter segment running roughly northwest-southeast marks the northern limit of the thick midden deposits ringing the village. Although the ditch is not visible on the surface at this point, linear vegetation patterns evident in historic aerial photographs appear to coincide with the 
location of this segment. However, just east of the E460 grid line the ditch seems to disappear or perhaps turn and pass under a large mound. One of Alfred Bowers' 1929 excavation units (Work D), a deep, southwest-northeast oriented trench (Figure 2.8), likely crossed Ditch 3 at this point, perhaps obscuring its magnetic signature. The ditch appears to pick up again immediately north of the $520 \mathrm{~N}$ grid line. However, it is also possible that the "floating" bastion to the east may at one time have been a part of Ditch 3 . South of the $500 \mathrm{~N}$ grid line the track of Ditch 3 is obscured by the pasture fence and by overlying midden mounds.

The north-south oriented excavation block was placed over the best-expressed segment of the ditch, and positioned so that the northern wall would be exposed. In this part of the site the plowzone, containing few artifacts, ranges from 15 to $20 \mathrm{~cm}$ thick (Figure 4.16). Below that is a layer of homogeneous dark brown silt 10 to $35 \mathrm{~cm}$ thick. Artifact density is moderate and charcoal flecks are present. The stratum is thickest over the centerline of the ditch. Below this homogenous layer are a series of strata that fill the ditch but also spill out onto the surrounding surface. These

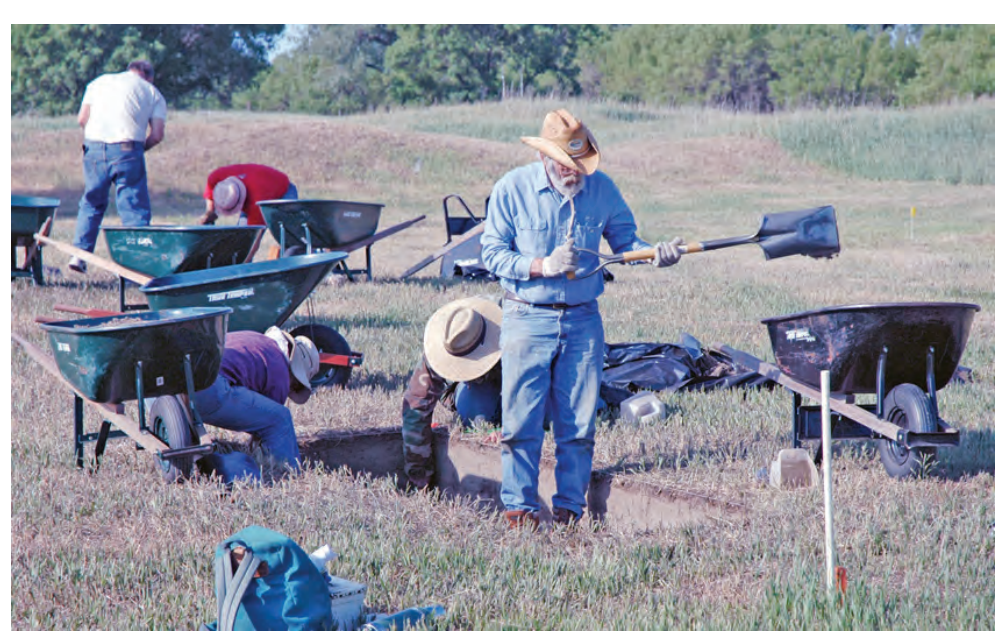

Figure 4.15. Richard Krause (r), Craig Johnson, and Janet Griffitts working in Ditch 3. extensive sheet midden deposits appear not to have been substantially reworked by later village activities.

The ditch itself is filled with a complex sequence of alternating natural and cultural strata, distinguishable by color, structure, and content (Figure 4.17). Cultural strata consist of relatively thick layers containing abundant charcoal, animal bones, and artifacts, including several dense concentrations of charcoal, ash, and fire-cracked rock. By contrast, the natural infill strata consisting of olive silt or alternating bands of light and

dark silt are generally thinner, more compact, and contain fewer artifacts. By the time the uppermost of these aeolian and alluvial strata was deposited the ditch had been nearly filled.

Immediately after the last natural stratum was laid down, several thick, mounded layers of earth containing few artifacts were deposited on the village side of the ditch. This mounding may have been due to the presence of an interior earthen berm on which the palisade might have stood, or it may represent an initial phase of mound construction. Several low, rounded mounds are located west and north of the Ditch 3 excavation block. It is likely that these mounds have been flattened somewhat by plowing.

Ditch 3 originated at $70 \mathrm{~cm} \mathrm{SD}$, or perhaps slightly higher, and was initially at least $135 \mathrm{~cm}$ deep. Some difficulty was encountered in defining the northern edge of the ditch, due mainly to the presence of numerous rodent burrows, but compounded by the fact that several of the nearly sterile ditch fill strata rise with and are therefore almost parallel to the wall of the ditch. The first feature level was begun at a depth of $50 \mathrm{~cm}$ SD; however, during the excavation of FL4 it became clear that the ditch wall was in fact slightly farther north than initially defined. Accordingly, additional sediment was removed from the north end of the block to better define the wall of the ditch. This 

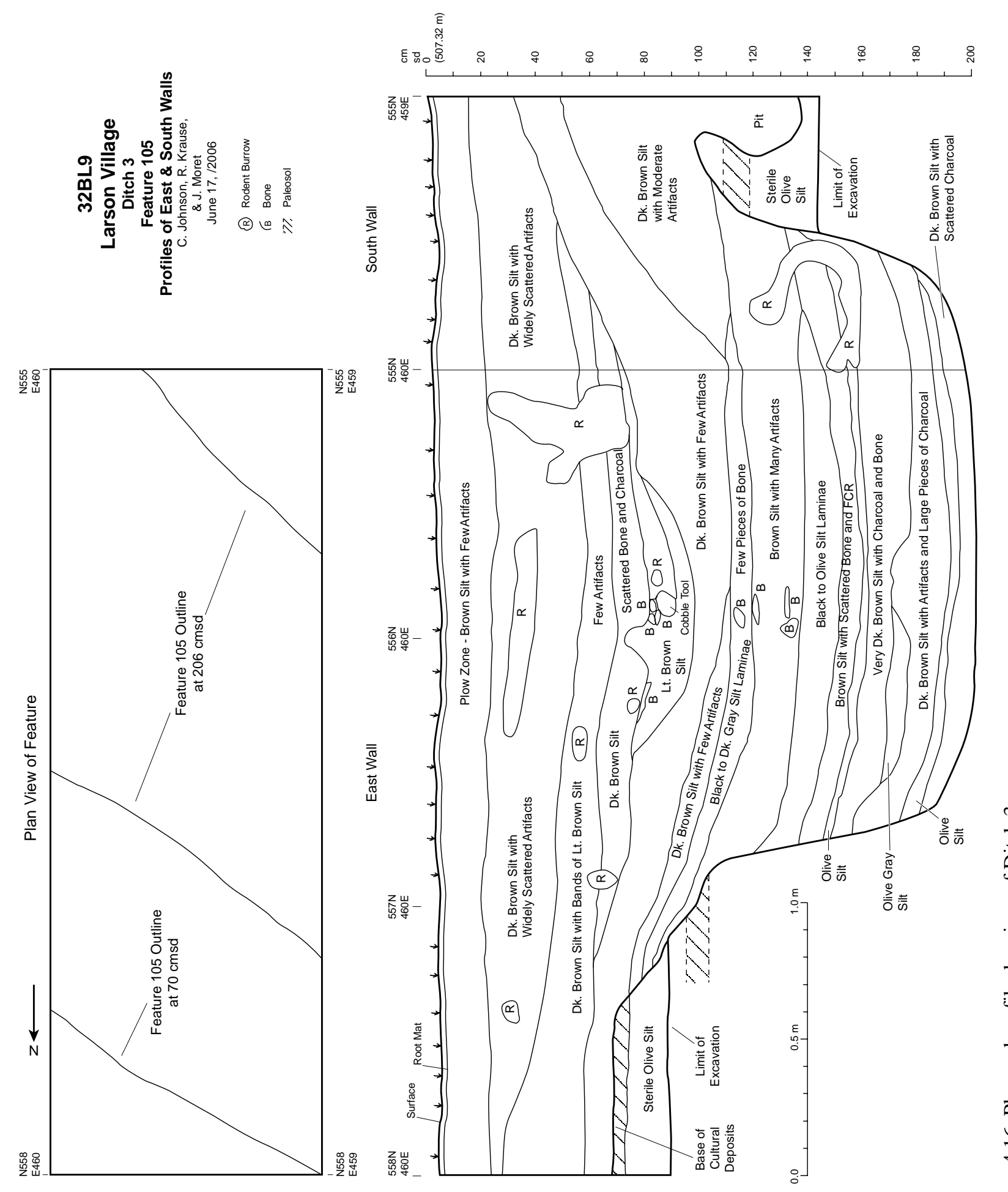
material was added to previously excavated material from FL1, FL2, and FL3 (50 to $80 \mathrm{~cm} \mathrm{SD).} \mathrm{The} \mathrm{upper}$ part of the ditch is relatively broad, with gently sloping sides, but the lower part has nearly vertical sides. The floor of the ditch is flat and is $135 \mathrm{~cm}$ across. A small pit, or perhaps a posthole, located just beyond the ditch wall on the south was exposed in the south wall of the excavation block. The strata filling the pit spill out into the ditch, indicating that they were filled at the same time.

Two buried soils were observed in the wall of Ditch 3. The ditch appears to originate from the upper soil, at a depth of about $70 \mathrm{~cm} \mathrm{SD}$. The A horizon is 5 to $7 \mathrm{~cm}$ thick, but may have been truncated. The lower soil is about $10 \mathrm{~cm}$ thick and lies at a depth of $92 \mathrm{~cm} \mathrm{SD}$ on the north side of the ditch and about $110 \mathrm{~cm}$ SD on the south side.

The stratigraphic data suggest that Ditch 3 was filled episodically over a period of time. Perhaps twothirds of the fill consists of dumps of domestic refuse mixed with sediment, while one-third consists of relatively sterile silt layers that were blown or washed

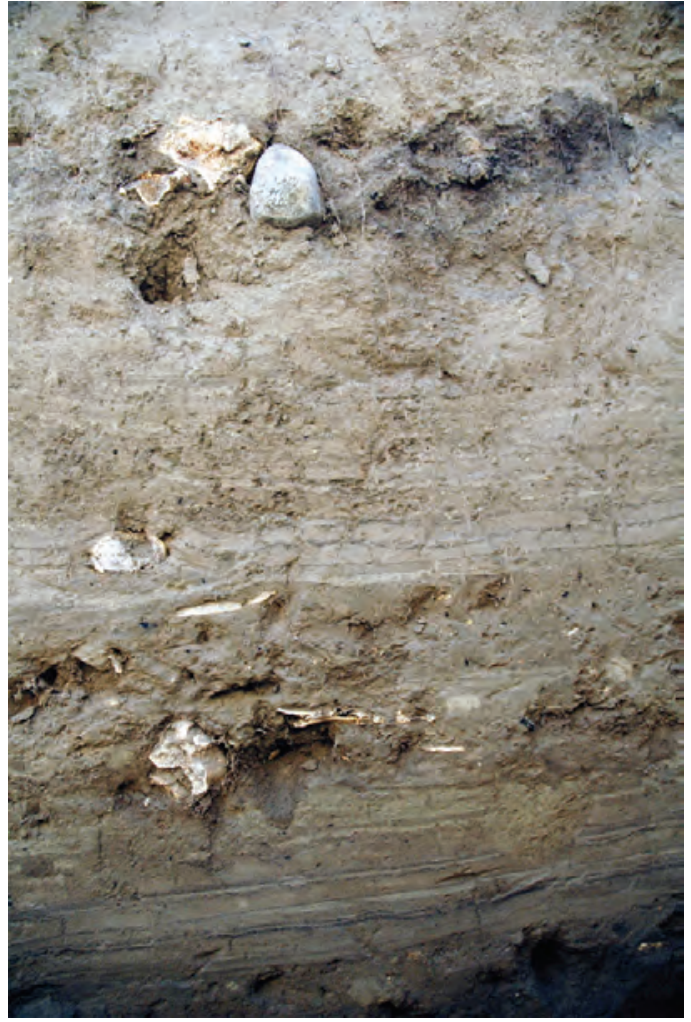

Figure 4.17. Close-up of strata filling Ditch 3. into the open ditch. Interestingly, the alternating deposition of natural layers derived from the erosion of nearby surfaces and cultural layers derived from the disposal of domestic debris began very early in the use-life of the fortification, suggesting that the need for stout, well-maintained defensive features may have waxed and waned during the period that Ditch 3 was in use.

These data also confirm the absence at Larson Village of a "zone of obliteration" comparable to that at Double Ditch Village. Stratified deposits are present immediately below the plowzone. Ditch fill strata rise to within $30 \mathrm{~cm}$ of the modern ground surface, or $15 \mathrm{~cm}$ below the base of the plowzone. The only stratigraphic unit that shows any sign of having been truncated is the uppermost, located immediately below the plowzone. If so, a shallow topographic expression of Ditch 3 may have been preserved until the site was plowed in the late nineteenth or early twentieth centuries.

Data on buried soils (discussed below) suggest that about $25 \mathrm{~cm}$ of sediment was removed from this part of the site prior to the construction of Ditch 3. This apparent borrowing supports the idea that earthlodges had been built somewhere nearby prior to the construction of Ditch 3 and therefore that Ditch 4 is somewhat older. After Ditch 3 was filled, an additional $70 \mathrm{~cm}$ of cultural deposits were laid down in this part of the site. The origin of these deposits is not clear, but it seems certain that at least some of them were laid down while the village was occupied. 


\section{Ditch 4}

Ditch 4 (Feature 106) was exposed in a 1x3 m block excavated by Fern Swenson, John Vicha, and Laurinda Porter (Figure 4.18). The magnetic signature of Ditch 4 is comparatively weak, but geophysical data indicate that it arcs around the northern perimeter of the village, well beyond the limit of visible surface features. It also contains at least two bastions and in that respect is remarkably similar to Ditch 4 at Double Ditch Village. Based on these data, it was assumed that Ditch 4 at Larson would prove to be the oldest feature investigated and that its age could be used to approximate the maximum age of the village. The east-west oriented test unit was placed over the ditch segment with the most robust magnetic expression. At that location the ditch runs from northwest to southeast, crossing the site grid at an approximately 45-degree angle. Initial coring at one-meter intervals along the $540 \mathrm{~N}$ grid line indicated that the floor of Ditch 4 is about 140 to 145 cm below the surface.

Owing to extensive badger burrowing in this part of the site, 10 to $13 \mathrm{~cm}$ of sod and disturbed sediment were removed prior to initiating controlled excavation (Figure 4.19).

Excavation was carried out with skim shovels and trowels, with the latter being used mainly for the final 2 to $4 \mathrm{~cm}$ of each 10-cm level. The base of the plowzone was encountered at about $20 \mathrm{~cm} \mathrm{SD}$ (the bottom of GL1). Beneath the plowzone are a series of spatially-extensive, homogeneous grayish brown silt layers. These units were rather difficult to recognize during excavation but subsequently could be identified in the profile by differences in compaction and especially artifact content. Most of the identified strata are thick, massive, and flat-lying, with gradual, undulating

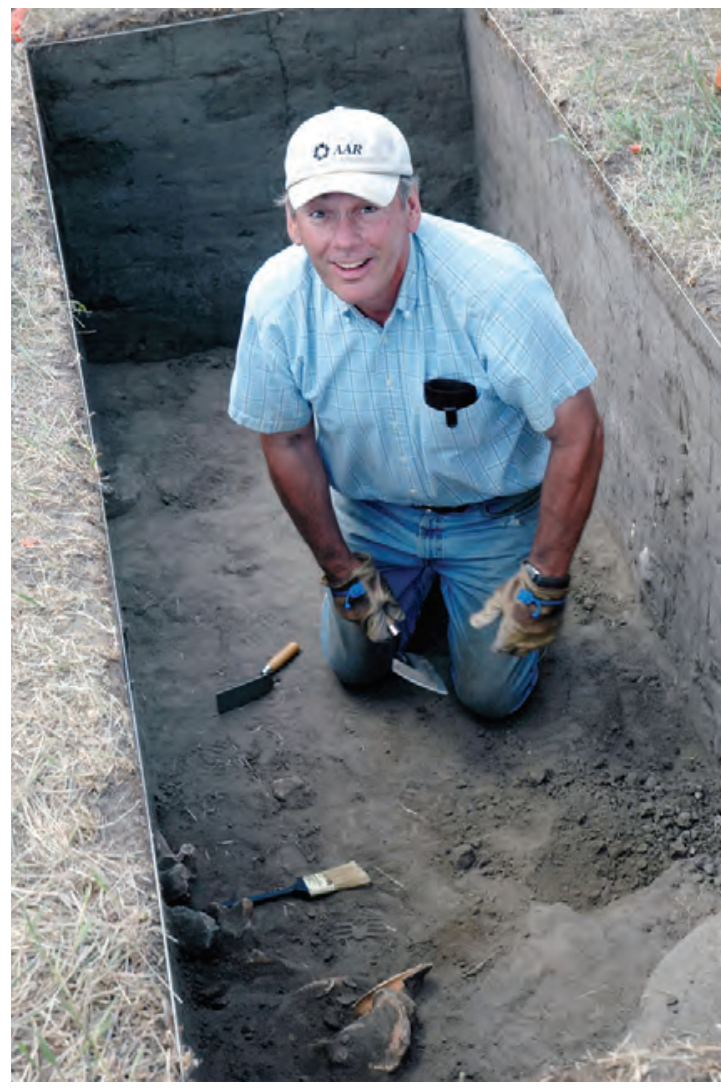

Figure 4.18. John Vicha working in Ditch 4. boundaries. Several are quite compact and some contain carbonate flecks. None of the boundaries mirror the shape of the ditch, as was seen in Ditch 3. Krotovina (made by both badgers and ground squirrels) are common, especially in the upper $70 \mathrm{~cm}$. Notably, no laminated or banded silt deposits, likely indicative of natural infilling, were observed in the fill of Ditch 4.

Large animal bones and fire-cracked rock are more abundant in the Ditch 4 deposits than they are in any of the others investigated in 2006, except those present in Block G. However, the density of other artifact classes is lower. A particularly dense layer of bone, which includes the remains of both bison and dog, was encountered between 75 and $90 \mathrm{~cm} \mathrm{SD.} \mathrm{As}$ mentioned previously, a very similar layer of bone was encountered in Block $\mathrm{G}$ between 70 and $90 \mathrm{~cm} \mathrm{SD}$.

The northern edge of the ditch was first defined at about $57 \mathrm{~cm} \mathrm{SD}$ in the northeastern corner of the excavation block, although general level excavation continued to $60 \mathrm{~cm} \mathrm{SD}$ to better define the boundary. A total of 9 feature levels were excavated, to a depth of $147 \mathrm{~cm}$ SD. The maximum original depth of Ditch 4 was therefore appears to have been no more than 90 

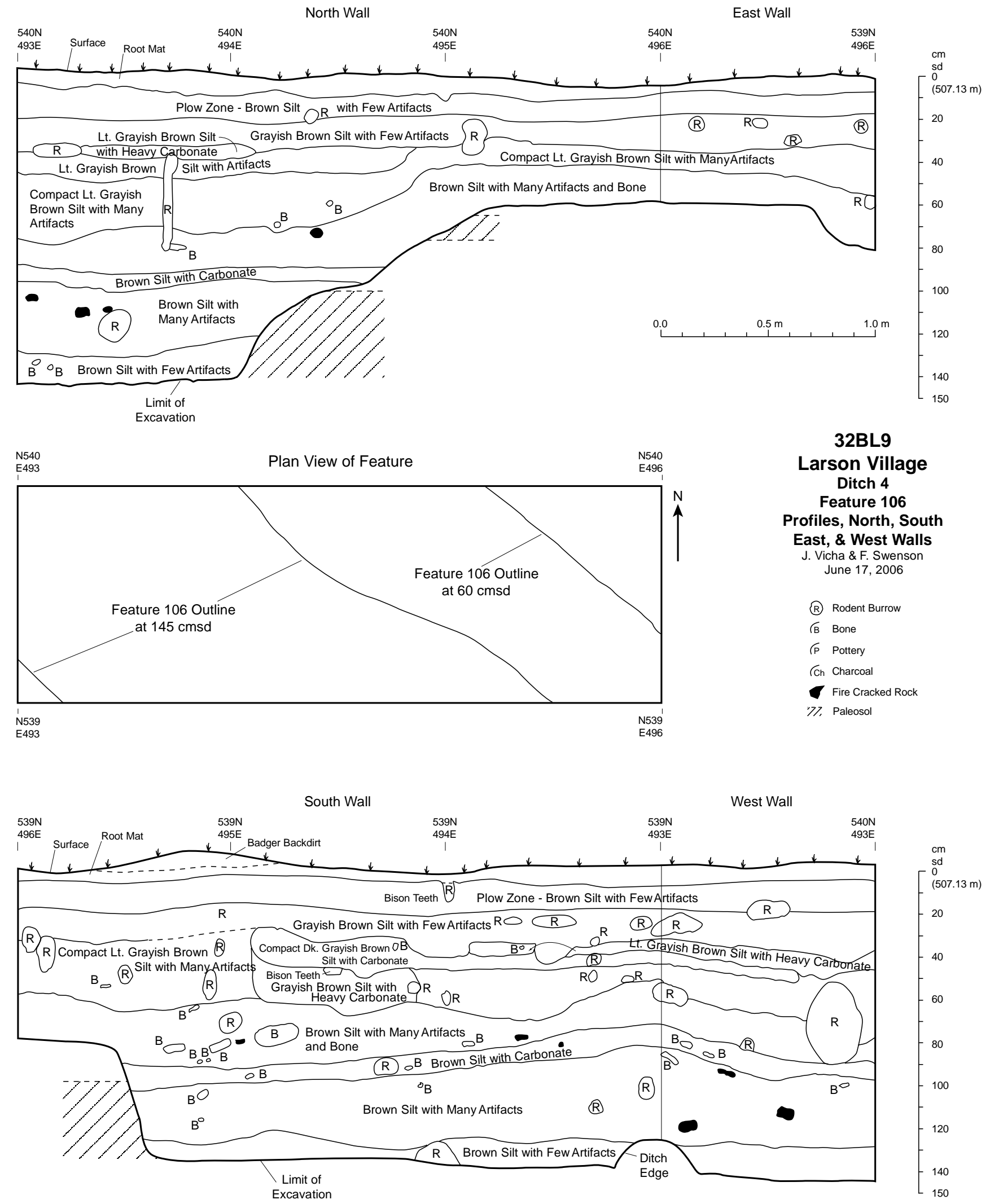

Figure 4.19. Plan and profile drawings of Ditch 4. 
$\mathrm{cm}$. In places, the edge of the ditch was difficult to follow because the ditch fill (compact, with comparatively few artifacts) is similar in color and texture to the sediment into which it was dug. A small sliver of the southern edge of the ditch was first encountered near the base of FL7 at $127 \mathrm{~cm}$ SD. The floor of Ditch 4 is flat and about $125 \mathrm{~cm}$ across. Unlike those of Ditch 3, the walls of Ditch 4 slope gradually, with only the last $25 \mathrm{~cm}$ being nearly vertical. No other features, such as pits or postholes, were observed in or adjacent to this segment of Ditch 4.

Two paleosols were observed in the walls of the ditch. Both are formed in alluvial clays and contain carbonate stringers and blebs. However, the lower soil is much better developed, has a finer texture, and contains more carbonate. In fact, the clay content of the lower soil is so high that an Oakfield soil probe could not penetrate far enough to determine its thickness. The A horizon and upper part of the B horizon are together at least $40 \mathrm{~cm}$ thick, judging by their exposure in the lower walls of the ditch. The A and B horizons of the upper soil are about $12 \mathrm{~cm}$ thick.

The thick strata filling Ditch 4 are quite distinct from the alternating natural and cultural strata filling Ditch 3. No thin laminae, representing sediment eroded from the surrounding landscape and deposited by wind or water, were observed in Ditch 4. Artifact densities are markedly lower in Ditch 4 than in Ditch 3, and consist mainly of large dumps of animal bone and fire-cracked rock. The contacts between the strata in Ditch 4 do not follow the contours of the ditch as they do in Ditch 3. These data suggest that Ditch 4 was filled intentionally over a comparatively short period of time using sediment derived from several sources. If so, the contents of the ditch may not be entirely representative of the period when Ditch 4 was abandoned.

The fill of Ditch 4 differs in other ways from the fill of Ditch 3. None of the strata filling or overlying Ditch 3 appear to have been truncated, with the possible exception of the uppermost. By contrast, at least two strata filling Ditch 4 may have been truncated. This line of truncation is best seen in the north wall profile illustrated in Figure 4.19. This might indicate that sediment borrowing took place on the margins of the village long after Ditch 4 had been abandoned, or perhaps that one or more of the processes responsible for the "zone of obliteration" at Double Ditch Village also operated at Larson. If so, the effects appear to be limited entirely to the outermost periphery of the settlement.

\section{Stratigraphic Correlation of Buried Soils}

Figure 4.20 depicts the stratigraphic relationships among the paleosols observed in each of the six excavation blocks. The highest soil occurs in Blocks A, D, and F, at an elevation of about $506.89 \mathrm{~m}$. This soil is not well developed, with an A horizon just $10 \mathrm{~cm}$ thick. Given its consistent depth, its position relative to various cultural features, and the fact that it is covered in Blocks D and F with displaced subsoil, it is likely that this soil represents the surface on which the village was initially constructed. It is absent in the Ditch 3 excavation unit, indicating that about $25 \mathrm{~cm}$ of sediment was removed from this part of the site before Ditch 3 was built. It also is absent in Block $\mathrm{G}$ and Ditch 4; however, it is not clear that this is due to sediment removal. It seems likely that the finer sediment encountered in those blocks accumulated in a shallow natural depression. If so, that depression would have been at least $35 \mathrm{~cm}$ deep, judging by the elevation of the Ditch 4 wall. 


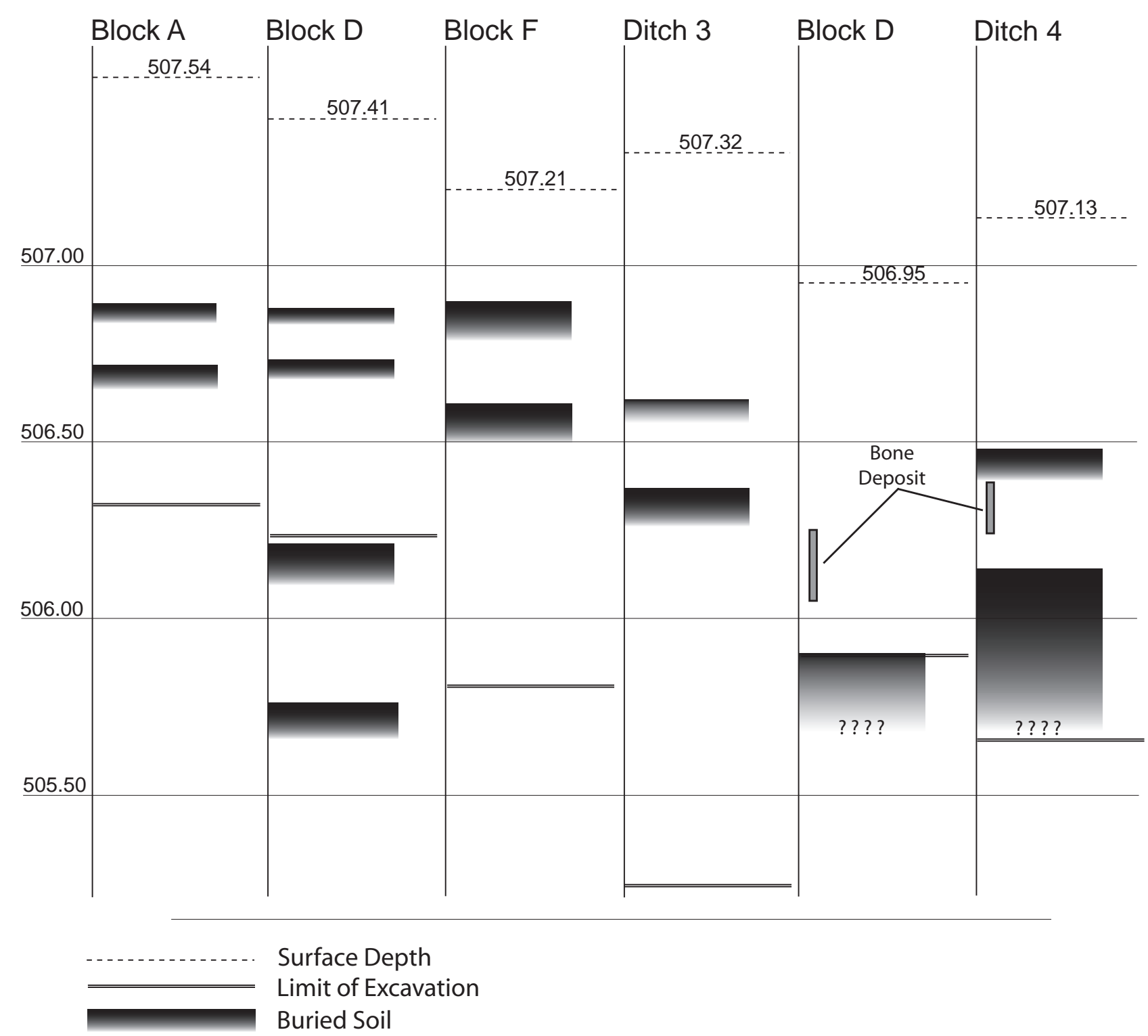

Figure 4.20. Correlation of buried soils across six excavation units.

The pre-village surface is underlain in Blocks A, D, F, and Ditch 3 by a second soil, the upper surface of which ranges in elevation from 506.61 to 506.73. In the Ditch 3 excavation block this soil was probably partially truncated by sediment borrowing. The relationship of this earlier buried soil to the soils observed in Block $G$ and Ditch 4 is not known. Evidence for even older soils was observed in Block D and Ditch 3, but the precise relationships among them are unclear.

The most well developed soil occurs only on the eastern third of the site where it was observed in Block G and Ditch 4 and in probe holes in geophysical blocks 11, 24, and 29. This soil was formed in clay and has a dark A horizon about $20 \mathrm{~cm}$ thick. The A horizon rests on a well developed $\mathrm{B}$ horizon exhibiting granular structure and containing numerous carbonate stringers and blebs. The total thickness of this soil could not be determined. 


\section{Coring Transect}

Soil coring was used to explore the large, flat bottomed basin just north of the village core. In the Heart region, coring has become a routine method for rapidly sampling geophysical anomalies and for investigating the depth and character of natural and cultural deposits (e.g. Ahler and Swenson 2003:36). Generally, an Oakfield soil probe has been used to extract a column or plug of sediment 1-inch in diameter at intervals along a linear transect or from point locations determined through geophysical survey. Each segment of the extracted core is approximately $20 \mathrm{~cm}$ long. Data on the strata observed and the artifacts encountered in the core are recorded on standardized forms. All depths are calculated from the modern ground surface; coordinate data provided by a total station are used to calculate the absolute elevations of the recorded strata.

Thirty-one cores were taken at 2-m intervals along a single north-south transect across the basin (on the E440 grid line). On the north, coring began at the $480 \mathrm{~N}$ grid line, on a nearly level surface between several possible earthlodge depressions. On the south, the transect terminated at the $420 \mathrm{~N}$ grid line, just inside the village core. In the center of the basin, the transect passed through a low, rounded mound about $3 \mathrm{~m}$ in diameter. Figure $4 . .21$ depicts the surface topography as well as the contact between cultural and sterile deposits along the transect. To emphasize the relationship between surface topography and the depth of the underlying cultural deposits, elevations are vertically exaggerated. The projected elevation of the pre-village ground surface (discussed above) also is shown.

North of the basin, cultural deposits vary in thickness from 100 to $256 \mathrm{~cm}$. In some cases, probe holes intersected trash-filled pits containing many artifacts, ash, burned rock, and bone. In other cases, coring revealed the presence of cultural deposits exhibiting markedly lower artifact densities. Ditch 1, which skirts the southern edge of the basin, is filled with cultural deposits at least $235 \mathrm{~cm}$ deep. However, within the basin, cultural deposits are virtually absent. The complete lack of cultural features was later confirmed by the geophysical survey which showed that no magnetic anomalies are present in the eastern half of the basin. Interestingly, the low mound at the center of the basin is composed of sterile, intact sediment, rather than cultural debris, indicating that it is a remnant feature left by the removal of surrounding sediment. Somewhat surprisingly, the cultural deposits in the village core seem to be thinner than those on the north side of the basin.

A rather similar, though somewhat larger, depression (designated Basin 1) is a prominent feature at Double Ditch Village as well. Like the basin at Larson, the Double Ditch basin is located north of and just outside Ditch 1 . It too is free of large magnetic anomalies generally interpreted as pits or hearths and contains no cultural deposits. The basin at Double Ditch also incorporates a remnant sediment feature, although it consists of a low, linear partition or ramp running from the center of the basin to eastern edge rather than an isolated mound.

Alfred Bowers (1940) interprets the large basin at Larson as an open plaza and the low central mound as the former location of the Lone Man shrine. By contrast, Ahler and others (2005:58) argue that the large basin at Double Ditch is most likely an enormous borrow feature, rather than a plaza. Data on the depth of a prominent and distinctive buried soil underlying Double Ditch indicate that at least $1.3 \mathrm{~m}$ of sediment has been removed from Basin 1, obliterating any features that may have been present before it was created. At Larson, the floor of the depression is 50 to $90 \mathrm{~cm}$ below the projected pre-village ground surface, indicating that a substantial amount of 


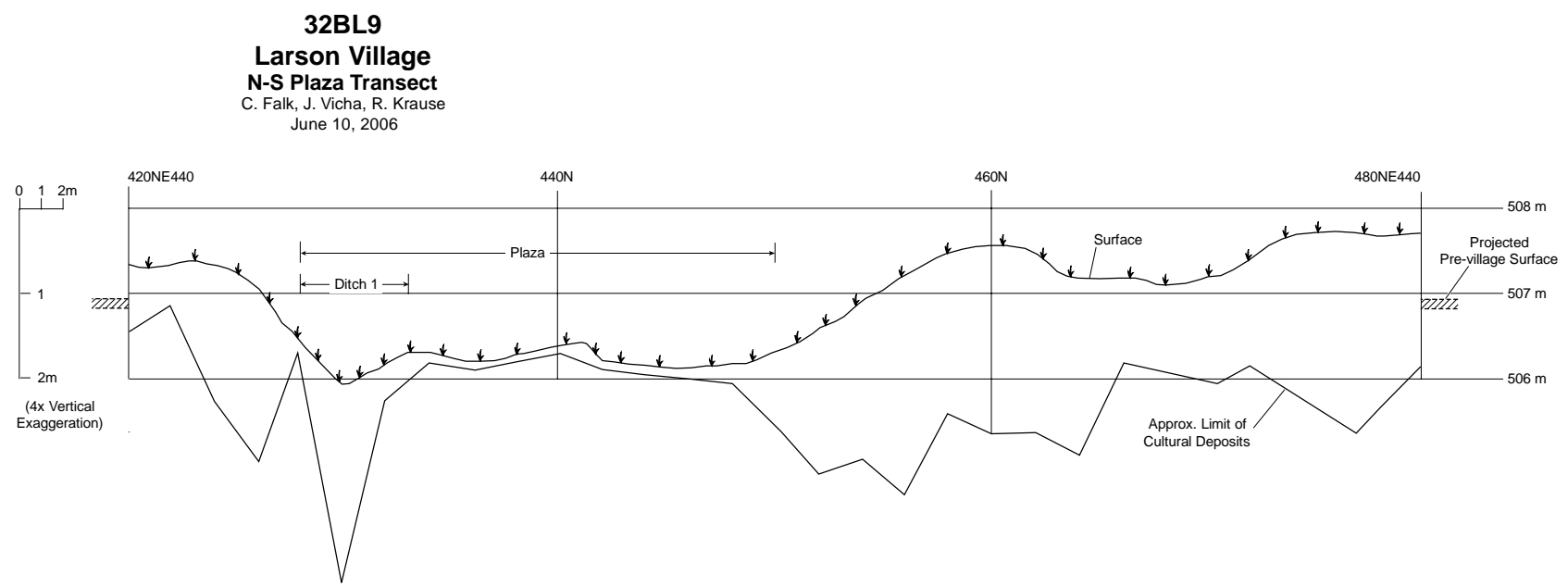

Figure 4.21. Depth of cultural deposits along a north-south transect through the Larson Village plaza.

sediment was removed from this part of the site as well. However, it must be the case that this borrowing began early in the occupation of the village and that earthlodges never were built there, given the typical depths of associated cache pits and other features. If the borrowing had taken place after lodges had been constructed and abandoned, the remnants of pits or other features would still be present, and would be evident in the magnetic data. The fact that cultural deposits extend well below the floor of the basin on both the north and the south sides of the basin suggests instead that it remained open from the time the village was founded. Moreover, the absence of any domestic debris in the basin suggests that it continued to be used as an open and presumably public space even after the settlement contracted inside Ditch 1. Overall, these data suggest that the interpretations offered both by Ahler and others and by Bowers are correct; the large basins at Larson and at Double Ditch functioned both as central plazas and, periodically, as borrow areas.

\section{Summary}

This analysis of stratigraphic and other data obtained during the 2006 field season yields new insights into the chronology, layout, and occupational history of Larson Village. Major findings include:

1. Excavation confirmed the presence of two buried fortification ditches ringing the settlement just outside the largest midden mounds. The ditches are similar in form, but were filled in very different ways. Ditch 3 appears to have been abandoned gradually, while Ditch 4 was abandoned and filled rapidly. If Ditch 3 was constructed as a replacement for Ditch 4, as seems likely, then the village's occupants may have filled Ditch 4 intentionally to deprive would-be attackers of a place to hide close to the new defensive perimeter.

2. Evidence from Block G, Ditch 3, and the central plaza indicates that large-scale sediment borrowing has taken place at several locations within the village. It is probable that this borrowing began shortly after the settlement was founded. In Block $\mathrm{G}$, at least $60 \mathrm{~cm}$ and perhaps as much as $1 \mathrm{~m}$ of sediment was removed. Twenty-five $\mathrm{cm}$ of sediment was stripped away prior to the construction of Ditch 3 and in the plaza as much as $90 \mathrm{~cm}$ was removed. It is logical to assume that sediment removed from these basins was used in the 
construction of earthlodges. Similar borrow zones have been observed in many locations at Double Ditch.

3. At Double Ditch, a more extensive form of sediment borrowing also took place. This "planar borrowing" resulted in the removal of the upper $50 \mathrm{~cm}$ to $1 \mathrm{~m}$ of cultural deposits over about 90 percent of the area inside Ditch 2 (Ahler 2005:331). Outside the core residential area surrounded by Ditch 1 , these deposits were subsequently replaced with relatively homogeneous sediment $30 \mathrm{~cm}$ to $1 \mathrm{~m}$ thick containing few artifacts. Inside Ditch 1 , lodges were constructed on a truncated, sterile surface. The purpose of this large-scale borrowing is not clear, but it may have been related to the construction of mounds for defensive purposes. At Larson, evidence of extensive planar borrowing is equivocal. With the exception of the open plaza, the area between Ditch 1 and Ditch 2 appears to contain thick cultural deposits, extending more that $2 \mathrm{~m}$ below the surface. A similar conclusion was drawn by Bowers (1940), who observed superimposed features in his Work $\mathrm{H}$ excavation. Mounded cultural deposits also appear to be present inside Ditch 1, but limited evidence suggests that sterile terrace deposits may be present fairly near the surface.

4. At Larson, the northern periphery of the site has been plowed, but stratified cultural deposits are present immediately below the plowzone. Postmolds and a variety of small features were also observed, hinting at the possibility that portions of intact lodge floors or outdoor activitity areas may be preserved there. This contrasts rather dramatically with the situation at Double Ditch, where cultural features and natural soil horizons on the perimeter of the village have been obliterated to a depth of 50 to $80 \mathrm{~cm}$. The process or processes responsible for this vertical churning are not known, but likely include gardening and perhaps, late in the occupation sequence, hobbling of horses outside Ditch 2 (Ahler 2005:333). At Larson, possibly similar but much thinner homogenized deposits may be present over Ditch 4, but elsewhere are entirely absent. This suggests that the perimeter of the settlement was used by later residents in ways that differed markedly from the ways the perimeter of Double Ditch was used.

5. The 2006 field investigation revealed a surprisingly complex sequence of superimposed features on the northern perimeter of the village. Based largely on its position and form, Ditch 4 is thought to be the earliest feature encountered. Similarities between the strata filling Ditch 4 and those filling the basin exposed in Block $G$ suggest that both were abandoned at about the same time and in the same manner. Ditch 3 is probably younger than Ditch 4, judging mainly by its position relative to Ditch 4. Features originating on the pre-village surface inside Ditch 3 (notably pit F107 and post F103) could have been associated either of the two outer fortifications, although it is assumed here that they were contemporaneous with Ditch 3. After the abandonment of these early features, the northern part of the site continued to be used at least for underground storage and very likely for other purposes as well. Rather limited evidence from Block A suggests that the large perimeter mounds may have begun to form after that time. In any case, the northern part of the site is covered by thin but spatially-extensive sheet midden deposits that must have been laid down long after this part of the site was no longer used for habitation. 


\section{References Cited}

Ahler, Stanley A.

2005 Summary and Conclusions. In Archaeological Investigations During 2004 at Double Ditch State Historic Site, North Dakota, edited by Stanley A. Ahler, pp. 327-336. Research Contribution No. 65. PaleoCultural Research Group, Flagstaff, Arizona. Submitted to the State Historical Society of North Dakota, Bismarck.

Ahler, Stanley A., Fern E. Swenson

2003 Investigations During 2001. In Archaeological Investigations During 2001 and 2002 at Double Ditch State Historic Site, North Dakota, edited by Stanley A. Ahler, pp. 35-52. Research Contribution No. 56. PaleoCultural Research Group, Flagstaff, Arizona. Submitted to the State Historical Society of North Dakota, Bismarck.

Ahler, Stanley A., Fern E. Swenson, Eileen Ernenwein, and Christine Markussen 2005 Interpreted Mapping. In Archaeological Investigations During 2004 at Double Ditch State Historic Site, North Dakota, edited by Stanley A. Ahler, pp. 33-61. Research Contribution No. 65. PaleoCultural Research Group, Flagstaff, Arizona. Submitted to the State Historical Society of North Dakota, Bismarck.

Bowers, Alfred W.

1940 Missouri River Earthlodge Archaeology of North and South Dakota. Ms. on file, Logan Museum of Anthropology, Beloit College, Beloit, Wisconsin. 


\title{
5. LABORATORY METHODS AND ANALYTIC STRATEgY
}

\author{
Stanley A. Ahler and Mark D. Mitchell
}

\section{Introduction}

The laboratory procedures applied to the 2006 collection from Larson Village intentionally duplicated those applied to collections from the 2002 - 2004 field programs at Double Ditch Village and the 2005 field program at Boley Village. Most of the information presented in this chapter about basic lab methods is taken directly from Ahler and Crawford (2003). The excavated samples from Larson Village recovered by waterscreening and individual piece-plotting were processed to a certain level of detail in a single, standardized fashion in the lab. These excavated materials were subjected to a common series of size-grading, floating, and sorting steps that divided the recovered remains into a standard series of artifact and material categories. These methods and artifact sort categories have been used for analyses of many Plains Village collections over a period of more than 25 years (e.g., Ahler 1977:39-45; Lee 1980; Ahler and Swenson 1985:69-85; Ahler 1997:2732; Ahler 2002).

Certain categories of artifacts are more data-rich than others, and extraction of useful information from some artifact classes such as pottery, stone tools, and vertebrate remains can take a great deal of time and effort in the lab. Because the Larson Village project was basically a testing and evaluation program with a finite analytic time frame and budget, with the main analytic goals being to advance the site chronological structure and basic content information according to this chronology, we made several important decisions about the intensity with which various types of artifacts would be studied. Most significantly, we abbreviated and streamlined the intensive, second-stage analysis of several categories of artifacts such as stone tools, bone tools, and vertebrate faunal remains, thereby reducing the amount of time devoted to study of such remains. Because we had very little "over-excavation" of specific contexts - in the sense that we needed to understand the full content of each of the pit feature or ditch contexts we had sampled - we did not designate any subpart of the Larson collection as "secondary priority" requiring less complete study or perhaps no processing at all. We therefore treated all samples as useful for study, and treated all waterscreened materials in a uniform manner regarding intensity of analysis.

In the following section we discuss routine size grading, floating, and sorting procedures and guidelines applied to all contexts subjected to those procedures. In the final section of the chapter, we discuss the decisions that were made regarding exclusion and inclusion of various contexts in the processes of more intensive analysis, and we give an overview of the reduced analysis applied to certain classes of data-rich remains.

\section{Basic Size-Grading, Floating, and Sorting Procedures}

All waterscreened samples were subjected to three basic processing steps: size-grading over nested screens, water flotation, and detailed sorting into artifact and material classes. During 
fieldwork a small number of items were individually piece-plotted in three dimensions and were assigned individual catalog numbers. These items were also individually size-graded and assigned to an appropriate sort category for purposes of additional study. Several discrete record-keeping steps designed to track the history of each sample occurred during the size-grading, floating, and sorting processes, as discussed in a processing guide that was used by lab workers, as reproduced below.

\section{PROCESSING GUIDE - STEPS IN PROCESSING WATERSCREENED FIELD SAMPLES - 2006 LARSON VILLAGE EXCAVATIONS}

1. Set up the fan and dust filter system before starting to process samples.

2. Use the field catalog or an external list and check the number of field bags expected for a given catalog number. Do not process a catalog number until all field bags have been brought together. Check with a supervisor if all field bags cannot be located. Log in the number of bags expected and the number found when size grading is started.

3. Size-grade by hand, manipulating $\mathrm{G} 1$ and $\mathrm{G} 2$, then vigorously shaking $\mathrm{G} 3$, G4, and G5 for 30 seconds.

4. Record catalog number and check off size grading in the Processing Log.

5. Set size $G 1, G 2$, and $G 3$ samples aside and float and separate $\mathbf{G} 4$ and $\mathbf{G 5}$ samples into heavy and light fractions; label appropriately for drying. (Float G3 also in special circumstances of high organics.)

6. Record that floating has been done for that catalog number in Processing Log.

7. When dry, bag in plastic the heavy and light fractions of G4 and G5 remains, place light fraction in appropriate box, and set all heavy fraction size-graded samples aside for sorting. See section 12 below for bag labeling instructions.

8. Record that bagging has been done for this catalog number in the Processing Log.

9. Conduct the sorting process using the Sorting Guide. Have your sort decisions and categories checked by a supervisor unless you have been cleared to sort without checking. Check to see if sample-sorting of size G4 is in order; if so, follow guidelines (below).

10. After sorting $\mathrm{G} 4$ and $\mathrm{G} 5$, weigh the unsorted residue to the nearest 5 grams on the electronic scale, and write down weights.

11. Bag appropriately, using cover bags for multiple size grades. Place bags of ID Bone in G4 and $G 5$ in any size grade within plastic vials for protection.

12. BAG LABELING PROTOCOL: Place the SHSND Accession Number for the LARSON collection [2006.369] in upper right corner of every plastic bag. Place Catalog Number over a line over the Site Number in the upper left corner. Place one of the following on the next line: Block No or Ditch No. (Ditch 3 or Ditch 4, Block A, D, F, or G). On the next line write the Feature Number (F109, etc.) and then Feature Level No. (FL1, FL3, etc.). Place size grade (G1, G2, G3 etc.) and material class information below. Examples:

\begin{tabular}{|c|c|}
\hline$\frac{1016}{32 B L 9}$ & 2006.369 \\
\hline Block A & \\
\hline G.L. 3 & \\
\hline G2 & \\
\hline Nat Rock & \\
\hline
\end{tabular}

\begin{tabular}{|c|c|}
\hline$\frac{1027}{32 \mathrm{BL} 9}$ & 2006.369 \\
\hline Ditch 3 & \\
\hline F105 & \\
\hline F.L. 2 & \\
\hline G4 & \\
\hline Mod Stone & \\
\hline
\end{tabular}

\begin{tabular}{|c|c|}
\hline$\frac{1040}{32 \mathrm{BL} 9}$ & 2006.369 \\
\hline Block A & \\
\hline F108 & \\
\hline F.L. 1 & \\
\hline G1 & \\
\hline Bone & \\
\hline
\end{tabular}


13. Enter data on counts of bags and weight of G4 and G5 residue in the appropriate Sort Completion Check List for the site.

14. Cut out and save the labeled area from one of the paper field bags.

15. Place all bags of sorted material and bag labels in appropriate boxes for accumulation.

During size-grading, samples were manipulated or shaken over graduated screens with five square mesh opening sizes (U.S. Standard Sieve Cloth): G1 = 1.000 in; G2 = 0.500 in; G3 = 0.223 in; G4 = $0.100 \mathrm{in}$; and G5 = 0.046 in. To minimize damage, artifacts were manipulated by hand through size G1 and G2 screens. Samples were shaken for a standard 30-second interval over size G3, G4, and G5 screens. Size-grading assists in the efficiency of the sorting process that follows, allowing the sorter to examine batches of specimens that are all approximately the same size. Size-grading also allows use of objective, size-determined cut-off points for the sorting of different types of artifacts. For example, sorting pottery can effectively cease at size G3 samples, while glass trade beads and fragments of trade metal must be sorted from size G4 and G5 samples. In addition, size distribution data for certain artifact classes are in themselves useful for study of site formation processes as well as the technological history of artifacts. Artifacts with different depositional histories (primary, secondary, and de facto refuse) can exhibit contrastive size distributions (Behm 1983; Sherwood et al. 1995). Distinct processing histories, as subtle as distinct stone knapping technologies (e.g., Ahler 1989a, 1989b), can be isolated through careful attention to data controlled by size grade.

Standard artifact and material sorting categories are identified in Table 5.1, along with the size cut-off point for sorting each category. All of the objects in sizes G1, G2, and G3 are sorted into some named artifact or material category, while only selected objects are sorted from the size G4 and G5 fractions, creating by this process an "unsorted residue” class for G4 and G5 remains.

Table 5.1. Sorting guide for heavy fraction remains from waterscreened samples.

\begin{tabular}{|c|c|c|c|c|c|}
\hline \multirow[b]{2}{*}{ Artifact or Material Class } & \multicolumn{5}{|c|}{ Size Grade } \\
\hline & G1 & G2 & G3 & G4 & G5 \\
\hline Pottery (rim sherds and body sherds) & $\mathrm{X}$ & $\mathrm{X}$ & $\mathrm{X}$ & & \\
\hline Fire-Cracked Rock & $\mathrm{X}$ & $\mathrm{X}$ & $\mathrm{X}$ & & \\
\hline Natural Rock & $\mathrm{X}$ & $\mathrm{X}$ & $\mathrm{X}$ & & \\
\hline Clinker & X & $X$ & X & & \\
\hline Fired Clay (dense, squeezed) & $\mathrm{X}$ & $\mathrm{X}$ & $\mathrm{X}$ & & \\
\hline Burned Earth (porous, earthy) & $\mathrm{X}$ & $\mathrm{X}$ & $\mathrm{X}$ & & \\
\hline Ash (lumps, consolidated) & $\mathrm{X}$ & $\mathrm{X}$ & $\mathrm{X}$ & & \\
\hline Charcoal/Wood & $\mathrm{X}$ & $\mathrm{X}$ & $\mathrm{X}$ & & \\
\hline Charred Seeds, Maize, Uncharred Squash, Bots & $\mathrm{X}$ & $\mathrm{X}$ & $\mathrm{X}$ & $\mathrm{X}$ & \\
\hline Modified Stone (stone tools \& flaking debris) & $X$ & $\mathrm{X}$ & $\mathrm{X}$ & $X$ & \\
\hline Ochre/Pigment (hematite/limonite) & $\mathrm{X}$ & $\mathrm{X}$ & $\mathrm{X}$ & $\mathrm{X}$ & \\
\hline Gypsum/Minerals & $\mathrm{X}$ & $\mathrm{X}$ & $\mathrm{X}$ & $\mathrm{X}$ & \\
\hline Fossils/Concretions (stone) & $\mathrm{X}$ & $\mathrm{X}$ & $\mathrm{X}$ & $\mathrm{X}$ & \\
\hline Bone (all bone) & $\mathrm{X}$ & $\mathrm{X}$ & $\mathrm{X}$ & & \\
\hline Identifiable Bone & & & & $\mathrm{X}$ & \\
\hline Modified Bone (worked) & & & & $\mathrm{X}$ & $\mathrm{X}$ \\
\hline
\end{tabular}


Table 5.1. Sorting guide for heavy fraction remains from waterscreened samples (concluded).

\begin{tabular}{lccccc}
\hline & \multicolumn{5}{c}{ Size Grade } \\
Artifact or Material Class & $\mathrm{G} 1$ & $\mathrm{G} 2$ & $\mathrm{G} 3$ & $\mathrm{G} 4$ & $\mathrm{G} 5$ \\
\hline Shell (all shell including fossils) & $\mathrm{X}$ & $\mathrm{X}$ & $\mathrm{X}$ & & \\
$\quad$ & & & & $\mathrm{X}$ & \\
$\quad$ ID Shell (gastropods or fossils) & & & & $\mathrm{X}$ & $\mathrm{X}$ \\
$\quad$ Modified Shell (worked) & $\mathrm{X}$ & $\mathrm{X}$ & $\mathrm{X}$ & $\mathrm{X}$ & $\mathrm{X}$ \\
Metal (trade or native; exclude recent historic) & $\mathrm{X}$ & $\mathrm{X}$ & $\mathrm{X}$ & $\mathrm{X}$ & $\mathrm{X}$ \\
Glass Beads (trade beads) & $\mathrm{X}$ & $\mathrm{X}$ & $\mathrm{X}$ & $\mathrm{X}$ & $\mathrm{X}$ \\
Recent Historic Material (bottle/window glass, & & & & & \\
concrete, asphalt, plastic, aluminum foil, cartridges, & & & & & \\
slugs, nails, etc.) & $\mathrm{X}$ & $\mathrm{X}$ & $\mathrm{X}$ & $\mathrm{X}$ & $\mathrm{X}$ \\
Misc. Plains Village (leather, any oddities) & & & & $\mathrm{X}$ & $\mathrm{X}$ \\
Unsorted Residue & & & & & \\
\hline
\end{tabular}

\section{More Intensive Analyses}

As mentioned in the introduction, the basic level of analysis applied to the whole collection was uniform. Table 5.2 provides a very brief summary of quantitative and analytic information collected for various kinds of artifacts in all contexts. Detailed methods of analysis for the more complex and data-rich artifact classes are discussed in subsequent chapters, as indicated in the table. Quantitative and analytic data were stored in a single relational database developed in

Table 5.2. Summary of analysis and data tables for artifact categories in 2006 Larson Village collections.

\begin{tabular}{|c|c|c|c|}
\hline General Class & Specific Class & How Studied & Database Tables \\
\hline \multirow{2}{*}{ Pottery } & rim sherds & semi-detailed, Ch. 7 & VesselQuickCode \\
\hline & body sherds & detailed, Ch. 7 & BodySherds;StampSpacing \\
\hline \multirow[t]{2}{*}{ Modified Stone } & stone tools & semi-detailed, Ch. 8 & StoneToolProv \\
\hline & flaking debris & semi-detailed, Ch. 8 & FlakingDebriProv \\
\hline Bone & unmodified & count by class, Ch. 9 & UnmodBoneWt; IDBone \\
\hline Botanicals & all & detailed, Ch. 11 & Seeds \\
\hline Trade Metal & trade metal & detailed, Ch. 12 & TradeMetal \\
\hline Glass Beads & all & semi-detailed, Ch. 12 & No data table \\
\hline Shell & all & category, count \& wt., Ch. 12 & Shell \\
\hline Misc. Plains Village & all & category, count \& wt., Ch 12 & Misc Plains Village \\
\hline Fire Cracked Rock & all & weight \& some count, Ch. 12 & GenQuant Pt 1\&2 Combined \\
\hline Natural Rock & all & weight, Ch. 12 & GenQuant Pt 1\&2 Combined \\
\hline \multirow[t]{2}{*}{ Clinker } & modified & semi-detailed, Ch. 8 & StoneToolProv \\
\hline & unmodified & count \& weight, Ch. 12 & GenQuant Pt 1\&2 Combined \\
\hline Fired Clay & all & weight, Ch. 12 & GenQuant Pt 1\&2 Combined \\
\hline Burned Earth & all & weight, Ch. 12 & GenQuant Pt 1\&2 Combined \\
\hline Ash & all & weight, Ch. 12 & GenQuant Pt 1\&2 Combined \\
\hline Charcoal/Wood & all & not quantified & - \\
\hline Ochre/Pigment & all & count \& weight by color, Ch. 12 & GenQuant Pt 1\&2 Combined \\
\hline Gypsum & all & count and weight, Ch. 12 & GenQuant Pt 1\&2 Combined \\
\hline Recent Historic & all & not quantified & - \\
\hline Unsort. Residue & all & weight & GenQuant Pt 1\&2 Combined \\
\hline
\end{tabular}


Microsoft Access (Office 2002), and Table 5.2 lists the specific data tables where coded or quantified information for the artifact collection resides. With the exception of miscellaneous historic items and charcoal/wood, some form of quantitative information was collected for all artifact classes, regardless of context. Provenience data are stored in a table called Catalog\&Processing, along with data on time period, site locus, and stratigraphic group (see Chapter 6). Queries that link this and other data tables allow generation of artifact data according to useful provenience information, which is a necessary bridging step in the production of interpretable analytic information. As needed, data queries developed in Access were compiled in SPSS (Version 15) for purposes of further analysis and data summation by analytic unit. 


\section{References Cited}

Ahler, Stanley A.

1977 Archeological Reconnaissance and Test Excavation at the Jake White Bull Site, 39CO6, Oahe Reservoir, South Dakota. Department of Anthropology and Archaeology, University of North Dakota, Grand Forks. Submitted to the U.S. Army Corps of Engineers, Omaha District.

1989a Mass Analysis of Flaking Debris: Studying the Forest Rather than the Tree. In Alternative Approaches to Lithic Analysis, edited by D. Henry and G. Odell, pp. 85-119.

Archaeological Papers of the American Anthropological Association 1, Washington, D.C.

1989b Experimental Knapping with KRF and Midcontinent Cherts: Overview and Applications. In Experiments in Lithic Technology, edited by Daniel S. Amick and Raymond P. Mauldin, pp. 199-234. BAR International Series 528, Oxford.

1997 Background. In Archaeology of the Mandan Indians at On-A-Slant Village (32MO26), Fort Abraham Lincoln State Park, Morton County, North Dakota, edited by Stanley A. Ahler, pp. 13-32. Office of Research and Graduate Studies, Northern Arizona University. Submitted to the North Dakota Parks and Recreation Department, Bismarck.

2002 Laboratory Procedures, Analytic Units, Data Bases. In Archaeology of Menoken Village, A Fortified Late Plains Woodland Community in Central North Dakota, edited by Stanley A. Ahler, pp. 207-230. PaleoCultural Research Group, Flagstaff, AZ. Submitted to the State Historical Society of North Dakota, Bismarck.

2004 Laboratory Methods and Analytic Strategy. In Archaeological Investigations During 2003 at Double Ditch State Historic Site, North Dakota, edited by Stanley A. Ahler, pp. 123132. PaleoCultural Research Group, Flagstaff, Arizona. Submitted to the State Historical Society of North Dakota, Bismarck.

Ahler, Stanley A. and George Crawford

2003 Laboratory Methods and Analytic Strategy. In Archaeological Investigations During 2001 and 2002 at Double Ditch State Historic Site, North Dakota, edited by Stanley A. Ahler, pp. 35-52. PaleoCultural Research Group, Flagstaff, Arizona. Submitted to the State Historical Society of North Dakota, Bismarck.

Ahler, Stanley A. and Anthony A. Swenson

1985b Test Excavations at Big Hidatsa Village (32ME12), Knife River Indian Villages National Historic Site. Department of Anthropology, University of North Dakota, Grand Forks. Submitted to the National Park Service, Midwest Archaeological Center, Lincoln.

Behm, Jeffery A.

1983 Flake Concentrations: Distinguishing Between Flintworking Activity Areas and Secondary Deposits. Lithic Technology 12(1)9-16.

Lee, Chung Ho

1980 Laboratory Procedures. In The Archeology of the White Buffalo Robe Site, vol. 1, edited by Chung Ho Lee, pp. 68-81. Department of Anthropology and Archeology, University of North Dakota, Grand Forks. Submitted to Stearns-Roger Engineering Corporation, Denver, Colorado.

Sherwood, S. C., Simek, J. F., and R. R. Polhemus

1995 Artifact Size and Spatial Process: Macro- and Microartifacts in a Mississippian House. Geoarchaeology 10(6): 429-455. 


\title{
6. ANALYTiC Units AND Collection Chronology
}

\author{
Mark D. Mitchell
}

\section{Introduction}

In this chapter data bearing on the age of the deposits investigated during the 2006 fieldwork are discussed and temporal relationships among the excavated contexts are examined. To provide a framework for subsequent analysis and comparison, excavated proveniences are grouped into "analytic units" or excavation loci. Each locus consists of one or more proveniences (each of which was assigned a separate catalog number in the field) that share a common location within the site (block and feature), a common depositional context (deposit type), and a common stratigraphic or temporal position. For analytic purposes, excavation loci can therefore be combined into spatial sets (excavation areas), temporal sets (stratigraphic groups), or depositional sets (deposit types). Each of these groupings is used in the balance of the report to organize data pertaining to each artifact or material class. The following sections discuss aspects of the three primary analytic dimensions and provide details on the rationale used to assign particular provenience lots to particular analytic units.

\section{Depositional Context}

Six deposit types are recognized in the blocks investigated during 2006. These can be grouped into three classes: contained deposits, uncontained deposits and mixed deposits. Contained deposits occur within discrete features and likely accumulated over comparatively brief periods of time. Uncontained deposits were laid down on surfaces or in large basins or trenches; the rate at which they were filled likely varied significantly. Due to erosion and other processes, unconformities are more likely to occur in uncontained deposits than in contained deposits. Mixed deposits include materials from more than one depositional context. A brief description of each is provided in the following paragraphs.

Contained Deposits. The fill of excavated pit features can be divided into two types. The content of small pits can vary substantially, but most often consists of earth with relatively few artifacts. Among the small pits investigated at Larson, one contained the decomposed remains of a wooden post. Two other small pits appeared to have been filled by discrete dumps of burned rock (Pit F108) and pottery and bison bones (Pit F104). Due to their small size, the contents of small pits can easily become mixed with overlying deposits. By contrast, the fill of large cache pits, such as Feature 107 in Block F, typically is better contained. The diameters of such features usually are about equal to their depths and their walls range from slightly to sharply undercut. The fill often is rich in artifacts and faunal materials and frequently includes large primary dumps of ash and charcoal. Large cache pits also sometimes contain human interments, although none were encountered during the 2006 fieldwork. 
Uncontained Deposits. These deposits consist of laterally extensive, stratified accumulations of domestic debris and earth. In some cases individual basket loads of debris can be identified, but more commonly such deposits consists of stratigraphic units having an area greater than several square meters. They may be flat lying, dipping, or mounded, and may contain varying amounts of ash and charcoal. In some cases in situ burning is evident. Midden deposits exhibit moderate to high artifact densities and range from loose and unconsolidated to moderately compact in texture.

Midden and earth deposits exhibit comparatively low artifact densities and typically are moderately to very compact. The fill of large basins (Block $G$ ) and fortification trenches (features 105 and 106) also are considered unconstrained deposits. As sediment was accumulating in them people and animals would have walked across them, trampling and dispersing associated artifacts. Episodes of sediment borrowing and re-filling also may have taken place.

Mixed Deposits. Two types of mixed deposits can be defined. Undifferentiated deposits were clearly disturbed after they were laid down. The original source or sources of these deposits is not known. Most likely they include a mixture of sediment and artifacts originally accumulated in both pits and stratified middens. At Larson, the only deposits classified as undifferentiated are those disturbed by plowing. Mixed deposits include sediments and artifacts from known contexts that were accidentally combined, generally during the course of fieldwork.

\section{Spatial Context}

For purposes of simple inventory, each excavation unit can be considered a separate location. However, data on the overall spatial structure of the village (provided mainly by geophysical surveys) also can be translated in chronological terms. Magnetic data shows that the village was enclosed by a series of concentric fortification systems. Based on their similarities to those at Double Ditch Village, it seems likely that these fortifications were built sequentially (see Chapters 1 and 4). Because it is unlikely that many features were built outside an active fortification, it can be assumed that features located inside Ditch 4 but outside Ditch 3 pre-date the construction of Ditch 3. Those located inside Ditch 3 could be associated either with Ditch 3 or Ditch 4. However, it is here assumed that intact features located inside the Ditch 3 perimeter are more likely to post-date the construction of Ditch 3. At Larson, Block G is located between Ditch 3 and Ditch 4, suggesting that the deposits encountered there pre-date Ditch 3.

\section{Temporal Context}

Multiple lines of evidence are available to assess the relative and absolute ages of the 2006 excavated contexts. The most important data consist of stratigraphic relationships, pottery content, trade artifact composition and density, and radiocarbon dates. As noted previously, in some cases temporal determinations are in partly dependent on spatial and depositional factors.

Stratigraphy. Stratigraphic data include observed patterns of superimposition, estimated or projected relationships between features or strata and laterally extensive soil horizons, and similarities in content or texture between cognate strata. The most important of these are direct stratigraphic relationships among the features and deposits encountered in each of the excavation blocks. For example, in Blocks A and F, the presence of superimposed features can be used to 
assess overall chronological relationships. In addition, the presence of a series of weakly-developed soils in the undisturbed loess underlying the village makes it possible to partially correlate the features encountered in Blocks A, D, F, and Ditch 3 (see Chapter 4). Finally, the artifacts and faunal remains observed in the fill of Ditch 4 match closely the artifacts and fill observed in Block $\mathrm{G}$, suggesting that the two contexts were filled at approximately the same time.

Pottery Content. Broad patterns of ceramic style variation over time can be used to assess the relative as well as the absolute ages of excavated deposits. The notable lack of ceramic variation among the contexts investigated during 2006 (see Chapter 7) suggests that relatively little time depth is represented. Virtually all contexts contain both Le Beau and Knife River wares, with Le Beau dominating. Rims representing varieties thought to have been produced only until the early 1500s, (Stanton and Sanger wares) are widely scattered throughout the deposits, especially in Block G, the lower strata of Ditch 3, and Pit F107. Later seventeenth century varieties, such as Transitional ware and Le Beau Sperry variety are rare or absent.

Trade Artifacts. It has generally been assumed that European trade goods-consisting mainly of copper or brass artifacts-first appeared in the northern Middle Missouri about 1600 or shortly thereafter (Ahler and Drybread 1993). After 1650, iron tools became more widely available and the proportion of the trade metal assemblage made up of cuprous items decreased from about 80 percent to about 20 percent. Glass beads appeared in larger numbers at the end of the seventeenth century. The number and variety of iron trade items and glass beads increased dramatically during the middle of the eighteenth century. Based on these patterns, data on the type and density of trade items have been used to construct chronologies for each of the recently-investigated settlements in the Heart region. Trade artifact density data from Double Ditch, Boley, and Larson villages are compared in Table 6.1.

Table 6.1. Trade artifact composition and density data organized by time period for recently excavated contexts at Double Ditch, Boley, and Larson villages. Density values are expressed as either counts or grams per $\mathrm{m}^{3}$ excavated volume. "Bone” frequencies are for bone specimens thought to have been shaped or modified by metal tools. For Double Ditch and Boley, Period 0=1725-1785, Period 1=1675-1725, Period 2=1650-1700, Period 3=1600-1650 (Ahler 2006).

\begin{tabular}{|c|c|c|c|c|c|c|c|c|c|c|c|}
\hline $\begin{array}{l}\text { Site and Time } \\
\text { Period }\end{array}$ & $\begin{array}{l}\text { Vol. } \\
\text { cu. m }\end{array}$ & $\begin{array}{c}\mathrm{N} \\
\mathrm{Cu}\end{array}$ & $\begin{array}{c}\mathrm{N} \\
\text { Iron }\end{array}$ & $\begin{array}{c}\mathrm{N} \\
\text { Bead }\end{array}$ & $\begin{array}{c}\mathrm{N} \\
\text { Bone }\end{array}$ & $\begin{array}{c}\text { Trade Sum } \\
\text { N }\end{array}$ & $\begin{array}{l}\text { Total } \\
\text { Wt g }\end{array}$ & $\begin{array}{l}\text { Total N } \\
\text { Density }\end{array}$ & $\begin{array}{l}\text { Bead N } \\
\text { Density }\end{array}$ & $\begin{array}{l}\text { Weight } \\
\text { Density }\end{array}$ & $\begin{array}{c}\% \\
\mathrm{Cu}\end{array}$ \\
\hline DD Period 0 & 6.752 & 11 & 232 & 27 & 6 & 276 & 145.87 & 40.88 & 4.00 & 21.604 & .04 \\
\hline DD Period 1 & 12.514 & 44 & 96 & 32 & 6 & 187 & 51.65 & 14.94 & 2.56 & 4.127 & .23 \\
\hline DD Period 2 & 5.229 & 15 & 55 & 0 & 7 & 77 & 33.42 & 14.73 & 0.00 & 6.391 & .19 \\
\hline DD Period 3 & 27.191 & 48 & 8 & 1 & 3 & 58 & 6.91 & 2.13 & 0.04 & 0.254 & .83 \\
\hline Boley Period 1 & 3.319 & 10 & 17 & 3 & 11 & 41 & 6.28 & 12.35 & 0.90 & 1.892 & .24 \\
\hline Boley Period 2 & 0.861 & 0 & 2 & 0 & 0 & 2 & 0.40 & 2.32 & 0.00 & 0.465 & .00 \\
\hline Boley Period 3/4 & 2.878 & 4 & 1 & 0 & 1 & 6 & 0.93 & 2.08 & 0.00 & 0.323 & .67 \\
\hline Larson & 14.306 & 6 & 1 & 1 & $\mathbf{0}$ & 8 & 0.52 & 0.56 & 0.07 & 0.036 & .75 \\
\hline
\end{tabular}

Very few trade artifacts were recovered from the contexts investigated at Larson (see Chapter 12). All of the trade materials from unmixed loci consist of rolled cuprous tubes or beads or irregular sheets. A single glass bead and one fragment of possible trade iron were recovered from undifferentiated plowzone deposits. No cutmarks made by metal tools were observed on any of the modified or unmodified vertebrate remains (see Chapters 9 and 10). These data indicate, minimally, that the features excavated at Larson were abandoned and filled before 1650. However, 
it is possible that some or all of the cuprous artifacts in the 2006 Larson collection were made from native copper. If so, features on the northern periphery of the site, including the two outer fortification ditches, likely predate 1600 .

Radiocarbon Dates. In the Heart region, radiocarbon dating has been used to establish the founding dates for many settlements. To be meaningful, radiocarbon ages, expressed as radiocarbon years before 1950 (B.P.), must be converted to calendar dates. Two calibration programs are available for doing so, CALIB (Stuiver and Reimer 1993) and OxCal (Bronk Ramsey 2005). Both use a correction or calibration curve derived from radiocarbon ages measured on wood samples of known age. The curve for the period after about 1650 is very irregular and as a result radiocarbon samples younger than that (about 250 B.P.) produce essentially uninterpretable results. In addition, prior to 1650 , the calibration curve exhibits periodic "plateaus” or "reversals.” During these periods, variations in the atmospheric concentration of ${ }^{14} \mathrm{C}$ result in samples of different ages having the same ${ }^{14} \mathrm{C}$ content and therefore the same radiocarbon age. As previously mentioned, European trade goods probably first appeared in the Heart region about 1600 . So, by coincidence, the presence of copper, iron, or glass artifacts signals that a context probably dates to the period for which radiocarbon dating will not produce useful results. For this reason, samples have generally been selected from contexts lacking trade goods. However, as will be discussed in more detail below, a calibration plateau stretching from about 1500 to 1600 further complicates the interpretation of radiocarbon dates from Larson and other Heart region villages.

\section{Analytic Units}

This section briefly discusses each of the 20 analytic units into which the provenience lots recovered during the 2006 fieldwork have been grouped. Data on each unit are summarized in Table 6.2

\section{Mixed Contexts}

Plowzone. Stratigraphic evidence for a 15- to 20-cm thick plowzone was observed in all six excavation blocks. The two uppermost general levels of each unit are considered an undifferentiated mixed deposit and are assigned to a plowzone locus.

Mixed. During the course of waterscreening, artifacts from Block A (GL1, $0.1 \mathrm{cu}$. m) were inadvertently mixed with artifacts from Ditch 3 ( $4 / 5^{\text {ths }}$ of GL2, $0.24 \mathrm{cu}$. m). Had they not been combined, all of these artifacts would have been assigned to the Plowzone locus.

\section{Contained and Uncontained Deposits}

Ditch 4. Materials from Ditch 4 are divided into three loci. General levels 2 through 4 are assigned to the Ditch 4 Midden locus. Based on stratigraphic data, the contents of GL5 are added to feature levels 1 through 9 and together this aggregate is divided into two loci, Ditch 4, UP and Ditch 4, LO. All of the Ditch 4 deposits are considered to be uncontained. All three are assigned to the earliest stratigraphic position, based mainly on their location within the site. 
Ditch 3. Materials from Ditch 3 are separated in similar fashion. The overlying midden deposits are assigned to the Ditch 3 Midden locus and the two lowermost general levels and all 15 feature levels are assigned to one of two feature loci. As in Ditch 4, all of the Ditch 3 deposits are uncontained. However, they are comparatively artifact rich and therefore are classified as midden, rather than midden and earth, deposits. Feature loci (Ditch 3, LO and Ditch 3, UP) are assigned to Stratigraphic Group 2 while the Ditch 3 Midden locus is assigned to Stratigraphic Group 3.

Blocks $A, D$, and $F$. A similar approach was used to organize artifacts and samples from each of these three blocks into loci. In each case the general levels below the plowzone are combined into block-specific midden loci (e.g. Block A Midden). The content of each of the excavated features is assigned to a separate locus. The uncontained midden deposits are included in Stratigraphic Group 3 and the contained pit deposits (both large and small) are included in Stratigraphic Group 2.

Block $G$. All of the general levels below the plowzone are combined into a single locus, Block $G$ Midden. The deposits are classified as midden and earth and are assigned along with Ditch 4 to Stratigraphic Group 1.

Table 6.2. Summary data on analytic units, 2006 PCRG Larson Village excavations.

\begin{tabular}{|c|c|c|c|c|c|c|c|}
\hline Locus & Area & Levels & Deposit Type & Vol. & $\begin{array}{l}\text { Strat. } \\
\text { Group }\end{array}$ & Copper & ${ }^{14} \mathrm{C}$ Date \\
\hline Ditch 4 Midden & Ditch 4 & GL2-4 & Midden & 0.900 & 1 & no & no \\
\hline Ditch 4, UP & Ditch 4 & $\begin{array}{l}\text { GL5 } \\
\text { FL1-4 }\end{array}$ & $\begin{array}{l}\text { Midden and } \\
\text { earth }\end{array}$ & 1.247 & 1 & no & no \\
\hline Ditch 4, LO & Ditch 4 & FL5-9 & $\begin{array}{l}\text { Midden and } \\
\text { earth }\end{array}$ & 0.796 & 1 & no & yes (2-FL7) \\
\hline Ditch 3 Midden & Ditch 3 & $\begin{array}{c}\text { GL3-4 } \\
\text { FL1 }\end{array}$ & Midden & 0.836 & 3 & no & no \\
\hline Ditch 3, UP & Ditch 3 & $\begin{array}{l}\text { FL2-6 } \\
\text { GL3-4 }\end{array}$ & Midden & 1.451 & 2 & no & no \\
\hline Ditch 3, LO & Ditch 3 & FL7-15 & Midden & 1.821 & 2 & yes & yes (2-FL15) \\
\hline Block A Midden & Block A & GL3-5 & Midden & 0.600 & 3 & no & no \\
\hline Pit F109 & Block A & FL1-7 & Pit & 0.505 & 2 & no & $\begin{array}{c}\text { yes (1-FL4, } \\
1 \text {-FL5) }\end{array}$ \\
\hline Pit F111 & Block A & FL1 & Small pit & 0.006 & 2 & no & no \\
\hline Pit F108 & Block A & FL1 & Small pit & 0.011 & 2 & no & no \\
\hline Block D Midden & Block D & GL3-6 & Midden & 0.800 & 3 & no & no \\
\hline Pit F101 & Block D & FL1 & Small pit & 0.003 & 2 & no & no \\
\hline Pit F102 & Block D & FL1 & Small pit & 0.001 & 2 & no & no \\
\hline Pit F103 & Block D & FL1-4 & Small pit & 0.064 & 2 & no & no \\
\hline Block F Midden & Block F & GL3-4 & Midden & 0.400 & 3 & no & no \\
\hline Pit F104 & Block F & FL1 & Small pit & 0.044 & 2 & no & no \\
\hline Pit F107 & Block F & FL1-11 & Pit & 0.901 & 2 & yes & yes (2-FL10) \\
\hline Block G Midden & Block G & GL3-11 & $\begin{array}{l}\text { Midden and } \\
\text { earth }\end{array}$ & 1.585 & 1 & yes & no \\
\hline Mixed & Block A/D & GL1-2 & Mixed & 0.340 & $\mathrm{n} / \mathrm{a}$ & no & no \\
\hline Plowzone & All & GL1-2 & Undiff. & 1.995 & $\mathrm{n} / \mathrm{a}$ & no & no \\
\hline
\end{tabular}




\section{Radiocarbon Dating}

Eight radiocarbon samples from four excavation loci were submitted for pretreatment and AMS dating at the University of Arizona (Haas 2007). Provenience and other data on the samples are provided in Table 6.3. Each chosen sample consists of a short-lived cultigen associated directly with the occupation of the village. To assess the integrity of the excavated contexts and to check for radiocarbon lab errors, sample contamination, or other sources of error, paired samples from each of the excavation contexts were selected for dating. Based on stratigraphic and other data observed in the field it was thought that Ditch 4 was likely to be the earliest feature sampled. Suitable samples were not available from the lowest feature level (FL9), but two were selected from FL7 (120-130 SD), at the base of second oldest stratigraphic unit filling the ditch. No cuprous artifacts were recovered from Ditch 4, but an apparently cognate stratum in Block G did contain an irregular copper sheet. Two samples were available from the lowest feature level (FL15) in Ditch 3. Based on its spatial relationship to Ditch 4, Ditch 3 was thought to be more recent. Two irregular copper sheets were recovered from the fill of Ditch 3 (FL8).

Table 6.3. Provenience and other data for samples submitted for AMS radiocarbon dating from the 2006 fieldwork at Larson Village.

\begin{tabular}{|c|c|c|c|c|c|c|c|}
\hline $\begin{array}{l}\text { Sample } \\
\text { No. }\end{array}$ & Cat. No. & Block & Feature & FL & $\begin{array}{c}\text { Depth } \\
\text { (cmsd) }\end{array}$ & Material & Context \\
\hline 1 & 1070 & Ditch 4 & 106 & 7 & $120-130$ & Charred maize kernel & $\begin{array}{l}\text { Lower ditch } \\
\text { fill }\end{array}$ \\
\hline 2 & 1070 & Ditch 4 & 106 & 7 & $120-130$ & Charred maize kernel & $\begin{array}{l}\text { Lower ditch } \\
\text { fill }\end{array}$ \\
\hline 3 & 1095 & Ditch 3 & 105 & 15 & $190-206$ & Charred maize cob & $\begin{array}{l}\text { Lower ditch } \\
\text { fill w/ cu }\end{array}$ \\
\hline 4 & 1095 & Ditch 3 & 105 & 15 & $190-206$ & Charred maize kernel & $\begin{array}{l}\text { Lower ditch } \\
\text { fill w/cu }\end{array}$ \\
\hline 5 & 1093 & Block F & 107 & 10 & $130-140$ & Charred maize cupule & Pit fill w/ cu \\
\hline 6 & 1093 & Block F & 107 & 10 & $130-140$ & Charred maize cob & Pit fill w/ cu \\
\hline 7 & 1076 & Block A & 109 & 5 & $90-100$ & Charred maize kernel & Pit fill \\
\hline 8 & 1071 & Block A & 109 & 4 & $80-90$ & Charred maize kernel & Pit fill \\
\hline
\end{tabular}

Two cache pits also were selected for dating. Two samples were chosen from the lowest excavated level of pit F107. (The bottom of the pit was not reached during excavation [see Chapter 4]). A copper bead and a copper sheet were recovered from the fill of the pit. Two samples also were chosen from pit F109. Maize remains sufficiently large for dating were not available from the lowest level, but one kernel each was selected from FL4 and FL5. No cuprous artifacts were recovered from F109, but based on stratigraphic data it was thought likely that this pit was among the most recent features excavated in 2006.

The selected samples were pretreated and prepared for AMS dating by Dr. Herbert Haas of RC Consultants, Inc. All eight samples consisted of chemically robust charcoal and contained only small amounts of organic contamination, which was completely extracted during pretreatment (Haas 2007). Haas submitted the samples for AMS dating to the University of Arizona accelerator in Tucson. Tables 6.4 and 6.5 display the results, which are presented and evaluated using the OxCal (v3.10) program (Bronk Ramsey 2005). 
Table 6.4. Results of AMS radiocarbon dating for eight samples from Larson Village analyzed by the University of Arizona.

\begin{tabular}{lcccccc}
\hline & \multicolumn{3}{c}{$\begin{array}{c}\text { Corrected } \\
\text { Age }\end{array}$} \\
Feature & Sample No. & Arizona No. & $\begin{array}{c}\text { (B.P.) } \\
\delta^{13} /{ }_{12} \mathrm{C}\end{array}$ & $\begin{array}{c}\text { Weighted } \\
\text { Statistics }\end{array}$ & $\begin{array}{c}\text { Mean Age } \\
\text { (B.P.) }\end{array}$ \\
\hline Ditch 4 & $1 \_1070$ & AA73000 & $306 \pm 33$ & $-9.6 \pm 0.1$ & $\mathrm{df}=1, \mathrm{~T}=4.5$ & \\
& $2 \_1070$ & AA73001 & $409 \pm 36$ & $-9.2 \pm 0.1$ & $(5 \%, 3.8) ;$ Fail & n/a \\
\hline Ditch 3 & 3_1095 & AA73002 & $396 \pm 33$ & $-9.9 \pm 0.1$ & $\mathrm{df}=1, \mathrm{~T}=1.7$ & \\
& $4 \_1095$ & AA73003 & $335 \pm 33$ & $-8.7 \pm 0.1$ & $(5 \%, 3.8) ;$ Pass & $366 \pm 23$ \\
\hline Feature 107 & 5_1093 & AA73004 & $340 \pm 33$ & $-9.8 \pm 0.1$ & $\mathrm{df}=1, \mathrm{~T}=0.0$ & \\
& $6 \_1093$ & AA73005 & $343 \pm 33$ & $-10.2 \pm 0.1$ & $(5 \%, 3.8) ;$ Pass & $342 \pm 23$ \\
\hline Feature 109 & 7_1076 & AA73006 & $334 \pm 34$ & $-8.7 \pm 0.1$ & $\mathrm{df}=1, \mathrm{~T}=2.0$ & \\
& 8_1071 & AA73007 & $401 \pm 33$ & $-8.3 \pm 0.1$ & $(5 \%, 3.8) ;$ Pass & $369 \pm 24$ \\
\hline
\end{tabular}

To evaluate the integrity of the excavated contexts, radiocarbon age pairs from each locus were first compared. Chi-square tests indicate that pairs from Ditch 3, pit F107, and pit F109 are statistically equivalent, meaning that the samples derive from the same population. Accordingly, these sample pairs can be combined, yielding a weighted mean age for each locus with a somewhat smaller standard deviation. The chi-square test for the combination of all six ages indicates that they are internally consistent and can themselves be combined, yielding a weighted mean age of $359 \pm 14$ (df=5, $\mathrm{T}=4.5[5 \%, 11.1])$. The two samples from Ditch 4 are not internally consistent (do not derive from the same population), an unsurprising result given that they include the youngest and the oldest in the series. This result bolsters the conclusion that Ditch 4 was filled rapidly, using sediment from more than one source (see Chapter 4).

As mentioned previously, to compare and interpret corrected ${ }^{14} \mathrm{C}$ ages in terms of calendar dates they must be calibrated against a tree-ring chronology. Table 6.5 presents data on calibrated calendar dates for each of the eight radiocarbon samples and for the calculated mean ages. The oldest sample (AA73001, from Ditch 4) very likely dates to the fifteenth century. One sample from Ditch 3 and one sample from F109 are only slightly younger. By themselves these dates suggest that Larson may have been founded sometime in the 1400s. However, the calibrated distributions of the remaining uncombined dates are very nearly rectangular, meaning that the true ages of the

Table 6.5. Calibration data for eight radiocarbon samples and calculated weighted means, 2006 excavations at Larson Village.

\begin{tabular}{lcccc}
\hline Feature & AZ No. & $\begin{array}{c}\text { Corrected Age } \\
\text { (B.P.) }\end{array}$ & $\begin{array}{c}\text { Calendar Date Range } \\
(1-\sigma)\end{array}$ & $\begin{array}{c}\text { Calendar Date Range } \\
(2-\sigma)\end{array}$ \\
\hline Ditch 4 & AZ73000 & $306 \pm 33$ & $1521(51.0 \%) 1591$ & $1482(95.4 \%) 1653$ \\
Ditch 4 & AA73001 & $409 \pm 36$ & $1620(17.2 \%) 1644$ & $1438(59.6 \%) 1494$ \\
& & & $1602(8.6 \%) 1615$ & $1430(75.8 \%) 1523$ \\
\hline Ditch 3 & AA73002 & $396 \pm 33$ & $1444(56.7 \%) 1495$ & $1472(19.6 \%) 1629$ \\
\hline & & & $1601(11.5 \%) 1615$ & $1570(24.5 \%) 1631$ \\
Ditch 3 & AA73003 & \multirow{2}{*}{$335 \pm 33$} & $1491(21.9 \%) 1528$ & $1471(95.4 \%) 1642$ \\
& & & $1551(32.2 \%) 1603$ & \\
& & & $1610(14.1 \%) 1633$ & \\
\hline
\end{tabular}


Table 6.5. Calibration data for eight radiocarbon samples and calculated weighted means, 2006 excavations at Larson Village (concluded).

\begin{tabular}{|c|c|c|c|c|}
\hline Feature & AZ No. & $\begin{array}{l}\text { Corrected Age } \\
\text { (B.P.) }\end{array}$ & $\begin{array}{l}\text { Calendar Date Range } \\
(1-\sigma)\end{array}$ & $\begin{array}{c}\text { Calendar Date Range } \\
(2-\sigma)\end{array}$ \\
\hline \multirow[t]{3}{*}{ F107 } & AA73004 & $340 \pm 33$ & $1489(23.3 \%) 1526$ & 1469 (95.4\%) 1640 \\
\hline & & & 1556 (30.2\%) 1603 & \\
\hline & & & 1608 (14.1\%) 1632 & \\
\hline \multirow[t]{2}{*}{ F107 } & AA73005 & $343 \pm 33$ & 1486 (24.0\%) 1526 & 1465 (95.4\%) 1640 \\
\hline & & & $1556(44.2 \%) 1632$ & \\
\hline \multirow[t]{3}{*}{ F109 } & AA73006 & $334 \pm 34$ & $1492(20.9 \%) 1528$ & $1470(95.4 \%) 1642$ \\
\hline & & & 1544 (34.1\%) 1602 & \\
\hline & & & 1611 (13.1\%) 1633 & \\
\hline \multirow[t]{2}{*}{ F109 } & AA73007 & $401 \pm 33$ & 1442 (57.9\%) 1494 & 1435 (73.8\%) 1523 \\
\hline & & & $1601(10.3 \%) 1615$ & $1572(21.6 \%) 1630$ \\
\hline \multirow[t]{2}{*}{ Ditch 3 Mean } & -- & $366 \pm 23$ & $1460(46.9 \%) 1520$ & 1450 (55.1\%) 1530 \\
\hline & & & 1590 (21.3\%) 1620 & $1550(40.3 \%) 1640$ \\
\hline \multirow{2}{*}{ F107 Mean } & -- & $342 \pm 23$ & $1490(23.1 \%) 1530$ & $1470(95.4 \%) 1640$ \\
\hline & & & 1550 (45.1\%) 1640 & \\
\hline \multirow[t]{2}{*}{ F109 Mean } & -- & $369 \pm 24$ & $1450(49.4 \%) 1520$ & $1440(57.6 \%) 1520$ \\
\hline & & & 1590 (18.8\%) 1620 & $1550(37.8 \%) 1640$ \\
\hline \multirow[t]{2}{*}{ 6-date Mean } & -- & $359 \pm 14$ & $1470(42.6 \%) 1520$ & $1460(55.2 \%) 1530$ \\
\hline & & & 1590 (25.6\%) 1620 & $1550(40.2 \%) 1630$ \\
\hline
\end{tabular}

samples are nearly equally likely to fall in any year between about 1500 and 1625 . The calibrated distributions of the weighted mean dates all exhibit a bi-modal pattern, with about half of the distribution falling around 1500 and half falling around 1600.

A feature of the OxCal program provides a mechanism for further evaluating the calibrated date distributions of the calculated mean ages. Using the R_Simulate function, it is possible to predict the radiocarbon measurements that could be expected from a sample of known age, given a likely lab error factor. By combining (using the R_Combine function) multiple simulated radiocarbon determinations on samples of the same known date it is possible to closely approximate the shape of the calibrated date distribution characteristic of that date. Actual date distributions can then be compared visually to the simulated distributions. Figure 6.1 illustrates the calibrated date distribution for the six-sample calculated mean from Larson, along with distributions for nine simulated ages spanning the period between 1450 and 1650. Additional data on the age simulations are provided in Table 6.6.

Table 6.6. Ages and calibrated date ranges for simulated radiocarbon measurements on samples of known date. Thirty simulated dates were combined to obtain the ${ }^{14} \mathrm{C}$ age for each target date.

\begin{tabular}{|c|c|c|c|c|}
\hline Target Date & $\begin{array}{l}{ }^{14} \mathrm{C} \\
\text { Age }\end{array}$ & $\begin{array}{c}\text { Calendar Date Range } \\
(1-\sigma)\end{array}$ & $\begin{array}{c}\text { Calendar Date Range } \\
(2-\sigma)\end{array}$ & $\mathrm{X}^{2}$ Test Statistics \\
\hline 1450 & $411 \pm 6$ & 1445 (68.2\%) 1465 & $1440(95.4 \%) 1470$ & $\mathrm{df}=29, \mathrm{~T}=28.1(5 \% 42.2)$ \\
\hline 1475 & $376 \pm 6$ & $\begin{array}{l}1460(55.9 \%) 1490 \\
1600(12.3 \%) 1610\end{array}$ & $\begin{array}{l}1450(76.2 \%) 1510 \\
1600(19.2 \%) 1620\end{array}$ & $\mathrm{df}=29, \mathrm{~T}=27.8(5 \% 42.2)$ \\
\hline 1500 & $346 \pm 6$ & $\begin{array}{l}1480(38.8 \%) 1530 \\
1570(29.4 \%) 1620\end{array}$ & $\begin{array}{l}1480(45.0 \%) 1530 \\
1550(50.4 \%) 1640\end{array}$ & $\mathrm{df}=29, \mathrm{~T}=26.7(5 \% 42.2)$ \\
\hline
\end{tabular}


Table 6.6. Ages and calibrated date ranges for simulated radiocarbon measurements on samples of known date. Thirty simulated dates were combined to obtain the ${ }^{14} \mathrm{C}$ age for each target date (concluded).

\begin{tabular}{|c|c|c|c|c|}
\hline Target Date & $\begin{array}{l}{ }^{14} \mathrm{C} \\
\text { Age }\end{array}$ & $\begin{array}{c}\text { Calendar Date Range } \\
(1-\sigma)\end{array}$ & $\begin{array}{c}\text { Calendar Date Range } \\
(2-\sigma)\end{array}$ & $\mathrm{X}^{2}$ Test Statistics \\
\hline \multirow[t]{2}{*}{1525} & $330 \pm 6$ & 1555 (49.4\%) 1595 & $1490(16.7 \%) 1530$ & $\mathrm{df}=29, \mathrm{~T}=28.2(5 \% 42.2)$ \\
\hline & & $1615(18.8 \%) 1635$ & $1540(78.7 \%) 1640$ & \\
\hline \multirow[t]{2}{*}{1550} & $319 \pm 6$ & $1520(61.1 \%) 1590$ & $1520(80.2 \%) 1600$ & $\mathrm{df}=29, \mathrm{~T}=28.4(5 \% 42.2)$ \\
\hline & & $1620(7.1 \%) 1640$ & $1610(15.2 \%) 1640$ & \\
\hline \multirow[t]{2}{*}{1575} & $330 \pm 6$ & 1555 (49.6\%) 1595 & $1490(17.0 \%) 1530$ & $\mathrm{df}=29, \mathrm{~T}=29.8(5 \% 42.2)$ \\
\hline & & 1615 (18.6\%) 1635 & $1540(78.4 \%) 1640$ & \\
\hline \multirow[t]{2}{*}{1600} & $343 \pm 6$ & $1490(33.8 \%) 1530$ & $1480(38.7 \%) 1530$ & $\mathrm{df}=29, \mathrm{~T}=22.0(5 \% 42.2)$ \\
\hline & & $1570(34.4 \%) 1630$ & $1550(56.7 \%) 1640$ & \\
\hline \multirow[t]{3}{*}{1625} & $333 \pm 6$ & 1510 (6.8\%) 1530 & $1490(20.9 \%) 1530$ & $\mathrm{df}=29, \mathrm{~T}=29.7(5 \% 42.2)$ \\
\hline & & 1550 (43.8\%) 1600 & 1550 (74.5\%) 1640 & \\
\hline & & $1610(17.6 \%) 1640$ & & \\
\hline 1650 & $247 \pm 6$ & $1645(68.2 \%) 1660$ & $1645(95.4 \%) 1665$ & $\mathrm{df}=29, \mathrm{t}=29.6(5 \% 42.2)$ \\
\hline
\end{tabular}

The simulation exercise shows that calendar dates around 1500 and 1600 produce strongly bi-modal distributions, but that dates in the sixteenth-century produce complex, multi-modal distributions. Dates before and after the calibration "plateau,” in 1450 and 1650, produce discrete,

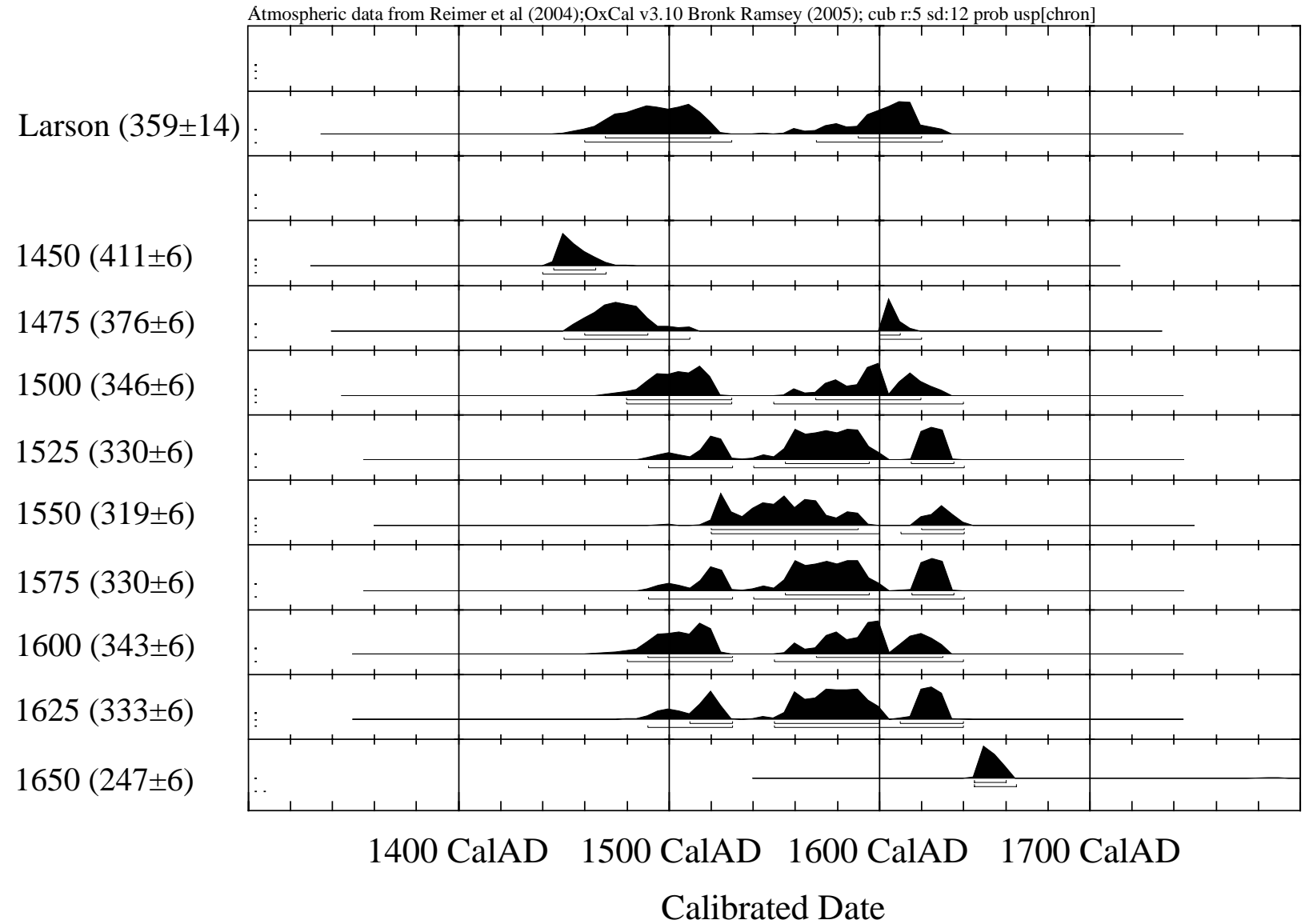

Figure 6.1. Calibrated radiocarbon date distributions for Larson Village (six sample calculated weighted mean) and nine simulated dates. Additional data on simulated dates are presented in Table 6.6. 
uni-modal distributions. Thus, the distribution of the six-date mean very likely reflects a true date of about 1500 or 1600 . Unfortunately, the radiocarbon determinations alone do not provide a basis for determining which of these peaks is more probable, although the early Ditch 4 date supports the former.

\section{Tree-ring Dates}

In the 1940’s, George Will (1946) worked out a master tree-ring chronology for the Heart region, which he applied to archaeological wood samples from a series of earthlodge villages, including Larson. The validity of Will's chronology has not been established and in fact there are reasons to believe that it contains significant errors. Specifically, the dates he obtained on architectural timbers from Huff Village suggest that his chronology may be too recent. Radiocarbon dating securely places the occupation in the middle decades of the fifteenth century (Ahler and Kvamme 2000), but most of Will's tree ring samples date to the early sixteenth century. Will's dates from Larson are presented in Table 6.7. The provenience of the dated logs is not known, but they may derive from excavations Will and Thad Hecker carried out just south of the settlement's central core, near the point at which the southern limb of Ditch 2 intersects the terrace edge. If so, the dates may accurately reflect the age of this portion of the site.

Table 6.7. Tree-ring dates on architectural timbers from Larson Village (Will 1946:13).

\begin{tabular}{cccc}
\hline Sample No. & Species & Log Diameter (Inches) & Date \\
\hline 1 & Oak & n/a & 1641 \\
2 & Oak & 4.5 & 1615 \\
3 & n/a & 7.5 & 1618 \\
4 & Oak & 7 & 1635 \\
5 & n/a & n/a & 1613 \\
6 & n/a & n/a & 1637 \\
\hline
\end{tabular}

\section{Discussion}

Several lines of non-radiometric evidence are available to assess the results of the radiocarbon dating effort. The presence of cuprous artifacts in the deposits, coupled with the paucity of iron artifacts and glass beads, seems to suggest that the excavated features were filled between 1600 and 1650, equivalent to Time Period 3 at Double Ditch Village. Some aspects of the Larson pottery assemblage (which is discussed in detail in Chapter 7) also could be construed to support an early seventeenth century date. For example, Knife River ware is a comparatively uncommon constituent of the pre-1600 Heart region ceramic assemblages studied to date. At Larson, just over one-fifth of the studied rims can be classified as Knife River ware and it occurs in nearly every excavated context. At Double Ditch, about 16 to 17 percent of the Time Period 3 assemblage consists of Knife River ware vessels.

However, the Larson pottery assemblage also includes types thought to have been produced well before 1600. About 4 percent of the assemblage consists of straight rim vessels lacking braces, a rim form common in fifteenth and sixteenth century assemblages. Sanger ware, an S-rim type that dominates pottery assemblages dating to the late 1400s and early 1500s, makes up as much as 14 
percent of the Larson assemblage. The pottery from Larson also includes a large number of toolimpressed straight-rim vessels (both with and without braces) and a relatively large number of vessels bearing trailed decoration on the upper body. Both decorative techniques are relatively uncommon in Heart region assemblages post-dating 1500. At Double Ditch, decorated body sherds are more common in earlier contexts, but overall they are not as abundant as they appear to be in the Larson sample. Trailed decoration also is comparatively uncommon in the early assemblages at Slant and Scattered villages.

Data derived from the geophysical survey (see Chapter 3) also support a pre-1600 date for the founding of Larson Village. The regular spacing of bastions evident in the design of Ditch 4 is a common feature of fortifications built during the 1400s. Bastions appear to have been used less frequently and less consistently in later fortification systems, although they were used in some defensive works built during the 1600s and later.

Thus, clear archaeological evidence supporting either of the two dating possibilities presented by the radiocarbon data is lacking. Several scenarios may account for this apparent ambiguity. First, the contexts sampled during 2006 may contain mixed secondary deposits of materials dating to more than one period. This might especially be true of the fortification ditches, and in particular Ditch 4 given the non-contemporaneity of the associated radiocarbon dates. The fill of Ditch 3, which was deposited incrementally over time, may have originated in mounds or sheet middens of different ages. The fill of Ditch 4, which appears to have been deposited intentionally and rapidly, also may have been transported from several sources of different ages. In both cases fifteenth- or sixteenth-century pottery could easily have become commingled with seventeenth-century pottery and cuprous trade artifacts. Data discussed in chapters 7 and 8 indicate that the ditches (but probably not the cache pits) on the northern periphery of the village are in fact filled with secondary deposits. However, these data also suggest that the potential for temporal mixing is relatively low.

Alternatively, the sampled deposits may in fact date to the early seventeenth century, as apparently indicated by the presence of copper beads and sheets, and the character of the ceramic assemblage may simply reflect unexpected and previously unrecognized complexity in Heart region pottery. However, it is both logical and possible that the cuprous artifacts are not European trade items at all, but rather were made from North American copper by native craftsman. If so, the sampled deposits could easily date to 1500. Data on the elemental composition of the cuprous artifacts will be required to sort out these competing hypotheses.

The preponderance of available archaeological evidence, especially data on village fortifications, stratigraphy, and ceramic style, seems to support the earlier of the two date ranges obtained from the interpretation of the radiocarbon data. However, this conclusion is far from persuasive and additional information (such as compositional data on metal artifacts or dates derived from an independent chronometric method) will be necessary to firmly establish the age of the village.

\section{Summary}

Data on the material remains recovered during the 2006 field effort are organized and 
presented in the following chapters in terms of the relative ages, spatial locations, and depositional types of the defined excavation loci (see Table 6.2). The most straightforward data presentation groups loci according to excavation block, and basic information on most material classes is organized in this way. Interpretations on the kinds of formation processes affecting the investigated deposits rely on data organized according to deposit type. Three general and six specific deposit types are recognized. These include contained (large and small pits), uncontained (midden and midden and earth strata), and mixed (undifferentiated and inadvertently mixed) deposits. The relative temporal relationships among loci are expressed in terms of three stratigraphic groups. Group 1 is the earliest and includes Ditch 4 and Block G. Group 2 is more recent and includes Ditch 3 and all of the features encountered in Blocks A, D, and F. Group 3 includes all of the midden deposits overlying Ditch 3 and the features and surfaces in Blocks A, D, and F. Mixed deposits are not assigned to a temporal group. Given the overall ceramic similarities among these groups it is likely that relatively little time is represented by them.

In terms of absolute chronology, all of the intact contexts investigated at Larson Village in 2006 are assigned to a rather broad temporal period spanning time periods 3 and 4 at Double Ditch (1500-1650). Although the earlier portion of this range seems most probable, a more precise chronology must await additional research. 


\section{References Cited}

Ahler, Stanley A.

2006 Radiocarbon Dating, Site Chronology, and Analytic Units. In Geophysical Survey and Test Excavation During 2005 at Boley Village (32MO37), North Dakota, edited by Stanley A. Ahler, pp. 71-75. Research Contribution No. 74. PaleoCultural Research Group, Flagstaff, Arizona. Submitted to the State Historical Society of North Dakota, Bismarck.

Ahler, Stanley A., and Amy Drybred

1993 Analysis of Euroamerican Trade Artifacts. In The Phase I Archaeological Research Program for the Knife River Indian Villages National Historic Site: Part III Analysis of the Physical Remains, edited by Thomas D. Thiessen, pp. 289-340. Occasional Studies in Anthropology No. 27. National Park Service, Midwest Archaeological Center, Lincoln, Nebraska.

Ahler, Stanley A., and Kenneth L. Kvamme

2000 New Geophysical and Archaeological Investigations at Huff Village State Historic Site (32MO11), Morton County, North Dakota. Research Contribution No. 26. PaleoCultural Research Group, Flagstaff, Arizona. Submitted to the State Historical Society of North Dakota, Bismarck.

Bronk Ramsey, Christopher

2005 OxCal Program v3.10. Oxford Radiocarbon Accelerator Unit, Research Lab for Archaeology, Oxford University. Available at www.rlaha.ox.ac.uk/O/index.php

Haas, Herbert

2007 Letter Report on Radiocarbon Dating Results, Larson Village, 32BL9, April 12, 2007. Ms. on file, PaleoCultural Research Group, Flagstaff, Arizona.

Stuiver, Mintze, and P. J. Reimer

1993 Extended ${ }^{14} \mathrm{C}$ Data Base and Revised CALIB $3.0{ }^{14} \mathrm{C}$ Age Calibration Program. Radiocarbon 35:215-230.

Will, George F.

1946 Tree Ring Studies in North Dakota. Bulletin 338. Agricultural Experiment Station, North Dakota Agricultural College, Fargo. 


\title{
7. Pottery Analysis
}

\author{
Mark D. Mitchell, Stacey Madden, and Stanley A. Ahler
}

\section{Introduction}

This chapter describes the methods used in the analysis of ceramic remains recovered during the 2006 excavations, briefly discusses the morphological and decorative characteristics of the pottery types that make up the collection, sketches several typological problems raised by the collection, and presents data on the distribution and form of various ceramic classes. Data on the size and density of ceramic remains also are used to assess the nature of the formation processes to which the 2006 collection has been subjected. The detailed analysis emphasizes ceramic attributes thought to be the most sensitive temporal indicators. The data presentation focuses on describing the ceramic content of the 2006 Larson collection and on synchronic comparisons with other contemporaneous Heart region settlements. Comparisons are drawn mainly with Double Ditch and Boley villages, and to a lesser degree with Scattered and Slant villages. To simplify the presentation of the comparative data, Table 7.1 provides references to ceramic data from other Heart region sites discussed in this chapter.

Table 7.1. Sources of comparative data used in the Larson Village pottery study.

\begin{tabular}{lcl}
\hline Village & Sample Size (Sherds) & Reference \\
\hline Boley (2005) & 12,464 & Ahler et al. 2006 \\
Double Ditch (2002) & $32,831^{*}$ & Ahler and Warner 2003 \\
Double Ditch (2003) & $164,018^{*}$ & Ahler and Stanford 2004 \\
Double Ditch (2004) & 99,061 & Ahler and Madden 2005 \\
Scattered (1998) & 179,303 & Ahler et al. 2002 \\
Slant (1980) & 47,419 & Speakman et al. 1997 \\
\hline
\end{tabular}

* Select or Priority 1 contexts only.

Data on rim and body sherd frequencies, body sherd surface treatment, and simple-stamp spacing were collected by Madden. Mitchell collected nominal data on rim sherd ware and variety, decorative technique, and vessel lip shape and metric data on cord spacing, cord diameter, and brace height. Mitchell performed the data analysis and wrote the chapter, based to a large degree on analytic methods and pottery type descriptions developed over the course of many projects by Ahler.

\section{Analytic Methods}

The methods used to study pottery body sherds largely replicate those applied to the 2005 ceramic sample from Boley Village (Ahler et al. 2006). Procedures for the ware and variety classification (the "quick-code system"), and for the brief attribute analysis applied to rim sherds, vary slightly from those used in earlier projects; the new methods are discussed below. For both body sherds and rim sherds the analytic approach used represents an elaboration and refinement of 
the basic system devised originally for the study of ceramic remains recovered from Hidatsa villages located in the Knife region. Recent changes to the system have been driven by the presence in Heart region ceramic assemblages of previously unknown decorative and technological features, as well by the comparatively precise temporal resolution made possible by well-controlled excavations. As each successive project has revealed new ceramic forms, new attributes have been added to the analysis system. In some cases, the definitions of particular variables or attributes have been clarified or redefined. Modifications to the system developed for the Larson Village project are discussed in some detail below.

\section{Rim and Body Sherd Separation and Quantification and Body Sherd Analysis}

Table 7.2 lists the variables and attributes used in the initial classification and quantification of ceramic remains from Larson Village. The excavated ceramic assemblage was first partitioned into four categories (CLASS), including body sherds, rim sherds, miniature vessel parts (rims and body sherds), and worked sherds. None of the ceramic remains from Larson fell into two other commonly recognized categories, slipped sherds and unidentified tempered objects. Miniature

Table 7.2. Summary of variables and attribute codes recorded in the initial inventory of ceramic remains and the study of exterior surface treatment for body sherds from Larson Village, 2006 collection.

\begin{tabular}{|c|c|c|}
\hline CAT NO & \multicolumn{2}{|l|}{ Catalog Number } \\
\hline SIZE & \multicolumn{2}{|l|}{ size grade $(1,2,3)$} \\
\hline CLASS & \multicolumn{2}{|l|}{ ceramic category } \\
\hline & 4-miniature vessel or vessel part \\
\hline & 2-rim sherd (zone 2 or higher is present) & 5-worked sherd \\
\hline \multicolumn{2}{|c|}{ 3-slipped } & 6-unknown tempered object \\
\hline \multicolumn{3}{|c|}{ PART $\quad$ part of vessel present } \\
\hline \multicolumn{2}{|c|}{ 1.1-zone 1 only (body sherd) lacking angular shoulder } & 3-zone 3 only (nothing above or below zone 3 ) \\
\hline \multicolumn{2}{|c|}{ 1.2-zone 1 only (body sherds) with angular shoulder part } & 7-zone 7 only (lip sherd only with no lower zones) \\
\hline \multicolumn{2}{|c|}{$\begin{array}{l}\text { 2.1-zone } 2 \text { only or zone } 2 \text { and } 1 \text { (neck or neck and body) lacking } \\
\text { angular shoulder }\end{array}$} & 8-multiple adjoining zones $(2+3 ; 2+7 ; 2+3+7$, etc. $)$ \\
\hline \multicolumn{3}{|c|}{$\begin{array}{l}\text { 2.2-zone } 2 \text { only or zone } 2 \text { and } 1 \text { (neck or neck and body) with } \\
\text { angular shoulder part }\end{array}$} \\
\hline \multicolumn{3}{|c|}{ OCHRE ochre residue } \\
\hline 0-none & & 4-yellow exterior \\
\hline 1-red, interior & & 6-yellow slip/wash exterior \\
\hline 2-yellow, interior & & 7-orange interior \\
\hline 3-red, exterior & & 8-purple stain interior \\
\hline SURF & \multicolumn{2}{|c|}{$\begin{array}{l}\text { body \& neck sherd (zone } 1 \text { \& } 2 \text { ) exterior surface treatment and decoration - size G1 and G2 } \\
\text { only; for bodies, record only surface treatment in zone } 1 \text {; for necks record only surface } \\
\text { treatment in zone } 2 \text { and ignore zone } 1 \text {; if decoration occurs, it takes precedence over surface } \\
\text { treatment }\end{array}$} \\
\hline \multicolumn{2}{|c|}{ Surface Treatment } & Decoration \\
\hline \multicolumn{2}{|l|}{ 1-plain / smoothed } & 6-incised (takes precedence over surface treat.) \\
\hline \multicolumn{2}{|l|}{ 2-simple-stamped } & 7-trailed (takes precedence over surface treat.) \\
\hline \multicolumn{2}{|l|}{ 3-check-stamped } & 8-cord-impressed (takes precedence over surface treat.) \\
\hline \multirow{2}{*}{\multicolumn{2}{|c|}{$\begin{array}{l}\text { 4-brushed } \\
\text { 5-cord-roughened }\end{array}$}} & 10-tool-marked (takes precedence over surface treat.) \\
\hline & & \\
\hline \multirow{2}{*}{\multicolumn{2}{|c|}{$\begin{array}{l}\text { 9-other / not determined (used for G3 body and neck sherds) } \\
\text { 11-micro-grooved simple-stamped }\end{array}$}} & blank = vessel part in zone 3 or higher \\
\hline & & 0 -indeterminate (eroded away or obscured) \\
\hline \multicolumn{3}{|c|}{ COUNT $\quad$ count of sherds having a common code on all preceding variables } \\
\hline WEIGHT & \multicolumn{2}{|c|}{ combined weight of sherds for this data case, to 0.1 gram } \\
\hline COMMENT & \multicolumn{2}{|l|}{ comments about matching, etc. } \\
\hline
\end{tabular}


vessels are here defined as relatively crude "practice" pots likely produced by children or novice potters. Miniature vessels frequently were made from clays having little or no temper and are usually undecorated.

Rim and body sherds were further classified according to the number of vessel zones present and the angularity of the vessel shoulder (PART). Each zone is a defined segment of a vessel bounded by defined inflection points or changes in the direction of curvature of the vessel wall (Ahler and Swenson 1985:5-7). Seven zones can be defined, with Zone 1 corresponding to the body of the vessel and Zone 7 corresponding to the lip. Zones 2 through 6 correspond to special features of particular ceramic forms and may or may not have been present in any particular vessel. Sherds representing Zones 1 and 2 are further subdivided according to the presence of an angular shoulder. In the samples from Double Ditch and Boley villages a minority of the vessels exhibited a sharply angular shoulder, where the curvature of the vessel wall changes abruptly from the comparatively horizontal upper part of the vessel body to the nearly vertical lower part of the vessel body. Typically a row of finger or tool impressions is located on the apex of the shoulder. Vessels of this type also are present in the Larson collection.

Neck and body sherds were further classified by exterior surface treatment and decoration (SURF) and by the presence of red or yellow ochre (OCHRE). Sherds in each sort class in size grades 1 and 2 were counted and weighed. Size grade 3 sherds in most sort classes were weighed but not counted, with estimated counts calculated using a mean per sherd weight of $0.5 \mathrm{~g}$. Neck and rim sherds in size grade 3 samples were isolated and data were recorded on surface treatment in G3 neck sherds. Surface treatment data were not recorded for G3 body sherds.

An unusual form of surface treatment known as "micro-grooved simple-stamped" is present in the Larson collection. This treatment was first observed by W. Raymond Wood (who used the term "linear check-stamping") on body sherds from the Biesterfeldt site located in the Sheyenne River valley of eastern North Dakota (Wood 1971:25), but was unknown in the Heart region until it was noted in the 2003 collection from Double Ditch Village. Since then it has been observed at Boley Village and now at Larson Village. Because it is a comparatively subtle feature it may be that it is more common in Plains Village ceramics than has been supposed. The temporal or technological significance of micro-grooved simple stamping is not known.

Previous studies have shown that the spacing of lands and grooves cut into the wooden paddles used in the manufacture of Plains Village pots varied over time, with very wide spacing present in some assemblages postdating the sixteenth century but absent in earlier assemblages. Data on stamp spacing were recorded for a sample of size grade 1 body sherds. Data were recorded only when a clear set of at least three lands and two grooves was present and when the lands and grooves were not obscured by offset or overlapping impressions. A mean center-to-center spacing value was recorded to $0.1 \mathrm{~mm}$.

Previous investigations also have recorded maximum thickness data for a sample of size grade 2 body sherds. However, such data were not collected for this project. It became clear during the analysis of Boley Village pottery that synchronic differences in body sherd thickness among Heart region sites are more significant than broad-scale temporal differences (Ahler et al.

2006:112). This result indicates that body sherd thickness data cannot be used to order Heart region ceramic assemblages in time. However, it does suggest that somewhat distinct manufacturing practices were followed in each village. 


\section{Rim Sherd Ware and Variety Analysis and Attribute Coding}

The analysis system developed for the study of ceramic remains from Hidatsa sites in the Knife region emphasized the collection of detailed attribute data on pottery vessel fragments consisting of one or more rim sherds. The comparatively limited scope of many recent Heart region projects has meant that time and resources have sometimes not been available to conduct the intensive refitting studies necessary to identify individual ceramic vessels. The limited scope of these projects also has meant that it has not always been possible to implement the complete attribute coding system. The result has been the development of a ware and variety "quick-code" analysis focused on size grade 1 and 2 rim sherds. This method resembles traditional type-variety systems, but also incorporates aspects of the more complete attribute system.

In the quick-code system, individual sherds are classified according to pottery ware and variety and data on a limited number of metric and non-metric variables are collected. When obvious refits are present within a ceramic lot they are combined into a single data case, but no substantial effort is directed toward systematic vessel matching. Variables thought to be temporally sensitive, or those that can aid in distinguishing related wares, often are chosen for detailed study. Table 7.3 lists the variables and attributes used in the study of the 2006 collection. The following paragraphs briefly describe the ceramic wares and varieties present in the Larson collection, noting especially modifications developed for this analysis.

Northern Middle Missouri ceramics are classified by according to a typological system developed initially by Don Lehmer, as modified and expanded by Stan Ahler. In Lehmer's (1954:41-42) system, pottery wares consist of groups of types sharing a range of technological characteristics, including paste, vessel form, rim form, and surface finish. Over time, a fundamental distinction has developed between S-rim wares and straight-rim wares. Within each ware, type distinctions (now, generally called "varieties”) reflect differences in dominant decorative technique and decorative patterns. There are several notable exceptions to this general approach (Ahler and Swenson 1985:24), one of which is discussed in more detail in the sections on Stanton and Knife River wares.

In the Heart region, four major S-rim wares and three major straight-rim wares have been defined, some of which have been subdivided into two or more varieties. Several "catch-all” varieties also have been defined. The following descriptions are paraphrased from more detailed descriptions provided in Ahler (2001), Ahler and Swenson (1985), and Ahler and others (2006). Illustrations depicting examples of these wares and varieties can be found in Ahler (2001) and Ahler and others (2002).

\section{S-rim Wares and Varieties}

Fort Yates Ware (Variety 1). Fort Yates ware was the dominant S-rim ware in the Heart region until about 1400, when it was supplanted by Sanger ware. It is distinguished by a comparatively tall zone 3 (relative to the height of zone 2) and an angular lower zone 3 . Cord impression is the dominant decorative technique. Cords are large and widely spaced. The most common decorative pattern consists of 3 to 6 horizontal impressions, broken by four or more angular designs arranged 
symmetrically around the rim. Lips are frequently flat rather than rounded. No Fort Yates ware rims have been identified in the 2006 Larson collection.

Sanger Ware (Variety 2). Sanger ware is chronologically and morphologically intermediate between Fort Yates ware and Le Beau ware (see below). Sanger ware is distinguished by a subangular to non-angular lower zone 3. On most Sanger ware vessels, the height of zone 2 is roughly equivalent to the height of zone 3 . Cord impression also is the dominant decorative technique, but horizontal cord impression frequency is higher, cord diameter is smaller, and the cords are more closely spaced than on Fort Yates vessels. Many Sanger ware vessels bear four equally-spaced sets of chevron-shaped cord impression. Often these chevron or angular rainbow patterns are centered around a node attached to the rim at or just below the lip. Lip shapes are more variable in Sanger ware than in Fort Yates ware. Sanger ware was most popular between 1400 and 1525.

Because Sanger ware grades into both Fort Yates ware and Le Beau ware it can be difficult to classify some rims. This problem is particularly acute when only one or two of the possible distinguishing variables are considered. The correlations among the variables defining each ware are not perfect and other factors, such as village-specific production practices, may complicate these relationships. This is especially true of cord size and impression spacing. While it is apparent that both decreased over time, cord size and impression spacing distributions for each ware overlap substantially. That is, vessels exhibiting the rim form characteristics of Le Beau ware were sometimes decorated with large, widely-spaced cords, while vessels with the characteristics of Sanger ware were sometimes decorated with smaller, more closely spaced cords.

Table 7.3. Summary of variables and attribute codes recorded in the study of 2006 rim sherd collection from Larson Village.

\begin{tabular}{lll}
\hline SIZE & largest size grade (1, 2, 3) among matched sherds \\
\hline SEQ & data case within size grade \\
\hline $\mathbf{C N}$ & catalog number for largest sherd \\
\hline RIMFORM & rim form class based on zones present and their placement \\
1-lip sherd (zone 7 only) & 15-zone 2-3 fragment (zone 2,3 only) \\
2-bowl or jar (zone 1+7 only) & 16-zone 3 fragment w/ exterior brace (zone 3,5 only) \\
3-straight or outflared rim (zone 1,2,7) & 19-lip fragment w/ exterior brace (zone 5,7) or brace frag. only (Z 5) \\
4-straight rim w/ brace (zone 1,2,5,7) & 20-zone 3 fragment (zone 3 only) \\
5-straight rim w/ fillet (zone 1,2,6,7) & 21-appendage only (no zone designation) \\
7-S-rim (zone 1,2,3,7) & 23-straight rim w/ interior brace(zone 1,2,5,7) \\
8-S-rim w/ exterior brace (zone 1,2,3,5,7) & 24-S-rim w/ interior brace(zone 1,2,3,5,7) \\
9-S-rim w/ fillet (on interior)(zone 1,2,3,6,7) & 25-recurved S-rim w/ interior brace(zone 1,2,3,4,5,7) \\
11-recurved S-rim (zone 1,2,3,4,7) & 26-zone 2-3 fragment w interior brace (zone 2,3,5) \\
12-recurved S-rim w/ exterior brace (zone1,2,3,4,5,7) & 27-lip fragment w/ interior brace (zone 5,7) \\
\multicolumn{2}{l}{ 28-S-rim w/ interior and exterior brace } \\
\hline ZONE7 & condition and shape of zone 7 \\
1-rounded & 7-pointed \\
2-flattened & 8-beaded, round \\
3-in-slanted & 10-round beaded on exterior \\
4-out-slanted & 11-round beaded on interior \\
5-L-shaped & 12-inslanted, beaded interior and exterior \\
6-T-shaped & 99-unobservable, broken away \\
\hline CRDSPC & mean horizontal parallel cord impress. spacing above zone 1, 0.1 mm \\
\hline CRDWDTH & mean cord impression width (diameter) anywhere above zone 1, 0.1 mm \\
\hline NLINES & count of parallel horizontal lines used in decoration on zone 3 \\
\hline
\end{tabular}


Table 7.3. Summary of variables and attribute codes recorded in the study of 2006 rim sherd collection from Larson Village (concluded).

\begin{tabular}{|c|c|c|}
\hline ZN5WDTH & \multicolumn{2}{|l|}{ width of brace, whole mm } \\
\hline WARE & \multicolumn{2}{|c|}{ ware classification (see Ahler and Swenson 1985 for complete list) } \\
\hline \multicolumn{2}{|c|}{ 0.0-unnamed straight rim, late or indeterminate ware } & 8-Knife River Fine ware \\
\hline \multicolumn{2}{|l|}{ 0.1-Stanton ware } & 9-Transitional ware \\
\hline \multirow{2}{*}{\multicolumn{2}{|c|}{ 1.0-unnamed S-rim, late or indeterminate ware }} & 10-Unclassifiable S-rim ware (Le Beau or Sanger) \\
\hline & 1.1-Sanger ware & 32-Le Beau Fine ware \\
\hline \multirow{2}{*}{\multicolumn{2}{|c|}{$\begin{array}{l}\text { 5-Le Beau ware } \\
\text { 6-Knife River ware }\end{array}$}} & 99-fragment, unclassifiable \\
\hline & & \\
\hline VARIETY & \multicolumn{2}{|c|}{ ware-variety classification (varieties identified in 2006 Larson collection are listed in bold.) } \\
\hline \multicolumn{2}{|l|}{ 1-Ft. Yates } & 15-Stanton \\
\hline \multirow{2}{*}{\multicolumn{2}{|c|}{$\begin{array}{l}\text { 2-Sanger } \\
\text { 3-Unnamed Early S-Rim }\end{array}$}} & 16-Unnamed Late Straight Rim without Brace \\
\hline & & 16.1-Cross-Hatched Straight or S-Rim \\
\hline \multicolumn{2}{|c|}{ 4-Le Beau Classic } & 17-Unnamed Late Straight Rim w/ Brace (usually trailed or tool edge \\
\hline \multicolumn{2}{|l|}{ 4.1-Le Beau Fine } & decorated) \\
\hline \multicolumn{2}{|c|}{ 4.2-Le Beau Classic T-Lip } & 19-Transitional \\
\hline \multicolumn{2}{|c|}{ 5-Le Beau Recurved } & 21.0-Knife River Large, lacking interior cord dec \\
\hline \multicolumn{2}{|l|}{ 6-Le Beau Sperry } & 21.1-Knife River Large, with interior cord dec \\
\hline \multicolumn{2}{|c|}{ 6.1-Le Beau Sperry Recurved } & 22.0-Knife River Intermediate, lacking interior cord dec \\
\hline \multicolumn{2}{|c|}{ 7-Le Beau High Rim } & 22.1-Knife River Intermediate, with interior cord dec \\
\hline \multicolumn{2}{|c|}{ 8-Le Beau Paddle Stamped } & 23.0-Knife River Fine, lacking interior cord dec \\
\hline \multirow{2}{*}{\multicolumn{2}{|c|}{$\begin{array}{l}\text { 9-Le Beau Plain } \\
\text { 10-Le Beau Classic } 4 \text { or } 5\end{array}$}} & 23.1-Knife River Fine, with interior cord dec \\
\hline & & 26-Rolled Rim Jar \\
\hline \multicolumn{2}{|c|}{ 11-Le Beau Sperry 6 or 6.1 (zone 3 fragments) } & 27.0-Bowl without Flange 27.1 Bowl with Flange \\
\hline \multicolumn{2}{|c|}{ 12-Unnamed Late S-Rim } & 31-Unclassifiable Zone 2/3 Fragments (indeterminate Le Beau Classic or \\
\hline \multirow{2}{*}{\multicolumn{2}{|c|}{ 14-Riggs }} & 33-Unclassifiable S-rim (indeterminate Le Beau or Sanger) \\
\hline & & 99-fragment, unclassifiable \\
\hline \multicolumn{3}{|c|}{ TYPE $\quad$ new type based on decoration only } \\
\hline & 8-cord-wrapped-tool-impressed \\
\hline \multirow{2}{*}{\multicolumn{2}{|c|}{$\begin{array}{l}\text { 1-cord impressed } \\
\text { 2-tool impressed }\end{array}$}} & 9-finger impressed \\
\hline & & 10-simple stamped (paddle stamped) \\
\hline \multicolumn{2}{|c|}{ 3-incised (includes trailed) } & 11-brushed \\
\hline \multicolumn{2}{|c|}{$\begin{array}{l}\text { 3-incised (includes trailed) } \\
\text { 4-pinched }\end{array}$} & $12-$ \\
\hline \multicolumn{2}{|l|}{ 5-filleted } & 13-multiple \\
\hline \multicolumn{2}{|l|}{ 6-punctate } & 99-unclassifiable fragment \\
\hline ILLUST & $1=$ potential for illustration & \\
\hline COUNT & number of sherds in data case & \\
\hline WEIGHT & measured to $0.1 \mathrm{~g}$ & \\
\hline COMMENT & $1=$ comment exists, recorded & outside data base on note sheets \\
\hline
\end{tabular}

This problem is evident in the analyses of pottery vessels recovered from Boley and Double Ditch villages. At both sites a small number of Sanger ware rims have been identified. Most of these consist only of zone 3 fragments and as a consequence the identification is based mainly on decorative characteristics (large, widely-spaced cord impressions) rather than on rim form characteristics. Because the deposits investigated at Larson may date to the early sixteenth century, precisely the period when Sanger ware was being replaced by Le Beau ware, we believed that it is important to distinguish typical Sanger ware rims exhibiting the morphological characteristics central to the definition of the ware from rims or rim fragments exhibiting robust decoration. We created a new variety (Variety 33, see below) to capture data on zone 3 (or zones 2 and 3) fragments that are comparatively tall and that have robust, widely-spaced cord impressions but that are too small or fragmented to permit a positive identification as Sanger ware. Thus, the criteria defining Variety 33 rims are similar to those used to designate Variety 2 rims in the Boley and Double Ditch analyses. 
Le Beau Classic (Variety 4). Chronologically, Le Beau ware first appeared in the northern Middle Missouri about 1500 or perhaps a little earlier. In Le Beau ware vessels the height of zone 3 is markedly less than the height of zone 2 and the juncture between zone 3 and zone 2 is smoothly curved. Cord impressing remains the dominant decorative technique, but impression spacing is narrow and cord sizes are small. Decorative pattern often consists of many closely-spaced horizontal cord impressions (up to 18), broken by four curvilinear "rainbow" motifs arranged symmetrically around the vessel. Frequently these curved motifs are centered on a small node. Another common zone 3 decorative pattern consists of a bounded zone filled with diagonal or zoned triangle cord lines. A variety of lip forms occur. Interior braces are common.

Le Beau Classic Fine (Variety 4.1). Le Beau Fine vessels are morphologically similar to Le Beau Classic vessels, but are much smaller. Such vessels are often highly decorated and well made.

Le Beau T-Lip (Variety 4.2). Le Beau T-lip vessels are decoratively and morphologically like Le Beau Classic vessels, but exhibit a pronounced T-shaped lip.

Le Beau Recurved (Variety 5). This variety also is decoratively similar to Le Beau Classic, but has zone 4 , or an outwardly curved addition, above zone 3 . In some cases, zone 4 is formed by the addition of an exterior brace on the upper surface of zone 3. When formed this way the interior and exterior surfaces of the vessel wall are not parallel. In other cases, zone 4 is formed by bending the vessel wall outward and in these cases the interior and exterior vessel walls are parallel to one another. These two forms have not been given separate variety designations, but in the future it may be useful to isolate them to track their temporal and spatial distributions. In the Heart region, recurved S-rim vessels appear to have been most popular during the later 1500s.

Le Beau High Rim (Variety 7). Le Beau High Rim variety is distinguished by a vertically asymmetrical upper zone 3, with the inward curvature of the vessel wall tightening progressively toward the lip. Le Beau High Rim appears to have been common at during the late 1600s at Scattered Village, where it was first identified. No High Rim variety vessels are present in the 2006 Larson collection.

Le Beau Classic/Le Beau Recurved/Le Beau T-Lip/Le Beau High Rim (Variety 10). This category includes zone 3 or zone 2 and 3 fragments that lack distinguishing features that would allow for a more specific identification, but that exhibit decorative features present in one of those four varieties.

Le Beau Sperry (Variety 6). Owing to its S-rim form, Le Beau Sperry variety has been considered a division of Le Beau ware, but it differs significantly from Le Beau Classic both morphologically and decoratively. Sperry variety vessels are distinguished by a subtle but distinctive subangular lower zone 3, expressed most clearly on the exterior rather than the interior wall. Decoratively, Sperry vessels are both distinct and notably uniform. Cord impression is the only known decorative technique. The decorative pattern generally consists of 4 (occasionally 3 or 5) horizontal cord impressions on zone 3, with no use of curvilinear "rainbow" motifs. Nodes, handles and other appendages have not been recorded on Sperry vessels, but interior bracing is common, as is a "wavy" vessel orifice created by repeated deformation of the lip and upper rim. Commonly, both interior and exterior vessel surfaces are burnished. The name "Sperry" comes from the fact that this variety is a very prominent part of the assemblage at Sperry Village (32BL4), several miles 
downstream from Larson. At Double Ditch Village, Sperry vessels appear abruptly in deposits postdating 1650. No Le Beau Sperry variety vessels are present in the 2006 Larson collection.

Le Beau Sperry Recurved (Variety 6.1). This variety is similar to Le Beau Sperry, but has zone 4. No Sperry Recurved vessels are present in the 2006 Larson collection.

Le Beau Sperry/Le Beau Sperry Recurved (Variety 11). This category includes zone 3 or zone 2 and 3 fragments that exhibit the distinctive subangular lower zone 3 , but lack the upper portion of zone 3.

Le Beau Paddle-Stamped (Variety 8). Although morphologically similar to Le Beau Classic vessels, Le Beau Paddle-Stamped vessels are decorated with carefully placed, vertical simple stamping on zone 2 and zone 3, extending continuously from the body to the lip. No Le Beau Paddle-Stamped vessels are present in the 2006 Larson collection.

Le Beau Plain (Variety 9). This variety lacks decoration but retains the basic rim form characteristic of Le Beau ware. At Scattered and Slant villages, Le Beau Plain became more abundant during the latter part of the 1600s.

Unclassified Late S-Rim (Variety 12). This is a catch-all category that includes rims that do not fall into one of the above classes, either because of an unusual rim form, decorative technique, or decorative pattern. Vessels previously placed in this category include those with cord-wrappedtool-impressed decoration; plain vessels with a double-double S-rim form; an S-rim with an uncommon combination of multiple horizontal lines and diagonal cord-impressed lines with an uncommon manipulation of the lip; and a short S-rim with diagonal cord-impressions above a row of square tool-impressions.

Transitional Ware (Variety 19). Transitional ware combines the S-rim form of Le Beau ware with the bold exterior brace and decorative pattern of Knife River ware (see below). The brace is generally so large that it nearly covers the exterior face of zone 3. Decoration generally consists of diagonal cord impressions on the brace, with a row of finger or tool impressions at the juncture between the brace and the exterior vessel wall. First identified in studies of Hidatsa sites in the Knife region, Transitional ware has been considered a companion to Knife River ware. Transitional ware was produced over a long period of time and can be found at many sites in both the Knife and Heart regions, although nowhere can it be considered abundant. At Double Ditch, Transitional ware becomes much more common after 1650 .

Zone 3 or Zone 2-3 Fragments (Variety 31). This category includes parts of S-rim vessels that are too fragmentary to assign to a specific variety. This code was not used in the analysis of the 2006 Larson collection.

Le Beau or Sanger (Variety 33). This class includes zone 3 (or zones 2 and 3) fragments that are decorated with large, widely-spaced cord impressions characteristic of Sanger ware, but that are too small to be positively identify as Sanger ware. See discussion of Variety 2 for additional description of this class. 


\section{Straight-Rim Wares and Varieties}

Riggs Ware (Variety 14). Riggs ware has an unbraced straight rim form and usually is decorated with repetitive tool marks or finger impressions. Decoration is confined to the top or outer edge of the lip or sometimes to a fillet on the upper rim. Riggs ware is associated with the earliest village sites in most of North Dakota and is not present in the 2006 Larson collection.

Stanton Ware (Variety 15). Stanton ware replaced Riggs ware in the 1300s and was particularly popular, along with Sanger ware, between 1400 and 1525. Stanton ware is a straight rim form that may or may not have a small exterior brace or a fillet. The rim is typically shorter than in Riggs ware. The upper rim sometimes is gently curved rather than straight and zone 2 is usually less angular. Particularly in the Knife region, the lips of Stanton ware vessels are heavily modeled, with T-shaped, L-shaped, beaded and inslanted lip forms common. Most commonly, Stanton ware vessels are decorated with repetitive tool impressions on the lip or upper rim.

Originally, Stanton ware was conceived as a "somewhat open-ended ware-like group" of vessels that did not easily fit the definition of Riggs ware or Knife River ware (see below) (Ahler and Swenson 1985:28). Because it was a group rather than a class no specific criteria were established for membership, and in fact most of the included vessels exhibited morphological or decorative characteristics intermediate in one way or another between Riggs ware and Knife River ware. Based on studies of recently excavated collections as well as surface collections from the Heart region, Stanton ware is now better defined (Ahler 2001). However, like Sanger ware, Stanton ware grades into both earlier and later related forms.

Ahler (2001) has argued that the technological characteristics of Knife River ware, especially its bold exterior bracing and its apparent lower technical quality, set it apart from earlier straight rim wares. However, as research in the Heart region has progressed it has become clear that Knife River did not appear abruptly, as once thought. It also is clear that the technical quality of various ceramic wares varies independently across sites and over time (e.g. Ahler, Warner, and Smail 2002). Moreover, some vessels classified as Knife River ware have very small braces, while some classified as Stanton ware have rather prominent braces. This ambiguity has been accentuated by the inclusion of decorative variables in the criteria used to determine ware class. Rims exhibiting diagonal cord impressions generally have been classified as Knife River ware even if they are not braced, while rims with tool impressions have been classified as Stanton ware even if they are braced. (Vessels exhibiting such "unusual" combinations of rim form and decoration also sometimes have been put into one of two catch-all varieties, described below). To determine the chronological, spatial, and cultural relationships among various straight rim forms in the Heart region it is necessary to sharpen the definitions of each ware.

In this analysis, unbraced vessels, or those bearing ephemeral braces, having predominantly straight rather than outflaring rims are classified as Stanton ware, even if they are decorated with cord impressions. Braced vessels with outflaring rims are classified as Knife River ware, even if they are decorated with tool impressions. Variety 17 rims (see below) only include those with unusual forms or decorations.

Unclassified Late Straight Rim without Brace (Variety 16). This is a catch-all category that includes unbraced rims bearing unusual decoration or other features precluding their assignment to 
a better defined ware or variety. Forms in this group include vessels with tall curved rims and many parallel cord impressions.

Crosshatched (Variety 16.1). The distinctive decorative technique and pattern of these vessels was first recognized at Double Ditch Village. Crosshatched variety vessels are decorated with widelyspaced cord impressions made with large, loosely twisted cords. The impressions are arranged in a crisscross pattern bounded above and below by single horizontal cord impressions. At Double Ditch, this distinctive decorative pattern occurs mostly on vertical straight rim vessels, but occasionally also on rims having a faint $\mathrm{S}$ curvature. Vessels bearing this decorative pattern only had been identified at Double Ditch prior to the analysis of the 2006 Larson collection.

Unclassified Late Straight Rim with Brace (Variety 17). In previous analyses, this category has been used to isolate vessels combining the rim form characteristics of Knife River ware (gently flaring rims with a prominent exterior brace) with the decorative characteristics of Stanton ware (repetitive tool impression on the lip or upper rim). As mentioned in the preceding discussion of Stanton ware, such a definition potentially obscures the cultural and chronological relationships between Knife River ware and Stanton ware and is not used in this analysis. Instead, this variety is a catch-all that includes braced straight rim forms bearing unusual decoration or other features.

Knife River Ware (Varieties 21.0, 21.1, 22.0, and 22.1). Knife River ware is distinguished by a high, gently and evenly curving rim to which a prominent brace was added. Lips usually are round and the brace shape is curved or, less commonly, wedge-shaped. The dominant decorative technique is cord impression, although other techniques also were used. Decorative pattern commonly consists of diagonal impressions on the brace and lip. In some cases, parallel horizontal cord impressions occur in zone 2. Later Knife River ware frequently includes spouts, handles, castellations, and other appendages. Knife River ware was first defined by Lehmer and others (1978) based on collections from Hidatsa sites in the Knife region. Its popularity increased in both the Knife and Heart regions throughout the seventeenth and eighteenth centuries. By the early 1800s it had completely replaced Le Beau ware and was by far the dominant ceramic type. Knife River ware was still being produced in the 1860s and 1870s at Like-a-Fishhook Village, the last earthlodge settlement in North Dakota.

In the analysis of ceramic collections from the Knife River Indian Villages National Historic Site, two distinct sizes of Knife River ware were recognized. The term "Knife River ware” was retained for the larger vessels, but the smaller pots were classified as "Knife River Fine ware.” The latter ware is described below. In the Heart region by contrast, a continuous gradation of braced straight rim vessels, from quite small to very large, has been recognized (e.g. Ahler, Warner, and Smail 2002). Accordingly, Knife River ware proper found there has been subdivided into two varieties, Knife River Large (Variety 21) and Knife River Intermediate (Variety 22). Minor decorative and morphological differences have been noted between the two varieties. Knife River Large captures the upper end of the size range. The brace is generally large and decoration on the neck (zone 2) is uncommon. Cord impressions on the interior of the vessel, just below the lip, are more common in Knife River Large variety vessels. Knife River Intermediate variety vessels often bear more complex decorative patterns, are somewhat smaller, and are less frequently decorated on the interior.

Knife River Fine Ware (Varieties 23.0 and 23.1). This category comprises relatively small pots that typically are decorated on the brace, interior surface near the lip, exterior neck, and on the shoulder. 
Shoulder decorations are generally incised while decoration elsewhere consists of cord impressions. These vessels have the rim morphology of Knife River ware, but are set apart by their small size and high degree of decoration. Most are very well made and may have been special function pots. They are widely distributed but generally rare in both the Knife and Heart regions. As with Knife River Large and Knife River Intermediate varieties, vessels with interior cord impressions (Variety 23.1) are distinguished from those without (Variety 23.0).

Bowl Form without Flange (Variety 27). This category includes open-mouthed containers lacking inflection points in vertical section and lacking a rim as a separate vessel element. In the Heart region, vessels of this type were first identified during the analysis of the 2003 Double Ditch collection.

Unclassifiable Lips and Other Fragments (Variety 99). This group includes rim pieces that cannot be assigned to any of the other categories discussed above.

\section{Pottery Distribution and Body Sherd Analysis}

The 2006 excavated pottery sample from Larson Village consists of just over 31,000 sherds weighing nearly $28 \mathrm{~kg}$. Table 7.4 provides data on the distribution of ceramic remains by excavation context. Counts for size grade 3 sherds are estimates, based on a mean weight of $0.5 \mathrm{~g}$ per sherd; those for size grades 1 and 2 are not.

Table 7.4. Pottery count and weight data by size grade and excavation context for the 2006 Larson Village collection.

\begin{tabular}{|c|c|c|c|c|c|c|c|c|}
\hline \multirow[b]{2}{*}{ Block } & \multicolumn{3}{|c|}{ Count by Size Grade } & \multirow[b]{2}{*}{ Total } & \multicolumn{3}{|c|}{ Weight (g) by Size Grade } & \multirow[b]{2}{*}{ Total } \\
\hline & G1 & G2 & G3 & & G1 & G2 & G3 & \\
\hline Blk. A & 10 & 349 & 3406 & 3765 & 206.7 & 1129.5 & 1810.5 & 3146.7 \\
\hline Blk. D & 7 & 299 & 3521 & 3827 & 138.3 & 852.3 & 1846.0 & 2836.6 \\
\hline Blk. F & 65 & 545 & 4367 & 4977 & 1374.8 & 1746.1 & 2295.2 & 5416.1 \\
\hline Blk. G & 10 & 247 & 2185 & 2442 & 122.5 & 823.8 & 1162.9 & 2109.2 \\
\hline Ditch 3 & 76 & 1285 & 11188 & 12549 & 1046.5 & 4191.3 & 5983.2 & 11221.0 \\
\hline Ditch 4 & 11 & 316 & 2759 & 3086 & 166.7 & 1023.6 & 1475.0 & 2665.3 \\
\hline Mixed & 2 & 38 & 713 & 753 & 29.2 & 126.8 & 379.5 & 535.5 \\
\hline Total & 181 & 3079 & 28139 & 31399 & 3084.7 & 9893.4 & 14952.3 & 27930.4 \\
\hline
\end{tabular}

Table 7.5 organizes the 2006 ceramic collection by category and vessel part. Just less than 12 percent of the assemblage consists of rim sherds from non-miniature vessels. Eight worked sherds (edge-ground ceramic body fragments) were identified, as were 28 fragments (rims and body sherds) from miniature vessels. Miniature vessels and worked sherds were not studied further. About 88.1 percent of the collection consists of zone 1 body sherds, of which 47 sherds exhibit angular shoulders. At Boley Village, angular-shouldered body sherds are more than twice as common (0.43 percent v. 0.17 percent at Larson). At Double Ditch Village about 0.3 percent of all body sherds exhibit angular shoulders. Roughly 6.1 percent of the Larson collection consists of zone 2 neck sherds. The balance, 5.7 percent, consists of sherds exhibiting one or more zones above zone 2 . 
Data on surface treatment for sizes G1 and G2 body sherds from unmixed samples are presented in Table 7.6. Only a few significant differences are evident among the six excavation blocks. Micro-grooved simple stamped body sherds are most common in Block A, while decorated body sherds are most common in Ditch 3. In the collection as a whole, decorated body sherds mainly bear trailed designs ( 82.5 percent), although cord-impressed (11.3 percent), tool impressed (5.5 percent) and incised ( 0.8 percent) designs also are present. Cord-roughened body sherds occur only in a single lot from Block G.

Table 7.5. Ceramic category and vessel part data by size grade for the 2006 Larson Village collection.

\begin{tabular}{|c|c|c|c|c|c|}
\hline & & \multicolumn{3}{|c|}{ Count by Size Grade } & \multirow[b]{2}{*}{ Total } \\
\hline & & G1 & G2 & G3 & \\
\hline \multirow[t]{5}{*}{ Ceramic Category } & 1 body sherd & 72 & 2008 & 25558 & 27638 \\
\hline & 2 rim sherd & 109 & 1058 & 2558 & 3725 \\
\hline & 4 miniature & & 11 & 17 & 28 \\
\hline & 5 worked sherd & & 2 & 6 & 8 \\
\hline & Total & 181 & 3079 & 28139 & 31399 \\
\hline \multirow[t]{7}{*}{ Vessel Part } & 1.1 Z1 body only & 71 & 1998 & 25543 & 27612 \\
\hline & 1.2 Z1 body w/ angular shoulder & 1 & 16 & 30 & 47 \\
\hline & $2.1 \mathrm{Z} 2$ neck (with Z1) & 29 & 609 & 1291 & 1929 \\
\hline & 3 Z3 only (face) & 2 & 83 & 620 & 705 \\
\hline & 7 Z7 only (lip) & & & 84 & 84 \\
\hline & 8 rim, multiple zones & 78 & 373 & 571 & 1022 \\
\hline & Total & 181 & 3079 & 28139 & 31399 \\
\hline
\end{tabular}

Micro-grooved simple-stamped body sherds, a recently recognized form, make up 2.5 percent of the 2006 Larson collection. They also are present at Boley Village, where they constitute 3.3 percent of the size G1 and G2 body sherds, and at Double Ditch Village, where constitute 3.8 percent of the 2004 collection of body sherds. No particular temporal trend is evident in the collections from either site. Regionally, decorated body sherds appear to be more common in contexts dating to the 1400s, 1500s, and early 1600s than they are in later contexts. At Huff Village, a mid-fifteenth century settlement, 13.2 percent of the body sherds (1999 collection) bear trailed or incised decorations (Ahler and Johnson 2000:Table 10). At Double Ditch, they make up 3.3 (2002-2003 collection) to 4.3 (2004 collection) percent of the total assemblage. At Boley, they are somewhat more common (4.6 percent).

Several weak temporal trends are evident in the Larson surface treatment data (data not presented). The earliest contexts contain a slightly higher frequency of simple-stamped body sherds (84.4 percent) than the latest (75.6 percent). Check-stamped sherds are slightly more common in the latest deposits (2.7 percent compared to 0.3 percent for the earliest deposits). Plains sherds also are more common in the latest deposits (8.4 percent compared to 5.5 percent). However, none of these trends (with the exception of the increase in check-stamping) are statistically significant.

However, significant temporal trends in vessel surface treatment have been documented in some Heart region assemblages. At Double Ditch and at Boley villages the frequency of simplestamped sherds generally increases over time, while the frequencies of check-stamped and decorated body sherds decrease. Check-stamped sherds occur mainly in the earliest deposits at both sites. However, these trends are not evident in every studied collection. At Scattered Village, simple-stamped surface treatment is far less common in all time periods than it is at Double Ditch, 
Boley, or Slant villages. Check-stamped surface treatment is generally quite rare in assemblages postdating 1500, but in earlier assemblages ranges from entirely absent to dominant (Ahler 2001). At Larson, the proportions of sherds exhibiting simple-stamped or decorated surface treatment, along with the occurrence of check-stamped sherds in most contexts, suggests that the assemblage falls early in the post-1500 sequence. Moreover, the overall homogeneity of vessel surface treatment (as well as the apparent reversal of some regional trends) supports the notion that the 2006 collection accumulated over a relatively short period of time.

Table 7.6. Body sherd surface treatment data organized by excavation area for the 2006 Larson collection. Cells with standard residual values greater than +2.0 are shaded.

\begin{tabular}{|c|c|c|c|c|c|c|c|c|}
\hline \multirow[b]{2}{*}{ Surface Treatment Class } & & \multicolumn{6}{|c|}{ Excavation Area } & \multirow[b]{2}{*}{ Total } \\
\hline & & BLK A & BLK D & BLK F & BLK G & Ditch 3 & Ditch 4 & \\
\hline \multirow[t]{2}{*}{.00 indeterminate } & $n$ & 8 & 5 & 9 & 3 & 12 & 5 & 42 \\
\hline & $\%$ & $3.5 \%$ & $2.7 \%$ & $2.4 \%$ & $1.8 \%$ & $1.3 \%$ & $2.3 \%$ & $2.0 \%$ \\
\hline \multirow[t]{2}{*}{1.00 plain/smooth } & $n$ & 28 & 12 & 26 & 5 & 87 & 16 & 174 \\
\hline & $\%$ & $12.1 \%$ & $6.5 \%$ & $7.0 \%$ & $3.1 \%$ & $9.8 \%$ & $7.3 \%$ & $8.4 \%$ \\
\hline \multirow[t]{2}{*}{2.00 simple-stamped } & $n$ & 168 & 150 & 295 & 137 & 653 & 184 & 1587 \\
\hline & $\%$ & $72.7 \%$ & $81.1 \%$ & $79.1 \%$ & $84.0 \%$ & $73.4 \%$ & $84.0 \%$ & $77.0 \%$ \\
\hline \multirow[t]{2}{*}{3.00 check-stamped } & $n$ & 3 & 5 & 8 & 1 & 9 & & 26 \\
\hline & $\%$ & $1.3 \%$ & $2.7 \%$ & $2.1 \%$ & $.6 \%$ & $1.0 \%$ & & $1.3 \%$ \\
\hline \multirow[t]{2}{*}{4.00 brushed } & $n$ & 1 & 4 & 3 & 2 & 10 & 5 & 25 \\
\hline & $\%$ & $.4 \%$ & $2.2 \%$ & $.8 \%$ & $1.2 \%$ & $1.1 \%$ & $2.3 \%$ & $1.2 \%$ \\
\hline \multirow[t]{2}{*}{5.00 cord-roughened } & $n$ & & & & 3 & & & 3 \\
\hline & $\%$ & & & & $1.8 \%$ & & & $.1 \%$ \\
\hline \multirow[t]{2}{*}{11.00 microgrooved ss } & $n$ & 11 & 2 & 6 & 6 & 24 & 2 & 51 \\
\hline & $\%$ & $4.8 \%$ & $1.1 \%$ & $1.6 \%$ & $3.7 \%$ & $2.7 \%$ & $.9 \%$ & $2.5 \%$ \\
\hline \multirow[t]{2}{*}{12.00 decorated } & $n$ & 12 & 7 & 26 & 6 & 95 & 7 & 153 \\
\hline & $\%$ & $5.2 \%$ & $3.8 \%$ & $7.0 \%$ & $3.7 \%$ & $10.7 \%$ & $3.2 \%$ & $7.4 \%$ \\
\hline \multirow[t]{2}{*}{ Total } & $n$ & 231 & 185 & 373 & 163 & 890 & 219 & 2061 \\
\hline & $\%$ & $100.0 \%$ & $100.0 \%$ & $100.0 \%$ & $100.0 \%$ & $100.0 \%$ & $100.0 \%$ & $100.0 \%$ \\
\hline
\end{tabular}

Tables 7.7 and 7.8 present count and weight data on pottery body and rim sherds organized by size grade and deposit type. These data can be used to assess the relative degree of artifact fragmentation in different types of deposits. Higher percentages of size G3 sherds indicate greater fragmentation of the assemblage, and imply that different depositional and post-depositional processes may have been responsible for their accumulation. Specifically, trampling and repeated transport are likely to produce more fragmented assemblages, while primary deposition in enclosed contexts such as pits is less likely to result in fragmentation.

As might be expected, the plowzone assemblage is more fragmented than the large pit assemblage, whether measured in terms of sherd counts or weights. The small pit assemblage is the least fragmented, but this mainly reflects the presence in Feature 104 of a small number of very large sherds. Significantly, the proportions (by both count and weight) of sherds in each size grade for midden and midden and earth deposits are nearly identical, but the densities are notably different. The processes responsible for artifact fragmentation and size sorting (such as sweeping, trampling, or selective disposal) acted on both types of deposits in similar ways, but earth containing comparatively few or no artifacts was added by some means to the midden and earth deposits. This suggests that both the midden and the midden and earth deposits are secondary (a 
product of repeated transport), but that midden and earth deposits also contain natural sediment, presumably from a nearby borrow.

Table 7.7. Body and rim sherd counts and percentages according to size grade and deposit type, along with calculated densities.

\begin{tabular}{|c|c|c|c|c|c|c|c|}
\hline \multirow[b]{2}{*}{ Deposit Type } & & \multicolumn{3}{|c|}{ Count by Size Grade } & \multirow[b]{2}{*}{ Total } & \multirow[b]{2}{*}{$\begin{array}{c}\text { Deposit Volume } \\
\text { (cu. m) }\end{array}$} & \multirow[b]{2}{*}{$\begin{array}{c}\text { Density } \\
\text { (sherds/cu. m) }\end{array}$} \\
\hline & & G1 & G2 & G3 & & & \\
\hline \multirow[t]{2}{*}{ Pit } & $n$ & 46 & 473 & 3288 & 3807 & 1.406 & 2708 \\
\hline & $\%$ & $1.2 \%$ & $12.4 \%$ & $86.4 \%$ & & & \\
\hline \multirow[t]{2}{*}{ Small Pit } & $n$ & 16 & 29 & 200 & 245 & 0.129 & 1899 \\
\hline & $\%$ & $6.5 \%$ & $11.8 \%$ & $81.6 \%$ & & & \\
\hline \multirow[t]{2}{*}{ Midden } & $n$ & 92 & 1732 & 15203 & 17027 & 6.808 & 2501 \\
\hline & $\%$ & $.5 \%$ & $10.2 \%$ & $89.3 \%$ & & & \\
\hline \multirow[t]{2}{*}{ Midden and Earth } & $n$ & 19 & 458 & 3651 & 4128 & 3.628 & 1138 \\
\hline & $\%$ & $.5 \%$ & $11.1 \%$ & $88.4 \%$ & & & \\
\hline \multirow[t]{2}{*}{ Plowzone } & $n$ & 6 & 336 & 5061 & 5403 & 1.995 & 2708 \\
\hline & $\%$ & $.1 \%$ & $6.2 \%$ & $93.7 \%$ & & & \\
\hline \multirow[t]{2}{*}{ Mixed } & $n$ & 2 & 38 & 713 & 753 & 0.340 & 2214 \\
\hline & $\%$ & $.3 \%$ & $5.0 \%$ & $94.7 \%$ & & & \\
\hline \multirow[t]{2}{*}{ Total } & $n$ & 181 & 3066 & 28116 & 31363 & 14.306 & 2192 \\
\hline & $\%$ & $.6 \%$ & $9.8 \%$ & $89.6 \%$ & & & \\
\hline
\end{tabular}

Table 7.8. Body and rim sherd weights and percentages according to size grade and deposit type, along with calculated densities.

\begin{tabular}{|c|c|c|c|c|c|c|c|}
\hline \multirow[b]{2}{*}{ Deposit Type } & \multicolumn{4}{|c|}{ Weight (g) by Size Grade } & \multirow[b]{2}{*}{ Total } & \multirow[b]{2}{*}{$\begin{array}{l}\text { Deposit Volume } \\
\text { (cu. m.) }\end{array}$} & \multirow[b]{2}{*}{$\begin{array}{l}\text { Density } \\
\text { (g/cu. m.) }\end{array}$} \\
\hline & & G1 & G2 & G3 & & & \\
\hline \multirow[t]{2}{*}{ Pit } & $n$ & 702.5 & 1607.5 & 1742.7 & 4052.7 & 1.406 & 2882 \\
\hline & $\%$ & $17.3 \%$ & $39.7 \%$ & $43.0 \%$ & & & \\
\hline \multirow[t]{2}{*}{ Small Pit } & $n$ & 570.4 & 108.5 & 104.2 & 783.1 & 0.129 & 6070 \\
\hline & $\%$ & $72.8 \%$ & $13.9 \%$ & $13.3 \%$ & & & \\
\hline \multirow[t]{2}{*}{ Midden } & $n$ & 1441.9 & 5548.1 & 8080.3 & 15070.3 & 6.808 & 2214 \\
\hline & $\%$ & $9.6 \%$ & $36.8 \%$ & $53.6 \%$ & & & \\
\hline \multirow{2}{*}{ Midden and Earth } & $n$ & 257.7 & 1497.5 & 1942.8 & 3698.0 & 3.628 & 1019 \\
\hline & $\%$ & $7.0 \%$ & $40.5 \%$ & $52.5 \%$ & & & \\
\hline \multirow[t]{2}{*}{ Plowzone } & $n$ & 83.0 & 972.3 & 2684.8 & 3740.1 & 1.995 & 1875 \\
\hline & $\%$ & $2.2 \%$ & $26.0 \%$ & $71.8 \%$ & & & \\
\hline \multirow[t]{2}{*}{ Mixed } & $n$ & 29.2 & 126.8 & 379.5 & 535.5 & 0.340 & 1575 \\
\hline & $\%$ & $5.5 \%$ & $23.7 \%$ & $70.9 \%$ & & & \\
\hline \multirow[t]{2}{*}{ Total } & $n$ & 3084.7 & 9860.7 & 14934.3 & 27879.7 & 14.306 & 1949 \\
\hline & $\%$ & $11.1 \%$ & $35.4 \%$ & $53.6 \%$ & & & \\
\hline
\end{tabular}

Table 7.9 compares sherd weight data from Larson Village with data from Double Ditch and Boley villages. The Boley assemblage is the least fragmented, followed by Double Ditch and Larson. The differences between Larson and the other two villages are quite striking and clearly indicate that the contexts investigated at Larson contained artifacts that were transported repeatedly and that likely derive from more than one source. This no doubt is closely linked to the dominant contribution made by ditch fill contexts to the overall make up of the Larson assemblage. 
Table 7.9. Percentage by weight according to size grade of body and rim sherds from three Heart region villages.

\begin{tabular}{lccccr}
\hline & & \multicolumn{3}{c}{ Size Grade } & Total (g) \\
\cline { 3 - 5 } Village & $\%$ & G1 & G2 & G3 & $\mathbf{2 7 8 8 0}$ \\
Larson & $\%$ & $\mathbf{1 1 . 1 \%}$ & $\mathbf{3 5 . 4 \%}$ & $\mathbf{5 3 . 6 \%}$ & 18949 \\
Boley & $\%$ & $31.6 \%$ & $39.9 \%$ & $28.5 \%$ & 128729 \\
Double Ditch (2004) & $\%$ & $27.6 \%$ & $38.6 \%$ & $33.8 \%$ & 193816 \\
Double Ditch (2002-2003)* & $\%$ & $20.5 \%$ & $41.4 \%$ & $38.1 \%$ & \\
\hline
\end{tabular}

* Priority 1 contexts only.

\section{Ware and Variety Quick-code Analysis}

The quick-code sample includes a total of 502 rims represented by size grade 1 and 2 sherds (a few rims include two or more conjoining sherds). No size grade 3 rim sherds were studied. The frequency and distribution of these artifacts are summarized in Table 7.10. Representative examples of some of the ceramic wares are illustrated in Figures 7.1 through 7.6, along with several unique vessels. The Larson collection is diverse, but is dominated by Le Beau ware (65.7 percent). Knife River ware is the second most common type (14.1 percent), followed by much smaller numbers of Sanger ware, Stanton ware, and Transitional ware rims. Various unclassified straight and S-rim specimens make up 8.4 percent of the collection.

It should be noted that the strong dominance of Le Beau ware in Heart region rim sherd assemblages is partly a function of the analytic methods used to study ceramic remains. When rim sherds are separated from neck and body sherds, those bearing a portion of zone 3 (the upper part of the S) but lacking zone 7 (the lip) are designated as rims. The majority of these are classified during the quick-code analysis as Variety 10, Le Beau Classic or Recurved, though a few with large, widely spaced cords are classified as Sanger ware (Variety 2) or possible Sanger ware (Variety 33). By contrast, sherds bearing a portion of zone 2 (the neck) but lacking zones 3 or 7 are designated as neck sherds and are not included in the ware and variety analysis. Thus, some fragments of Knife River ware vessels are not included in the rim sherd sample, because correct identification of Knife River ware vessels is dependent to a greater degree on the presence of zone 7. The effect of this difference on assemblage composition is not known, but it likely is relatively small.

Table 7.10. Size G1 and G2 rim sherd counts organized by excavation area and pottery type for the 2006 Larson collection.

\begin{tabular}{|c|c|c|c|c|c|c|c|c|}
\hline \multirow[b]{2}{*}{ Variety } & \multicolumn{7}{|c|}{ Excavation Area } & \multirow[b]{2}{*}{ Total } \\
\hline & BLK A & Mixed & BLK D & BLK F & BLK G & Ditch 3 & Ditch 4 & \\
\hline 2.00 Sanger & 1 & & & 1 & 2 & 2 & 1 & 7 \\
\hline 3.00 Un Early S & 1 & & & 1 & & & & 2 \\
\hline 4.00 LB Classic & 19 & 2 & 14 & 34 & 7 & 45 & 19 & 140 \\
\hline 4.10 LB Fine & 1 & & 2 & 2 & & 3 & & 8 \\
\hline 4.20 LB T-lip & & & & 1 & 1 & 1 & & 3 \\
\hline 5.00 LB Recurved & 3 & & & 2 & 2 & 4 & & 11 \\
\hline 9.00 LB Plain & 1 & & 2 & 1 & & 3 & & 7 \\
\hline $10.00 \mathrm{LB} 4+5$ & 31 & 5 & 20 & 29 & 8 & 58 & 10 & 161 \\
\hline 12.00 Un Late S-rim & 3 & & 1 & 3 & 2 & 4 & 2 & 15 \\
\hline 15.00 Stanton & 1 & & & 1 & 1 & 8 & 1 & 12 \\
\hline
\end{tabular}


Table 7.10. Size G1 and G2 rim sherd counts organized by excavation area and pottery type (concluded).

\begin{tabular}{|c|c|c|c|c|c|c|c|c|}
\hline \multirow[b]{2}{*}{ Variety } & \multicolumn{7}{|c|}{ Excavation Area } & \multirow[b]{2}{*}{ Total } \\
\hline & BLK A & Mixed & BLK D & BLK F & BLK G & Ditch 3 & Ditch 4 & \\
\hline 16.00 Un Late Str.-rim & 1 & & 1 & 1 & 3 & 6 & 1 & 13 \\
\hline 16.10 Cross-hatched & & & 2 & & & 1 & & 3 \\
\hline 17.00 Un Late Str Brace & 1 & 1 & & & 1 & & & 3 \\
\hline 19.00 Transitional & 1 & & 1 & & & & & 2 \\
\hline 21.00 KR Large & 1 & & & 1 & & 3 & & 5 \\
\hline 21.10 KR Large, int. cord & 1 & & & & & 4 & 1 & 6 \\
\hline 22.00 KR Inter. & 4 & 4 & 2 & 10 & 5 & 24 & 6 & 55 \\
\hline 22.10 KR Inter., int. cord & & & & & & 2 & & 2 \\
\hline 23.00 KR Fine & & & & & & 2 & & 2 \\
\hline 23.10 KR Fine, int. cord & & & & 1 & & & & 1 \\
\hline 27.00 Bowl w/out Flange & & & 1 & & & & & 1 \\
\hline 33.00 LB or Sanger & 4 & 1 & 2 & 10 & 7 & 10 & 4 & 38 \\
\hline 99.00 Unclassified & & & & 2 & 1 & 2 & & 5 \\
\hline Total & 74 & 13 & 48 & 100 & 40 & 182 & 45 & 502 \\
\hline
\end{tabular}

The effect of differential breakage patterns on assemblage composition is likely to be more important. Size G3 rim sherds were not included in the quick-code analysis, but casual inspection suggests that straight rim vessels (especially unbraced straight rims) may be relatively more abundant in G3 samples than they are in G1 or G2 samples. This seems reasonable from a ceramic engineering standpoint, because the curvature of most S-rim vessels likely makes them more durable than comparably-sized straight rim vessels. Moreover, many S-rim vessels are large and therefore on average have thicker walls. The extent of this effect is determined by between-village differences in average sherd size. As the data in Table 7.9 indicate, the Larson assemblage is more fragmented than the assemblages from some other sites in the region. This suggests that straight rim vessels (principally Knife River ware, but also Stanton ware) may be underrepresented at Larson. Additional analyses will be needed to confirm this possibility.

For purposes of comparison, the data presented in Table 7.10 can be simplified by combining certain varieties and by eliminating others. A very similar procedure has been used to highlight trends in the ceramic collections recovered from Double Ditch Village in 2002 and 2003 (Ahler and Stanford 2004:178-180). For the Larson analysis, the potentially early S-rims (varieties 2, 3, and 33) were collapsed into a single class. Le Beau Classic (Variety 4) and Le Beau Fine (Variety 4.1) sherds were combined. Le Beau Recurved sherds (Variety 5) were combined with the morphologically similar Le Beau T-Lip sherds (Variety 4.2). All of the unclassified straight- and Srim sherds (varieties 12, 16, 16.1, 17, and 27) were combined into a single category. Knife River ware sherds in each size category (Large [Variety 21], Intermediate [Variety 22], and Fine [Variety 23]) bearing cord impressions on the interior were combined with vessels from the same size class lacking such impressions. Sherds classified as Stanton ware (Variety 15), Transitional ware (Variety 19), and Le Beau Plain variety (Variety 9) were kept in separate categories. Finally, sherds in two categories were omitted from the collapsed data set. Comparatively non-diagnostic zone 3 (or zones 2 and 3) sherds classified as Variety 10, which could include fragments of Le Beau Classic, Recurved, or T-Lip vessels, were eliminated, as were unclassifiable sherds assigned to Variety 99. These omissions reduce the number of rims in the sample to 335. 


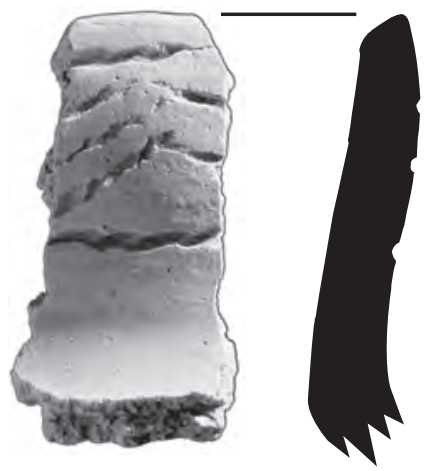

a

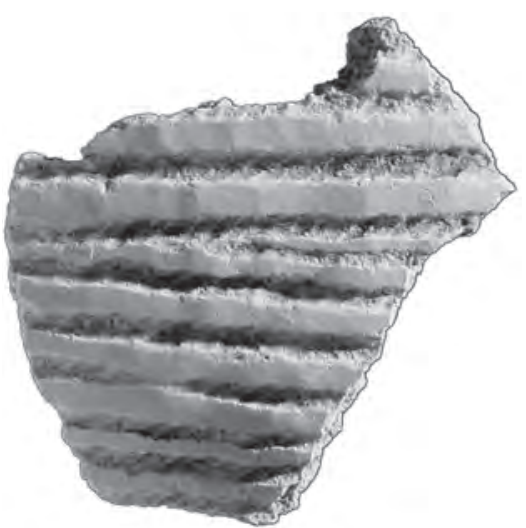

b
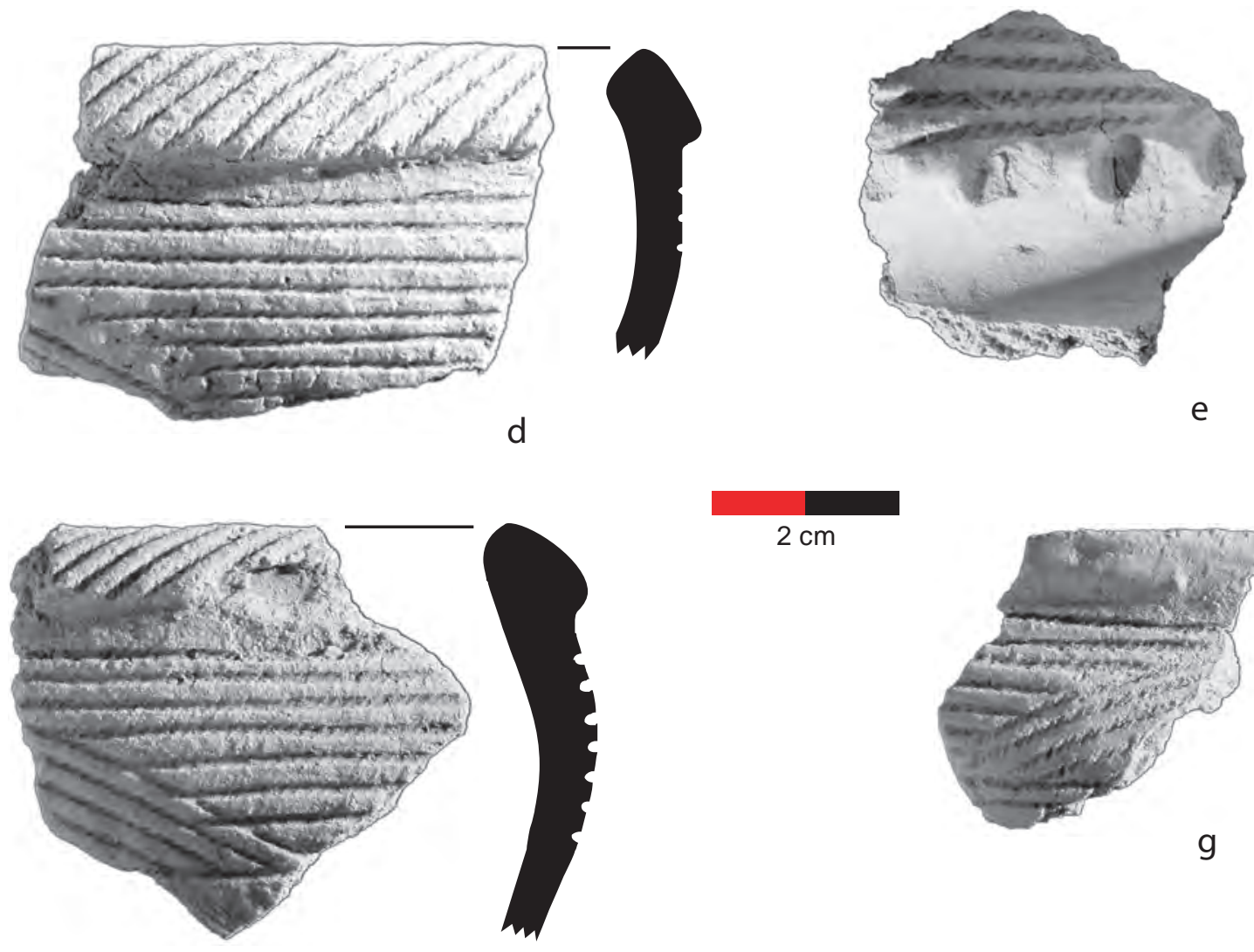

e
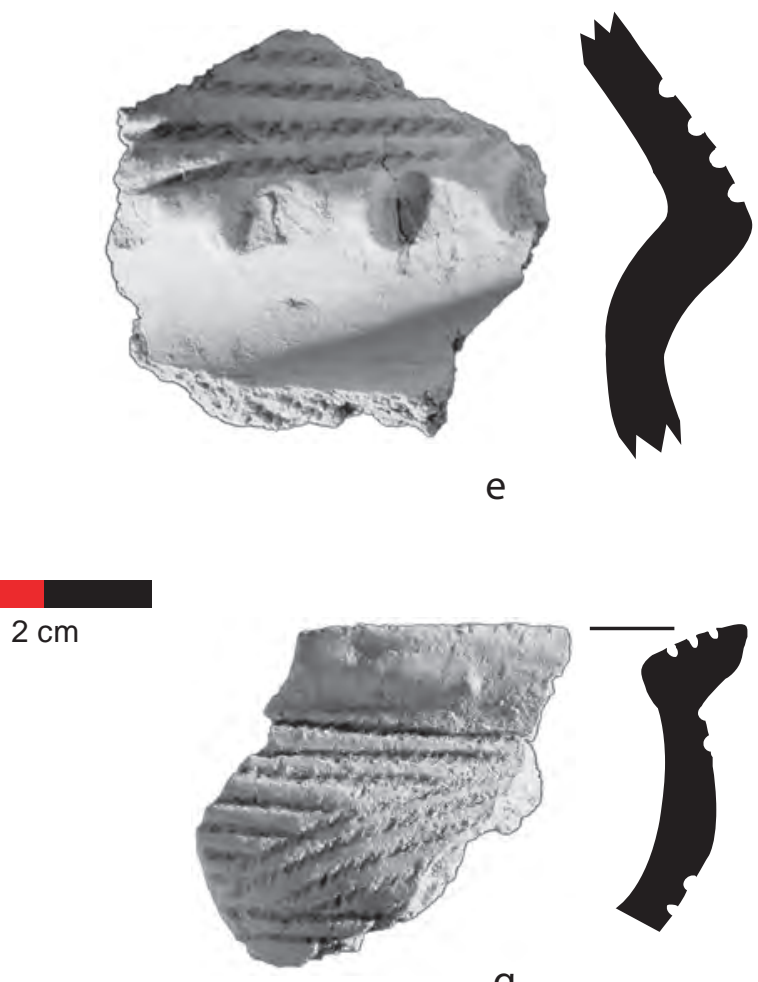

9

Figure 7.1. Pottery from the 2006 Larson collection. a, b: Sanger ware; c, e: Early S-rim variety; d, f, g: Le Beau Recurved variety.

Tables 7.11 through 7.13 present the collapsed variety data. Table 7.11 shows counts and percentages, along with standard cell residual values, organized by excavation locus. Cell residuals effectively are Z-scores; those equal to or greater than +2.0 are shaded, indicating statistically significant differences among cells. The small number of cells with residual values greater than 2.0 indicates that the assemblage is relatively homogeneous. Most of these (5 of the 7 cells exhibiting statistically significant differences) occur in ceramic classes or loci containing relatively few specimens. The remaining two cells highlight a significant concentration of Stanton ware sherds in 


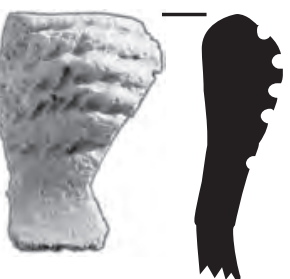

a

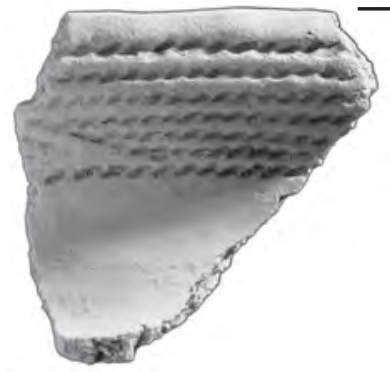

b

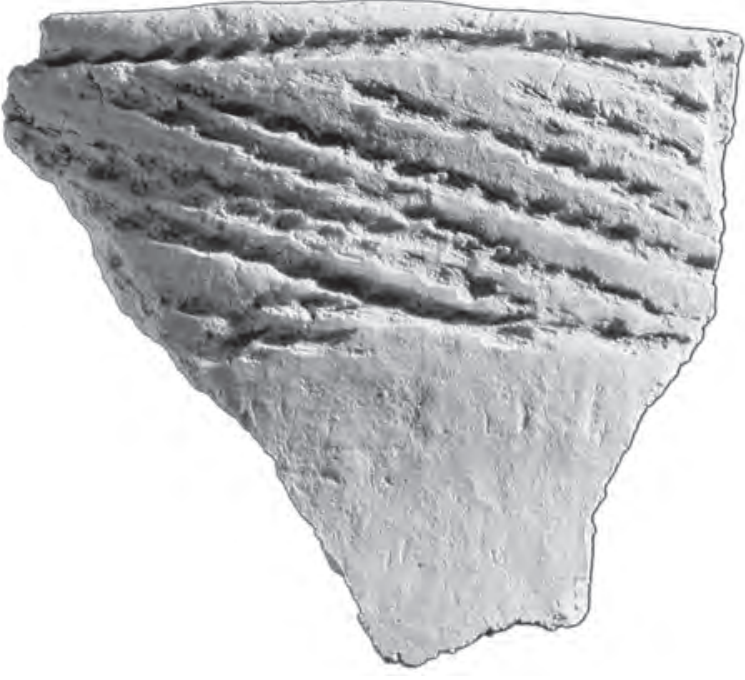

e

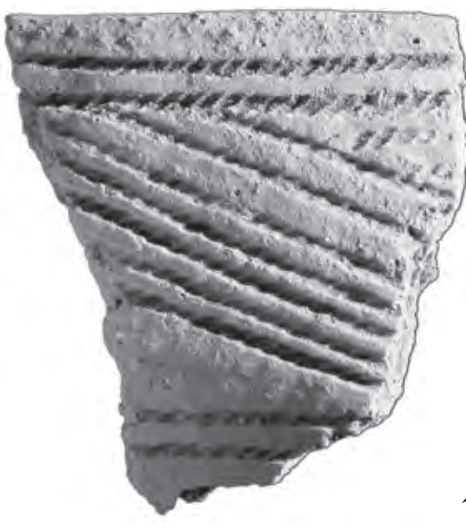

9

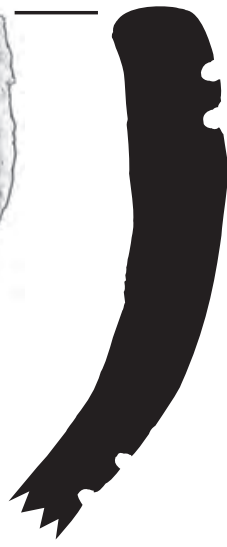

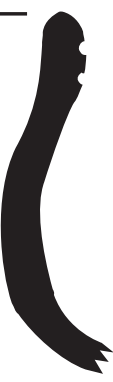

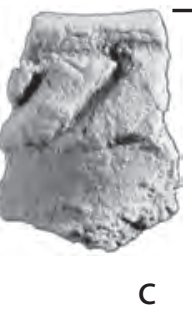

C
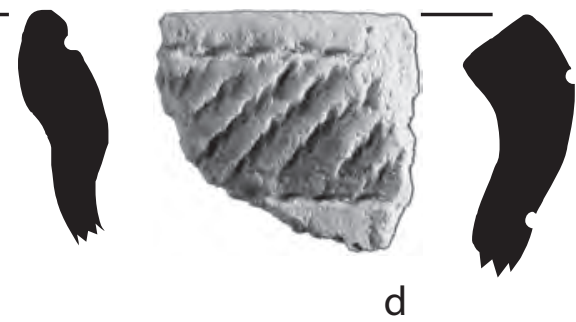

$2 \mathrm{~cm}$
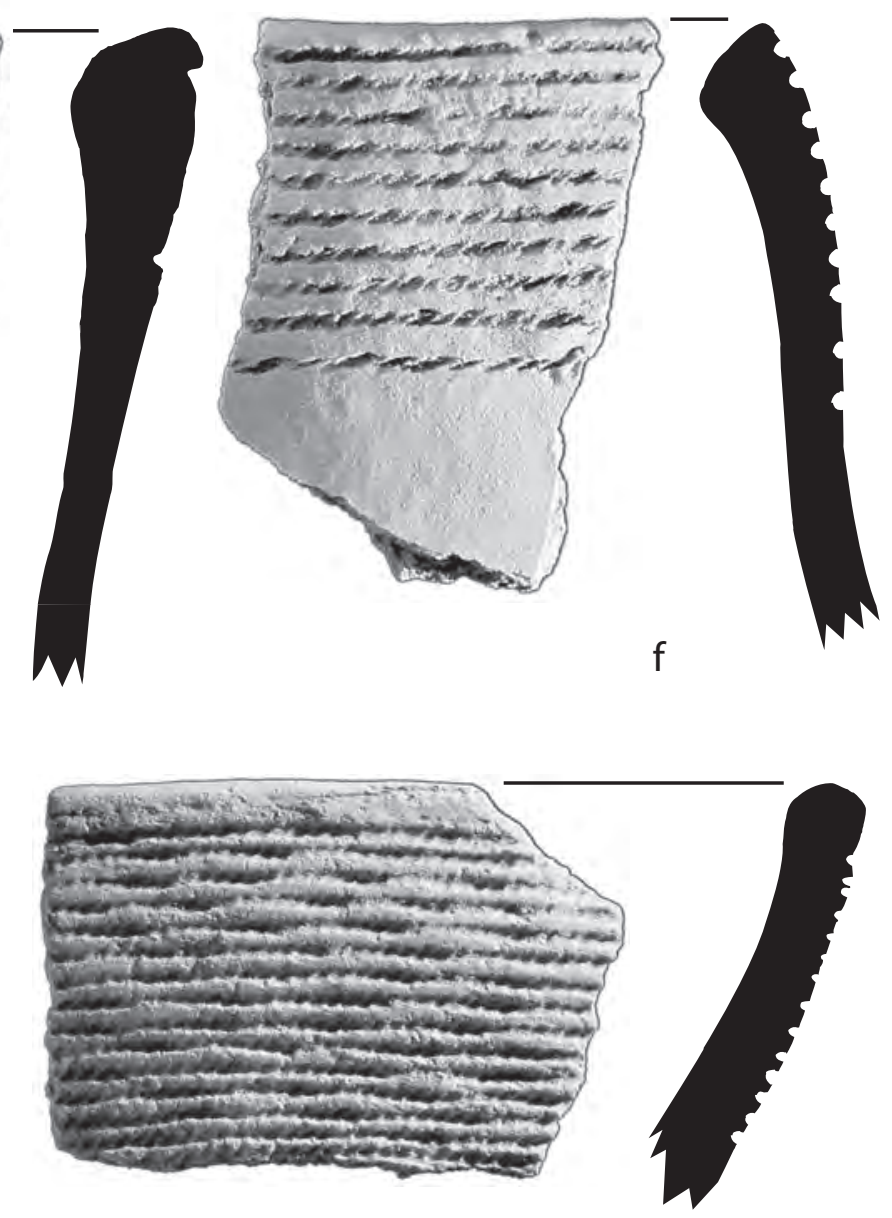

$\mathrm{h}$

Figure 7.2. Pottery from the 2006 Larson collection. a-c: Le Beau Fine variety; d-h: Le Beau Classic variety.

the lower levels of Ditch 3 and a concentration of unclassified straight and S-rim vessels in Block G.

Table 7.12 partitions the collapsed variety data by stratigraphic group. Sherds from plowzone and mixed loci have been eliminated from this table, leaving 289 occurrences. The excavation loci have been arranged into “early," "intermediate,” and “late” groups (see Chapter 6). 
No statistically significant trends are evident, a result that can be interpreted in several ways. Such homogeneity could result from the mixing of primary deposits dating to different periods. In that case, roughly equal numbers of "early" and "late" sherds would be present in most of the contexts investigated in 2006. Alternatively, the homogeneity of the assemblage could indicate that relatively little time passed between the filling of Ditch 4 (and other contexts assigned to stratigraphic group 1) and the creation of the mounds and sheet middens capping both ditches and features 107 and 109.

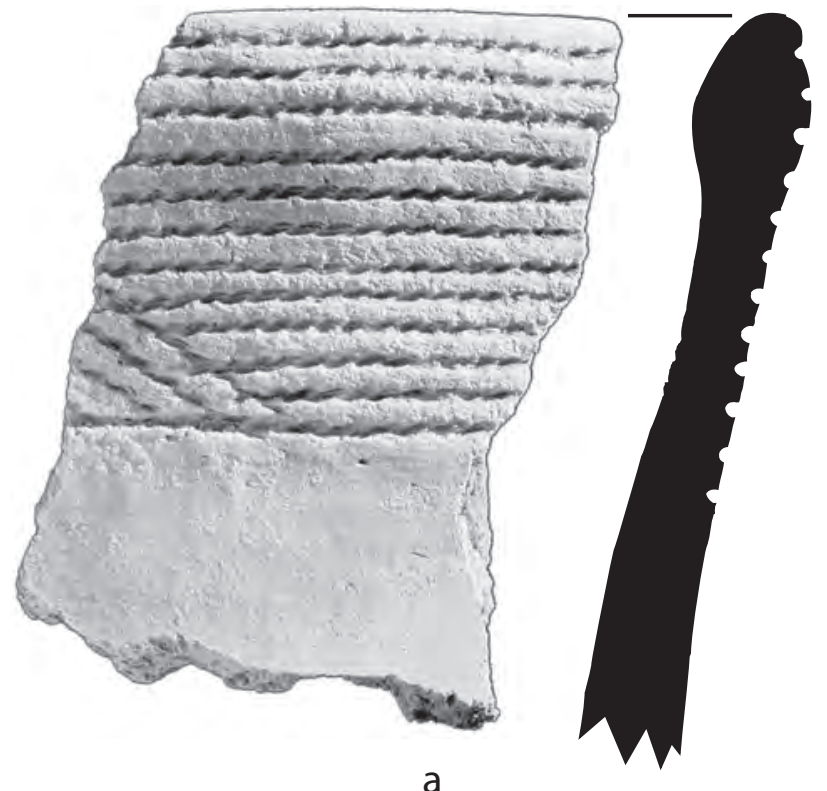

a

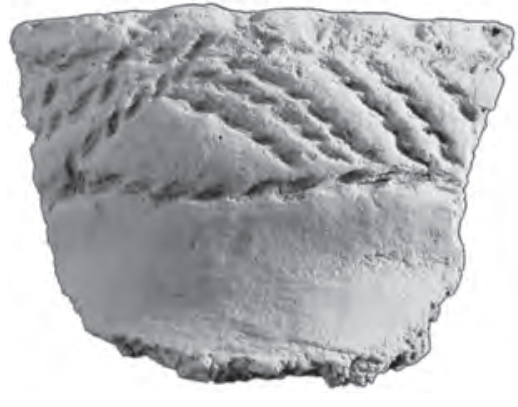

C

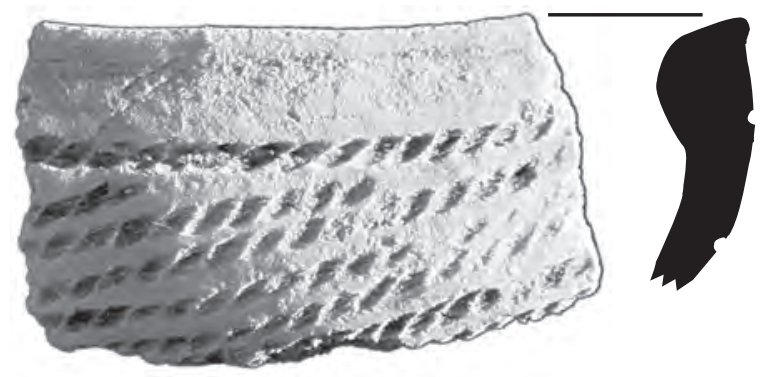

e

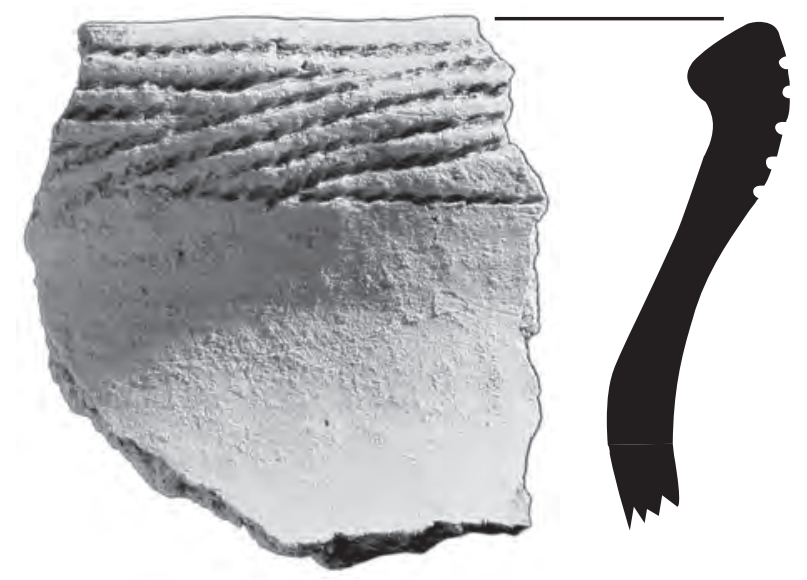

b
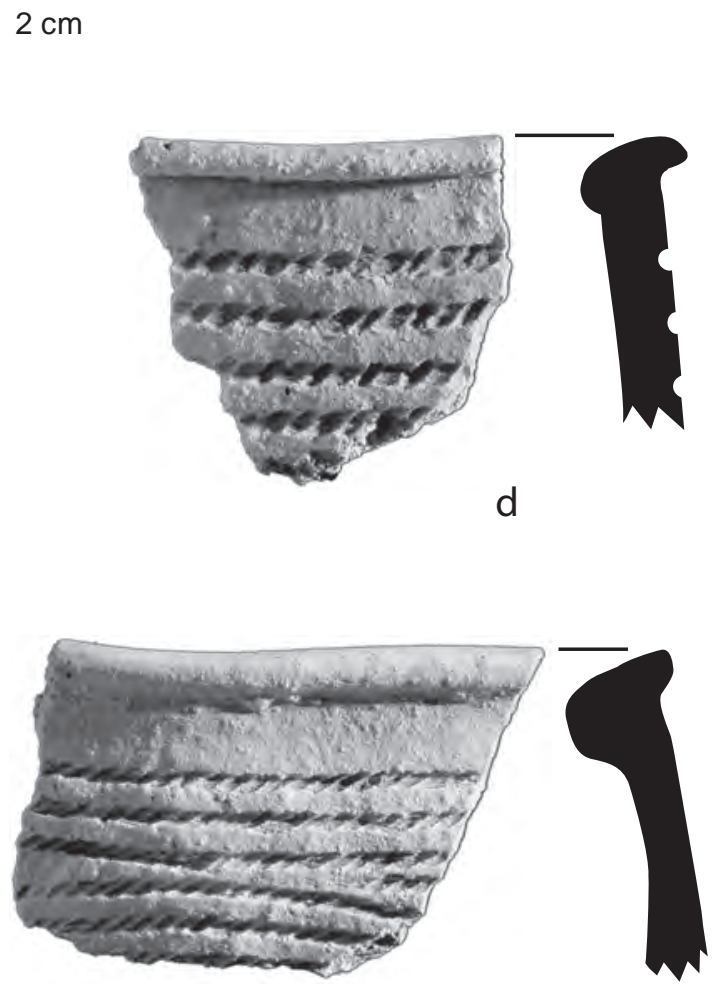

$f$

Figure 7.3. Pottery from the 2006 Larson collection. a-c, e: Le Beau Classic variety; d, f: Le Beau T-lip variety. 
Table 7.11. Collapsed rim sherd variety data organized by excavation locus. The top section lists counts, the middle percentages, and the lower standardized cell residual values. Cell residuals greater than +2.0 are shaded.

\begin{tabular}{|c|c|c|c|c|c|c|c|c|c|c|c|}
\hline \multirow[b]{2}{*}{ Locus } & \multicolumn{10}{|c|}{ Collapsed Variety } & \multirow[b]{2}{*}{ Total } \\
\hline & 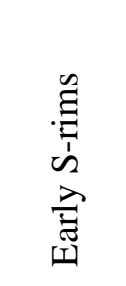 & $\begin{array}{l}\text { 营 } \\
\text { 苞 }\end{array}$ & 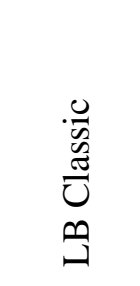 & 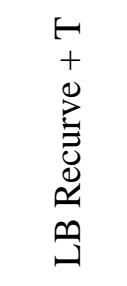 & $\begin{array}{l}\frac{\Xi}{\pi} \\
\frac{\pi}{2} \\
\text { 年 }\end{array}$ & 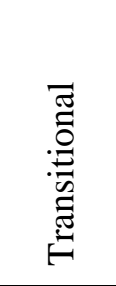 & 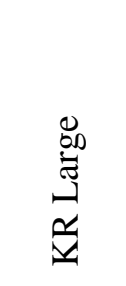 & $\begin{array}{l}\stackrel{\Delta}{\Xi} \\
\stackrel{\Xi}{\Xi} \\
\check{\Xi}\end{array}$ & $\begin{array}{l}\stackrel{g}{\Xi} \\
\underline{\Sigma} \\
\underline{\Sigma}\end{array}$ & 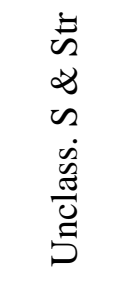 & \\
\hline Plowzone & 9 & 1 & 12 & 2 & 2 & 2 & 2 & 5 & & 3 & 38 \\
\hline Block A Mn. & 2 & & 12 & 1 & & & & 1 & & 3 & 19 \\
\hline Block D Mn. & 1 & & 10 & & 2 & & & 1 & & 4 & 18 \\
\hline Block F Mn. & 3 & & 9 & 1 & & & & 0 & & 1 & 14 \\
\hline Block G Mn & 5 & 1 & 6 & 1 & & & & 4 & & 6 & 23 \\
\hline Ditch 3 Mn. & & & 6 & & 1 & & 3 & 1 & & 3 & 14 \\
\hline Ditch 3, LO & 6 & 7 & 29 & 3 & 1 & & 3 & 15 & 2 & 3 & 69 \\
\hline Ditch 3, UP & 4 & 1 & 11 & 2 & & & & 8 & & 5 & 31 \\
\hline Ditch 4 Mn. & 2 & & 7 & & & & & 0 & & 1 & 10 \\
\hline Ditch 4, LO & 2 & & 6 & & & & & 3 & & & 11 \\
\hline Ditch 4, UP & 1 & 1 & 6 & & & & & 3 & & 1 & 12 \\
\hline Mixed & 1 & & 2 & & & & & 4 & & 1 & 8 \\
\hline Pit F104 & & & 1 & & & & & 2 & & & 3 \\
\hline Pit F107 & 9 & 1 & 24 & 2 & & & 1 & 7 & 1 & 3 & 48 \\
\hline Pit F109 & 2 & & 5 & 2 & 1 & & 2 & 3 & & 1 & 16 \\
\hline Pit F111 & & & 1 & & & & & & & & 1 \\
\hline Total & 47 & 12 & 147 & 14 & 7 & 2 & 11 & 57 & 3 & 35 & 335 \\
\hline Plowzone & $23.7 \%$ & $2.6 \%$ & $31.6 \%$ & $5.3 \%$ & $5.3 \%$ & $5.3 \%$ & $5.3 \%$ & $13.2 \%$ & $.0 \%$ & $7.9 \%$ & $100.0 \%$ \\
\hline Block A Mn. & $10.5 \%$ & $.0 \%$ & $63.2 \%$ & $5.3 \%$ & $.0 \%$ & $.0 \%$ & $.0 \%$ & $5.3 \%$ & $.0 \%$ & $15.8 \%$ & $100.0 \%$ \\
\hline Block D Mn. & $5.6 \%$ & $.0 \%$ & $55.6 \%$ & $.0 \%$ & $11.1 \%$ & $.0 \%$ & $.0 \%$ & $5.6 \%$ & $.0 \%$ & $22.2 \%$ & $100.0 \%$ \\
\hline Block F Mn. & $21.4 \%$ & $.0 \%$ & $64.3 \%$ & $7.1 \%$ & $.0 \%$ & $.0 \%$ & $.0 \%$ & $.0 \%$ & $.0 \%$ & $7.1 \%$ & $100.0 \%$ \\
\hline Block G Mn & $21.7 \%$ & $4.3 \%$ & $26.1 \%$ & $4.3 \%$ & $.0 \%$ & $.0 \%$ & $.0 \%$ & $17.4 \%$ & $.0 \%$ & $26.1 \%$ & $100.0 \%$ \\
\hline Ditch 3 Mn. & $.0 \%$ & $.0 \%$ & $42.9 \%$ & $.0 \%$ & $7.1 \%$ & $.0 \%$ & $21.4 \%$ & $7.1 \%$ & $.0 \%$ & $21.4 \%$ & $100.0 \%$ \\
\hline Ditch 3, LO & $8.7 \%$ & $10.1 \%$ & $42.0 \%$ & $4.3 \%$ & $1.4 \%$ & $.0 \%$ & $4.3 \%$ & $21.7 \%$ & $2.9 \%$ & $4.3 \%$ & $100.0 \%$ \\
\hline Ditch 3, UP & $12.9 \%$ & $3.2 \%$ & $35.5 \%$ & $6.5 \%$ & $.0 \%$ & $.0 \%$ & $.0 \%$ & $25.8 \%$ & $.0 \%$ & $16.1 \%$ & $100.0 \%$ \\
\hline Ditch 4 Mn. & $20.0 \%$ & $.0 \%$ & $70.0 \%$ & $.0 \%$ & $.0 \%$ & $.0 \%$ & $.0 \%$ & $.0 \%$ & $.0 \%$ & $10.0 \%$ & $100.0 \%$ \\
\hline Ditch 4, LO & $18.2 \%$ & $.0 \%$ & $54.5 \%$ & $.0 \%$ & $.0 \%$ & $.0 \%$ & $.0 \%$ & $27.3 \%$ & $.0 \%$ & $.0 \%$ & $100.0 \%$ \\
\hline Ditch 4, UP & $8.3 \%$ & $8.3 \%$ & $50.0 \%$ & $.0 \%$ & $.0 \%$ & $.0 \%$ & $.0 \%$ & $25.0 \%$ & $.0 \%$ & $8.3 \%$ & $100.0 \%$ \\
\hline Mixed & $12.5 \%$ & $.0 \%$ & $25.0 \%$ & $.0 \%$ & $.0 \%$ & $.0 \%$ & $.0 \%$ & $50.0 \%$ & $.0 \%$ & $12.5 \%$ & $100.0 \%$ \\
\hline Pit F104 & $.0 \%$ & $.0 \%$ & $33.3 \%$ & $.0 \%$ & $.0 \%$ & $.0 \%$ & $.0 \%$ & $66.7 \%$ & $.0 \%$ & $.0 \%$ & $100.0 \%$ \\
\hline Pit F107 & $18.8 \%$ & $2.1 \%$ & $50.0 \%$ & $4.2 \%$ & $.0 \%$ & $.0 \%$ & $2.1 \%$ & $14.6 \%$ & $2.1 \%$ & $6.3 \%$ & $100.0 \%$ \\
\hline Pit F109 & $12.5 \%$ & $.0 \%$ & $31.3 \%$ & $12.5 \%$ & $6.3 \%$ & $.0 \%$ & $12.5 \%$ & $18.8 \%$ & $.0 \%$ & $6.3 \%$ & $100.0 \%$ \\
\hline Pit F111 & $.0 \%$ & $.0 \%$ & $100.0 \%$ & $.0 \%$ & $.0 \%$ & $.0 \%$ & $.0 \%$ & $.0 \%$ & $.0 \%$ & $.0 \%$ & $100.0 \%$ \\
\hline Total & $14.0 \%$ & $3.6 \%$ & $43.9 \%$ & $4.2 \%$ & $2.1 \%$ & $.6 \%$ & $3.3 \%$ & $17.0 \%$ & $.9 \%$ & $10.4 \%$ & $100.0 \%$ \\
\hline Plowzone & 1.6 & -.3 & -1.1 & .3 & 1.4 & 3.7 & .7 & -.6 & -.6 & -.5 & \\
\hline Block A Mn. & -.4 & -.8 & 1.3 & .2 & -.6 & -.3 & -.8 & -1.2 & -.4 & .7 & \\
\hline Block D Mn. & -1.0 & -.8 & .7 & -.9 & 2.6 & -.3 & -.8 & -1.2 & -.4 & 1.5 & \\
\hline Block F Mn. & .7 & -.7 & 1.2 & .5 & -.5 & -.3 & -.7 & -1.5 & -.4 & -.4 & \\
\hline Block G Mn & 1.0 & .2 & -1.3 & .0 & -.7 & -.4 & -.9 & .0 & -.5 & 2.3 & \\
\hline Ditch 3 Mn. & -1.4 & -.7 & -.1 & -.8 & 1.3 & -.3 & 3.7 & -.9 & -.4 & 1.3 & \\
\hline
\end{tabular}


Table 7.11. Collapsed rim sherd variety data organized by excavation locus. The top section lists counts, the middle percentages, and the lower standardized cell residual values (concluded).

\begin{tabular}{|c|c|c|c|c|c|c|c|c|c|c|c|}
\hline \multirow[b]{2}{*}{ Locus } & \multicolumn{10}{|c|}{ Collapsed Variety } & \multirow[b]{2}{*}{ Total } \\
\hline & 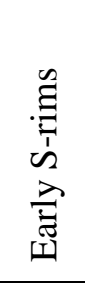 & $\begin{array}{l}\text { D्: } \\
\text { 芯 }\end{array}$ & 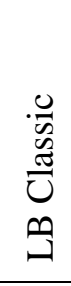 & 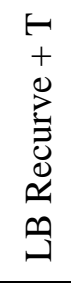 & 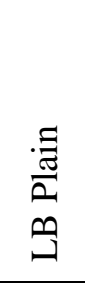 & 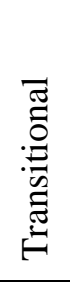 & 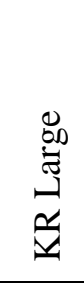 & $\begin{array}{l}\dot{\Xi} \\
\stackrel{\Xi}{\Xi} \\
\underline{z}\end{array}$ & $\begin{array}{l}\stackrel{g}{\Xi} \\
\text { I }\end{array}$ & 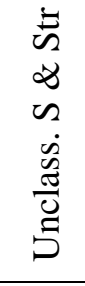 & \\
\hline Ditch 3, LO & -1.2 & 2.9 & -.2 & .1 & -.4 & -.6 & .5 & 1.0 & 1.8 & -1.6 & \\
\hline Ditch 3, UP & -.2 & -.1 & -.7 & .6 & -.8 & -.4 & -1.0 & 1.2 & -.5 & 1.0 & \\
\hline Ditch 4 Mn. & .5 & -.6 & 1.2 & -.6 & -.5 & -.2 & -.6 & -1.3 & -.3 & .0 & \\
\hline Ditch 4, LO & .4 & -.6 & .5 & -.7 & -.5 & -.3 & -.6 & .8 & -.3 & -1.1 & \\
\hline Ditch 4, UP & -.5 & .9 & .3 & -.7 & -.5 & -.3 & -.6 & .7 & -.3 & -.2 & \\
\hline Mixed & -.1 & -.5 & -.8 & -.6 & -.4 & -.2 & -.5 & 2.3 & -.3 & .2 & \\
\hline Pit F104 & -.6 & -.3 & -.3 & -.4 & -.3 & -.1 & -.3 & 2.1 & -.2 & -.6 & \\
\hline Pit F107 & .9 & -.5 & .6 & .0 & -1.0 & -.5 & -.5 & -.4 & .9 & -.9 & \\
\hline Pit F109 & -.2 & -.8 & -.8 & 1.6 & 1.2 & -.3 & 2.0 & .2 & -.4 & -.5 & \\
\hline Pit F111 & -.4 & -.2 & .8 & -.2 & -.1 & -.1 & -.2 & -.4 & -.1 & -.3 & \\
\hline
\end{tabular}

The fragmented condition of the ceramic assemblage suggests that mixing might be a factor; however, data (not presented) on the distribution of collapsed varieties by deposit type suggests that the latter explanation better accounts for the situation. There are no statistically significant differences in the frequencies of pottery varieties found in pit contexts compared to midden or

Table 7.12. Collapsed rim sherd variety data organized by stratigraphic group. None of the cells exhibit standard residual values greater than +2.0 .

\begin{tabular}{|c|c|c|c|c|c|}
\hline \multirow[b]{2}{*}{ Collapsed Variety } & & \multicolumn{3}{|c|}{ Stratigraphic Group } & \multirow[b]{2}{*}{ Total } \\
\hline & & 1 Early & 2 Middle & 3 Late & \\
\hline \multirow[t]{2}{*}{1.00 Early S-rims } & $n$ & 10 & 21 & 6 & 37 \\
\hline & $\%$ & $17.9 \%$ & $12.5 \%$ & $9.2 \%$ & $12.8 \%$ \\
\hline \multirow[t]{2}{*}{ 10.00 Stanton } & $n$ & 2 & 9 & & 11 \\
\hline & $\%$ & $3.6 \%$ & $5.4 \%$ & & $3.8 \%$ \\
\hline \multirow[t]{2}{*}{ 2.00 Le Beau Classic } & $n$ & 25 & 71 & 37 & 133 \\
\hline & $\%$ & $44.6 \%$ & $42.3 \%$ & $56.9 \%$ & $46.0 \%$ \\
\hline \multirow[t]{2}{*}{ 3.00 Le Beau Recurved/T-lip } & $n$ & 1 & 9 & 2 & 12 \\
\hline & $\%$ & $1.8 \%$ & $5.4 \%$ & $3.1 \%$ & $4.2 \%$ \\
\hline \multirow[t]{2}{*}{ 4.00 Le Beau Plain } & $n$ & & 2 & 3 & 5 \\
\hline & $\%$ & & $1.2 \%$ & $4.6 \%$ & $1.7 \%$ \\
\hline \multirow[t]{2}{*}{ 7.00 KR Large } & $n$ & & 6 & 3 & 9 \\
\hline & $\%$ & & $3.6 \%$ & $4.6 \%$ & $3.1 \%$ \\
\hline \multirow[t]{2}{*}{ 8.00 KR Intermediate } & $n$ & 10 & 35 & 3 & 48 \\
\hline & $\%$ & $17.9 \%$ & $20.8 \%$ & $4.6 \%$ & $16.6 \%$ \\
\hline \multirow[t]{2}{*}{9.00 KR Fine } & $n$ & & 3 & & 3 \\
\hline & $\%$ & & $1.8 \%$ & & $1.0 \%$ \\
\hline \multirow[t]{2}{*}{ 5.00 Unclassified S \& Str } & $n$ & 8 & 12 & 11 & 31 \\
\hline & $\%$ & $14.3 \%$ & $7.1 \%$ & $16.9 \%$ & $10.7 \%$ \\
\hline \multirow[t]{2}{*}{ Total } & $n$ & 56 & 168 & 65 & 289 \\
\hline & $\%$ & $100.0 \%$ & $100.0 \%$ & $100.0 \%$ & $100.0 \%$ \\
\hline
\end{tabular}



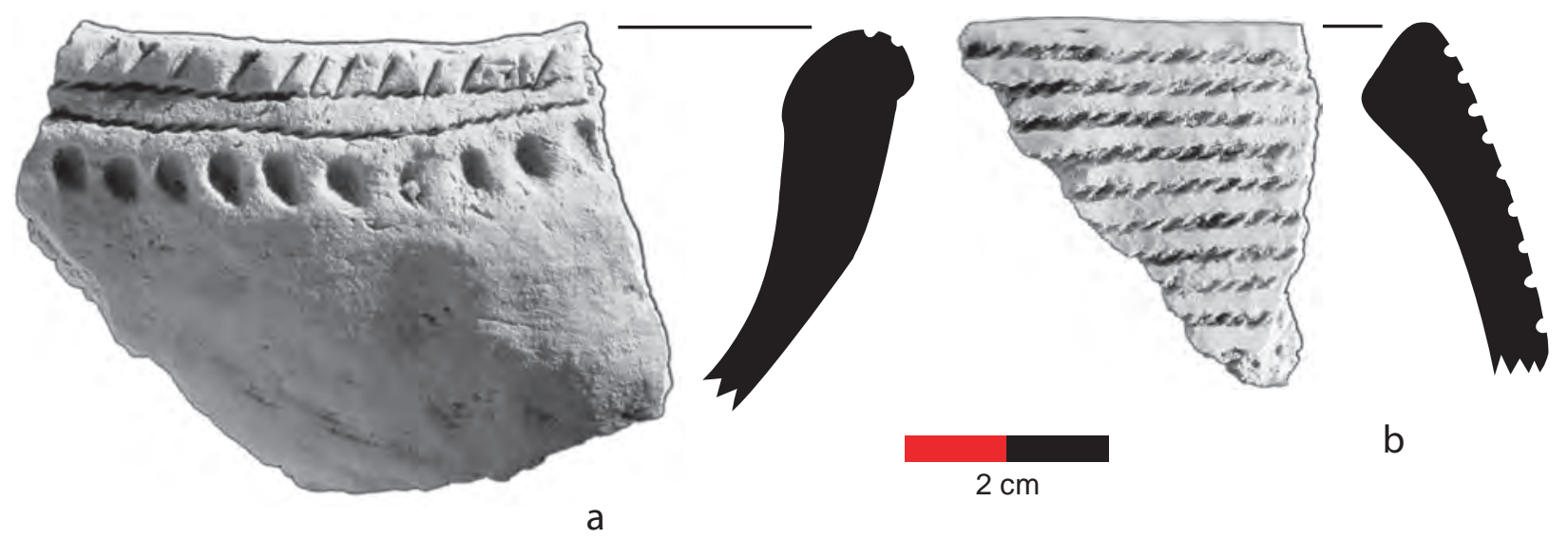

$\mathrm{b}$
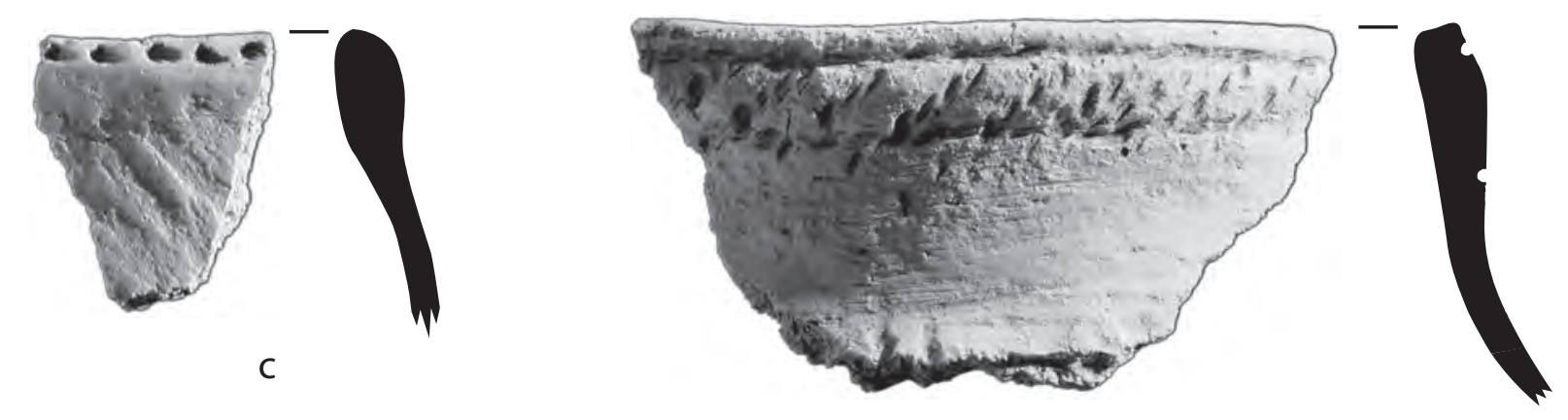

e

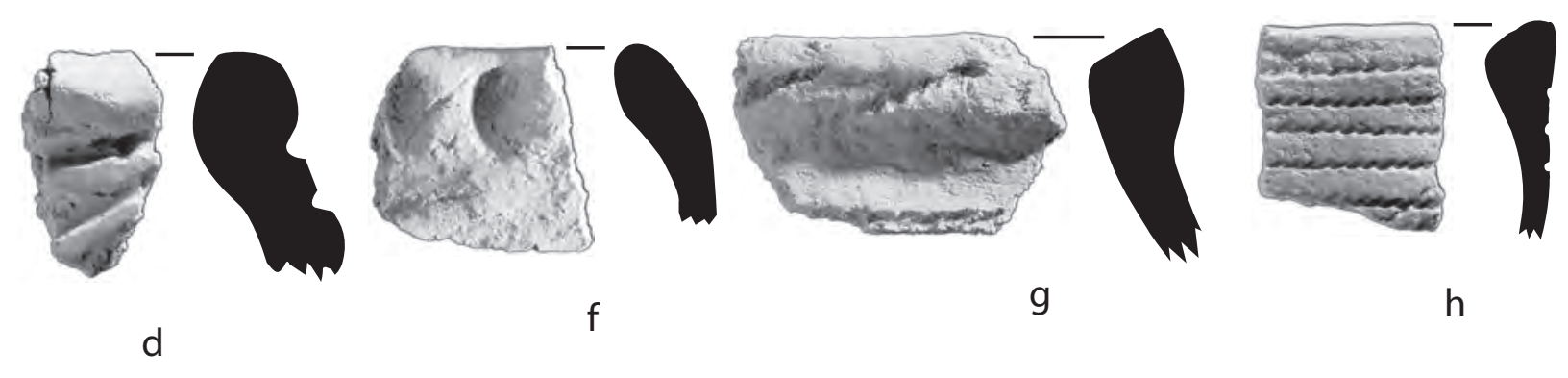

Figure 7.4. Pottery from 2006 Larson collection. a: Bowl without flange variety; b, e: Le Beau Classic variety; c, d, f, g, h: Unclassified Late S-rim variety.

midden and earth contexts, even though sherds from the latter two contexts are much smaller on average (Table 7.8). Because the distribution of pottery types is the same in large pits, which likely were filled quickly, and fortification ditches, which filled much more slowly, it seems probable that all of the features encountered on the northern periphery of the village date to approximately the same period.

Finally, Table 7.13 compares the Larson collapsed variety data with similar data from Double Ditch Village. The methods used to combine pottery types in each collection differed only slightly (see Ahler and Stanford 2004:178-180). Two columns of data are presented summarizing the 2002 and 2003 collections from Double Ditch. The first gives collapsed variety percentages for the Time Period 4 (1490-1600) assemblage only, while the second averages percentages for the Time Period 3 (1600-1650) and Time Period 4 assemblages. There are several informative similarities between the Larson and Double Ditch collections. Le Beau Sperry variety and 
Transitional ware rims, both of which likely first appeared in the middle or latter part of the seventeenth century, are nearly absent from both assemblages. Le Beau Classic, Le Beau Plain, Knife River Large, and Knife River Fine rims are equally common in both collections. These later similarities also suggest that the Larson assemblage pre-dates 1650.

There also are interesting differences between the assemblages. The 2006 Larson collection includes a greater number of rims from types thought to have been manufactured in the early part of the sixteenth century. These include Sanger ware and other early S-rims and Stanton ware. At Double Ditch as well as other sites, unclassified wares (both straight- and S-rims) are more common in the sixteenth century than they are later in time. The percentage of such varieties at Larson is among the highest in the region. Le Beau High Rim, which became progressively more common through time at Slant and Scattered villages, is absent at Larson. Similarly, the relatively small number of Le Beau Recurved rims may also indicate that the Larson assemblage dates to the early 1500s. At Double Ditch, and at Slant Village, Recurved rims are a hallmark of the late 1500s and early 1600s, but are virtually absent at Huff Village and at 32MO291, both of which were occupied in the mid- to late-1400s (Ahler 2000; Ahler and Johnson 2000). So, several indicators suggest that the Larson pottery assemblage dates to the first half of the 1500s.

Table 7.13. Comparison of collapsed variety data from Larson and Double Ditch villages.

\begin{tabular}{ccccc}
\hline & & \multicolumn{3}{c}{ Site } \\
\cline { 3 - 5 } Collapsed Variety & & Larson & $\begin{array}{c}\text { Double Ditch } \\
\text { (TP3 and TP4) }\end{array}$ & $\begin{array}{c}\text { Double Ditch } \\
\text { (TP4 only) }\end{array}$ \\
\hline Early S-rims & & $14.0 \%$ & $7.0 \%$ & $7.0 \%$ \\
Stanton & $\%$ & $3.6 \%$ & $0.0 \%$ & $0.0 \%$ \\
Le Beau Classic & $\%$ & $43.9 \%$ & $44.2 \%$ & $47.9 \%$ \\
Le Beau Recurved/T-lip & $\%$ & $4.2 \%$ & $16.6 \%$ & $18.8 \%$ \\
Le Beau High Rim & $\%$ & $0.0 \%$ & $7.9 \%$ & $2.0 \%$ \\
Le Beau Plain & $\%$ & $2.1 \%$ & $1.1 \%$ & $0.8 \%$ \\
Le Beau Sperry & $\%$ & $0.0 \%$ & $0.6 \%$ & $0.0 \%$ \\
Transitional & $\%$ & $0.6 \%$ & $0.2 \%$ & $0.0 \%$ \\
KR Large & $\%$ & $3.3 \%$ & $3.4 \%$ & $2.3 \%$ \\
KR Intermediate & $\%$ & $17.0 \%$ & $11.3 \%$ & $8.5 \%$ \\
KR Fine & $\%$ & $0.9 \%$ & $2.2 \%$ & $1.8 \%$ \\
Unclassified S \& Str & $\%$ & $10.4 \%$ & $5.4 \%$ & $7.3 \%$ \\
\hline Total $(n)$ & $n$ & 335 & 1136 & 399 \\
\hline
\end{tabular}

Interestingly, Knife River Intermediate variety rims are comparatively common at Larson. The high frequency of Knife River ware is due partly to differences in the pottery ware definitions applied to the Larson assemblage. As discussed previously, rims exhibiting the morphological characteristics of Knife River ware-prominent braces and flaring rims - were classified as Knife River ware, even if they bore tool impressed decoration. At Double Ditch, rims of that type were assigned to the "Unclassified Late Braced Straight Rim" category (Variety 17). Such rims are rare at Double Ditch, making up only 1.8 percent of the Time Period 4 assemblage in the 2002 and 2003 collections. At Larson, they constitute 7.5 percent of the assemblage. Thus, about 9.5 percent of the Larson assemblage (17 percent less 7.5 percent) consists of what can be called "Knife River Cord Impressed.” This is nearly identical to the frequency of such rims at Double Ditch. The strong association at Larson of this variety with what can be called "Knife River Tool Impressed” variety 


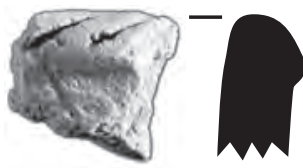

a

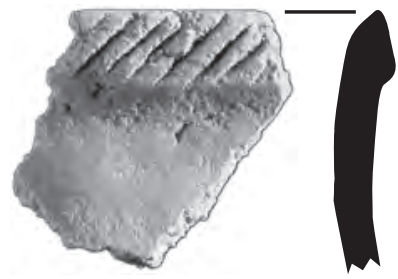

b

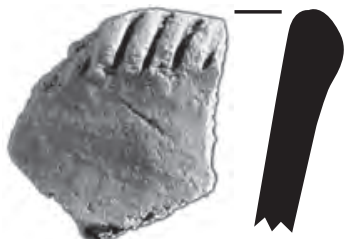

e

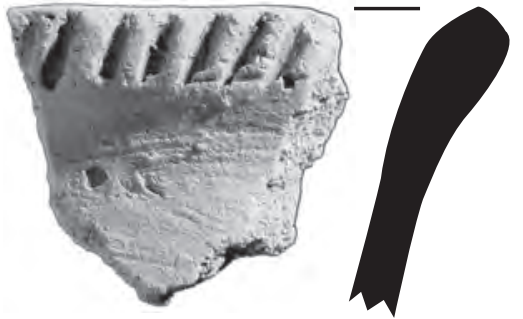

i

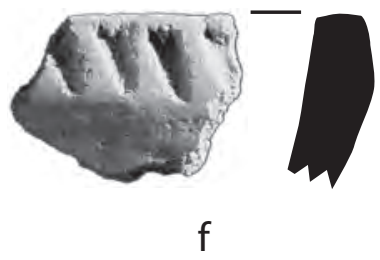

f

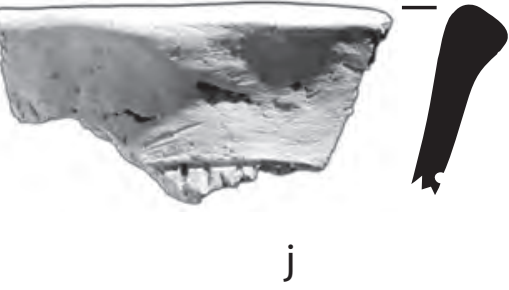

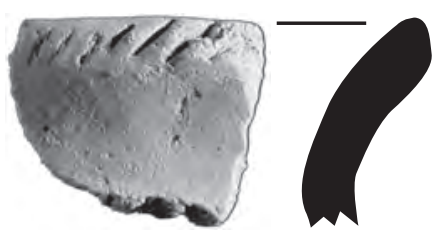

d

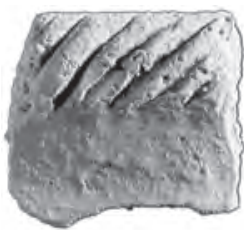

g
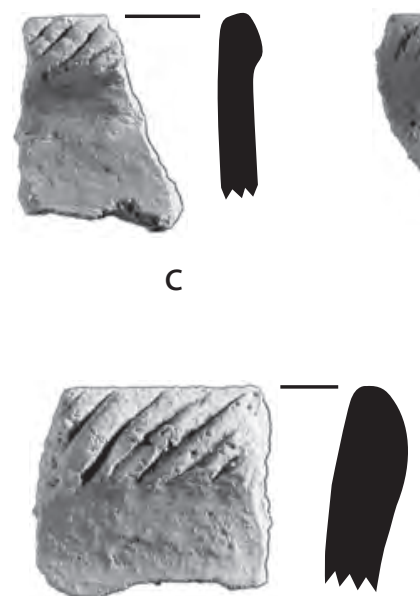

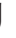

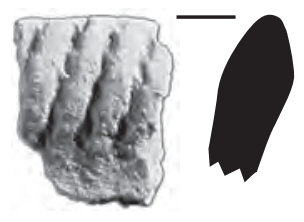

h
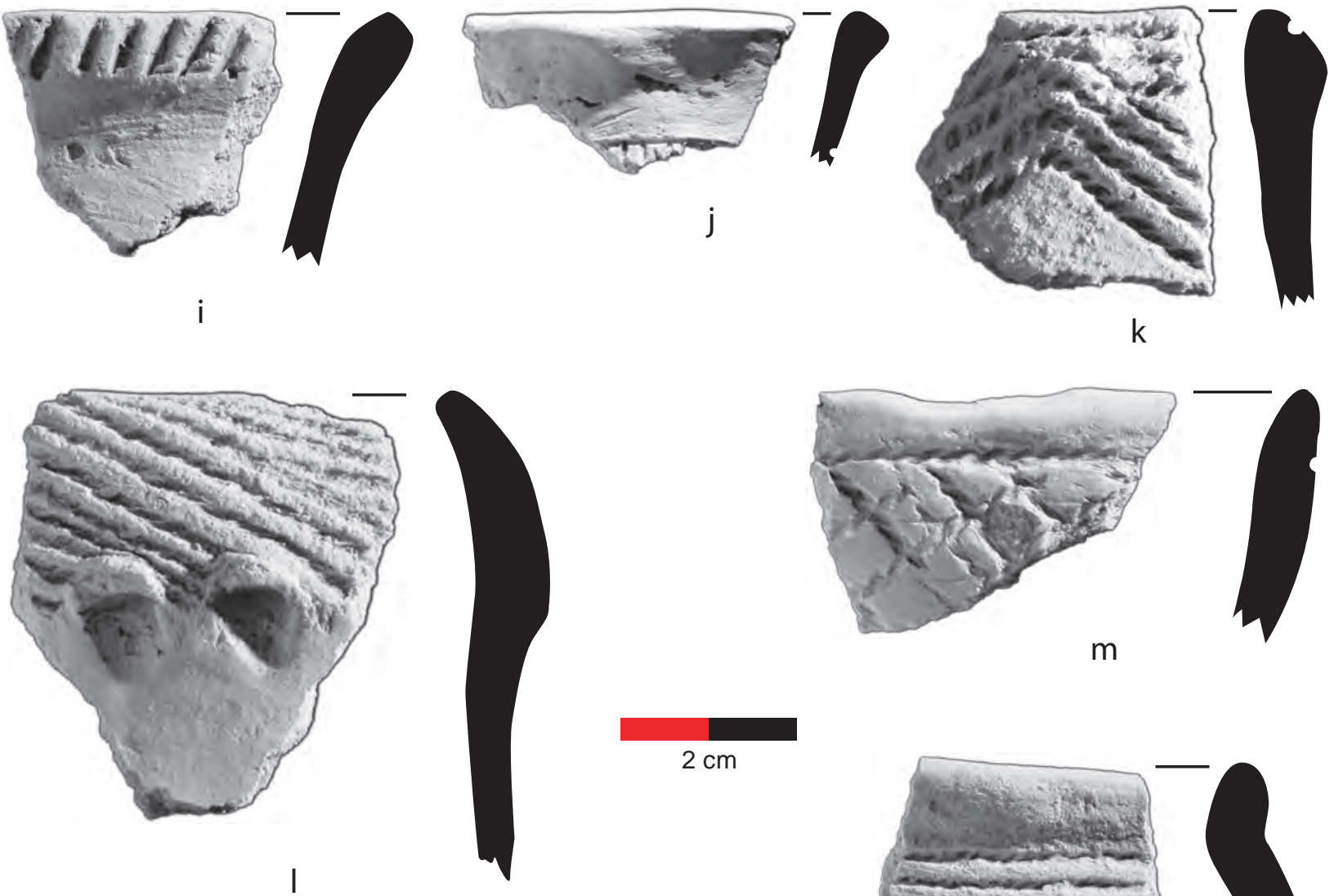

$\mathrm{m}$
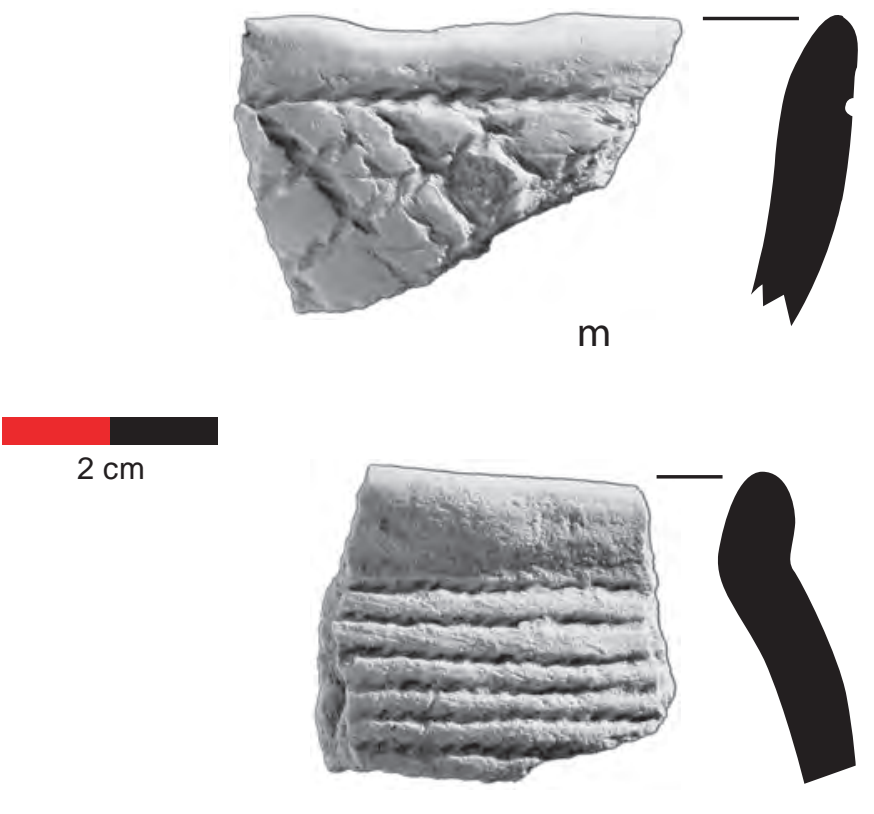

n

Figure 7.5. Pottery from the 2006 Larson collection. a-c: Stanton ware; d-j: Unclassified Late Straight Rim variety; k: Le Beau Classic variety; l: Transitional ware; m: Crosshatched variety; n: Le Beau Recurved variety.

(subsumed under Variety 17 at Double Ditch) and Stanton ware rims has important implications for the origins of Knife River ware. 

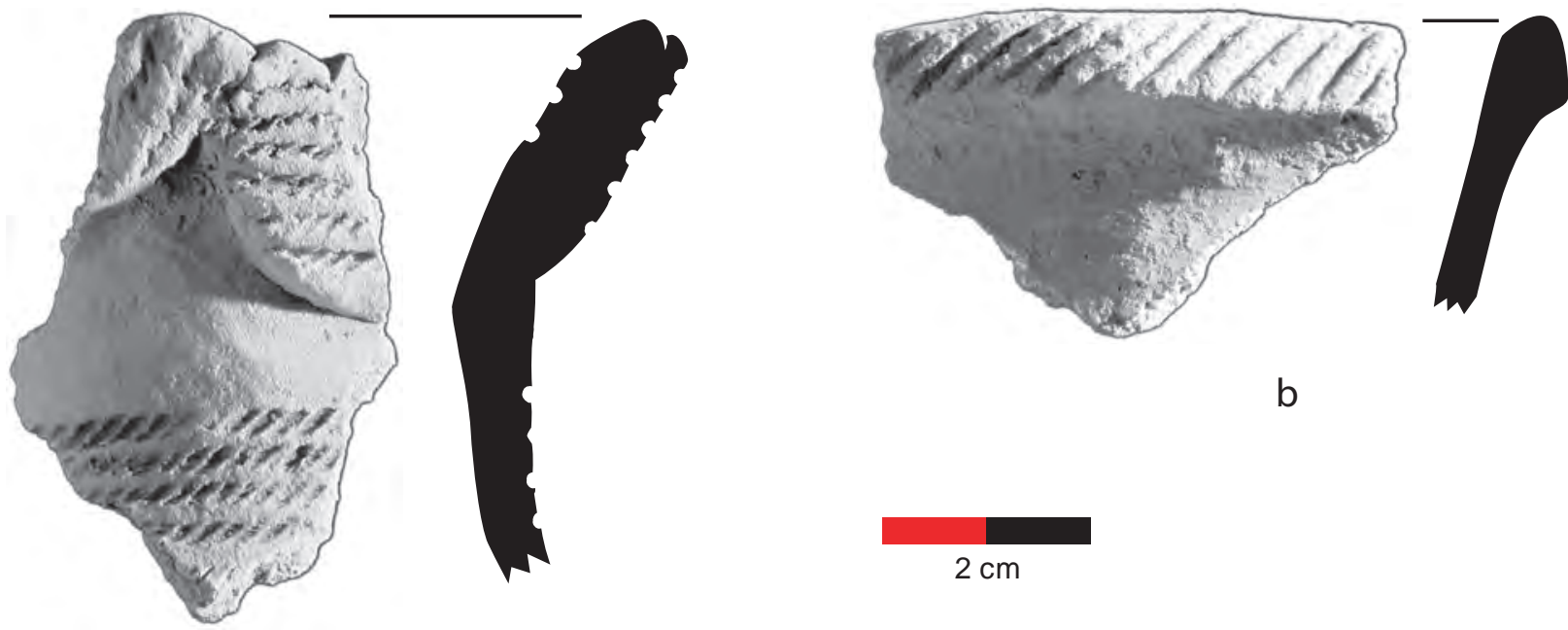

b

a

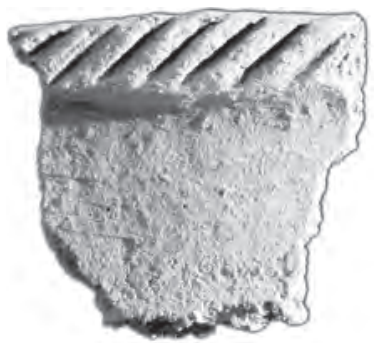

C

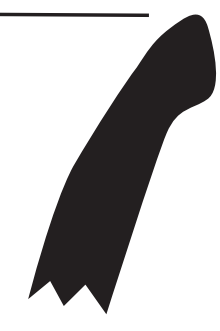

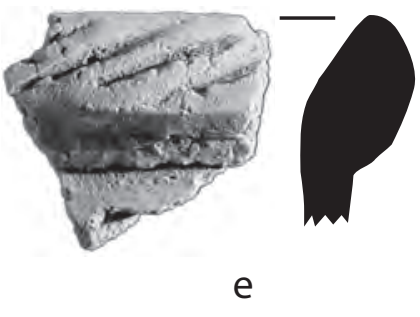

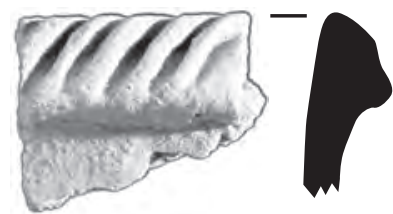

$\mathrm{h}$

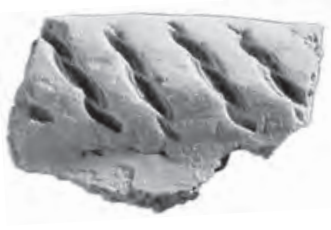

f

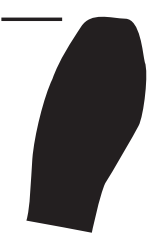

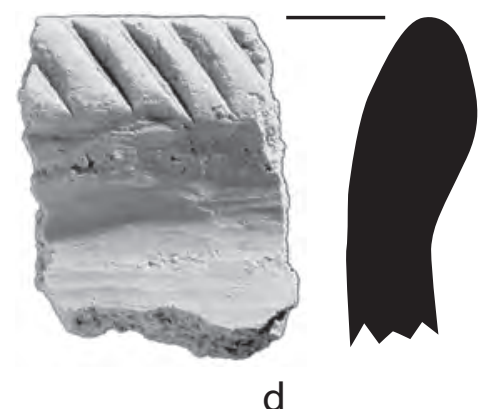

d
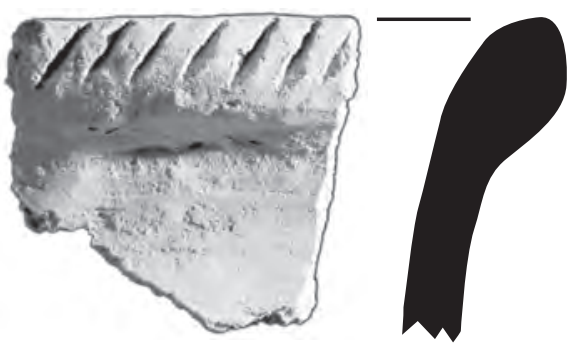

$2 \mathrm{~cm}$

9

Figure 7.6. Pottery from the 2006 Larson collection. a-h: Knife River ware.

It has been known for some time that Knife River ware entered the Heart River ceramic inventory at least by the mid-1500s, rather than the 1600s or even later as was once thought (Ahler et al. 2002; Lehmer et al. 1978). However, scholars have assumed that it was nevertheless introduced from elsewhere, perhaps by one or more of the Hidatsa groups who immigrated to the Heart region at that time. The co-occurrence with Knife River Cord Impressed variety and Stanton ware with Knife River Tool Impressed, which combines the decorative pattern of Stanton ware with the morphology of Knife River ware, in a sixteenth-century context suggests that Knife River ware instead may have developed in the Heart region out of earlier straight-rim wares. If so, the 2006 Larson collection may be fairly typical of early 1500s pottery assemblages in the region. Other 
similar assemblages include those from the Square Butte Creek, Dennison, and Hensler sites, which Ahler (2001:83) assigns to Pottery Group 4.

\section{Rim Form and Attribute Analysis}

This section presents data derived from detailed coding of seven variables. Nominal data were collected on rim form (not presented), lip shape, and dominant decorative technique. Metric data were collected on the number of parallel horizontal cord impressions, on the width and spacing of cord impressions, and on brace height. The sample of 502 size G1 and G2 rim sherds used in the ceramic quick-code study also was used for this analysis. No vessel matching was attempted and no data were collected on size G3 sherds. The distribution of brace heights and the frequencies of various decorative techniques likely have been affected by the exclusion of small rim sherds, as mentioned previously.

Table 7.14 presents data on the distribution of lip shapes. Rounded lips are the most common, but inslanted lips occur on 13.7 percent of the rims. It should be noted that this is a minimum figure, because the data in Table 7.14 include Variety 10 rims (Le Beau Classic or Recurved) for which lip shape generally cannot be determined. Inslanted lips are less common at Slant (9.3 percent) and far less common at Boley (3.3 percent). Lip shape data have not been recorded for the Double Ditch collections. The high frequency of inslanted lips at Larson does not seem to be related to overall rim form. Some S-rim vessels exhibit an interior brace just below the lip, which gives the interior wall a different shape than the exterior, making the lip appear asymmetrical. In the Boley assemblage, 55.3 percent of the Le Beau Classic variety vessels have an interior brace and 6.5 percent have inslanted lips. By contrast, 30.9 percent of the Le Beau Classic rims in the Larson collection have an interior brace, but 34.5 percent have inslanted lips. Thus, lip form does not appear to be correlated with rim form. Stanton ware rims in the 2006 Larson collection exhibit several different lip shapes, but the complex lip shapes seen in Stanton ware rims from the Knife region are absent.

Table 7.14. Frequency of pottery lip shape classes organized by variety, 2006 Larson collection.

\begin{tabular}{|c|c|c|c|c|c|c|c|c|c|}
\hline \multirow[b]{2}{*}{ Variety } & \multicolumn{8}{|c|}{ Lip Shape } & \multirow[b]{2}{*}{ Total } \\
\hline & 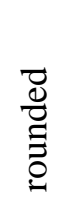 & & 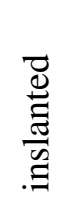 & 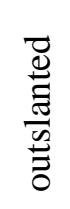 & 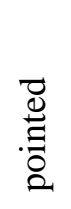 & 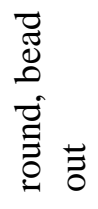 & 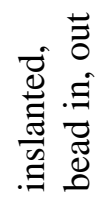 & 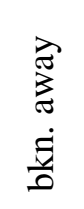 & \\
\hline 2 Sanger & & & 3 & & & & & 4 & 7 \\
\hline 3 Un Early S & & & & & & & & 2 & 2 \\
\hline 4 LB Classic & 77 & 7 & 48 & & 4 & & & 3 & 139 \\
\hline 4.1 LB Fine & 2 & 1 & & & & & & 5 & 8 \\
\hline 4.2 LB T-lip & & & & & & 2 & 1 & & 3 \\
\hline 5 LB Recurv & 3 & 1 & 6 & & & & & 1 & 11 \\
\hline 9 LB Plain & 5 & 1 & 1 & & & & & & 7 \\
\hline $10 \mathrm{LB} 4+5$ & 1 & & 1 & & & & & 160 & 162 \\
\hline 12 Un Late S & 6 & 2 & 5 & & & & & 2 & 15 \\
\hline 15 Stanton & 7 & 1 & 2 & 1 & 1 & & & & 12 \\
\hline 16 Un Late Str & 10 & 3 & & & & & & & 13 \\
\hline
\end{tabular}


Table 7.14. Frequency of pottery lip shape classes organized by variety, 2006 Larson collection (concluded).

\begin{tabular}{|c|c|c|c|c|c|c|c|c|c|}
\hline \multirow[b]{2}{*}{ Variety } & \multicolumn{8}{|c|}{ Lip Shape } & \multirow[b]{2}{*}{ Total } \\
\hline & 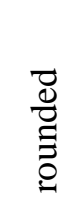 & 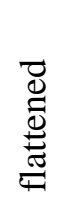 & 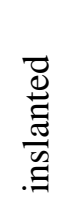 & 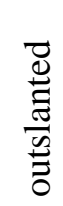 & 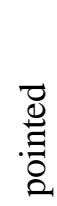 & 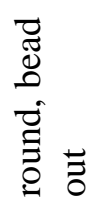 & 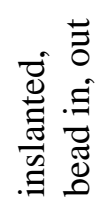 & 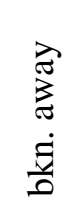 & \\
\hline 16.1 Cross-hatched & 3 & & & & & & & & 3 \\
\hline 17 Un Late Str Br & & & & & 1 & & & 2 & 3 \\
\hline 19 Transitional & 2 & & & & & & & & 2 \\
\hline 21.0 KR Large & 4 & & & & & & & 1 & 5 \\
\hline 21.1 KR Large, cord & 6 & & & & & & & & 6 \\
\hline 22.0 KR Inter. & 39 & 3 & 2 & & 3 & & & 8 & 55 \\
\hline 22.1 KR Inter., cord & 2 & & & & & & & & 2 \\
\hline 23.0 KR Fine & 2 & & & & & & & & 2 \\
\hline 23.1 KR Fine, cord & 1 & & & & & & & & 1 \\
\hline 27 Bowl, no flange & & 1 & & & & & & & 1 \\
\hline 33 LB or Sanger & 4 & 1 & 1 & & & & & 32 & 38 \\
\hline 99 Unclassified & & & & & & & & 5 & 5 \\
\hline Total & 174 & 21 & 69 & 1 & 9 & 2 & 1 & 225 & 502 \\
\hline
\end{tabular}

Table 7.15 presents data on decorative technique. Cord impression is the dominant technique, but two secondary patterns are noteworthy. The first is the decorative diversity present in the Unclassified Late S-rim category (Variety 12). Five different techniques are represented and only about half of the rims are cord impressed. The second pattern is the large number of tool impressed Knife River Intermediate variety rims. As mentioned above, tool impression is the dominant technique used to decorate Stanton ware vessels but it was used to decorate Knife River ware so infrequently that such vessels almost always have been put into a separate class (Variety 17). However, if Knife River ware developed from Stanton ware, it seems reasonable that assemblages dating to the early 1500s, including the 2006 Larson collection, would contain vessels exhibiting morphologically and decoratively intermediate or transitional characteristics. If so, it appears that changes in rim form (from straight and unbraced to outflaring and braced) took place before changes in decorative technique (from tool impressed to cord impressed).

Table 7.15. Frequency of various decorative techniques organized by variety, 2006 Larson collection.

\begin{tabular}{|c|c|c|c|c|c|c|c|c|}
\hline \multirow[b]{2}{*}{ Variety } & \multicolumn{7}{|c|}{ Dominant Decorative Technique } & \multirow[b]{2}{*}{ Total } \\
\hline & 0 Plain & 1 Cord & 2 Tool & 3 Incise & 9 Finger & 13 Multi. & 99 Uncl. & \\
\hline 2.00 Sanger & & 7 & & & & & & 7 \\
\hline 3.00 Un Earl S & 1 & 1 & & & & & & 2 \\
\hline 4.00 LB Classic & & 137 & & & & & 2 & 139 \\
\hline 4.10 LB Fine & & 7 & 1 & & & & & 8 \\
\hline 4.20 LB T-lip & & 3 & & & & & & 3 \\
\hline 5.00 LB Recurv & & 11 & & & & & & 11 \\
\hline 9.00 LB Plain & 7 & & & & & & & 7 \\
\hline $10.00 \mathrm{LB} 4+5$ & & 157 & & & & & 5 & 162 \\
\hline 12.00 Un Late S & & 8 & 3 & 2 & 1 & 1 & & 15 \\
\hline 15.00 Stanton & 1 & 1 & 10 & & & & & 12 \\
\hline 16.00 Un Late Str & & 5 & 7 & 1 & & & & 13 \\
\hline
\end{tabular}


Table 7.15. Frequency of various decorative techniques organized by variety, 2006 Larson collection (concluded).

\begin{tabular}{|c|c|c|c|c|c|c|c|c|}
\hline \multirow[b]{2}{*}{ Variety } & \multicolumn{7}{|c|}{ Dominant Decorative Technique } & \multirow[b]{2}{*}{ Total } \\
\hline & 0 Plain & 1 Cord & 2 Tool & 3 Incise & 9 Finger & 13 Multi. & 99 Uncl. & \\
\hline 16.10 Cross-hatch & & 3 & & & & & & 3 \\
\hline 17.00 Un Late Str $\mathrm{Br}$ & 1 & 1 & 1 & & & & & 3 \\
\hline 19.00 Transitional & & 2 & & & & & & 2 \\
\hline 21.00 KR Large & & 4 & 1 & & & & & 5 \\
\hline 21.10 KR Large, int. & & 6 & & & & & & 6 \\
\hline 22.00 KR Inter. & & 27 & 25 & & & & 3 & 55 \\
\hline 22.10 KR Inter., int. & & 2 & & & & & & 2 \\
\hline 23.00 KR Fine & & 2 & & & & & & 2 \\
\hline 23.10 KR Fine, int. & & 1 & & & & & & 1 \\
\hline 27.00 Bowl w/o flge & & & & & & 1 & & 1 \\
\hline 33.00 LB or Sanger & & 38 & & & & & & 38 \\
\hline 99.00 Unclass & 1 & 1 & & & & & 3 & 5 \\
\hline Total & 11 & 424 & 48 & 3 & 1 & 2 & 13 & 502 \\
\hline
\end{tabular}

Data on the number of parallel horizontal cord impressions are given in Table 7.16. The median number of cord lines is 7 and the mode is 5 . These results do not differ greatly from those of other recent analyses. At Boley Village, the number of horizontal lines on 14 vessels for which data are available ranges from 3 to 8, with a median and mode of 4 . Similar data are not available for Double Ditch village.

Table 7.16. Number of parallel horizontal cord impressions on Le Beau and Knife River ware rims.

\begin{tabular}{lcllllllrr}
\hline & \multicolumn{7}{c}{ Number of Cord Impressions } & \\
\cline { 2 - 9 } Variety & 4 & 5 & 6 & 7 & 8 & 9 & 10 & 12 & Total \\
\hline 4.00 LB Classic & 1 & 4 & 2 & 1 & 1 & 2 & 2 & 1 & 14 \\
4.10 LB Fine & & & & 1 & & & & & 1 \\
22.00 KR Intermediate & & & & & 1 & & & 1 \\
\hline Total & 1 & 4 & 2 & 2 & 2 & 2 & 2 & 1 & 16 \\
\hline
\end{tabular}

Figure 7.7 illustrates the weak but statistically significant relationship between cord diameter and cord spacing on Le Beau and Sanger ware rims. In the graph, Le Beau ware rims (all varieties) are represented by crosses, Sanger ware rims (Variety 2) are represented by closed triangles, and possible Sanger ware rims (Variety 33) are represented by closed squares. The correlation between cord diameter and spacing is significant $(p \leq 0.01)$, although the $\mathrm{r}^{2}$ value is just 0.42. As cord diameter increases, cord spacing also increases. It seems likely that these two variables are not entirely independent, because thick cords require more space. However, there are few examples of widely-spaced thin cords, indicating that the correlation between them also reflects aesthetic factors. Interestingly, although the distributions of both cord spacing and cord diameter values for Le Beau and Sanger ware overlap substantially they are statistically different (Table 7.17). If in fact the Le Beau ware vessels in the collection were in use at approximately the same time as the Sanger ware vessels, which as mentioned previously seems probable, then this result indicates that the reduction in cord size and diameter thought to be a region-wide temporal trend is also a synchronic stylistic feature. That is, decoration with large, widely-spaced cords is an essential feature of Sanger ware, not simply a byproduct of its greater mean age. Because the characteristics of cord impressed decoration do not appear to vary independently, it is possible to 


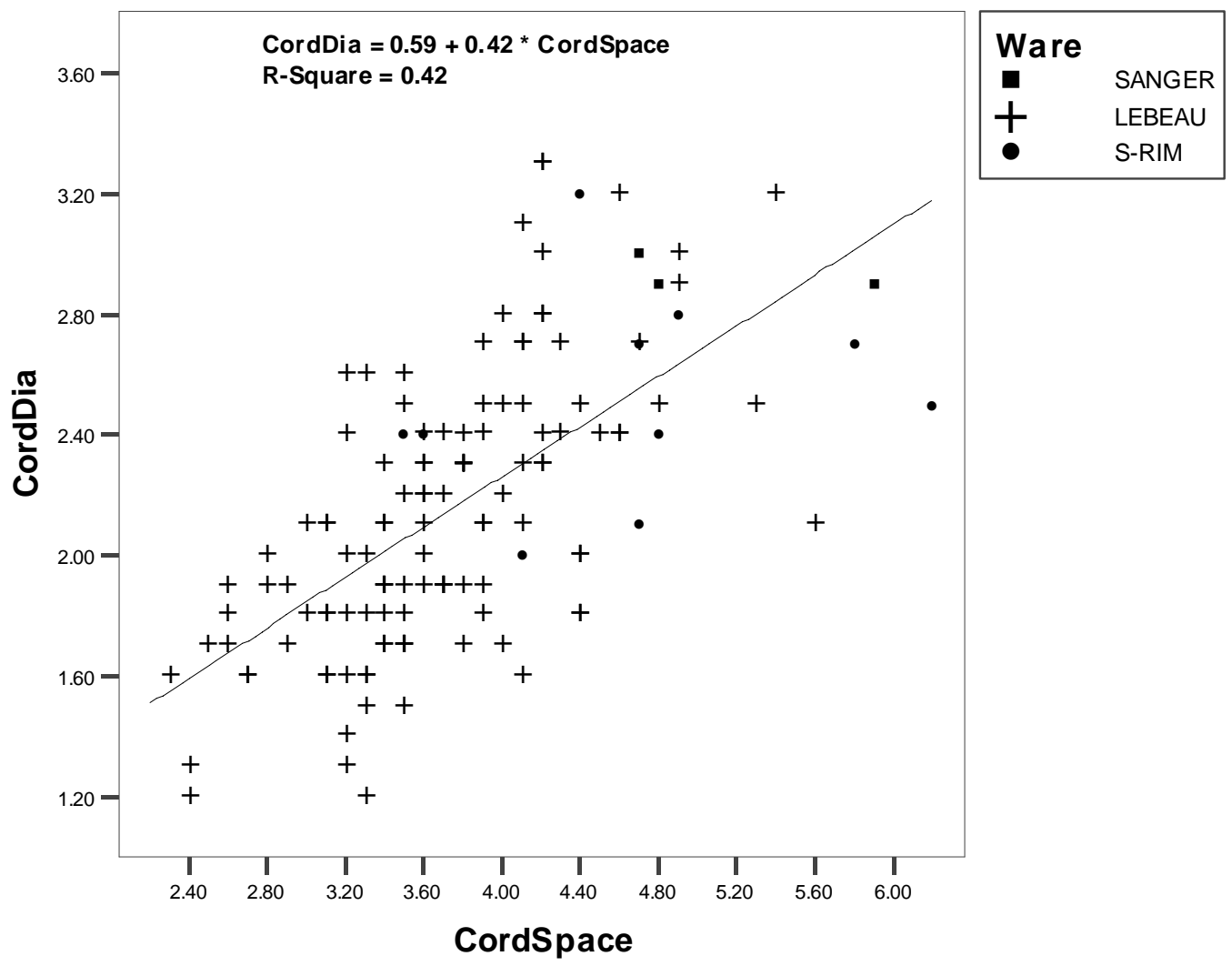

Figure 7.7. Scatterplot showing the relationship between cord impression spacing and cord impression diameter for three pottery varieties, 2006 Larson collection.

Table 7.17. Comparison of cord diameter and cord spacing measurements for three ceramic ware groups, 2006 Larson collection.

\begin{tabular}{|c|c|c|c|c|c|c|c|c|c|}
\hline & & \multirow[t]{2}{*}{$n$} & \multirow[t]{2}{*}{ Mean } & \multirow[t]{2}{*}{$\begin{array}{c}\text { Std. } \\
\text { Deviation }\end{array}$} & \multirow[t]{2}{*}{$\begin{array}{l}\text { Std. } \\
\text { Error }\end{array}$} & \multicolumn{2}{|c|}{$\begin{array}{l}\text { 95\% Confidence } \\
\text { Interval for Mean }\end{array}$} & \multirow[t]{2}{*}{ Min. } & \multirow[t]{2}{*}{ Max. } \\
\hline & & & & & & Lower & Upper & & \\
\hline \multirow[t]{4}{*}{ CordSpace } & 1.10 SANGER & 3 & 5.1333 & .66583 & .38442 & 3.4793 & 6.7874 & 4.70 & 5.90 \\
\hline & 5.00 LEBEAU & 116 & 3.6776 & .63740 & .05918 & 3.5604 & 3.7948 & 2.30 & 5.60 \\
\hline & 10.00 S-RIM & 10 & 4.6700 & .85641 & .27082 & 4.0574 & 5.2826 & 3.50 & 6.20 \\
\hline & Total & 129 & 3.7884 & .73332 & .06456 & 3.6606 & 3.9161 & 2.30 & 6.20 \\
\hline \multirow[t]{4}{*}{ CordDia } & 1.10 SANGER & 7 & 2.7429 & .43534 & .16454 & 2.3402 & 3.1455 & 2.10 & 3.30 \\
\hline & 5.00 LEBEAU & 174 & 2.1247 & .46473 & .03523 & 2.0552 & 2.1943 & 1.20 & 3.50 \\
\hline & 10.00 S-RIM & 21 & 2.5810 & .32957 & .07192 & 2.4309 & 2.7310 & 2.00 & 3.20 \\
\hline & Total & 202 & 2.1936 & .48233 & .03394 & 2.1266 & 2.2605 & 1.20 & 3.50 \\
\hline & & & \multicolumn{2}{|c|}{ Sum of Squares } & $\mathrm{df}$ & \multicolumn{2}{|c|}{ Mean Square } & $\mathrm{F}$ & Sig. \\
\hline \multirow[t]{3}{*}{ CordSpace } & \multirow{2}{*}{\multicolumn{2}{|c|}{$\begin{array}{l}\text { Between Groups } \\
\text { Within Groups }\end{array}$}} & \multicolumn{2}{|c|}{14.623} & 2 & 7.31 & & \multirow[t]{2}{*}{16.994} & .000 \\
\hline & & & \multicolumn{2}{|c|}{54.209} & 126 & .430 & & & \\
\hline & \multicolumn{2}{|l|}{ Total } & \multicolumn{2}{|c|}{68.833} & 128 & & & \multirow{3}{*}{14.894} & \\
\hline \multirow[t]{3}{*}{ CordDia } & \multirow{2}{*}{\multicolumn{2}{|c|}{$\begin{array}{l}\text { Between Groups } \\
\text { Within Grouns }\end{array}$}} & \multicolumn{2}{|c|}{6.088} & 2 & 3.04 & & & .000 \\
\hline & & & \multirow{2}{*}{\multicolumn{2}{|c|}{$\frac{40.673}{46.762}$}} & 199 & .204 & & & \\
\hline & \multicolumn{2}{|l|}{ Total } & & & 201 & & & & \\
\hline
\end{tabular}


have greater confidence in the assignment of particular specimens to particular types using those criteria alone.

Figure 7.8 illustrates the distribution of Knife River ware brace heights. The mean brace height is $12.9 \mathrm{~mm}$, with a standard deviation of $2.6 \mathrm{~mm}$. At Slant Village, mean brace heights increased over time, from $15.5 \mathrm{~mm}$ for the earliest time period to 16.8 for the most recent.

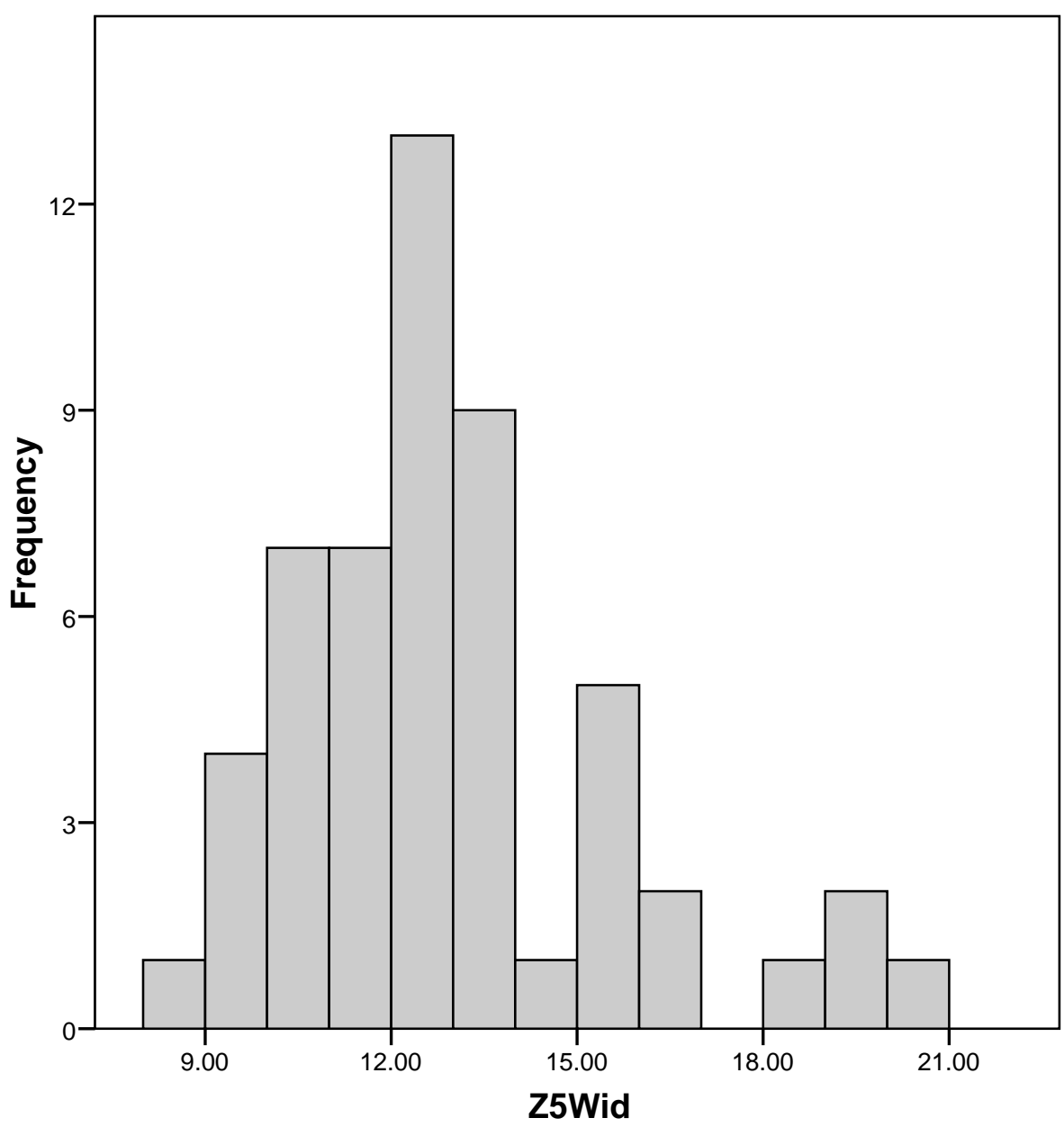

Mean $=12.8943$ Std. Dev. $=2.62908$ $N=53$

Figure 7.8. Distribution of brace heights on Knife River ware rims, 2006 Larson collection.

\section{Summary}

Analysis of the ceramic sample from the 2006 excavations at Larson Village has provided information about the likely age of the village, about formation processes affecting the make up of the excavated assemblage, and about the connections between Larson and other settlements in the Heart region. The findings include: 
1. Data on sherd size indicate that, compared to assemblages from other Heart region sites, the Larson assemblage is moderately to severely fragmented. Very likely this is a result of trampling and repeated transport. The remains of broken ceramic vessels initially would have been deposited in abandoned pits or midden mounds along with other kinds of domestic refuse. People or animals walking on or digging into the mounds and pits would have scattered their contents, causing further fragmentation. Later, these artifacts were washed or dumped into nearby topographic depressions, including disused fortification ditches or borrow basins, either by gradual surface erosion or by intentional sediment transport. Because these secondary deposits may derive from several sources, caution should be used in making chronological interpretations about their contents. This problem may be particularly acute for the Ditch 4 assemblage, given the non-contemporaneity of the associated radiocarbon dates.

2. Typologically, the Larson assemblage is fairly homogenous. Early S-rims are present in all but three contexts (two of which include fewer than 4 rims), at frequencies ranging from 6 to 24 percent. The distribution of Knife River ware is similar. Only 12 Stanton ware rims were documented, but those occur in 6 separate loci. Body sherd surface treatment data also show a similar homogeneous pattern. The potential for mixed deposits notwithstanding, these results suggest that the deposits investigated in 2006 do not vary greatly in age. This interpretation is bolstered by the fact that the frequencies of different pottery wares and varieties do no vary among deposit types.

3. Ware and variety data support the conclusion that the village was founded well before 1650 . Sperry ware, a late-seventeenth century horizon marker, is entirely absent. Transitional ware, thought to post-date 1650 is present only in the plowzone. The presence of a few Stanton ware rims and a significant number of early S-rims suggests that the founding date of the village is very likely to have been much earlier, in the late fifteenth or early sixteenth centuries. In fact, the 2006 Larson assemblage is quite similar in make up to Ahler's (2001:83) Pottery Group 4, thought to date to the period 1475-1525. Perhaps significantly, one of the sites assigned to Pottery Group 4, the Square Butte Creek site, is located directly across the Missouri from Larson, while two others (Dennison and Hensler) are located upstream in the Knife region.

4. The Larson assemblage shares a number of characteristics with the Time Period 4 assemblage from Double Ditch. The proportion of Le Beau Classic variety in both assemblages is roughly equal. A small number of Knife River Large and Knife River Fine vessels are present in both assemblages. Unclassified wares are abundant in both villages. However, there also are significant differences. Le Beau Recurved vessels are far less common at Larson. Early wares (both straight and S-rim) are more common. These differences may signal that Larson was founded slightly earlier than Double Ditch, given what is known about regional ceramic trends in the fifteenth and sixteenth centuries.

5. However, and somewhat surprisingly, Knife River Intermediate vessels are more common at Larson than they are in pre-1600 contexts at Double Ditch. For some time it has been argued that Knife River ware made its appearance in the Heart region during the 1500s, and that it slowly increased in frequency over time, eventually supplanting Le Beau ware as the dominant ceramic type in the late 1700s. The high percentage of Knife River ware in the Larson assemblage may indicate that it was produced even earlier than has been thought, in the early 1500s. The fact that nearly half of the braced, excurvate rims are decorated with tool impressions lends support to the argument that Knife River ware developed out of earlier forms. 
6. Data on the size and spacing of cords used to decorate Sanger ware and Le Beau ware vessels indicate that decorative techniques are correlated with rim forms. It has been known for some time that cord diameters and cord spacing decreased over time (e.g. Ahler et al. 2002:11.82). The Larson data suggest that this is not merely a temporal trend, but is linked also to ceramic style. If the Le Beau and Sanger rims in the collection were produced at roughly the same time, then on average different sized cords were used to decorate each type. This supports the notion that Sanger ware and Le Beau ware vessels can be considered useful types, even though they grade into one another. 


\section{References Cited}

Ahler, Stanley A.

2000 Pottery and Related Objects. In Report of Archaeological Investigations Along Highway 1806, Morton County, North Dakota, edited by Stanley A. Ahler, Michael D. Metcalf, and Carole L. Graham, pp. 209-256. Metcalf Archaeological Consultants, Eagle, Colorado. Submitted to the North Dakota Department of Transportation, Bismarck.

2001 Analysis of Curated Plains Village Artifact Collections from the Heart, Knife, and Cannonball Regions, North Dakota. Research Contribution No. 42. PaleoCultural Research Group, Flagstaff, Arizona. Submitted to the State Historical Society of North Dakota, Bismarck.

Ahler, Stanley A., and Kenneth L. Kvamme (editors)

2000 New Geophysical and Archaeological Investigations at Huff Village State Historic Site (32MO11), Morton County, North Dakota. Research Contribution No. 26. PaleoCultural Research Group, Flagstaff, Arizona. Submitted to the State Historical Society of North Dakota, Bismarck.

Ahler, Stanley A., and Craig Johnson

2000 Pottery Analysis. In New Geophysical and Archaeological Investigations at Huff Village State Historic Site (32MO11), Morton County, North Dakota, edited by Stanley A. Ahler, pp. 67-79. Research Contribution No. 26. PaleoCultural Research Group, Flagstaff,

Arizona. Submitted to the State Historical Society of North Dakota, Bismarck.

Ahler, Stanley A., and Anthony A. Swenson

1985 A Manual for Describing and Coding Ceramic Vessels from the Knife-Heart Region of the Middle Missouri Subarea, North Dakota. Contribution No. 227. Department of

Anthropology, University of North Dakota, Grand Forks. Submitted to the National Park Service, Midwest Archaeological Center, Lincoln, Nebraska.

Ahler, Stanley A., and Stacey Madden

2005 Pottery Analysis. In Archaeological Investigations During 2004 at Double Ditch State Historic Site, North Dakota, edited by Stanley A. Ahler, pp. 181-220. Research

Contribution No. 65. PaleoCultural Research Group, Flagstaff, Arizona. Submitted to the State Historical Society of North Dakota, Bismarck.

Ahler, Stanley A., Stacey Madden, and Mark D. Mitchell

2006 Pottery Analysis. In Geophysical Survey and Test Excavation During 2005 at Boley Village (32MO37), North Dakota, edited by Stanley A. Ahler, pp. 83-137. Research Contribution No. 74. PaleoCultural Research Group, Flagstaff, Arizona. Submitted to the State Historical Society of North Dakota, Bismarck.

Ahler, Stanley A., and Stephanie Stanford

2004 Pottery Analysis. In Archaeological Investigations During 2003 at Double Ditch State Historic Site, North Dakota, edited by Stanley A. Ahler, pp. 153-186. Research

Contribution No. 60. PaleoCultural Research Group, Flagstaff, Arizona. Submitted to the State Historical Society of North Dakota, Bismarck.

Ahler, Stanley A., and Vince Warner

2003 Pottery Analysis. In Archaeological Investigations During 2001 and 2002 at Double Ditch State Historic Site, North Dakota, edited by Stanley A. Ahler, pp. 141-170. Research Contribution No. 56. PaleoCultural Research Group, Flagstaff, Arizona. Submitted to the State Historical Society of North Dakota, Bismarck. 
Ahler, Stanley A., Vince Warner, and Monicque Smail

2002 Pottery Analysis. In Prehistory on First Street NE: The Archaeology of Scattered Village in Mandan, North Dakota, edited by Stanley A. Ahler, pp. 11.1-11.88. Research

Contribution No. 40. PaleoCultural Research Group, Flagstaff, Arizona. Submitted to the City of Mandan, North Dakota, and the North Dakota Department of Transportation, Bismarck.

Lehmer, Donald J.

1954 Archaeological Investigations in the Oahe Dam Area, South Dakota, 1950-1951. Bureau of American Ethnology Bulletin 158. River Basin Surveys Papers. Smithsonian Institution, Washington, D.C.

Lehmer, Donald J., Christopher L. Dill, and W. Raymond Wood

1978 The Knife River Phase. Department of Anthropology and Sociology, Dana College, Blair, Nebraska. Submitted to USDI, Interagency Archaeological Services, Denver.

Speakman, Robert J., Stanley A. Ahler, and Kim Breakey

1997 Pottery. In Archaeology of the Mandan Indians at On-A-Slant Village (32MO26), Fort Abraham Lincoln State Park, Morton County, North Dakota, edited by Stanley A. Ahler, pp. 197-260. Office of Research and Graduate Studies, Northern Arizona University, Flagstaff. Submitted to the North Dakota Parks and Recreation Department, Bismarck.

Wood, W. Raymond

1971 Biesterfeldt: A Post-Contact Coalescent Site on the Northeastern Plains. Contributions to Anthropology No 15. Smithsonian Institution, Washington, D.C. 


\title{
8. Modified Stone AnAlysis
}

\author{
George T. Crawford and Mark D. Mitchell
}

\section{Introduction}

This chapter discusses the analytic methods used in the study of modified stone remains and presents data on the distribution of chipped stone flaking debris and stone tool classes among the six excavation blocks and 20 analytic loci. Notable stone tools are illustrated and limited comparisons are drawn between the Larson collection and recently-excavated collections from contemporaneous sites in the Heart region. The main goal of this analysis is to generate a basic descriptive data set that eventually can be integrated with comparable data sets from other villages. To do so, we focus on two common analytic domains, raw material selection and production technology. Data on raw material selection can be used to map out regions from which the settlement's residents most frequently obtained raw materials. In addition, the presence of exotic raw materials can provide some clues about contacts with other groups outside the local resource area. Data on stone tool technology provide insights into the kinds of productive activities taking place within the village. Another goal of this analysis is to investigate the formation processes affecting the composition of the 2006 collection. Data on the size, density, and distribution of flaking debris are used to do so.

Crawford and Mitchell classified the stone tools, with assistance from PCRG Lab Supervisor Stacey Madden. Lab Assistant Tracy Ellefson coded the flaking debris, with input and quality checks from Madden. Mitchell generated the data tables and performed the statistical analyses and Crawford wrote the chapter, with input from Mitchell.

\section{Stone Tool and Flaking Debris Analysis Methods}

Lithic raw material types and stone tool production methods have been intensively studied in the Heart region. Over time, a complex analysis protocol has developed that includes a large number of variables (e.g. Ahler et al. 1997; Ahler et al. 2002; Ahler, Kellet, and Crawford 2003). Unfortunately, time did not permit a similar level of effort for the Larson collection; instead, the analysis focused on a few of the most widely used variables. Size-grading is fundamental to this type of analysis and is performed with a series of nested square-mesh box-screens (see Ahler and Swenson 1985:69-70). Modified stone was sorted into four size grades (see Chapter 5). Each size graded sample was then divided into two groups or lots, one composed of stone tools and the other composed of flaking debris. A tool is defined as any intentionally shaped stone object, a stone exhibiting use-wear, or the remnant material core from which flakes were removed for some purpose. Intentionally shaped objects range from a simple flake with a shaped or sharpened edge to a purposefully sculpted object modified by flaking, pecking, or grinding (e.g., knife, point, celt, or pendant). Flakes bear no evidence of use or modification other than that produced by transport, tramping, or other post-depositional factors. 
In order to understand patterns in procurement and use, flaking debris was further quantified by raw material type, evidence of burning, and degree of patination. Intentional heat-treatment was not recorded for flaking debris. Rather, signs of heat alteration such as color or luster change, stress cracking, and so forth were taken as an indication that the flake had been burned. Burning and patination were recorded only for specimens of Knife River flint (KRF). Experience has shown that evidence of these two attributes often is clearly seen on KRF, whereas such evidence may be difficult to detect on other material types such as smooth gray Tongue River silicified sediment (TRSS). Finally, counts and weights were recorded for each sort group.

The raw material types used in the analysis are identified in Table 8.1. The same types were used for both tools and flaking debris. For this analysis, a new material type was added to those previously identified in other Heart region collections. Miocene flint, also known as Sentinel Butte flint (Raw Material 51), has been recognized for some time as a usable stone, but because it is visually similar to other material types (notably to clear/gray chalcedony [Raw Material 8]), particularly when heat treated, it has not until now been coded separately (Ahler, Root, Schifrin, and William 1994). However, several rather clear examples of this material were observed in the Larson collection.

Due to the large number of size G4 flakes, we applied a standard sampling procedure previously developed for other recent analyses. The following description of the method is taken directly from Ahler, Ritter, and Crawford (2003:171-172). A bent spatula tool was used to extract a flake sample from each batch. The spatula is known, from previous research, to hold between 150 and 175 G4 flakes. After weighing the total batch, two spatulas full of flakes were extracted from each (about 300-350 flakes). The sample was subsequently weighed (to $0.1 \mathrm{~g}$ ) and was used as a ratio to estimate the total counts of flake classes in the total sample based on these sample counts. After the pulled sample of G4 flakes was completely analyzed, the remainder of the flakes was sorted for the occurrence of 'rare' material types. These "rare" types were determined after some of the first lots were examined. This sampling greatly reduced the amount of time spent sorting and coding G4 flakes while providing a safe estimate of common materials and recording occurrences of rare raw materials in the collection.

Each stone tool was individually examined and data were collected on the seven variables listed in Table 8.2. The most important of these are technological class, raw material, and original input blank. Data also were collected on descriptive class, burning, and heat treatment. Evidence of burning includes discoloration or the presence of irregular fracture surfaces, potlids, or crazing. Collection of heat treatment data was limited to KRF specimens. Characteristics of intentional heat alteration to KRF are discussed in detail in Ahler (1983). It has been previously determined that in at least some Knife River villages, that heat treatment was used primarily on arrow points, probably to improve the workability by pressure flaking.

\section{Technological Classes}

The thirteen technological classes used in this study are described briefly in the following paragraphs and more fully in Ahler, Root, and Feiler (1994). Technological analysis classifies tools according to the methods used to produce them. The classes used for the Larson analysis are identical to those used elsewhere in the Heart region, as well as those used in the Knife region (e.g. 
Ahler, Root, and Feiler 1994; Ahler and Toom 1993:173-255). Generally, technological classes distinguish the manufacturing trajectory involved in tool production. The first technological divergence is found in the segregation of chipped versus pecked or ground tools followed by further separation into patterned versus unpatterned trajectories.

Table 8.1. Variables and attribute codes used in the analysis of chipped stone flaking debris from Larson Village, 2006 collection.

\begin{tabular}{|c|c|c|}
\hline CATNO & \multicolumn{2}{|l|}{ catalog number } \\
\hline SIZE & \multicolumn{2}{|l|}{ size grade $(1,2,3$, or 4$)$} \\
\hline G4SAM & \multicolumn{2}{|c|}{ weight of the size grade 4 flake sample, if the batch was sampled } \\
\hline G4TOT & \multicolumn{2}{|c|}{ total weight of the size grade 4 flakes, if the batch was sampled } \\
\hline $\mathbf{R M}$ & \multicolumn{2}{|c|}{ raw material type } \\
\hline \multicolumn{3}{|c|}{ 1-smooth gray Tongue River silicified sediment } \\
\hline \multicolumn{2}{|c|}{ 2-coarse yellow Tongue River silicified sediment or silcrete } & 31-blonde French flint \\
\hline \multicolumn{2}{|c|}{ 3-coarse red Tongue River silicified sediment } & 32-Thames River (Dover) flint \\
\hline \multicolumn{2}{|c|}{ 4-solid quartzite (fine-grained orthoquartzite) } & 33-light yellow pigment stone \\
\hline \multicolumn{2}{|c|}{ 5-Swan River chert (porous quartzite) } & 34-historic period glass \\
\hline \multicolumn{2}{|c|}{ 6.0-miscellaneous jasper/chert } & 35-metaquartzite (not class 4 ) \\
\hline \multicolumn{2}{|c|}{ 6.7-dendritic chert } & 36-scoria \\
\hline \multicolumn{2}{|c|}{ 7-White River Group silicates } & 37-siltstone/limestone/mudstone \\
\hline \multicolumn{2}{|c|}{ 8-clear/gray chalcedony (not obvious silicified wood) } & 38-steatite \\
\hline \multicolumn{2}{|c|}{ 9-yellow/light brown chalcedony (not obvious silicified wood) } & 39-burned Knife River flint (use is optional) \\
\hline \multicolumn{2}{|c|}{ 10-dark brown chalcedony (non-KRF, non-silicified wood) } & 40-non-volcanic natural glass \\
\hline \multicolumn{2}{|c|}{ 11-plate chalcedony } & 41-opal \\
\hline \multicolumn{2}{|c|}{ 12-burned chalcedony (not further identifiable) (not used w/ } & 42-feldspar \\
\hline \multicolumn{2}{|c|}{ Larson) } & $43-$ \\
\hline \multicolumn{2}{|c|}{ 13-basaltic material } & 50-Charlie Creek chert \\
\hline \multicolumn{2}{|c|}{ 14-other unclassifiable } & 51-Miocene flint (Sentinel Butte flint) (not used w/ Slant) \\
\hline \multicolumn{2}{|c|}{ 15-Bijou Hills silicified sediment } & 52-obvious silicified wood \\
\hline \multicolumn{2}{|c|}{ 16-milk or vein quartz } & 53-moss agate \\
\hline \multicolumn{2}{|c|}{ 17-porcellanite } & 54-antelope chert \\
\hline \multicolumn{2}{|c|}{ 18-obsidian (any source) } & 55-gray silcrete (non-Tongue River types) \\
\hline \multicolumn{2}{|c|}{ 19-granitic material } & 56-Scenic chalcedony \\
\hline 20-coarse poro & tone & 57-Hartville Uplift chert (not used w/ DD) \\
\hline 21-compact sa & & 58-Yellowstone agate (not used w/Slant) \\
\hline 22-fossil or co & & 59-Turtle Valley orthoquartzite (not used w/ Slant) \\
\hline 23-clinker & & 60-68- KRF quality and heat treatment codes (not used \\
\hline 24-catlinite & & w/Larson) \\
\hline 25-hematite (re & & 69-Schmidtt chert (not used w/Slant) \\
\hline 26-limonite (y & are) & 70-schist \\
\hline 27-gypsum & & 71-Hixton Silicified sandstone \\
\hline 28-unburned K & er flint & \\
\hline 29-Rainy Butte & ed wood & \\
\hline BURN & burning or heat treatment - REC & RDED ONLY FOR KRF \\
\hline 0-no heat appli & tectable & 2-application of heat is apparent \\
\hline PATI & patination intensity - RECORD & ONLY FOR KRF \\
\hline 0-absent & & 3-pronounced \\
\hline 1-light & & blank-not applicable (all raw materials except 28) \\
\hline 2-moderate & & \\
\hline COUNT & count of flakes having a commo & ode on all preceding variables \\
\hline WEIGHT & combined weight of flakes for th & data case. If weight $=0.0$, record as $<0.1$ \\
\hline
\end{tabular}

1 Patterned Small Thin Biface. These include chipped-stone tools produced by pressure flaking. Virtually all specimens that fit this category are arrow points, either completed or unfinished, but might also include small, symmetrical perforators. Arrow point fragments in this category are often very small fragments of tips or barbs resulting from manufacturing failure during the production 
process. There are 180 specimens assigned to this technological class, or about $15.9 \%$ of the tools from the 2006 excavations.

2 Patterned Large Biface. These tools are the product of controlled percussion thinning with the possible addition of some pressure flaking for final finishing and shaping. Included in this category are most hafted and some unhafted bifacial cutting tools. This category also captures projectile points curated or mixed from earlier (pre-archery) horizons. This category includes 105 specimens (9.3\% of all tools in the sample).

3 Unpatterned Small to Medium Biface. Unpatterned bifaces are expediently produced tools with one or more bifacial edges but with an overall irregular morphology. These are often the result of poorly controlled flaking of small pebbles or tabular pieces with the intent to create a usable cutting edge. The overall shape of the finished product is determined more by the morphology of the input blank than the pre-conception of the producer. Fifty-one specimens (4.5\% of the total) are identified in this category.

4 Patterned Steeply Beveled Flake Tool. This category includes unifacial flake tools associated with hide scraping. In most cases, these are produced on a thick flake with a distinct dorsal ridge or ridges with no flake scars on the ventral face. These specimens tend to have a convex working edge perpendicular to the long axis of the tool. For the purpose of this study, no distinction is made by gross morphology or use-wear to separate types of hide scrapers, or to distinguish hide-working tools from tools that exhibit directional crushing or other wear indicative of scraping, planing, adzing or other work on hard materials such as wood, bone, antler, or horn. There are 32 specimens identified in this technological class from this analysis, or about $2.8 \%$ of the tools. This is a fairly small number of scrapers, perhaps indicating that certain domestic activities are not well represented in this sample.

5 Unpatterned Other Flake Tool, Retouched or Use-Modified. This technological class encompasses a wide array of tools probably representing nearly every cutting, scraping, and piercing operation in daily life. The key to this group is that they are unpatterned in form, made on a flake, and may be modified by a range of techniques including unifacial or bifacial percussion, pressure flaking, shear flaking, or may exhibit wear from use-modification. This tool type is by far the most abundant identified in this study with 418 specimens (37\% of the total tool sample).

6 Large, Thick Bifacial Core-Tool. These tools are characterized by their bifacial edge formation through hard-hammer freehand percussion made on cobbles, large nodules, or chunks of raw material. No specimens of this type are included in the 2006 Larson collection.

7 Nonbipolar Core or Core-Tool. This class includes cores made by freehand percussion applied in a non-bifacial manner to raw cobbles, chunks, or other nuclear pieces of stone. Three subcategories are recognized, including "tested raw material" (Class 7.1), "cores with substantial flake removals" (Class 7.2), and "aimlessly flaked pieces” (Class 7.3). Actual tools in this category are large coretools such as choppers, core-hammers, pecking stones, and so forth. There are 73 cores in this sample comprising about $6.4 \%$ of the total tools. This suggests that while some lithic reduction occurred in the areas studied, it was not a major activity here. 
8 Bipolar Core and Core-Tool. These are unpatterned cores manufactured through bipolar flaking. This category may apply to any size product and may include punch/wedge tools. Ten bipolar specimens are present in the 2006 Larson collection.

Table 8.2. Variables and attributes used in the abbreviated analysis of stone tools from Larson Village, 2006 collection.

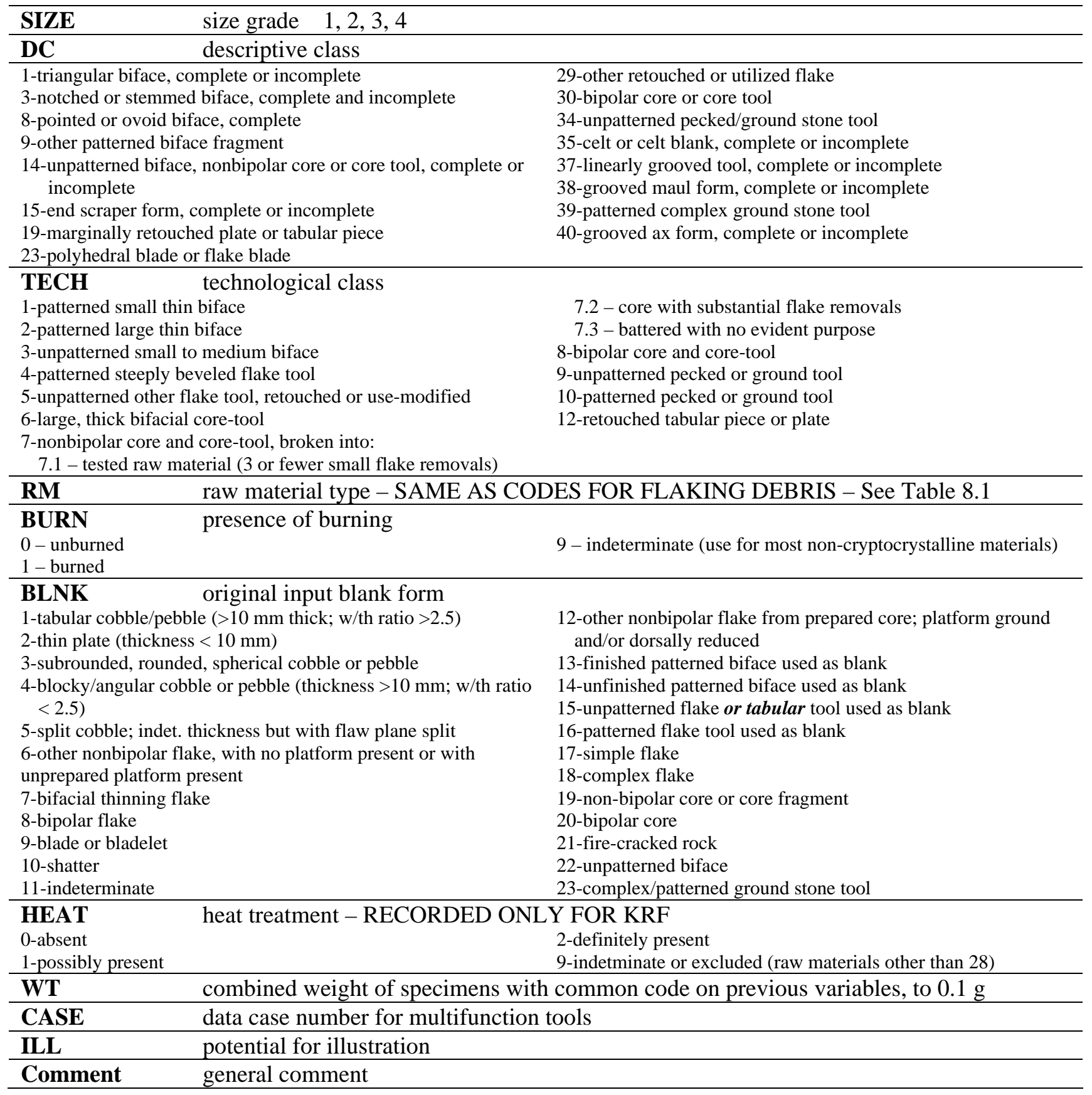

9 Unpatterned Pecked or Ground Tool. These are mostly cobbles or pebbles modified through use. In the Knife and Heart regions, this category may often be dominated by naturally occurring clinker abraders with little use-wear or shaping. The somewhat friable nature of this material, along with its irregular morphology makes it susceptible to trampling and transport damage. However, brief examination of other sites in the Heart region indicates that there is no significant difference in the 
size distribution of clinker tools at Larson. The original shape of the raw material largely determines the morphology of these tools. There are 204 specimens of unpatterned pecked or ground stone tools identified in this collection.

10 Patterned Pecked or Ground Tool. These tools are created by pecking, grinding, sawing, or polishing to form a highly modified tool (e.g., an axe), heavily stylized objects (e.g., pipes or pendants), or other objects, often of unknown function. Only 13 patterned ground stone tools (1.2\% of the total tools) were identified.

12 Retouched Tabular Piece or Plate. These tools are essentially a special case of core tools where the original raw material was selected for its flat, relatively thin shape that can be easily flaked into a useful cutting edge. Membership in this class is frequently determined by raw material type such as platy KRF, plate chalcedony, or silicified wood. Generally, only the working edge is modified. Forty-three retouched tabular pieces (3.8\% of the total) were identified in this collection.

\section{Flaking Debris Analysis}

The total sample of chipped stone flaking debris from the 2006 excavations at Larson Village weighs just under $7.8 \mathrm{~kg}$ and consists of 55,684 pieces of debitage. Count, weight and size data are summarized by area in Table 8.3. Provenance data is provided by size grade in Table 8.4. Although the lithic artifacts are predominantly only two types of stone, thirty different raw material types were identified in this analysis. These material types are the same ones that occur in other village samples from the Heart region. The common lithic materials identified here have been discussed in detail in previous PCRG reports on nearby Slant Village (Ahler et al. 1997:272-276) and Scattered Village (Ahler et al. 2002:12.2-12.8).

Table 8.3. Counts and weights of chipped stone flaking debris by excavation area from 2006 Larson Village excavations.

\begin{tabular}{lccccc|ccccr}
\hline & \multicolumn{4}{c}{ Count by Size Grade } & & \multicolumn{5}{c}{ Weight (g) by Size Grade } \\
\cline { 2 - 3 } Area & G1 & G2 & G3 & G4 & Total & G1 & G2 & G3 & G4 & Total \\
\hline BLK A & 3 & 63 & 1,032 & 6,888 & 7,986 & 53.1 & 217.9 & 386.9 & 226.8 & 884.7 \\
BLK D & 1 & 63 & 939 & 5,878 & 6,881 & 74.8 & 262.7 & 391.4 & 223.1 & 952.1 \\
BLK F & 5 & 130 & 1,622 & 10,839 & 12,596 & 150.7 & 428.0 & 664.1 & 451.6 & $1,694.5$ \\
BLK G & & 28 & 524 & 3,517 & 4,069 & & 135.9 & 212.4 & 122.0 & 470.3 \\
Ditch 3 & 13 & 191 & 2,656 & 16,992 & 19,852 & 363.3 & 767.2 & $1,104.4$ & 664.6 & $2,899.5$ \\
Ditch 4 & 8 & 53 & 530 & 2,657 & 3,248 & 198.4 & 211.1 & 226.7 & 1.1 & 736.2 \\
Mixed & & 8 & 160 & 884 & 1,052 & & 35.9 & 80.4 & 43.6 & 159.9 \\
\hline Total & 30 & 536 & 7,463 & 47,655 & 55,684 & 840.3 & $2,058.7$ & $3,066.3$ & $1,831.8$ & $7,797.1$ \\
\hline
\end{tabular}

Specific raw material types are discussed below, but a brief general overview of the main raw material groups is presented here. These groups are used to show the direction and relative distance (near or far) where each raw material can be found. The first two groups are "Near-Local Southwest" and "Near-Local Northwest." The Near-Local Southwest group includes smooth gray Tongue River silicified sediment (TRSS) and gray silcrete and the Near-Local Northwest group includes only Knife River flint (KRF). Although neither group has a primary source in the immediate vicinity of the village they are both available across a broad region extending from a few $\mathrm{km}$ to as much as $60 \mathrm{~km}$ from the village. In both cases, better quality stone can most commonly be 
found 30 to $60 \mathrm{~km}$ from the village. TRSS was probably available south of the city of Mandan, with coarser specimens collected from surface lag deposits and finer materials collected from quarry areas further south. While the nearest known quarry for KRF lies approximately $70 \mathrm{~km}$ west northwest of Larson Village, medium sized cobbles can be found in some abundance on the Missouri River terraces on the Cross Ranch in Oliver County, about $25 \mathrm{~km}$ north, and as small cobbles as far south as Buffalo County, South Dakota (Ahler et al. 2002:12.3).

Raw materials included in the "Near-Local West" group include chalcedonies and silicified wood. These materials are abundant as surface lag and alluvial deposits in the unglaciated portions of North Dakota and in adjacent regions of South Dakota. These materials occur in the major streams of this region draining toward the Missouri River. On the north, distributions of these materials overlap the natural distribution of KRF, while on the east they co-occur with TRSS (Ahler et al. 2002:12.6).

Exotic raw materials are rare in the Larson collection and generally are found farther than 60 $\mathrm{km}$ from the village. Orthoquartzite in this group is a high-quality, fine-grained stone available in the Hartville uplift area (Reher 1991) as well as from several sources south and northwest of the Black Hills (Ahler et al. 2002:12.6). Jaspers and exotic cherts (including dendritic cherts) in the collection can be obtained from sources near the Black Hills as well as from more distant locales in Wyoming and Montana. Porcellanite, non-volcanic glass, and Rainy Buttes silicified wood are found in extreme western North Dakota or eastern Montana. High quality non-volcanic natural glass is thought to occur primarily within the upper Tongue River and middle Powder River drainages, probably associated with the most dense and extensive porcellanite deposits (Keyser and Davis 1981, cited in Clark 1985:41).

Raw materials from more distant sources include White River group silicates (such as Flattop chalcedony), plate chalcedony, and obsidian. All of these materials derive from the far west and southwest of the project area. The White River silicates probably derive from the Big Badlands of South Dakota (the nearest known source) or as far away as western Nebraska or Colorado (Hoard et al. 1993). The small but distinct sample of plate chalcedony at Larson probably also derives from a source in the Big Badlands (Porter 1962). Obsidian was also found in the Larson collection. Although not sourced, it likely originated in the Yellowstone region (Ahler and Haas 1993:150151).

Table 8.4 presents an inventory of flaking debris according to raw material type and size grade. Quantities for each sample are given both as actual counts and as a percent of each sample size grade. Each size grade is further given as a percentage of the total sample. As can be seen, size G1 flaking debris is nearly absent from the sample $(n=30)$ but these few flakes represent about 10.8 percent of the total weight of the collection. Most of the flaking debris (85.6 percent by count) is size G4. However, the largest samples by weight are sizes G3 and G2.

The collection from the 2006 excavations is dominated by two materials, one by count and one by weight. The most prominent material by count is KRF comprising 46.5 percent (33.5 percent by weight) of the flaking debris. KRF is a fine-grained stone found in the unglaciated plains on the west side of the Missouri River. This resource was collected as larger pieces at the primary source to the west or northwest of the Larson site (in Dunn and Mercer counties) or as smaller pieces from gravel deposits in streams such as the Knife River or perhaps Square Butte Creek that drain from the west into the Missouri (Ahler, Ritter, and Crawford 2003:182). KRF can 
also sometimes be found in terraces adjacent to the Missouri. The most prominent raw material by weight is TRSS, making up 49.1 percent of the collection (37.5 percent by count). Like KRF, this material is also found near locally, south of Larson to the west of the Missouri River, probably obtainable as or near bedrock deposits in Morton and Sioux counties of North Dakota near the mouth of the Cannonball River and to the south (Ahler and Smail 2000:133; Ahler, Ritter, and Crawford 2003:182).

Table 8.4. Flaking debris counts and percentages organized by size grade and provenance for the 2006 Larson Village collection.

\begin{tabular}{|c|c|c|c|c|c|c|}
\hline \multirow[b]{2}{*}{ Raw Material Type } & \multicolumn{5}{|c|}{ Size Grade } & \multirow[b]{2}{*}{ Total } \\
\hline & & G1 & $\mathrm{G} 2$ & G3 & G4 & \\
\hline \multicolumn{7}{|c|}{$\begin{array}{l}\text { Near-Local, Southwest } \\
\end{array}$} \\
\hline \multirow[t]{2}{*}{ smooth gray trss } & $n$ & 14 & 315 & 3322 & 17242 & 20893 \\
\hline & $\%$ & $46.7 \%$ & $58.8 \%$ & $44.5 \%$ & $36.2 \%$ & $37.5 \%$ \\
\hline \multirow[t]{2}{*}{ gray silcrete } & $n$ & 2 & 25 & 157 & 431 & 615 \\
\hline & $\%$ & $6.7 \%$ & $4.7 \%$ & $2.1 \%$ & $.9 \%$ & $1.1 \%$ \\
\hline \multicolumn{7}{|c|}{ Near-Local, West } \\
\hline \multirow{2}{*}{ clear/gray chalcedony } & $n$ & & & 47 & 983 & 1030 \\
\hline & $\%$ & & & $.6 \%$ & $2.1 \%$ & $1.8 \%$ \\
\hline \multirow[t]{2}{*}{ yel./lt. brn. chalcedony } & $n$ & & 4 & 393 & 4759 & 5156 \\
\hline & $\%$ & & $.7 \%$ & $5.3 \%$ & $10.0 \%$ & $9.3 \%$ \\
\hline \multirow[t]{2}{*}{ dark brn. chalcedony } & $n$ & & 1 & 69 & 307 & 377 \\
\hline & $\%$ & & $.2 \%$ & $.9 \%$ & $.6 \%$ & $.7 \%$ \\
\hline \multirow[t]{2}{*}{ silicified wood } & $n$ & & & 38 & 183 & 221 \\
\hline & $\%$ & & & $.5 \%$ & $.4 \%$ & $.4 \%$ \\
\hline \multicolumn{7}{|c|}{ Near-Local, Northwest } \\
\hline \multirow[t]{2}{*}{ KRF } & $n$ & 1 & 164 & 3164 & 22549 & 25878 \\
\hline & $\%$ & $3.3 \%$ & $30.6 \%$ & $42.4 \%$ & $47.3 \%$ & $46.5 \%$ \\
\hline \multicolumn{7}{|c|}{ Exotic, Southwest } \\
\hline \multirow[t]{2}{*}{ other dendritic chert } & $n$ & & & 2 & 27 & 29 \\
\hline & $\%$ & & & $.0 \%$ & $.1 \%$ & $.1 \%$ \\
\hline \multirow[t]{2}{*}{ White River silicates } & $n$ & & & 3 & 4 & 7 \\
\hline & $\%$ & & & $.0 \%$ & $.0 \%$ & $.0 \%$ \\
\hline \multirow[t]{2}{*}{ orthoquartzite } & $n$ & & & 37 & 302 & 339 \\
\hline & $\%$ & & & $.5 \%$ & $.6 \%$ & $.6 \%$ \\
\hline \multirow[t]{2}{*}{ jasper/chert unspecified } & $n$ & & & 11 & 46 & 57 \\
\hline & $\%$ & & & $.1 \%$ & $.1 \%$ & $.1 \%$ \\
\hline \multirow[t]{2}{*}{ plate chalcedony } & $n$ & & & 8 & 17 & 25 \\
\hline & $\%$ & & & $.1 \%$ & $.0 \%$ & $.0 \%$ \\
\hline \multicolumn{7}{|c|}{ Exotic, West } \\
\hline \multirow[t]{2}{*}{ obsidian } & $n$ & & & & 6 & 6 \\
\hline & $\%$ & & & & $.0 \%$ & $.0 \%$ \\
\hline \multirow[t]{2}{*}{ Sentinel Butte flint } & $n$ & & 1 & 8 & 16 & 25 \\
\hline & $\%$ & & $.2 \%$ & $.1 \%$ & $.0 \%$ & $.0 \%$ \\
\hline \multirow[t]{2}{*}{ non-vol. natural glass } & $n$ & & & & 2 & 2 \\
\hline & $\%$ & & & & $.0 \%$ & $.0 \%$ \\
\hline \multirow{2}{*}{ moss agate } & $n$ & & & 5 & 27 & 32 \\
\hline & $\%$ & & & $.1 \%$ & $.1 \%$ & $.1 \%$ \\
\hline \multirow[t]{2}{*}{ porcellanite } & $n$ & & 1 & 5 & 45 & 51 \\
\hline & $\%$ & & $.2 \%$ & $.1 \%$ & $.1 \%$ & $.1 \%$ \\
\hline
\end{tabular}


Table 8.4. Flaking debris counts and percentages organized by size grade and provenance for the 2006 Larson Village collection (concluded).

\begin{tabular}{|c|c|c|c|c|c|c|}
\hline \multirow[b]{2}{*}{ Raw Material Type } & \multicolumn{5}{|c|}{ Size Grade } & \multirow[b]{2}{*}{ Total } \\
\hline & & G1 & G2 & G3 & G4 & \\
\hline \multirow[t]{2}{*}{ Rainy Buttes sil. wood } & $n$ & & & 5 & 21 & 26 \\
\hline & $\%$ & & & $.1 \%$ & $.0 \%$ & $.0 \%$ \\
\hline \multicolumn{7}{|l|}{ Local, Coarse } \\
\hline \multirow[t]{2}{*}{ basaltic material } & $n$ & 9 & 13 & 99 & 419 & 540 \\
\hline & $\%$ & $30.0 \%$ & $2.4 \%$ & $1.3 \%$ & $.9 \%$ & $1.0 \%$ \\
\hline \multirow[t]{2}{*}{ Bijou Hills silicified sediment } & $n$ & & & 2 & 1 & 3 \\
\hline & $\%$ & & & $.0 \%$ & $.0 \%$ & $.0 \%$ \\
\hline \multirow[t]{2}{*}{ quartz } & $n$ & & & 1 & 5 & 6 \\
\hline & $\%$ & & & $.0 \%$ & $.0 \%$ & $.0 \%$ \\
\hline \multirow[t]{2}{*}{ granitic mat. } & $n$ & & & 5 & 10 & 15 \\
\hline & $\%$ & & & $.1 \%$ & $.0 \%$ & $.0 \%$ \\
\hline \multirow[t]{2}{*}{ Swan River chert } & $n$ & & 1 & 8 & 32 & 41 \\
\hline & $\%$ & & $.2 \%$ & $.1 \%$ & $.1 \%$ & $.1 \%$ \\
\hline \multirow[t]{2}{*}{ coarse yellow trss } & $n$ & & 3 & 9 & 30 & 42 \\
\hline & $\%$ & & $.6 \%$ & $.1 \%$ & $.1 \%$ & $.1 \%$ \\
\hline \multirow[t]{2}{*}{ coarse red trss } & $n$ & 3 & 8 & 45 & 144 & 200 \\
\hline & $\%$ & $10.0 \%$ & $1.5 \%$ & $.6 \%$ & $.3 \%$ & $.4 \%$ \\
\hline \multirow[t]{2}{*}{ schist } & $n$ & & & 6 & 9 & 15 \\
\hline & $\%$ & & & $.1 \%$ & $.0 \%$ & $.0 \%$ \\
\hline \multirow[t]{2}{*}{ metaquartzite } & $n$ & 1 & & 13 & 35 & 49 \\
\hline & $\%$ & $3.3 \%$ & & $.2 \%$ & $.1 \%$ & $.1 \%$ \\
\hline \multirow{3}{*}{ opal } & & & & & & \\
\hline & $n$ & & & 1 & & 1 \\
\hline & $\%$ & & & $.0 \%$ & & $.0 \%$ \\
\hline \multirow[t]{2}{*}{ scoria } & $n$ & & & & 2 & 2 \\
\hline & $\%$ & & & & $.0 \%$ & $.0 \%$ \\
\hline \multirow[t]{2}{*}{ other unclassifiable } & $n$ & & & & 1 & 1 \\
\hline & $\%$ & & & & $.0 \%$ & $.0 \%$ \\
\hline \multirow[t]{2}{*}{ Total } & $n$ & 30 & 536 & 7463 & 47655 & 55684 \\
\hline & $\%$ & $.1 \%$ & $1.0 \%$ & $13.4 \%$ & $85.6 \%$ & $100.0 \%$ \\
\hline
\end{tabular}

Combined, KRF and TRSS make up 84 percent of the collection by count and 82.6 percent of the collection by weight. This may indicate a regular route of procurement either directly or through an intermediate source. Figure 8.1 illustrates the proportional difference between smooth gray TRSS and KRF in the flaking debris. It can be seen that as the size of the flaking debris decreases so does the count and weight of TRSS. By contrast, quantities of KRF increase in the smaller size grades. As indicated in Figure 8.1, there are two divergent patterns of raw material use between KRF and TRSS. The proportion of KRF flakes increases as flake size decreases and the proportion by weight is less than the proportion by count for each grade. The exact opposite is evident for TRSS. The proportion of TRSS flakes decrease as size decreases from size G2 to size G4 and the proportion by weight is greater than by count. This is essentially telling us that the average KRF flake is smaller and lighter than the average TRSS flake and implies that there are two very different reduction trajectories were being pursued with these two materials.

The remainder of the collection, 16 percent by count (17.4 percent by weight), is comprised of a wide variety of local and a few exotic cherts, chalcedonies, and other workable materials. Of 
these, the "Near-Local, West” group composed of chalcedonies and silicified woods makes up about 12.2 percent (4.3 percent by weight) of the entire collection. The difference between count and weight in these fine-grained chalcedonies and silicified woods appears to follow the pattern of KRF with more smaller, lighter flakes. These are almost certainly associated with the final stage of tool production or edge rejuvenation. The other near-local raw materials probably represent opportunistic collection of useful material from local gravels or till deposits while away from the village when the more common KRF or TRSS were not readily available. However, some of these, as well as the more exotic materials probably indicate trade or distant forays beyond the normal procurement range.

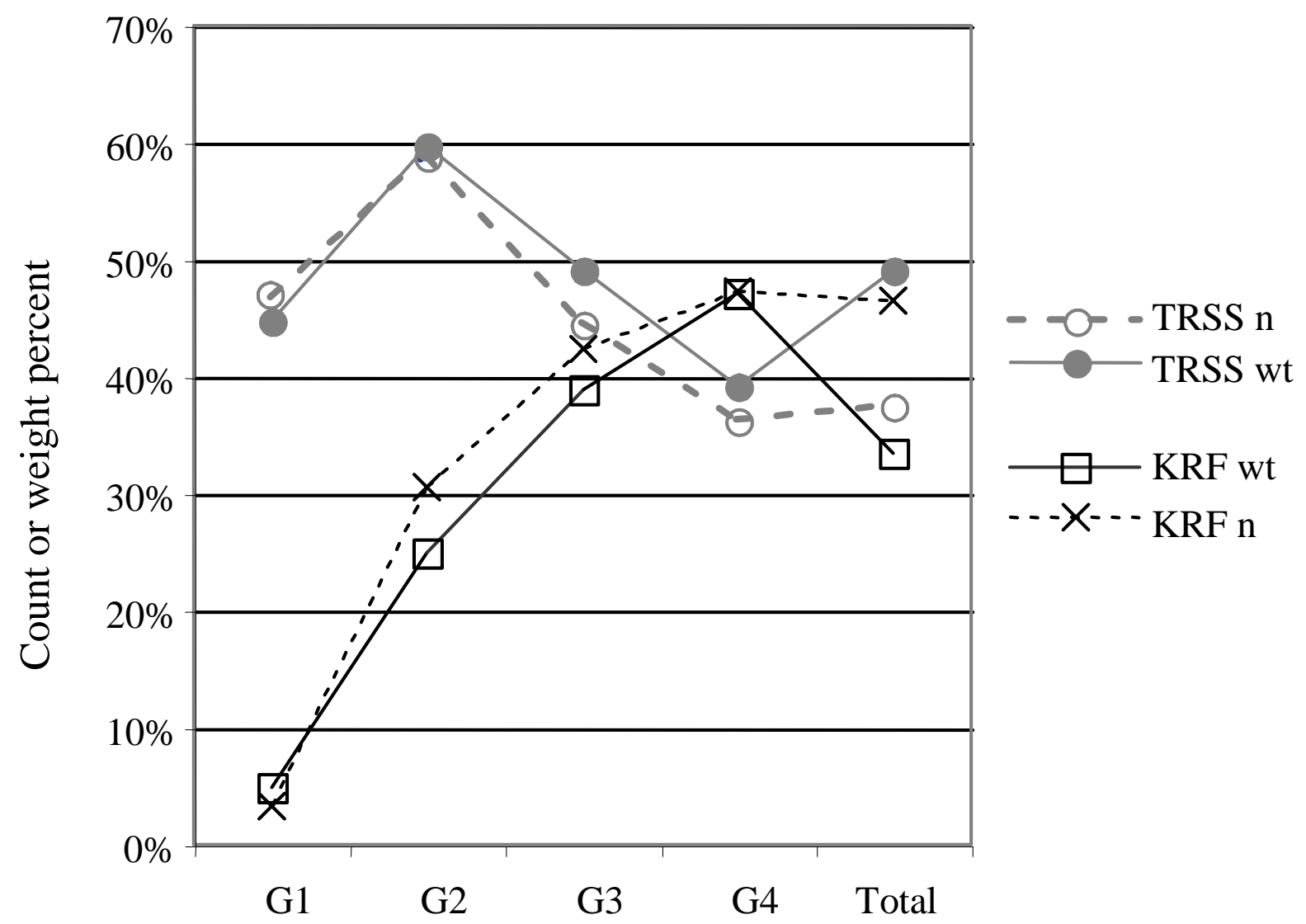

Figure 8.1. A comparison of KRF and TRSS flaking debris by count and weight.

The 2006 sample from Larson indicates that TRSS occasionally entered the village as larger cobbles, whereas it appears that raw pieces of KRF were substantially smaller and probably further along a production trajectory when they entered the village and were ultimately worked into smaller or finer edge tools. This difference reflects the different used to which TRSS and KRF were put (see below). It also may reflect a lack of access to the primary KRF source or initial reduction occurring off-site.

Table 8.4 also illustrates the relative quantities of stone resources that are not TRSS or KRF. The only other lithic material found in any significant numbers in the flaking debris is yellow/light brown chalcedony. This material is found locally in surface lag deposits and in the high terrace 
gravels along the Missouri River and more abundantly in the unglaciated region of southwestern North Dakota. It would not be amiss to place the various colored chalcedonies together when discussing procurement as these may all be found, along with obvious silicified wood, in the same depositional environments. Combined, the local chalcedonies make up over $12 \%$ of the flaking debris. Incidentally, in the Knife region these same deposits are known to yield Swan River chert, yellow and red TRSS, gray silcrete, as well as several other cherts and jaspers found in this sample (Ahler and Toom 1993:226).

Flaking debris raw materials listed as exotic to the Larson Village area comprise just over 1 percent of the total sample. By far, the largest exotic group is orthoquartzite found to the southwest of the site. Otherwise, each variety of exotic flaking debris is a small enough sample that it could represent a single procurement episode either through direct collection or trade. Consistent with the more common raw materials, nearly all of the exotic flaking debris is found in the size G4 samples, with some size G3 and almost no size G2 or G1.

Table 8.5 presents data on flake counts organized by size grade and deposit type and gives flake counts per cubic meter. This allows us to see actual flake densities for various types of deposits. As can be seen in the table, the densities are quite different for each deposit type. The relatively high densities in pit features are probably due to primary cleaning episodes. The high G4/G1-3 ratio indicates that size G4 flakes are proportionally more abundant in pit contexts than they are elsewhere. Since size G4 flakes are too small to be fashioned into other tools, they are thereby removed from further advancement in the tool production trajectory and are either abandoned or disposed of. Note that the G4/G1-3 ratio is very similar for midden and midden and earth deposits (and that both are close to the mean for all deposit types), but that the density of flakes in midden and earth deposits is much lower. This suggests that midden and earth deposits were "diluted" by the addition of sediment rather than by the selective removal of flakes that might be expected from clean-up.

Table 8.5. Flaking debris counts by deposit type and size grade, along with calculated flake size ratios and densities.

\begin{tabular}{lcccrr|rrr}
\hline & \multicolumn{4}{c}{$n$ by Size Grade } & & G4/G1-3 & $\begin{array}{c}\text { Deposit } \\
\text { Vol. (cu. m.) }\end{array}$ & $\begin{array}{c}\text { Flakes/ } \\
\text { cu. m. }\end{array}$ \\
\cline { 2 - 5 } Deposit Type & G1 & G2 & G3 & G4 & Total & Ratio & Vol \\
\hline Pit & 5 & 119 & 1409 & 9555 & 11088 & 6.233 & 1.406 & 7886 \\
Small Pit & 0 & 2 & 55 & 272 & 329 & 4.772 & 0.129 & 2550 \\
Midden & 16 & 280 & 3771 & 23495 & 27562 & 5.777 & 6.808 & 4048 \\
Midden and Earth & 7 & 61 & 788 & 4560 & 5416 & 5.327 & 3.628 & 1493 \\
Plowzone & 2 & 66 & 1280 & 8889 & 10237 & 6.594 & 1.995 & 5236 \\
Mixed & 0 & 8 & 160 & 884 & 1052 & 5.262 & 0.340 & 3094 \\
\hline Total & 30 & 536 & 7463 & 47655 & 55684 & 5.935 & 14.306 & 3892 \\
\hline
\end{tabular}

Larson Village is one of several recently-investigated, contemporaneous villages in the Heart region. Table 8.6 illustrates raw materials by group from pre-1650 contexts. Although Larson compares favorably to several of the sites shown here, there is a remarkable similarity in the raw material distributions from Slant Village, especially in the frequency of Near-Local Southwest and Near-Local Northwest stones. These two categories are predominantly TRSS and KRF, respectively. As can be seen here, the Larson sample, along with 32MO291, and Slant Village favors the southwest materials and compares only to 32MO291 in lack of exotic materials. Slant, 
Boley, and Scattered Villages have significantly higher proportions of exotic raw materials in their assemblages. Double Ditch, lying very nearby to the south is remarkably different in raw material distribution, favoring the KRF connection to the northwest with a somewhat lesser emphasis on the TRSS (more like Scattered Village).

Table 8.6. A comparison of flaking debris provenance among pre-1650 villages in the Heart region.

\begin{tabular}{|c|c|c|c|c|c|c|c|}
\hline \multirow[b]{2}{*}{ Site } & \multicolumn{6}{|c|}{ Raw Material Group } & \multirow[b]{2}{*}{ Total $(n)$} \\
\hline & 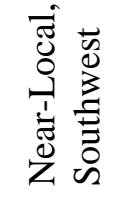 & 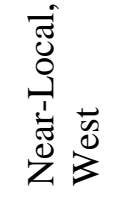 & 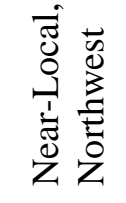 & 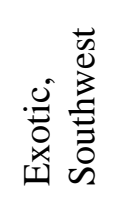 & 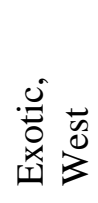 & 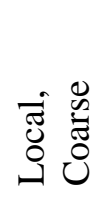 & \\
\hline Larson & $38.6 \%$ & $12.2 \%$ & $46.5 \%$ & $.8 \%$ & $.3 \%$ & $1.6 \%$ & 55,680 \\
\hline 32MO291 & $58.5 \%$ & $6.8 \%$ & $33.4 \%$ & $.1 \%$ & $.8 \%$ & $.3 \%$ & 28,209 \\
\hline Slant (TP3) & $38.3 \%$ & $9.8 \%$ & $45.9 \%$ & $5.4 \%$ & $.6 \%$ & $.1 \%$ & 17,752 \\
\hline Boley (Early) & $21.0 \%$ & $22.2 \%$ & $43.0 \%$ & $9.9 \%$ & $3.2 \%$ & $.6 \%$ & 11,446 \\
\hline Scattered (TP3) & $15.5 \%$ & $14.6 \%$ & $58.9 \%$ & $9.3 \%$ & $.6 \%$ & $1.2 \%$ & 32,196 \\
\hline Scattered (TP4) & $15.2 \%$ & $12.9 \%$ & $62.4 \%$ & $6.9 \%$ & $1.5 \%$ & $1.0 \%$ & 17,180 \\
\hline Double Ditch (TP3) & $19.7 \%$ & $6.7 \%$ & $71.4 \%$ & $1.4 \%$ & $.3 \%$ & $.5 \%$ & 107,296 \\
\hline Double Ditch (TP4) & $26.7 \%$ & $7.4 \%$ & $63.5 \%$ & $1.4 \%$ & $.3 \%$ & $.7 \%$ & 36,042 \\
\hline Total & $28.0 \%$ & $9.7 \%$ & $58.1 \%$ & $2.9 \%$ & $.6 \%$ & $.7 \%$ & 305,603 \\
\hline
\end{tabular}

\section{Stone Tool Analysis}

The 2006 Larson collection includes 1,129 stone tools weighing more than $17 \mathrm{~kg}$. Table 8.7 presents count and weight data on the stone tool sample, organized by excavation locus. Data on the primary variables of interest for this analysis, technological class and raw material type, are crosstabulated in Table 8.8. A selection of flaked stone tools is illustrated in Figure 8.2. The two most common raw materials are TRSS and KRF, which together make up about 75 percent of the collection. Individually, TRSS makes up 37.5 percent of the sample and KRF accounts for 37.4 percent When raw materials representing groundstone are removed (e.g., clinker, sandstone, scoria) these materials represent 44.3 percent and 44.2 percent of the tools. With groundstone removed from the sample, these numbers are similar to that found in the chipped-stone flaking debris sample.

\section{Technological Composition of the Stone Tool Sample}

Not surprisingly, TRSS and KRF dominate the sample in all categories, representing 90 percent of the small bifaces (in the form of arrow points), over 94 percent of the large bifaces, and 100 percent of all scrapers. By far, the most common stone tools recovered from Larson Village in 2006 were unpatterned flake tools. These account for 37 percent of the collection. The most common patterned chipped-stone tools were small thin bifaces (mainly arrow points) and patterned large bifaces (mainly knives). Small, unpatterned abrading tools, in the form of clinker chunks were surprisingly common, making up 12.2 percent of the collection. This is somewhat higher than other villages in the region. The presence of more exotic raw materials in the tool kit is extremely small (1.5 percent of the total tool sample). Even in arrow points, where it is not uncommon to find 
a wide array of material types in a large collection, exotic raw materials only account for 3.3 percent of the sample.

Table 8.7. Count and weight data on stone tools in the 2006 Larson collection, organized by excavation locus and size grade.

\begin{tabular}{|c|c|c|c|c|c|c|c|c|c|c|}
\hline \multirow[b]{2}{*}{ Excavation Locus } & \multicolumn{4}{|c|}{ Count by Size Grade } & \multirow[b]{2}{*}{ Total } & \multicolumn{4}{|c|}{ Weight (g) by Size Grade } & \multirow[b]{2}{*}{ Total } \\
\hline & G1 & G2 & G3 & G4 & & G1 & $\mathrm{G} 2$ & G3 & G4 & \\
\hline Plowzone & 6 & 50 & 96 & 19 & 171 & 241.1 & 235.2 & 68.4 & 1.2 & 545.9 \\
\hline Block A Midden & 9 & 11 & 18 & 1 & 39 & 3195.6 & 81.9 & 15.4 & .030 & 3292.9 \\
\hline Block D Midden & 10 & 18 & 31 & 12 & 71 & 259.8 & 93.8 & 24.4 & 1.1 & 379.1 \\
\hline Block F Midden & 3 & 16 & 28 & 5 & 52 & 74.7 & 63.0 & 21.9 & .2 & 159.8 \\
\hline Block G Midden & 10 & 26 & 40 & 8 & 84 & 872.7 & 238.7 & 30.1 & .2 & 1141.8 \\
\hline Ditch 3 Midden & 6 & 19 & 33 & 3 & 61 & 283.8 & 140.6 & 27.3 & .3 & 452.0 \\
\hline Ditch 3, LO & 11 & 66 & 77 & 13 & 167 & 2479.2 & 399.9 & 65.4 & 1.9 & 2946.4 \\
\hline Ditch 3, UP & 17 & 22 & 51 & 12 & 102 & 1179.0 & 152.8 & 38.8 & 1.0 & 1371.6 \\
\hline Ditch 4 Midden & 4 & 6 & 7 & 1 & 18 & 244.6 & 20.2 & 4.3 & .1 & 269.2 \\
\hline Ditch 4, LO & 4 & 6 & 16 & 1 & 27 & 727.4 & 27.4 & 18.8 & .1 & 773.7 \\
\hline Ditch 4, UP & 8 & 7 & 11 & & 26 & 2170.0 & 65.0 & 9.2 & & 2244.2 \\
\hline Mixed & & 3 & 6 & 1 & 10 & & 38.6 & 2.4 & .1 & 41.1 \\
\hline Pit F101 & 1 & & & & 1 & 68.2 & & & & 68.2 \\
\hline Pit F103 & 1 & 1 & 1 & 1 & 4 & 14.6 & 3.3 & 2.2 & .1 & 20.1 \\
\hline Pit F104 & 1 & 10 & 4 & 3 & 18 & 28.7 & 99.6 & 1.1 & .2 & 129.6 \\
\hline Pit F107 & 36 & 79 & 91 & 11 & 217 & 2140.1 & 523.1 & 102.8 & 1.0 & 2767.0 \\
\hline Pit F108 & & & 1 & & 1 & & & 1.8 & & 1.8 \\
\hline Pit F109 & 9 & 33 & 15 & 3 & 60 & 292.1 & 210.5 & 13.7 & .2 & 516.5 \\
\hline Total & 136 & 373 & 526 & 94 & 1129 & 14271.6 & 2393.6 & 448.1 & 7.7 & 17121.1 \\
\hline
\end{tabular}

Heat treatment and burning were recorded for KRF tools in the Larson collection. Evidence of both kinds of alteration is generally fairly clear in KRF. No significant differences were observed in the frequency of burned artifacts present in different deposit types (data not presented). Approximately one-third of the sample (32 percent) showed evidence of burning. This is precisely the proportion of burned KRF tools from Double Ditch (Ahler, Ritter, and Crawford 2003:189) and about 12 percent more than found at Scattered Village (Ahler et al. 2002:12.28). This suggests that tools may have been discarded into fires at the end of their useful lives. Table 8.9 shows the counts and percentages of heat-treated KRF tools. Overall, more than 12 percent of the Larson sample shows certain evidence of intentional heat-treatment. Patterned bifaces are the most commonly heat treated objects, especially the small bifaces which were finished by pressure flaking. Cores and tested raw materials were almost never heated. Heat treatment was far more common at Double Ditch, where about half of the small thin bifaces and 25 to 40 percent of the large thin bifaces were treated (Ahler et al. 2004:222).

An important technological comparison can be made by examining only the dominant raw material types by technological class from the collection (Table 8.10). Examination of these data reinforces the conclusion that TRSS and KRF were used in very different ways. TRSS was selected for unpatterned flake tools almost twice as frequently as KRF, whereas KRF was more often chosen for bifaces and scrapers. Generally speaking, TRSS entered the site in a larger, less reduced state and was subsequently most likely to be used as a large flake tool and KRF entered the site in smaller pieces and was reduced into proportionally smaller, more finely flaked tools. 


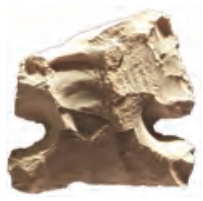

a

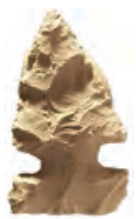

b

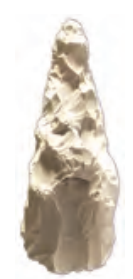

C

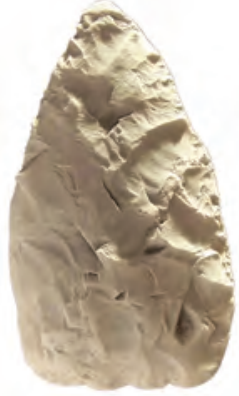

d

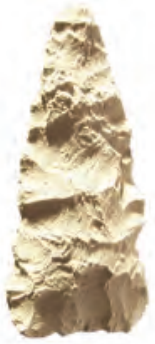

e

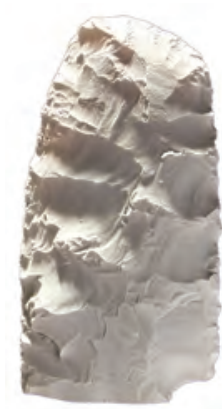

f

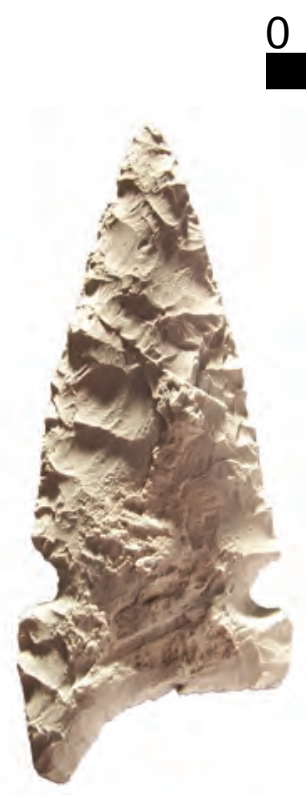

g
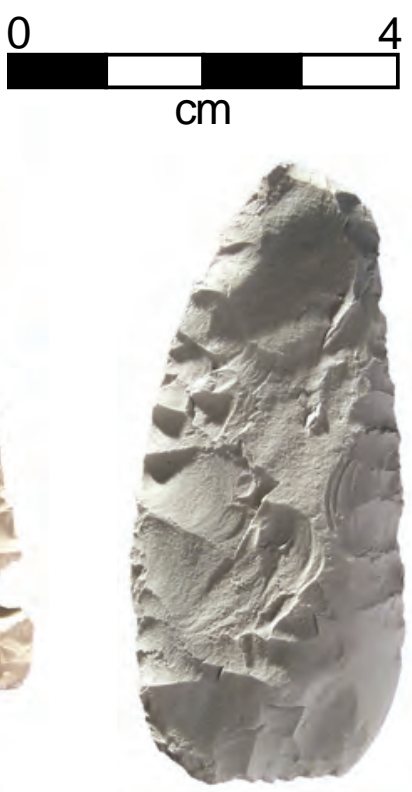

$\mathrm{h}$

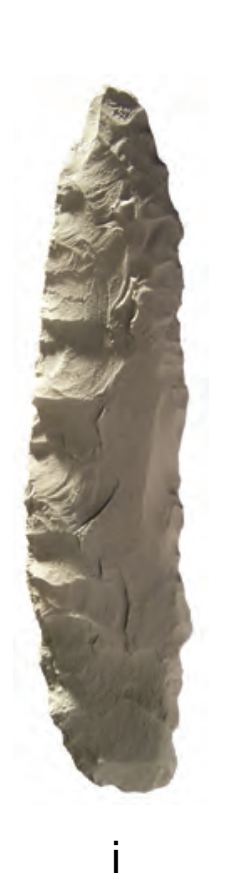

\section{西}

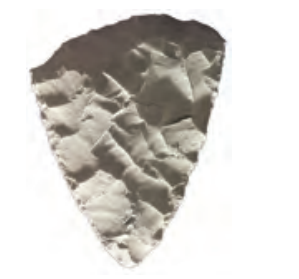

$\mathrm{k}$

Figure 8.2. Stone tools from Larson Village. a-e: small thin patterned bifaces; f-i: large thin patterned bifaces; j-k: steeply beveled flake tools. Specimens a, c, d, f, g, j, and k were made from KRF; b, e, h, and i were made from TRSS. Specimen d is a basal scraper/grinder; $k$ was made on a recycled bifacial knife.

Groundstone at Larson Village accounts for just over 23 percent of the lithic tools by count, over half of which is unpatterned clinker abrader fragments. Clinker is a ready-made abrasive material found and used throughout the region for shaping and sharpening soft materials such as bone or antler and for finishing or dressing the nap on hides. The soft and crumbling nature of this stone causes there to be high counts in of this material in the assemblage when it is found at all.

Tongue River silicified sediment occurs at precisely the same percentage by count (37.5 percent) in the tool assemblage as it does in the flaking debris. Knife River flint occurs at about the same frequency as TRSS in the tool assemblage at 37.4 percent, but is more common in the flaking debris (46.5 percent). The few true exotics in the Larson tool sample are limited to 11 patterned bifaces, 5 unpatterned flake tools, and a single retouched chalcedony plate. Based on these data, it appears that the tool makers from Larson Village had access to two dependable lithic raw material 
sources that served for all their flaked tool needs and that occasionally, through trade or direct procurement, other raw materials filtered into the tool kits.

Table 8.8. Stone tool counts and percentages organized by raw material type and technological class for the 2006 Larson collection.

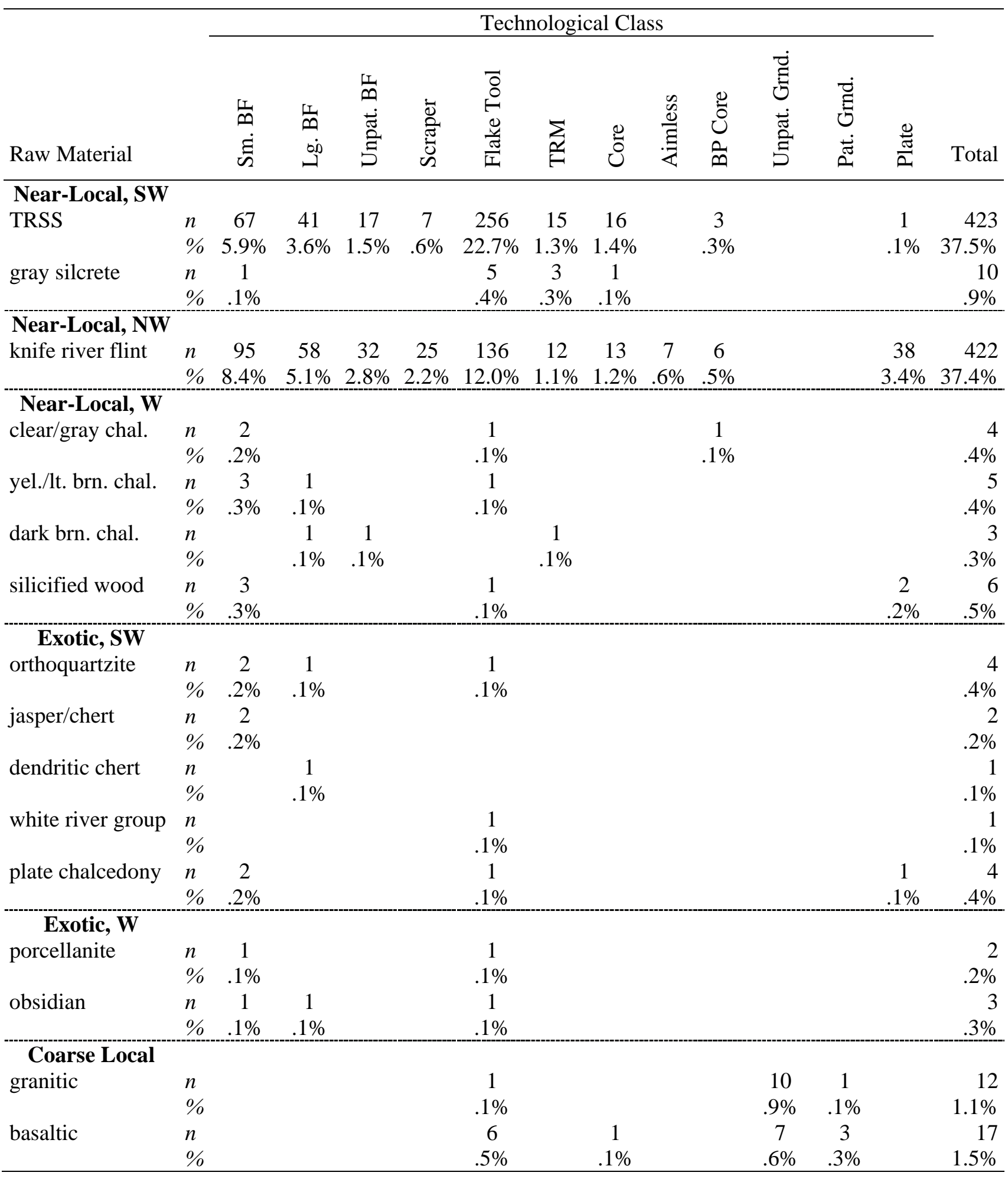


Table 8.8. Stone tool counts and percentages organized by raw material type and technological class (concluded.)

\begin{tabular}{|c|c|c|c|c|c|c|c|c|c|c|c|c|c|c|}
\hline \multirow[b]{2}{*}{ Raw Material } & \multicolumn{13}{|c|}{ Technological Class } & \multirow[b]{2}{*}{ Total } \\
\hline & & $\begin{array}{l}\dot{\omega} \\
\dot{\Xi} \\
\dot{\tilde{n}}\end{array}$ & $\begin{array}{l}\text { DI } \\
\text { D. } \\
\text { D. }\end{array}$ & 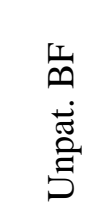 & 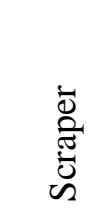 & 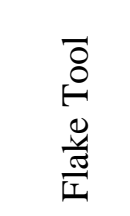 & $\underset{⿱ ㇒}{\sum_{1}}$ & ठ̃ & $\frac{\mathscr{Q}}{\stackrel{B}{Z}}$ & 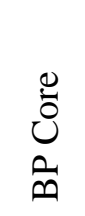 & 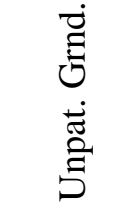 & $\begin{array}{l}\dot{\vec{E}} \\
\dot{U} \\
\dot{\tilde{U}} \\
\text { D. }\end{array}$ & $\frac{\stackrel{\pi}{\pi}}{2}$ & \\
\hline \multirow[t]{2}{*}{ Swan River cht } & $n$ & 1 & 1 & & & & & & & & & & & 2 \\
\hline & $\%$ & $.1 \%$ & $.1 \%$ & & & & & & & & & & & $.2 \%$ \\
\hline \multirow[t]{2}{*}{ yellow TRSS } & $n$ & & & 1 & & 1 & 1 & 1 & & & & & & 4 \\
\hline & $\%$ & & & $.1 \%$ & & $.1 \%$ & $.1 \%$ & $.1 \%$ & & & & & & $.4 \%$ \\
\hline \multirow[t]{2}{*}{ red TRSS } & $n$ & & & & & & 1 & 1 & & & & & & 2 \\
\hline & $\%$ & & & & & & $.1 \%$ & $.1 \%$ & & & & & & $.2 \%$ \\
\hline \multirow[t]{2}{*}{ compact sandst. } & $n$ & & & & & 3 & & & & & 7 & 1 & & 11 \\
\hline & $\%$ & & & & & $.3 \%$ & & & & & $.6 \%$ & $.1 \%$ & & $1.0 \%$ \\
\hline \multirow{2}{*}{ metaquartzite } & $n$ & & & & & & & & & & 2 & & & 2 \\
\hline & $\%$ & & & & & & & & & & $.2 \%$ & & & $.2 \%$ \\
\hline \multirow[t]{2}{*}{ schist } & $n$ & & & & & 1 & & & & & 3 & 1 & & 5 \\
\hline & $\%$ & & & & & $.1 \%$ & & & & & $.3 \%$ & $.1 \%$ & & $.4 \%$ \\
\hline \multirow{2}{*}{ silt/lime/mudst. } & $n$ & & & & & 1 & & & & & 5 & 2 & 1 & 9 \\
\hline & $\%$ & & & & & $.1 \%$ & & & & & $.4 \%$ & $.2 \%$ & $.1 \%$ & $.8 \%$ \\
\hline \multirow[t]{2}{*}{ coarse sandst. } & $n$ & & & & & & & & & & 12 & 1 & & 13 \\
\hline & $\%$ & & & & & & & & & & $1.1 \%$ & $.1 \%$ & & $1.2 \%$ \\
\hline \multicolumn{15}{|l|}{ Other } \\
\hline \multirow[t]{2}{*}{ clinker } & $n$ & & & & & & & & & & 138 & & & 138 \\
\hline & $\%$ & & & & & & & & & & $12.2 \%$ & & & $12.2 \%$ \\
\hline \multirow[t]{2}{*}{ scoria } & $n$ & & & & & & & & & & 15 & 4 & & 19 \\
\hline & $\%$ & & & & & & & & & & $1.3 \%$ & $.4 \%$ & & $1.7 \%$ \\
\hline \multirow{2}{*}{ unclassifiable } & $n$ & & & & & & & & & & 5 & & & 5 \\
\hline & $\%$ & & & & & & & & & & $.4 \%$ & & & $.4 \%$ \\
\hline \multirow[t]{2}{*}{ Total } & $n$ & 180 & 105 & 51 & 32 & 418 & 33 & 33 & 7 & 10 & 204 & 13 & 43 & 1129 \\
\hline & $\%$ & $15.9 \%$ & $9.3 \%$ & $4.5 \%$ & $2.8 \%$ & $37.0 \%$ & $2.9 \%$ & $2.9 \%$ & $.6 \%$ & $.9 \%$ & $18.1 \%$ & $1.2 \%$ & $3.8 \%$ & $100 \%$ \\
\hline
\end{tabular}

Table 8.9. Heat treatment data on KRF stone tools from the 2006 Larson excavations.

\begin{tabular}{|c|c|c|c|c|c|c|}
\hline \multirow{2}{*}{ Technological Class } & & \multicolumn{4}{|c|}{ Heat Treatment Class } & \multirow[b]{2}{*}{ Total } \\
\hline & & Unheated & Possible & Certain & Indeterminate & \\
\hline \multirow[t]{2}{*}{ Small Biface } & $n$ & 52 & 14 & 16 & 13 & 95 \\
\hline & $\%$ & $54.7 \%$ & $14.7 \%$ & $16.8 \%$ & $13.7 \%$ & \\
\hline \multirow[t]{2}{*}{ Large Biface } & $n$ & 36 & 7 & 7 & 8 & 58 \\
\hline & $\%$ & $62.1 \%$ & $12.1 \%$ & $12.1 \%$ & $13.8 \%$ & \\
\hline \multirow{2}{*}{ Unpatterned Biface } & $n$ & 23 & 2 & 1 & 6 & 32 \\
\hline & $\%$ & $71.9 \%$ & $6.3 \%$ & $3.1 \%$ & $18.8 \%$ & \\
\hline \multirow[t]{2}{*}{ Scraper } & $n$ & 13 & 3 & 3 & 6 & 25 \\
\hline & $\%$ & $52.0 \%$ & $12.0 \%$ & $12.0 \%$ & $24.0 \%$ & \\
\hline \multirow[t]{2}{*}{ Flake Tool } & $n$ & 99 & 6 & 16 & 15 & 136 \\
\hline & $\%$ & $72.8 \%$ & $4.4 \%$ & $11.8 \%$ & $11.0 \%$ & \\
\hline \multirow[t]{2}{*}{ TRM } & $n$ & 9 & 1 & & 2 & 12 \\
\hline & $\%$ & $75.0 \%$ & $8.3 \%$ & & $16.7 \%$ & \\
\hline
\end{tabular}


Table 8.9. Heat treatment data on KRF stone tools from the 2006 Larson excavations (concluded).

\begin{tabular}{|c|c|c|c|c|c|c|}
\hline \multirow[b]{2}{*}{ Technological Class } & & \multicolumn{4}{|c|}{ Heat Treatment Class } & \multirow[b]{2}{*}{ Total } \\
\hline & & Unheated & Possible & Certain & Indeterminate & \\
\hline \multirow[t]{2}{*}{ Freehand Core } & $n$ & 12 & & 1 & & 13 \\
\hline & $\%$ & $92.3 \%$ & & $7.7 \%$ & & \\
\hline \multirow[t]{2}{*}{ Aimless Core } & $n$ & 7 & & & & 7 \\
\hline & $\%$ & $100.0 \%$ & & & & \\
\hline \multirow[t]{2}{*}{ Bipolar Core/Tool } & $n$ & 6 & & & & 6 \\
\hline & $\%$ & $100.0 \%$ & & & & \\
\hline \multirow[t]{2}{*}{ Retouched Plate } & $n$ & 25 & 6 & 7 & & 38 \\
\hline & $\%$ & $65.8 \%$ & $15.8 \%$ & $18.4 \%$ & & \\
\hline \multirow[t]{2}{*}{ Total } & $n$ & 282 & 39 & 51 & 50 & 422 \\
\hline & $\%$ & $66.8 \%$ & $9.2 \%$ & $12.1 \%$ & $11.8 \%$ & $100.0 \%$ \\
\hline
\end{tabular}

Table 8.10. Comparison of technological class of chipped stone tools made from TRSS and KRF.

\begin{tabular}{|c|c|c|c|c|c|c|c|c|c|c|c|c|}
\hline \multirow[b]{2}{*}{$\begin{array}{l}\text { Raw } \\
\text { Material }\end{array}$} & & \multicolumn{10}{|c|}{ Technological Class } & \multirow[b]{2}{*}{ Total } \\
\hline & & 莺 & 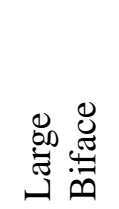 & 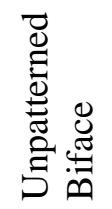 & 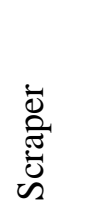 & 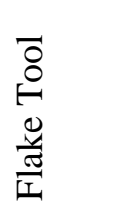 & $\sum_{\substack{|| r \mid}}$ & 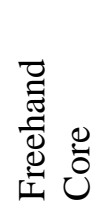 & 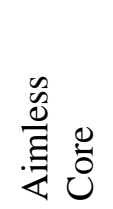 & 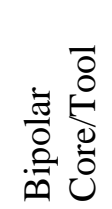 & 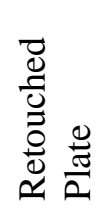 & \\
\hline \multirow[t]{2}{*}{ TRSS } & $n$ & 67 & 41 & 17 & 7 & 256 & 15 & 16 & 0 & 3 & 1 & 423 \\
\hline & $\%$ & $15.8 \%$ & $9.7 \%$ & $4.0 \%$ & $1.7 \%$ & $60.5 \%$ & $3.5 \%$ & $3.8 \%$ & $0.0 \%$ & $.7 \%$ & $0.2 \%$ & $100.0 \%$ \\
\hline \multirow[t]{2}{*}{ KRF } & $n$ & 95 & 58 & 32 & 25 & 136 & 12 & 13 & 7 & 6 & 38 & 422 \\
\hline & $\%$ & $22.5 \%$ & $13.7 \%$ & $7.6 \%$ & $5.9 \%$ & $32.2 \%$ & $2.8 \%$ & $3.1 \%$ & $1.7 \%$ & $1.4 \%$ & $9.0 \%$ & $100.0 \%$ \\
\hline \multirow[t]{2}{*}{ Total } & $n$ & 162 & 99 & 49 & 32 & 392 & 27 & 29 & 7 & 9 & 39 & 845 \\
\hline & $\%$ & $19.2 \%$ & $11.7 \%$ & $5.8 \%$ & $3.8 \%$ & $46.4 \%$ & $3.2 \%$ & $3.4 \%$ & $0.8 \%$ & $1.1 \%$ & $4.6 \%$ & $100.0 \%$ \\
\hline
\end{tabular}

\section{Regional Comparison of Stone Tool Technological Classes}

Table 8.11 presents data on the kinds of stone tools that make up pre-1650 assemblages in the Heart region. While tools of each type are present in all of the collections, the frequencies vary significantly, suggesting that very different activities were taking place in different villages. In some cases, these differences may be caused in part by sampling or by the segregation of certain activities in different sectors of the village. However, data from Double Ditch and Scattered villages (the most intensively investigated settlements) indicate that for the most part these patterns are duplicated in deposits across each site, suggesting that they were both widespread and temporally persistent. Larson has the highest percentage of unpatterned bifaces of the villages as well as the greatest proportion of unpatterned groundstone. The frequency of unpatterned groundstone tools reflects the large number of clinker abraders identified in this sample. It is also noteworthy that Larson has the smallest proportion of scraping tools of any of the villages included here. As with most of the other villages, it is clear that bipolar tool production was not a significant part of the Larson tool kit as compared to Scattered Village. Scattered Village is unique in the region with the high proportion of bipolar core tools. Larson Village yielded the smallest proportion of scrapers of any of the local contemporaneous villages and most of these were made from KRF. 
Table 8.11. Comparison of stone tool technological classes among pre-1650 villages in the Heart region.

Technological Class

\begin{tabular}{|c|c|c|c|c|c|c|c|c|c|c|c|c|c|}
\hline ite & & 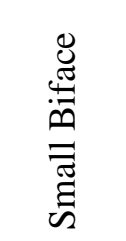 & 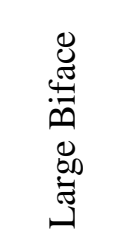 & 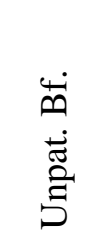 & 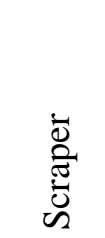 & 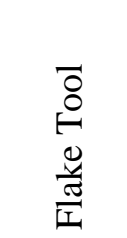 & $\begin{array}{l}\overline{8} \\
\circ \\
\stackrel{0}{0} \\
0 \\
0\end{array}$ & 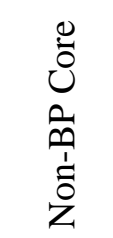 & 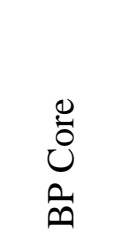 & $\begin{array}{l}\dot{\vec{U}} \\
\dot{\tilde{J}} \\
\text { 它 }\end{array}$ & 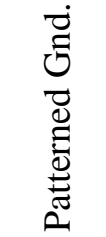 & 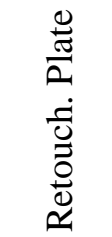 & Total \\
\hline arson & $\begin{array}{l}n \\
\%\end{array}$ & $\begin{array}{c}180 \\
15.9 \%\end{array}$ & $\begin{array}{c}105 \\
9.3 \%\end{array}$ & $\begin{array}{c}51 \\
4.5 \%\end{array}$ & $\begin{array}{c}32 \\
2.8 \%\end{array}$ & $\begin{array}{c}418 \\
37.0 \%\end{array}$ & $\begin{array}{c}0 \\
.0 \%\end{array}$ & $\begin{array}{c}73 \\
6.5 \% \\
\end{array}$ & $\begin{array}{c}10 \\
.9 \%\end{array}$ & $\begin{array}{c}204 \\
18.1 \%\end{array}$ & $\begin{array}{c}13 \\
1.2 \%\end{array}$ & $\begin{array}{c}43 \\
3.8 \% \\
\end{array}$ & \\
\hline $32 \mathrm{MC}$ & $\begin{array}{l}n \\
\%\end{array}$ & $\begin{array}{c}105 \\
17.9 \%\end{array}$ & $14.5 \%$ & $\begin{array}{c}32 \\
5.5 \% \\
\end{array}$ & $\begin{array}{c}18 \\
3.1 \% \\
\end{array}$ & $\begin{array}{c}171 \\
29.2 \%\end{array}$ & $\begin{array}{c}3 \\
.5 \% \\
\end{array}$ & $\begin{array}{c}75 \\
12.8 \% \\
\end{array}$ & $\begin{array}{c}6 \\
1.0 \%\end{array}$ & $\begin{array}{c}49 \\
8.4 \% \\
\end{array}$ & $\begin{array}{c}33 \\
5.6 \% \\
\end{array}$ & $\begin{array}{c}9 \\
1.5 \% \\
\end{array}$ & 586 \\
\hline ole & $\begin{array}{l}n \\
\%\end{array}$ & $\begin{array}{c}30 \\
13.0 \%\end{array}$ & $\begin{array}{c}28 \\
12.2 \%\end{array}$ & $\begin{array}{c}3 \\
1.3 \% \\
\end{array}$ & $\begin{array}{c}15 \\
6.5 \%\end{array}$ & $\begin{array}{c}76 \\
33.0 \% \\
\end{array}$ & $\begin{array}{c}1 \\
.4 \% \\
\end{array}$ & $\begin{array}{c}17 \\
7.4 \%\end{array}$ & $\begin{array}{c}11 \\
4.8 \%\end{array}$ & $\begin{array}{c}30 \\
13.0 \%\end{array}$ & $\begin{array}{c}1 \\
.4 \% \\
\end{array}$ & $\begin{array}{c}18 \\
7.8 \% \\
\end{array}$ & 230 \\
\hline ). Di & $\begin{array}{l}n \\
\%\end{array}$ & $\begin{array}{c}316 \\
18.2 \%\end{array}$ & $\begin{array}{c}245 \\
14.1 \%\end{array}$ & $\begin{array}{c}25 \\
1.4 \%\end{array}$ & $\begin{array}{c}65 \\
3.7 \% \\
\end{array}$ & $\begin{array}{c}668 \\
38.4 \%\end{array}$ & $\begin{array}{c}1 \\
.1 \%\end{array}$ & $\begin{array}{c}152 \\
8.7 \%\end{array}$ & $\begin{array}{l}16 \\
.9 \%\end{array}$ & $\begin{array}{c}205 \\
11.8 \%\end{array}$ & $\begin{array}{l}10 \\
.6 \%\end{array}$ & $\begin{array}{c}37 \\
2.1 \% \\
\end{array}$ & 1740 \\
\hline 5. I & $\begin{array}{l}n \\
\%\end{array}$ & $\begin{array}{c}114 \\
14.4 \%\end{array}$ & $\begin{array}{c}91 \\
11.5 \%\end{array}$ & $\begin{array}{c}13 \\
1.6 \%\end{array}$ & $\begin{array}{c}27 \\
3.4 \%\end{array}$ & $\begin{array}{c}358 \\
45.1 \% \\
\end{array}$ & $\begin{array}{c}2 \\
.3 \%\end{array}$ & $\begin{array}{c}73 \\
9.2 \% \\
\end{array}$ & $\begin{array}{c}5 \\
.6 \%\end{array}$ & $\begin{array}{c}95 \\
12.0 \%\end{array}$ & $\begin{array}{c}6 \\
.8 \% \\
\end{array}$ & $\begin{array}{c}9 \\
1.1 \%\end{array}$ & 793 \\
\hline cat & $\begin{array}{l}n \\
\%\end{array}$ & $\begin{array}{c}113 \\
15.1 \%\end{array}$ & & $\begin{array}{c}22 \\
2.9 \%\end{array}$ & $\begin{array}{c}45 \\
6.0 \%\end{array}$ & $\begin{array}{c}224 \\
30.0 \% \\
\end{array}$ & $\begin{array}{c}3 \\
.4 \% \\
\end{array}$ & $\begin{array}{c}37 \\
5.0 \% \\
\end{array}$ & $\begin{array}{c}59 \\
7.9 \%\end{array}$ & $\begin{array}{c}75 \\
10.0 \%\end{array}$ & $\begin{array}{c}7 \\
.9 \% \\
\end{array}$ & $\begin{array}{c}56 \\
7.5 \% \\
\end{array}$ & 747 \\
\hline Scatt & $\begin{array}{l}n \\
\%\end{array}$ & $\begin{array}{c}62 \\
14.4 \%\end{array}$ & $\begin{array}{c}71 \\
16.4 \%\end{array}$ & $\begin{array}{c}15 \\
3.5 \% \\
\end{array}$ & $\begin{array}{c}24 \\
5.6 \% \\
\end{array}$ & $\begin{array}{c}129 \\
29.9 \% \\
\end{array}$ & $\begin{array}{c}2 \\
.5 \%\end{array}$ & $\begin{array}{c}13 \\
3.0 \% \\
\end{array}$ & $\begin{array}{c}48 \\
11.1 \%\end{array}$ & $\begin{array}{c}39 \\
9.0 \%\end{array}$ & $\begin{array}{c}4 \\
.9 \% \\
\end{array}$ & $\begin{array}{c}25 \\
5.8 \% \\
\end{array}$ & 432 \\
\hline (2) ( & $\begin{array}{l}n \\
\% \\
\end{array}$ & $\begin{array}{c}51 \\
17.6 \% \\
\end{array}$ & $\begin{array}{c}22 \\
7.6 \% \\
\end{array}$ & $\begin{array}{c}8 \\
2.8 \% \\
\end{array}$ & $\begin{array}{c}11 \\
3.8 \% \\
\end{array}$ & $\begin{array}{c}120 \\
41.5 \% \\
\end{array}$ & $\begin{array}{c}7 \\
2.4 \% \\
\end{array}$ & $\begin{array}{c}15 \\
5.2 \% \\
\end{array}$ & $\begin{array}{c}5 \\
1.7 \% \\
\end{array}$ & $\begin{array}{c}43 \\
14.9 \% \\
\end{array}$ & $\begin{array}{c}4 \\
1.4 \% \\
\end{array}$ & $\begin{array}{c}3 \\
1.0 \% \\
\end{array}$ & 289 \\
\hline JedI & $\begin{array}{l}n \\
\% \\
\end{array}$ & $\begin{array}{c}971 \\
16.3 \% \\
\end{array}$ & $\begin{array}{c}753 \\
12.7 \% \\
\end{array}$ & $\begin{array}{c}169 \\
2.8 \% \\
\end{array}$ & $\begin{array}{c}237 \\
4.0 \% \\
\end{array}$ & $\begin{array}{c}2164 \\
36.4 \% \\
\end{array}$ & $\begin{array}{c}19 \\
.3 \% \\
\end{array}$ & $\begin{array}{c}455 \\
7.7 \% \\
\end{array}$ & $\begin{array}{c}160 \\
2.7 \% \\
\end{array}$ & $\begin{array}{c}740 \\
12.4 \% \\
\end{array}$ & $\begin{array}{c}78 \\
1.3 \% \\
\end{array}$ & $\begin{array}{c}200 \\
3.4 \% \\
\end{array}$ & 5946 \\
\hline
\end{tabular}

\section{Summary}

The vast majority of the tools in the 2006 collection from Larson were made from TRSS and KRF. These two types of stone could be available near the village, but better, more reliable sources are located to the southwest and northwest respectively, 30 to $60 \mathrm{~km}$ away. Unpatterned flake tools, the most common tool type, make up 37 percent of the assemblage. The data from village contexts in the area suggests that a large proportion of the flaking debris of any significant size was used for some task and was either intentionally modified to create a working edge or was modified through use. The next most common tool type, unpatterned groundstone tools, makes up about 18 percent. About 16 percent of the assemblage consists of patterned small thin bifaces. The range of variation in the proportion of this tool type is remarkably low across the region. TRSS and KRF supply the raw material for 90 percent of all arrow points at Larson. Exotic raw materials only account for about 1.5 percent of the tools and that may suggest a lack of long-distance trade or travel or simply an abundance of adequate material close at hand. However, it should be noted that the exotic lithic materials recovered from Larson all tend to indicate a connection toward the west and southwest into the Big Badlands, the Black Hills, and as far away as the Yellowstone region. The few patterned tools not made from TRSS or KRF were made from a variety of materials without any apparent preference for a single material. Any given tool type has no more than three specimens for any type of raw material. Among Heart region sites studied so far, Larson Village has the lowest percentage of exotic flaking debris. Interestingly, the frequency of exotic stones also is low at 
Double Ditch, the only other east bank village for which detailed data are available. However, the overall composition of the Larson flaking debris assemblage more closely resembles that of Slant Village, a west bank settlement located much closer to high-quality TRSS sources.

Some of the strongest patterns evident in the modified stone assemblage have to do with the distinctly different ways the two dominant raw materials were used. Much of the TRSS was brought to the village in the form of comparatively large flakes or nodules, and was used mainly for the production of unpatterned flake tools. By contrast, KRF generally entered the village as smaller flakes, or perhaps as tool performs, and was used mainly for the production of arrow points, bifacial knives, and scrapers. A somewhat similar pattern is evident at Double Ditch, where TRSS was acquired as flakes struck from well-made cores or as large blocks and was used to produce flake tools and large patterned bifaces (Ahler et al. 2004:223). These data suggest that the residents of both Larson and Double Ditch enjoyed regular, direct access to sources of TRSS.

Flake size and density data indicate that midden and midden and earth deposits were subjected to similar formation processes, but that culturally sterile sediment was added to the latter. This supports the idea that Ditch 4 and Block G, both of which were filled with the latter type of deposit, were backfilled intentionally, probably over a comparatively short period of time. 


\section{References Cited}

Ahler, Stanley A.

1983 Heat Treatment of Knife River Flint. Lithic Technology 12:1-8.

1989a Mass Analysis of Flaking Debris: Studying the Forest Rather than the Tree. In Alternative Approaches to Lithic Analysis, edited by D. Henry and G. Odell, pp. 85-119.

Archaeological Papers No. 1. American Anthropological Association, Washington, D.C.

1989b Experimental Knapping with KRF and Midcontinent Cherts: Overview and Applications. In Experiments in Lithic Technology, edited by Daniel S. Amick and Raymond P. Mauldin, pp. 199-234. BAR International Series 528, Oxford.

1992 Use-Phase Classification and Manufacturing Technology in Plains Village Arrowpoints. In Piecing Together the Past: Applications of Refitting Studies in Archaeology, edited by Jack L. Hofman and James G. Enloe, pp. 36-62. BAR International Series 578, Oxford.

Ahler, Stanley A., Eric Feiler, Chad Badorek, and Monicque Smail

2002 Stone Tools and Flaking Debris. In Prehistory on First Street NE: The Archaeology of Scattered Village in Mandan, North Dakota, edited by Stanley A. Ahler, pp. 12.1-12.81. Research Contribution No. 40. PaleoCultural Research Group, Flagstaff, Arizona. Submitted to the City of Mandan, North Dakota, and the north Dakota Department of Transportation, Bismarck.

Ahler, Stanley A., and Herbert Haas

1993 The KNRI Phase I Chronometric Subprogram. In The Phase I Archaeological Research Program for the Knife River Indian Villages National Historic Site, Part 1, edited by Thomas Thiessen, pp. 115-166. Occasional Studies in Anthropology 27. National Park Service, Midwest Archaeological Center, Lincoln.

Ahler, Stanley A., Lucas Kellet, and George T. Crawford

2003 Stone Artifact Analysis: Stone Tools and Flaking Debris. In Archaeology at Menoken Village, A Fortified Late Plains Woodland Community in Central North Dakota, edited by Stanley A. Ahler, pp. 357-450. PaleoCultural Research Group, Flagstaff, Arizona. Submitted to the State Historical Society of North Dakota, Bismarck.

Ahler, Stanley A., Jennifer Minor, and Monicque Smail

1997 Stone Tools and Flaking Debris. In Archaeology of the Mandan Indians at On-A-Slant Village (32M026), Fort Abraham Lincoln State Park, Morton County, North Dakota, edited by Stanley A. Ahler, pp. 261-350. Office of Research and Graduate Studies, Northern Arizona University, Flagstaff. Submitted to the North Dakota Parks and Recreation Department, Bismarck.

Ahler, Stanley A., Kelly Ritter, and George T. Crawford

2003 Analysis of Stone Tools and Flaking Debris. In Archaeological Investigations During 2001 and 2002 at Double Ditch State Historic Site, North Dakota, edited by Stanley A. Ahler, pp. 171-196. PaleoCultural Research Group, Flagstaff, Arizona. Submitted to the State Historical Society of North Dakota, Bismarck.

Ahler, Stanley A., Matthew J. Root, and Eric J. Feiler

1994 Methods for Stone Tool Analysis. In A Working Manual for Field and Laboratory Techniques and Methods for the 1992-1996 Lake Ilo Archaeological Project, edited by Stanley A. Ahler, pp. 27-121. Quaternary Studies Program, Northern Arizona University. Submitted to the University of North Dakota, Grand Forks, and the U.S. Fish and Wildlife Service, Denver. 
Ahler, Stanley A., Matthew J. Root, Lisa K. Shifrin, and Jerry D. William

1994 Methods for Analysis of Chipped Stone Flaking Debris. In A Working Manual for Field and Laboratory Techniques and Methods for the 1992-1996 Lake Ilo Archaeological Project. Quaternary Studies Program, Northern Arizona University, edited by Stanley A. Ahler, pp. 119-129. Submitted to the University of North Dakota, Grand Forks, and the U.S. Fish and Wildlife Service, Denver.

Ahler, Stanley A., Grant Shimer, Kelly Ritter, and Karla Borrud

2004 Analysis of Stone Tools and Flaking Debris. In Archaeological Investigations During 2003 at Double Ditch State Historic Site, North Dakota, edited by Stanley A. Ahler, pp. 187-225. Research Contribution No. 60. PaleoCultural Research Group, Flagstaff, Arizona. Submitted to the State Historical Society of North Dakota, Bismarck.

Ahler, Stanley A., and Anthony A. Swenson

1985 Test Excavations at Big Hidatsa Village (32ME407), Knife River Indian Villages National Historic Site. University of North Dakota. Submitted to the National Park Service, Midwest Archaeological Center, Lincoln.

Ahler, Stanley A., and Dennis L. Toom

1993 KNRI and Upper Knife-Heart Region Lithic Artifact Analysis. In The Phase I Archaeological Research Program for the Knife River Indian Villages National Historic Site, Part III, edited by Thomas Thiessen, pp. 173-262. Midwest Archaeological Center Occasional Studies in Anthropology 27. U.S. National Park Service, Lincoln.

Clark, G.R.

1985 The Distribution and Procurement of Lithic Raw Material of Coal Burn Origin in Eastern Montana. Archaeology in Montana 26(1):36-43.

Hoard, Robert J., J.R. Bozell, Stephen R. Holen, Michael D. Glascock, Hector Neff, and J.M. Elam 1993 Source Determination of White River Group Silicates from Two Archaeological Sites in the Great Plains. American Antiquity 58:698-710.

Porter, J.W.

1962 Notes on Four Lithic Types Found in Archaeological Sites Near Mobridge, South Dakota. Plains Anthropologist 7:267-269.

Reher, Charles A.

1991 Large Scale Lithic Quarries and Regional Transport Systems on the High Plains of Eastern Wyoming: Spanish Diggings Revisited. In Raw Material Economies Among Prehistoric Hunter-Gatherers, edited by A. Monet-White and S. Holden, pp. 251-284. Publications in Anthropology No. 19. University of Kansas, Lawrence. 


\title{
9. UNMODIFIED VERTEBRATE REMAINS
}

\author{
Carl R. Falk
}

\section{Introduction}

Substantial quantities of animal bone refuse were recovered during archaeological test excavations at the Larson Village site (32BL9) in 2006. The bone is well preserved. Sample characteristics are generally similar to those of assemblages recovered from village sites recently investigated in the general area: On-A-Slant (Schubert and Cruz-Uribe 1997; Falk 1997), Scattered (Cruz-Uribe 2002; Falk 2002), Double Ditch (Lee and Ahler 2003; Falk and Ahler 2004, 2005), and Boley (Falk 2006). Given available funding and time constraints, analysis of the 2006 Larson bone sample is limited to a broad evaluation of assemblage content and examination of intra-site specimen distributions. This approach is consistent with the methodology employed for recent work at both the Double Ditch and Boley village sites. Laboratory procedures duplicate those employed for these earlier studies and include physical separation of modified and unmodified remains, collection of weights and/or counts for the unmodified sample, and a general taxonomic assessment of identifiable remains. The resulting data set permits, in addition to internal comparisons at Larson, limited comparisons between bone remains from Larson and other villages within the Knife-Heart Region.

Under the direction of Stacey Madden, PCRG lab assistants in Flagstaff, Arizona accomplished the initial processing of screened materials. Following basic size grading procedures (see Chapter 5), all bone was sorted and separately packaged for the size G1 through G3 fractions. The G1 to G3 bone remains (including both modified and unmodified specimens) were further separated into burned and unburned portions and quantified by weight for each size grade. Counts for size G1 specimens were recorded; counts were not recorded for size G2 and G3 pieces. In addition, potentially identifiable bone specimens were sorted from all size G4 samples, but not from the size grade G5 fractions. Modified pieces were sorted from both size G4 and G5 fractions.

The sorted bone remains were shipped to the author in Cape May, New Jersey for further processing and analysis. Upon receipt, samples were organized for study by excavation unit. Each catalog lot was carefully examined for the presence of modified bone and antler pieces. Modified specimens were segregated, weighed, and set aside for further study (see Chapter10); weights for sizes G1 to G3 modified specimens and counts for size G1 specimens were subtracted from weight values previously recorded in Flagstaff. The identifiable sizes G1 to G4 specimens were separated and basic taxonomic and element identifications were recorded. A collection of modern reference skeletons was available for this phase of the study.

\section{Size Grade and Bone Weight Distributions}

Size G1 specimen counts and sizes G1 to G3 weight data are organized by excavation unit in Table 9.1. A total of $98.9 \mathrm{~kg}$ of unmodified bone was recovered during the 2006 test investigation. 
The size G1 sample includes 1,400 specimens. During the field investigation, one wheelbarrow load of fill from Block A (GL1) was accidentally mixed with material from Ditch 3 (GL2). These materials are labeled as 'mixed' in subsequent presentations.

Table 9.1. Count (G1) and weight (G1-3) distributions for unmodified vertebrate remains organized by excavation unit for the 2006 test excavations at Larson Village.

\begin{tabular}{|c|c|c|c|c|c|c|}
\hline \multirow[b]{2}{*}{ Excavation Unit } & \multirow{2}{*}{$\begin{array}{c}\text { Count } \\
\text { G1 }\end{array}$} & \multicolumn{3}{|c|}{ Weight (g) by Size Grade } & \multirow[b]{2}{*}{ Total Wt. } & \multirow[b]{2}{*}{ Pct. Burned } \\
\hline & & G1 & G2 & G3 & & \\
\hline Block A -midden & 60 & 2528 & 1855 & 2227 & 6610 & 7.2 \\
\hline Block A - F108 & 5 & 130 & 33 & 33 & 196 & 7.6 \\
\hline Block A - F109 & 96 & 2743 & 2333 & 1922 & 6998 & 24.8 \\
\hline Block A - F111 & - & - & - & 5 & 5 & 60.0 \\
\hline Subtotal & 161 & 5401 & 4221 & 4187 & 13809 & 16.1 \\
\hline Block D - midden & 40 & 899 & 1593 & 2620 & 5112 & 8.4 \\
\hline Block D - F101 & 1 & 17 & 6 & 5 & 28 & - \\
\hline Block D - F102 & - & - & 3 & 2 & 5 & - \\
\hline Block D - F103 & 1 & 11 & 72 & 72 & 155 & 58.7 \\
\hline Subtotal & 42 & 927 & 1674 & 2699 & 5300 & 9.8 \\
\hline Block F - midden & 33 & 583 & 1283 & 1355 & 3221 & 7.4 \\
\hline Block F - F104 & 30 & 1217 & 406 & 286 & 1909 & 1.8 \\
\hline Block F - F107 & 453 & 9232 & 5442 & 4095 & 18769 & 7.6 \\
\hline Subtotal & 516 & 11032 & 7131 & 5735 & 23899 & 7.1 \\
\hline Block $\mathrm{G}$ - midden & 66 & 2770 & 1806 & 2172 & 6748 & 3.7 \\
\hline Subtotal & 66 & 2770 & 1806 & 2172 & 6748 & 3.7 \\
\hline Ditch 3 - midden & 15 & 193 & 701 & 1307 & 2201 & 12.9 \\
\hline Ditch 3 - F105 & 352 & 10975 & 9257 & 9627 & 29859 & 5.0 \\
\hline Subtotal & 367 & 11168 & 9958 & 10934 & 32060 & 5.5 \\
\hline Ditch 4 - midden & 23 & 460 & 398 & 683 & 1541 & 33.2 \\
\hline Ditch 4- F106 & 223 & 10544 & 2595 & 1922 & 15061 & 2.2 \\
\hline Subtotal & 246 & 11004 & 2993 & 2605 & 16602 & 5.1 \\
\hline Mixed Blk A/D 3 & 2 & 34 & 164 & 360 & 558 & 9.0 \\
\hline Subtotal & 2 & 34 & 164 & 360 & 558 & 9.0 \\
\hline Total & 1400 & 42336 & 27947 & 28693 & 98976 & 7.4 \\
\hline
\end{tabular}

Approximately 7.4 percent of the unmodified bone sample shows some degree of burning (Table 9.1). The relative frequency of burned specimens varies markedly between the six excavation units. Comparatively low values (3.7 to 5.5 percent) are noted for Block G, Ditch 3 and Ditch 4 while 16.1 percent of the Block A sample is burned. Burned bone is most common in the small pits located in Block A (F111) and Block D (F103), as well as in a large trash-filled pit also located in Block A (F109).

Based on a total excavated (and screened) volume of $14.3 \mathrm{cu} . \mathrm{m}$, unmodified bone density for the 2006 Larson sample is $6.92 \mathrm{~kg} / \mathrm{cu}$. m. Comparisons with the Boley (Falk 2006) and Double 
Ditch site samples (Lee and Ahler 2003; Falk and Ahler 2005) show that Larson is within the general range of reported bone density. A value of $4.58 \mathrm{~kg} / \mathrm{cu}$. $\mathrm{m}$ is recorded for Boley while values ranging from 5.92 to $14.97 \mathrm{~kg} / \mathrm{cu}$. m are noted for the 2004 and combined 2002-2003 Double Ditch test samples. The meaning of the density calculations is unclear. The actual values may have little if any significance given differences in depositional contexts actually sampled and varying analytic priorities (see Falk and Ahler 2005:249-151).

At Larson, variations between site areas reflect, in part, dissimilar depositional histories and/or functional variations in contexts sampled. For example, bone density values are relatively high for pit fill - ranging from $43.4 \mathrm{~kg} / \mathrm{cu}$. m (F104, Block F) to $20.8 \mathrm{~kg} / \mathrm{cu}$. m (F107, Block F). Bone density is lower in the fill taken from the ditch tests, with values varying from $8.34 \mathrm{~kg} / \mathrm{cu} . \mathrm{m}$ (F105, Ditch 3) to $8.66 \mathrm{~kg} / \mathrm{cu}$. m (F106, Ditch 4). These distinctions are further illustrated in Table 9.2 where bone density data are organized by deposit type, as well as by general temporal sequence. Relatively low values are recorded for uncontained midden deposits, regardless of temporal association. Higher values are noted for pit fill (i.e., contained deposits), both from small and large pits.

Table 9.2. Bone weight (G1-3), excavated volume and bone density organized by temporal sequence and deposit type for the 2006 test excavations at Larson Village.

\begin{tabular}{ccccc}
\hline Stratigraphic Group & Deposit Type & $\begin{array}{c}\text { Bone Weight } \\
\text { (g) }\end{array}$ & $\begin{array}{c}\text { Excavated Volume } \\
\text { (cu. m) }\end{array}$ & $\begin{array}{c}\text { Bone Density } \\
\text { (kg/cu. m) }\end{array}$ \\
\hline Latest & Midden & 15147 & 2.64 & 5.74 \\
Later & Cache Pit & 25767 & 1.41 & 18.27 \\
Later & Small Pit & 2298 & 0.12 & 19.15 \\
Later & Midden & 28388 & 3.34 & 8.50 \\
Earliest & Midden & 1097 & 0.90 & 1.22 \\
Earliest & Midden w/Earth & 21870 & 3.55 & 6.16 \\
Unassigned & Plowzone & 3851 & 2.00 & 1.92 \\
Unassigned & Mixed & 558 & 0.34 & 1.64 \\
\hline Total & & & 14.3 & 6.92 \\
\hline
\end{tabular}

\section{Identified Vertebrate Specimens}

As noted above, identification of unmodified bone from the 2006 test investigation of Larson Village made use of the basic approach employed for the Double Ditch (Lee and Ahler 2003:199; Falk and Ahler, 2004:229; Falk and Ahler 2005:251) and Boley (Falk 2006) projects. Specimens are considered "identifiable” if the anatomical element or element group (e.g., rib, thoracic vertebra, proximal phalanx, etc.), side (left, right, axial) and portion (e.g., proximal, distal, cranial, caudal, etc.) are established. Additional data concerning relative age of the animal represented, as well as presence/absence information on burning, tool marks, and carnivore and/or rodent gnawing are also recorded. Other than the incidence of burning, little of this information is presented here but is included with site records. Following a procedure initiated in a previous study (Lee and Ahler 2003), counts of identified specimens are tabulated according to varying levels of 
taxonomic specificity: (1) large artiodactyl (bison, Bison bison, and/or elk, Cervus elaphus); (2) small artiodactyl (deer, Odocoileus sp., and/or pronghorn, Antilocapra americana); (3) large canid (domestic/feral dog, Canis familiaris, coyote, Canis latrans, and/or gray wolf, Canis lupus); (4) medium to small mammal (all lagomorphs; beaver, Castor canadensis; muskrat, Ondatra zibethicus; small canids; mustelids; mephitids; and felids); (5) fish; (6) bird; (7) reptile and amphibian; (8) dental elements for micromammals (here, insectivores, bats, squirrels, pocket gophers, heteromyids, mice, rats and voles), and (9) other cranial and all postcranial elements for micromammals.

Table 9.3 provides an inventory by size grade and taxonomic grouping for specimens recovered from the 2006 investigation, including materials from mixed proveniences. The total count of identified specimens is 3857. The remains of large artiodactyls dominate the size G1 and G2 fractions and comprise 21.2 percent of the identified sample. Eighty-one bones are from small artiodactyls, representing 2.1 percent of the total. Small artiodactyls are more-or-less evenly distributed through the sizes G1 to G3 samples. Large canid specimens comprise nearly 10.0 percent of the total. Medium-small mammals ( 9.0 percent) and birds ( 7.5 percent) are also well represented. Fish contribute 6.0 percent of the total NISP. Medium-small mammal, bird and fish bones are most numerous in the size G4 fraction. The pooled reptile (NISP=3) and amphibian (NISP=98) sample-recovered almost exclusively from the G4 fraction-contributes an additional 2.6 percent of the total. Finally, micromammal dental elements and other cranial and post-cranial specimens make up 41.6 percent of the sample.

Table 9.3. Identified vertebrate specimens (NISP) organized by size grade and taxonomic group for the 2006 test excavations at Larson Village.

\begin{tabular}{|c|c|c|c|c|c|c|}
\hline \multirow[b]{2}{*}{ Taxonomic Group } & \multicolumn{4}{|c|}{ Size Grade } & \multirow[b]{2}{*}{ Total } & \multirow[b]{2}{*}{ Percent Burned } \\
\hline & G1 & $\mathrm{G} 2$ & G3 & G4 & & \\
\hline 1 large artiodactyl & 537 & 253 & 26 & & 816 & 2.9 \\
\hline 2 small artiodactyl & 23 & 32 & 26 & & 81 & 6.2 \\
\hline 3 large canid & 40 & 93 & 206 & 45 & 384 & 8.3 \\
\hline 4 medium-small mammal & & 30 & 125 & 194 & 349 & 16.0 \\
\hline 5 fish & & 1 & 22 & 208 & 231 & 6.9 \\
\hline 6 bird & & 16 & 68 & 206 & 290 & 9.3 \\
\hline 7 reptile/amphibian & & & 3 & 98 & 101 & 0.0 \\
\hline 8 micromammal dental & & & 25 & 275 & 300 & 2.0 \\
\hline 9 micromammal other & & 1 & 62 & 1242 & 1305 & 1.7 \\
\hline $\begin{array}{l}\text { Total } \\
\end{array}$ & 600 & 426 & 563 & 2268 & 3857 & 4.9 \\
\hline
\end{tabular}

Approximately 4.9 percent of the identified sample is burned. The medium-small mammal sample shows the highest proportion of burned specimens (16.0 percent), followed by bird (9.3 percent), large canid (8.3 percent), fish (6.9 percent), and small artiodactyl (6.2 percent). None of the amphibian or reptile specimens are burned. Twenty-eight (1.7 percent) micromammal specimens are burned, signifying that some of these remains are perhaps contemporaneous with the village occupation. Burned micromammal specimens represent ground squirrel, gopher and unidentified mouse.

As suggested elsewhere (Lee and Ahler 2003; Falk and Ahler 2004, 2005; Falk 2006), animals represented by groups 1-6 undoubtedly contributed in varying ways to the subsistence requirements of villagers and/or provided a vital source of bone for tools and ornaments, as well as 
for hides, furs, plumage, and other raw materials. At Larson, all identified large artiodactyl specimens are almost certainly bison, although many fragments can only be identified as "large artiodactyl” based on morphological criteria. However, with the possible exception of modified antler pieces (see Chapter 10), elk do not appear to be represented in the collection. Small artiodactyls are represented by deer and pronghorn. The bones of large canids are familiar in nearly every reported village assemblage in the northern Plains. Whiles no systematic attempt was made to identify large canid remains beyond genus, most Larson specimens are domestic dog and/or gray wolf. Coyote bones are also recorded but are not common. In the identified sample, medium to small mammal remains include the bones of cottontail (Sylvilagus sp.), white-tailed jackrabbit (Lepus townsendii), muskrat (Ondatra zibethicus), beaver (Castor canadensis), swift fox (Vulpes velox), badger, (Taxidea taxus) and long-tailed weasel (Mustela cf. M frenata).

A variety of birds are represented in the sample. These include: unidentified goose (Anserinae), teal (Anas sp.), unidentified hawks (Accipitridae), golden (Aquila chrysaetos) and/or bald eagle (Haliaeetus leucocephalus), grouse (Tetraonidae), great horned owl (Bubo virginianus), woodpecker (Picidae), northern raven (Corvus corax), black-billed magpie (Pica pica), and an assortment of unidentified small passerines (Passeriformes). The sample of fish is dominated by bullhead catfish (Ictaluridae). Nearly all of these are the remains of channel catfish (Ictalurus punctatus). Goldeye (Hiodon alosoides), cyprinids (mostly flathead chub, Platygobio gracilis), unidentified suckers (Catostomidae), burbot (lota lota), and sauger (Stizostedion canadense) and/or walleye (S. vitreum) are also recorded.

Reptile and amphibian specimens represent animals that - for the most part - are of comparatively recent origin and/or not directly linked to village occupation. This is especially likely for toad (Bufonidae), frog (leopard frog, Rana pipiens), and tiger salamander (Ambystoma tigrinum) remains that dominate the sample of herps. Only a few reptile bones were recovered, including the remains of snapping turtle (Chelydra serpentina), painted turtle (Chrysemys picta) and unidentified snake vertebrae. The turtle bones are likely associated with the village occupation, though none of these specimens are burned or show obvious tool marks.

Specimens assigned to groups 8 and 9 represent several species of mouse and vole, as well as Richardson's ground squirrel (Spermophilus richardsonii), thirteen-lined ground squirrel (S. tridecemlineatus), prairie dog (Cynomys sp.), and northern pocket gopher (Thomomys talpoides). Micromammal bones are plentiful in the excavated deposits and may be useful for paleoenvironmental studies if future analysis is able to establish the association of these remains with significant cultural and/or temporal units.

Table 9.4 summarizes presence/absence data for the animals or groups of animals identified during the preliminary descriptive phase of the analysis. Although it is obvious that this presentation is of limited value it does document the ubiquitous character of certain taxa - at least within the areas sampled by the 2006 test excavations - and provides a glimpse of taxonomic diversity within the recovered assemblage. Among mammals, the remains of large canids, swift fox, deer and bison are found in all excavation units while prairie dog, muskrat, and badger are each represented in only one unit. Minnow and catfish bones are common; goldeye, burbot and sauger/walleye specimens are relatively uncommon. Hawks and eagles, along with the remains of grouse and various passerine are also relatively common, but those of waterfowl are less so. 
Table 9.4. Presence (X) - absence distributions for identified remains organized by excavation unit for the 2006 test excavations at Larson Village.

\begin{tabular}{|c|c|c|c|c|c|c|}
\hline \multirow{2}{*}{ Scientific Name (common name) } & \multicolumn{6}{|c|}{ Excavation Unit } \\
\hline & Block A & Block D & Block F & Block G & Ditch 3 & Ditch 4 \\
\hline Hiodon alosoides (goldeye) & & & $\mathrm{X}$ & & $\mathrm{X}$ & \\
\hline Cyprinidae (carps and minnows) & $\mathrm{X}$ & $\mathrm{X}$ & $\mathrm{X}$ & $\mathrm{X}$ & $\mathrm{X}$ & $\mathrm{X}$ \\
\hline Catostomidae (suckers) & & & & & & $\mathrm{X}$ \\
\hline Ictaluridae (bullhead catfishes) & $\mathrm{X}$ & $\mathrm{X}$ & & $\mathrm{X}$ & $\mathrm{X}$ & $\mathrm{X}$ \\
\hline Lota lota (burbot) & $\mathrm{X}$ & & & & & \\
\hline Stizostedion sp. (sauger/walleye) & & & & & $\mathrm{X}$ & \\
\hline Ambystoma tigrinum (tiger salamander) & & & $\mathrm{X}$ & & $\mathrm{X}$ & $\mathrm{X}$ \\
\hline Anura (toads and frogs) & $\mathrm{X}$ & $\mathrm{X}$ & $\mathrm{X}$ & $\mathrm{X}$ & $\mathrm{X}$ & $\mathrm{X}$ \\
\hline Chelydra serpentina (snapping turtle) & & & & $\mathrm{X}$ & & \\
\hline Chrysemys picta (painted turtle) & & & & & $\mathrm{X}$ & \\
\hline Serpentes (snakes) & & & & $\mathrm{X}$ & & \\
\hline Anserinae (geese) & & & & & $\mathrm{X}$ & \\
\hline Anas crecca/discors (grn/blue winged teal) & & & $\mathrm{X}$ & & & \\
\hline Accipitridae (hawks, eagles) & $\mathrm{X}$ & $\mathrm{X}$ & $\mathrm{X}$ & $\mathrm{X}$ & $\mathrm{X}$ & $\mathrm{X}$ \\
\hline Buteoninae (eagles - in part) & & $\mathrm{X}$ & & & $\mathrm{X}$ & $\mathrm{X}$ \\
\hline Tetraonidae (grouse) & $\mathrm{X}$ & $\mathrm{X}$ & $\mathrm{X}$ & & $\mathrm{X}$ & \\
\hline Bubo virginianus (great horned owl) & & & & & $\mathrm{X}$ & \\
\hline Picidae (woodpeckers) & & & $\mathrm{X}$ & & & \\
\hline Passeriformes (perching birds) unident. & $\mathrm{X}$ & $\mathrm{X}$ & $\mathrm{X}$ & & $\mathrm{X}$ & $\mathrm{X}$ \\
\hline Pica pica (black-billed magpie) & $\mathrm{X}$ & & $\mathrm{X}$ & & $\mathrm{X}$ & \\
\hline Corvus corax (northern raven) & $\mathrm{X}$ & $\mathrm{X}$ & $\mathrm{X}$ & & $\mathrm{X}$ & $\mathrm{X}$ \\
\hline Sylvilagus sp. (cottontail) & & & $\mathrm{X}$ & & $\mathrm{X}$ & $\mathrm{X}$ \\
\hline Lepus townsendii (white-tailed jackrabbit) & $\mathrm{X}$ & & $\mathrm{X}$ & $\mathrm{X}$ & $\mathrm{X}$ & $\mathrm{X}$ \\
\hline Spermophilus spp. (ground squirrel) & $\mathrm{X}$ & $\mathrm{X}$ & $\mathrm{X}$ & $\mathrm{X}$ & $\mathrm{X}$ & $\mathrm{X}$ \\
\hline Cynomys sp. (prairie-dog) & & & $\mathrm{X}$ & & & \\
\hline Thomomys talpoides (no. pocket gopher) & & & $\mathrm{X}$ & & $\mathrm{X}$ & $\mathrm{X}$ \\
\hline Castor canadensis (beaver) & & $\mathrm{X}$ & & & $\mathrm{X}$ & \\
\hline Muridae (mice, rats and voles) & $\mathrm{X}$ & $\mathrm{X}$ & $\mathrm{X}$ & $\mathrm{X}$ & $\mathrm{X}$ & $\mathrm{X}$ \\
\hline Ondatra zibethicus (muskrat) & & & & & $\mathrm{X}$ & \\
\hline Canis spp. (dog, coyote, gray wolf) & $\mathrm{X}$ & $\mathrm{X}$ & $\mathrm{X}$ & $\mathrm{X}$ & $\mathrm{X}$ & $\mathrm{X}$ \\
\hline Vulpes velox (swift fox) & $\mathrm{X}$ & $\mathrm{X}$ & $\mathrm{X}$ & $\mathrm{X}$ & $\mathrm{X}$ & $\mathrm{X}$ \\
\hline Mustela cf. M. frenata (long-tailed weasel) & & & $\mathrm{X}$ & $\mathrm{X}$ & & \\
\hline Taxidea taxus (American badger) & & & & & $\mathrm{X}$ & \\
\hline Odocoileus sp. (deer) & $\mathrm{X}$ & $\mathrm{X}$ & $\mathrm{X}$ & $\mathrm{X}$ & $\mathrm{X}$ & $\mathrm{X}$ \\
\hline Antilocapra americana (pronghorn) & & & $\mathrm{X}$ & $X$ & $\mathrm{X}$ & \\
\hline Bison bison (American buffalo) & $\mathrm{X}$ & $\mathrm{X}$ & $\mathrm{X}$ & $\mathrm{X}$ & $\mathrm{X}$ & $\mathrm{X}$ \\
\hline
\end{tabular}

\section{Distribution of Identified Remains}

The following sections summarize spatial and temporal distributions for identified Larson specimens and provide comparison of the Larson sample with assemblages recovered from generally equivalent Plains Village contexts within the region. Comparisons are based on counts of numbers of identified specimens (NISP) representing animals likely to have played a role in the village economy as explained in a previous section. Specimen counts for inter-site comparisons are taken from the works of several analysts but in each case the methods followed for generation of 
basic NISP data appear to have yielded broadly comparable results. These issues are discussed in more detail elsewhere (Lee and Ahler 2003:199-200; Falk and Ahler 2004:230).

Table 9.5 provides specimen density information (i.e., NISP/ cu. m) for six depositional contexts. Mirroring bone weight data (Table 9.2), density values for all identified specimens (groups 1-9) are highest in contained deposits (cache pits, small pits) and lower in uncontained deposits (midden, midden with earth, plowzone). This pattern remains constant when amphibians, reptiles and micromammals (groups 7-9) are considered separately from fish, birds and larger mammals (groups 1-6). Again, specimen densities are high in cache pit fill and lower in midden and plowzone deposits. A more detailed breakdown of specimen counts for taxa judged to be of economic importance (groups 1-6) is offered in Table 9.6; plowzone specimens and a small sample of mixed materials are excluded.

Table 9.5. Specimen count (NISP) and density (NISP/ cu. m) information organized by deposit type for the 2006 test excavations at Larson Village.

\begin{tabular}{lccccccc}
\hline & \multicolumn{7}{c}{ Deposit Type } \\
\cline { 2 - 6 } & $\begin{array}{c}\text { Cache } \\
\text { pit }\end{array}$ & $\begin{array}{c}\text { Small } \\
\text { pit }\end{array}$ & Midden & $\begin{array}{c}\text { Midden } \\
\text { w/earth }\end{array}$ & $\begin{array}{c}\text { Plow- } \\
\text { zone }\end{array}$ & $\begin{array}{c}\text { Mixed } \\
\text { Deposit }\end{array}$ & Totals \\
\hline Excavated Volume $\left(\mathrm{m}^{3}\right)$ & 1.41 & 0.12 & 6.88 & 3.55 & 2.00 & 0.34 & 14.3 \\
\hline Specimen Count (Groups 1-9) & 881 & 54 & 2054 & 628 & 217 & 23 & 3857 \\
Density (Groups 1-9) & 624.8 & 450.0 & 298.5 & 176.9 & 108.5 & 67.6 & 269.7 \\
\hline Specimen Count (Groups 1-6) & 590 & 37 & 1065 & 360 & 91 & 8 & 2151 \\
Density (Groups 1-6) & 418.4 & 308.3 & 154.8 & 101.4 & 45.5 & 23.5 & 17.6 \\
\hline Specimen Count (Groups 7-9) & 291 & 17 & 989 & 268 & 126 & 15 & 1706 \\
Density (Groups 7-9) & 206.4 & 141.7 & 143.8 & 75.5 & 63.0 & 44.1 & 119.3 \\
\hline
\end{tabular}

Table 9.6. Specimen counts (NISP) for major mammals, birds and fish organized by deposit type for the 2006 test excavations at Larson Village.

\begin{tabular}{|c|c|c|c|c|c|c|c|c|c|}
\hline \multirow{3}{*}{$\begin{array}{c}\text { Taxonomic } \\
\text { Group }\end{array}$} & \multicolumn{8}{|c|}{ Deposit Type } & \multirow{3}{*}{$\begin{array}{l}\text { Total } \\
\text { NISP }\end{array}$} \\
\hline & \multicolumn{2}{|c|}{ Cache Pit } & \multicolumn{2}{|c|}{ Small Pit } & \multicolumn{2}{|c|}{ Midden } & \multicolumn{2}{|c|}{ Midden/Earth } & \\
\hline & NISP & $\%$ & NISP & $\%$ & NISP & $\%$ & NISP & $\%$ & \\
\hline 1 large artiodactyls & 243 & 41.2 & 28 & 75.7 & 375 & 35.2 & 153 & 42.5 & 799 \\
\hline 2 small artiodactyls & 22 & 3.7 & 1 & 2.7 & 37 & 3.5 & 21 & 5.8 & 81 \\
\hline 3 large canid & 108 & 18.3 & 4 & 10.8 & 157 & 14.7 & 101 & 28.1 & 370 \\
\hline 4 med.-sm. mammal & 97 & 16.5 & 2 & 5.4 & 186 & 17.4 & 31 & 8.6 & 316 \\
\hline 5 fish & 81 & 13.7 & 1 & 2.7 & 155 & 14.6 & 34 & 9.4 & 271 \\
\hline 6 bird & 39 & 6.6 & 1 & 2.7 & 155 & 14.6 & 20 & 5.6 & 215 \\
\hline Total & 590 & 100.0 & 37 & 100.0 & 1065 & 100.0 & 360 & 100.0 & 2052 \\
\hline
\end{tabular}

Table 9.7 provides specimen counts for taxonomic groups 1-6 organized by stratigraphic group and excavation unit. Total counts by unit highlight the variability of sample size between analytic contexts.

Table 9.8 summarizes specimen counts for taxonomic groups and relative temporal units. Chi-square analysis indicates a significant non-random relationship between taxonomic group and temporal unit $\left(\mathrm{X}^{2}=64.9, \mathrm{df}=10, \mathrm{p}=<0.001\right)$. This result is expected given the large total count of specimens and the uneven character of specimen distributions. Relative proportions for large 
Table 9.7. Specimen counts (NISP) for six taxonomic groups organized by temporal sequence for the 2006 test excavations at Larson Village. Plowzone and mixed deposits excluded.

\begin{tabular}{ccccccccc}
\hline \multirow{2}{*}{$\begin{array}{c}\text { Strat. } \\
\text { Grp. }\end{array}$} & Excavation & Unit & $\begin{array}{c}\text { large } \\
\text { artiodactyl artiodactyls }\end{array}$ & $\begin{array}{c}\text { small } \\
\text { canid }\end{array}$ & $\begin{array}{c}\text { med-small } \\
\text { mammal }\end{array}$ & bird & fish & Total \\
\hline 3 & Block A & 48 & 6 & 21 & 20 & 22 & 6 & 123 \\
& Block D & 38 & 3 & 16 & 19 & 21 & 25 & 122 \\
& Block F & 21 & 8 & 8 & 13 & 6 & 3 & 59 \\
& Ditch 3 & 6 & 3 & 6 & 9 & 7 & 4 & 35 \\
& Ditch 3- F105 & 9 & & 10 & 3 & 3 & 5 & 30 \\
\hline & Subtotal & 122 & 20 & 61 & 64 & 59 & 43 & 369 \\
\hline 2 & Block A - F108 & 3 & & & & 1 & 4 \\
& Block A - F109 & 59 & 5 & 61 & 55 & 45 & 13 & 238 \\
& Block D - F101 & 2 & & & & & 2 \\
& Block D - F102 & & & 1 & & & 1 \\
& Block D - F103 & 1 & 1 & & 2 & & 5 \\
& Block F - F104 & 22 & & 3 & & & 25 \\
& Block F - F107 & 184 & 17 & 47 & 42 & 36 & 26 & 352 \\
& Ditch 3 - F105 & 236 & 17 & 89 & 117 & 90 & 111 & 660 \\
\hline & Subtotal & 507 & 40 & 201 & 216 & 172 & 151 & 1287 \\
\hline 1 & Block G & 55 & 7 & 24 & 20 & 13 & 10 & 129 \\
& Ditch 4 & 20 & 1 & 12 & 6 & 7 & 3 & 49 \\
& Ditch 4 - F106 & 95 & 13 & 72 & 10 & 20 & 8 & 218 \\
\hline
\end{tabular}

artiodactyls and birds decrease through time. Large canid specimens are common in each period, decreasing markedly from the earliest period in comparison to the following two periods. Mediumsmall mammals and fish increase through time. Small artiodactyl materials decrease slightly from the earliest to the later period but increase slightly in the latest period.

Table 9.8. Specimen counts (NISP) for six taxonomic groups organized by temporal sequence for the 2006 test excavations at Larson Village. Plowzone and mixed deposits excluded.

\begin{tabular}{|c|c|c|c|c|c|c|c|c|}
\hline \multirow[b]{2}{*}{ Stratigraphic Group } & & \multicolumn{6}{|c|}{ Taxonomic Group } & \multirow[b]{2}{*}{ Total } \\
\hline & & $\begin{array}{c}\text { large } \\
\text { artiodactyl }\end{array}$ & $\begin{array}{c}\text { small } \\
\text { artiodactyls }\end{array}$ & $\begin{array}{l}\text { Large } \\
\text { canid }\end{array}$ & $\begin{array}{c}\text { med-small } \\
\text { mammal }\end{array}$ & bird & fish & \\
\hline \multirow[t]{2}{*}{3 Latest Group } & $n$ & 122 & 20 & 61 & 64 & 59 & 43 & 369 \\
\hline & $\%$ & 33.1 & 5.4 & 16.5 & 17.3 & 16.0 & 11.7 & 100.0 \\
\hline \multirow[t]{2}{*}{2 Later Group } & $n$ & 507 & 40 & 201 & 216 & 172 & 151 & 1287 \\
\hline & $\%$ & 39.4 & 3.1 & 15.6 & 16.8 & 13.4 & 11.7 & 100.0 \\
\hline \multirow[t]{2}{*}{1 Earliest Group } & $n$ & 170 & 21 & 108 & 36 & 40 & 21 & 396 \\
\hline & $\%$ & 42.9 & 5.3 & 27.3 & 9.1 & 10.1 & 5.3 & 100.0 \\
\hline \multirow[t]{2}{*}{ Total } & $n$ & 799 & 81 & 370 & 316 & 271 & 215 & 2052 \\
\hline & $\%$ & 38.9 & 4.0 & 18.0 & 15.4 & 13.2 & 10.5 & 100.0 \\
\hline
\end{tabular}

\section{Regional Comparisons}

This section provides comparisons between identified Larson remains and materials from generally contemporaneous villages sites located within the Knife and Heart regions. In addition to 
Larson, specimen data from four traditional Mandan settlements is used. These sites include: Boley Village, situated on the west bank of the Missouri River north of the city of Mandan (Falk 2006:

Tables 57 and 58); On-A-Slant Village, located on the Missouri River just below the mouth of the Heart River (Schubert and Cruz-Uribe 1997:Table 20; Falk 1997:Table 35; Falk, unpublished notes); Scattered Village on the Heart River near its confluence with the Missouri (Cruz-Uribe 2002:Table 6.2; Falk 2002:Tables 7.2, 7.10); and Double Ditch Village, located on the east bank of the Missouri River about 15 km north of the Heart River (Falk and Ahler 2005: Tables 48, 49).

Additional comparisons are provided by data from Lower Hidatsa Village and Big Hidatsa Village-both traditional Hidatsa sites located to the north on the Knife River (Ahler et al.

1993:Table 19.2; Falk et al. 1991:Tables 9 and 26). Table 9.9 provides comparative data for a range of mammals, birds and fish from each of the seven sites, while Table 9.10 is limited to a comparison of only mammal data.

Table 9.9. Specimen counts (NISP) for six taxonomic groups organized by village.

\begin{tabular}{|c|c|c|c|c|c|c|c|c|}
\hline \multirow[b]{2}{*}{ Village Component } & & \multicolumn{6}{|c|}{ Taxonomic Group } & \multirow[b]{2}{*}{ Total } \\
\hline & & $\begin{array}{c}\text { Large } \\
\text { artiodactyl }\end{array}$ & $\begin{array}{c}\text { small } \\
\text { artiodactyls }\end{array}$ & $\begin{array}{l}\text { large } \\
\text { canid }\end{array}$ & $\begin{array}{c}\text { med-small } \\
\text { mammal }\end{array}$ & bird & fish & \\
\hline Slant & $n$ & 641 & 133 & 55 & 89 & 505 & 2846 & 4269 \\
\hline AD 1575-1785 & $\%$ & 15.0 & 3.1 & 1.3 & 2.1 & 11.8 & 66.7 & 100.0 \\
\hline Scattered & $n$ & 4365 & 1834 & 764 & 1746 & 2574 & 5679 & 16953 \\
\hline AD 1550-1700 & $\%$ & 25.7 & 10.8 & 4.5 & 10.3 & 15.2 & 33.5 & 100.0 \\
\hline Boley & $n$ & 871 & 37 & 91 & 149 & 272 & 1037 & 2457 \\
\hline AD $1490-1725$ & $\%$ & 35.4 & 1.5 & 3.7 & 6.1 & 11.1 & 42.2 & 100.0 \\
\hline Double Ditch & $n$ & 5547 & 777 & 1401 & 1890 & 2834 & 2900 & 15349 \\
\hline AD 1490-1785 & $\%$ & 36.1 & 5.1 & 9.1 & 12.3 & 18.5 & 18.9 & 100.0 \\
\hline Larson & $n$ & 799 & 81 & 370 & 316 & 271 & 215 & 2052 \\
\hline $\mathrm{AD} 1500-1650$ & $\%$ & 38.9 & 4.0 & 18.0 & 15.4 & 13.2 & 10.5 & 100.0 \\
\hline Lower Hidatsa & $n$ & 3223 & 273 & 269 & 30 & 72 & 358 & 4225 \\
\hline AD 1525-1780 & $\%$ & 76.3 & 6.5 & 6.4 & 0.7 & 1.7 & 8.5 & 100.1 \\
\hline Big Hidatsa & $n$ & 1766 & 80 & 317 & 53 & 64 & 573 & 2853 \\
\hline AD $1600-1780$ & $\%$ & 61.9 & 2.8 & 11.1 & 1.8 & 2.2 & 20.1 & 100.0 \\
\hline
\end{tabular}

Data presented in Table 9.9 show that all taxonomic groups considered are represented in the five Mandan and two Hidatsa samples. The two Hidatsa sites show a relatively high proportion of large artiodactyls when compared to Mandan samples. Small artiodactyls are represented in comparatively high proportion at Scattered and to a lesser extent at Double Ditch, Larson and Lower Hidatsa. Proportionately, they are weakly represented at Slant, Boley and Big Hidatsa. Large canid remains are most heavily represented at Larson. Larson and Double Ditch contrast with other Heart River components that show relatively low percentages of large canid bone.

Assessment of fish, bird and small-medium mammal data is more problematic because there is some inconsistency between the samples with respect to sorting and analysis of size G4 and G5 fractions, undoubtedly skewing the comparisons. The Slant, Boley, and Scattered samples show relatively high proportions of fish in comparison to Double Ditch and Big Hidatsa and, especially to Larson and Lower Hidatsa. Fish comprise 67 percent of NISP counts at Slant Village, 42 percent of the total at Boley Village and 33 percent of the Scattered Village total, suggesting a consistent and possibly significant role for fish in the subsistence base at each of the three west bank villages. Fish comprises only about 18 percent of the NISP count at Double Ditch and only 10.5 percent of the 
count at Larson. These comparisons are somewhat misleading, however, since the Larson, Boley, and Double Ditch samples do not include counts for size G5 fish bone. Size G5 fish specimens are included in the Slant and Scattered samples, as they are in the two Hidatsa samples. The preliminary data may suggest that fishing was somewhat less important at Lower Hidatsa sites and, also perhaps, at Big Hidatsa and the more northern Mandan villages - Larson and Double Ditch. All five Mandan samples show a greater relative abundance of bird in comparison to the Hidatsa sites. Again, however, assessment of the Knife River assemblages is difficult since only bird remains are represented in the size G4 and G5 counts. Medium-small mammals are well represented at Larson, Double Ditch and Scattered but poorly represented in the Hidatsa assemblages, as they are at Slant and Boley. Again, however, the Knife River samples do not include counts for identified size G4 or G5 small-medium mammals; the Larson, Boley, and Double Ditch size G5 data is also lacking.

Table 9.10. Specimen counts (NISP) for major mammals organized by village.

\begin{tabular}{|c|c|c|c|c|c|c|}
\hline \multirow[b]{2}{*}{ Village Component } & & \multicolumn{4}{|c|}{ Taxonomic Group } & \multirow[b]{2}{*}{ Total } \\
\hline & & $\begin{array}{c}\text { large } \\
\text { artiodactyl }\end{array}$ & $\begin{array}{c}\text { small } \\
\text { artiodactyls }\end{array}$ & $\begin{array}{l}\text { large } \\
\text { canid }\end{array}$ & $\begin{array}{c}\text { med-small } \\
\text { mammal }\end{array}$ & \\
\hline Slant & $n$ & 641 & 133 & 55 & 89 & 918 \\
\hline AD 1575-1785 & $\%$ & 69.8 & 14.5 & 6.0 & 9.7 & 100.0 \\
\hline Scattered & $n$ & 4365 & 1834 & 764 & 1746 & 8709 \\
\hline AD 1550-1700 & $\%$ & 50.1 & 21.1 & 8.8 & 20.0 & 100.0 \\
\hline Boley & $n$ & 871 & 37 & 91 & 149 & 1148 \\
\hline AD $1490-1725$ & $\%$ & 75.9 & 3.2 & 7.9 & 13.0 & 100.0 \\
\hline Double Ditch & $n$ & 5547 & 777 & 1401 & 1890 & 9615 \\
\hline AD 1490-1785 & $\%$ & 57.7 & 8.1 & 14.6 & 19.6 & 100.0 \\
\hline Larson & $n$ & 799 & 81 & 370 & 316 & 1566 \\
\hline AD 1500-1650 & $\%$ & 51.0 & 5.2 & 23.6 & 20.2 & 100.0 \\
\hline Lower Hidatsa & $n$ & 3223 & 273 & 269 & 30 & 3795 \\
\hline AD 1525-1780 & $\%$ & 84.9 & 7.2 & 7.1 & 0.8 & 100.0 \\
\hline Big Hidatsa & $n$ & 1766 & 80 & 317 & 53 & 2216 \\
\hline AD $1600-1780$ & $\%$ & 79.7 & 3.6 & 14.3 & 2.4 & 100.0 \\
\hline
\end{tabular}

Turning attention to the mammal counts in Table 9.10, large artiodactyls dominate the Knife River, Boley and Slant samples. At Larson and Scattered they comprise just over half of the mammal assemblage, slightly more at Double Ditch. Small artiodactyls show relatively high percentages at Slant and Scattered but generally lower proportions elsewhere. Larson, Double Ditch and Big Hidatsa show higher percentages of large canids when compared to the southern Mandan villages and Lower Hidatsa. As a group the Mandan samples show higher proportions of small-medium mammals but, as noted above, the Knife River samples do not include counts for identified size G4 and G5 specimens and size G5 specimens are not available for Larson, Boley and Double Ditch.

In conclusion, it is useful to repeat comments made elsewhere (Falk 2006: 179; Falk and Ahler 2005:257). Comparisons presented here indicate that while vertebrate assemblages from each village are in some ways unique, they share striking similarities, particularly the overwhelming importance of bison as well as the consistent use of a wide variety of locally available animal resources. It is important to stress that these comparisons offered here do not take into consideration spatial and/or temporal variability found within each site and provide, at best, only the 
most basic information regarding assemblage composition. Only Scattered Village and Double Ditch Village have been extensively sampled. Fieldwork at other locations, including the Larson, Boley, and Slant sites, has been limited to a small number of relatively scattered test units.

Differences and similarities among the villages discussed here may reflect excavation sampling strategies - along with poorly understood patterns of refuse disposal within each village_-as much as they do with the actual organization and content of the faunal component of the late prehistoric and protohistoric subsistence economies. 


\section{References Cited}

Ahler, Stanley A., Lynn M. Snyder, Carl R. Falk, and Holmes A. Semken, Jr.

1993 KNRI and Upper Knife-Heart Region Unmodified Faunal Remains. In The Phase I Archaeological Research Program for the Knife River Indian Villages National Historic Site, Part III: Analysis of the Physical Remains, edited by Thomas D. Thiessen, pp. 263272. Midwest Archeological Center Occasional Studies in Anthropology No. 27. National Park Service, Midwest Archeological Center, Lincoln.

Cruz-Uribe, Kathryn

2002 Faunal Analysis of Unmodified Larger Mammal Remains. In Prehistory on First Street NE: the Archaeology of Scattered Village in Mandan, North Dakota, edited by Stanley A. Ahler, pp. 6.1-6.25. PaleoCultural Research Group, Flagstaff, Arizona. Submitted to the City of Mandan, North Dakota, and North Dakota Department of Transportation, Bismarck.

Falk, Carl R.

1997 Description and Distributional Analysis of Fish Bone from On-A-Slant Village, 32MO26, 1980 Investigations. In Archaeology of the Mandan Indians at On-A-Slant Village (32MO26), Fort Abraham Lincoln State Park, Morton County, North Dakota, edited by Stanley A. Ahler, pp. 127-154. Office of Research and Graduate Studies, Northern Arizona University, Flagstaff. Submitted to the North Dakota Parks and Recreation Department, Bismarck.

2002 Fish, Amphibian, Reptile, and Bird Remains. In Prehistory on First Street NE: the Archaeology of Scattered Village in Mandan, North Dakota, edited by Stanley A. Ahler, pp. 7.1-7.25. PaleoCultural Research Group, Flagstaff, Arizona. Submitted to the City of Mandan, North Dakota, and North Dakota Department of Transportation, Bismarck.

2006 Unmodified Vertebrate Remains. In Geophysical Survey and Test Excavation During 2005 at Boley Village (32MO37), North Dakota, edited by Stanley A. Ahler, pp. 173-180. PaleoCultural Research Group, Flagstaff, Arizona. Submitted to the State Historical Society of North Dakota.

Falk, Carl R., and Stanley A. Ahler

2004 Analysis of Unmodified Vertebrate Faunal Remains. In Archaeological Investigations during 2003 at Double Ditch State Historic Site, North Dakota, edited by Stanley A. Ahler, pp. 227-236). PaleoCultural Research Group, Flagstaff, Arizona. Submitted to the State Historical Society of North Dakota.

2005 Analysis of Unmodified Vertebrate Faunal Remains. In Archaeological Investigations during 2004 at Double Ditch State Historic Site, North Dakota, edited by Stanley A. Ahler, pp. 249-258). PaleoCultural Research Group, Flagstaff, Arizona. Submitted to the State Historical Society of North Dakota.

Falk, Carl R., Holmes A. Semken, Jr., Lynn M. Snyder, Carole A. Angus, Darcy F. Morey, Danny E. Olinger, and R. S. Rosenberg

1991 Inventory of Identified Vertebrate Specimens from Phase I Archaeological Investigations at the Knife River Indian Villages National Historic Site, Mercer County, North Dakota. University of North Dakota, Grand Forks. Submitted to the Midwest Archaeological Center, U.S. National Park Service, Lincoln, Nebraska.

Lee, Jennie Borresen, and Stanley A. Ahler

2003 Analysis of Unmodified Vertebrate Faunal Remains. In Archaeological Investigations during 2001 and 2002 at Double Ditch State Historic Site, North Dakota, edited by 
Stanley A. Ahler, pp. 197-203. PaleoCultural Research Group, Flagstaff, Arizona. Submitted to the State Historical Society of North Dakota.

Schubert, W. Blaine and Kathryn Cruz-Uribe

1997 Faunal Analysis of Culturally Significant and Unmodified Mammal Remains. In Archaeology of the Mandan Indians at On-A-Slant Village (32MO26), Fort Abraham Lincoln State Park, Morton County, North Dakota, edited by Stanley A. Ahler, pp. 99-126. Office of Research and Graduate Studies, Northern Arizona University, Flagstaff. Submitted to the North Dakota Parks and Recreation Department, Bismarck. 


\title{
10. Modified Bone ANd ANTLER ARTIFACTS
}

\author{
Carl R. Falk
}

\section{Introduction and Methods}

Analysis presented in this chapter is intended to parallel and complement recent studies of modified bone and antler assemblages from Plains Village tradition sites in the immediate Heart River area, specifically On-A-Slant (Ahler and Ryser 1997; Moore 1985), Double Ditch (Ahler 2003, 2004, 2005), Scattered (Ahler and Falk 2002), and Boley villages (Ahler and Falk 2006), as well as the nearby Late Woodland Menoken Village site (Ahler and Crawford 2003). In keeping with previous efforts, this investigation has several basic objectives: a descriptive account of modified remains, with emphasis on specimen function and raw material selection; an examination of distributions of modified remains within and between certain site contexts; and a comparison of the Larson sample with materials from select village sites located within the Knife and Heart regions.

Initial size grading and sorting of bone was carried out in Flagstaff, Arizona (see Chapter 5). Sizes G1 to G3 bones, along with potential identifiable size G4 specimens and likely modified size G4 and G5 specimens were shipped to the author. A final separation of modified specimens from unmodified remains was accomplished during the sorting and analysis of the unmodified sample (see Chapter 9). Modified specimens were processed with a coding and classification system used for analysis of materials from Boley Village (Ahler and Falk 2006). This system was a somewhat simplified version of an approach developed by Stan Ahler and others for work at the above cited Slant and Scattered Village projects and adapted for analysis of modified bone and antler recovered during the multi-year Double Ditch Village program (Ahler 2003, 2004, 2005).

Variables and applicable code values recorded for each specimen are detailed in Table 10.1. As in the previous studies, the focus is on functional classification at both general and specific levels, as well as use-phase classification, and recording of taxonomic and skeletal elements identifications for materials selected in the manufacture of modified pieces. In the analysis of the Boley sample we used a general expedient tool functional class (code 60) that was intended to incorporate more specific expedient tool classes identified in earlier studies (i.e., codes 41, 42, 44, 48, 49, and 50; see also Ahler 2004:237). Assignment of specimens to the more general class was

Table 10.1.Variables and attribute codes applied to modified bone and antler artifacts from Larson Village.

\begin{tabular}{|c|c|c|}
\hline SPECNO & \multicolumn{2}{|l|}{ individual specimen number $(001-217)$} \\
\hline CATNO & \multicolumn{2}{|l|}{ catalog number $(1003-1096)$} \\
\hline SIZE & \multicolumn{2}{|l|}{ size grade (1-5 for Grade 1- Grade 5) } \\
\hline SPECNO & \multicolumn{2}{|c|}{ four digit within size, $1001,1002,3001,3002$, 3003, etc. } \\
\hline \multirow[t]{5}{*}{ GENFUN } & grouped functional class & \\
\hline & 1 digging tools (hoes, expedient tools) & 5 other patterned tools \\
\hline & 2 patterned piercing tools & 6 other expedient tools \\
\hline & 3 pressure flakers (patt. and unpatt.) & 7 ornamental and nonutilitarian \\
\hline & 4 fish hooks & 8 unknown, utilitarian? \\
\hline
\end{tabular}


Table 10.1. Variables and attribute codes applied to modified bone and antler artifacts (concluded).

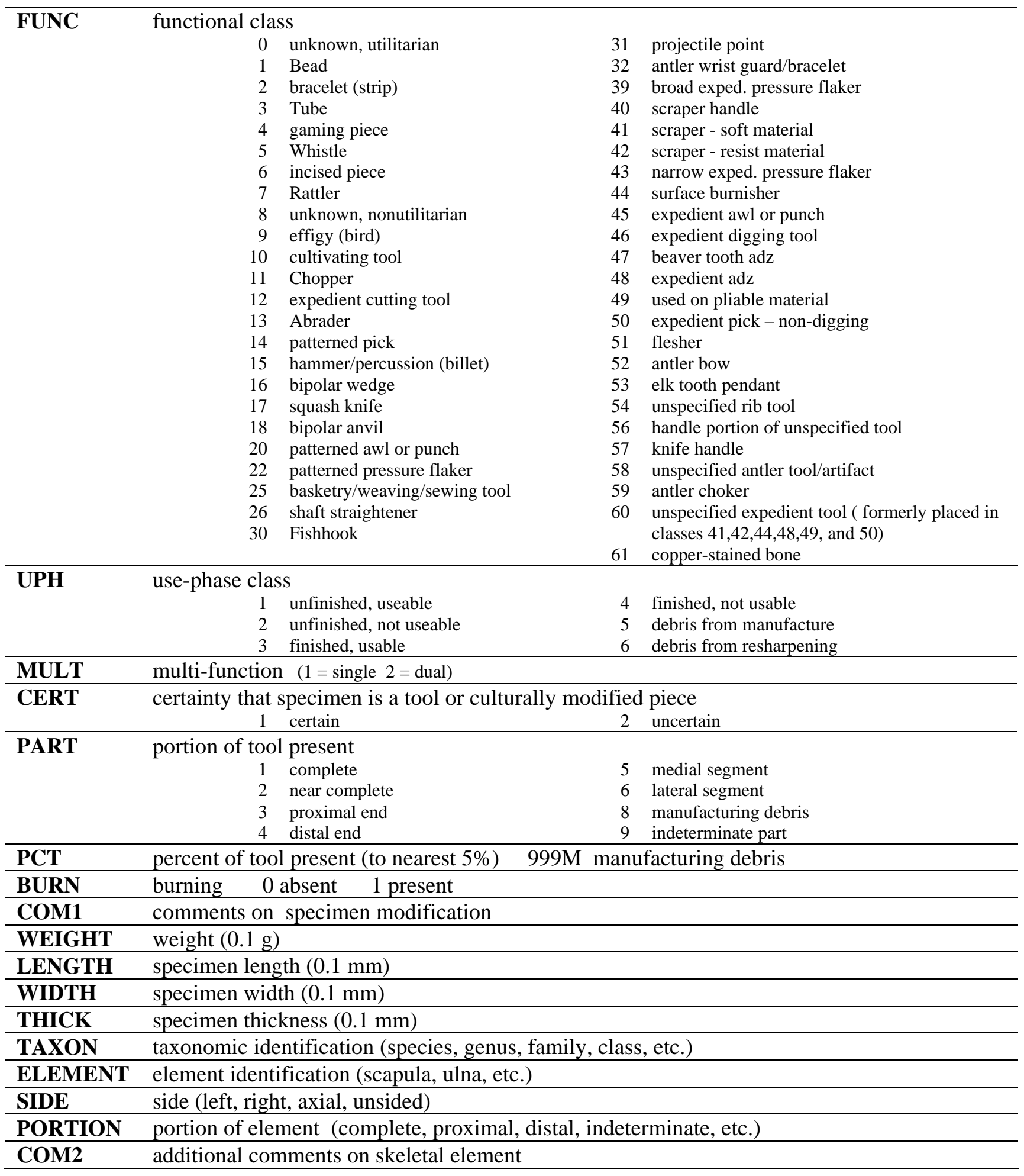

thus accomplished without the detailed microscopic analysis that would have been necessary for more specific functional evaluation. Throughout the coding process attention was paid to identifying evidence for the use of metal tools in the manufacture process, particularly in the production of scapula digging tools (see Ahler and Falk 2002: 13.39) or other tool types requiring 
substantial alteration to the original bone or antler piece. Unequivocal evidence for the use of metal tools was not recorded. The Larson bone and antler specimens are consistent with those reported (and well illustrated) from the above cited village assemblages; the Larson specimens are not illustrated here.

\section{Sample Description}

The 2006 Larson sample includes 217 specimens. Table 10.2 summarizes the modified sample by size grade and excavation context. Sizes G1 to G3 specimens dominate the sample; size G4 are well represented and size G5 somewhat less so. Modified materials are unevenly distributed across excavation units. Over half of the sample was recovered from two units: F105, Ditch 3 (34.5 percent) and F107, Block F (19.8 percent). Calculation of specimen density data also highlights the

Table 10.2. Distribution of modified bone and antler specimens according to size grade and excavation context for the 2006 test excavations at Larson Village.

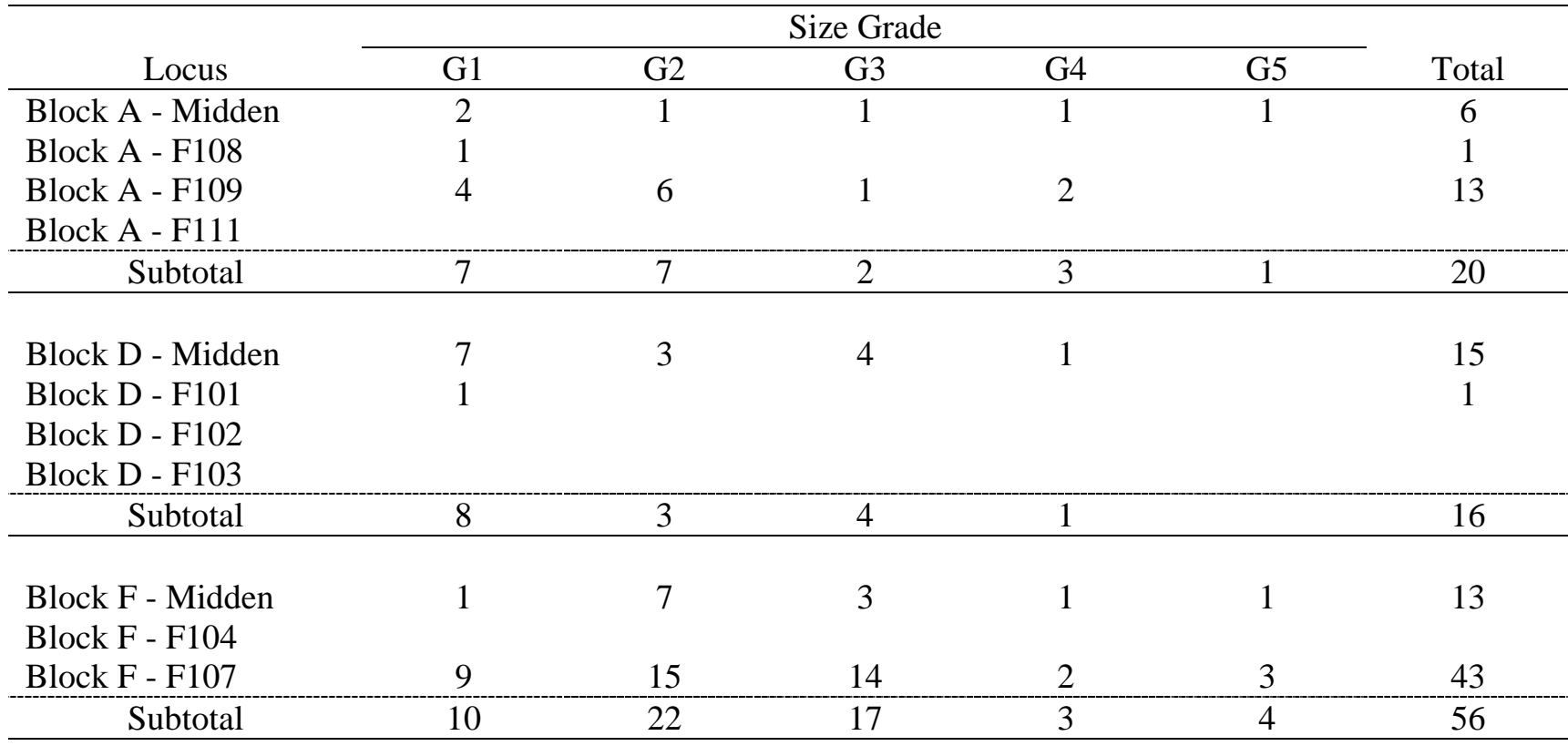

\begin{tabular}{ccccccc} 
Block G - Midden & 3 & 4 & 9 & 5 & 1 & 22 \\
\hline Subtotal & 3 & 4 & 9 & 5 & 1 & 22 \\
\hline
\end{tabular}

\begin{tabular}{|c|c|c|c|c|c|c|}
\hline $\begin{array}{l}\text { Ditch } 3 \text { - Midden } \\
\text { Ditch } 3 \text { - F105 }\end{array}$ & 19 & 2 & & $\begin{array}{c}2 \\
10\end{array}$ & 2 & $\begin{array}{c}2 \\
73\end{array}$ \\
\hline Subtotal & 19 & 27 & 15 & 12 & 2 & 75 \\
\hline
\end{tabular}

\begin{tabular}{cccccc} 
Ditch 4 - Midden & 1 & 1 & 3 & 1 & 6 \\
Ditch 4 - F106 & 6 & 9 & 6 & & 21 \\
Subtotal & 7 & 10 & 9 & 1 & 27 \\
\hline
\end{tabular}

\begin{tabular}{lcccccc} 
Mixed Blk A/Ditch 3 & & 1 & & 1 \\
\hline & Subtotal & & & 1 & & 1 \\
\hline Total & 54 & 73 & 57 & 25 & 8 & 217 \\
\hline
\end{tabular}


uneven distributions. Twenty-one items were recovered from F106 ditch fill $(1.743 \mathrm{cu}$. m of excavated fill), a density of 12.0 specimens/cu. m. Seventy-three specimens were found in F105 ditch fill (3.508 cu. m), a density of 20.8 specimens/cu. m. Density values are even higher in contained deposits. For example, F107 (0.901 cu. m), a cache pit in Block F contained 43 specimens or 47.7 specimens/cu. m.

Table 10.3 presents modified specimens organized by general and specific functional classes and use-phase class. Finished, usable specimens (use-phase 3) make-up 16.1 percent of the sample. Most of these specimens are complete though some are broken but still usable. Use-phase 4 specimens are broken, discarded fragments of finished artifacts; 74.6 percent of the total is assigned to this class. One specimen reflects the resharpening (use-phase 6) of a bone awl or punch. Two unfinished pieces, a patterned pressure flaker and an unknown utilitarian specimen, were discarded during the manufacturing process (use-phase 1). Three tools - a patterned awl or punch, a patterned pressure flaker and a squash knife - appear to have been broken and discarded during manufacture (use-phase 2). Finally 14 specimens, 6.5 percent of the total, are manufacturing residue (use phase 5). Many of these are proximal or distal ends of long bones, removed by the 'groove and snap' technique during the manufacture of beads and/or tubes.

Table 10.3. Distribution of modified bone and antler artifacts from the 2006 excavations at Larson Village organized by general and specific functional class and use-phase class.

\begin{tabular}{|c|c|c|c|c|c|c|c|c|}
\hline \multirow[b]{2}{*}{ Functional Class } & \multicolumn{6}{|c|}{ Use-Phase Class } & \multicolumn{2}{|c|}{ Total } \\
\hline & $\begin{array}{c}1 \\
\text { unfinished } \\
\text { useable }\end{array}$ & $\begin{array}{c}2 \\
\text { unfinished } \\
\text { nonuseable }\end{array}$ & $\begin{array}{c}3 \\
\text { finished, } \\
\text { useable }\end{array}$ & $\begin{array}{c}4 \\
\text { finished, } \\
\text { nonuseable }\end{array}$ & $\begin{array}{c}5 \\
\text { manuf. } \\
\text { debris }\end{array}$ & $\begin{array}{c}6 \\
\text { resharp } \\
\text { debris. }\end{array}$ & $n$ & $\%$ \\
\hline \multicolumn{9}{|l|}{ Digging Tools } \\
\hline 10 cultivating tool & & & 2 & 41 & & & 43 & \\
\hline 46 exp. digging & & & & 2 & & & 2 & \\
\hline Subtotal & & & 2 & 43 & & & 45 & 20.7 \\
\hline$\%$ & & & 4.4 & 95.6 & & & 100.0 & \\
\hline \multicolumn{9}{|l|}{ Piercing Tools } \\
\hline 20 patt. awl/punch & & 1 & 5 & 21 & & 1 & 28 & \\
\hline 45 exped. punch & & & 10 & 1 & & & 11 & \\
\hline Subtotal & & 1 & 15 & 22 & & 1 & 39 & 18.0 \\
\hline$\%$ & & 2.6 & 38.4 & 56.4 & & 2.6 & 100.0 & \\
\hline \multicolumn{9}{|l|}{ Pressure Flakers } \\
\hline 22 patt. press. flkr & 1 & 1 & 3 & 4 & & & 9 & \\
\hline 39 brd. exped. flkr & & & 3 & & & & 3 & \\
\hline Subtotal & 1 & 1 & 6 & 4 & & & 12 & 5.5 \\
\hline$\%$ & 8.3 & $8 . .3$ & 50.0 & 33.3 & & & 99.9 & \\
\hline \multicolumn{9}{|l|}{ Fishhooks } \\
\hline 30 fishhook & & & & 2 & 1 & & 3 & \\
\hline Subtotal & & & & 2 & 1 & & 3 & 1.4 \\
\hline$\%$ & & & & 33.3 & 66.7 & & 100.0 & \\
\hline \multicolumn{9}{|l|}{ Other Patt. Tools } \\
\hline 0 unknown, util. & & & & 8 & 2 & & 10 & \\
\hline 15 hammer/billet & & & & 1 & & & 1 & \\
\hline 17 squash knife & & 1 & & 4 & & & 5 & \\
\hline
\end{tabular}


Table 10.3. Distribution of modified bone and antler artifacts organized by general and specific functional class and usephase class (concluded).

\begin{tabular}{|c|c|c|c|c|c|c|c|c|}
\hline \multirow[b]{2}{*}{ Functional Class } & \multicolumn{6}{|c|}{ Use-Phase Class } & \multicolumn{2}{|c|}{ Total } \\
\hline & $\begin{array}{c}1 \\
\text { unfinished } \\
\text { useable }\end{array}$ & $\begin{array}{c}2 \\
\text { unfinished } \\
\text { nonuseable }\end{array}$ & $\begin{array}{c}3 \\
\text { finished, } \\
\text { useable }\end{array}$ & $\begin{array}{c}4 \\
\text { finished, } \\
\text { nonuseable }\end{array}$ & $\begin{array}{c}5 \\
\text { manuf. } \\
\text { debris }\end{array}$ & $\begin{array}{c}6 \\
\text { resharp } \\
\text { debris. }\end{array}$ & $n$ & $\%$ \\
\hline 25 basket/sewing & & & & 1 & & & 1 & \\
\hline 26 shaft straight & & & & 2 & & & 2 & \\
\hline 54 unspec. rib tool & & & & 1 & & & 1 & \\
\hline Subtotal & & 1 & & 17 & 2 & & 20 & 9.2 \\
\hline$\%$ & & 5.0 & & 85.0 & 10.5 & & 100.0 & \\
\hline \multicolumn{9}{|l|}{ Other Exped. Tools } \\
\hline 15 hammer/billet & & & 1 & & & & 1 & \\
\hline 16 bipolar wedge & & & & 1 & & & 1 & \\
\hline 54 unspec. rib tool & & & 2 & 1 & & & 3 & \\
\hline 60 unspec. exped. & & & 9 & 13 & & & 22 & \\
\hline Subtotal & & & 12 & 15 & & & 27 & 12.4 \\
\hline$\%$ & & & 44.4 & 55.6 & & & 100.0 & \\
\hline \multicolumn{9}{|l|}{ Non-Utilitarian } \\
\hline 1 bead & & & & 2 & 2 & & 4 & \\
\hline 2 bracelet & & & & 3 & & & 3 & \\
\hline 3 tube & & & & 6 & 3 & & 9 & \\
\hline 4 gaming piece & & & & 1 & & & 1 & \\
\hline 8 unkn, nonutilitar & & & & 1 & 1 & & 2 & \\
\hline Subtotal & & & & 13 & 6 & & 19 & 8.8 \\
\hline$\%$ & & & & 68.4 & 31.6 & & 100.0 & \\
\hline \multicolumn{9}{|l|}{ Unkn., Utilitarian? } \\
\hline 0 unkn, utilitarian & 1 & & & 39 & 5 & & 45 & \\
\hline 54 unspec. rib tool & & & & 7 & & & 7 & \\
\hline Subtotal & 1 & & & 46 & 5 & & 52 & 24.0 \\
\hline$\%$ & 1.9 & & & 88.5 & 9.6 & & 100.0 & \\
\hline Total & 2 & 3 & 35 & 162 & 14 & 1 & 217 & \\
\hline$\%$ & 0.9 & 1.4 & 16.1 & 74.6 & 6.5 & 0.5 & 100.0 & \\
\hline
\end{tabular}

Table 10.4 summarizes taxonomic identifications for specimens organized by general functional class. Taken together, artifacts fashioned from bison and large artiodactyl bone comprises 69.6 percent of the sample; the large artiodactyl materials are almost certainly bison. Elk bone was not represented in the unmodified sample (see Chapter 9) and none of the modified antler can be positively identified as elk. Bison (large artiodactyl) bone was extensively used for the manufacture of digging implements, pressure flakers and a variety of patterned and expedient tools. Large canid, fox, indeterminate bird, and eagle bones are represented primarily in the ornamental and/or nonutilitarian class.

Table 10.5 presents a breakdown of skeletal element identifications for major taxonomic groups. Bison (large artiodactyl) scapula, ribs and various long bones dominate the sample of identified pieces. Deer and/or pronghorn metacarpals and/or metatarsals were used primarily for piercing implements. The long bones and metapodial bones of large canids and fox, as well as bird long bones, were used in the manufacture of non-utilitarian items, including beads and tubes. 
Table 10.4. Taxonomic makeup of the modified vertebrate sample from Larson Village 2006 organized by generalized functional class.

\begin{tabular}{|c|c|c|c|c|c|c|c|c|c|}
\hline \multirow[b]{2}{*}{ Taxon } & \multicolumn{8}{|c|}{ Generalized Functional Class } & \multirow[b]{2}{*}{ Total } \\
\hline & $\begin{array}{c}\text { Digging } \\
\text { Tools }\end{array}$ & $\begin{array}{c}\text { Piercing } \\
\text { Tools }\end{array}$ & $\begin{array}{c}\text { Pressure } \\
\text { Flakers }\end{array}$ & $\begin{array}{l}\text { Fish- } \\
\text { hooks }\end{array}$ & $\begin{array}{c}\text { Other } \\
\text { Patterned } \\
\text { Tools }\end{array}$ & $\begin{array}{c}\text { Other } \\
\text { Expedient } \\
\text { Tools }\end{array}$ & $\begin{array}{c}\text { Non } \\
\text { Utilitar. } \\
\text { Items }\end{array}$ & $\begin{array}{c}\text { Unknown } \\
\text { Utilitar.? } \\
\text { Tools }\end{array}$ & \\
\hline Bison bison & 14 & 1 & & & & 9 & & & 24 \\
\hline Bison bison? & 4 & 2 & & & 2 & 3 & 1 & 1 & 13 \\
\hline Cervidae & & $1 ?$ & & & 1 & & 4 & 1 & 7 \\
\hline A. americana & & & & & 1 & & & & 1 \\
\hline Odocoileus sp. & & 3 & & & 1 & 1 & & & 5 \\
\hline Canis sp. & & & & & & 1 & 2 & & 3 \\
\hline Vulpes velox & & & & & & & 2 & & 2 \\
\hline Bird & & & & & & & 6 & 1 & 7 \\
\hline Eagle & & & & & & & 2 & & 2 \\
\hline Lrg. artiodactyl & 27 & 17 & 12 & & 13 & 13 & & 32 & 114 \\
\hline Sm. artiodactyl & & 1 & & & & & & & 1 \\
\hline Lrg. mammal & & & & & & & 1 & 5 & 6 \\
\hline Mammal & & 11 & & 2 & 1 & & & 3 & 17 \\
\hline Med/lrg. mamm. & & 1 & & 1 & 1 & & & 9 & 12 \\
\hline Indeterminate & & 2 & & & & & 1 & & 3 \\
\hline Total & 45 & 39 & 12 & 3 & 20 & 27 & 19 & 52 & 217 \\
\hline
\end{tabular}

Table 10.5. Modified bone and antler specimens from the 2006 excavations at the Larson village site organized by element and taxonomic identifications.

\begin{tabular}{|c|c|c|c|c|c|c|c|c|c|}
\hline \multirow[b]{2}{*}{$\begin{array}{l}\text { Skeletal } \\
\text { Element }\end{array}$} & \multicolumn{8}{|c|}{ Taxon } & \multirow[b]{2}{*}{ Total } \\
\hline & bison & $\begin{array}{c}\text { large } \\
\text { artiodactyl }\end{array}$ & $\begin{array}{c}\text { small } \\
\text { artiodactyl }\end{array}$ & cervid & $\begin{array}{l}\text { large } \\
\text { canid }\end{array}$ & $\begin{array}{l}\text { swift } \\
\text { fox }\end{array}$ & bird & $\begin{array}{l}\text { other/ } \\
\text { indet. }\end{array}$ & \\
\hline Antler & & & & 7 & & & & & 7 \\
\hline mandible & & & 1 & & & & & & 1 \\
\hline Tooth & 1 & & & & & & & & 1 \\
\hline Rib & & 47 & & & & & & 1 & 49 \\
\hline rib/vert spine & & 1 & & & & & & & 1 \\
\hline Scapula & 21 & 31 & & & & & & & 52 \\
\hline Humerus & 2 & & & & & & 2 & & 4 \\
\hline Radius & 4 & & & & & & & & 4 \\
\hline Ulna & 3 & & & & & & & & 3 \\
\hline metacarpal & 1 & & & & & & & & 1 \\
\hline Pelvis & 1 & 1 & & & & & & & 2 \\
\hline Femur & & 1 & & & 1 & 2 & & & 4 \\
\hline Tibia & 3 & 1 & & & $1 ?$ & & & & 5 \\
\hline metatarsal & & 1 & 4 & & & & & & 5 \\
\hline metapodial & 1 & & 1 & & 1 & & & & 2 \\
\hline long bone & & 10 & 1 & & & & 7 & & 18 \\
\hline indeterminate & & 21 & & & & & & 37 & 58 \\
\hline Total & 37 & 114 & 7 & 7 & 3 & 2 & 9 & 38 & 217 \\
\hline
\end{tabular}

Table 10.6 offers information regarding specimen fragmentation based on tool part present for each generalized functional group and complements the use-phase data in Table 10.3. Complete or nearly complete specimens comprise 19.3 percent of the total. Tools fragments comprise nearly 
three-quarters of the sample. Specimens classified as manufacture debris add an additional 6.4 percent.

Table 10.6. Modified bone and antler specimens from the 2006 excavations at the Larson village site organized by generalized functional group and specimen completeness.

\begin{tabular}{|c|c|c|c|c|c|c|c|c|c|c|}
\hline \multirow[b]{2}{*}{$\begin{array}{l}\text { Generalized } \\
\text { Functional Class }\end{array}$} & & \multicolumn{8}{|c|}{ Tool Part Present } & \multirow[b]{2}{*}{ Total } \\
\hline & & $\frac{\frac{9}{9}}{\frac{1}{3}}$ & $\begin{array}{l}\frac{0}{0} \\
\frac{0}{3} \\
3 \\
\stackrel{0}{0} \\
\stackrel{\Xi}{\Xi}\end{array}$ & 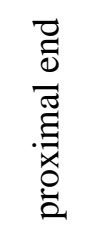 & 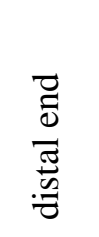 & 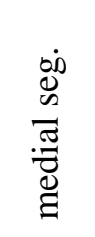 & 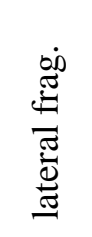 & 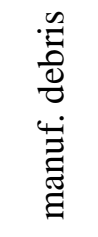 & 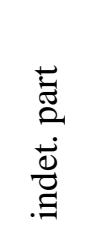 & \\
\hline \multirow{2}{*}{ digging tools } & $n$ & & 5 & 7 & 18 & 1 & 11 & & 3 & 45 \\
\hline & $\%$ & & 11.1 & 15.6 & 40.0 & 2.2 & 24.4 & & 6.7 & 100.0 \\
\hline \multirow[t]{2}{*}{ piercing tools } & $n$ & 8 & 5 & & 22 & 3 & & 1 & & 39 \\
\hline & $\%$ & 20.5 & 12.8 & & 56.4 & 7.7 & & 2.6 & & 100.0 \\
\hline \multirow[t]{2}{*}{ pressure flakers } & $n$ & 2 & 6 & & 3 & 1 & & & & 12 \\
\hline & $\%$ & 16.7 & 50.0 & & 25.0 & 8.3 & & & & 100.0 \\
\hline \multirow[t]{2}{*}{ fishhooks } & $n$ & & & 2 & & & & 1 & & 3 \\
\hline & $\%$ & & & 66.7 & & & & 33.3 & & 100.0 \\
\hline \multirow[t]{2}{*}{ other patt. tools } & $n$ & & 2 & & 2 & 1 & 10 & 2 & 3 & 20 \\
\hline & $\%$ & & 10.0 & & 10.0 & 5.0 & 50.0 & 10.0 & 15.0 & 100.0 \\
\hline \multirow[t]{2}{*}{ other exp. tools } & $n$ & 8 & 5 & 1 & 13 & & & & & 27 \\
\hline & $\%$ & 29.6 & 18.5 & 3.7 & 48.2 & & & & & 100.0 \\
\hline \multirow[t]{2}{*}{ non-util. items } & $n$ & & & 1 & & 2 & 7 & 6 & 3 & 19 \\
\hline & $\%$ & & & 5.3 & & 10.5 & 36.8 & 31.6 & 15.8 & 100.0 \\
\hline \multirow[t]{2}{*}{ unk., utilitarian? } & $n$ & & 1 & & 4 & 3 & 8 & 4 & 32 & 52 \\
\hline & $\%$ & & 1.9 & & 7.7 & 5.8 & 15.4 & 7.7 & 61.5 & 100.0 \\
\hline \multirow[t]{2}{*}{ Total } & $n$ & 18 & 24 & 11 & 62 & 11 & 36 & 14 & 41 & 217 \\
\hline & $\%$ & 8.3 & 11.0 & 5.1 & 16.6 & 5.1 & 16.6 & 6.4 & 18.9 & 100.0 \\
\hline
\end{tabular}

\section{Functional Class Descriptions}

\section{Digging Tools}

Forty-five digging tools comprise 20.7 percent of the sample from the 2006 Larson investigation. Two specimens are classified as expedient digging tools. The remaining 43 specimens are patterned digging tools or tool fragments. Three fragments are burned. The expedient tools each show chipped and worn distal margins with a near-glossy polish. One is a proximal bison radius; the other is a large artiodactyl's long bone diaphysis fragment.

The patterned digging tools are manufactured from bison scapula. However, the incomplete character of many specimens precludes certain taxonomic identification and these pieces are classified as large artiodactyl in Table 10.4 and 10.5. Although four specimens are nearly complete only two are classified as finished and usable; the distal end of both tools show considerable excavation damage. Two additional specimens are nearly complete but lack the distal end. In each case the scapular spine and portions of the caudal and cranial borders are trimmed. The glenoid, 
tuber and neck are essentially intact. In two examples the medial lip of the glenoid is worn and polished. The blade margins of one specimen are chipped and worn, perhaps to facilitate hafting. The remainder of the digging tool sample includes 7 proximal and 17 distal pieces, 11 lateral fragments, 1 medial tool fragment and 3 indeterminate pieces showing a characteristic glossy polish.

\section{Piercing Tools}

This group includes 39 specimens, or 18.0 percent of the sample. The majority $(n=28)$ of these are patterned awls or punches; the distal end of each tool is cut and ground to form a tapered, relatively sharp point. Five specimens are manufactured from split rib shaft segments; the ribs are from a large artiodactyl, almost certainly bison given the complete lack of identified elk bone. Each specimen is heavily ground and shaped. Two tools are cut from the edge of a rib shaft but lack the flattened, near biplano cross-section evidenced by the other rib tools. Three tools are fashioned from deer metapodials. Two are complete and each retains a vestige of the proximal articular surface. The third specimen is an unfinished piece with deep transverse and longitudinal cuts, evidently discarded during the manufacturing process. A fourth small artiodactyl long bone fragment is likely a metapodial but identification is uncertain. One heavily ground and polished distal fragment appears to be made from a piece of antler but the identification is also uncertain. The remaining 16 pieces are fragments of indeterminate origin, but are most likely mammal bone. Five complete specimens range in length from 75.2 to $100.0 \mathrm{~mm}$. One distal fragment shows a transverse cut where it was snapped from the tool shaft. This piece represents resharpening debris (Ahler and Ryser 1997:368). Six specimens are burned.

An additional 11 specimens are classified as expedient awls or punches. These are fashioned from a variety of skeletal elements: scapula, rib, ulna, pelvis, metacarpal, and unidentified long bone shaft fragments. As with the patterned pieces, the distal end of each tool tapers to a relatively narrow point. However, the rest of the tool shows no significant preparation or modification. The working end of each tool is worn from use against a relatively soft or pliable material. Complete pieces range from 43 to $145 \mathrm{~mm}$ in length.

\section{Pressure Flakers}

Twelve pressure flakers constitute 5.5 percent of the collection. This group includes nine patterned pressure flakers. The patterned specimens are made from relatively short bison/large artiodactyl rib sections. Most segments are split and lateral margins are trimmed and ground. The exposed cancellous tissue is also ground. Tool ends are slightly tapered to rounded and show scarring consistent with use as flaking tools. One specimen is "double ended"-one end is rounded while the opposite end supports a more tapered point; both ends show clear scaring. This complete specimen is $144.4 \mathrm{~mm}$ in length. The lateral margins of one rib section have been removed and the proximal tool end has been roughly chipped to produce a squared form. The rib is split at the distal (working) end, exposing ca. $30 \mathrm{~mm}$ of cancellous tissue. The distal tool margins are ground in a manner similar to the split rib tools noted above. The tip is ground to form a broad blunt, slightly pointed, tip. This specimen is $194.0 \mathrm{~mm}$ in length. Two additional specimens are unfinished and likely represent early stages in the manufacture of split rib flakers. Two specimens are burned. 
Two large artiodactyl rib splinters and a scapula caudal border fragment were classified as broad-tipped expedient pressure flakers and complete this tool group. Distal tool ends are worn and scarred but additional modification is lacking. The ribs are multi-function tools; the opposite ends of each tool show polish and wear consistent with use against a soft or pliable material.

\section{Fishhooks}

Fishhooks are often plentiful in Mandan village deposits (e.g., Ahler and Falk 2006:188; Ahler and Falk 2002:13.19) but only three small (size G4) fragments, comprising 1.4 percent of the sample, were found at Larson. One piece is a short $(6.9 \mathrm{~mm})$ shank segment with deep notches cut into opposing faces; the cross-section is somewhat rectangular. A second shank fragment, $12.9 \mathrm{~mm}$ in length, is also notched. The third specimen is a $12.9 \mathrm{~mm}$ long fragment of ground and polished compact bone cut at each end. This piece is tentatively classified as a manufacturing discard.

\section{Other Patterned Tools}

This grouping includes 20 specimens or 9.2 percent of the assemblage. Ten pieces exhibit use-wear and appear to be parts of patterned tools but are too small or incomplete to permit further classification. Six pieces are burned. In addition to the unclassified specimen, several specific functional classes are represented within the general group, although in each case frequencies are comparatively low. One antler hammer or billet was recovered from Ditch 3 (F105). The specimen was fragmented during excavation but includes portions of the burr and a short section of beam. Taxonomic identification of this piece is uncertain. It was classified as cervid due to its fragmented condition but is probably deer, rather than elk. Five specimens are identified as scapula cutting tools or squash knives. One specimen is an incomplete manufacture discard; the other four pieces are fragments of finished specimens. A distal tool fragment is tentatively classified as a basketry, sewing, or weaving tool. It is manufactured from a thin flat scapula blade section. The distal tip is well worn and polished; the flat faces show what appears to be a somewhat jumbled decoration consisting of relatively fine shallow incised parallel and intersecting lines. At first glance, some of the incised lines seemed to have been scored by a metal tool but closer examination was inconclusive. Two additional fragments represent shaft straighteners fashioned from large artiodactyl rib segments. Both pieces are from midden deposits in Block D and Ditch 4, respectively; the Block $\mathrm{D}$ specimen is burned. The final specimen in this group is an unspecified rib tool from Block F (F107).

\section{Other Expedient Tools}

Twenty-seven specimens, comprising 12.4 percent of the total, are grouped here. The majority of these specimens, 22 pieces, are classified as unspecified expedient tools. This group consists primarily of relatively large fractured pieces of long bone (humerus, ulna, radius, femur, and tibia), scapula, pelvis or rib. Most are bison, though deer and large canid are also recorded. These specimens show little or no significant modification and generally only minor use-wear. Preliminary analysis suggests that a number of functionally distinct tools are represented, including 
picks, adzes, and scraping tools. Also included in this expedient tool group is a nearly complete deer mandible with a light polish evident on the lateral body face. In addition, a single bipolar wedge or punch was recovered from Block F (F107). A nearly complete bison ulna found in Ditch 3 (F105) was used as a mallet or hammer. The shaft shows light wear and smoothing. The anconeal process is heavily battered and flattened. Localized battering along the caudal margin of the olecranon is also evident. Finally, three specimens are classified as unspecified rib tools; each shows evidence of use-wear but specific function is unclear.

\section{Ornamental and Non-Utilitarian Items}

Nineteen specimens are classified as ornamental or non-utilitarian items and make up 8.8 percent of the sample. Both bone beads $(n=4)$ and bone tubes $(n=9)$ are present. Two bead fragments are burned. The distinction between beads and tubes is based on a simple length/diameter ratio (Ahler and Falk 2002:13.31); specimens with a ratio less than 3:1 are beads while those with a ratio greater than 3:1 are defined as tubes. At Larson, the beads are all mammal bone. One bead is manufactured from the metapodial of a large canid. A second specimen is made from the long bone (metapodial?) shaft of a small to medium-sized mammal. Two specimens classified as beads are manufacture discard; both are pieces of the proximal ends of small fox femora. Six items, fragments of completed specimens, and three pieces of manufacture discard are classified as tubes. Each of the tube fragments shows fine, longitudinal striations - likely from the process of cleaning and scraping shafts - as well as general wear and polish on convex surfaces. Eight of the nine specimens are from the long bones of large to medium-sized birds. Two distal left humeri, identified as bald and/or golden eagle, are manufacture discard. In each case, the distal ends were removed from the shaft using the 'groove and snap' procedure. The third piece of discard is the distal shaft of a canid long bone (femur?), also removed by the "groove and snap" technique.

Three thin, narrow, slightly curved antler pieces are classified as bracelet fragments. Crosssections are rectangular to oval. Two specimens are medial segments while the third specimen exhibits a perforated slot $(2.0 \mathrm{~mm}$ by $5.3 \mathrm{~mm})$ at one finished end. This group also includes a small, split gaming piece fragment. This specimen is burned. The finished piece was circular to oval in outline with an estimated maximum diameter of about $15 \mathrm{~mm}$ to $17 \mathrm{~mm}$. The recovered fragment includes a portion of the original circular edge and a remnant of one face; both surfaces are ground, worn and polished. The face is flat and exhibits a decorative pattern of incised lines radiating from an incised central axis. A similar piece is reported from Scattered Village but shows only parallel incised lines on one face (Ahler and Falk 2002:13.35). A gaming piece from Double Ditch (Ahler 2004:251) also shows an incised linear decoration. One final specimen is considered a

nonutilitarian item of unspecified function. The piece is a crown fragment from the lower incisor of a large artiodactyl. Fine transverse striations and polish are evident on the enamel surface.

Unclassified, Utilitarian (?) Items

Fifty-two specimens, 24.0 percent of the total sample, are classified as utilitarian items of unknown function; 22 of these are burned. Forty-five specimens exhibit evidence of the manufacturing process and/or polish or other indications of tool use but are too small or incomplete 
to permit assignment to a general or specific functional class. Seven small modified rib fragments of unknown function are also included here.

\section{Distribution of Modified Bone and Antler}

This section provides a summary and discussion of within-site specimen distributions. Table 10.7 provides a breakdown of generalized functional classes organized by deposit type. Nearly half, 49.3 percent, of the sample was recovered from sediments classified as midden and an additional 18.9 percent was found in the midden with earth deposits. Contained feature fill (cache pits and small pits) contributed and additional 26.7 percent of the total.

Table 10.8 present a summary of specimen distributions by general functional class and excavation context. Feature and general excavation levels within each test unit are assigned to one of three sequential stratigraphic groups (see Chapter 6). Materials recovered from the plowzone and from mixed deposits are regarded as unassigned. Over 57 percent of the sample is from Group 2 contexts and most of these materials are from F107 (Block F) and the lower 14 levels of F105 (Ditch 3).

Table 10.7. Distribution of generalized functional class organized by deposit type for modified bone and antler from the 2006 investigations at Larson Village.

\begin{tabular}{|c|c|c|c|c|c|c|c|c|c|c|c|}
\hline \multirow[b]{2}{*}{ Deposit Type } & \multicolumn{8}{|c|}{ Generalized Functional Class } & \multirow[b]{2}{*}{ Total } & \multirow[b]{2}{*}{$\begin{array}{c}\text { Vol. } \\
\text { (cu. m) }\end{array}$} & \multirow[b]{2}{*}{$\begin{array}{c}\text { Density } \\
\text { (tools/ } \\
\text { cu. m) }\end{array}$} \\
\hline & 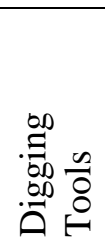 & 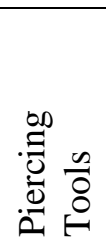 & 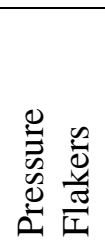 & 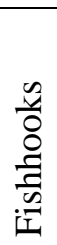 & 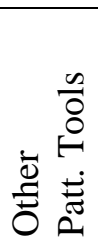 & 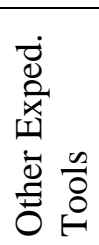 & 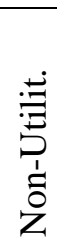 & 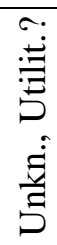 & & & \\
\hline Cache Pit & 7 & 12 & 3 & 1 & 3 & 12 & 5 & 13 & 56 & 1.406 & 39 \\
\hline Small Pit & & & 1 & & & 1 & & & 2 & 0.129 & 16 \\
\hline Midden & 27 & 19 & 7 & 2 & 14 & 8 & 5 & 25 & 107 & 6.808 & 16 \\
\hline Md./Earth & 9 & 6 & & & 2 & 6 & 9 & 9 & 41 & 3.628 & 11 \\
\hline Plowzone & 1 & 2 & 1 & & 1 & & & 5 & 10 & 1.995 & 5 \\
\hline Mixed & 1 & & & & & & & & 1 & 0.340 & 3 \\
\hline Total & 45 & 39 & 12 & 3 & 20 & 27 & 19 & 52 & 217 & 14.306 & 15 \\
\hline
\end{tabular}

Table 10.8. Distribution of generalized functional classes organized by stratigraphic group and locsu for modified bone and antler from the 2006 investigations at Larson Village.

\section{Generalized Functional Class}

\begin{tabular}{|c|c|c|c|c|c|c|c|c|c|}
\hline $\begin{array}{l}\text { Stratigraphic } \\
\text { Group and Locus }\end{array}$ & 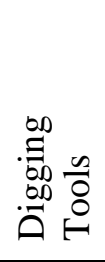 & 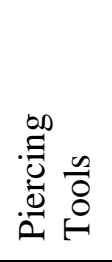 & 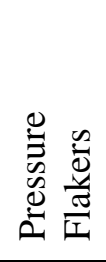 & 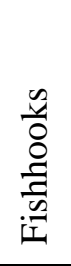 & 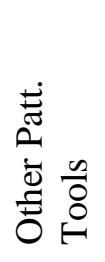 & 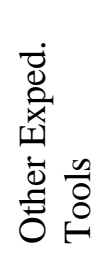 & 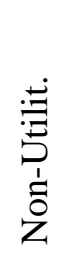 & 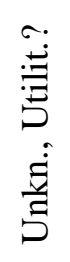 & Total \\
\hline \multicolumn{10}{|l|}{3 Latest } \\
\hline Block A & & 1 & & & & 1 & & 4 & 6 \\
\hline Block D & 6 & 2 & & & 3 & & 1 & 2 & 14 \\
\hline
\end{tabular}


Table 10.8. Distribution and generalized functional classes organized by stratigraphic group and locus (concluded).

\begin{tabular}{|c|c|c|c|c|c|c|c|c|c|}
\hline \multirow[b]{2}{*}{$\begin{array}{l}\text { Stratigraphic } \\
\text { Group and Locus }\end{array}$} & \multicolumn{8}{|c|}{ Generalized Functional Class } & \multirow[b]{2}{*}{ Total } \\
\hline & 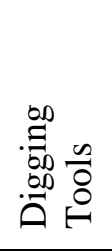 & 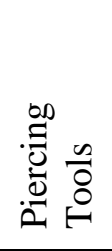 & 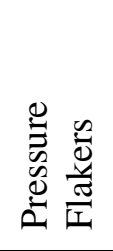 & 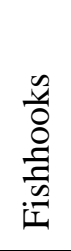 & 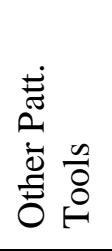 & 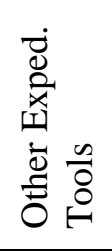 & 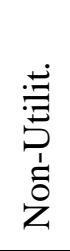 & 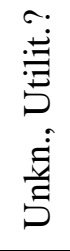 & \\
\hline Block F & 3 & 2 & 2 & & & 1 & & 1 & 9 \\
\hline Ditch 3 & & 1 & & & & & & & 1 \\
\hline Ditch 3 - F105 & 2 & & & & 2 & 1 & 2 & & 7 \\
\hline Subtotal & 11 & 6 & 2 & & 5 & 3 & 3 & 7 & 37 \\
\hline \multicolumn{10}{|l|}{2 Later } \\
\hline Block A - F108 & & & & & & 1 & & & 1 \\
\hline Block A - F109 & 1 & 2 & 2 & 1 & & 2 & 2 & 3 & 13 \\
\hline Block D - F101 & & & 1 & & & & & & 1 \\
\hline Block F - F107 & 6 & 10 & 1 & & 3 & 10 & 3 & 10 & 43 \\
\hline Ditch $3-$ F105 & 16 & 13 & 5 & 2 & 8 & 5 & 2 & 15 & 66 \\
\hline Subtotal & 23 & 25 & 9 & 3 & 11 & 18 & 7 & 28 & 124 \\
\hline \multicolumn{10}{|l|}{1 Earliest } \\
\hline Block G & 3 & 2 & & & & 1 & 5 & 7 & 18 \\
\hline Ditch 4 & 1 & & & & 2 & & & 3 & 6 \\
\hline Ditch 4 - F106 & 5 & 4 & & & 1 & 5 & 4 & 2 & 21 \\
\hline Subtotal & 9 & 6 & & & 3 & 6 & 9 & 12 & 45 \\
\hline \multicolumn{10}{|l|}{0 Unassigned } \\
\hline Block D & & & & & & & & 1 & 1 \\
\hline Block F & 1 & 2 & & & & & & 1 & 4 \\
\hline Block G & & & 1 & & & & & 3 & 4 \\
\hline Ditch 3 & & & & & 1 & & & & 1 \\
\hline Mixed Deposits & & & & & 1 & & & & 1 \\
\hline Subtotal & 1 & 2 & 1 & & 2 & & & 5 & 11 \\
\hline Total & 45 & 39 & 12 & 3 & 20 & 27 & 19 & 52 & 217 \\
\hline
\end{tabular}

Table 10.9 provides a detailed breakdown for specific functional classes according to time period but ignores excavation units. Unassigned specimens are excluded.

Table 10.9. Distribution of specific functional classes organized by time sequence for modified bone and antler from the 2006 excavations at Larson Village. Unassigned specimens $(n=11)$ excluded.

\begin{tabular}{|c|c|c|c|c|}
\hline \multirow[b]{2}{*}{$\begin{array}{l}\text { General and Specific } \\
\text { Functional Class }\end{array}$} & \multicolumn{3}{|c|}{ Stratigraphic Group } & \multirow[b]{2}{*}{ Total } \\
\hline & 1 Earliest & 2 Later & 3 Latest & \\
\hline \multicolumn{5}{|l|}{ Digging Tools } \\
\hline 10 cultivating tool & 9 & 21 & 11 & 41 \\
\hline 46 exp. digging tool & & 2 & & 2 \\
\hline \multicolumn{5}{|l|}{ Piercing Tools } \\
\hline 20 patt. awl/punch & 6 & 15 & 5 & 26 \\
\hline 45 exped. awl/punch & & 10 & 1 & 11 \\
\hline \multicolumn{5}{|l|}{ Pressure Flakers } \\
\hline 22 patt. Press. Flaker & & 8 & & 8 \\
\hline
\end{tabular}


Table 10.9. Distribution of specific functional classes organized by time sequence for modified bone and antler (concluded).

\begin{tabular}{|c|c|c|c|c|}
\hline \multirow[b]{2}{*}{$\begin{array}{l}\text { General and Specific } \\
\text { Functional Class }\end{array}$} & \multicolumn{3}{|c|}{ Stratigraphic Group } & \multirow[b]{2}{*}{ Total } \\
\hline & 1 Earliest & 2 Later & 3 Latest & \\
\hline 39 brd exped. flaker & & 1 & 2 & 3 \\
\hline \multicolumn{5}{|l|}{ Fishhooks } \\
\hline 30 fishhook & & 3 & & 3 \\
\hline \multicolumn{5}{|l|}{ Other Patt. Tools } \\
\hline 0 unkwn, utilitarian & 1 & 6 & 2 & 9 \\
\hline 15 hammer/billet & & 1 & & 1 \\
\hline 17 squash knife & 1 & 2 & 2 & 5 \\
\hline 25 basket/sewing tool & & 1 & & 1 \\
\hline 26 shaft straightener & 1 & & 1 & 2 \\
\hline 54 unspec. rib tool & & 1 & & 1 \\
\hline \multicolumn{5}{|l|}{ Other Exped. Tools } \\
\hline 15 hammer/billet & & 1 & & 1 \\
\hline 16 bipolar wedge & & 1 & & 1 \\
\hline 54 unspec. rib tool & & 2 & 1 & 3 \\
\hline 60 unspec. exped. & 1 & 14 & 2 & 22 \\
\hline \multicolumn{5}{|l|}{ Non-Utilitarian } \\
\hline 1 bead & 1 & 1 & 1 & 4 \\
\hline 2 bracelet & 1 & 2 & & 3 \\
\hline 3 tube & 5 & 3 & 1 & 9 \\
\hline 4 gaming piece & & & 1 & 1 \\
\hline 8 unkn, nonutilitar & 1 & 1 & & 2 \\
\hline \multicolumn{5}{|l|}{ Unkn., Utilitarian? } \\
\hline 0 unkn, utilitarian & 11 & 24 & 5 & 40 \\
\hline 54 unspec. rib tool & 1 & 4 & 2 & 7 \\
\hline Total & 45 & 124 & 37 & 206 \\
\hline
\end{tabular}

Finally, Table 10.10 collapses specific functional classes into more generalized groups organized by temporal unit. Most functional classes are represented in each of the three time periods; however, pressure flakers are absent in Group 1 and fishhooks are found only in Group 2. Digging tools and digging tool fragments decrease slightly from Group 1 to Group 2 but appear to increase from the middle of the sequence to the latest period. Piercing tools show the reverse: they increase from Group 1 through Group 2 and decrease from Group 2 to Group 3. Other patterned tools increase in relative numbers from Group 1 through Group 3. Non-utilitarian items decrease markedly from Group 1 to Group 2 but then increase slightly in Group 3. Other expedient tools and unknown (utilitarian?) tools decrease in relative importance through time. The meaning of these time trends is unclear. The Larson sample is a comparatively small one the observed patterning is not statistically significant.

\section{Regional Comparisons}

This section offers broad comparisons between modified bone and antler from Larson and samples from generally contemporaneous Plains Village sites located within the Knife and Heart regions. Heart River area sites include Slant (Ahler and Ryser 1997:362-363, Table 135), Scattered 
(Ahler and Falk 2002:13.5-13.6, Table 13.2), Double Ditch (Ahler 2005:278, Table 57) and Boley (Ahler and Falk 2006:195, Table 67) villages. The Knife River area is represented by pooled data from five village sites (White Buffalo Robe, Lower Hidatsa, Big Hidatsa, Sakakawea and Taylor Bluff [Weston and Ahler 1993:281, Table 20.3]). Table 10.11 provides comparative data on generalized functional class for each of the five Heart region sites and the combined Knife region sample. In order to maintain consistency with earlier analyses it was necessary to reorganize the Larson data slightly. Unknown/unclassified tools (generalized functional group 8) are excluded and expedient pressure flakers are removed from group 3 and included with other expedient tools (group 6). Finally, the unknown/utilitarian tools included with other patterned tools (group 5) have also been excluded. Also, for the Knife region components, following Ahler and Falk (2006:194-195), Weston and Ahler's “antler tools" group was divided equally between other patterned tools and "ornamental/non-utilitarian."

Table 10.10. Distribution of generalized functional classes organized by general time sequence for modified bone and antler from the 2006 excavations at Larson Village. Unassigned specimens $(\mathrm{n}=11)$ excluded. Chisquare $=17.851, \mathrm{df}=14, \mathrm{p}=0.2136$.

\begin{tabular}{|c|c|c|c|c|c|}
\hline \multirow[b]{2}{*}{$\begin{array}{l}\text { Generalized } \\
\text { Functional Class }\end{array}$} & & \multicolumn{3}{|c|}{ Time Sequence } & \multirow[b]{2}{*}{ Total } \\
\hline & & 1 Earliest & 2 Later & 3 Latest & \\
\hline \multirow[t]{2}{*}{1 Digging Tools } & $n$ & 9 & 23 & 11 & 43 \\
\hline & $\%$ & 20.0 & 18.5 & 29.7 & 20.9 \\
\hline \multirow[t]{2}{*}{2 Piercing Tools } & $n$ & 6 & 25 & 6 & 37 \\
\hline & $\%$ & 13.3 & 20.2 & 16.2 & 18.0 \\
\hline \multirow[t]{2}{*}{3 Pressure Flakers } & $n$ & & 9 & 2 & 11 \\
\hline & $\%$ & & 7.3 & 5.4 & 5.3 \\
\hline \multirow[t]{2}{*}{4 Fishhooks } & $n$ & & 3 & & 3 \\
\hline & $\%$ & & 2.4 & & 1.5 \\
\hline \multirow[t]{2}{*}{5 Other Patt. Tools } & $n$ & 3 & 11 & 5 & 19 \\
\hline & $\%$ & 6.7 & 8.0 & 13.5 & 9.2 \\
\hline \multirow{2}{*}{6 Otr Exped. Tools } & $n$ & 6 & 18 & 3 & 27 \\
\hline & $\%$ & 1.3 & 14.5 & 8.1 & 13.1 \\
\hline \multirow[t]{2}{*}{7 Non-Utilitarian } & $n$ & 9 & 7 & 3 & 19 \\
\hline & $\%$ & 20.0 & 5.6 & 8.1 & 9.2 \\
\hline \multirow[t]{2}{*}{8 Unk., Utilitarian? } & $n$ & 12 & 28 & 7 & 47 \\
\hline & $\%$ & 26.7 & 22.6 & 18.9 & 22.8 \\
\hline \multirow[t]{2}{*}{ Total } & $n$ & 45 & 124 & 37 & 206 \\
\hline & $\%$ & 100.0 & 100.0 & 99.9 & 100.0 \\
\hline
\end{tabular}

Examination of frequency data presented in Table 10.11 supports general observations offered by Ahler and Falk (2006:195-196) in a comparative discussion of remains from Boley and other village sites. Cell frequencies showing positive deviations (higher values) than expected are shaded. In the present analysis, Larson and Double Ditch are characterized by relatively large percentages of expedient tools and both also have comparatively low percentages of non-utilitarian items. The relative percentage of piercing tools is also high at Double Ditch. In comparison to other samples, Boley is distinctive for comparatively high percentages of flakers and fishhooks, though the number of flakers may be somewhat inflated due to differences in classification procedures (Ahler and Falk 2005:195). Scattered Village shows a high percentage of non-utilitarian pieces and, to a lesser degree, fishhooks. The combined Knife region components are distinguished 
by higher percentages of digging tools and other patterned tools in comparison to the Heart River sites.

Table 10.11. Comparison of generalized functional class occurrences across several Heart region and Knife region villages. Chi-square $=530.314, \mathrm{df}=30, \mathrm{p}=<0.0001$.

\begin{tabular}{|c|c|c|c|c|c|c|c|c|}
\hline \multirow[b]{2}{*}{ Generalized } & & \multirow[b]{2}{*}{ Slant } & \multicolumn{3}{|c|}{ Double } & \multicolumn{3}{|c|}{ Knife } \\
\hline & & & Scattered & Ditch & Larson & Boley & Region & \\
\hline Functional Class & & $1575-1780$ & $1550-1700$ & $1490-1780$ & $1500-1650$ & $1550-1725$ & $1525-1845$ & Total \\
\hline \multirow[t]{2}{*}{1 Digging Tools } & $n$ & 73 & 183 & 573 & 43 & 49 & 302 & 1223 \\
\hline & $\%$ & $30.5 \%$ & $21.0 \%$ & $30.5 \%$ & $28.7 \%$ & $23.7 \%$ & $42.3 \%$ & $30.2 \%$ \\
\hline \multirow{2}{*}{2 Piercing Tools } & $n$ & 42 & 93 & 309 & 26 & 30 & 51 & 551 \\
\hline & $\%$ & $17.6 \%$ & $10.7 \%$ & $16.5 \%$ & $17.3 \%$ & $14.5 \%$ & $7.1 \%$ & $13.6 \%$ \\
\hline \multirow[t]{2}{*}{3 Pressure Flakers } & $n$ & 11 & 52 & 115 & 11 & 27 & 52 & 268 \\
\hline & $\%$ & $4.6 \%$ & $6.0 \%$ & $6.1 \%$ & $7.3 \%$ & $13.0 \%$ & $7.3 \%$ & $6.6 \%$ \\
\hline \multirow[t]{2}{*}{4 Fishhooks } & $n$ & 8 & 44 & 30 & 3 & 26 & 8 & 119 \\
\hline & $\%$ & $3.3 \%$ & $5.1 \%$ & $1.6 \%$ & $2.0 \%$ & $12.6 \%$ & $1.1 \%$ & $2.9 \%$ \\
\hline \multirow{2}{*}{5 Other Patterned } & $n$ & 16 & 79 & 108 & 10 & 9 & 95 & 317 \\
\hline & $\%$ & $6.7 \%$ & $9.1 \%$ & $5.8 \%$ & $6.7 \%$ & $4.3 \%$ & $13.3 \%$ & $7.8 \%$ \\
\hline \multirow[t]{2}{*}{6 Other Expedient } & $n$ & 41 & 60 & 402 & 38 & 26 & 94 & 661 \\
\hline & $\%$ & $17.2 \%$ & $6.9 \%$ & $21.4 \%$ & $25.3 \%$ & $12.6 \%$ & $13.2 \%$ & $16.3 \%$ \\
\hline \multirow[t]{2}{*}{7 Non-Utilitarian } & $n$ & 48 & 360 & 339 & 19 & 40 & 112 & 918 \\
\hline & $\%$ & $20.1 \%$ & $41.3 \%$ & $18.1 \%$ & $12.7 \%$ & $19.3 \%$ & $15.7 \%$ & $22.6 \%$ \\
\hline \multirow[t]{2}{*}{ Total } & $n$ & 239 & 871 & 1876 & 150 & 207 & 714 & 4057 \\
\hline & $\%$ & $100.0 \%$ & $100.0 \%$ & $100.0 \%$ & $100.0 \%$ & $100.0 \%$ & $100.0 \%$ & $100.0 \%$ \\
\hline
\end{tabular}

\section{Summary}

This chapter presents a descriptive account of modified bone and antler from 2006 test investigations at the Larson Village. A total 217 specimens, organized into eight general and 21 specific functional classes, are described. Approximately 75 percent of the sample consists of tool/ornament fragments; just over 18 percent of the sample is comprised of complete or near complete items. The remaining specimens are classified as manufacturing debris. Over half (54.3 percent) of the collection is from two excavation units: F105 (Ditch 3 fill) and F107 (a pit in Block F). When considered by deposit type, 68.2 percent of the sample is from deposits classified as midden or midden with earth; 26.7 percent of the total is from cache pits or other small, contained features. An additional 5.1 percent of the assemblage is from the plowzone or mixed deposits. At least 70 percent of the described specimens are manufactured from bison/large artiodactyl skeletal elements, primarily scapulae, ribs and various long bones. Deer, pronghorn, large canid, fox, and eagle bones are also present.

Beyond differences noted for deposit types (e.g., midden vs. cache pit), analysis of within site distributions for generalized function classes shows no statistically significant temporal patterning. Most functional classes are represented in each of the defined stratigraphic groups (earliest, later, latest) and over 57 percent of the sample is associated with units assigned to Group 2 (later). Most period 2 specimens are from F107 and F105 (Ditch 3, excavation levels 2-14).

Comparison with materials from nearby Heart River and select Knife River area sites shows that bone and antler tool assemblages are broadly similar, but some differences are discernable. 
Relatively high percentages of expedient tools and comparatively low percentages of non-utilitarian items differentiate the Larson sample; a similar pattern is noted for Double Ditch. As discussed in Chapter 9, however, it is quite possible that differences within and between each of the excavated samples are, at least partly, a reflection of unrecognized variations/differences in excavated contexts and, in some instances, minor variations in application of analytic techniques. 


\section{References Cited}

Ahler, Stanley A.

2003 Modified Bone and Antler Artifacts. In Archaeological Investigations During 2001 and 2002 at Double Ditch State Historic Site, North Dakota, edited by Stanley A. Ahler, pp. 205-215. PaleoCultural Research Group, Flagstaff, Arizona. Submitted to the State Historical Society of North Dakota.

2004 Modified Bone and Antler Artifacts. In Archaeological Investigations During 2003 at Double Ditch State Historic Site, North Dakota, edited by Stanley A. Ahler, pp. 237-258. PaleoCultural Research Group, Flagstaff, Arizona. Submitted to the State Historical Society of North Dakota.

2005 Modified Bone and Antler Artifacts. In Archaeological Investigations During 2004 at Double Ditch State Historic Site, North Dakota, edited by Stanley A. Ahler, pp. 259-280. PaleoCultural Research Group, Flagstaff, Arizona. Submitted to the State Historical Society of North Dakota.

Ahler, Stanley A. and George T. Crawford

2003 Modified Bone and Antler Artifacts. In Archaeology at Menoken Village, A Fortified Late Plains Woodland Community in Central North Dakota, edited by Stanley A. Ahler, pp. 451-486. PaleoCultural Research Group, Flagstaff, Arizona. Submitted to the State Historical Society of North Dakota, Bismarck.

Ahler, Stanley A. and Carl R. Falk

2002 Modified Bone and Antler Remains. In Prehistory on First Street: The Archaeology of Scattered Village in Mandan, North Dakota, edited by Stanley A. Ahler, pp. 13.1-13.45. PaleoCultural Research Group. Submitted to the North Dakota Department of Transportation and the City of Mandan, North Dakota.

2006 Modified Bone and Antler Artifacts. In Geophysical Survey and Test Excavation During 2005 at Boley Village (32MO37), North Dakota, edited by Stanley A. Ahler, pp. 181-197. PaleoCultural Research Group, Flagstaff, Arizona. Submitted to the State Historical Society of North Dakota.

Ahler, Stanley A. and Gail Ryser

1997 Modified Bone and Antler. In Archaeology of the Mandan Indians at On-A-Slant Village (32MO26), fort Abraham Lincoln State Park, Morton County, North Dakota, edited by Stanely A. Ahler, pp. 351-390. Office of Research and Graduate Studies, Northern Arizona University. Submitted to North Dakota Parks and Recreation Department, Bismarck, North Dakota.

Moore, Sarah M.

1985 Modified Bone and Antler from On-A-Slant Village (32MO26). Journal of the North Dakota Archaeological Association, Vol. 2. Department of Anthropology, University of North Dakota, Grand Forks.

Weston, Timothy A., and Stanley A. Ahler

1993 Modified Bone and Antler Remains from the KNRI and the Upper Knife-Heart Region. In The Phase I Archaeological Research Program for the Knife River Indian Villages National Historic Site, Part III: Analysis of the Physical Remains, edited by Thomas D. Thiessen, pp. 273-288. Occasional Studies in Anthropology No. 27. National Park Service, Midwest Archeological Center, Lincoln, Nebraska. 


\title{
11. BotanicAl REMAins
}

\author{
Robert K. Nickel
}

\section{Introduction}

The current sample of charcoal fragments and botanical remains was recovered from Larson Village in 2006. Seeds and related materials were identified in 86 catalog lots from six excavation units. In all, 99 catalog numbers were assigned to 2006 excavation units, however not all catalog lots produced identifiable seeds. The excavation units were selected with the goal of determining periods of occupation and examining the relationship of visible surface features to those revealed by magnetic gradiometry (Mitchell et al. 2006). The work at Larson Village was a continuation of a program designed by Stanley A. Ahler to elucidate the details of the prehistoric and early historic occupation of the Missouri River region near Bismarck and Mandan, North Dakota (Ahler, ed. 2003, 2004; Ahler and Kvamme 2000).

Initial processing of the botanical sample was supervised by Stacey Madden, PCRG Lab Supervisor. This work was carried out at PCRG's lab in Flagstaff, Arizona. Waterscreen samples were first size graded, and sizes G4 and G5 samples were floated and separated into light and heavy fractions. Bulk sediment samples were floated first, retaining all heavy- and light-fraction materials greater than $0.5 \mathrm{~mm}$, then size graded into sizes $\mathrm{G} 2$ to $<\mathrm{G} 5$. The resulting light-fraction samples, as well as botanical remains segregated from the heavy fractions of all samples during routine sorting in the lab were forwarded to the author for sorting and identification. The lots were inspected with a microscope at low magnification and all identifiable seeds, fruits, or similar botanical materials were noted and tabulated. As is often the case in Plains Village sites, the upper portion of the site deposit contains many fine roots that appear in the final samples as short hair-like root segments. The root segments tend to decrease in number with increasing depth. When they are most numerous, they often constitute over 95 percent of the volume of a sample. Their presence greatly increases the time required to identify and quantify the archeological seeds.

Archeological specimens were identified either by comparing them with modern seeds and fruits from known plants or by referring to published guides (e.g. Hitchcock 1950; Martin and Barkley 1961; Slife et al. 1960). Modern comparative material includes specimens collected by the author and collections available from universities and departments of agriculture in Nebraska and the Dakotas. Ethnobotanical literature based on native accounts from the early twentieth century was used when it provided possible indications of species preference, processing, and seasonality, even though the native botany of the Mandans is not well documented in published literature. Archeological data from other Plains Village occupations along the Missouri River near the cities of Bismarck and Mandan were also used.

Counts of identified plant remains are presented in Table 11.1. Corn (Zea mays), beans (Phaseolus vulgaris), and squash (Cucurbita pepo), the most significant exotic cultigens in the region, are all present as carbonized specimens in the 2006 sample, but not all of these species occur in all excavation units. Uncarbonized squash seeds are also present in the Larson collection as they 


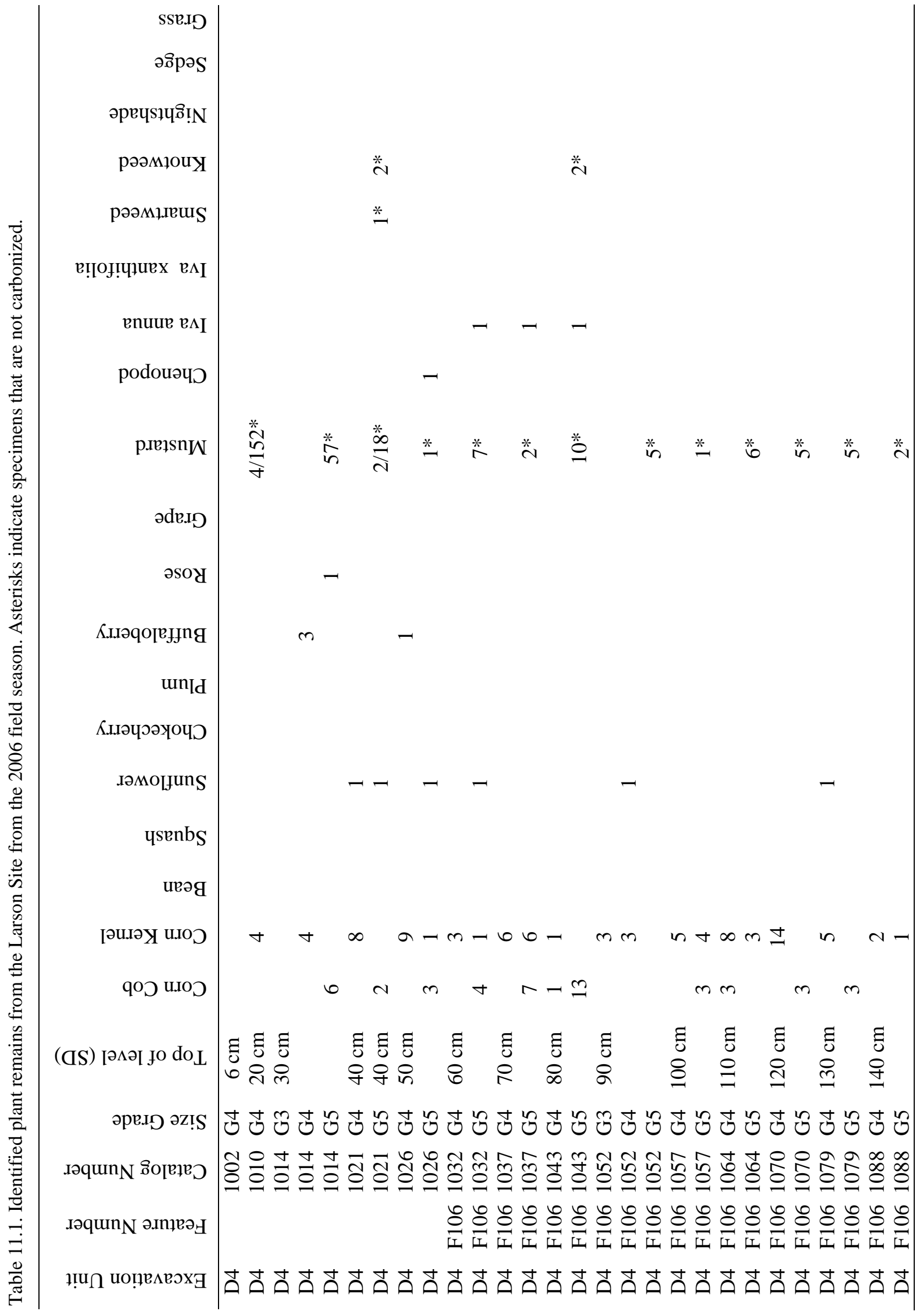




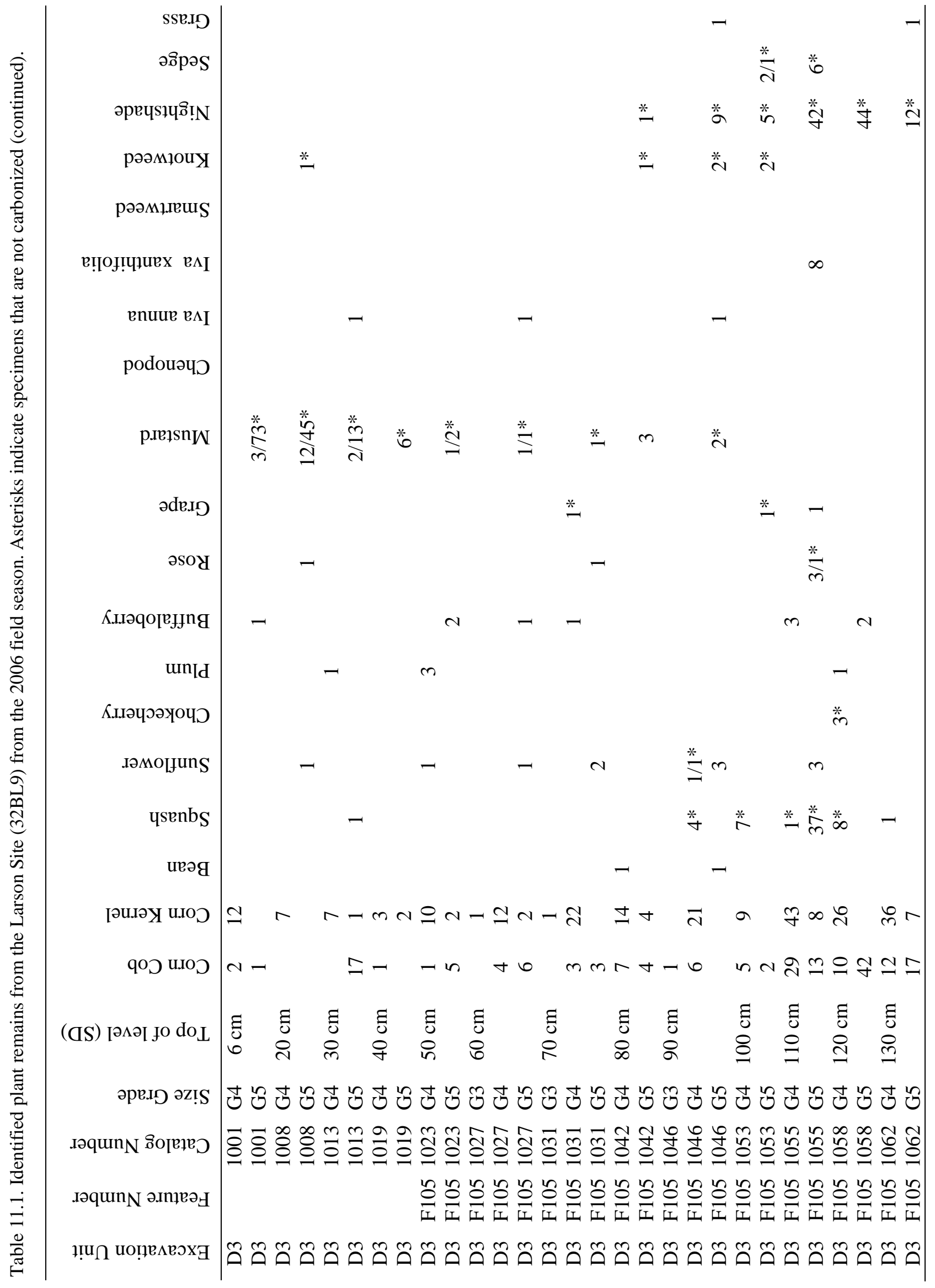




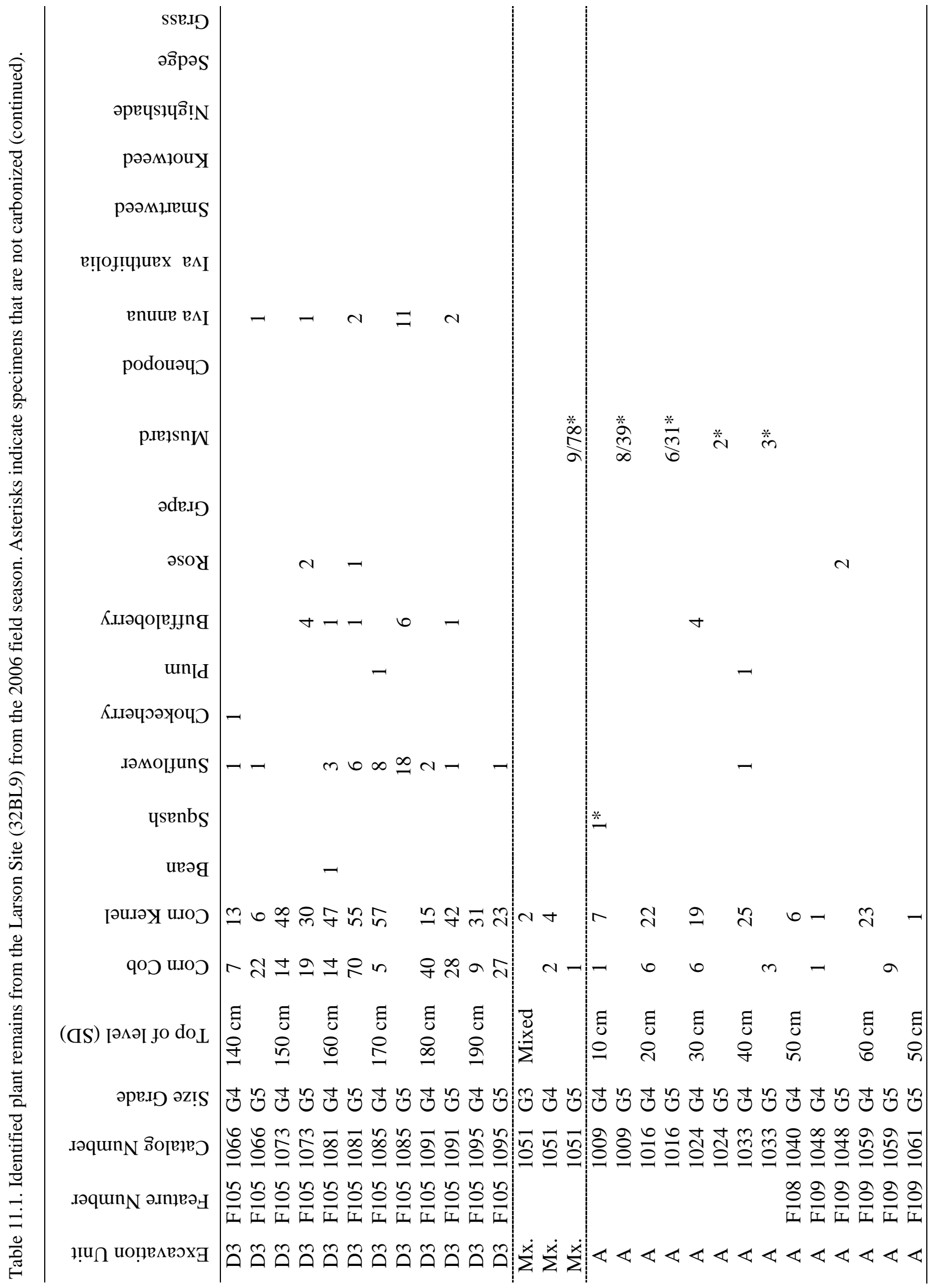




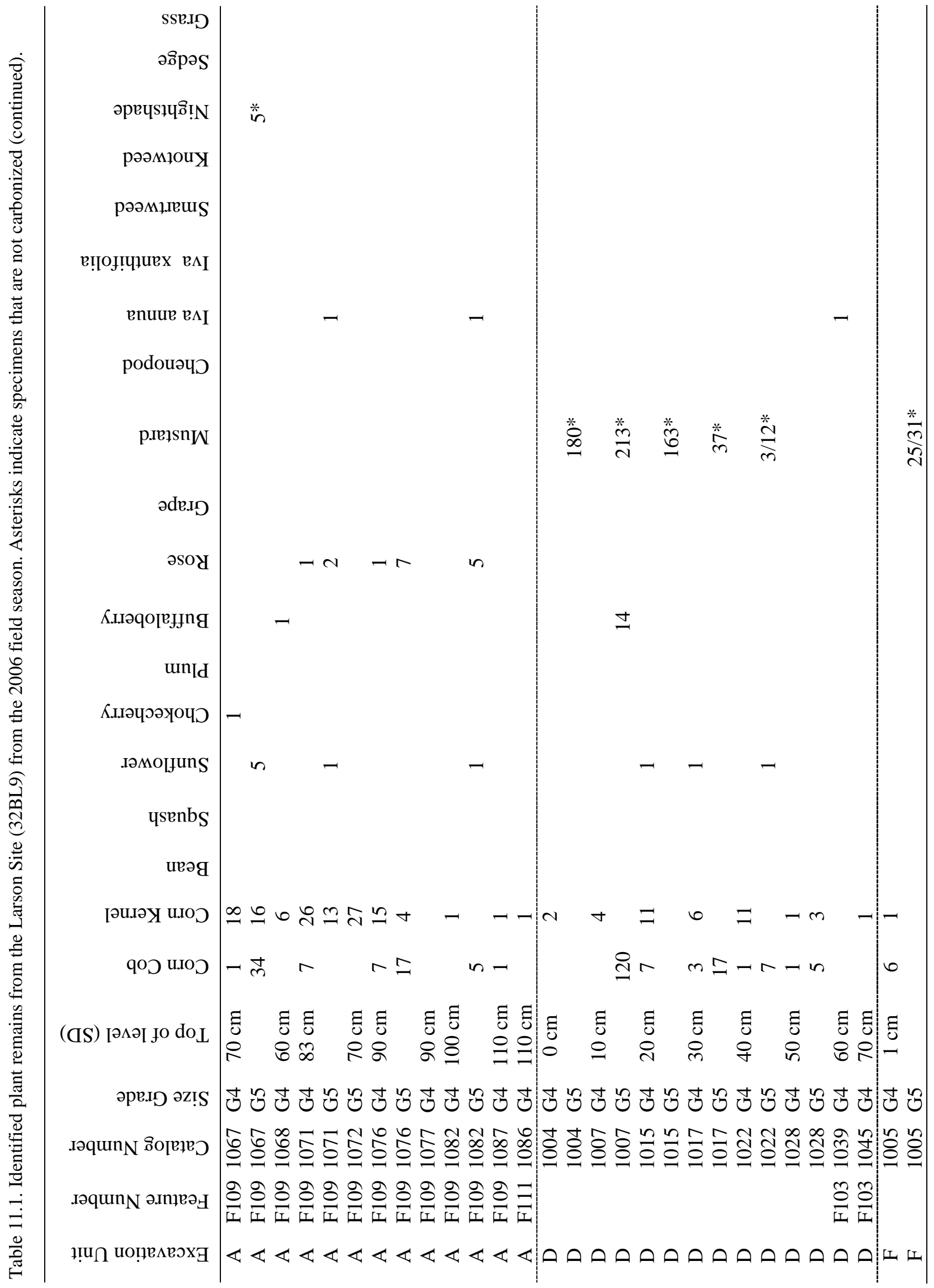




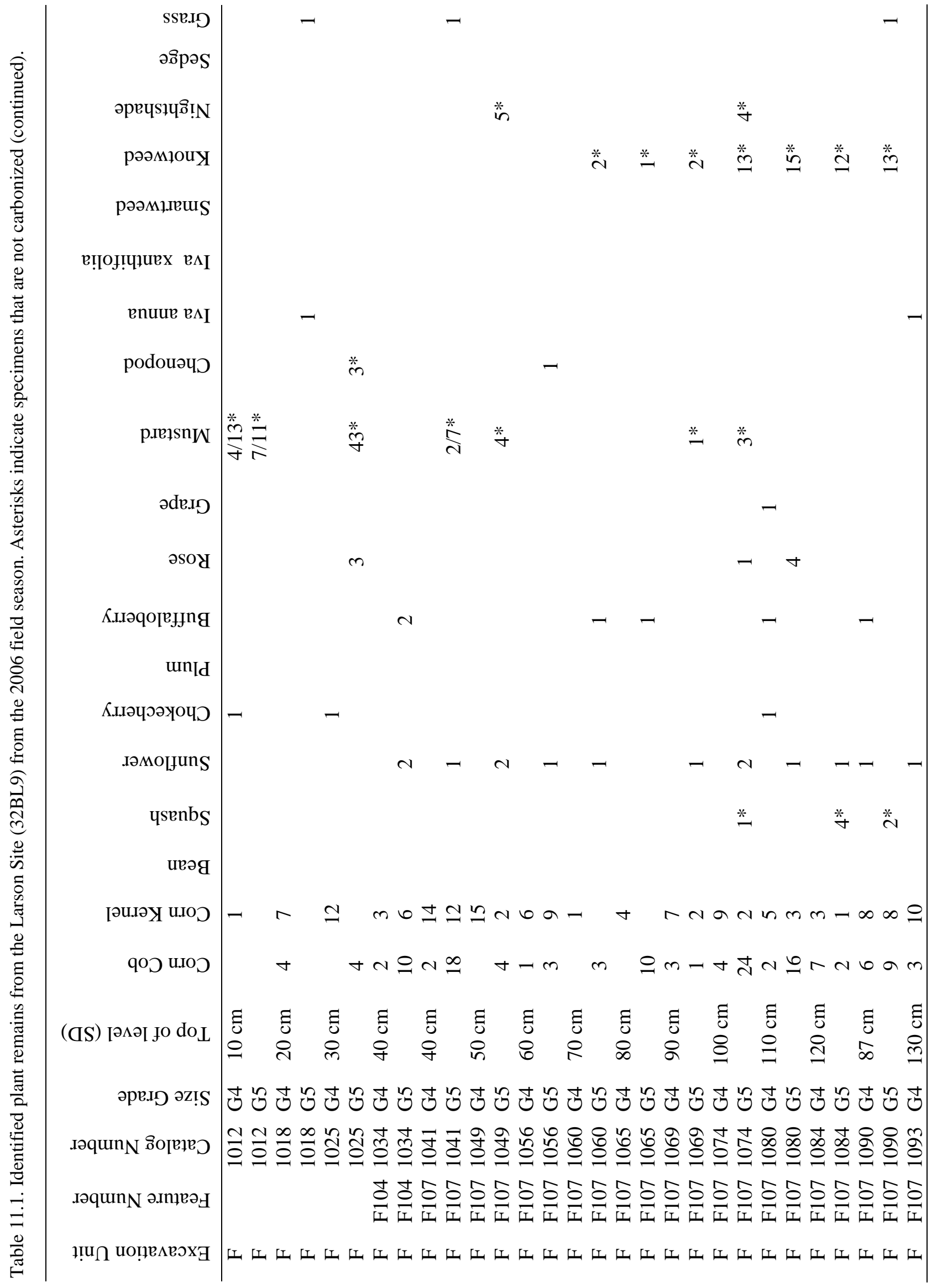

을 


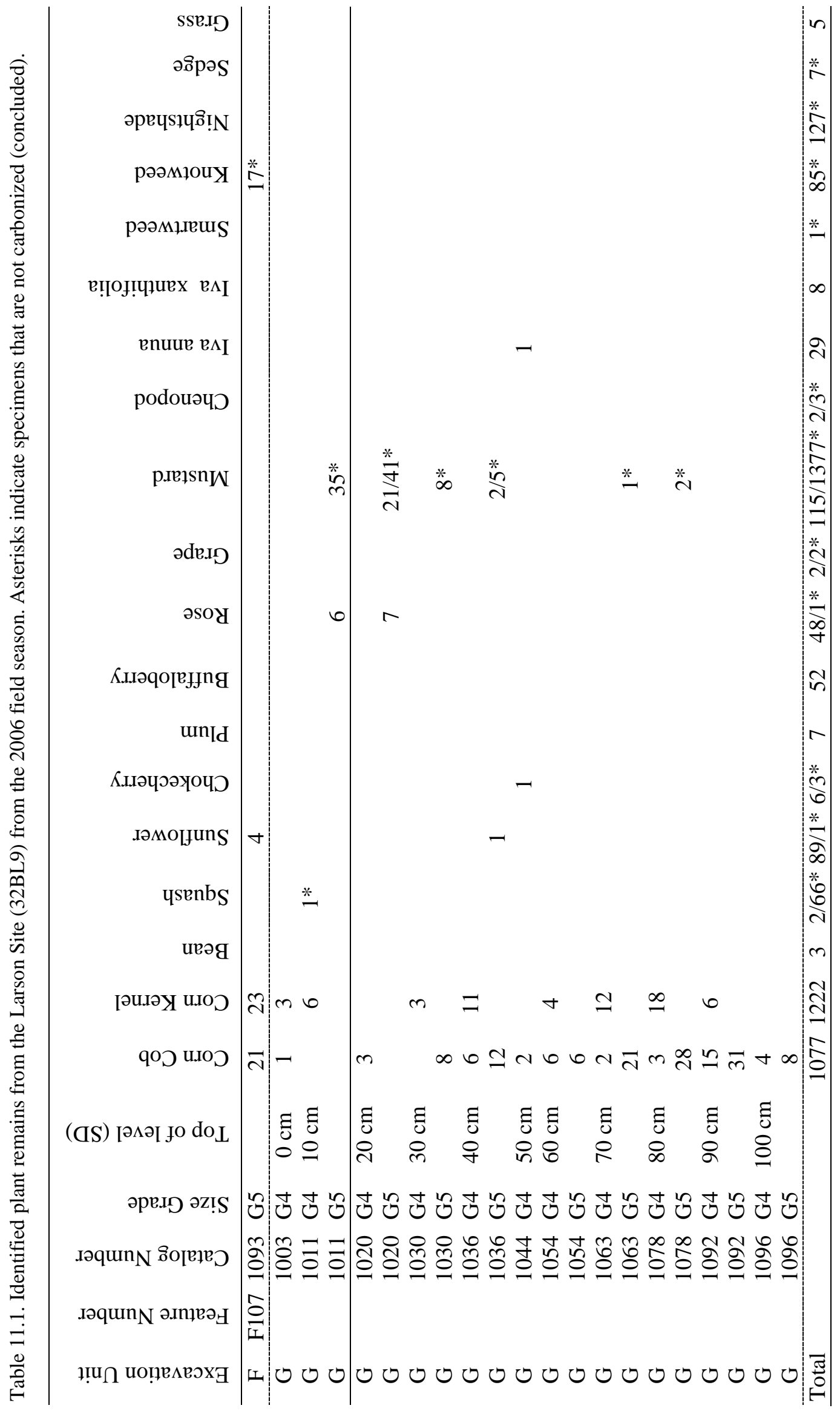


are in most regional collections. Corn kernels and cob fragments are present in all excavation units and either kernels or cob fragments occur in every excavation level. Neither beans or squash seeds are numerous, nor are they widely distributed among the excavation units. Several wild fruits are present in the 2006 Larson Village sample. These include chokecherry (Prunus virginiana), plum (Prunus americana), buffaloberry (Shepherdia argentea), rose (Rosa sp.), and grape (Vitis sp.). Of the other local wild fruits frequently observed in archeobotanical collections from nearby sites, dogwood (Cornus stolonifera) is conspicuously absent. In some of the other archeological collections from sites near Bismarck, dogwood barely trails buffaloberry in quantity and ubiquity. Snowberry (Symphoricarpos occidentalis) usually occurs in small numbers but it is completely absent from the current Larson collection.

The array of seeds from weedy plants at Larson Village is similar to that of some other regional collections, particularly that from Double Ditch. The Larson collection includes both small-seeded weedy forms of sunflower (Helianthus annuus), marshelder (Iva annua) and burweed (Iva xanthifolia). Large-seeded forms of sunflower and marshelder, both of which are considered indigenous cultivars, are also present. Burweed has not yet been recovered at archeological sites in a form that clearly indicates cultivation but its increasingly common discovery in archeological collections suggests that it may have functioned as a useful but uncultivated subsistence resource for prehistoric Plains villagers (Adair 1999; Asch and Green 1992; Scullin and Scullin 2007; Nickel 1977, 2002). Notable for their virtual absence from the Larson Village collection are carbonized seeds of chenopods (Chenopodium sp.). Chenopods are relatively common in the recently recovered Double Ditch collections, and Will and Spinden noted these seeds in their Double Ditch work in the early 1900s (Will and Spinden 1906).

The 2006 Larson collection contains surprisingly few of the modern looking seeds of other weeds and grasses. The present assemblage contains small numbers the seeds of mustard (cf. Brassica juncea), smartweed (cf. Polygonum pennsylvanicum), knotweed (cf. Polygonum erectum), nightshade (Solanum sp.), and one or more grasses. Only the mustard seeds are common in the Larson collection, while modern seeds of sunflowers and chenopods are surprisingly scarce or absent, in contrast to Double Ditch. Fernald (1950) considers most mustard species to be recent introductions to North America.

Not listed in the tabular summary is a fragment of a single uncarbonized seed of a hackberry (Celtis occidentalis). According to Stevens (1963:116), hackberry trees are rare in North Dakota except along the Red River in the vicinity of Fargo, North Dakota; however, they have been widely planted as street trees in cities and towns in the Dakotas. While hackberry seeds were common in collections from Coalescent tradition villages near Mobridge, South Dakota (Nickel 1988), Scattered Village is the only site near Mandan from which the author has identified a hackberry seed (Nickel 2002:9.25). The Scattered Village site is located within a residential neighborhood in the city of Mandan. It is not clear whether the hackberry seeds at Larson and Scattered Village are cultural specimens.

\section{The Identified Plants}

The following paragraphs discuss the results of the analysis, provide background data on each of the identified species, and draw comparisons to collections from other Heart region villages. 


\section{Corn}

Corn or maize (Zea mays) was the primary food plant of the semi-sedentary villagers during the historic period. The accounts of Euroamerican explorers (summarized in Will and Hyde [1964 (1917)]) and ethnographers (Wilson 1916, 1917; Gilmore 1919), focus on corn horticulture. Beans, squash and sunflowers were cultivated in and around cornfields but no historic account ranks them at the same level of productivity as corn. George Will's work (Will and Hyde 1964 [1917]) combined his interest in archeology with his family's commercial interests in the seed business (Walster 1956). Hugh Cutler, working at the Missouri Botanical Gardens in St. Louis, examined much of the botanical material recovered during the Smithsonian Institution's major salvage excavations along the Missouri River in the Dakotas (Cutler and Blake 1973:6). Will's work with heritage corn varieties and Cutler's work on salvage archeological collections provide the basis for our current understanding of Native American corn varieties from the Middle Missouri.

The Larson Village corn is more fragmentary than the bulk of the material from many regional collections, although the corn specimens from some features at other sites are also highly fragmentary. Only a few of the Larson cob specimens consists of more than a single cupule. Whether this is a function of pre-disposal processing or related to disposal activities is not clear. It does not appear to be related to the type of recovery (waterscreen vs. flotation).

Cutler identified mostly 8-rowed varieties of corn from Middle Missouri sites, with 10rowed forms the next most common (Cutler and Blake 1973:53-55). The same study indicates that for collections in which the mean number of rows on corncobs was between 8 and 9, the median cupule-width ranged from $7.2 \mathrm{~mm}$ to $9.4 \mathrm{~mm}$. In the Larson collection a few cupules between 8 $\mathrm{mm}$ and $9 \mathrm{~mm}$ wide were recorded but most were too fragmentary to measure. Also, many cupule fragments occurred in the smallest size-grade (G5) and may not be representative of the varieties being grown at Larson. The number of rows of kernels in the present Larson sample was not determined. A couple of cob tips were from 8-rowed cobs but most of the specimens were not sufficiently intact to yield valid measurements. There is little reason to expect that the Larson corncobs differed greatly from Cutler's norm. Collections from nearby sites often contain a few small cobs that represent "sport ears” (Wilson 1917:67). With the exception of the cob tips mentioned above, the Larson sample lacked both sport ears and segments of larger normal cobs.

Almost all of the corn kernels in the Larson collection were fragmentary. Only a few complete kernels typical of mature kernels of northern flint corns were present in this sample, although a larger number of kernels without embryos were observed. Most of the specimens were fragments of large kernels but a few small teardrop-shaped kernels were present. These appear to be from the tips of cobs where anomalously small kernels often form. Other complete or nearly complete corn kernels yielded kernel widths of $6 \mathrm{~mm}$ to $7 \mathrm{~mm}$. Some Larson kernels were represented only by the kernel's embryo without the normally attached endosperm.

Corn kernels and cob fragments are widely distributed in the catalog lots from Larson, although cob fragments are somewhat under-represented compared to many collections from the region. Larson cob fragments are both smaller and less numerous than those from nearby sites but the differences may be attributed to the considerable variation that archeological collections of botanical specimens often exhibit. In the Ditch 4 excavation at Larson, corn is most common in the upper levels of the ditch itself (Feature 106). In Ditch 3, the corn is concentrated in the lower levels 
of the ditch (Feature 105). In Blocks A and F, corn is concentrated in features F109 and F107 respectively. Block D exhibits a single concentration of corn in the G5 sample from a general level near the surface (CN 1007). In Block $\mathrm{G}$, a unit comprised of midden deposits, the corn is somewhat sparse near the surface but otherwise is fairly evenly distributed.

\section{Squash}

Squash is the cultivated plant second to corn in the frequency of recovery from archeological sites during the salvage era (Nickel 1977:55). In their compendium of identified specimens from the Dakotas, Cutler and Blake (1973) report finding examples of four species of squash, but Cucurbita pepo was by far the most common. The 2006 Larson sample included fragmentary uncarbonized squash seeds and a few small segments of carbonized squash rind. The Larson squash seeds are not inconsistent with those of Cucurbita pepo (Cutler and Whitaker 1961) but they are too fragmentary to be confidently identified to the species level. No squash seeds were identified in the samples from Ditch 4 but Ditch 3 contained a relatively large number of squash seed fragments. There is no significant pattern to the distribution of the squash seed fragments in the other excavation units.

\section{Beans and Sunflowers}

Common garden beans (Phaseolus vulgaris) are the least common garden crop represented in the salvage-era collections from the Middle Missouri. Waterscreen recovery has generally produced a few bean seeds in Plains Village botanical collections. It is likely that the low level of occurrence reflects both a relatively small number of beans harvested and a high degree of fragility. At Larson, bean seed segments were present only in Ditch 3. Will and Spinden (1906:180) describe large and small beans recovered from Double Ditch Village that ranged from as long as $16 \mathrm{~mm}$ in length to about $6 \mathrm{~mm}$ in length. The few Larson bean seeds average $4.2 \times 7.2 \mathrm{~mm}$, which puts them at the lower end of the size range reported by Will and Spinden.

Sunflowers (Helianthus annuus) are the traditional cultivated food plant least frequently represented in archeological collections from the Great Plains. The small size of sunflower seeds and achenes, even of the domesticated sunflowers, as well as their fragility explains their absence in the salvage-era excavations. At Larson, carbonized sunflower seeds and achenes are numerous in Ditch 3, are present in modest numbers in Feature 107 in Block F, and occur in small numbers in Ditch 4. Measurable sunflower achenes from Larson ranged from $1.5 \times 5 \mathrm{~mm}$ to $2 \times 8 \mathrm{~mm}$. There were more sunflower seeds than achenes, and the seeds ranged between $1.5 \times 6 \mathrm{~mm}$ to $3 \times 10 \mathrm{~mm}$. The mean dimensions for the Larson achenes are $1.9 \times 6.5 \mathrm{~mm}$ and for the sunflower seeds it is 2.25 x $7.5 \mathrm{~mm}$. Heiser (1985:162) estimated that achenes shrank by 10-15 percent when carbonized, an amount that seems conservative. Although the genus is one with considerable variation, Heiser's measurements of the length of achenes collected in the American West would place most modern weedy specimens below the mean of the carbonized Larson specimens. Like the Double Ditch specimens, when allowance is made for shrinkage during carbonization, most of the Larson sunflower specimens can probably be attributed to cultivated varieties (Heiser 1954:295). 
Buffalo Bird Woman, Gilbert Wilson's Hidatsa informant, described both large flower heads (producing large seeds) and small flower heads (producing small seeds) on the sunflower plants that grew from the large seeds the Hidatsa planted in their gardens (Wilson 1917:16-19). The small ancillary flower heads on the cultivated sunflower plants were similar to those of wild sunflowers, and the small seeds of cultivated and wild plants were harvested, processed and stored together. According to Buffalo Bird Woman, the small sunflower seeds (wild and cultivated) were kept separate from the large cultivated seeds, and only large seeds were used for planting in the year following a harvest. Heiser (1965:399) observed that, when stressed, the large monocephalic sunflowers plants produced seeds as much as 50 percent smaller than normal while wild varieties produced fewer flowers and fewer seeds but without a change in seed size. Whether or not this would apply to the large headed sunflower cultivars grown by the Hidatsa and Mandan is unclear. Uncarbonized small sunflower achenes that can be attributed to modern seed rain are absent in the Larson samples.

\section{Wild Fruits}

As was the case at Double Ditch, carbonized buffaloberry (Shepherdia argentea) specimens are represented in larger numbers and in more units at Larson than the other fleshy fruits. Some of the buffaloberry seeds are still embedded in bits of dried and carbonized berries. In Ditch 4 at the Larson site, the buffaloberry specimens occur in midden deposits in the top of the ditch fill. They are not present in the ditch itself. In Ditch 3, the buffaloberries are concentrated in the ditch. They are also well represented in Feature 107 in the Block F excavation. In other units, the buffaloberry specimens are sparse and not concentrated in features. Carbonized achenes of a local wild rose (cf. Rosa arkansana) are not numerous but occur in every excavation unit except Block D. In the Ditch 3 and Block A excavation units, the rose specimens are concentrated in the ditch (Feature 105) and in pit Feature 109 respectively. No rose hips were identified. Pits from chokecherry (Prunus virginiana) and plum (Prunus americana) are present in small numbers but they do not have a particular association with features or fortification ditches. Grape seeds (Vitis sp.) occurred in Features 105 and 107 but the number of specimens is very small.

\section{Local Grasses and Weedy Plants}

Carbonized seeds of grasses (other than corn) have not been recovered in large numbers from village sites in the region and they are rarely identified to species. Grasses belong to a large family with many genera and species (Hitchcock 1950; Martin and Barkley 1961) and several of these are native to North Dakota (Stevens 1963). Species level identification is complicated by the many closely related forms of grasses as well as the absence of some floral parts in carbonized archeological specimens. Aaberg (1997:183) noted that Native American groups in the Plains had many non-subsistence uses for grasses but few if any grasses were documented as foodstuffs. All of the grass seeds at Larson appear to be from the same type and are represented by small triangular specimens. They appear to have been distorted during carbonization and may be from a species of Panicum. The Larson grass specimens are distinctly different from the grass seeds at Double Ditch and Scattered Village that compared most closely with species in the genus Bouteloua (Nickel 2002:9.25). The carbonized grass seeds at Larson are not numerous. Two occur in Ditch 3. The 
three other grass seeds occur in Block F, with two of these in Feature 107. Grass seeds do not occur frequently or in large numbers compared to other seeds of similar size.

Achenes of the local Iva xanthifolia or burweed were identified in one catalog lot within Ditch 3. In 1972 this author identified a number of burweed achenes in the collection of material from a burned lodge at the Bagnell site (Nickel 1977:56). Bagnell (32OL16) is a Middle Missouri tradition site located about $30 \mathrm{~km}$ north of the Larson Village site. Burweed (I. xanthifolia) achenes were also identified in previously analyzed collections from the 2002 and 2003 seasons at Double Ditch (Nickel 2003:223, 2004:265), Boley (Nickel 2006), Scattered (Nickel 2002), and Menoken (Nickel 2007) villages. Aaberg (1997:181-182) identified six achenes of I. xanthifolia from On-ASlant Village (32MO26). Farther south, examples of I. xanthifolia have been identified in archeological collections from the Blood Run site (13LO2) in northwestern Iowa (Asch and Green 1992: 24) and from the Patterson site (25SY31) in eastern Nebraska (Adair 1999:90). Burweed is a plant common to disturbed habitats across North Dakota (Stevens 1963: 281). During a botanical survey of the region around the Menoken site, Michael and Wendy Scullin (2007) identified Iva xanthifolia. They noted that I. xanthifolia occurred in "almost solid stands in disturbed areas." They concluded that because of the dense stands it could have been harvested as a "pseudograin." While the number of burweed achenes at Larson is small, no subsistence plant other than corn occurs in large numbers. The continued recovery of carbonized achenes of I. xanthifolia in pit features alongside other food remains provides an argument for its harvesting, at least on an opportunistic basis.

The achenes of Iva annua, which is also known as marshelder or sumpweed, are distinct from those of Iva xanthifolia. In this report marshelder refers to I. annua and burweed refers $I$. xanthifolia. Marshelder is a plant that has been well documented as a prehistoric cultigen with a form (I. annua var macrocarpa) exhibiting seeds and achenes much larger than those of modern wild populations. In the Ditch 4 excavation at Larson Village, marshelder specimens were concentrated inside the ditch. They are most numerous in Ditch 3. One or more marshelder specimens occur in each of the four block excavations. At the Larson site, marshelder seeds were more numerous than complete achenes. Marshelder seeds ranged from 2.5 x $3.5 \mathrm{~mm}$ to 3.0 x 4.9 $\mathrm{mm}$. Marshelder achenes measured $2.5 \times 3.5 \mathrm{~mm}$ to $3.0 \times 6.0 \mathrm{~mm}$. The mean dimension of the seeds is $2.7 \times 4.1 \mathrm{~mm}$ and that of the achenes is $2.6 \times 4.2 \mathrm{~mm}$. The mean dimensions as well as the dimensions of some individual Larson marshelder fall in the size range for the cultivated variety (Asch and Green 1992:22). Asch and Green (1992:23) observe that the chance of an uncarbonized wild marshelder achene exceeding $4.0 \mathrm{~mm}$ in length is "around 1\% or less." Large-seeded I. annua were recorded in the recent analyses of collections from Huff Village (32MO11), Double Ditch Village, and Boley Village (Nickel 2000:107, 2005:9, 2006:208). Stevens (1963:281) reports Iva ciliata from Walsh County along the far eastern boundary of North Dakota. Jackson (1960:794) considers I. ciliata a misnomer for I. annua. Other than Stevens' Walsh County collection, Iva annua does not appear to be common in Plains states north of Nebraska (Jackson 1960:808-812). The presence of archeological I. annua at or above the size limits of modern wild populations in multiple sites near the city of Bismarck, North Dakota, continues to argue for its systematic cultivation as a food source.

Chenopod (Chenopodium sp.) seeds are all but absent in the present Larson collection. In 1843, Audubon (1960[2]:10) observed large stands of plants that he identified as Chenopodium album growing near Mandan villages in North Dakota. Uncarbonized chenopod seeds are common in floatation and waterscreened archeological collections from the region. In some collections these 
are likely modern and often number in the thousands. At Double Ditch both carbonized and uncarbonized chenopods were present (Nickel 2005). In the current Larson collection chenopod seeds occur in three units. Three uncarbonized seeds occurred in the 30 to $40 \mathrm{~cm}$ deep level of Block F. A carbonized chenopod seed occurred in each of two units. One carbonized chenopod seed was identified in Feature 107 in Block $\mathrm{F}$ and another was recorded in the midden fill above Ditch 4. The carbonized seeds of Chenopodium from Larson are small (ca. $1 \mathrm{~mm}$ ) and appear to be from the indigenous Chenopodium berlandieri. Both carbonized seeds "popped” in response to heat when they were carbonized and are in poor condition.

Other weedy seeds in the Larson collection include those of a sedge (Carex sp.), a nightshade (Solanum sp. or Physalis sp.), a smartweed (cf. Polygonum pennsylvanicum), a knotweed (cf. Polygonum erectum), and a mustard (Brassica juncea). Except for the mustard, none of these are numerous. Most of the Larson specimens are not carbonized. The nightshade specimens are concentrated in Ditch 3 and may indicate the consumption of the fruit, which in some species is quite palatable and in others is toxic. Stevens (1963:248) identified Solanum triflorum as associated with Mandan gardens but reported the fruit had a "bite" that made it unpalatable. The mustard seeds, of which a minority are carbonized, are most numerous in the upper midden deposits in each of the excavation units (e.g. CNs 1001, 1002, 1007, 1008, 1016). Many of the uncarbonized mustard specimens appear quite fresh and are probably intrusive. It is certainly possible that even the carbonized specimens are the result of recent agriculture-related activities and are also intrusive.

\section{Discussion and Conclusions}

Data derived from the botanical analysis can be used to address some but not all of the research questions posed in Chapter 1 . The small number of specimens limits the potential for comparing and contrasting the various analytical units. No difference in the varieties of corn can be recognized between the early and late units but there is no reason to expect much change in the varieties during this time span. The corn from the early locations (Ditch 4 and Block $\mathrm{G}$ ) is less voluminous than that from the more recent units (Ditch 3 and Blocks D and F). Beans and squash

are restricted to later contexts with the exception of a single squash seed fragment in Block $G$ which lies between Ditch 3 and Ditch 4. Although Block G probably contained material that predated the construction of Ditch 3, the squash specimen occurred high in the pit and may have been derived from later (post-Ditch 3) midden material. Sunflower and marshelder specimens are clearly concentrated in the more recent F105 in Ditch 3 although both sunflower and marshelder occur in small numbers in the earlier F106 from Ditch 4. Both of these plants have a long history of cultivation in North America and their weak representation in the older Larson deposits should not be taken as an indication that they were not available to the earliest occupants of Larson Village. The mustard specimens occur primarily in the shallow uncontained midden deposits across the site and are probably intrusive modern weed seeds. Uncarbonized nightshade seeds are concentrated in a single late feature (F105) in Ditch 3. Uncarbonized knotweed seeds are concentrated in another late feature (F107) in Block F. Both small mammals and insects can be expected to introduce some naturally-occurring seeds into deeper deposits.

Botanical remains do vary significantly among depositional contexts. Table 11.2 provides data on the density of maize remains (both cob and kernel fragments) in various deposit types. As with other artifact classes, maize remains are proportionally far more common in contained 
deposits, especially large cache pits. This is a rather clear indication that domestic debris was deposited directly in such contexts, probably over a relatively short period of time. The lower densities characteristic of uncontained midden deposits suggest that they were filled mainly by secondary deposits.

Table 11.2. Counts and densities of maize cob and kernel fragments from the 2006 Larson collection, organized by deposit type.

\begin{tabular}{lccr|rr}
\hline Deposit Type & $\begin{array}{c}\text { Cob Fragments } \\
(n)\end{array}$ & $\begin{array}{c}\text { Kernel Fragments } \\
(n)\end{array}$ & $\begin{array}{c}\text { Total } \\
(n)\end{array}$ & $\begin{array}{c}\text { Excavated } \\
\text { Volume (cu. m) }\end{array}$ & $\begin{array}{r}\text { Density } \\
(\text { frag./cu. m) }\end{array}$ \\
\hline Large Pit & 221 & 296 & 517 & 1.406 & 368 \\
Small Pit & 12 & 17 & 29 & 0.129 & 225 \\
Midden & 515 & 731 & 1246 & 6.808 & 183 \\
Midden and Earth & 195 & 129 & 324 & 3.628 & 89 \\
Plowzone & 131 & 43 & 174 & 1.995 & 87 \\
Mixed & 3 & 6 & 9 & 0.34 & 26 \\
\hline Total & 1077 & 1222 & 2299 & 14.306 & 161 \\
\hline
\end{tabular}

Although comparisons with other regional collections have been offered in the preceding discussion of individual plants, some bear repeating here. At Double Ditch, carbonized chenopod seeds were numerous and nearly as ubiquitous as corn cob fragments, although some variation was noted between 2002 and 2003 samples (Nickel 2004). By contrast, both carbonized and uncarbonized chenopods are very scarce in the Larson collection. On the other hand, potentially intrusive mustard seeds are relatively common at the Larson site. At Double Ditch uncarbonized seeds of sedge, nightshade, sunflowers, and chenopods were common, usually outnumbering carbonized specimens of these plants. Variations in the frequencies of various uncarbonized grass and weedy plant seeds at different sites may be indicative of differences in modern land use and surface stability.

Marshelder (Iva annua), including the large-seeded form, have become a regular, albeit minor, component in the archeological collections from the Mandan vicinity including Huff Village, Double Ditch Village, and Boley Village. Although it is clear that marshelder was once a cultivated plant used for human consumption, we do not yet know how recently the large-seeded variety of marshelder was dropped from the suite of cultivated plants or how early it was adopted by villagers in the Dakotas. The presence of large-seeded marshelder specimens in relatively recent provenience units at Larson and in similarly dated Time Period 3 and Time Period 4 deposits at Double Ditch is significant in this regard. Small sample size probably accounts for some of the idiosyncrasies of the 2006 Larson collection. However, taken together with collections from culturally related sites in the locality, the Larson assemblage helps to define a persistent pattern of marshelder (Iva annua) use by Mandan villagers from the prehistoric period through the early contact period. The occupants of Larson Village, like those at Huff, Double Ditch, and Boley, relied upon three exotic cultigens (corn, beans, and squash) and at least two North American domesticates (sunflower and marshelder) for food. In addition to these cultivated plants, their horticultural pattern appears to have included regular use of weedy plants such as sunflowers, chenopods and burweed. Virtually all the locally available edible wild fruits have been found in local archeological collections, and most are present in the 2006 collection from Larson Village. 


\section{References Cited}

Aaberg, Stephen A.

1997 Paleoethnobotanical Analysis. In Archaeology of the Mandan Indians At On-A-Slant Village (32MO26), Fort Abraham Lincoln State Park, Morton County, North Dakota, edited by Stanley A. Ahler, pp.163-195. Office of Research and Graduate Studies, Northern Arizona University, Flagstaff. Submitted to the State Historical Society of North Dakota, Bismarck.

Adair, Mary J.

1999 Botanical Remains. In Archeology of the Patterson Site, Native American Life in the Lower Platte Valley, A.D. 1000-1300, edited by J. R. Bozell and J. Ludwickson, pp.85100. Nebraska State Historical Society, Lincoln.

Ahler, Stanley A. (editor)

2003 Archaeology at Menoken Village. A Fortified Late Plains Woodland Community in North Central North Dakota. PaleoCultural Research Group, Flagstaff, Arizona. Submitted to the State Historical Society of North Dakota, Bismarck.

2004 Archaeological Investigations During 2003 at Double Ditch State Historic Site, North Dakota. Research Contribution No. 60. PaleoCultural Research Group, Flagstaff, Arizona. Submitted to the State Historical Society of North Dakota, Bismarck.

Ahler, Stanley A., and Kenneth L. Kvamme

2000 New Geophysical and Archaeological Investigations at Huff Village State Historic Site (32MO11), Morton County, North Dakota. Research Contribution No. 26. PaleoCultural Research Group, Flagstaff, Arizona. Submitted to the State Historical Society of North Dakota, Bismarck.

Asch, D., and W. Green

1992 Crops of Ancient Iowa: Native Plant Use and Farming Systems. Prepared for the Leopold Center for Sustainable Agriculture. Office of the State Archaeologist, University of Iowa, Iowa City.

Audubon, John J.

1960 Audubon and His Journals, 2 vols. Edited by Maria R. Audubon and Elliot Coues. Dover Publications, Inc., New York. Originally published by C. Scribner’s Sons, New York in 1897.

Cutler, Hugh C., and L. W. Blake

1973 Plants from Archeological Sites East of the Rockies. Ms. on file with the Missouri Botanical Garden. St. Louis.

Cutler, Hugh C., and T. W. Whitaker

1961 History and Distribution of the Cultivated Cucurbits in the Americas. American Antiquity 26(4):469-485.

Gilmore, Melvin R.

1919 Uses of Plants by the Indians of the Missouri River Region. Bureau of American Ethnology $33^{\text {rd }}$ Annual Report. Smithsonian Institution, Washington, D.C.

Fernald, M. L.

1950 Grays Manual of Botany: A Handbook of the Flowering Plants and Ferns of the Central and Northeastern United States and Adjacent Canada. Eighth ed. American Book Company, New York. 
Hitchcock, A. S.

1950 Manual of the Grasses of the United States. Dover Publications Inc. 1971 edition of the U.S. Department of Agriculture Miscellaneous Publication No. 200. Dover Publications Inc., New York.

Heiser, C. B., Jr.

1954 Variation and Subspeciation in the Common Sunflower, Helianthus annus. The American Midland Naturalist 51(1):287-305.

1965 Sunflowers, Weeds, and Cultivated Plants. In The Genetics of Colonizing Species, edited by H.G. Baker and G.L. Stebbins, pp. 391-401. Academic Press, New York.

1985 Some Botanical Considerations of the Early Domesticated Plants North of Mexico. In Prehistoric Food Production in North America, edited by Richard I. Ford.

Anthropological Papers No. 75 University of Michigan Museum of Anthropology, Ann Arbor.

Jackson, R. C.

1960 A Revision of the Genus Iva L. University of Kansas Science Bulletin 41(7):793-855.

Martin, A. C. and W. D. Barkley

1961 Seed Identification Manual. University of California Press, Berkeley.

Mitchell, Mark D., Stacey Madden, Fern E. Swenson, and Stanley A. Ahler

2006 The Archaeology of Larson Village, North Dakota: Results of the 2006 Field Investigations in Regional Context. Paper presented at the $64^{\text {th }}$ Plains Anthropological Conference, 2006, Topeka, Kansas.

Nickel, Robert K.

1977 The Study of Archeologically Derived Plant Materials from the Middle Missouri Subarea. In Trends in Middle Missouri Prehistory: A Festschrift Honoring the Contributions of Donald J. Lehmer, edited by W. Raymond Wood. Plains Anthropologist, Memoir 13 22(78, Pt. 2):53-58.

1988 Botanical Remains from the Lower Grand (1969 Season) and Walth Bay (1970 Season) Sites. In Archeological Investigations in the Mobridge Area, South Dakota, 1969-1970: Lower Grand (Davis), 39CO14; Walth Bay, 39WW203; and Helb, 39CA208, edited by Carl R. Falk and Stanley A. Ahler, Appendix C. National Park Service, Rocky Mountain Region, Denver, Colorado.

2000 Subsistence Plant Remains. In New Geophysical and Archeological Investigations at Huff Village State Historic Site (32MO11), Morton County, North Dakota, edited by Stanely A. Ahler and Kenneth L. Kvamme, pp. 104-108. PaleoCultural Research Group, Flagstaff, Arizona. Submitted to the State Historical Society of North Dakota, Bismarck.

2002 Plants Used by the Occupants of Scattered Village. In Prehistory on First Street NE, The Archaeology of Scattered Village in Mandan, North Dakota, edited by Stanely A. Ahler, pp. 9.1-9.26. PaleoCultural Research Group, Flagstaff, Arizona. Submitted to North Dakota Department of Transportation, Bismarck.

2003 Analysis of Botanical Remains from Selected Contexts. In Archaeological Investigations During 2001 and 2002 at Double Ditch Historic Site, North Dakota, edited by Stanley A. Ahler, pp. 217-228. PaleoCultural Research Group, Flagstaff, Arizona. Submitted to the State Historical Society of North Dakota, Bismarck.

2004 Analysis of Botanical Remains. In Archaeological Investigations during 2003 at Double Ditch Historic Site, North Dakota, edited by Stanley A. Ahler, pp. 259-268. PaleoCultural Research Group, Flagstaff, Arizona. Submitted to the State Historical Society of North Dakota, Bismarck. 
2005 Botanical Remains from the Double Ditch Village Site, 2004 and 2003 Excavations. Report prepared for PaleoCultural Research Group, Flagstaff, Arizona.

2006 Botanical Remains. In Geophysical Survey and Test Excavations During 2005 at Boley Village (32MO37), North Dakota, edited by Stanley A. Ahler, pp. 199-211. PaleoCultural Research Group, Flagstaff, Arizona. Submitted to the State Historical Society of North Dakota, Bismarck.

2007 Botanical Remains. In Archaeological Investigations During 2005 at Menoken Village State Historic Site, North Dakota, edited by Stanley A. Ahler, Carl R. Falk, and Fern E. Swenson. PaleoCultural Research Group, Flagstaff, Arizona. Submitted to the State Historical Society of North Dakota, Bismarck.

Scullin, Michael, and Wendy M. Scullin

2007 A Survey of Plants of Cultural Significance in the Vicinity of Menoken Village State Historic Site. In Archaeological Investigations During 2005 at Menoken Village State Historic Site, North Dakota, edited by Stanley A. Ahler, Carl R. Falk, and Fern E. Swenson. PaleoCultural Research Group, Flagstaff, Arizona. Submitted to the State Historical Society of North Dakota, Bismarck.

Slife, F. W., K. P. Buchholtz, and T. Kommedahl

1960 Weeds of the North Central States. Revised Edition. Agricultural Experiment Station Circular 178. University of Illinois, Urbana.

Stevens, O. A.

1963 Handbook of North Dakota Plants. North Dakota Institute for Regional Studies, Fargo. Walster, H. L.

1956 George Francis Will 1884-1955, Archaeologist, Anthropologist, Ethnologist, Naturalist, Nurseryman, Seedman, Historian: A Biography. North Dakota History 23(1):4-25.

Will, George F. and George E. Hyde

1964 [1917] Corn Among the Indians of the Upper Missouri. University of Nebraska Press, Lincoln.

Will, George F. and Herbert J. Spinden

1906 The Mandans: A Study of their Culture, Archaeology, and Language. Papers of the Peabody Museum of American Archaeology and Ethnology Vol. 3(4):81-219.

Wilson, Gilbert L.

1916 Native Hidatsa Botany. Unpublished field notes from 1916. American Museum of Natural History, New York.

1917 Agriculture of the Hidatsa Indians, An Indian Interpretation. Studies in the Social Sciences Number 9. University of Minnesota, Minneapolis. 


\title{
12. Other Artifact AND Material Classes
}

\author{
Mark D. Mitchell, Paul R. Picha, and Stacey Madden
}

\section{Introduction}

This chapter presents descriptive information and limited analyses on several types of artifacts and other remains that are rare or that were not analyzed in detail. The former include metal artifacts and glass beads, modified and unmodified shell remains, and pottery manufacturing debris. The latter include ochre, ash, fire-cracked rock, unmodified clinker, and other kinds of widely-occurring materials. Stacey Madden conducted the analysis and data coding for the miscellaneous Plains Village artifact category. Several lab assistants working in PCRG's Flagstaff lab collected general quantification data on other common material classes. Paul Picha analyzed the modified shell artifacts and wrote the portion of the chapter describing his results. Madden quantified the unmodified shell remains. Mitchell analyzed the trade metal artifacts, generated the data tables, and wrote the balance of the chapter.

\section{Metal Artifacts}

The 2006 Larson collection includes a just 6 cuprous artifacts and one ferrous artifact, all of which were analyzed and coded in detail. The methods used to analyze them duplicate those applied to studies of similar artifacts recovered from Double Ditch and Boley villages (Ahler 2005; Ahler et al. 2006). The variables recorded in the analysis are discussed in this paragraph and are listed in Table 12.1. Metal artifacts were classified either as "patterned” or "unpatterned” (UNPAT). Patterned objects possess a regular form and usually can be assigned to a functional class. Unpatterned cuprous objects include irregularly-shaped pieces of scrap or foil, while unpatterned ferrous objects include amorphous lumps or chunks. Each artifact was then assigned to a general type (GENTYPE) that combines material type and patternedness. Patterned artifacts were further classified according to specific functional class (FUNC). Weights of all artifacts from a single catalog number were combined. Length and width were measured only for individual patterned objects. Thickness was recorded for all artifacts; mean thickness was calculated when more than one artifact occurred in a single lot.

Because densities of artifacts obtained through direct or indirect trade with European merchants form the primary bases for the post-1600 chronology in the Heart region, data have been collected on the certainty that an artifact can be traced to a European source and that it dates to the seventeenth or eighteenth centuries. For this analysis, as for prior analyses, all cuprous artifacts have been classified as “certain” trade items. However, data from Double Ditch Village and elsewhere hint at the possibility that some of these artifacts may derive from native rather than European sources. Resolution of this issue, through compositional analyses or other methods, is critical for determining the age of Larson Village and other Heart region settlements, but is beyond the scope of the work described in this report. Ferrous objects were coded as "certain" or "probable" trade items if they were encased in a crust of sediment and charcoal or organic matter fused together 
by oxidation. If they were relatively clean and were not encased in a layer of adhering material, ferrous objects were coded as "uncertain" trade artifacts. These items were classified as recent historic artifacts and not analyzed further.

Table 12.1. Variables recorded in the analysis of trade metal artifacts in the 2006 Larson collection.

\begin{tabular}{|c|c|c|c|c|}
\hline \multirow{2}{*}{$\begin{array}{l}\text { CATNO } \\
\text { UNPAT }\end{array}$} & & \multicolumn{3}{|l|}{ catalog number } \\
\hline & & \multicolumn{2}{|l|}{ patterned or unpatterned } & 1=unpatterned; 2=patterned \\
\hline CERT & & \multicolumn{2}{|l|}{ certainty the artifact is trade } & 1=certain; 2=uncertain \\
\hline SIZE & & \multicolumn{2}{|l|}{ size grade } & $\mathrm{G} 1-\mathrm{G} 4$ \\
\hline GENTYPE & & \multicolumn{3}{|l|}{ material and patternedness } \\
\hline & 1 & unpatterned copper/brass & 3 & unpatterned iron \\
\hline & 2 & patterned copper/brass & 4 & patterned iron \\
\hline \multirow[t]{8}{*}{ FUNC } & & \multicolumn{3}{|l|}{ specific functional class } \\
\hline & 1 & rolled tube & 8 & rolled hook \\
\hline & 2 & probable awl & 9 & pin or shaft with head \\
\hline & 3 & knife blade & 10 & coil spring \\
\hline & 4 & rolled cone & 11 & pressure flaker \\
\hline & 5 & rolled bead & 12 & headed pin \\
\hline & 6 & rolled ring & 13 & shaped, unknown function \\
\hline & 7 & arrowpoint & 14 & lead inlay \\
\hline \multirow[t]{3}{*}{ GENFUNC } & & \multicolumn{3}{|l|}{ general functional group } \\
\hline & 1 & weapons/hunting gear & 3 & Native-made ornaments \\
\hline & 2 & domestic items & 4 & miscellaneous \\
\hline \multicolumn{5}{|l|}{ COUNT } \\
\hline \multicolumn{2}{|l|}{ WEIGHT } & \multicolumn{3}{|l|}{ to 0.1 gram } \\
\hline \multicolumn{2}{|l|}{ ILLUS } & \multicolumn{3}{|l|}{1 - suitable for illustration } \\
\hline \multicolumn{2}{|l|}{ LENGTH } & \multicolumn{3}{|c|}{ to $0.1 \mathrm{~mm}$ for patterned artifacts only } \\
\hline \multicolumn{2}{|l|}{ WIDTH } & \multicolumn{3}{|c|}{ to $0.1 \mathrm{~mm}$ for patterned artifacts only } \\
\hline \multicolumn{2}{|l|}{ THICKNESS } & \multicolumn{3}{|c|}{ to $0.1 \mathrm{~mm}$ for patterned artifacts only } \\
\hline \multicolumn{2}{|l|}{ COMM } & \multicolumn{3}{|l|}{ comments as necessary } \\
\hline
\end{tabular}

Data on the type, number, and weight of metal artifacts in the 2006 Larson collection are presented in Table 12.2. The single ferrous object was coded as a "probable," rather than a "certain" trade item. All of the pieces were recovered from size G4 fractions. Six of the 7 artifacts (86 percent by count; 94 percent by weight) are made from copper or brass. Two of the 6 cuprous items are patterned. One is a rolled tube $14.5 \mathrm{~mm}$ long and $3.7 \mathrm{~mm}$ in diameter. The other is a rolled bead $3.7 \mathrm{~mm}$ long and $3.8 \mathrm{~mm}$ in diameter. The stock from which these objects were made varies from $0.37 \mathrm{~mm}$ thick in the case of the tube to $0.40 \mathrm{~mm}$ thick in the case of the bead. The remaining cuprous artifacts consist of irregular sheets varying in thickness from 0.18 to $0.25 \mathrm{~mm}$ thick.

Table 12.2. Summary distribution of trade metal artifacts in the 2006 Larson collection, organized by excavation block and general type.

\begin{tabular}{|c|c|c|c|c|c|}
\hline \multirow[b]{2}{*}{ Area } & \multicolumn{4}{|c|}{ General Type } & \multirow[b]{2}{*}{ Total } \\
\hline & 1 unpat cupric & 2 pat cupric & 3 unpat iron & 4 pat iron & \\
\hline Block G & $1(0.03 \mathrm{~g})$ & $1(0.30 \mathrm{~g})$ & $1(0.03 \mathrm{~g})$ & & $3(0.36 \mathrm{~g})$ \\
\hline Block F & 1 (0.03 g) & 1 (0.03 g) & & & 2 (0.06 g) \\
\hline Ditch 3 & $2(0.10 \mathrm{~g})$ & & & & $2(0.10 \mathrm{~g})$ \\
\hline Total & $4(0.16 \mathrm{~g})$ & $2(0.33 \mathrm{~g})$ & $1(0.03 \mathrm{~g})$ & & 7 (0.52 g) \\
\hline
\end{tabular}


Cuprous artifacts occur in one context assigned to Stratigraphic Group 1 and two contexts assigned to Stratigraphic Group 2. In Block G (Group 1), a piece of scrap was recovered from GL8 and a rolled tube was recovered from GL4. In Feature 107 in Block F (Group 2), a bead was recovered from FL7 and a piece of scrap was recovered from FL11. Two pieces of scrap were recovered from FL8 in Ditch 3 (Group 2). The single ferrous artifact occurs in the plowzone (GL1) in Block G; plowzone contexts were not assigned to a stratigraphic group. Very low densities of trade metal, along with a high proportion of copper artifacts are the hallmarks of Time Period 3 at Double Ditch (1600-1650). If the cuprous artifacts from Larson are European trade items, a conclusion that is in doubt, and if the available radiocarbon dates accurately reflect the period of occupation, then it must be the case that all of the pits and ditches investigated in 2006 were abandoned and filled during a very short period in the early 1600s. Alternatively, these objects may have been made from native copper, in which case abandonment of the outermost ditches and lodges likely was earlier and perhaps more protracted.

\section{Glass Bead}

The 2006 Larson collection includes a single glass trade bead. The bead was recovered from plowzone deposits (GL1) in Block F. The bead is blue, opaque, and disk- or donut-shaped and falls into the small size class ( $2 \mathrm{~mm}$ to $4 \mathrm{~mm}$ ). Like the vast majority of glass beads recovered from villages in the Heart and Knife region it was drawn and exhibits a simple structure. Overall, it is similar to Variety 25 beads from Fort Clark trading post (Billeck and Badorek 2003).

The age of this artifact cannot be determined from its intrinsic attributes alone. Blue, drawn beads in the small size class are among the most common in all time periods in the northern Middle Missouri. They first became available in the seventeenth century, and continued to dominate most collections in the nineteenth century (Ahler and Drybred 1993). Chronological interpretations of glass trade beads are based on the central tendencies of large samples, rather than on the characteristics of individual specimens.

\section{Shell Remains}

The methods used to study shell artifacts in the 2006 Larson collection were similar to those used to analyze the 2005 Boley Village sample (Ahler et al. 2006), as well as samples from Double Ditch Village (Ahler et al. 2005). Each sample of shell was sorted hierarchically over four variables, with count and weight data recorded for each of the resulting sort groups. The samples were first sorted by size grade, then by the presence or absence of intentional modification, then by class, and finally by the presence or absence of burning. Five groups were recognized, including unidentified bivalves (Class 1), identifiable bivalves (Class 2), modern gastropods (Class 3), fossil gastropods (Class 4), and dentalium or tusk shells (Class 5). Any of the classes could include modified or unmodified specimens, except dentalium shells which by definition are always considered modified. Data on the complete inventory of shell remains in the 2006 Larson collection are presented in Tables 12.3 and 12.4. 
Table 12.3. Summary of modification and classification data on shell remains in the 2006 Larson collection, organized by size grade.

\begin{tabular}{|c|c|c|c|c|}
\hline \multirow[b]{2}{*}{ Shell Class } & \multicolumn{3}{|c|}{ Size Grade } & \multirow[b]{2}{*}{ Total } \\
\hline & $\mathrm{G} 2$ & G3 & G4 & \\
\hline \multicolumn{5}{|l|}{ Unmodified } \\
\hline 1 Unidentifiable bivalve & 2 & 100 & 66 & 168 \\
\hline 2 Identifiable bivalve & 2 & 12 & 4 & 18 \\
\hline 3 Modern gastropod & & 2 & 18 & 20 \\
\hline 4 Fossil gastropod & 3 & 26 & 138 & 167 \\
\hline Total & 7 & 140 & 226 & 373 \\
\hline \multicolumn{5}{|l|}{ Modified } \\
\hline 1 Unidentifiable bivalve & 2 & 2 & 1 & 5 \\
\hline 4 Fossil gastropod & & 4 & 1 & 5 \\
\hline 5 Dentalium & & & 3 & 3 \\
\hline Total & 2 & 6 & 5 & 13 \\
\hline
\end{tabular}

Most of the remains consist of unmodified freshwater clams of various sizes, although they occur at densities lower than at some other Heart region sites. At Double Ditch, unmodified bivalves (identifiable and unidentified) are nearly twice as common (Ahler et al. 2005) and at Boley they are over three times as common (Ahler et al. 2006). The density of modified shell artifacts at Larson is comparable to that at Boley.

Table 12.4. Distribution of modified and unmodified shell remains in the 2006 Larson collection, organized by excavation area.

\begin{tabular}{|c|c|c|c|c|c|c|c|c|}
\hline \multirow[b]{2}{*}{ Shell Class } & \multicolumn{7}{|c|}{ Excavation Area } & \multirow[b]{2}{*}{ Total } \\
\hline & Blk A & Mixed & Blk D & Blk F & Blk G & Ditch 3 & Ditch 4 & \\
\hline \multicolumn{9}{|l|}{ Unmodified } \\
\hline 1 Unidentifiable bivalve & 19 & 4 & 16 & 25 & 9 & 87 & 8 & 168 \\
\hline 2 Identifiable bivalve & 3 & & 5 & 4 & 1 & 5 & & 18 \\
\hline 3 Modern gastropod & & & 1 & 8 & & 10 & 1 & 20 \\
\hline 4 Fossil gastropod & 19 & 3 & 19 & 35 & 26 & 56 & 9 & 167 \\
\hline Total & 41 & 7 & 41 & 72 & 36 & 158 & 18 & 373 \\
\hline \multicolumn{9}{|l|}{ Modified } \\
\hline 1 Unidentifiable bivalve & 1 & & & 2 & 2 & & & 5 \\
\hline 4 Fossil gastropod & & & 1 & 1 & 1 & 2 & & 5 \\
\hline 5 Dentalium & & & 1 & & & 2 & & 3 \\
\hline Total & 1 & & 2 & 3 & 3 & 4 & & 13 \\
\hline
\end{tabular}

\section{Marine Shell}

Marginella (Prunus sp.) shells have been reported from Mandan and putative Hidatsa villages at Heart River confluence. The specimen from Larson (CN 1023) was recovered from near-surface fill in Feature 105, Ditch 3 midden. The small size G4 valve $(\mathrm{L}=9.01 \mathrm{~mm}$, dia. $=5.56$ $\mathrm{mm}$, wt. $=0.15 \mathrm{~g}$ ) exhibits shell wall attrition and breakage possibly masking modification by grinding for suspension. Residual grinding is apparent on the apex and shell wall. This decorative item was likely discarded with other debris but is thought to have been functional (Use Phase 3). Marginella sp. shell occurs in post-contact contexts at Scattered Village (Ahler 2002:Figure 14.20- 
p) and at Double Ditch Village. It is not currently known if a particular Mandan village served as a primary aggregation node for these marine shells with subsequent redistribution, or if marine shells were arriving in similar frequencies at contemporaneous villages at the confluence area through existing exchange systems.

A worked size G3 columella blank (CN 1030), derived from a large marine gastropod such as a whelk, Busycon sp., was recovered from Block $\mathrm{G}$ midden deposits. The central pillar $(\mathrm{L}=8.68$ $\mathrm{mm}$, dia. $=8.83 \mathrm{~mm}$, wt. $=0.84 \mathrm{~g}$ ) exhibits grinding and groove-and-snap cut marks with accompanying bulbs on both ends. The unfinished blank (Use Phase 2) was likely intended to be a barrel-like bead or similar ornament. Other specimens occur in Plains Village samples but often as finished forms. Marine-shell manufacturing debris, including columellae, are typically rare in village samples suggesting that ornamental items often were arriving in nearly finished form. Columellae items, such as pillar columns with suspension perforations and barrel- and tube beads, occur in early village contexts (Picha 2003; Steinacher 1988). The recovery context for this specimen may reflect an early episode in the Larson occupation sequence.

Tusk, or Dentalium sp., shell occurs in the Larson sample as small (size G4), often fragmented segments. Estimated bore diameters of the examined specimens (e.g., CN 1017, dia. = $0.20 \mathrm{~mm}$ ) are consistent with shells derived from a marine, rather than fossil, origin. Similar occurrences have been reported at On-A-Slant, Double Ditch, and Boley villages. An ornamental function, such as hair decoration or strung for suspension beads, is presumed for these shells. Village occupation sequences exhibiting moderate amounts of tusk shell correspond with temporal placement in the late 1500s and continue to the nineteenth century as documented in fur-trade inventories and other historical documents.

\section{Freshwater Bivalve Shell}

Unmodified freshwater bivalve shell is a major constituent of the 2006 aggregate. Much of the shell is fragmented with few specimens retaining the beak or umbone necessary for taxonomic identification. Both thick- and thin-shelled species are represented. Lampsilis sp. shell occurs in CN 1018. Other examples (CN 1017, CN 1036) of eroded beaks with accompanying hinge teeth are present. Taxonomic candidates for the Larson aggregate include the species suite (Lasmigona complanata, Lampsilis siliquoidea, Lampsilis cardium, and Anodonta grandis) reported from other village samples studied to date. East bank villages, such as Double Ditch, typically contain less mussel shell than do their west bank counterparts. The 2006 Larson sample is consistent in that regard to Double Ditch. The lack of larger east-bank tributary streams near these villages comparable to the Heart River likely accounts for this difference in mussel shell frequency and occurrence in site deposits. Modified bivalve specimens are possibly represented by preforms or blank-like pieces derived from thickened valve margins. Examples of thick-shell valve debris occur in CN 1041 from Block F. These modified pieces may have been intended to serve both utilitarian and decorative functions.

\section{Univalve Shell}

Univalve or sub-fossil snails are represented by two size G4 specimens (CN 1026 and CN 
1018). Both snails have a conspiral form. Taxonomic identification is tentative for both but each shares traits with aquatic forms of Stagnicola sp. (Cvancara 1983:Plate 4). Stagnicola sp. snails occur in a variety of aquatic habitats, with "decaying, terrestrial plant matter to be a preferred substrate” (Cvancara 1983:68).

\section{Fossil Shell}

Fossil Viviparid (size G2 to G4) gastropods or snails of Campeloma, Lioplacodes, and Viviparus sp. occur in the 2006 Larson shell aggregate. These snails occur in varying frequencies in other village shell aggregates examined to date from the Heart River confluence. Whorl scrap is typically represented by size G4 debris in the Larson sample. Fossil shell occurs as both burned and unburned specimens in the aggregate suggesting different origins and cultural-formation processes may account for them.

Aperture breakage occurs on a number of the larger specimens (size G2 and G3) that precludes positive identification of modification either by scoring or punching for suspension. Examples of fossil snails modified in this manner are illustrated in Ahler (2002:Figure 14.2) from Scattered Village. Local outcrops of Late Cretaceous strata likely are the source of the fossil gastropods found at Larson. Village catchments between Double Ditch and Larson villages on the east bank of the Missouri presumably included these outcrop sources. Fossil shell was being collected by the Larson villagers in some frequency and was likely intended for ornamental purposes.

\section{Miscellaneous Plains Village Artifacts}

This group includes nearly any notable or unusual item that does not fit into one of the major sort classes. Objects in this category were examined closely and were assigned to a specific group. Recent studies of artifacts from Double Ditch, Scattered, and Boley villages added greatly to the number of categories of artifacts recognized under the general group. At Double Ditch, intentionally formed fired clay objects are particularly abundant, and among there are enigmatic "appliqué” pieces of uncertain function. Also very abundant at Double Ditch are materials related to pottery production, including unfired clay, fired clay pieces, and fragments of broken, but unfired, pots. Analysis of the specimens from Larson consisted of categorizing and quantifying them according to the previously-generated list of artifact classes developed for other recent projects. New groups were added to this list as necessary.

Table 12.5 gives an inventory of the miscellaneous Plains Village artifacts in the 2006 Larson collection. One-hundred-six items were identified. By contrast, a total of 132 items was documented at Boley, although only about $7.1 \mathrm{cu}$. m were excavated. At Double Ditch, miscellaneous Plains Village artifacts are nearly four times as common in the 2002 and 2003 collection as they are in the 2006 Larson collection. At Larson, the most abundant category is fired clay pieces exhibiting dowel or stick impressions. Fired clay pieces dominate the Double Ditch collection as well. Among the three sites, evidence for pottery production is most abundant at Larson. 
Table 12.5. Classification of miscellaneous Plains Village artifacts in the 2006 Larson collection, organized by size grade.

\begin{tabular}{|c|c|c|c|c|}
\hline \multirow[b]{2}{*}{ Class } & \multicolumn{3}{|c|}{ Size Grade } & \multirow[b]{2}{*}{ Total } \\
\hline & G2 & G3 & G4 & \\
\hline \multicolumn{5}{|l|}{ Fired Clay Classes } \\
\hline --appliqué edge or fragment w/ indeterminate shape & 1 & 5 & & 6 \\
\hline --w/ dowel or stick impression & 4 & 15 & & 19 \\
\hline --irregular form, misc. pieces & 5 & 5 & & 10 \\
\hline --with grass impressions & & 9 & & 9 \\
\hline --sphere, sometimes with stick hole (w/ or w/out temper) & 2 & 6 & & 8 \\
\hline --appliqué with pottery rim impression & & 3 & & 3 \\
\hline --appliqué with pottery body impression & 2 & & & 2 \\
\hline --fired clay filling cupules on corn cob & & & 5 & 5 \\
\hline --snake, worm, coil w/out temper & & 5 & 1 & 6 \\
\hline --snake, worm, coil w/ temper & & 3 & & 3 \\
\hline \multicolumn{5}{|l|}{ Related to Pottery Production } \\
\hline --unfired potting clay w/out temper & 1 & 3 & & 4 \\
\hline --unfired potting clay with temper & 2 & 6 & & 8 \\
\hline --partially prepared potting clay (angular) w/out temper & 1 & & & 1 \\
\hline --fired clay with temper (amorphous) & 2 & 10 & & 12 \\
\hline --unfired sherds & & 1 & & 1 \\
\hline Coprolite & 1 & & & 1 \\
\hline Leather & & 2 & & 2 \\
\hline Melted silica material & & & 1 & 1 \\
\hline Burned earth with incisions & & 1 & & 1 \\
\hline Unidentified organic material & 1 & & & 1 \\
\hline Red ochre sediment sample with multiple tool marks & & 2 & & 2 \\
\hline Unidentified artifact & & 1 & & 1 \\
\hline Total & 22 & 77 & 7 & 106 \\
\hline
\end{tabular}

\section{Other Widely Occurring Artifact Categories}

Table 12.6 provides count or weight data for several other categories of remains. These materials are widely distributed throughout the contexts investigated in 2006 but are not analyzed here in detail. The densities of these remains are far lower than at Boley (Ahler et al. 2006). For example, just over $124 \mathrm{~kg}$ of fire-cracked rock were recovered from a total excavated volume of about $14.3 \mathrm{cu}$. $\mathrm{m}$ at Larson, whereas $90 \mathrm{~kg}$ were recovered from $7.1 \mathrm{cu} . \mathrm{m}$ at Boley. Counts of ochre nodules and weights of burned earth, fired clay, and natural rock are comparable for both sites, even though the volume of sediment excavated at Larson was twice as great.

Table 12.6. Distribution by count and weight of various sort classes in the 2006 Larson collection, organized by size grade.

\begin{tabular}{lcccrr}
\hline & \multicolumn{3}{c}{ Size Grade } & \multicolumn{2}{r}{} \\
Class & G1 & G2 & G3 & G4 & Total \\
\hline Red Ochre (n) & & & 14 & 243 & 257 \\
Yellow Ochre (n) & & & & 25 & 25 \\
Other Pigment (n) & & & & 17 & 17 \\
Gypsum (n) & & 1 & 6 & 32 & 39 \\
\hline
\end{tabular}


Table 12.6. Distribution by count and weight of various sort classes in the 2006 Larson collection (concluded).

\begin{tabular}{|c|c|c|c|c|c|}
\hline \multirow[b]{2}{*}{ Class } & \multicolumn{4}{|c|}{ Size Grade } & \multirow[b]{2}{*}{ Total } \\
\hline & G1 & G2 & G3 & G4 & \\
\hline Fossil/Concretion (n) & 1 & 2 & 1 & & 4 \\
\hline Total & 1 & 3 & 21 & 317 & 342 \\
\hline Fire-cracked Rock (g) & 106617.0 & 119.0 & 6547.0 & & 124173.0 \\
\hline Fired Clay (g) & & 9.5 & 493.8 & & 503.3 \\
\hline Burned Earth (g) & & 26.1 & 166.7 & & 192.8 \\
\hline Ash (g) & 289.6 & 217.4 & 130.2 & & 637.2 \\
\hline Unmodified Clinker (g) & 9.1 & 19.5 & 34.6 & & 63.2 \\
\hline Charcoal (g) & 1.9 & 35.2 & 331.7 & & 368.8 \\
\hline Unsorted Light Fraction (g) & & & 16.0 & & 16.0 \\
\hline Natural Rock (g) & 905.0 & 1063.0 & 916.0 & & 2884.0 \\
\hline Total & 107822.6 & 12379.7 & 8636.0 & & 128838.3 \\
\hline
\end{tabular}

\section{Summary}

Metal and glass artifacts occur in exceedingly low densities on the northern periphery of Larson village, indicating that that part of the site had been abandoned at least by the mid-1600s. Data on the densities of miscellaneous Plains Village artifacts and other remains bolster the conclusion that the features and contexts investigated in 2006 are filled primarily with secondary deposits containing comparatively few larger or potentially reusable artifacts.

Other notable occurrences include the comparatively large number of items related to ceramic production. About 25 percent of all miscellaneous Plains Village artifacts recovered from Larson are associated with pottery production. Another notable occurrence is the presence of marine shell bead manufacturing debris, indicating that fabrication or substantial modification was taking place at Larson. 


\section{References Cited}

Ahler, Stanley A.

2002 Fossil and Modified Shell Remains. In Prehistory on First Street NE: The Archaeology of Scattered Village in Mandan, North Dakota, edited by Stanley A. Ahler, pp. 14.1-14.10. PaleoCultural Research Group, Flagstaff, Arizona submitted to the City of Mandan, North Dakota and the North Dakota Department of Transportation, Bismarck, ND.

2003a Analysis of Trade Artifacts. In Archaeological Investigations During 2001 and 2002 at Double Ditch State Historic Site, North Dakota, edited by Stanley A. Ahler, pp. 229-246. PaleoCultural Research Group, Flagstaff, Arizona. Submitted to the State Historical Society of North Dakota, Bismarck.

2003b Other Artifacts. In Archaeological Investigations During 2001 and 2002 at Double Ditch State Historic Site, North Dakota, edited by Stanley A. Ahler, pp. 247-253. PaleoCultural Research Group, Flagstaff, Arizona. Submitted to the State Historical Society of North Dakota, Bismarck.

2004 Analysis of Trade Artifacts. In Archaeological Investigations During 2003 at Double Ditch State Historic Site, North Dakota, edited by Stanley A. Ahler, pp. 247-253. PaleoCultural Research Group, Flagstaff, Arizona. Submitted to the State Historical Society of North Dakota, Bismarck.

2005 Analysis of Trade Artifacts. In Archaeological Investigations During 2004 at Double Ditch State Historic Site, North Dakota, edited by Stanley A. Ahler, pp. 295-313. Research Contribution No. 65. PaleoCultural Research Group, Flagstaff, Arizona. Submitted to the State Historical Society of North Dakota, Bismarck.

Ahler, Stanley A., and Amy Drybred

1993 Analysis of Euroamerican Trade Artifacts. In The Phase I Archaeological Research Program for the Knife River Indian Villages National Historic Site, Part III: Analysis of the Physical Remains, edited by Thomas Theissen, pp. 289-340. Occasional Studies in Anthropology No. 27. National Park Service, Midwest Archaeological Center, Lincoln, Nebraka.

Ahler, Stanley A., Stacey Madden, and Tracy Ellefson

2006 Other Artifacts and Material Classes. In Geophysical Survey and Test Excavation During 2005 at Boley Village (32MO37), North Dakota, edited by Stanley A. Ahler, pp. 213-222. Research Contribution No. 74. PaleoCultural Research Group, Flagstaff, Arizona. Submitted to the State Historical Society of North Dakota, Bismarck.

Ahler, Stanley A., Stacey Madden, and L. Gracey McMain

2005 Other Artifacts. In Archaeological Investigations During 2004 at Double Ditch State Historic Site, North Dakota, edited by Stanley A. Ahler, pp. 315-326. Research Contribution No. 65. PaleoCultural Research Group, Flagstaff, Arizona. Submitted to the State Historical Society of North Dakota, Bismarck.

Ahler, Stanley A., and Gail Ryser

1997 Other Artifacts and Materials. In Archaeology of the Mandan Indians at On-A-Slant Village (32MO26), Fort Abraham Lincoln State Park, Morton County, North Dakota, edited by Stanley A. Ahler, pp. 391-417. Office of Research and Graduate Studies, Northern Arizona University, Flagstaff, Arizona. Submitted to North Dakota Parks and Recreation Department, Bismarck.

2000 Shell Remains. In Report of Archaeological Investigations Along Highway 1806 Morton County, North Dakota, edited by Stanley A. Ahler, Carole L. Graham, and Michael D. 
Metcalf, pp. 283-297. Metcalf Archaeological Consultants, Eagle, Colorado, and PaleoCultural Research Group, Flagstaff, Arizona. Submitted to North Dakota Department of Transportation, Bismarck.

Billeck, William T., and Chad Badorek

2003 Glass Trade Beads from Fort Clark Trading Post and Primeau’s Post. In Archaeological Investigations at Fort Clark State Historic Site North Dakota: 1973-2003 Studies at the Fort Clark and Primeau Trading Posts, edited by William J. Hunt, Jr., pp. 349-393. National Park Service, Midwest Archaeological Center, Lincoln, Nebraska, and PaleoCultural Research Group, Flagstaff, Arizona. Submitted to the State Historical Society of North Dakota, Bismarck.

Cvancara, A. M.

1983 Aquatic Mollusks of North Dakota. Report of Investigations No. 78. North Dakota Geological Survey, Grand Forks.

Picha, Paul R.

2003 Modified and Fossil Shell Artifacts. In Archaeology at Menoken Village, A Fortified Late Plains Woodland Community in Central North Dakota, edited by Stanley A. Ahler, pp. 487-504. PaleoCultural Research Group, Flagstaff, Arizona. Submitted to the State Historical Society of North Dakota, Bismarck.

Steinacher, Terry L.

1988 Shell and Bone Artifacts. In Archaeological Investigations at the Sommers Site (39ST56), 1964-1965, Stanley County, South Dakota, edited by Carl R. Falk, pp. 8.1-8.8. Division of Archeological Research, Department of Anthropology, University of Nebraska-Lincoln. Ms. in preparation for the U.S. National Park Service, Interagency Archeological Services, Denver. 


\title{
13. SUMMARY AND RECOMMENDATIONS
}

\author{
Mark D. Mitchell, Kenneth L. Kvamme, Fern E. Swenson, Carl R. Falk, \\ Robert K. Nickel, and George T. Crawford
}

\begin{abstract}
Summary
This project continues a focused effort by the State Historical Society of North Dakota and the PaleoCultural Research Group to investigate post-1500 culture change in the Heart region. This work began rather fortuitously in 1998 with the inadvertent discovery of substantial remnants of Scattered Village beneath the City of Mandan (Ahler, ed. 2002). Prior to that time, modern excavations had been carried out only at On-A-Slant Village (Ahler, ed. 1997). The Scattered Village project documented for the first time the dramatic differences among contemporaneous communities in the Heart region. Particularly as measured by pottery and stone tool types, the material content of Scattered Village is quite distinct from that of Slant Village, located just $10 \mathrm{~km}$ to the south, as well as that of the Hidatsa villages clustered around the mouth of the Knife River some $80 \mathrm{~km}$ to the north (Ahler 2002:18.2).
\end{abstract}

From Scattered Village, work shifted to Double Ditch Village, the largest and best preserved of the Mandan settlements near the Heart River. Over the course of four field seasons from 2001 to 2004, the research team explored the site using state-of-the-art geophysical techniques combined with targeted, small-scale excavations (Ahler, ed. 2003, 2004, 2005; Kvamme and Ahler 2007). This work documented the remarkably complex occupational history of the village. It revealed previously-unsuspected features of the settlement and offered a glimpse of the dynamic processes that shaped the settlement during its 300-year period of occupation. It also confirmed the conclusion reached by the Scattered Village project that the large, contemporaneous settlements near the Heart River differed from one another in important ways.

In 2005, the team moved to Boley Village, a little-known west bank settlement (Ahler, ed. 2006). Unlike Double Ditch, Boley has been severely impacted by cultivation, road and railroad construction, and recent development. However, by again combining geophysical surveys with targeted test excavations, significant new discoveries about the age and history of the site were made. In contrast to Double Ditch, where the village contracted progressively over time, Boley appears to have been reconstructed with substantial reorientation late in its history. Not only did the material content of the Heart region villages differ, but their occupational histories did as well.

The 2006 work at Larson was guided by the results obtained at Scattered, Double Ditch, and Boley villages, and by new research questions that arose during the course of those projects. To insure comparability of the data obtained, the field and laboratory methods used at Larson mirrored as closely as possible those of earlier projects. Because the project's principal research questions focused on the age and occupational history of the village, the 2006 field effort concentrated on the comparatively flat and featureless area north of the northernmost perimeter mounds. Based on data from Double Ditch and Boley, it was believed that this would be the best place to get a clear view of the settlement's earliest features. In the end, the geophysical surveys covered roughly 1.5 ha on the 
northern and eastern sides of the village. A sample of artifacts was obtained from six small excavation blocks, comprising 20 analytic units, with a combined total volume of about $14.3 \mathrm{cu} . \mathrm{m}$. The following paragraphs discuss some of the major findings of the project.

As the team suspected, the geophysical survey revealed the presence of two roughly parallel linear anomalies arcing around the settlement, just beyond and beneath the outermost midden mounds (Figure 13.1). Numerous discrete anomalies representing hearths, cache pits, and other features also were identified. Hand coring and two test excavation units confirmed that both linear anomalies were indeed fortification ditches. At least two bastions appear to have been constructed in the outermost fortification (Ditch 4); one other bastion may be a part of Ditch 3 or Ditch 4. Both ditches are similar in form, but were filled in very different ways. Ditch 3 appears to have been abandoned gradually, while Ditch 4 was abandoned and filled rapidly. Geophysical surveys also revealed a linear alignment of relatively non-magnetic sediment arcing through the middle of the site. Based on the results of magnetic surveys conducted at Double Ditch, this feature also is interpreted as a fortification ditch and has been designated Ditch 2.

The 2006 data indicate that Ditch 4 very likely was built when the village was founded and that Ditch 3 is slightly younger. Evidence obtained by Alfred Bowers (1940) clearly demonstrates that Ditch 1 is the most recent. Thus, the occupational history of Larson closely parallels that of Double Ditch. At both villages, the outermost fortification is the oldest and the innermost is the most recent. Over time, both villages diminished progressively in size and, presumably, in population. It is tempting to think that these fortification systems were constructed synchronously at both villages, but at present no evidence for the age of Ditch 1 or Ditch 2 at Larson is available. The difficulty encountered in differentiating the ages of Ditch 3 and Ditch 4 at both villages probably is a product of the sixteenth-century radiocarbon calibration plateau.

Geophysical survey and hand coring demonstrated that the large basin or plaza adjacent to the central core of the village lacks subsurface features or cultural deposits. It also appears that a substantial about of sediment has been removed from this part of the site, suggesting that the basin served both as an open, public space and as a source of sediment for the construction of earthlodges. The absence of storage pits and sheet midden deposits further suggests that the plaza was used throughout the history of the village, even after its residents withdrew inside Ditch 1.

Hand coring along a transect near the center of the village suggests that the "planar borrowing" responsible for the widespread removal of primary cultural deposits inside Ditch 2 at Double Ditch Village did not occur on the same scale at Larson Village. At Double Ditch, this form of sediment borrowing seems to have been connected to the construction of defensive mounds. The comparative absence of similar sediment borrowing and transport may indicate rather different processes were responsible for the formation of Larson's superficially similar mounds.

Guided by magnetic gradiometry data, four small test units placed on the northern edge of the village revealed the presence of a variety of features, including postholes, small basins, and cache pits. The presence of postholes and other small features may indicate that substantial portions of earthlodge floors or outdoor activity areas are preserved in this part of the site. In this respect Larson is differs significantly from Double Ditch. There, cultural features and natural soil horizons on the perimeter of the village have been obliterated to a depth of 50 to $80 \mathrm{~cm}$. The process or processes responsible for this vertical churning are not known, but gardening may be partly 


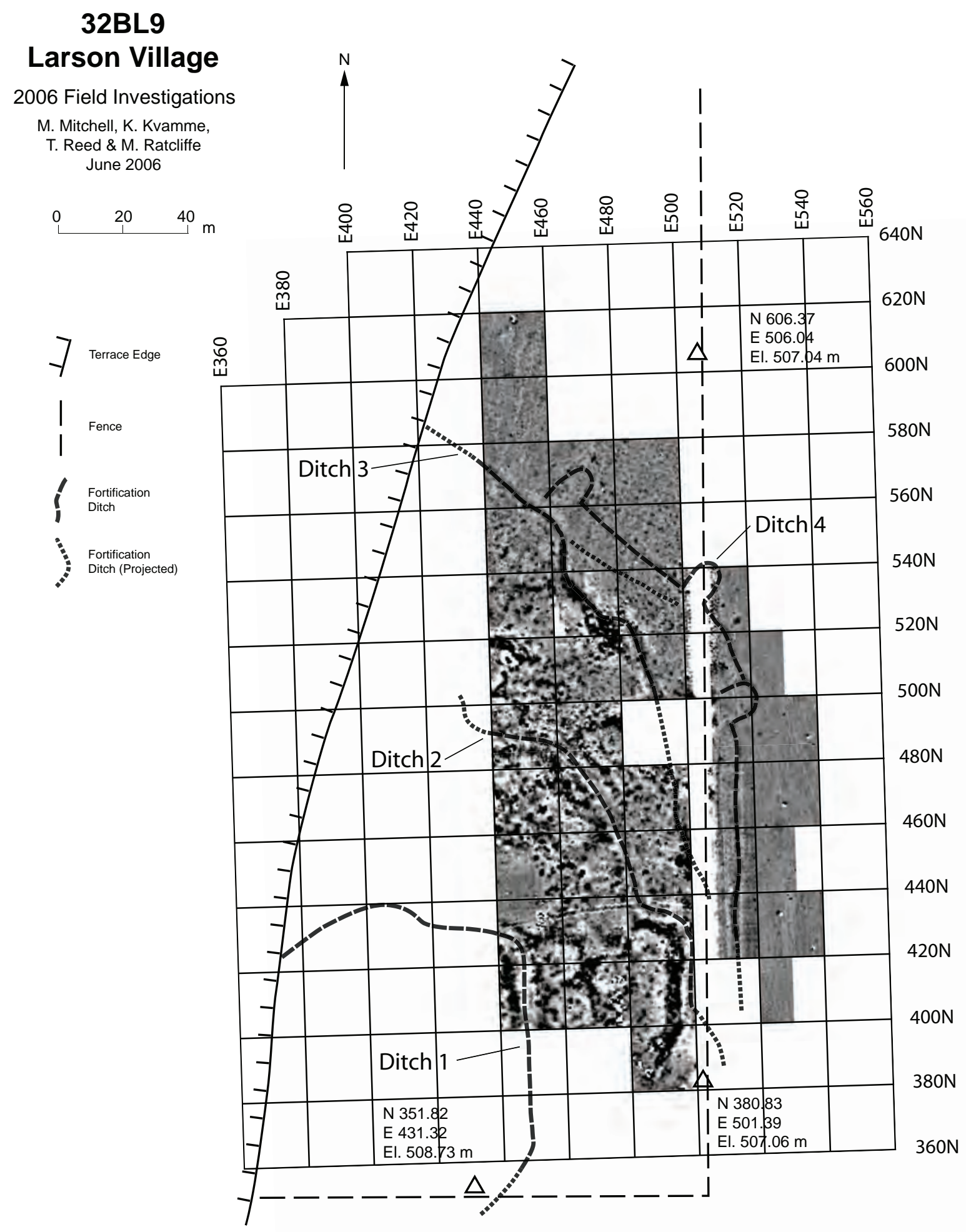

149th Street

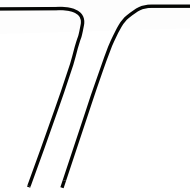

Figure 13.1. Map of Larson Village, showing the site's major features. 
responsible. By contrast, similar homogenized deposits are nearly absent at Larson. This suggests that the outskirts of the two villages were used by later residents in rather different ways.

The available chronological data suggest, but do not conclusively demonstrate, that the village was founded about 1500 . There is no doubt that the settlement was built before 1650 . The calibrated two-sigma radiocarbon date distribution of the six-sample weighted mean spans the periods from 1460 to 1530 and 1550 to 1630. Ceramic types manufactured during the second half of the seventeenth century are all but absent, as are iron trade goods and glass beads. But uncertainty about the provenance of the cuprous artifacts in the collection, coupled with the difficulty of interpreting radiocarbon ages falling between about 400 B.P. and 250 B.P., means that a precise founding date cannot yet be determined. The balance of archaeological evidence (principally the make-up of the pottery assemblage and the presence of bastioned fortifications) supports a late fifteenth or early sixteenth century date. If so, Larson and Double Ditch were founded at roughly the same time.

Analyses of modified stone and ceramic artifacts as well as botanical, unmodified vertebrate and other remains indicate that many of the features investigated in 2006 are filled with secondary deposits. Especially within the fortification ditches, which together account for nearly 40 percent of the total excavated volume, artifacts and other remains are comparatively fragmented and occur at lower densities than in cache pits. Although not demonstrated by the analyses conducted for this project, it is certainly possible that reusable or recyclable items were systematically removed from these secondary deposits by the village's inhabitants. This might especially be true of Ditch 4, which likely was filled intentionally. In any case, these data are a reminder that depositional context needs to be considered when comparisons are drawn among collections.

The Larson ceramic assemblage is similar to the Time Period 4 assemblage from Double Ditch. Both assemblages are dominated by Le Beau Classic variety rims. Transitional ware and Le Beau Sperry, Plain, and High Rim variety rims are absent or occur in very low numbers in both assemblages. Unclassified S-rim and straight-rim forms are common in both, as are decorated body sherds. However, there also are notable differences. Knife River ware is more common at Larson, while Le Beau Recurved variety is more common at Double Ditch. Early S-rims and Stanton ware rims are more common at Larson. Taken together these data suggest that Larson may have been founded slightly earlier than Double Ditch; however, the make up of the Larson collection also may reflect spatial differences within the Heart region. Like Larson, all of the components assigned to Pottery Group 4, which is thought to date to the late 1400s and early 1500s, are located on the northern edge of the Heart region or in the Knife region (Ahler 2001).

The Larson ceramic analysis also offers new insights into the relationships among several important ceramic types. Analysis of cord-impressed decoration on certain S-rim vessels corroborates the formal distinctions between Sanger ware and Le Beau ware. Sanger ware was decorated with larger, more widely spaced cord impressions than Le Beau ware, even when they were manufactured at about the same time. The presence of significant numbers of tool impressed Knife River ware vessels, along with a smaller number of Stanton ware vessels, lends support to the notion that Knife River ware developed in the Heart region in the late fifteenth or early sixteenth centuries. Additional chronometric data will be necessary to further evaluate this hypothesis. 
Like their neighbors at Double Ditch Village, the earliest residents of Larson Village made extensive use of smooth gray Tongue River silicified sediment (TRSS) for the production of stone tools. This material usually entered the site in the form of large flakes or blocks, and was used primarily for the production of unpatterned flake tools. By contrast, Knife River flint (KRF) was brought to the site in the form of small cobbles, tool preforms, or finished tools, and was used most often for the production of patterned tools, including arrow points, knives, and scrapers. Similar technological patterns are evident in the Double Ditch chipped stone assemblage. These data suggest that before 1650 the east bank villagers at Double Ditch and Larson enjoyed comparatively direct access to sources of good quality TRSS near or south of the Cannonball River, but that access to other sources west and northwest of the Heart region was more limited.

Analysis of unmodified vertebrate remains underscores important similarities and differences among Heart region and Knife region faunal assemblages. Although excavation sampling strategies and differences in the study of sizes G4 and G5 remains may be partly responsible for these patterns, several conclusions seem warranted. Without question, bison was the most important meat source throughout the northern Middle Missouri. However, communities in the Heart region appear to have enjoyed a more diverse diet than their neighbors in the Knife region. Fishing seems to have been an especially important activity among west bank villagers at Slant, Scattered, and Boley villages. Larson is notable for the very high number of large canid bones, although the meaning of this result is not clear.

Data on botanical remains from Larson confirm the importance of marshelder cultivation by fifteenth and sixteenth century Heart region communities. In addition to three tropical cultigens, the residents of Larson Village also grew a second North American domesticate, sunflower. They supplemented this suite of cultivated plants with a wide variety of wild fruits and seeds, including grape, plum, chokecherry, and buffaloberry.

These results indicate that Larson Village shares a number of important characteristics with Double Ditch Village. Like Double Ditch, Larson is surrounded by four concentric fortifications, the outermost of which was constructed with bastions. At Double Ditch, the fortifications were built sequentially, beginning in the last few decades of the 1400s, with the size of the village contracting progressively over time. Ceramic and radiocarbon data suggest that Larson too was founded in the late fifteenth or early sixteenth century. Data obtained by Alfred Bowers demonstrates that Ditch 1 at Larson is the most recent. Both villages contain large, open plazas that likely functioned as public spaces and as sediment borrow pits. Both communities engaged in similar subsistence practices and utilized similar stone tool raw material sources.

However, in other respects Larson and Double Ditch are markedly different. The comparatively thick cultural deposits present inside Ditch 2 at Larson indicate that the periodic removal of accumulated sediment that characterizes the occupational history of Double Ditch did not occur at the same scale at Larson. Except within the central plaza, cultural deposits appear to have accumulated progressively across much of the village. The preservation of significant architectural remains and stratified cultural deposits on the northern periphery of the settlement indicates that the outlying parts of the two villages were used by their inhabitants in very different ways. 


\section{Recommendations for Future Research}

Except for Double Ditch, Larson may be the best preserved of the post-1500 villages in the Heart region. More than half the site is in good condition. Moreover, it appears that Larson may be unsurpassed in its preservation of cultural deposits dating to the 1500s. For that reason, additional research at Larson could prove to be critical for understanding the decisive cultural and economic changes that took place in the Heart region during the sixteenth century. At that time, settlement occupation duration increased dramatically. Many of the large villages occupied at the end of the eighteenth century were founded during the 1500s, whereas earlier villages generally were occupied only for one or two generations. Concurrently, the long-rectangular lodges that had been built in the region for 300 years were replaced, apparently rapidly, by circular lodges. The 1500s also witnessed an increasing volume of long-distance exchange, culminating in the introduction early in the seventeenth century of European trade goods.

However, to realize the potential of this research new chronological tools are necessary. Foremost among these is a comprehensive, regional provenance study of cuprous artifacts. Scholars have generally assumed that all of the cuprous artifacts recovered from northern Middle Missouri villages were made from European copper or brass and therefore post-date 1600, or perhaps slightly later. The data discussed in this report, as well as data obtained from other Heart region villages (e.g. Ahler 2005), now call that assumption into question. Systematically obtained data on the elemental composition of these artifacts may help differentiate contexts dating to the 1500s from those dating to the 1600 s or later.

New absolute methods also are needed. These might include thermoluminscent dating of ceramic remains or archaeomagnetic dating of hearth features. Unfortunately, both of these methods have sometimes proven to be unreliable and for that reason should be rigorously tested before they are broadly applied. Nevertheless, a well-designed excavation and analysis program incorporating these methods in conjunction with more conventional AMS radiocarbon assays may make it possible to separate early sixteenth century contexts from late sixteenth century contexts. The ability to do so will be critical for studies of culture change during this pivotal period. 


\section{References Cited}

Ahler, Stanley A. (editor)

2002 Prehistory on First Street, NE: The Archaeology of Scattered Village in Mandan, North Dakota. Research Contribution No. 40. PaleoCultural Research Group, Flagstaff, Arizona. Submitted to the City of Mandan, North Dakota, and the North Dakota Department of Transportation, Bismarck.

2003 Archaeological Investigations During 2001 and 2002 at Double Ditch State Historic Site, North Dakota. Research Contribution No. 56. PaleoCultural Research Group, Flagstaff, Arizona. Submitted to the State Historical Society of North Dakota, Bismarck.

2004 Archaeological Investigations During 2003 at Double Ditch State Historic Site, North Dakota. Research Contribution No. 60. PaleoCultural Research Group, Flagstaff, Arizona. Submitted to the State Historical Society of North Dakota, Bismarck.

2005 Archaeological Investigations During 2004 at Double Ditch State Historic Site, North Dakota. Research Contribution No. 65. PaleoCultural Research Group, Flagstaff, Arizona. Submitted to the State Historical Society of North Dakota, Bismarck.

2006 Geophysical Survey and Test Excavation During 2005 at Boley Village (32MO37), North Dakota. Research Contribution No. 74. PaleoCultural Research Group, Flagstaff, Arizona. Submitted to the State Historical Society of North Dakota, Bismarck.

Ahler, Stanley A.

2001 Analysis of Curated Plains Village Artifact Collections from the Heart, Knife, and Cannonball Regions, North Dakota. Research Contribution No. 42. PaleoCultural Research Group, Flagstaff, Arizona. Submitted to the State Historical Society of North Dakota, Bismarck.

2002 Summary and Conclusions. In Prehistory on First Street, NE: The Archaeology of Scattered Village in Mandan, North Dakota, edited by Stanley A. Ahler, pp. 18.1-18.5. Research Contribution No. 40. PaleoCultural Research Group, Flagstaff, Arizona. Submitted to the City of Mandan, North Dakota, and the North Dakota Department of Transportation, Bismarck.

2005 Analysis of Trade Artifacts. In Archaeological Investigations During 2004 at Double Ditch State Historic Site, North Dakota, edited by Stanley A. Ahler, pp. 295-313. Research Contribution No. 65. PaleoCultural Research Group, Flagstaff, Arizona. Submitted to the State Historical Society of North Dakota, Bismarck.

Bowers, Alfred W.

1940 Missouri River Earthlodge Archaeology of North and South Dakota. Ms. on file, Logan Museum of Anthropology, Beloit College, Beloit, Wisconsin.

Kvamme, Kenneth L., and Stanley A. Ahler

2007 Integrated Remote Sensing and Excavation at Double Ditch State Historic Site, North Dakota. American Antiquity 72(3):539-561. 
